\title{
Value for Money in Project Alliances
}

\begin{abstract}
A thesis submitted in (partial) fulfilment of the requirements for the degree of Doctor of Project

Management
\end{abstract}

\section{Charles C. MacDonald}

\author{
B.Sc., M.Sc., M.B.A.
}

School of Property, Construction and Project Management RMIT University

April 2011 


\section{Declaration}

I certify that:

- except where due acknowledgement has been made, the work is that of the author alone:

- the work has not been submitted previously, in whole or in part, to qualify for any academic award:

- the content of this thesis is the result of the work which has been carried out since the official commencement date of the approve research program:

- any editorial work, paid or unpaid, carried out by a third party is acknowledged:

- and, ethics procedures and guidelines have been followed.

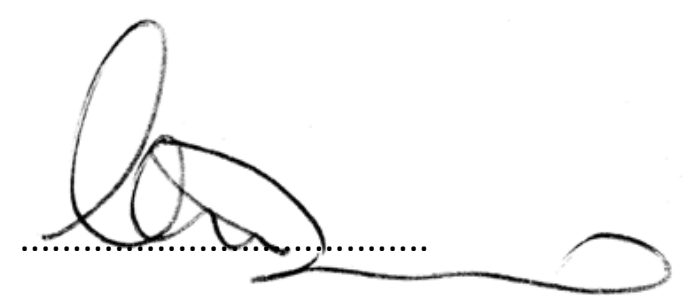

Charles C. MacDonald

29 April 2011 


\section{Acknowledgements}

I wish to thank Professor Derek Walker for his academic guidance and encouragement to start and then, as my Senior Supervisor, to complete this Professional Doctorate Program.

My Supervisor, for this research, has been Dr Neveen Moussa. I wish to formally acknowledge Neveen as a mentor, guide and friend who was always available to offer support and advice.

I wish to recognise the cooperation and support of my previous employer, Thiess Pty Ltd, the forbearance of my current employer, BrisConnections Pty Ltd, the time and commitment of all those who generously volunteered to participate in the data gathering stages of this research. I would also like to acknowledge Prue Conaghan for her invaluable assistance in the production of this document.

Finally, I am greatly indebted to my wife, Sylvia, and my son, Cameron, who have had to endure the difficulty of living with (or more accurately, not living with) someone undertaking long-term part-time study. Without their support and encouragement I would not have completed this journey. 


\section{Summary}

The aim of the research presented in this thesis is to determine the optimum configuration of a model that will assist all participants in project alliances to both ensure and demonstrate the achievement of Value for Money (VfM) or Best Value (BV). The research focused on project alliances established to deliver infrastructure works in Australia.

Despite the increasing adoption of project alliancing as a procurement approach for infrastructure projects, the absence of a sound methodology for ensuring and demonstrating VfM for such a commercial arrangement has proven to be the 'Achilles heel' of alliance contracting and is likely to limit the further and broader acceptance of this relationship based procurement approach. Those who have been closely involved in project alliances generally tend to the view that this procurement approach does genuinely deliver VfM. However, others, particularly those with limited involvement in alliances tend to more sceptical of the potential commercial benefits of such contracts and often question whether an approach, that lacks price competition in the selection process, can result in VfM. This conundrum has been described as either the 'VfM paradox' or the 'VfM puzzle' by different authors and these are terms which are explained and explored in this thesis.

The issue of VfM in alliances has received a degree of coverage in the literature, particularly since 2009 when the Inter- jurisdictional Alliancing Steering Committee (IASC) commenced research in this area. However, there is a widely held and long standing view in the construction industry that there is a real need to develop a tool that will more adequately substantiate whether $\mathrm{VfM}$ has been achieved on a given project.

Based on a detailed review of the construction procurement literature, a preliminary VfM/BV model was devised by the researcher which adopted the form of a lifecycle flowchart. This literature included a number of recent postgraduate theses relating to alliance procurement which assisted in defining a number of issues that the model needed to address. This preliminary model described the primary activities involved in delivering a project, from inception to completion, through the project alliance approach. The model identified milestones in the lifecycle, akin to gates in the Gateway ${ }^{\mathrm{TM}}$ Review process, at which the VfM 'health' of the project could be monitored and addressed to ensure that $\mathrm{VFM}$ is achieved.

The research included a series of stages further to the development of the preliminary VfM/BV model which were designed to test, refine and verify the applicability of the model. This program included two data gathering phases which exposed the model to critical review by a number of knowledgeable practitioners in the field 
The first of these data gathering stages incorporated personal structured interviews with 27 participants from 5 specific alliances seeking their views in the definition of $\mathrm{VFM}$ and the success of these projects in achieving such an outcome. During these interviews the preliminary VfM/BV model was introduced and the interviewees who were requested to complete a detailed questionnaire which related to the performance of the alliance and their assessment of the merit of the preliminary model. Following receipt of the questionnaires (21 returns), the model was amended to reflect the feedback received.

The second data gathering stage of the research involved obtaining feedback on the revised model, through a web based Delphi Survey process. A group of 12 recognised experts in the field of project alliancing participated in the three rounds of this survey. Responses to questions posed in each round of the process were received anonymously and circulated, unattributed, to all participants. During the first two rounds of the survey, the questions focused on the further development of the model. However, in the second round, questions were also posed regarding some statements, relevant to the purposes of the model that had been made in research report published by the IASC as a result of their study into the issue of VfM in project alliances.

The feedback obtained through the Delphi Survey has resulted in the model developing from a single page summary to a ten page document with a separate flowchart, and associated VfM checklist, for each of seven identified stages of the project lifecycle. The model offers a structured and disciplined approach to continuously monitor VfM throughout the lifecycle of a project and also facilitates the development of a record which demonstrates that this objective has been achieved.

Given the contemporary nature of the IASC Research it was considered appropriate to compare the recommended approach to VfM developed by that committee and the model developed through this research. This comparison indicates a strong degree of agreement between the two approaches. There are, however, some differences. The most notable of these are the mandated adoption of a price based criteria for the selection of the Non Owner Participants (NOPs) in the alliance and a transfer of authority from the Alliance Leadership Team (ALT) to the Owner directly, which are both features of the IASC approach. This research concludes that non- price based selection process is preferred and considers that a reduction in the authority of the ALT is not well aligned with the delivery of best value. Nevertheless, the VfM/BV model has been amended to specifically accommodate the price based selection process, given that this will, no doubt, be the default position for public sector alliances following the IASC recommendations. 


\section{Table of Contents}

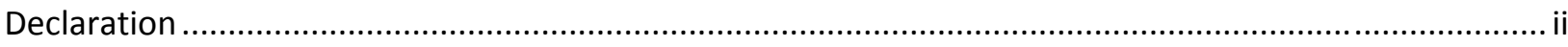

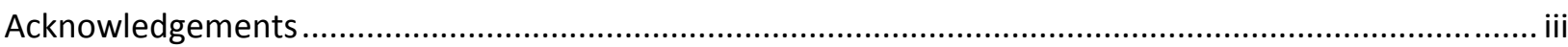

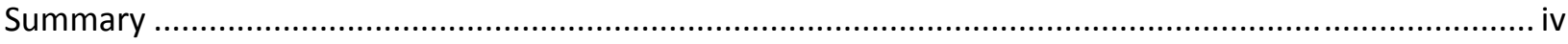

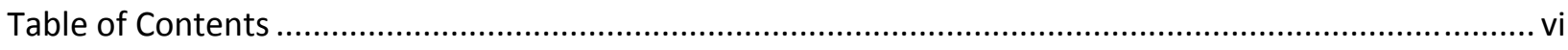

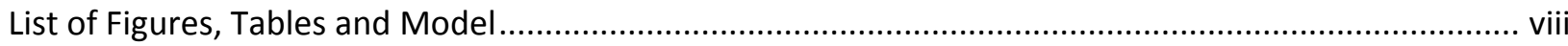

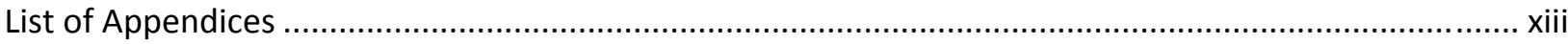

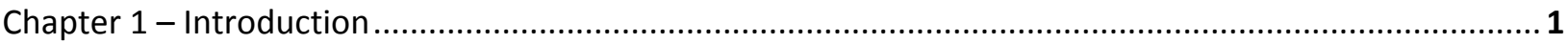

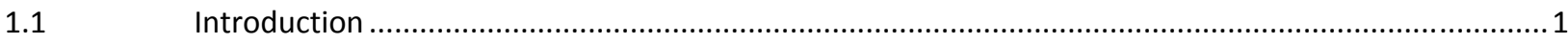

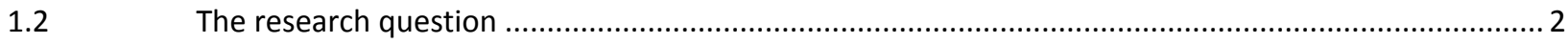

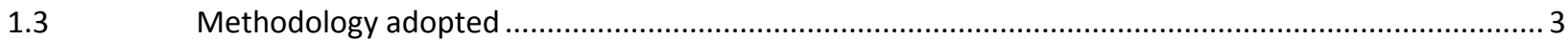

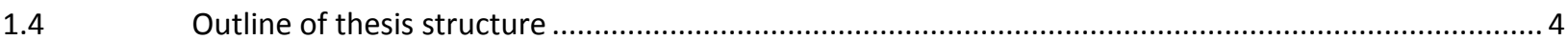

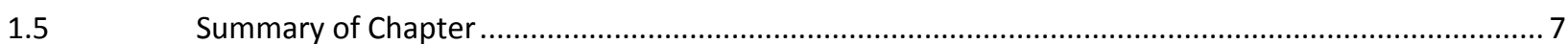

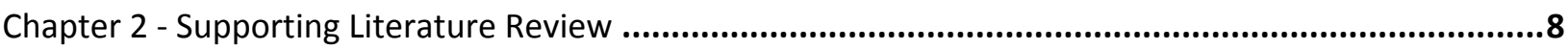

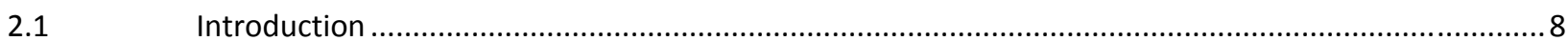

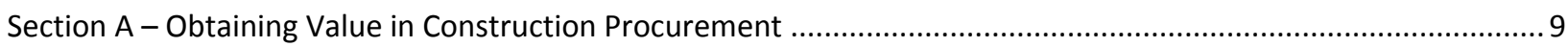

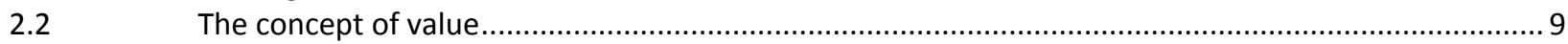

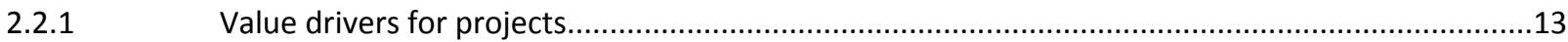

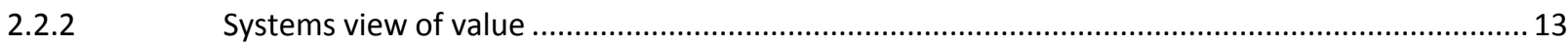

2.3 Value for money in construction procurement ........................................................................ 15

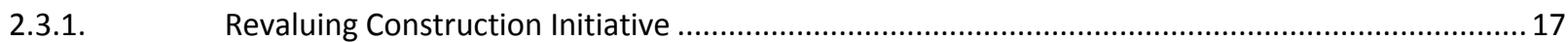

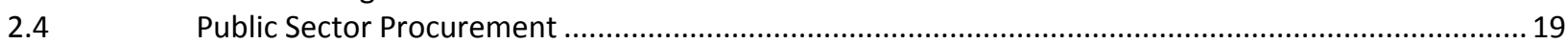

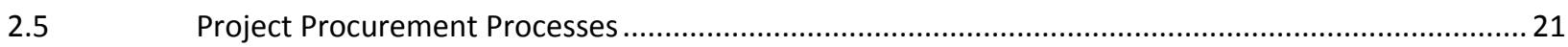

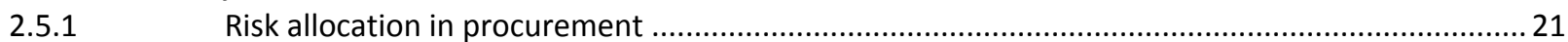

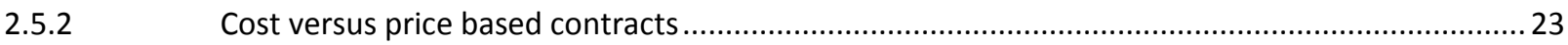

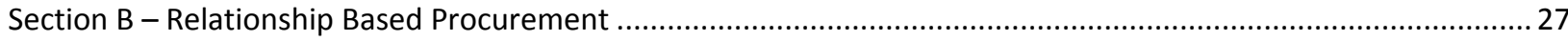

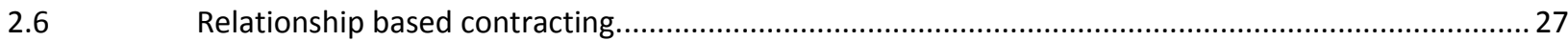

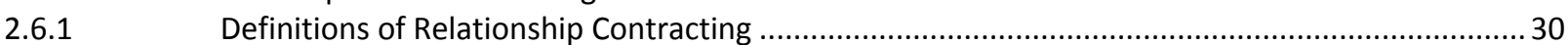

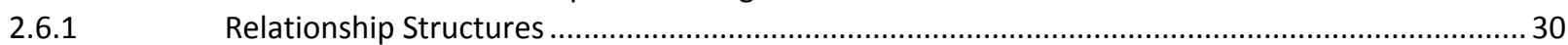

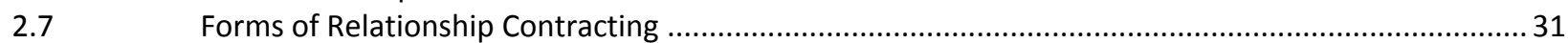

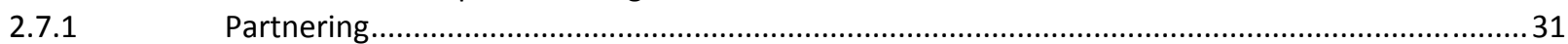

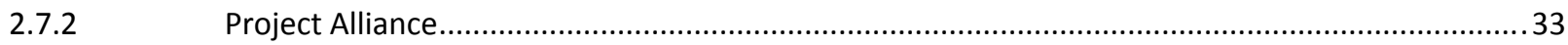

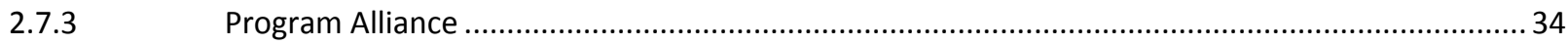

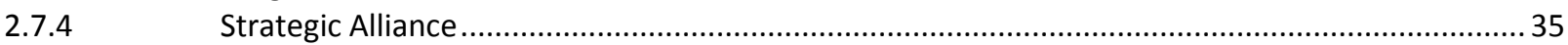

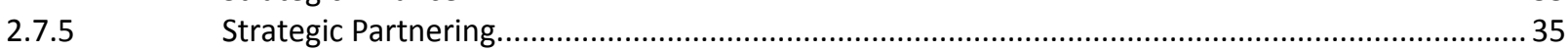

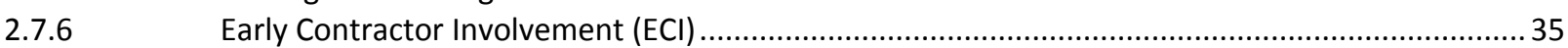

2.7.7 Training/coaching in relationship contracting ....................................................................... 36

2.8 Essential differences between partnering and alliancing ............................................................... 36

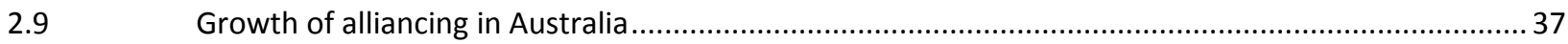

2.10 Distinction between 'pure' and 'price competitive' alliances............................................................. 40

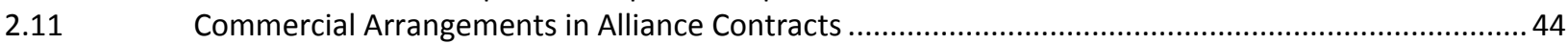

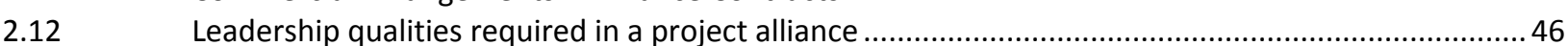

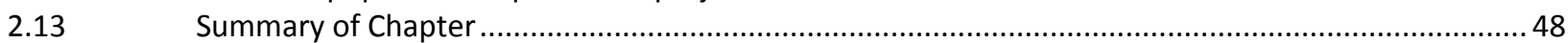


Chapter 3 - Developing the Preliminary Research Model 50

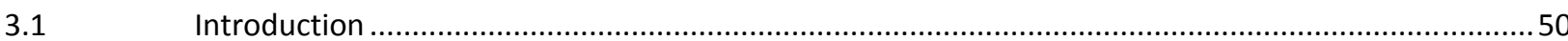

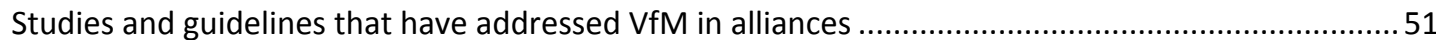

Obtaining VfM under the Alliance Procurement Model ....................................................................60

The VfM message from the Early Contractor Involvement (ECI) Model...........................................64

Recent relevant post-graduate research relevant to VfM in Project Alliances...................................65

Strengths and weaknesses analysis to determine the required attributes of the VfM/BV Model....... 71

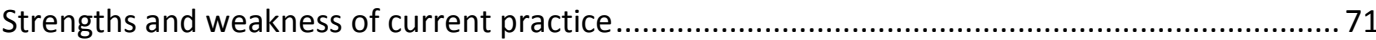
Required attributes of a VfM/BV Model ............................................................................... 72

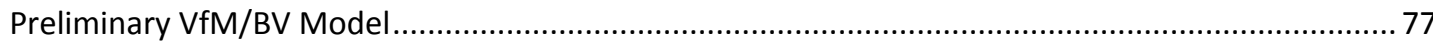

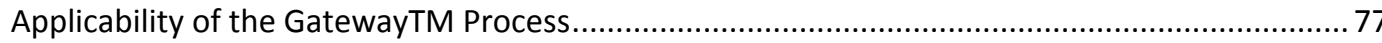

3.7 .2

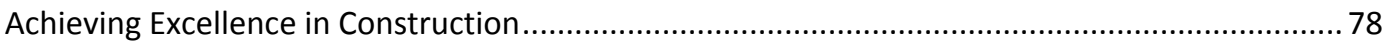

Project Alliancing Practioners' Guide (VDTF, 2006a) .......................................................... 80

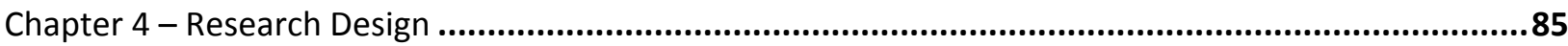

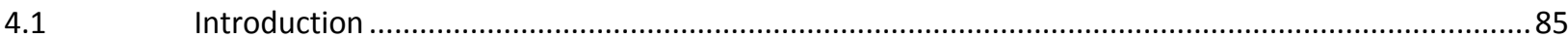

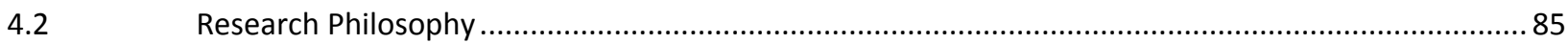

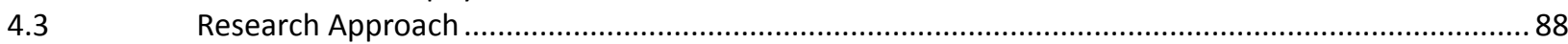

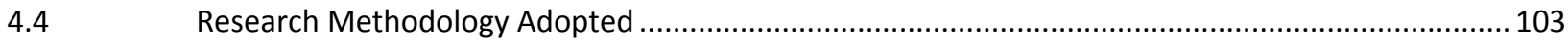

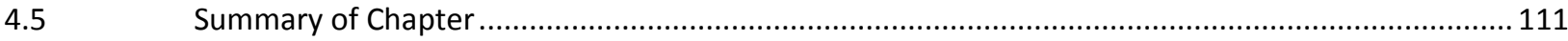

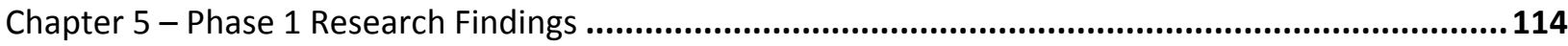

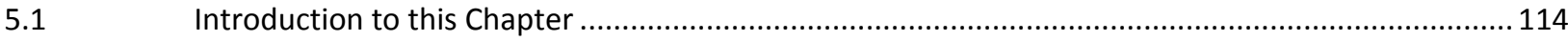

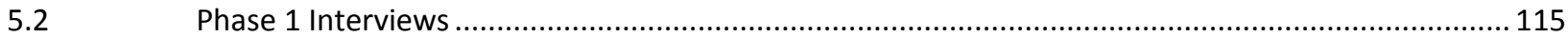

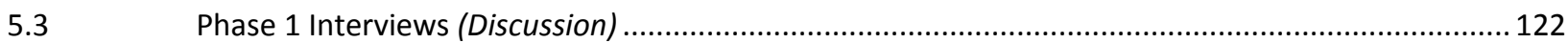

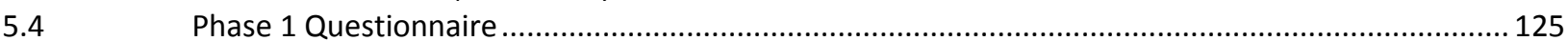

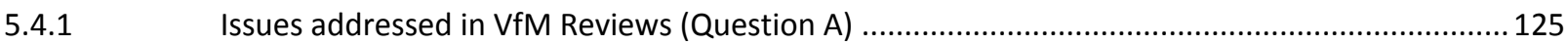

5.4.2 Issues addressed in VfM Reviews (Question A), (Discussion)..................................................... 131

5.4.3 Level of Maturity (LOM) in the consideration of VfM through the project lifecycle...........................

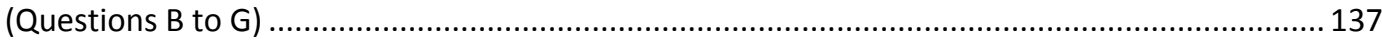

5.4.4 Level of Maturity (LOM) in the consideration of $\mathrm{VfM}$ through the project lifecycle ......................... (Questions B, C and D), (Discussion)..................................................................................... 141

5.4.5 General conclusions from feedback relating to the consideration of VfM in each alliance. ........144

5.4.6 Level of Maturity (LOM) in the consideration of VfM through the project lifecycle........................... (Questions E, F and G), (Discussion) .......................................................................... 148

5.4.7 General conclusions from questions relating to the VfM approach by each home organisation. 150

5.4.8 Responses to open questions regarding the preliminary VfM Framework/model.....................152

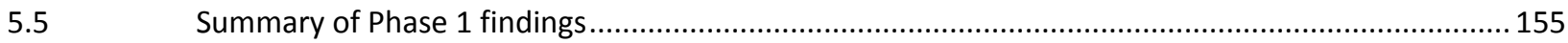

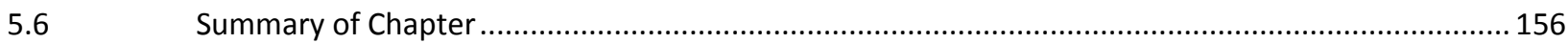

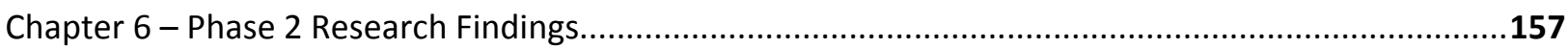

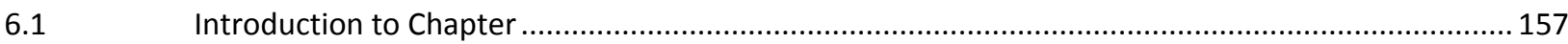

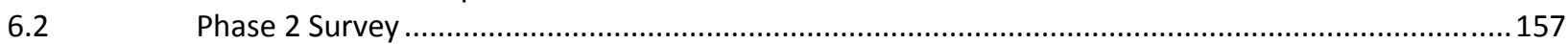

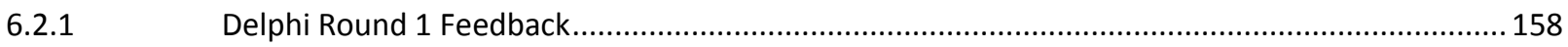

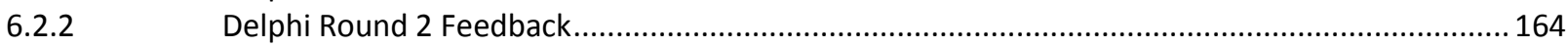

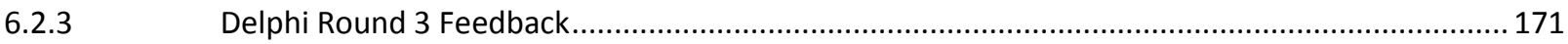


Chapter 7 - The work of the Inter- jurisdictional Alliancing Steering Committee (IASC).

Comparison between VDTF Research and this Research ......................................................... 188

7.4 .2

Similarities.

Relevance of IASC Research to development of the VfM/BV Model ......................................... 191

Appendices 


\section{List of Figures, Tables and Model}

\section{Chapter 2}

Figures

2.1 The value adding cycle

2.2 Procuring project value

2.3 The value context of projects

2.4 Schematic of procurement systems superimposed over the project value chain,

2.5 Global agenda for Revaluing Construction

2.6 CIB W065 Revaluing Construction agenda

2.7 The opportunities available in moving from a 'culture of confrontation' to a 'culture of cooperation'

2.8 Project delivery suitability vs project circumstances

2.9 The value of alliancing projects undertaken in each state

2.10 The value of alliancing projects undertaken by sector

2.11 Relative Outcomes of the traditional and alliance models

Tables

2.1 Values relevant to construction procurement

2.2 Comparative advantages of cost based payment

2.3 Definition of types of behaviour

\section{Chapter 3}

Figures

3.1 Gateway ${ }^{\mathrm{TM}}$ Review Process and the Procurement Lifecyle

3.2 Flowchart for VfM/BV Procurement Model

Tables

3.1 Significant reviews, reports and models on VfM since the NSWAG Performance Report (2003) regarding the Northside Storage Tunnel Project

3.2 Detailed consideration of reviews, reports and models on VfM since the NSWG Performance Report

3.3 Review of the current status of VfM in project alliance procurement using a Gateway ${ }^{\mathrm{TM}}$ Process framework

3.4 Specification for a VfM/BV Model for Project Alliances

3.5 Comparative Review of Gateway ${ }^{\mathrm{TM}}$ Review Process 


\section{Chapter 4}

Figures

4.1 The Research Sequence

4.2 A representation of the research activity as a knowledge creation process and the interconnectedness between its key elements

4.3 Choosing research strategies

4.4 An amended version of the above Figure 4.2 adapted to the specifics of this research

4.5 Relationships between core and action research projects

4.6 The relationship between thesis research, core action and thesis writing

4.7 The relationship between thesis research, core action research and thesis writing for this research

4.8 Representations of the Action Research Cycle as a single cycle

4.9 Concurrent cycles of problem solving and research interests

4.10 The stages of the Delphi process

4.11 Summary Flowchart of of DPM Research Process for a VfM/ BV Model for Project Alliancing

Tables

4.1 Relevant situations for different research strategies

4.2 Phase 1 Interviews and Responses to Questions

4.3 Timing of the Delphi Survey Process

4.4 Planned sequence for the Research Exercise

\section{Chapter 5}

Figures

5.1 Phase 1, Consolidated response: issues considered in VfM reviews, number of positive responses

5.2 Phase 1, Consolidated response: issues considered in VfM reviews, percentage of positive responses

5.3 Phase 1, Number of positive responses by issue

5.4 Phase 1, Percentage of positive responses by issue

5.5 Movement of issues considered during the lifecycle of a project

$5.6 \mathrm{VfM}$ issues considered frequently (>80\%) and infrequently $(\leq 30 \%)$

5.7 Phase 1, Question B, Frequency v LOM for each stage of the project lifecycle

- All participants

5.8 Phase 1, Question C, Frequency v LOM for each stage of the project lifecycle

- All participants 
5.9 Phase 1, Question D, Frequency v LOM for each stage of the project lifecycle - All participants

5.10 Responses to Questions regarding Level of Maturity (LOM) within the alliances considered

5.11 Phase 1, Question E, Frequency v LOM for each stage of the project lifecycle - All participants

5.12 Phase 1, Question F, Frequency v LOM for each stage of the project lifecycle - All participants

5.13 Phase 1, Question G, Frequency v LOM for each stage of the project lifecycle - All participants

5.14 Responses to Questions regarding Level of Maturity (LOM) within each 'home' organisation

Tables

5.1 Data/discussion coverage for Chapter 5

5.2 Alliance Blue (Railway works) - Comments from Phase 1 Participants

5.3 Alliance Red (Water treatment works) - Comments from Phase 1 Participants

5.4 Alliance Green (Interurban road works) - Comments from Phase 1 Participants

5.5 Alliance Purple (Dam works) - Comments from Phase 1 Participants

5.6 Alliance Black (Public transport infrastructure) - Comments from Phase 1 Participants

5.7 Structure of the preliminary VfM/BV Model

5.8 Questions posed in the Phase 1 Questionnaire

5.9 Issues which were listed in Question A

5.10 Summary of responses regarding issues considered in VfM Reviews (Question A)

5.11 Percentage of responses received indicating that issues were considered at VfM/BV Gate $3 A$ (Selection of NOPs)

\section{Chapter 6}

Figures

6.1 Phase 2, Delphi Survey, Summarised results for Round 1

6.2 Phase 2, Delphi Survey, Summarised results for Round 2

6.3 Phase 2, Delphi Survey, Summarised results from Round 3

Tables

6.1 Quantitative results from Delphi Survey, Round 1

6.2 Quantitative results from Delphi Survey, Round 2

6.3 Quantitative results regarding reflective value of framework/model

6.4 Response to the expert comments received through the Delphi Survey process 


\section{Chapter 7}

Figures

7.1 Hierarchy of steps for planning and reporting VfM outcomes in an Alliance and the role of parties in planning for, and reporting, VfM Outcomes

7.2 Alignment of the VfM/BV Model to IASC/VDTF hierarchy of planning and delivery steps Tables

7.1 Publications emanating for the work of the Inter-jurisdictional Alliancing Steering Committee (IASC) - IASC/VDTF Publications

7.2 Comparison of the findings/outcomes of IASC Research and this Study

7.3 Comparison between the VfM/BV Model with the IASC/VDFT Approach to VfM

\section{Chapter 8}

VfM/BV framework/model for Project Alliances

Cover Sheet for framework/model

Summary Level Flowchart

Strategic Need for Project Stage - VfM/BV Gate 0

Business case for Project Stage - VfM/BV Gate 1

Development of Procurement Strategy Stage - VfM/BV Gate 2

Selection of NOPs Stage - VfM/BV Gate 3A

Development of Project Proposal and TOC Approval Stage

(Multiple TOC) - VfM/BV Gates 3A\&B

Development of Project Proposal and TOC Approval Stage

(Single TOC) - VfM/BV Gates 3B

Detailed Design and Construction of Project Stage - VfM/BV Gate 4

Operational Evaluation Stage - VfM/BV Gates 5A\&B
Sheet 1 of 10

Sheet 2 of 10

Sheet 3 of 10

Sheet 4 of 10

Sheet 5 of 10

Sheet 6 of 10

Sheet 7 of 10

Sheet 8 of 10

Sheet 9 of 10

Sheet 10 of 10 


\section{List of Appendices}

\section{A Confidentiality Agreement}

A.1 Confidentiality Agreement (included at examination but not final version to preserve anonymity)

\section{B Phase 1 Research Documents}

B.1 List of Phase 1 Participants

B.2 Letter of Invitation to Phase 1 Participants

B.3 Documents forwarded to Phase 1 Participants prior to interview

- Preliminary VfM Model.

- Comparative Table of GatewayTM Reviews

B.4 Documents tabled at Phase 1 interviews

- Format of Phase 1 interviews

- Phase 1 questionnaire

\section{Phase 2 Research Documents}

C.1 List of Phase 2 Participants

C.2 Letter of Invitation to Phase 2 Participants

C.3 Sample pages of the Delphi Process website

\section{Round 1}

C.4 Documents forwarded to participants prior to the commencement of Round 1

- $\quad$ Briefing Paper for Phase 2, Round 1 Participants

- VfM Model

C.5 Round 1 Questions as posted to the Delphi Website to be addressed by participants

\section{Round 2}

C.6 Documents forwarded to participants prior to the commencement of Round 2

- $\quad$ Briefing paper for Phase 2, Round 2 participants

- VfM model

C.7 Round 2 Questions as posted to the Delphi Website to be addressed by the participants

\section{Round 3}

C.8 Documents forwarded to participants prior to the commencement of Round 3

- $\quad$ Briefing paper for Phase 2, Round 3

C.9 Round 3 Questions as posted to the Delphi Website to be addressed by the participants 
D Phase 1, Detailed results

D.1 Question A - Were the following issues addressed in any review of VfM at these stages of the project?

D.1.1 Issues addressed at the 'Strategic Need' Stage of the project lifecycle (VfM/BV Gate 0)

D.1.2 Issues addressed at the 'Business Case' Stage of the project lifecycle (VfM/BV Gate 1)

D.1.3 Issues addressed at the 'Procurement Strategy' Stage of the project lifecycle (VfM/BV Gate 2)

D.1.4 Issues addressed at the 'Selection of NOPs' Stage of the project lifecycle (VfM/BV Gate 3A)

D.1.5 Issues addressed at the 'TCE Approval' Stage of the project lifecycle (VfM/BV Gate 3B)

D.1.6 Issues addressed at the 'Readiness for Service' Stage of the project lifecycle (VfM/BV Gate 4)

D.1.7 Issues addressed at the 'Benefits Evaluation' Stage of the project lifecycle (VfM/BV Gate 5A\&B)

D.1.8 Economic Issues at each stage of the project lifecycle

D.1.9 Social Issues at each stage of the project lifecycle

D.1.10 Environmental Issues at each stage of the project lifecycle

D.1.11 Ethical Issues at each stage of the project lifecycle

D.1.12 Stakeholder Issues at each stage of the project lifecycle

D.1.13 Governance Issues at each stage of the project lifecycle

D.2 Question B - Is VfM an explicit project objective for the Alliance?

Frequency $v$ LOM for each stage of the project lifecycle

D.3 Question C - Are specific measures or procedures in place to ensure that VfM is achieved? Frequency $v$ LOM for the each stage of the project lifecycle

D.4 Question D - Are specific measures in place to ensure that VfM is demonstrated to have been achieved?

Frequency $v$ LOM for the each stage of the project lifecycle

D.5 Question E - Is VfM an explicit project objective for your Organisation?

Frequency $v$ LOM for the each stage of the project lifecycle

D.6 Question F - Are specific measures normally in place (within your Organisation) to ensure that VfM is achieved?

Frequency $v$ LOM for the each stage of the project lifecycle 
D.7 Question G - Are specific measures normally in place (within your Organisation) to ensure that VfM is demonstrated to have been achieved?

Frequency $v$ LOM for the each stage of the project lifecycle

D.8 Open Questions

Appendix 5.7.8 - Phase 1 Open Questions - Detailed Responses

E Phase 2: Detailed Results

E.1 Delphi Survey, Round 1

Consolidated Responses

E.2 Delphi Survey, Round 2

Consolidated Responses

E.3 Delphi Survey, Round 3

Consolidated Responses

F Comments on IASC Documents

F.1 In Pursuit of Additional Value - Key Findings

F.2 In Pursuit of Additional Value - Discussion Points

F.3 In Pursuit of Additional Value - Conclusions

F.4 In Pursuit of Additional Value - Recommendations

F.5 Guidance Note No. 4, Reporting VfM Outcomes in Alliance Contracting 


\section{Chapter 1 - Introduction}

\subsection{Introduction}

This chapter provides an introduction to the subject of this thesis, the context of the research, a statement of the research question that was addressed, a description of the methodology adopted, description of the model proposed and finally a brief description of the content of each of the chapters that comprise the document.

This work is presented as the concluding dissertation to a Doctor of Project Management (DPM) degree program. This professional doctorate program comprises a combination of coursework (33\%) and research (67\%), with a stated goal of furthering the interaction of the university, industry and the professions and the community to mutual advantage (RMIT, 2007). The program places a strong emphasis on the participating candidates reflecting upon their professional experience to achieve this goal.

The author of this thesis, hereafter referred to as 'the researcher', is a professional engineer with some 35 years experience in the design and construction of civil infrastructure works worldwide. The researcher has held senior positions with contractors, consultants, in the public sector and academia providing a broad background and comprehensive appreciation of technical, commercial and contractual issues. Between October 2007 and October 2010 the researcher was a Board member of the Alliancing Association of Australia having been involved with the organisation since its inception in 2003.

The aim of the research presented is to develop, test and validate a model which will facilitate the achievement and demonstration of 'value for money' (VfM), or 'best value' (BV) in project alliance contracts. The research was focused on project alliances established to deliver infrastructure works in Australia.

Despite the increasing adoption of project alliancing as a procurement approach for infrastructure projects, the absence of a sound methodology for ensuring and demonstrating VfM for such a commercial arrangement has proven to be the 'Achilles heel' of alliance contracting and, in the view of the researcher, is likely to limit the further and broader acceptance of this relationship based procurement approach. Those closely involved in project alliances generally tend to the view that the model does genuinely deliver VfM. However, others, particularly those with little or no involvement in alliances, tend to more sceptical of the potential commercial benefits of such contracts and often 
question whether an approach, that lacks price competition in the selection process, can result in VfM.

This issue has been addressed by a number of authors but two prominent practitioners in the field have both coined terms which are believed to capture the apparent enigma that alliances represent:

\section{VfM Paradox (Henneveld, 2006)}

- Alliances are perceived as 'soft' because they lack the tension of price competition in the selection process.

- When more closely examined and when VfM principles are understood, the alliance approach is a robust and sensible approach that not only improves all aspects of project delivery, it eliminates claims and disputes.

\section{VfM Puzzle (Quick, 2007)}

- The essence of VfM is putting public funds to use in the most efficient, transparent and accountable manner.

- The 'VfM Puzzle' is how to ensure competition and observation of these considerations in what is arguably procurement by sole invitation.

There is a widely held view in the construction industry that there is a real need to develop a tool that will substantiate whether VfM is being achieved on a given project such that the apparent 'paradox' will become quite logical and the 'puzzle' will be demystified.

In this thesis the organisational arrangements and philosophical commitments that define a project alliance are described in some detail as an understanding of these matters is considered to be critical to the development of a deeper appreciation of the context in which the issue of VfM is being considered in such a relationship based procurement arrangement.

\subsection{The research question}

The specific research question addressed was 'What is the optimum configuration of a model that will assist all participants in a project alliance to both ensure and demonstrate the achievement of VfM or best value'. The purpose of this question was to investigate how such a model could be best configured to provide a definitive, structured means of ensuring that a given project can deliver $\mathrm{VfM}$ when using the project alliance approach and then offer a means of demonstrating, through appropriate data capture and documented reviews, that VfM has actually been achieved. 
In addressing the issue of VfM or more accurately 'best value' the model was designed to adopt a comprehensive approach to the concept of value and look further than the conventional industry perspective of simply lowest cost or even the more developed concept of an increased return for the same expenditure. The model embraces the complete life-cycle of alliance from concept development through project execution to operation. Additional measures of value are considered including social, environmental, ethical, stakeholder and governance issues and Intangible outcomes are addressed.

\subsection{Methodology adopted}

The research was undertaken with the consent and agreement of the organisations involved in a number of alliance projects. The free consent of the individuals representing these organisations was also necessary prior to their participation in the exercise. The cooperation of all who participated is this research is gratefully acknowledged.

A confidentiality agreement was signed by the researcher and this was included in the version of this thesis presented for examination. However, in order to preserve the anonymity of the parties involved, this agreement has been omitted from this final version of the thesis (see note in Appendix A.1).

Based on a detailed review of the literature in the field a preliminary model was devised which adopted the form of a lifecycle flowchart. The model sought to describe all of the primary activities involved in delivering a project, from inception to completion through a project alliance procurement approach. The model also identified milestones in the lifecycle, akin to gates in the Gateway ${ }^{\mathrm{TM}}$ Review process originally developed by the Office of Government Commerce, at the time, a division of the UK Treasury. At these gates, the VfM 'health' of the project is to be monitored and addressed. The research was undertaken in a number of stages which included:

- A general literature review addressing the concept of value, VfM and relationship based procurement.

- A more specific literature review concerning VfM practice which led to the development of the preliminary VfM/BV model.

- Personal interviews with 27 participants from the 5 alliances that were investigated in detail. 
- A detailed questionnaire which was responded to by 21 participants. At the completion of the interviews and the analysis of the questionnaire responses, which were collectively termed Phase 1 of the data gathering, the model was updated.

- Three rounds of a Delphi survey process that obtained the feedback of 12 experts in the project alliancing field. This stage was termed Phase 2 of the data gathering.

- The finalisation of the VfM/BV model following consideration of feedback from the experts.

- A review of the research and other publications published by the Inter-jurisdictional Alliance Steering Committee (IASC). This committee was formed by treasury departments of four Australian states and led by the Victorian Department of Treasury and Finance (VDTF). This work also considered the delivery of VfM in project alliance contracts. This review included a direct comparison between the findings of the IASC/VDTF work and this research.

- Reflections on the outcome of the research, followed by the formulation of conclusions and recommendations.

\subsection{Outline of thesis structure}

\section{Chapter 2 - Supporting Literature Review}

The chapter is divided into two sections. The first section (Section A) reviews, and explains the relevance of, the general project management literature in the field of construction procurement as it relates to Value for Money (VfM) in 'relationship based' contracting. The concept of VfM is often regarded as a cornerstone of procurement policy, particularly in the public sector. However, before it is possible to adequately discuss the meaning of the term VfM it is necessary to explain what is meant by the concept of 'value' and this is examined both generally and from a construction industry perspective.

Having provided this definitional backdrop, the second section (Section B) examines, primarily through the UK and Australian literature, the circumstances that have led to a significant shift in the construction industry in the last fifteen years in moving from a 'traditional' adversarial contracting environment to the increasing adoption of a more collaborative approach to procurement. Consideration is then given to how this change of approach has led to the emergence and development of relationship based contracting. 


\section{Chapter 3 - Developing the Preliminary Research Model}

This chapter provides a review of a number of investigations undertaken regarding VfM for specific project alliances. This review also considered the content of published guidelines on VfM in alliance procurement and a number of recent Australian postgraduate research theses which examined project alliancing. The chapter then describes how the findings of this review were used to further refine the research question investigated in the work described in this thesis.

Further to the reviews described above, a specific examination of strengths and weaknesses of current VfM practice in project alliance contracts is presented. This examination was undertaken in order to clarify the research question and to ensure that a positive contribution could be made to the state of knowledge in the field.

The chapter concludes with an outline the structure of a preliminary model VfM Model that was developed by the researcher based on a project lifecycle cycle flowchart incorporating periodic reviews of VfM adopting the principles of the Gateway ${ }^{\mathrm{TM}}$ Review Process.

\section{Chapter 4 - Research Design}

This chapter describes the research methodology adopted. Initially, the chapter considers the holistic nature of the research process and the alterative research strategies available. This then leads to a description of the actual strategy selected and an exploration of why this was considered to be the methodology best suited to the research task.

The chapter then proceeds to describe the mechanics that were adopted in engaging with practitioners in the field of alliancing to obtain commentary upon the preliminary model as initially conceived by the researcher and to determine how it could be developed and refined to address the research question. This involves a detailed description of the methodology outlined above including both the Phase 1 data gathering (Interviews and Questionnaire) and the Phase 2 data gathering (Delphi survey process) stages of the research.

\section{Chapter 5 - Phase 1 Research Findings}

This chapter presents the findings of the interviews and questionnaire. The interpretation of these findings is also discussed. Further details regarding the breakdown of the responses gathered through the questionnaire, in particular, are contained in a series of charts in Appendix D.

\section{Chapter 6 - Phase 2 Research Findings}

This chapter presents the findings of the three round Delphi Survey process. Given the more iterative nature of the Delphi process, the responses received are presented in a different manner than the 'data followed by discussion' format, for each question, as adopted in Chapter 5. In this case, the 
response received for each round of the process and the adjustments made between the rounds is initially described. A discussion of the findings of the Delphi Survey is then presented including as summary if the researchers' response to the expert commentary gathered through the process. The full date set for the survey is contained in Appendix E.

\section{Chapter 7 - The work of the Inter-jurisdictional Alliance Steering Committee (IASC)}

As briefly eluded to in Section 1.1 above a very substantial program, initially of research and then publication of new policy, procedural and guidance documents, was undertaken by the Interjurisdictional Alliancing Steering Committee (IASC) between 2009 and 2010.

In this chapter the research work, which is referred to as IASC Research, is briefly described and comparisons are made between the outcomes that research and the work described in his thesis. Additionally, a review is provided of the publications that largely resulted from the IASC Research, These documents are referred to as the IASC/VDTF Publications.

This chapter concludes with a direct comparison of the approaches proposed to address VfM in project alliances as result of the two research activities. This includes the identification of the characteristics which they have in common and were they differ. The aspects, in which both approaches may be considered to be deficient, and capable of further development, are also briefly discussed.

\section{Chapter 8 - VfM/BV framework/model}

This chapter specifically outlines the development of the VfM/BV framework/model that was created through this research. The final form of the model is presented and its use to explained. The creation of the model was considered to be central to addressing the research question posed earlier in Chapter 5. (i.e. what is the optimum configuration of a model that will assist all participants in a project alliance to both ensure and demonstrate the achievement of VfM or best value?).

This model is believed to successfully address the research question described above and consequently it is believed that it makes a significant contribution to the practice of alliance procurement by providing a structured and disciplined approach to the establishment and documentation of VfM in the procurement of projects using the project alliance methodology.

\section{Chapter 9-Conclusions and Recommendations}

This chapter presents that the conclusions that the researcher believes can be drawn from the program of research that has been described in this thesis. The conclusions are informed by the outcomes of the general literature review and the more specific literature review which led to the 
development of the preliminary VfM/BV model. However, the primary source of the conclusions presented is the analysis of the findings gathered during Phase 1 (Interviews and questionnaire) and Phase 2 (Delphi survey of experts) in conjunction with the researchers own industrial experience both generally as a practitioner in the infrastructure construction field and as a previous Director of the Alliancing Association Australasia.

\subsection{Summary of Chapter}

This chapter seeks to introduce this thesis by describing its purpose and goals before outlining, in summary form, the structure of the document and the content of the respective chapters.

A detailed listing of the content of the document is provided in the table of contents and listings of figures, tables, model and appendices provided prior to this introductory chapter. 


\section{Chapter 2 - Supporting Literature Review}

'It is unwise to pay too much, but is worse to pay too little.

When you pay too much you lose a little money - that is all.

When you pay too little, you sometimes lose everything, because the thing you bought was incapable of doing the thing it was bought to do.

The common law of business balance prohibits paying a little and getting a lot - it can't be done.

If you deal with the lowest bidder, it is well to add something for the risk you run. And if you do that, you will have enough to pay for something better'.

(Ruskin, 1849)

\subsection{Introduction}

The chapter will review, and explain the relevance of, the general project management literature in the field of construction procurement as it relates to Value for Money (VfM) in 'relationship based' contracting. The concept of VfM is often regarded as a cornerstone of procurement policy, particularly in the public sector. This point is supported by reference to Commonwealth, Financial Management and Accountability Act (1997). It is important, therefore, to understand why there is no universal definition of the term and such a wide range views and interpretations exist.

To address this wide scope the chapter is divided into two sections that will address VfM in construction procurement and relations based procurement options respectively.

Before it is possible to adequately discuss the meaning of the term VfM it is necessary to explain what is meant by the concept of 'value' and this is examined both generally and from a construction industry perspective in Section A.

Having provided this definitional context, Section B of the chapter examines, primarily through the UK and Australian literature, the circumstances that have led to a significant shift in the construction industry in the last fifteen years in moving from a 'traditional' adversarial contracting environment to the increasing adoption of a more collaborative approach to procurement. Consideration is then given to how this change of approach has led to the emergence and development of relationship based contracting. 
In the view of the researcher, this radical change in the procurement environment has been primarily driven by concerns about the poor record of the construction industry in delivering $\mathrm{VfM}$ in the 'traditional' contracting environment and the move to a new paradigm is generally aimed at addressing this deficiency. Consequently, it is somewhat ironical that relationship based procurement approaches are sometimes challenged on the basis that they do not have mechanisms to ensure or demonstrate that VfM has been achieved in the procurement process when these approaches largely exist to address the failure of traditional procurement methods to do so.

A summary of the key findings from this general literature review is then provided prior to the more detailed review, in Chapter 3, of reports, guidelines and theses that have specifically addressed VfM in alliance projects.

\section{Section A - Obtaining Value in Construction Procurement}

\subsection{The concept of value}

To fully explore the issue of $\mathrm{VFM}$ it is important to develop a good understanding of what is meant by the terms 'value' and 'adding value'. This seemingly simple task is more difficult to address than it might first seem and has challenged a number of deep thinkers over the years (Morwood et al., 2008):

Warren Buffet, the American investor and businessman has stated that; 'Price is what you pay, value is what you get'.

Anglo Irish dramatist and wit, Oscar Wilde claimed that; 'Nowadays people know the price of everything and the value of nothing'.

In a more serious vein, Langford (2007) reflects that there are economic, cultural and social interpretations of what is meant by value with the best known interpretation drawing upon economics. Early thinkers on the subject of value include Ricardo (1817) who considered that the value of a commodity was linked to the amount of labour needed to produce it. Karl Marx (1867) extended this concept of value to include the costs of fixed capital and materials. Marx was also influenced by Adam Smith (1776) who argued that wealth was created by the act of producing goods and that the value of all commodities was proportional to the amount of labour applied to their manufacture.

Perry (1914) saw value as being present when a person is interested in an object and derives pleasure from it. Perry considered value to be divided into 'intrinsic' value where something is perceived to have value by the individual and 'extrinsic' value where the properties of an object create the value. 
A formal definition of value in construction is available through the British /European Standard, BS EN 1325-1:1997 published by the British Standards Institution (1997), which describes value as the relationship between functionality, user satisfaction and cost. However, this is seen as presenting a somewhat narrow view and does not consider how value can be distributed between all parties in the construction process.

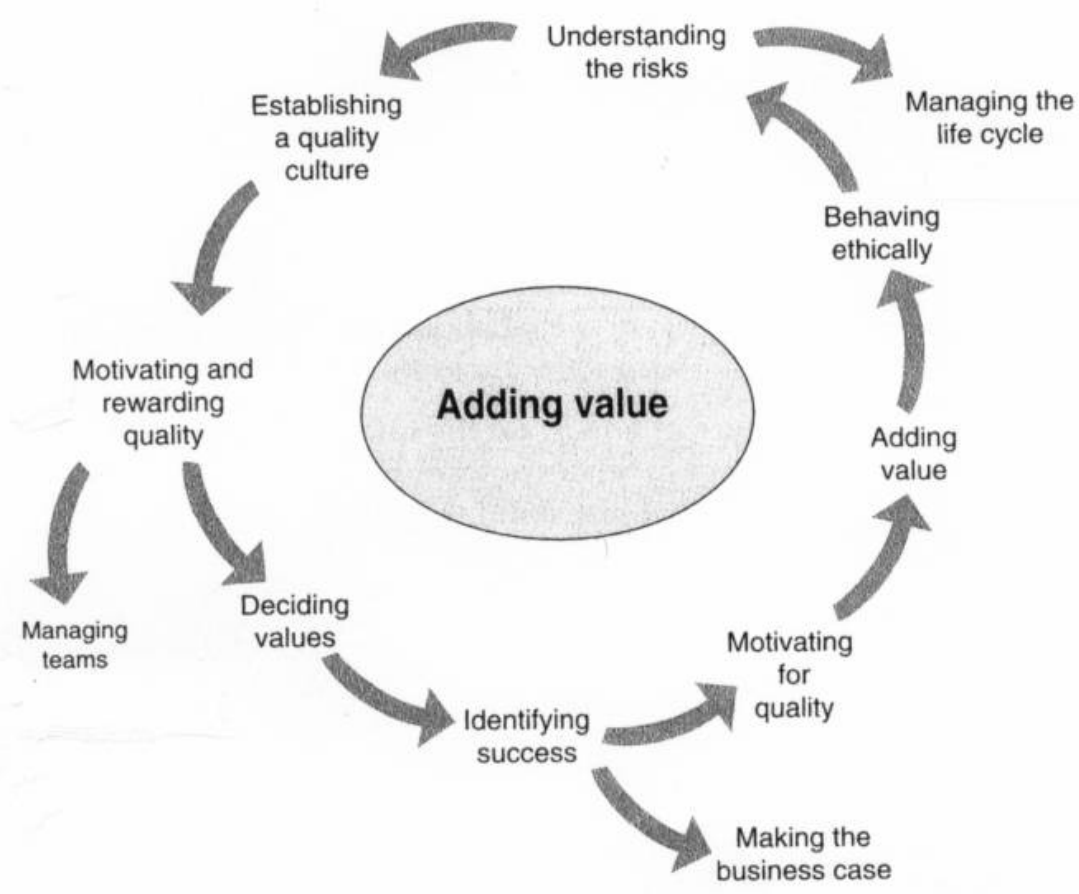

Figure 2.1 The value adding cycle from Blockley and Godfrey (2000), p143

In response to a number of the challenges which were posed to the construction industry by the Egan Report, 'Rethinking Construction'(1998), Blockley and Godfrey (2000) prepared a text entitled 'Doing it differently: systems for rethinking construction'. In addressing the meaning of value, Blockley and Godfrey explain that we make decisions based on our preferences. Decisions are based on the preference of one option over another. In order to make such decisions it is necessary to ascribe a 'worth' to the options. A worth is the attribute that we use in making choices and a value is simply that worth.

As is illustrated in Figure 2.1 above, 'adding value' is a driver of behaviour in many facets of a project and can be considered as a cycle that can pass through several iterations.

Blockley and Godfrey (2000) argue that some values are hard and some are soft. The worth of hard values is more easily measured whilst the worth of soft values are often partly personal, partly shared and can be difficult to measure dependably. There is a danger that we avoid or ignore those 
values where the worth is not easily measured. Money is one measure of worth but worth is not necessarily expressible in terms of money (Barton, 2000).

The issue is of hard and soft values is taken further by Nogeste and Walker (2005) who draw distinction between tangible and intangible outcomes of projects. They argue that there is growing unease with a sole reliance on the 'iron triangle' hard measures of time, cost and quality, which are 'lag' indicators of performance. They suggest that there is a desire to identify more visionary measures of performance which may be intangible but do provide 'leading' indicators of success. This theme was also investigated by Christensen and Walker (2004) and who found that a shared project vision contributed to the studied project delivering its intended goal despite poor project management practices.

Examples of values that are relevant in the context of construction procurement are shown in Table 2.1 below. This table also identifies whether these values can be classified as hard or soft.

Walker, Stark, Arlt and Rowlinson (2008b) state that value is actually the main purpose of project management . Further to the consideration of the work of Johnson (2004), which suggested that service excellence is much more than transactional and includes the satisfaction of intangible and often poorly explicated standards, they argue that value could be recognised as being not simply fitness for purpose at an agreed price in a timely manner but also as providing intangible deliverables for organisations that may include excellence in quality of relationships, leadership, learning, culture and values, reputation and trust. They suggest that value is an amalgam of the 'iron triangle' of performance measures described earlier together with expectations of anticipated delivery of softer and often unstated needs. They also suggest that whilst traditional project delivery procurement systems may be adequate in defining tangible and defined outputs they fall short in facilitating delivery of expected intangible and unstated outcomes.

Figure 2.2 below, taken from Walker, Rowlinson and Stark (2008a), was developed to describe the focus of their book 'Procurement Systems'. The researcher views this as an elegant illustration of the interplay between procuring project value and the associated issues of; understanding the nature of value and the value chain, balancing competition with cooperation, ethics and corporate governance, procurement options and defining or redefining the tendering process. 
Table 2.1 Values relevant to construction procurement, adapted from Blockley and Godfrey (2000), p146

\begin{tabular}{|c|c|c|}
\hline Values & Explanation & Hard or Soft \\
\hline Customer satisfaction & $\begin{array}{l}\text { Exceeding expectations providing what } \\
\text { is needed, fulfilling a desire }\end{array}$ & soft \\
\hline $\begin{array}{l}\text { Shareholder value (non } \\
\text { financial) }\end{array}$ & $\begin{array}{l}\text { Reputation, good will, customer loyalty, } \\
\text { desire to own }\end{array}$ & soft \\
\hline Money & $\begin{array}{l}\text { Profit, share price, financial measures } \\
\text { (such as return on capital, dividend } \\
\text { cover etc.), initial costs, life cycle costs, } \\
\text { opportunities, expectations about } \\
\text { future value }\end{array}$ & hard \\
\hline Utility & Usefulness, utility as in utility theory & hard and soft \\
\hline Health and safety & Harm, human life, injury, quality of life & hard and soft \\
\hline Performance & $\begin{array}{l}\text { Functionality, reliability, damage, } \\
\text { simplicity/complexity }\end{array}$ & hard and soft \\
\hline Buildability & $\begin{array}{l}\text { Constructability, level of } \\
\text { standardisation, waste }\end{array}$ & hard \\
\hline Operations & $\begin{array}{l}\text { Availability, efficiency, ease, } \\
\text { convenience/difficulty }\end{array}$ & hard and soft \\
\hline Environmental Impact & $\begin{array}{l}\text { Aesthetic, biological, loss of diversity, } \\
\text { elegance, pollution, waste, efficiency }\end{array}$ & hard and soft \\
\hline Sustainability & Natural resources, energy consumption & hard \\
\hline Ethics & $\begin{array}{l}\text { Individuals, groups, professional } \\
\text { standards, future generations }\end{array}$ & soft \\
\hline
\end{tabular}

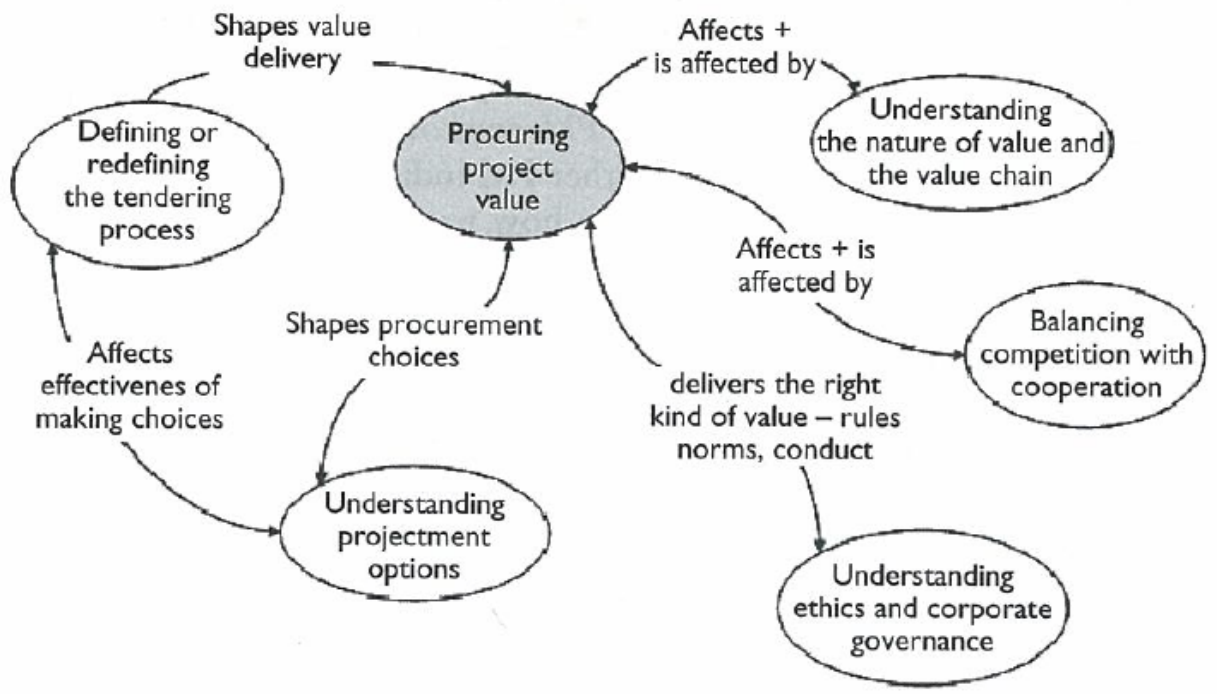

Figure 2.2 Procuring project value from Walker and Rowlinson (2008), pxvi 


\subsubsection{Value drivers for projects}

Male (2002) suggests that the reason for a project to exist is linked to the ongoing direction of the client's organisation. However, a project may also be influenced by its relationship to the asset base of the client. Further, depending on the core business activities of the client, the project may have to adapt to technological or organisational changes that are part of the development process. These factors constitute the value context, as depicted in Figure 2.3 below. The value context impacts directly on the strategic, and subsequently, tactical management process for the project(s) development.

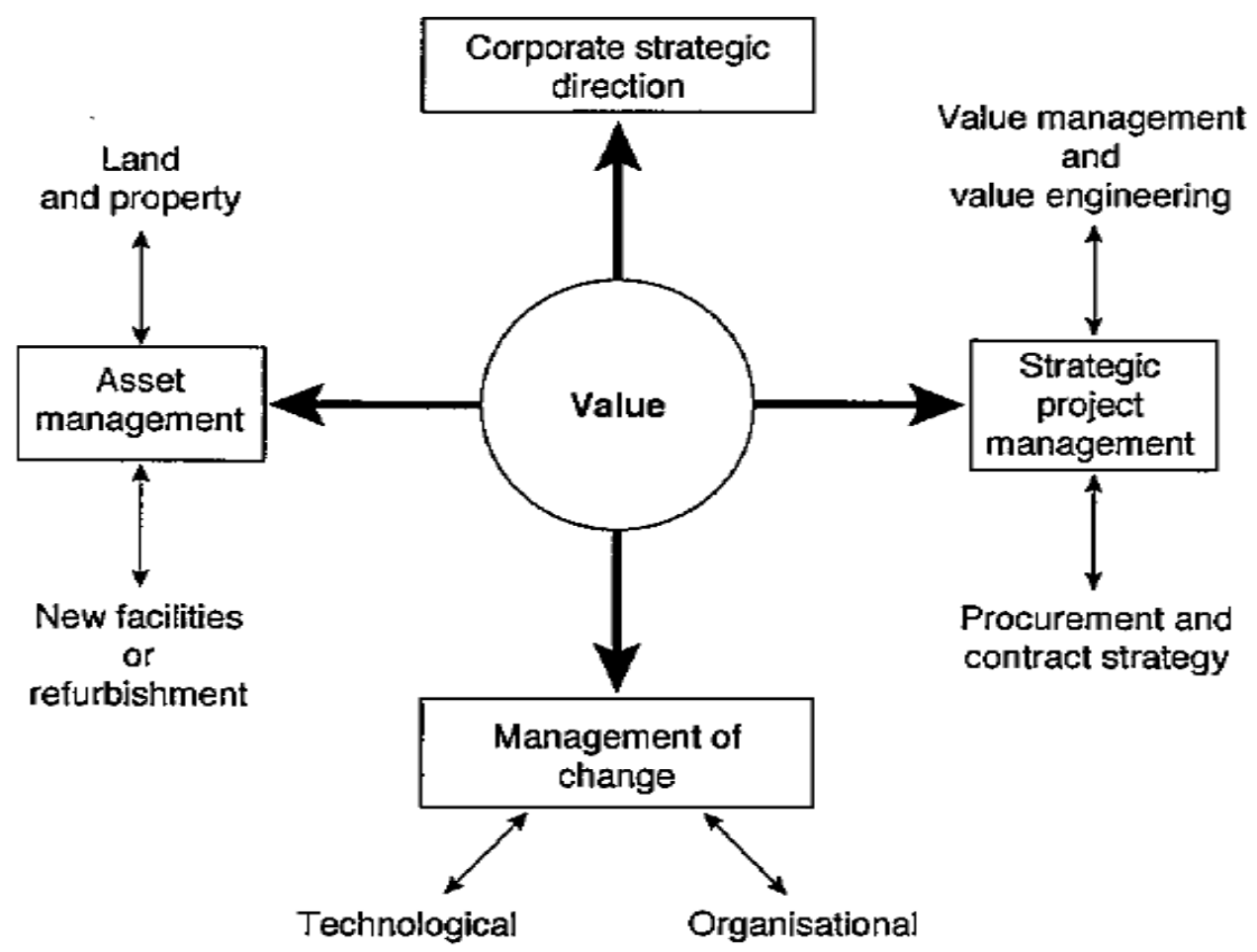

Figure 2.3 The value context of projects - source (Kelly et al., 2002), p19

\subsubsection{Systems view of value}

Value engineering is a discipline that has grown up around the notion that there is a need to identify explicitly the value of every function of each part of an engineering product. Every part is assessed for the value it brings to see how it might be improved. If parts are found to be redundant they can be removed and if parts can be redesigned to be more efficient, savings will be made (Adam, 1993). Value in value engineering is a particular subset of the broader definition of value described above.

Porter (1985) coined the term 'value chain' to describe a series of internal and external strategically important activities that when combined provide an organisation with advantage over competitors. 
Male and Kelly (1992) put forward the concept of the 'project as a value chain' within a value management framework for understanding a client organisation's requirements at the strategic and tactical stages of a project. This concept was taken further by Standing (1999) to look at a project holistically including the impact of procurement systems. Male (2002) reports that the project value chain consist of three distinct major value systems; the client value system, the multi-value system and the user value system. These reflect major transitions in any project. These value systems, in turn, consist of particular values which link, chronologically, to form the value chain for the project. The linkage between these value systems and values is shown in Figure 2.4 below which depicts the value systems of the principal parties in any contract for a variety of procurement methodologies.

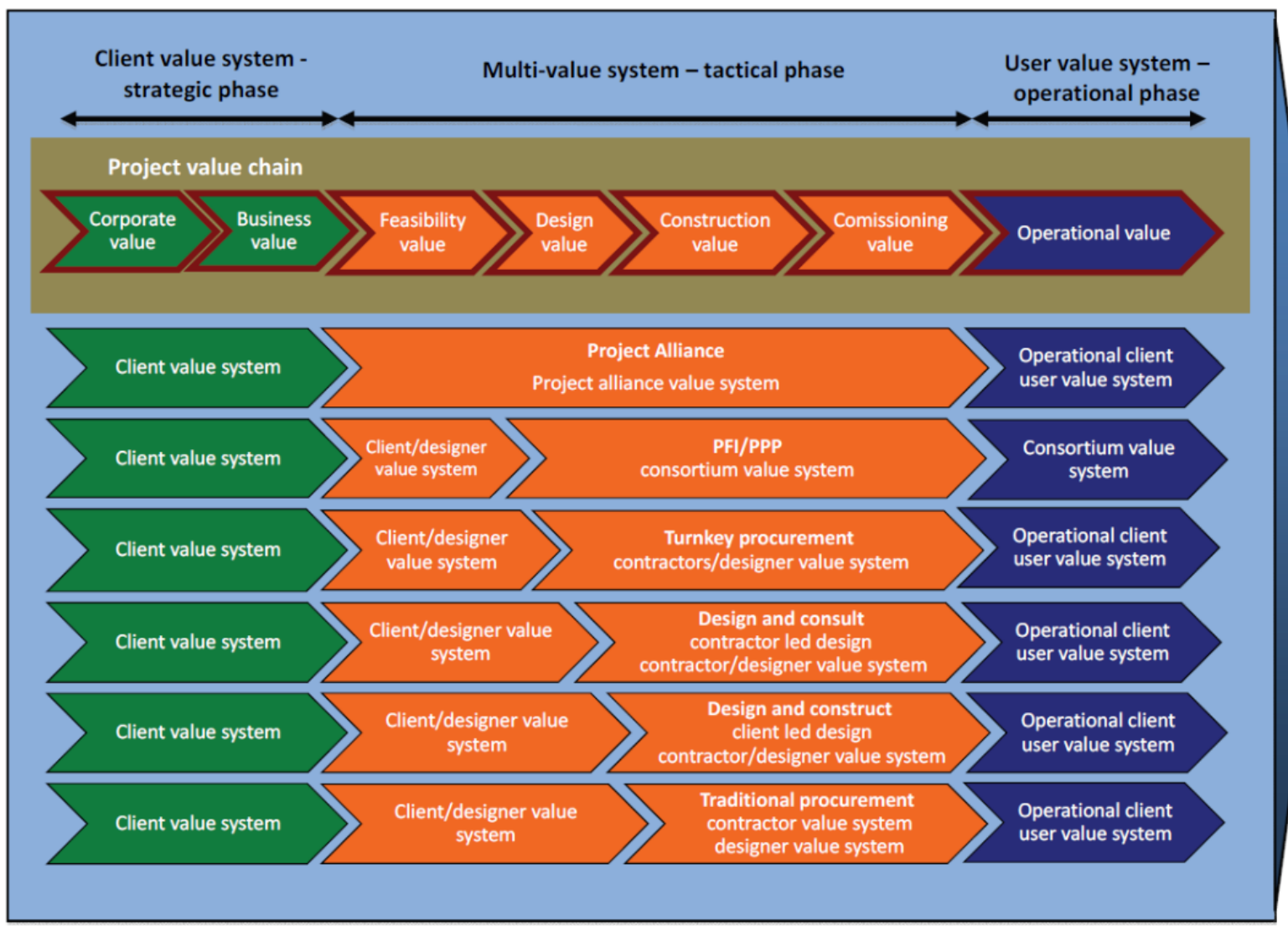

Figure 2.4 Schematic of procurement systems superimposed over the project value chain, adapted from Male (2002), p32: source Standing (1999)

Figure 2.4 above illustrates that the traditional procurement route is probably the most disruptive to the project value chain. By comparison, the project alliance model, which is described in some detail later in this thesis, is considered to better enable the value chain to be preserved. Consequently, the choice of procurement methodology is a strategic decision, made by the client, which has a fundamental impact on ensuring that value is delivered and has the capacity to assist or hinder the transfer of value through the project delivery process. 
Green and Lenard (1999) also recognise that the interfaces between organisations at the different stages of the construction supply chain, represent a problematic area in the procurement process. They argue that clear communication and clarity across each interface are vital in the establishment of a continuous value stream throughout the process from component supplier to the client organisation. Interestingly, they also state that, the interface they believe to be the most problematic, is that which exists between the client's organisation and the project. Consequently, the quest for downstream efficiencies in the supply chain must not be allowed to distract from the need to ensure that construction projects are properly assessed in terms of their contribution to the client's business processes. This emphasises the importance of the client developing a robust business case prior to selecting the procurement route. This is a theme that recurs throughout this thesis.

\subsection{Value for money in construction procurement}

It is fundamental to any discussion as to whether a particular procurement method provides $\mathrm{VfM}$, to first define what is meant or understood by the term 'value for money'. For a term which is so widely used it is surprisingly difficult to find a commonly accepted definition. At a superficial level, VfM is generally seen as obtaining goods or services for the cheapest possible price. This rather shortsighted approach has been commented upon extensively in the literature but is elegantly addressed by the UK National Audit Office (NAO) in their publication 'Modernising Construction' (2001). In the Executive Summary, p3, to this report the following comment is made:

'A succession of major studies (including Latham (1994) and Egan (1998)) have highlighted the inefficiencies of traditional methods of procuring and managing major projects - in particular the fallacy of awarding contracts solely on the basis of the lowest price bid only to see the final price of the work increasing significantly through variations with buildings often completed late. Experience has shown that acceptance of the lowest price bid does not provide value for money in both the final cost of construction or through life and operational costs. Relations between the construction industry and government departments have also often been typically characterised by conflict and distrust which have contributed to poor performance' (emphasis added).

The definition of VfM is directly addressed in the HM Treasury (UK) publication, 'Value for Money Assessment Guidance (2006), p7, which provides particular guidance in appraising the VfM of investment proposals to be procured under Private Finance Initiatives (PFI's). The definition used here is: 
'Value for Money is the optimum combination of whole of life cost and quality (or fitness for purpose) to meet the user's requirements and does not mean choosing the lowest cost bid' (emphasis added).

Whilst PFI's have their own specific commercial drivers, it is felt that this definition is universally applicable to any procurement method.

This theme of not reducing VfM to the consideration of the lowest cost is also developed in a further UK publication series produced by the Office of Government Commerce (OCG). This series is entitled 'Achieving Excellence in Construction'. Quoting from the first guide in the series entitled 'Initiative into Action' (OCG, 2007), p5;

'The key thrust of 'Achieving Excellence in Construction' is the delivery of value for money. This is not the lowest cost but the optimum combination of whole-life cost and quality to meet the user's requirement' (emphasis added.)

The fact that these sources all come from the UK is not simply a matter of coincidence. The UK construction industry has taken what might be termed in colloquial language 'a good long hard look at itself' in recent years having come to the realisation that it needed to understand why its performance was so poor, particularly in comparison with mainstream manufacturing industries. Whilst there had been a series of government sponsored reports into the performance of the industry between 1944 and 1998 (Murray and Langford, 2003) each suggesting some degree of reform, most of these documents had resulted in little or no action. However, the Latham (1994) and the Egan (1998) reports appear to have genuinely galvanised the industry into action. Both of these reports made specific reference to the issue of $\mathrm{VfM}$.

Latham (1994), p58, makes the following general point:

'Clients should choose contractors and consultants on a value for money basis with proper weighting of criteria for skill. Choice of the lowest tenderer may neglect considerations of cost in use or indeed final (out-turn) cost of the project' (emphasis added).

Egan (1998), p31, makes a more specific comment regarding VfM in alliances and partnering arrangements that goes to the very core of the question being raised in this thesis:

'The most immediate savings from alliances and partnering come from a reduced requirement for tendering. Whilst this may go against the grain, especially for the public sector, it is vital that a way is found to modify processes so that tendering is reduced. Clients 
may well ask how they can be satisfied that they are getting value for money. The answer lies in comparison between suppliers and rigorous measurement of their performance. With quantitative performance targets and open book accounting, together with demanding arrangements for selecting partners, the Task Force believes that value for money can be adequately demonstrated and properly audited' (emphasis added).

A report which addresses the status of the Australian construction industry and specifically refers to VfM is 'Building for Growth' published by the Commonwealth, Department of Industry, Science and Resources (1999). This report was prepared by the National Building and Construction Committee (NatBACC) an organisation formed by the Commonwealth in 1997. The report analysed the then current state of the Australian building and construction industry and identified areas where it intended to strengthen its capabilities, resulting in an 'Action Agenda' for the longer term.

The report warned about complacency and the 'business as usual' mindset that it believed existed in the industry. It was particularly concerned about the state of international competitiveness of the Australian industry.

The following quote from the document, $\mathrm{p} 49$, illustrates that the report recognised the need for change in the industry, the importance of VfM and the role that alliance contracting, in particular, might make in the development of more cooperative relationships.

'Alliances, however, may not be appropriate for all projects. The focus on the outcomes of projects, the needs of clients and value for money for the client will become more important throughout the industry, fuelled by the pace of technological change and the globalisation of markets. This means it is likely that the principles of project alliances will become more widespread as firms develop closer and more cooperative relationships with customers and suppliers' (emphasis added).

\subsubsection{Revaluing Construction Initiative}

'Revaluing Construction' is an initiative of the International Council for Research and Innovation in Building and Construction (CIB) that was initially agreed upon in 1997, formally commenced in 2001 and reported upon in 2005 (Barrett). In this report the objective of 'Revaluing Construction' (RVC) was clarified as 'the maximisation of the value jointly created by the stakeholders to construction and the equitable distribution of the resulting rewards. This report summarised several years of work, including surveys, workshops in five countries (USA, UK, Australia, Singapore and Canada) and five mini-reports commissioned for the project. 
The seven major factors that were identified as being critical to this objective are described in Figure 2.5 below. This has been labelled as the 'global agenda' in the form of an 'infinity diagram'. The important characteristic of this diagram is not its parts, but rather the connection between those parts. The left hand side, which 'looks out' emphasises the argument for looking broadly beyond existing categorisations, mindsets and images of the industry. The right hand side, which 'looks in', identifies actions to enhance the performance of the industry.

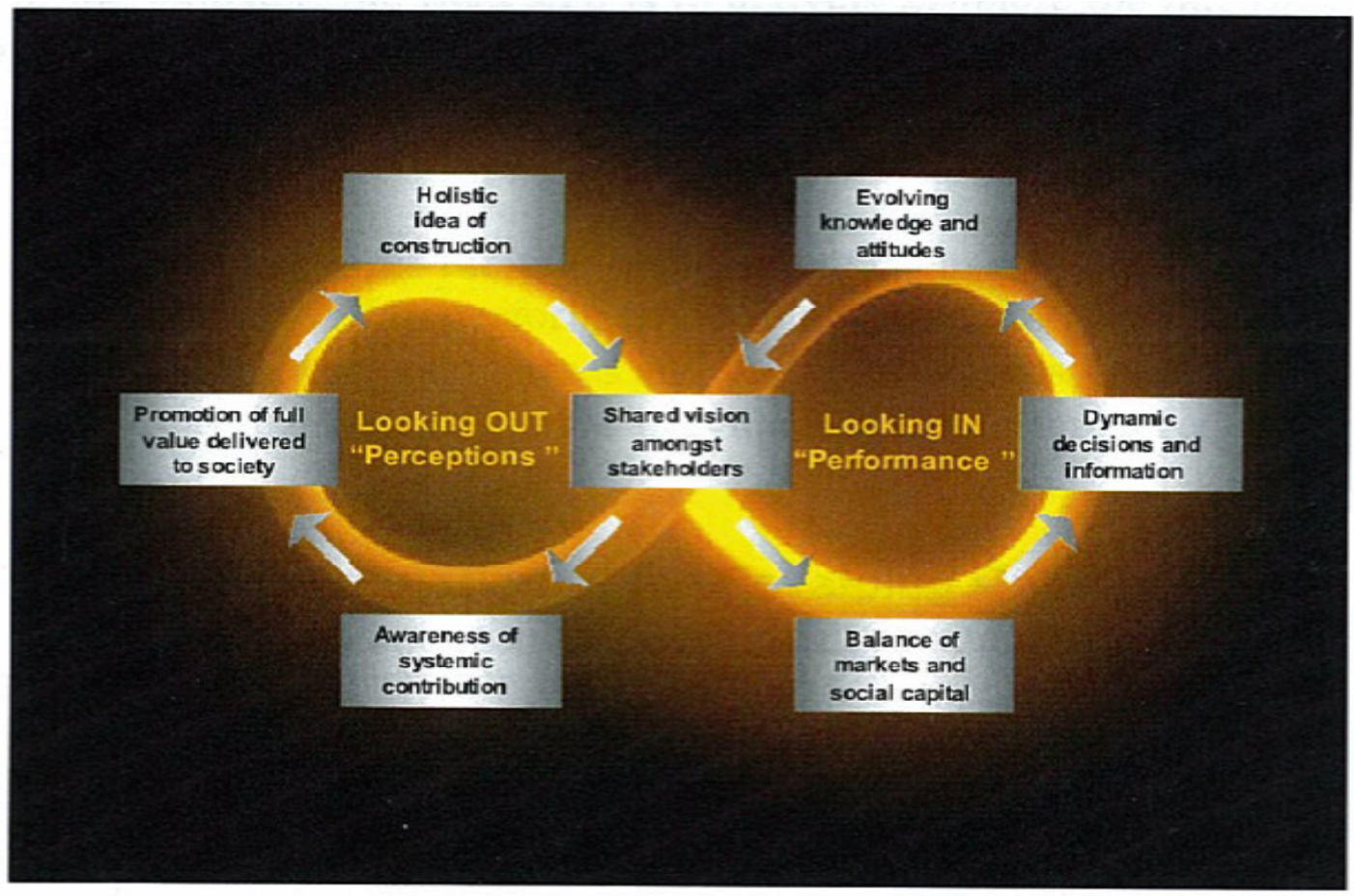

Figure 2.5 Global agenda for Revaluing Construction from Barrett (2005), p1

The 2005 report was considered at a CIB Symposium in Rome in 2006 following which the RVC model was adapted to define seven action areas as shown in Figure 2.6 below. A position paper was commissioned for each action area and these were reported in CIB Publication 313 (2007). The action area entitled 'Appreciation of soft and hard contributions' was addressed by a paper prepared by Langford (2007) entitled 'Revaluing Construction- hard and soft values' .

Langford (2007) takes issue with the orthodox view of HM Treasury (UK), described earlier, that value, whilst extending beyond an economic bottom line, is unambiguously to the benefit of the client. Langford argues that the hard values which had driven the reform agenda between 1996 and 2006 were based on rational instrumentalism and consequently were positivist in outlook. Langford also argues that, to that date, the underpinning ideology of value in construction had been dominated by economic ideas set in neo-liberal capitalism i.e. a condition in which stakeholders in 
construction are said to share the benefits of the process improvements which add 'value'. Langford suggests that at the date of his paper, there was little evidence that such an ideology offered equitable sharing of created value. For clients and users the value proposition is satisfaction of their expectations. Such value propositions will be subject to social and political interpretations of what constitutes value and these interpretations will go beyond the philosophy of instrumental rationality. The value of giving wealth on the supply side of industry and satisfaction (if not delight) to the demand side can help to balance the value delivered to stakeholders in the construction industry.

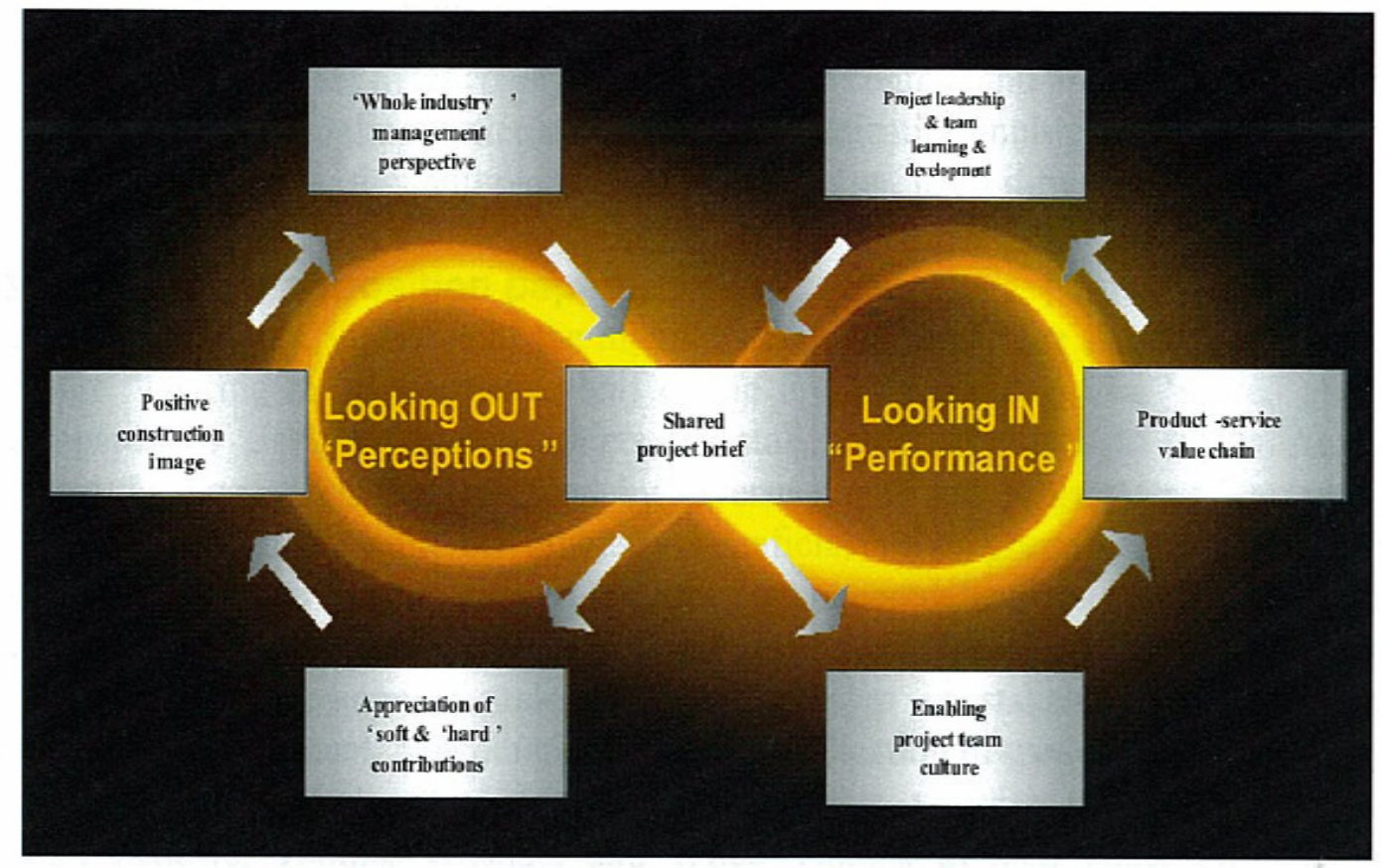

Figure 2.6 CIB W065 Revaluing Construction agenda from Barrett (2005), p10

\section{$2.4 \quad$ Public Sector Procurement}

Procurement of construction works involves the investment of considerable sums of money.

Consequently, in all construction spending, but particularly in the public sector, demands are made to demonstrate that value is being obtained for the expense incurred. This leads to a consideration of how VfM is specifically defined in the public sector. It is the role of governments to provide services and infrastructure for the 'good of the nation', utilising taxpayer's dollars for best VfM through 'the proper management of public money and public property' (Comm-Aust, 1997). Whilst each may have different ways of expressing their requirements, Federal, State and Local governments all place considerable emphasis on the need to achieve VfM, as remarked by the Australian National Audit Office (2003). Examples of VfM definitions and the expression of these requirements include: 
- Australian Commonwealth Government; '...officials buying goods and services need to be satisfied that the best possible outcome has been achieved taking into account all relevant costs and benefits over the whole of the procurement cycle' (Comm-Aust, 2005).

- New South Wales Government; 'Value for money is defined as the benefits compared to the whole of life cost' (NSW-Treasury, 2005).

- Queensland Government; 'Ensuring value for money is one of the three objectives of the State Purchasing Policy. Government purchasing must achieve the best return and performance for the money being spent. Price is not the sole indicator of value' (QLD-DPW, 2000).

Whilst it seems that there is general agreement in the Australian public sector that VfM is a good thing, there is less agreement over what VfM actually is. Hensher (2006) captures this point well with his statement, regarding the procurement of public transit services, that '...value for money ( $a$ popular phrase, defined so often as doing more with less), rather than the preferred definition (globally) of maximising accessibility or net social benefit per dollar of government spending' . This emphasises achieving the best outcome for the expenditure undertaken rather that minimising capital outlay. In the view of the researcher, this should be a fundamental principle but is, unfortunately, often disregarded, in favour of the cheapest price approach, particularly in government procurement.

The question arises 'Is VfM best served by the, so called, competitive tendering process'?

There is a deeply held view in many public bodies and also in some sections of the private sector that $\mathrm{VfM}$ is best achieved, or in the extreme, can only be achieved, through a procurement model that involves a competitive tendering process and contract.

This approach assumes a competitive market to ensure a fair and equitable price is paid for goods and services (NSWAG, 2003b). However, in Australia the market place for major construction projects is small and there are a limited number of suppliers in the marketplace. Whilst there are some projects which attract overseas interest, generally, the size and number of significant projects, the remoteness of the country and the relatively high level of competence of the local industry effectively act as 'barriers to entry' for overseas companies.

Consequently, for more complex construction projects it is very doubtful that the local industry acts as the 'perfect market' necessary to justify relying entirely on price competition to provide a guarantee of VfM. This issue is specifically addressed by Sweeney (2009) and a summary of his findings are provided in Chapter 3. 


\subsection{Project Procurement Processes}

Before introducing relationship contracting generally and alliancing in particular, as a form of procurement approach that directly considers VFM and addresses many of the 'ills' in construction procurement that have been identified above, the following matters are addressed in some detail in this section:

- risk allocation in procurement;

- cost versus price based procurement

\subsubsection{Risk allocation in procurement}

A fundamental difference between relationship contracting and more traditional procurement methods is the manner in which the risk is borne by the parties to the contract (MacDonald, 2001). Consequently, in order to understand the dynamics of an alliance contract it is necessary to address the issues of risk and risk sharing in construction contracts.

The US Construction Industry Institute, Partnering Task Force - Interim Report (USCII, 1989) states that;

'Project cost benefits can be realised when risk allocation is tailored to the circumstances of the individual project. Owners who routinely force maximum assumption of risk on the contractor are likely to incur higher project costs. Contract preparation that allocates risk with a balanced input from all parties will be most effective.'

This statement illustrates the key link between the appropriate allocation of risk and the achievement of VfM in the delivery of a project. It discussing the manner in which risk is shared in construction contracts it is helpful to start with a definition of risk. There are numerous definitions available in the literature but the following two are of assistance in introducing the points that will be addressed in this thesis.

Definition 1: 'Risk is the chance that a particular set of conditions will happen in a stated context'. (Blockley and Godfrey, 2000), p185.

Definition 2 : 'Risk is a source of uncertainty in achieving defined objectives, with the level of uncertainty associated with an individual risk being a combination of likelihood and the impact of the occurrence in those objectives' (Broome, 2002), p355.

This latter definition is similar to that adopted in a number of relevant ISO and national standards addressing risk and risk management. 
Abramson (1979), p439, stated, at a time when it was routinely expected that a contractor should assume all risks, that 'the draconian view which seeks to place all risk on the contractor and the belief that a contractor should be safeguarded against all risk and in effect guaranteed his costs plus a profit are both an over-simplification. Each risk has to be examined separately and it may be that different solutions are appropriate'.

Trench's view (1991) is that 'the more risk the employer transfers to other parties, the more he must expect to pay for the privilege. Thus the employer should ensure that risk is wisely transferred as it is in his own financial interests'.

The view expressed by the Australian Constructors Association (1999), p8, is that 'poorly defined objectives, inadequate time and cost planning, unreasonable risk allocation and inadequate project personnel contribute to the failure of traditional risk transfer strategies.'

Two further references regarding risk allocation, specific to the Australian industry, are:

'Construction 2020 - A vision for Australia's property and construction industry' produced by the Cooperative Research Centre (CRC) for Construction Innovation (2004)

'Construction 2020' in a similar fashion to 'Building for Growth' produced earlier by the Commonwealth Government Department of Industry, Science and Resources (1999), identified that globalisation, advances in technology, environmental factors and changes to the structure of the Australian economy were presenting new challenges to which the construction industry needed to respond. 'Construction 2020' was a research initiative that sought to capture what the Australian industry believed to be its future directions. It also aimed to explore the barriers to achieving this future and to identify further research required to facilitate the changes required.

It is noted that of the nine future visions identified for the industry, two related to 'meeting clients' needs and 'improved business environment' which specifically identify the fragmented and adversarial industry structure, inequitable risk sharing and poor image of the Australian industry. These visions call for a more collaborative and cooperative approach to address client and community needs whilst enhancing profitability.

'Scope for Improvement - A survey of pressure points in Australian construction and infrastructure projects' produced by the Australian Constructor's Association and Blake Dawson Waldron (2006).

'Scope for Improvement' identified five main issues that were considered to be hampering the performance of Australian construction and infrastructure projects. These issues included the use of 
inappropriate delivery methods and poor risk allocation. It was concluded that these issues created major pressure points across the life cycle of projects and significantly contributed to adverse outcomes such as cost overruns, delays and disputes.

A popular mantra in relation to risk is to allocate it to the party best able to manage it. This is, in reality, too simplistic and in any event is rarely truly adopted. The allocation of risk is a critical issue to address in determining the most appropriate procurement strategy for any given project.

\subsubsection{Cost versus price based contracts}

Whilst there are a large number of possible procurement options available to the owner to deliver a given project they all fall into one of two general types being either price or cost based;

\section{Price or output based contract}

In such a contract, the basis for paying the contractor is that an output is achieved or completed. Such an output is typically a milestone of some sort or a unit of quantity. In this type of contract the client is not directly concerned with what it costs the contractor to achieve that milestone or produce that quantity, as the contractor will only be paid the price offered and accepted by the client on entering the contract.

The price based philosophy is embraced in most traditional procurement options - including design followed by construction, design and construct contracts and to a great extent in construction management and prime cost contracts.

The claimed advantages of a price based approach are that (Broome, 2002), p70;

- The selection process uses competition to achieve the minimum price for the work.

- Once certain criteria are met, price becomes the only basis for selection and the winner is very easy to determine; it is therefore very auditable as the final selection process involves little subjectivity.

- The client, having had full responsibility for the design, gets exactly what is wanted.

- Provided that the client has specified exactly what is required, there is certainty of financial outcome.

There is a traditional view, particularly in the public sector that, unless a price based approach is adopted, the contractor may, and probably will, take advantage of the commercial situation. The implicit notion is that the contractor will only be kept 'honest' by the commercial pressure of 
competitive tendering and that $\mathrm{VfM}$ can only be guaranteed if the 'price' for the contract is firmly established prior to the commencement of any work.

It is the view of the researcher that this position is flawed and does not represent the reality of the modern construction industry.

Broome (2002), p70-71, also argues that all price based contracts have the following disadvantages:

- The client does not have any certainty regarding the build up of the contractor's price and such access is not provided. As a consequence, when variations or claims occur there are invariably disagreements or disputes over the cost of the charges. This is one of the biggest causes of disputes in the construction industry and, consequently, if a mechanism to avoid this conflict can be identified, a considerable advantage can be achieved. This is one of the major advantages of an alliance model as will be described later

- From a client's perspective, once the contract is signed, there is little or no incentive to minimise construction costs. The motivations of the client and the contractor are therefore not aligned.

Consequently, in price-based contracts, clients seek to restrict increases in prices rather than helping to reduce contractor's costs. Conversely, the contractor seeks to increase the price to cover his costs plus making a contribution to head office overheads and profit. This tension exposes a significant flaw in price-based procurement mechanisms i.e. that they do not create alignment of financial objectives.

As has been described earlier, traditional price based procurement methods have been in use for many years and whilst some dramatic examples are quoted to illustrate what can go wrong with such an approach, in reality, there are many more examples of the traditional methods being used quite successfully. It is, however, important, to ensure that the project is suited to the somewhat inflexible environment of such methods.

However, if the scope of the project is well defined, the client knows exactly what is required, the start and the end of the construction phase is not strictly time driven and the technology involved is well known and understood, then a price-based procurement approach using a conventional pricecompetitive tender is likely to provide a good fit and may well represent $\mathrm{VfM}$.

However, if the above ingredients are not in place i.e. there is a very pressing demand for an early start and completion, the scope is not well defined and understood or the technology is not well 
developed then alternative cost procurement methods, which align objectives, promote innovation and are founded on a cost-based approach are likely to be more suited.

\section{Cost based contracts}

Cost-based contracts can take many forms including (Walker and Hampson, 2003, Masterman, 2002):

- Cost reimbursable;

- Target cost; and

- Cost plus award fee.

The common element is that such contracts operate on the basis that the contractor should be reimbursed costs plus a fee as the contract progresses. At first sight it may seem cost-based contracts provide incentive for the contractor to maximise cost particularly if there is a fixed percentage fee. However, this perspective overlooks the point that such an approach is usually adopted, in the first place, precisely because the work is time driven, ill-defined and subject to a high level of risk. It also ignores to point out that under such circumstances, the final cost would probably be much higher if a price-based approach were adopted. The reasoning behind this later statement is explored later in Section 2.10 below.

A perceived disadvantage of the cost based approach is that contractor's accounts have to be auditable and transparent, so that a system needs to be in place to audit accounts on an ongoing basis. In fact open book accounting offers a number of major advantages to both client and contractor: These include (Blockley and Godfrey, 2000):

- Risk contingencies can be separated from the basic costs of construction and designed to become more visible to the client. Clients can then realise how much they are paying for contractors to take risks which may include several hierarchies of premium as provisions are added at each level of subcontracting. This encourages parties to take a more collaborative approach to risk management and more informed approach to risk allocation.

- Contractors are generally more aware of market rates and the programming and cost implications of alternative design strategies. Consequently early involvement of contractors and designers enables the process of designing to a client's budget rather than pricing what has been designed. $\quad$ The open book approach is complimentary to a two-stage selection process whereby the contractor is initially selected using a combination criteria designed to test their potential to 'add value' to the project processes and outcome. 
- Open book accounting assists in identifying the implications of unidentified risks and can trigger early activation of previously developed risk mitigation strategies. The client has full access to this information so that as risks do or do not occur, or greater than anticipated value engineering opportunities arise, the project can then be adjusted or restructured to come in on budget. This is to be contrasted to a traditional price-based approach where a client might be aware of claims being imminent but has little information regarding the reasoning and quantum of the claim and it could be several years before the matter is resolved and monies paid.

- A much more proactive approach to cost management compared to the reactive confrontational 'maximise claims' approach of price-based contracts.

- If a motivational target is established then any necessary adjustment can be easily made compared to a price-based contract. This is particularly the case if the adjustment is made before the work is done given that any exaggerated adjustment suggested by the contractor is more likely to be uncovered in the 'transparent' open book environment.

The primary comparative advantages of a cost based/open book approach compared to a traditional priced based approach are summarised in Table 2.2 below.

Table 2.2 Comparative advantages of cost based payment (Broome, 2002), p190

\begin{tabular}{|l|l|l|}
\hline Attribute & $\begin{array}{l}\text { Open book/cost-based } \\
\text { payment mechanisms }\end{array}$ & $\begin{array}{l}\text { Traditional price-based } \\
\text { payment mechanisms }\end{array}$ \\
\hline Cost visibility & Transparent & Little transparency to client \\
\hline Risk & Separate from cost & Hidden \\
\hline Design & Design to cost & Cost to design \\
\hline Pricing Structure & Various approaches & Predominantly competitive \\
\hline Monitoring/forecasting & More up to date & Wait for 'claim' \\
\hline Management approach & Proactive cost reduction & Reactive cost containment \\
\hline Agreeing adjustment to & High transparency so & Little transparency, so \\
\hline target /contract price & relatively easy & relatively difficult \\
\hline Incentives & As appropriate & No real consideration \\
\hline
\end{tabular}


If the 'secrecy' associated with price based contracts is avoided, the parties are far better placed to develop a trusting professional relationship that will truly deliver what the client actually wants rather that the minimum solution that the contractor can provide for the quoted price.

However, this is not to say that certain 'checks and balances' are not necessary to ensure that the parties do behave appropriately. Such measures, as they relate to alliance contracts in particular, are addressed later in this thesis.

To summarise, the key differences between price and cost based contracts are the transparency of cost based contracts and the open and candid discussion of risk and opportunities that provides, in the view of the researcher, the potential for delivering superior VfM for a client compared to traditional price based contracts.

\section{Section B - Relationship Based Procurement}

\subsection{Relationship based contracting}

Over the last fifteen years or so, there has been an increasing level of dissatisfaction amongst many of those involved within the Australian construction industry regarding the adversarial and inefficient environment in which construction projects are often undertaken (ACA, 1999). This problem is not unique to Australia and such concerns are widely reported in relation to construction contracts in a number of other countries including the UK and the USA (USCII, 1989, Latham, 1994, Egan, 1998, Blockley and Godfrey, 2000, Murray and Langford, 2003, Walker and Hampson, 2003, Davis, 2005).

There is deep concern that the construction industry, as a whole, has historically under-achieved. Over time, there has been a long record of low levels of profitability and low levels of investment into research and development and training. Importantly, a large proportion of the industry's clients are dissatisfied with its overall performance (Latham, 1994, Egan, 1998, DISR, 1999).

During a period when other industries have experienced radical change and improvement the construction industry remains a victim of the conflict inherent in many of the procurement models used to deliver construction works.

The researcher takes the view that the traditional contracting culture, which often results in a confrontational and an adversarial atmosphere, is often unsuited to the successful delivery of VfM in the contemporary construction industry. This position is supported by a number of sources, including industry reports relating to the construction industry both in the UK and Australia. The UK publications include 'Constructing the Team' (Latham, 1994), 'Rethinking Construction'(Egan, 1998). Australian publications include 'Building for Growth'(DISR, 1999), 'Construction 2020' published by 
the Cooperative Research Centre for Construction Innovation (2004) and 'Scope for Improvement' published by the Australian Constructors Association (ACA) and Blake Dawson Waldron (2006). The contents of the last two documents, as they relate to the allocation of risk in procurement, were discussed earlier in the Section 2.4.

A schematic diagram contrasting the potential differences between a confrontational and cooperative approach to construction procurement is provided in Figure 2.7 below. This diagram is based on a model developed by Blockley and Godfrey (2000) to illustrate the potential impact of systems thinking but serves to contrast what can potentially be achieved in moving from a 'culture of confrontation' to a 'culture of cooperation'.

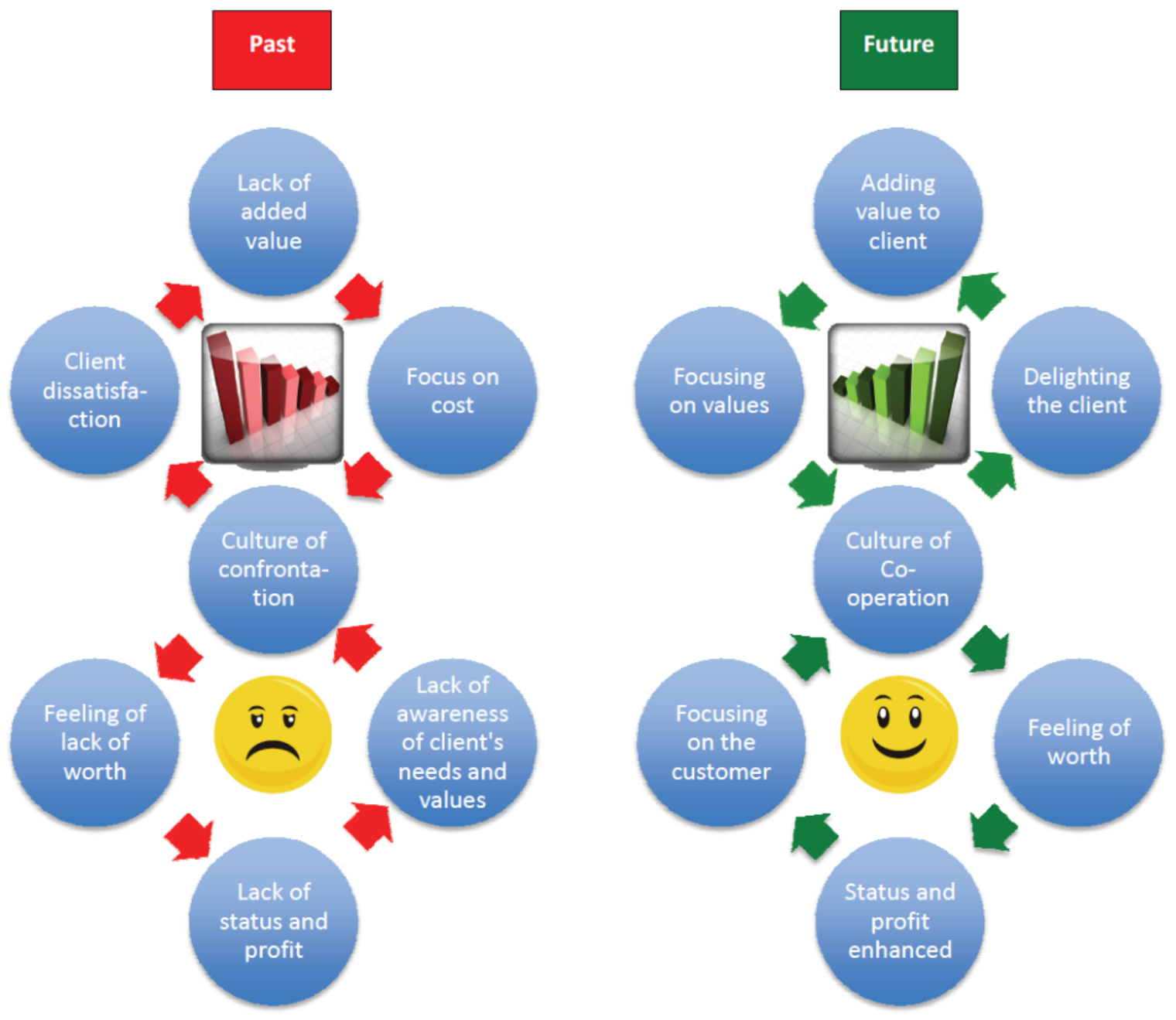

Figure 2.7 The opportunities available in moving from a 'culture of confrontation' to a 'culture of cooperation adapted from Blockley and Godfrey (2000), p5 
There is a procurement approach which, it is claimed (ACA, 1999, USCII, 1989), addresses a number of the shortcomings identified above and this is 'relationship contracting'. This form of procurement has emerged over the last twenty years and has been quite widely used in its various forms in a number of countries around the world. It has achieved some spectacular success and whilst there have been some notable failures; these are relatively few in number.

If this is the case one might well ask 'why has such a seemingly successful model not been more widely accepted by the industry'? The answer appears to be that relationship contracting requires the adoption of a different philosophical approach on the part of the project participants. It necessarily involves the development of mutual trust, open and honest communication and free sharing of information. Such conduct is quite contrary to the pattern of behaviour that is associated with, and normally conditioned by, the 'traditional' models of construction procurement. It should not be a surprise, therefore, that it is not easy for some people who have been involved in the industry in the past to suddenly change their mind set and embrace the 'brave new world' of relationship contracting.

Despite these hurdles, an increasing number of clients and contractors have shown interest in the model. Furthermore, it appears that in the majority of cases once parties have used such models they are keen to use them again, albeit that they may view them as only being appropriate for particular types of projects (Ross, 2003a, Ross and Purcell, 2005, Hutchinson and Gallagher, 2003).

One of the significant 'barriers to entry' of relationship contracting, particularly amongst those who normally participate in a role as an owner or in support of an owner, is a suspicion about the motivations of contractors who seem so keen to advocate this procurement approach. The experience of using the traditional adversarial approach leads these parties to the view that the contractor can only be interested in such a model if it offers them some significant advantage and thus by definition, this must represent their disadvantage. Such a view is not surprising given the 'rules of the game' that have applied for so long in construction contracting. The key point that needs to be appreciated by all potential participants to a relationship based contract is that the purpose of the exercise is to ensure that all parties benefit and a 'win-win' outcome results. It appears that some forms of relationship contracting are more successful than others in achieving this aim, but all set out to do so.

As is often the case with emerging fields there are a variety of definitions in use which often lead to misunderstandings and this problem seems to particularly plague the field on relationship 
contracting. Consequently it is important to precisely establish what is being described by the terms used.

\subsubsection{Definitions of Relationship Contracting}

The following definitions of relationship contracting assist in understanding the concept:

Gunn (2002) has described relationship contracting as follows, p2:

In the last decade the procurement, engineering and construction industries have experimented with new styles of contract in an attempt to achieve an outcome that is acceptable to all parties. The term 'relationship contracting' has been coined to describe these different approaches'.

The Australian Constructors Association (ACA) (1999), p4, has defined relationship contracting as:

'... a process to establish and manage the relationships between the parties that aims to "remove all barriers; encourage maximum contribution and allow all parties to achieve success'.

There is a wide range of possible arrangements within the spectrum of relationship contracting. At one end there is a basic partnering charter in which parties commit their best endeavours to creating a collaborative working relationship. At the other end of the spectrum is a formal alliance agreement. In between, there are a variety of contracts which involve some form of incentive and direct cost reimbursement.

Figure 2.8 below from Skinner (2006) illustrates that this range of relationship contracting options sits at the higher 'risk embrace - cooperative strategy' end of the broader spectrum of construction procurement options. The relationship contracting terms used in this figure i.e. 'pure alliance', 'competitive alliance' and 'early contractor involvement' are explained later in this chapter.

\subsubsection{Relationship Structures}

The structure of the relationship between project parties can be classified as either collaborative or cooperative. The term collaborative relates to arrangements where the parties work together in the short term and the term cooperative applies to longer term arrangements (Love et al., 2002).

The collaborative approach is focused on a single project which does not always provide opportunity to internalise a partner's skills (Holt et al., 2000). By contrast the cooperative approach is a strategic 
model that looks at a more enduring relationship, beyond a discrete project, and seeks to achieve specific business objectives by maximising the effectiveness of each participant's resources.

The project based collaborative approach is a method of transforming contractual relationships into a cohesive project team that complies with a common set of goals. The strategic model involves a cooperative relationship between at least two organisations which is established to achieve long term goals and objectives for the purpose of achieving competitive advantage (Cheng et al., 2001).

A clear difference between the project and strategic models is that the later cooperative approach specifically facilitates knowledge transfer. Whilst learning can occur under both models under the cooperative approach the learning is more intense and double loop learning, involving the change of an organisation's knowledge base, competencies and routines can occur (Holt et al., 2000).

An appreciation of these relationship structures is important in understanding the nature the various forms of relationship contracting described below.

\subsection{Forms of Relationship Contracting}

Further to the general description of relationship contracting and the fundamental structure such relationships provided in Section 2.6 above, the various forms of this approach are now described in more detail.

\subsubsection{Partnering}

Partnering is generally understood to mean: '.. a commitment by those involved in a project or outsourcing to work closely or cooperatively, rather than competitively and adversarial' (Gunn, 2002), p3.

Partnering, at least in a formal sense, is generally seen as having its origins in the United States although most of the processes adopted in partnering come from the Japanese construction industry and they are, in turn, the application of total quality management and lean manufacturing concepts from manufacturing industries. Partnering is a method which allows people to minimise or avoid conflict when they are engaged in a complex project. It is a way of unifying all the parties as stakeholders in a project into a team.

It is important to understand that partnering is in fact a code of conduct. There is no partnering contract, as such, rather an agreed partnering 'charter' forms the basis of a working agreement that is intended to shape a non-adversarial culture to promote a 'win-win' relationship between the parties. 


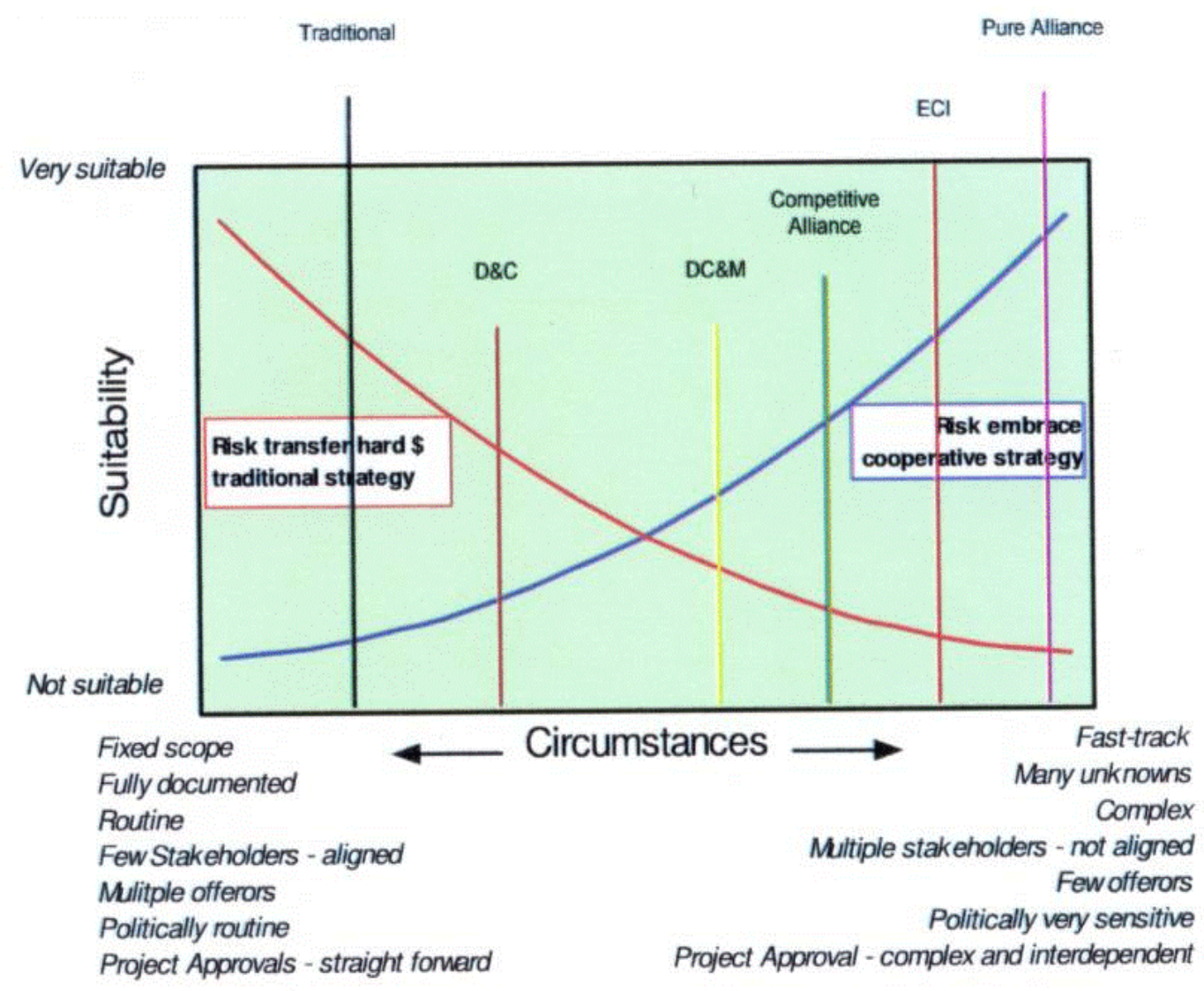

Figure 2.8 Project delivery suitability vs. project circumstances from Skinner (2006), p14, adopted from Ross (2000), p2

Partnering arrangements can range from short-term one-off arrangements associated with a single project to long term commitments between two or more organisations for the purpose of achieving specific business objectives by maximising the effectiveness of each participant's resources. The relationship is based on trust, dedication to common goals and an understanding of each other's individual expectations and values - US Construction Industry Institute (USCII, 1989). This longer term arrangement is sometimes referred to as a strategic alliance which leads to some considerable confusion in the literature and makes a discussion between the relative merits and disadvantages of partnering and alliancing difficult given the interchangeable way in which the terms are often used. Strategic Alliances and Strategic Partnering, as they are more formally defined, are discussed in further detail later in this section.

Partnering on a one-off project specific basis can start at the concept stage or more often after the contract has been awarded. Project based partnering was initially championed by Colonel Charles Cowan (1990), then of the US Army Corps of Engineers, with significant success. Partnering is now 
used by the Corps of Engineers in all construction contracts and has been widely embraced in the US in public sector procurement.

Partnering, particularly project-specific partnering has also been widely embraced in the UK following the Latham Report, (1994), which advocated the development of a team approach to construction. This movement was then given even further impetus by Egan Report, (1998) which identified integrated processes and teams as being amongst the key drivers needed to set an agenda of change for the construction industry as a whole.

\subsubsection{Project Alliance}

Alliance contracting is the term used to describe an arrangement where parties enter into an agreement to work cooperatively and to share risk and reward, measured against an agreed set of performance indicators. The owner and service providers work as a single integrated team to deliver a specific project under a contractual framework where their commercial interests are aligned with actual project objectives.

Alliancing involves a formal contract in which the parties undertake to act in the best interests of the project and this is a key difference from partnering where the undertaking to act in such a manner is purely voluntary.

It is generally understood, although perhaps not universally recognised, that a contactor must make a profit from a contract in order to survive commercially. It also needs to be recognised that the client has a direct influence on the way in which the contractor makes a profit, through the selection of the procurement strategy. The key philosophical principle in the selection of an alliance approach is the recognition that the contractor's profit should be earned through performance and not on the contractor's ability to make and win claims (Bowyer, 2003).

The essential components of a project alliance are as follows (Ross, 2003a):

- $\quad$ Participants are selected on capability, approaches and systems plus some subjective criteria such as enthusiasm, commitment, chemistry with the sponsor team and likelihood of the combined team delivering outstanding results. Price is not normally part of the selection process ('pure' alliance) although in recent years a 'competitive price' model has developed in which two parties develop a target cost before the alliance is formulated with a selection being made on the lowest price. Advocates of the 'pure' alliance approach argue that this amounts to little more than a regular design and construct contract in practice. 
- A commercial framework is created that drives 'best for project' decisions that are consistent with and create an environment of exceptional performance and enhanced reward for all participants.

- $\quad$ There is a commercial framework that shares the rewards of outstanding performance and shares the pain of poor performance. This is sometimes referred to as a 'gainshare/painshare' regime.

- $\quad$ All risks and rewards are shared by all the members of the alliance.

- The only way to increase "profit" is by performance which exceeds "business as usual" outcomes - sometimes referred to as minimum conditions of satisfaction.

- $\quad$ An integrated team is formed and personnel are selected on a "best for project" basis.

- $\quad$ All decisions at the most senior/Project Board level must be unanimous.

- A 'no blame' culture in which there can be no formal disputes.

Alliancing represents a 'risk sharing' culture under which the parties seek to better manage risks by embracing them (rather than trying to transfer them) and then work together to manage them within a flexible project delivery environment. It is an agreement between two or more entities who undertake to work cooperatively, on the basis of a sharing of project risk and reward, for the purpose of achieving agreed outcomes based on principles of good faith and trust and an open-book approach towards costs.

In contrast, traditional contracting creates a 'risk transfer' culture where the parties seek to transfer as much risk as possible to others under a range of separate contracts. Under a traditional contracting arrangement, the owner and the main contractor would enter into a master/servant style contract for the performance of the works and the main contractor would then flow-down as many risks as possible by using a series of master/servant style subcontracts.

\subsubsection{Program Alliance}

A program alliance is essentially a long term (5-10 year) arrangement where the participants are engaged to undertake a series of projects each delivered under a project alliance model. At the commencement of the arrangement, the specific number, scope and duration of the projects may be unknown. 


\subsubsection{Strategic Alliance}

A strategic alliance is one in which an agreement or contract has been reached between a client and contractor and consultant to undertake projects of a similar nature over an extended period, usually a number of years (Broome, 2002). However, the exact requirements of the work concerned are not known at the outset of the alliance.

Strategic Alliances can be delivered under a 'service agreement' or a 'service contract'. Under a 'service agreement' each project is let as a separate contract but governed by the terms of the alliance agreement. Alternatively, under a 'service contract' each project is a separate task or scheme governed by the original contract for the duration of the contract.

The advantage of the 'service agreement' is that it offers increased flexibility. Arguably, from a public sector procurement perspective, only 'service agreements' would satisfy statutory auditing guidelines. However, such a position is considered to be somewhat pedantic and both procurement arrangements are generally seen to be legitimate as long as the appropriate probity processes are in place.

\subsubsection{Strategic Partnering}

In contrast to the term 'Strategic Alliancing' the term 'Strategic Partnering' is seldom used at least in the construction field. In a similar manner to the use of the word in alliancing, the term strategic in the partnering context refers to the longer term in which there is a broader development of a relationship.

As indicated earlier, partnering can take many forms and as with alliancing, there is a spectrum of relationships that fall under the definition of partnering. It should be noted that many of the arrangements described in the broader non-construction based literature as strategic alliances are, in fact, strategic partnerships because they do not provide for the full sharing of risk between parties and often maintain arrangements where one party can take action against the other if they consider that the other party has failed to perform in some regard. For that reason they fail to meet the most critical test of a true alliancing arrangement.

\subsubsection{Early Contractor Involvement (ECI)}

Early contractor involvement is effectively a hybrid arrangement which employs alliancing principles up to the point at which the turn-out cost (TOC) is established and then reverts to a fixed price, risk allocated model similar to 'design and construct' contract, from that point onwards. A comprehensive discussion regarding the advantages and disadvantages of the $\mathrm{ECl}$ approach is provided by Quick (2007). ECl is similar to a Two Stage Managing Contractor model and both 
approaches are, at least in part, a reaction to the need for public sector clients to place a considerable number of personnel in alliance teams if the project alliance model is to be successful.

\subsubsection{Training/coaching in relationship contracting}

A clear understanding of the different forms of relationship contracting is important for parties who are seeking to enter into either an alliance or a partnering arrangement. Unfortunately, the terminology actually used every day to describe particular arrangements does not closely follow the definitions described above and there is considerable confusion as a consequence. This confusion can result in parties having unmatched expectations of what they might be entering into and such a misalignment can lead to trust between the parties being seriously undermined. To avoid such misunderstandings is usually necessary to provide appropriate coaching and training to members of organisations who wish to enter into relationship contracting and this must start at the senior levels of management. Whilst it is true in most major initiatives that senior management need to lead rather than follow, it is particularly the case in relationship contracting where a cultural change is often necessary to create a successful arrangement. This training needs to overcome possible established prejudices such as 'the contractor will simply wish to take advantage of the owner' or 'the owner has no commercial acumen and will not respond in a timely manner'. In reality, in the open and candid environment of a relationship contract the chances of such behaviours being perpetuated are limited. However, the opportunities for mutual gain and substantially increased levels of personal performance and job satisfaction are very considerable.

\subsection{Essential differences between partnering and alliancing}

As explained earlier, the important distinction between partnering and alliancing is that in a partnering arrangement, aims and goals are agreed upon and dispute resolution and escalation plans are established but partners still retain their independence and may individually suffer or gain from the relationship. However, in an alliance the parties form a cohesive entity that shares all risks and rewards based on an agreed formula. Consequently, if the project fails to meet pre-agreed performance indicators then all parties jointly share the agreed penalty. Alternatively, if the project exceeds the stated performance criteria all parties share the rewards. This creates a true 'win-win', 'lose-lose' environment which is the primary driver of behaviour in an alliance (Walker and Hampson, 2003). To restate this, the key and fundamental difference between alliancing, at least in its purest form, and partnering is that, in alliancing, all risks are shared by the parties and they are not in partnering arrangements (MacDonald, 2005).

The primary disadvantage of partnering, certainly as experienced in Australia, is that all the undertakings given by the parties, whilst invariably well intended and genuine, tend to be overtaken 
by the formal contractual relationship when significant problems arise. If problems of a minor nature arise the partnering 'charter' instrument used to record the intentions of the parties usually provides a mechanism for settling matters at whatever level is appropriate and thus the arrangement can be very successful. However, if a more serious dispute arises which cannot be readily resolved by the procedures described in the charter, the parties invariably 'reach to the bottom drawer' and pull out the contract document. Once that stage is reached parties revert to their formal position as prescribed in the adversarial language of the contract. Under these circumstances the situation can actually become more 'poisonous' than in a project where partnering has not been adopted in the first place. Having developed a closer sense of trust between the parties the reversion to the adversarial conduct associated with strict enforcement of a traditional contract can generate a sense of great disappointment and even betrayal.

This disadvantage of partnering is largely overcome by an alliance arrangement where the parties' futures are genuinely linked and aligned in a way that forces them to act together to achieve the best outcome for the project and hence deliver.

Interestingly, the emergence of relationship based contracting in Australia has primarily been in the form of project alliancing. This contrasts to the more widespread adoption of the partnering model in the UK and elsewhere. Why this should be the case in not totally clear as project alliancing did not originate in Australia rather it was first adopted in the Oil and Gas Industries in North Sea in the early 1990's. The researcher suggests that this 'all or nothing' approach to the sharing of risk is more appealing to the culture of the Australian construction industry, or perhaps the Australian psyche generally.

\subsection{Growth of alliancing in Australia}

As briefly described above, the first project alliances were reputedly the BP Hyde and the BP Andrew oil and gas projects in the North Sea undertaken in the early 1990's. In the case of the Andrew project an alliance between BP and seven contractors reduced the estimated cost to develop the field from an untenable $£ 450$ million to $£ 373$ million to enable the project to receive sanction and proceed. The project was delivered 6 months ahead of schedule for a final outturn cost of $£ 290$ million, an achievement previously considered impossible.

'Andrew stands out as a remarkable tribute to what can be achieved, indeed brought into the realms of possibility, by the sheer enthusiasm and commitment of individuals once they are freed from the constraints of traditional behaviour.' 
Since that time, project alliancing has become more established in the oil and gas industries in particular and some other major infrastructure industries in Europe. However project alliancing has yet to be embraced in the United States where, partnering remains the prevalent collaborative project approach. Incentive contracts are also widely accepted practice around the world but these differ from alliances in that such arrangements retain the traditional allocation of risks.

It is in Australia where project alliances have taken to a deeper level of sophistication and use than anywhere else in the world (Hutchinson and Gallagher, 2003), particularly in major public sector infrastructure projects. The first two project alliances in Australia were also oil and gas industry projects, the Ampolex Wandoo Alliance and the WMC East Spar Alliance. Both projects are said to have been inspired by managers making trips to the UK to meet owners and contractors from earlier alliances. Both projects lived up to expectations with each alliance receiving various industry excellence awards.

It was after completion of these two projects that in 1998 the first three government project alliances commenced. Sydney Water became the first public sector organisation to create a project alliance on the Northside Storage Tunnel Project, a $\mathrm{A} \$ 400 \mathrm{~m}, 26 \mathrm{~km}$ tunnel under the northern suburbs of Sydney with a firm schedule deadline (the Sydney Olympic Games). This was followed by the National Museum of Australia, better known as the Acton Peninsula Alliance (A\$150m), and the West Australian Water Corporation's Woodman Point Waste Water Treatment Alliance (A\$155m). The Acton Peninsula Alliance is also noteworthy because it was the first Federal Government Alliance and remains the only major public building delivered through a project alliance. The Australian National Audit Office (ANAO) (2000) gave approval to the core alliance development processes (selection process, governance and commercial framework) associated with this project stating, p12:

'The ANAO considers that the process for the appointment of Architects, Building and Services Contractors and Museum Exhibition Designers substantially comply with the Commonwealth requirements for the procurement of public works'.

It is noteworthy that the ANAO went on to say, p13:

'Project alliancing offers potential benefits over traditional construction contracting methodology but it raises new and different risks that have to be managed - in particular, determining the appropriate balance between maintaining the spirit of the alliance and protecting the Commonwealth's financial interests. Nevertheless, project alliancing is a contracting methodology worth consideration by agencies involved in major construction projects - particularly high profile, prestige Commonwealth projects.' 
Since then numerous project alliances have been undertaken by the public sector in both Australia and New Zealand where Transit New Zealand, now part of the New Zealand Transport Agency, have been notable pioneers of the procurement model.

The number of and value of projects undertaken using the alliance delivery method in Australia has grown significantly in recent years. The total value of alliance projects in the road rail and water sectors in New South Wales, Victoria, Queensland and Western Australia, over the period 2004 to 2009 was $\$ 32$ billion, as reported by the Victorian Department of Treasury and Finance (VDTF) (2009) based on data collected by the Australasian Alliancing Association (AAA). This is believed to represent approximately $30 \%$ of the total infrastructure spend in the road, rail and water sectors across the whole of Australia. The value of alliances undertaken in each state is shown in Figure 2.9 below and the value of alliances by sector is shown in Figure 2.10 below.

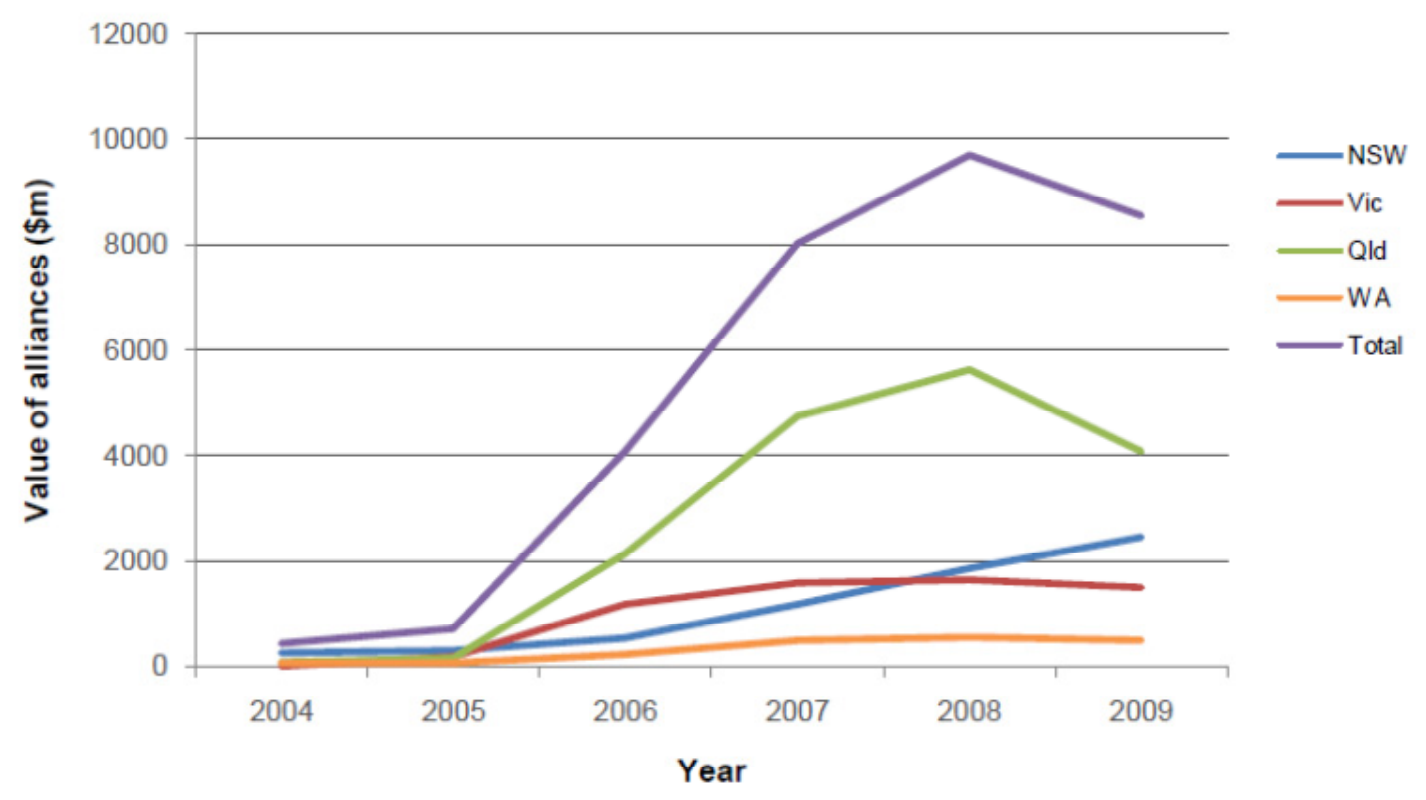

Figure 2.9 The value of alliancing projects undertaken in each state from 'In Pursuit of Additional Value' (2009), p7, based on data collected by the Alliancing Association of Australasia www.alliacingassociation.org (accessed 3 September 2009) 


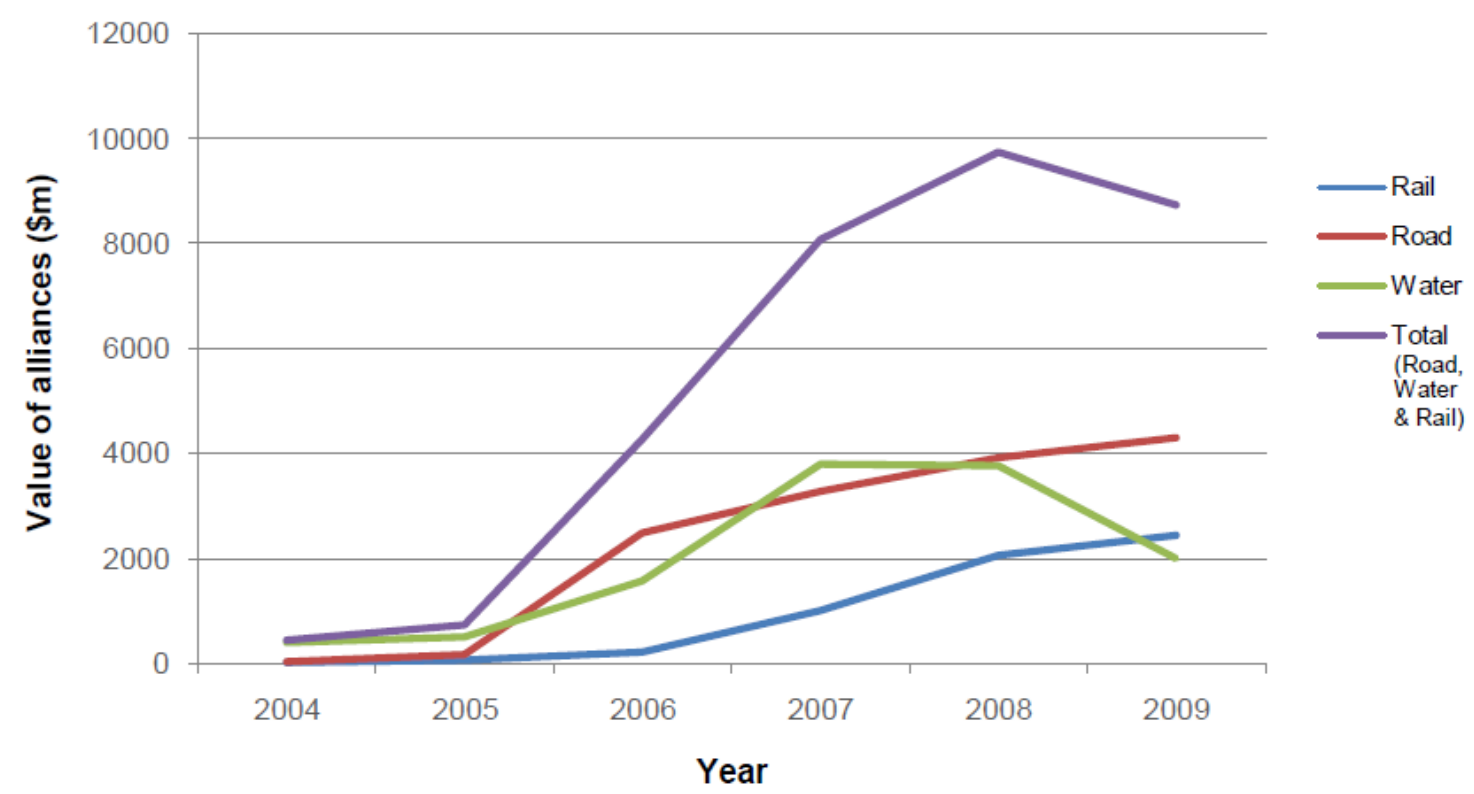

Figure 2.10 The value of alliancing projects undertaken by sector from 'In Pursuit of Additional Value' (2009), p8, based on data collected by the Alliancing Association of Australasia www.alliacingassociation.org (accessed 3 September 2009)

\subsection{Distinction between 'pure' and 'price competitive' alliances}

There are only 2 kinds of alliances - an alliance and something entirely different called an 'alliance'

(Feehely, 2007), p1.

Critics of the 'pure' or 'non-price' based selection process as originally adopted for project alliances question how $\mathrm{VfM}$ can be assured in the absence of price competition. Interestingly, some of these critics argue that the significant cost under-runs achieved in many project alliances are a clear indication that the Target Cost Estimate (TCE) derived following the selection process must have been inflated due to the lack of commercial pressures at the time of its finalisation.

Under a traditional procurement model, the owner attempts to gauge the relative 'value' offered by competing contractors by inviting tenders. On the assumption that there is strong competition in the market place and that the tender price will not be inflated (price -based approach). 
By contrast under an alliance, the 'cost' of the project is negotiated and the owner has, arguably, little or no definitive way of testing the negotiated cost against the open market (cost-based approach).

Is it the case, therefore, that the owner is entitled to question whether the alliance can really deliver $\mathrm{VfM}$ without price competition? This is a question which is not simply answered but there are a number of arguments which support the proposition that alliances in fact offer value for money despite the absence of price competition. This point was discussed at some length earlier in this chapter and is also extensively explored by Ross (Ross, 2003b, Ross, 2003a, Ross and Purcell, 2005).

Under conventional contract forms, the tender price is only the starting point. The contract sum is adjusted to take into account variations, delay, and latent conditions etc. which invariably result in additional payment being claimed. The final 'out-turn' price can be substantially greater than the tender price. By contrast, the total out-turn Cost (TOC) under an alliance is a genuine estimate of the final project cost. As explained earlier, it is generally the case that the final outturn cost is below the TOC and there are very few examples, at least, in the Australian experience, where the final outturn cost significantly exceeds the TOC. This proposition is supported by the surveys on alliance performance conducted by RMIT University on behalf of the AAA (Blismas and Harley, 2008, Mills and Harley, 2010).

As a consequence the relative outcomes of the traditional and alliance procurement methods can be illustrated as shown in Figure 2.11 below which is taken from Ross (2003a). The point illustrated in this figure is that even if the TOC exceeds the contract price that may have been obtained if a conventional tendering arrangement had been adopted, the final cost of the project under a traditional contract can exceed the actual out-turn cost $(A O C)$ of the alliance given the increase in the contract price normally experienced in traditional contracts.

The researcher suggests that it is entirely reasonable to expect that a group of highly aligned and motivated people working in an integrated team will deliver a project at an equal or lower cost than an equivalent team operating in an adversarial environment under a traditional model. Such a team will, of course, need good leadership and the qualities required of an alliance leader are addressed in Section 2.12.

In situations where there is only one buyer, as with most government procurement, the wasted effort expended on adversarial administration will, at least in the long term, be borne by the buyer. The eventual consequence of this is that fewer projects can be undertaken for the limited funds available. 


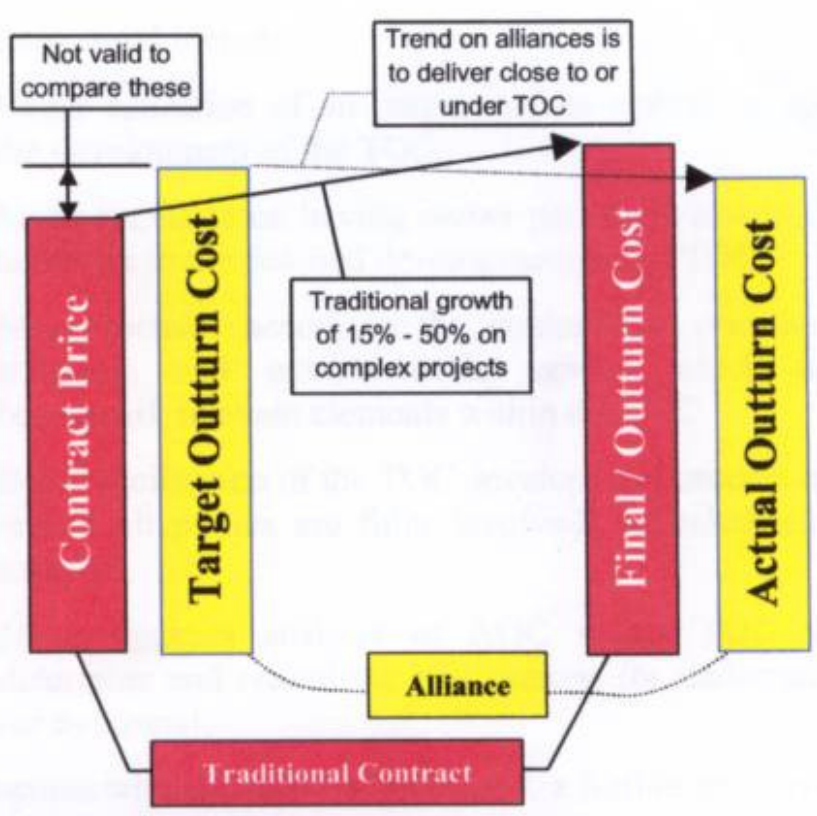

Figure 2.11 Relative Outcomes of the traditional and alliance models from Ross (2003a), p19

Despite the arguments presented above, a number of owners have tried to address the VfM paradox or puzzle, as defined in Chapter 1, by introducing TOC competition into the selection process for alliances. Such moves are no doubt prompted by a genuine concern of the part of owners. However, it is suggested that in the case of the public sector, at least, such concerns have been largely promoted by two particular factors:

- There have been some reports by Auditors General, notably the NSW Auditor General's Report (2003a) on the Northside Storage Tunnel Project in Sydney, that have raised questions as to whether the outcomes of some previous alliance projects truly represent VfM. Closer examination of the above reference, confirms that the Auditor General did not actually claim that VfM had not been achieved but, in fact, raised the valid point that processes had not been put in place to demonstrate that this was the case. This point is discussed in more depth in Chapter 3.

- Some consultants and procurement advisors operating in the alliancing field have, arguably, gained a position of competitive advantage (or perhaps sought to reduce the competitive advantage of those promoting 'pure' or non cost competitive alliances) by convincing owners that in the absence of price competition in the selection process, they could be accused of not behaving in the best interest of the public. 
Under the competitive TOC model two separate teams (each including different owner personnel) develop a TOC under separate interim alliance agreements. Each team bids the TOC which is then viewed as the major factor in determining which team is selected to go on to deliver the project under the full alliance. Supporters of this approach resist the notion that price is the only determinant of the outcome. However, other factors such as ability and working culture have already been assessed in the short listing process so cost is, presumably, the major distinguishing feature at this late stage.

A number of owners, who have previously adopted a non-price competitive (sometimes termed, single TOC) process have either freely chosen this option, or felt compelled to follow a competitive process. Whilst the experience of the price competitive (sometimes termed, multiple TOC) process, is less than the pure model it seems that few non owner and not all owner practitioners, have found such an approach to provide satisfactory outcomes.

If the relative advantages and disadvantages of such a process, as itemised below, are considered, it perhaps is not surprising that this might be the case.

Claimed advantages of 'competitive' alliance model are:

- Apparent greater transparency and clearer demonstration of VFM.

- Easier demonstration of appropriate probity to an auditor or third parties not involved in the project delivery.

However, some of the inherent disadvantages appear to be (Alchimie, 2004):

- The early development of an alliance culture within a team delivers very high levels of innovation and savings leading up to the determination of the TOC. This could be compromised by the fact that the full commitment of all parties is not possible. In particular the senior leaders from the owner's team have to avoid showing favour to one team and consequently tend to withdraw from the process. This could result in this phase of the project being little more than a 'quasi-design and construct' selection process.

- Direct comparison of the TOC's become difficult if the design has developed in different directions for the respective teams and they have developed a different understanding of the risks and possible.

- 'Pure' alliances appear to have worked well because all parties have accepted full ownership of targets that are jointly developed and risks they have collectively assumed. A TOC that has been developed to ' $w i n$ ' the job, rather than determining the most 'appropriate' solution, 
offers far more scope for disagreements in the future regarding what was included in the TOC.

There are also concerns that it could take some time for the complete trust, essential for a successful alliance, to develop following the qualified support offered by the owner during the development of the TOC.

It is understandable that owners, particularly in the public sector could be sensitive to criticism of the single TOC selection process on the basis that VfM can only be demonstrated through a price competitive process. Such a criticism does, however, highlight the superficiality of much of the debate regarding VfM and the need to develop a more systematic approach to ensuring and demonstrating VFM in alliance procurement.

That said, Davies (2007) examined this matter in some considerable depth and reached the conclusion that competitive alliances do not introduce any changes of behaviour of the alliance participants after the selection process when compared with the single TOC or 'pure' alliance approach. He also makes the point that price completion in the selection process eliminates many of 'the VfM concerns' as he terms them, being a failure to conform with normal public sector procurement procedures, associated with 'pure' alliances.

Love et al. (2010) investigated critical factors in successful development and management of the price competitive model. The conclusions of this research included a view that the nature of the model can lead to suboptimal solutions if the TOC is used as a mechanism to simply win the contract. However, it was also concluded that the model can facilitate the development of stronger relationships, as parties work closely to develop the TOC from the outset. Initially working together to establish a TOC enables parties to assess their capabilities and culture as well as compatibility to form an alliance.

\subsection{Commercial Arrangements in Alliance Contracts}

The commercial framework for an alliance is a primary point of difference from other procurement approaches and it is critical to the success of an alliance. Consequently, it is vital that it is set up in an appropriate manner and that all parties fully understand and take ownership of the commercial arrangements. Any misunderstandings could conspire against a 'win-win' outcome which would be totally contrary to the guiding principle of the arrangement.

Whilst a number of variations to the commercial framework are possible it is important that the terms must be such that they drive 'best for project' behaviours in the whole team. If the 
commercial framework is not appropriate or too complex, or not capable of providing incentive for innovative performance it will not drive the energy and vitality that can be achieved in such a structure.

Some of the key principles that should be incorporated in a project alliance commercial framework are:

- No matter what act, event, circumstance or degree of difficulty is encountered in performing the work under the alliance agreement, the commercial participants' sole entitlement to payment is limited to their direct cost, corporate overhead, normal profit and gainshare;

- Regardless of the actual outcomes on the project, the sponsor meets all of the direct costs incurred in performing the work under the alliance agreement;

- $\quad$ Corporate overhead and normal profit percentages are applied to either an alliance participant's actual direct costs or the actual project target out-turn cost (ToC) as agreed at the commercial alignment workshop;

- $\quad$ Any overrun on the target outturn cost is equitably shared between the sponsor and the commercial participants on a pre-agreed basis;

- The commercial participant's share of any overrun on the target outturn cost is "capped"; the value or limited on this pre-agreed cap would typically include all of the commercial participants' corporate overhead, normal profit and gainshare entitlements;

- A gainshare regime provides outstanding rewards for gamebreaking performance in cost and non-cost project objectives;

- $\quad$ There is a pre-agreed process for the determination and timing of gainshare payments; and

- Performance benchmarks for each of the key result areas identifying poor performance, minimum conditions of satisfaction and gamebreaking performance objectives and the value for the target outturn cost are determined and aligned upon by the alliance participants during the target outturn cost phase.

Love et al. (2011) interviewed twenty-nine industry practitioners involved in eight alliance projects to determine their experience with the risk/reward compensation model and this research provided some very interesting insights into the impact that commercial terms have on the behaviour of 
alliance participants. The research revealed that collaborative and cooperative behaviour between team members were espoused by:

- The perceived fairness and equity in payment structure;

- A mutual commercial interest in the alliance's performance outcomes;

- Incentive payments; and

- High performance culture through the joint establishment of achievable performance targets.

Interestingly, accountability, credibility, pride and reputation were considered to be the underlying driving forces of behaviours that contributed to good non-cost outcomes. It was concluded that risk/reward sharing is pivotal to obtaining a successful project outcome for the procurement of civil engineering infrastructure projects when using an alliance.

\subsection{Leadership qualities required in a project alliance}

The Egan Report (1998) identified five key drivers of change that were considered to be critical to establishing an agenda for change in the construction industry at large. The item at the top of that list was Committed Leadership. This was defined by Egan as follows;

\section{Committed leadership}

This is about management believing in and being totally committed to driving forward an agenda for improvement and communicating the required cultural and operational changes throughout the whole organisation.

The particular dynamics of an alliance team which draws together resources from different organisations, which often have quite different cultures, requires particular qualities in the alliance leader and these are briefly explored in this section.

Over the last fifty years or so there have been many studies and consequent models of leadership behaviour. Some of these models or taxonomies are relatively simple and involve small numbers of categories or skills that have been demonstrated to have an independently significant impact on the success of leaders. Other models present a more complex explanation of the behaviours that are deemed to characterise successful management.

Yukl (1999) describes a three dimensional taxonomy which recognises the interrelationship between behaviour and the concerns of leaders and not just the content of the behaviour. Concern for task efficiency, human relations and adaptive change are conceptualised as three dimensions rather than three mutually exclusive categories of specific behaviours. Specific leadership behaviours will involve 
a mix of the three concerns or objectives (Yukl, 2002). The three types of behaviour interact to jointly determine work unit performance. Their relative importance depends on the nature of the task and the work unit environment. Effective leaders determine which specific task, relations or change orientated behaviours are appropriate and mutually compatible for the given situation. Table 2 below shows specific types of behaviour that can be classified as higher in one objective than the others.

In the view of the researcher, a three dimensional taxonomy, such as that described above, provides a useful and efficient way of grouping the specific behaviours that are required in the successful leadership of any project but is particularly suited to a relationship contracting procurement approach such as alliancing.

Table 2.3 Definition of types of behaviour, adapted from Yukl (1999), p66

\begin{tabular}{|l|l|}
\hline Types of behaviour & Characteristics \\
\hline Task Orientated & $\begin{array}{l}\text { This type of behaviour is primarily concerned with } \\
\text { accomplishing the task, utilising personnel and } \\
\text { resources efficiently and maintaining orderly, } \\
\text { reliable operations. This is akin to 'production } \\
\text { centred leadership'. }\end{array}$ \\
\hline Relations Orientated & $\begin{array}{l}\text { This type of behaviour is primarily concerned with } \\
\text { improving relations and helping people, increasing } \\
\text { cooperation and teamwork, increasing subordinate } \\
\text { job satisfaction and building identification with the } \\
\text { organisation. This is akin to 'employee centred } \\
\text { leadership'. }\end{array}$ \\
\hline Change orientated & $\begin{array}{l}\text { This type of behaviour is primarily concerned with } \\
\text { improving strategic decisions, adapting to change in } \\
\text { the environment, increasing flexibility and } \\
\text { innovation, making major changes in process, } \\
\text { products or services and gaining commitment to } \\
\text { those changes. }\end{array}$ \\
\hline
\end{tabular}

The primary relevance of leadership and governance to the issue of value for money is that without the existence of the truly integrated team, the full range of skills and experience necessary to identify optimal solutions are unlikely to be assembled or indeed sufficiently understood and appreciated. Whilst it can be argued that this principle might apply to any project, it is particularly relevant in an alliance contract where the scope of the normally complex project is initially often loosely defined. 
The establishment of an integrated team places particular demands on the relationship and change orientated behavioural skills of the leadership team. Consequently, it is necessary for the Alliance (Project) Manager and other leaders to display strong relations and change orientated behaviours, particularly at the earlier stages of an alliance when the 'culture' is being established (MacDonald, 2007).

The behaviours described above are clearly of a 'higher order' than those typically required of leaders in a project delivered by more conventional procurement models. Stated in another way, alliances place higher demands on the leadership skills of the project or Alliance (Project) Manager, in particular. In a traditional contract a forceful task oriented leader with relatively weak relations and change orientated skills will probably get by but such a profile of skills is very unlikely to be adequate in alliance environment. One of the keys to obtaining value for money in an alliance is to foster the collective knowledge, skills and energy of the whole team. This demands a leader who can inspire the team and display high levels of leadership skills in all three areas of the model presented earlier.

This need for 'higher order' skills is emphasised through recent research by Walker and Lloyd-Walker (2011), on behalf of the AAA, who concluded that project alliances demanded a step change in the level of project management skills, attributes and experiences.

It is clear, in the view of the researcher, that leading, or preferably inspiring teams to a higher level of performance and output is a much more effective way of achieving value for money than simply trying to minimise costs. The alliance model does require a greater investment of time and resources, particularly in the establishment and coaching of the team and these cost need to be carefully monitored. However, an approach which continual focuses solely on reducing costs is unlikely to spark the imagination of the team and inspire them to lift their performance to a new level which can result in, what is described by Hutchinson and Gallagher (2003) as 'gamebreaking' outcomes.

These leadership requirements were considered in the design of the VfM/BV model that was developed through this research.

\subsection{Summary of Chapter}

In seeking to explore the issue of $\mathrm{VfM}$ in relationship based contracting it is clearly necessary to thoroughly review the meaning of the terms value and VfM. In the case of value this has been examined through various prisms in this chapter. This review concluded that value has many dimensions beyond the conventional economic perspective and includes the delivery of both tangible and intangible outcomes. 
Whilst conventional delivery methods have been successful in the past in addressing the delivery of tangible outcomes, a relationship based approach is seen as more suited to the delivery of intangible outcomes which are characteristic of the more complex projects with less defined scope.

The review of the definitions of the term VfM, similarly uncovered that there are multiple interpretations available in the literature. Further, despite numerous government publications, in particular, advocating that $\mathrm{VfM}$ should not be equated to lowest price, the researcher believes that this perception continues to prevail.

Although the point is not discussed in the body of the chapter, this association between $\mathrm{VFM}$ and cheapest cost is believed to be almost inevitable given the specific reference to the word 'money' within the term. It was noted during that in the recent UK literature, in particular, there appears to be a conscious move away from the term VfM to the expression 'best value' to convey the message that there is a broader meaning to the concept of value. This alternative term appeals to the researcher for that reason. However, whilst the term 'best value' has been introduced into the model/documentation as developed, due to the established nature of the term VfM in the construction industry the VfM has not been abandoned in this thesis. Nevertheless, when used, the terms are considered to be synonymous.

The various forms of relationship contracting now in regular use within the construction industry are explained at some length. This exercise was undertaken to carefully distinguish between the different models for two reasons. Firstly, the terminology on common use, particularly regarding partnering and alliancing, is typically employed in a casual manner resulting in considerable confusion regarding the correct meaning of the terms. Secondly, it was believed to be necessary to carefully address the specific and somewhat unique characteristics of project alliances which are considered, at least in part, to be critical to an understanding of why this form of procurement is well suited to the genuine delivery of $\mathrm{VFM}$ or best value in the execution of a project (MacDonald, 2008).

Finally, a description of the leadership qualities considered important for a project alliance are reviewed. This review confirms that the challenges and opportunities created by the alliance model require particular behavioural traits in the project leader/s in order to harness the full potential of this procurement approach to deliver value.

Having described the relevance of the broader project management literature to the topic being considered, Chapter 3 proceeds to examine the issue of VfM in project alliances more specifically. 


\section{Chapter 3 - Developing the Preliminary Research Model}

'There is a tide in the affairs of men,

Which, taken at the flood, leads on to fortune;

Omitted, all the voyage of their life

Is bound in shallows and in miseries

On such a partnering sea are we now afloat,

And we must take the current when it serves,

Or lose our joint ventures'.

William Shakespeare

Julius Caesar

Act 3, Scene 2

\subsection{Introduction}

Chapter 2 described a broad review of the background of alliance contracting and concluded with a specific consideration of particular issues that have emerged concerning the demonstration of value for money (VfM) for this relatively new procurement methodology.

Section 3.2 of this chapter describes a detailed review of a number of investigations that have been undertaken into the performance of specific alliance projects. Some guidelines to obtaining VfM in alliance procurement are also featured in this review. The purpose of this analysis was to understand the scope and content of previous investigations into the issues of ensuring and demonstrating VfM in project alliances.

Section 3.3 considers the challenges of obtaining VfM under the alliance procurement model in more detail.

Section 3.4 briefly explains a hybrid relationship contracting format entailed the Early Contractor Involvement $(\mathrm{ECl})$ model as it is considered that there are some interesting insights to be drawn from the increasing adoption of this format.

Section 3.5 describes a number of recent Australian postgraduate research assignments undertaken by practitioners experienced in project alliancing. The findings of this research were used to further refine the research question investigated in the work described in this thesis.

Further to the reviews described above, a specific examination of strengths and weaknesses of current VfM practice in project alliance contracts is presented in Section 3.5. This examination was undertaken in order to clarify the research question that needed to be addressed in the proposed research and to ensure that a positive contribution could be made to the state of knowledge in the 
field. This research question and the objectives that needed to be addressed in creating a VfM model are described in Section 3.6.

Section 3.7 outlines the structure of a preliminary model VfM Model that was developed by the Researcher based on a project lifecycle cycle flowchart incorporating periodic reviews of VfM adopting the principles of the Gateway ${ }^{\mathrm{TM}}$ Review Process.

Section 3.8 contains a summary of the coverage of this chapter.

\subsection{Studies and guidelines that have addressed VfM in alliances}

In the last seven years there have been a number of Australasian reviews and studies and even some methodologies proposed to address the issue of $\mathrm{VfM}$ or best value in alliance projects. The need for a systematic approach to $\mathrm{VFM}$ has been apparent to many of those involved in the delivery of alliances from the very inception of this delivery method given that, at least in the single TOC version of the project alliance model, there is no inherent price competition in the selection of the Non-Owner Participants (NoPs). This situation demands that there be a robust process or procedure for demonstrating VfM to address any concern that the best interests of the Owner and community (in the case of public works) are being adequately protected.

Whilst it has been acknowledged from the very outset of alliance contracting in Australasia, that VfM needed to be achieved, the watershed event that really drew attention to the issues of, not only achieving VfM, but demonstrating such achievement, was the 2003 performance audit review undertaken by the New South Wales Auditor General (NSWAG) of the Northside Tunnel Storage Project which has been undertaken in Sydney between 1997 and 2000 (NSWAG, 2003a).

This project involved the construction of an interceptor sewer, in the form of a large capacity tunnel which prevents sewerage being discharged into Sydney Harbour during major storm events. Such an outcome had occurred on a regular basis and the State Government made a commitment to construct and commission this facility prior to the opening of the Olympic Games in Sydney in September 2000.

This project had a relatively high capital value $(\$ 450 \mathrm{M})$ and a very tight time frame for completion, which was not negotiable as it was mandated that the project must be completed before the commencement of the Games. The government considered a number of procurement options, (Henderson and Cuttler, 1999, Clegg et al., 2002) and determined the adoption of project alliance was the only approach that was likely to enable them to achieve their objectives in the required time 
frame. This was the first time that this procurement approach had been adopted for a major project by the public sector in Australia.

Following the completion the work, which was substantially achieved by the opening of the Olympic Games, the NSWAG commented on the project as follows:

'Despite many constraints and difficulties;

- the facility was delivered as a 'fast-track' project

- was innovative in linking financial rewards to achievement of community, environment and safety objectives,

- the risk/reward arrangement worked effectively to pool responsibility, encourage innovation and promote cooperative problem resolution.'

'Whether the cost of the project represented 'value for money' was less clear, because;

- the original estimate at the planning stage was not soundly based,

- the project procurement method was selected on the basis of meeting the deadline rather than cost,

- the selection of private sector parties was not subject to price competition, albeit that this was inherent in the project alliance approach adopted.'

The NSWAG recommended that Sydney Water;

- complete a post implementation review of the project, and

- document the lessons learnt particularly in relation to refining how alliances are established, governance arrangements for the alliance, establishing more reliable cost estimates and assessing cost variations.

It is regularly suggested that the NSWAG directed that Sydney Water should consider price competition in the selection of partner and determination of the commercial conditions for future project alliances. In fact, this is not correct. The NSWAG simply noted that Sydney Water had advised him that this was an alternative approach that they were considering. Nevertheless the publication of this document is generally regarded as representing a 'defining moment' when the VfM delivered by projects alliances was first formally challenged and the led to;

- The adoption or consideration by some public bodies and a 'price competitive' model for project alliances, 
- Promotion, by some consultants in particular, of a alternative variants to the single TOC model for project alliances,

- An increased level of concern, particularly within the public sector, that the adoption of a single TOC model for project alliances would expose those responsible for delivering the project to criticism that the public interest was not necessarily being best served by this approach.

- The insistence by Owners that the achievement and, importantly, demonstration of VfM be a major priority and that the means of accomplishing both would represent criteria in the selection of a proponent to participate in the alliance.

The NSWAG report on the Northside Storage Tunnel, has in the view of the researcher, been ascribed a general applicability, particularly in the public sector, that was ever intended by the NSWAG who was simply drawing attention to some concerns that he had regarding the particular circumstance of one rather unique project. Nevertheless, from that point on there has been a substantially increased focus on addressing the issue of $\mathrm{VfM}$ in project alliances.

As was indicated earlier a number of reviews, studies and studies have been undertaken in the Australian and New Zealand context since the NSWAG report which have attempted to further addressed this issue. Whilst not necessarily representing a full listing of all the work in this field, the documents that are considered to be of particular significance to the issues that were considered in the research reported in this thesis are listed below in Table 3.1. Given that each of these documents is viewed as directly relevant to the thrust of the thesis, they are in turn examined in some detail in Table 3.2. This detail includes a critique of each document including an identification of the contribution made to the determination and demonstration of $\mathrm{VFM}$ and an identification of the perceived deficiencies in their content including 'gaps' that the respective documents do not address. 
Table 3.1 Significant reviews, reports and models on VfM since the NSWAG Performance Report (2003) regarding the Northside Storage Tunnel Project

\begin{tabular}{|c|c|c|c|}
\hline Document & Year & Nature & Author \\
\hline $\begin{array}{l}\text { Alliance Learning Experiences - Port } \\
\text { of Brisbane Motorway Alliance } \\
\text { (Evans\&Peck, 2003) }\end{array}$ & 2003 & $\begin{array}{l}\text { Specific independent } \\
\text { project post completion } \\
\text { review }\end{array}$ & $\begin{array}{l}\text { Evans and Peck } \\
\text { Consulting Pty Ltd }\end{array}$ \\
\hline $\begin{array}{l}\text { Do Alliance Projects offer Value for } \\
\text { Money? Survey Report(Keys, 2004) }\end{array}$ & 2004 & $\begin{array}{l}\text { General questionnaire } \\
\text { based study }\end{array}$ & $\begin{array}{l}\text { Currie and Brown Pty } \\
\text { Ltd }\end{array}$ \\
\hline $\begin{array}{l}\text { Northside Storage Tunnel Project- } \\
\text { Post Implementation Review } \\
\text { (Evans\&Peck, 2004) }\end{array}$ & 2004 & $\begin{array}{l}\text { Specific independent } \\
\text { project post completion } \\
\text { review }\end{array}$ & $\begin{array}{l}\text { Evans and Peck } \\
\text { Consulting Pty Ltd }\end{array}$ \\
\hline $\begin{array}{l}\text { Target Out-turn Cost: } \\
\text { Demonstrating value for Money } \\
\text { (Hutchinson, 2004) }\end{array}$ & 2004 & $\begin{array}{l}\text { Alliance facilitators } \\
\text { report/commentary }\end{array}$ & Alchimie Pty Ltd \\
\hline $\begin{array}{l}\text { Grafton Gully Project (GGP) - } \\
\text { Alliance Value for Money Project } \\
\text { (Transit-NZ, 2005) }\end{array}$ & 2005 & $\begin{array}{l}\text { Specific internal project } \\
\text { post completion -review }\end{array}$ & Transit New Zealand \\
\hline $\begin{array}{l}\text { Project Alliancing Practitioners } \\
\text { Guideline (VDTF, 2006a) }\end{array}$ & 2006 & $\begin{array}{l}\text { Government } \\
\text { procurement guidelines }\end{array}$ & $\begin{array}{l}\text { Victorian Government, } \\
\text { Department of Treasury } \\
\text { and Finance (VDTF) }\end{array}$ \\
\hline $\begin{array}{l}\text { Method for demonstrating value for } \\
\text { money (Washbourne, 2007) }\end{array}$ & 2007 & $\begin{array}{l}\text { Alliance facilitators } \\
\text { proposed model }\end{array}$ & SRD Consulting Pty Ltd \\
\hline $\begin{array}{l}\text { Performance of PPP's and } \\
\text { Traditional Procurement in Australia } \\
\text { (Allen, 2007) }\end{array}$ & 2007 & $\begin{array}{l}\text { Comparison of PPP } \\
\text { Performance with } \\
\text { traditional methods } \\
\text { (including Project } \\
\text { Alliancing) }\end{array}$ & $\begin{array}{l}\text { Allen Consulting Group } \\
\text { Pty Ltd }\end{array}$ \\
\hline $\begin{array}{l}\text { Review of South East Water's Works } \\
\text { Alliance Agreement (WIlliams, 2008) }\end{array}$ & 2008 & $\begin{array}{l}\text { Auditors report on the } \\
\text { establishment of a } \\
\text { service alliance }\end{array}$ & $\begin{array}{l}\text { Victorian Auditor } \\
\text { General }\end{array}$ \\
\hline $\begin{array}{l}\text { In Pursuit of Additional Value* } \\
\text { published by the VDTF (2009) }\end{array}$ & 2009 & $\begin{array}{l}\text { Benchmarking study } \\
\text { into alliancing in the } \\
\text { Australian Public Sector }\end{array}$ & $\begin{array}{l}\text { Evans and Peck } \\
\text { Consulting Pty Ltd and } \\
\text { the University of } \\
\text { Melbourne }\end{array}$ \\
\hline
\end{tabular}

*The publication 'In Pursuit of Additional Value' was first published in exposure draft form in November 2009 during Phase 2 of the research procedure described in this thesis. Consequently, it had not been published at the time the VfM literature was being reviewed prior to formulating the model which is developed in this thesis. The document is mentioned in Table 3.1 and 3.2. However, given that publication directly addresses the issue of demonstrating VfM it has been reviewed in some detail in Chapter 7. Additionally, the relevance of this publication and the subsequent documents published by the VDTF to the findings of this thesis are discussed in Chapters 7 and 9. 
Table 3.2 Detailed considerations of reviews, reports and models on VfM since the NSWG Performance Report (NSWAG, 2003a)

\begin{tabular}{|c|c|c|c|c|c|c|}
\hline \multirow[t]{2}{*}{ VfM Study } & \multirow[t]{2}{*}{ Date } & \multirow[t]{2}{*}{ Author } & \multirow[t]{2}{*}{ Rationale } & \multirow[t]{2}{*}{ Conclusions } & \multicolumn{2}{|l|}{ Critique } \\
\hline & & & & & Contributions & Deficiencies \\
\hline $\begin{array}{l}\text { Sydney Water } \\
\text { Corporation - } \\
\text { Northside Storage } \\
\text { Tunnel Report, } \\
\text { Performance } \\
\text { Audit }\end{array}$ & 2003 & $\begin{array}{l}\text { New South Wales } \\
\text { Auditor General }\end{array}$ & $\begin{array}{l}\text { This project involved the construction of } \\
\text { interceptor sewer. The State Government } \\
\text { made a commitment to construct and } \\
\text { commission this facility prior to the opening of } \\
\text { the Olympic Games in Sydney in September } \\
2000 \text {. } \\
\text { This project had a relatively high capital value } \\
\text { (\$450M) and to meet the very tight time } \\
\text { frame for completion the government } \\
\text { determined that the adoption of project } \\
\text { alliance was the only approach that was likely } \\
\text { to enable them to achieve their objectives in } \\
\text { the required time frame. This was the first } \\
\text { time that this procurement approach had } \\
\text { been adopted for a major project by the } \\
\text { public sector in Australia. } \\
\text { The project overran the budget and the } \\
\text { NSWAG undertook a performance audit which } \\
\text { commented on value for money }\end{array}$ & $\begin{array}{l}\text { The facility was delivered as a 'fast-track' project } \\
\text { and was innovative in linking financial rewards to } \\
\text { achievement of community, environment and } \\
\text { safety objectives } \\
\text { The risk/reward arrangement worked effectively to } \\
\text { pool responsibility, encourage innovation and } \\
\text { promote cooperative problem resolution. } \\
\text { Whether the cost of the project represented 'value } \\
\text { for money' was less clear, because; } \\
\text { - The original estimate at the planning stage } \\
\text { was not soundly based. } \\
\text { - The project procurement method was selected } \\
\text { on the basis of meeting the deadline rather } \\
\text { than cost. } \\
\text { The selection of private sector parties was not } \\
\text { subject to price competition, albeit that this } \\
\text { was inherent in the project alliance approach } \\
\text { adopted. } \\
\text { The NSWAG recommended that Sydney Water } \\
\text { complete a post implementation review of the } \\
\text { project. }\end{array}$ & $\begin{array}{l}\text { This document represented the first objective } \\
\text { performance review, in Australia, of a major } \\
\text { project delivered as a project alliance. } \\
\text { The report made a number of constructive and } \\
\text { encouraging comments regarding this new } \\
\text { delivery method but suggested that the Owner } \\
\text { should undertake further review in order to } \\
\text { ensure that lessons learnt from the project } \\
\text { were documented. Comment is also made that } \\
\text { the original estimating process needed to be } \\
\text { improved. } \\
\text { On reflection it was a relatively positive report } \\
\text { given the new and untried procurement } \\
\text { approach adopted which was not subject to } \\
\text { price competition. }\end{array}$ & $\begin{array}{l}\text { Negative comments regarding this report relate more } \\
\text { to the response the report received and what was } \\
\text { ascribed to the NSWAG rather than what was actually } \\
\text { stated in the document. } \\
\text { It is regularly suggested that the NSWAG suggested } \\
\text { that Sydney Water should consider price competition } \\
\text { in the selection of partner and determination of the } \\
\text { commercial conditions for future project alliances. In } \\
\text { fact, this is not correct. The NSWAG simply noted that } \\
\text { Sydney Water had advised him that this was an } \\
\text { alternative approach that they were considering. } \\
\text { The report does not really provide any firm guidance } \\
\text { regarding the demonstration of VfM for alliances but } \\
\text { it does make it clear that such a demonstration is } \\
\text { necessary if the procurement model is to be accepted } \\
\text { by those who audit the performance of major } \\
\text { projects. }\end{array}$ \\
\hline $\begin{array}{l}\text { Alliance Learning } \\
\text { Experiences - Port } \\
\text { of Brisbane } \\
\text { Motorway } \\
\text { Alliance }\end{array}$ & 2003 & $\begin{array}{l}\text { Evans and Peck } \\
\text { Consulting Pty Ltd }\end{array}$ & $\begin{array}{l}\text { This report was prepared by E\&P on behalf of } \\
\text { the Port of Brisbane Motorway Alliance and } \\
\text { was again a retrospective analysis of a project } \\
\text { alliance. The key focus of the report was to } \\
\text { identify any vevidence of a VfM outcome in the } \\
\text { project deliverables. } \\
\text { The Port of Brisbane Motorway Project Stage } \\
1 \text { involved the construction of an urban } \\
\text { motorway link from the GatewartM Motorway to } \\
\text { the Port of Brisbane. The contract was let by } \\
\text { Queensland Motorways Limited (QMLL) a } \\
\text { Queensland Government owned special } \\
\text { purpose company. } \\
\text { In a similar manner to the Northside Storage } \\
\text { Tunnel Report referred the report describes a } \\
\text { comparative predictive model which attempts } \\
\text { to compare what the likely commercial } \\
\text { outcome of this project should a D\&C method } \\
\text { of delivery have been used. }\end{array}$ & $\begin{array}{l}\text { Whilst such an approach necessarily involves a } \\
\text { number of assumptions which are subjective it } \\
\text { indicated, that anticipated } D \& C \text { cost }\left(P_{50}\right) \text { would } \\
\text { have been } \$ 116 \mathrm{M} \text {. This suggests that the TOC } \\
(\$ 112 \mathrm{M}) \text { already represented a saving over the } \\
\text { likely } D \& C \text { cost but that the actual outcome } \\
\text { achieved ( } \$ 101 \mathrm{M}) \text { represented a substantial } \\
\text { saving of approximately } \$ 15 \mathrm{M} \text { after adjustments } \\
\text { were made for the cost of the additional scope } \\
\text { delivered by the alliance. } \\
\text { The report suggests that this represents a } \\
\text { significant demonstration of VfM in the delivery of } \\
\text { this project. In support of this view a risk analysis } \\
\text { carried out by an Independent Estimator after } \\
\text { agreement of the TOC. This analysis indicated that } \\
\text { the agreed TOC amount fell marginally below the } \\
30 \% \text { probability outcome (i.e. } 70 \% \text { probability that } \\
\text { the project out-turn cost will be higher) and } \\
\text { therefore represented VfM for the works involved, } \\
\text { based on the state of knowledge of the project } \\
\text { scope at that time. }\end{array}$ & $\begin{array}{l}\text { The report used a rational basis to } \\
\text { demonstrate that significant value was added } \\
\text { to the project during the delivery phase. } \\
\text { The report also drew attention to the less } \\
\text { tangible value adding outcomes were also } \\
\text { achieved including; } \\
\text { - Higher design standards than formally } \\
\text { required. } \\
\text { - Superior aesthetic and urban design } \\
\text { standards. } \\
\text { - Project safety, quality and environmental } \\
\text { standards that were considered to be } \\
\text { exceptional' } \\
\text { That the highly focussed and fully } \\
\text { integrated team addressed such issues as } \\
\text { continual design innovation rather than } \\
\text { the pursuit of variations and claims. } \\
\text { This was the first attempt to try to identify } \\
\text { some of the softer intangible benefits of the } \\
\text { project alliance approach. }\end{array}$ & $\begin{array}{l}\text { Again the analysis was limited to purely financial } \\
\text { outcomes even though the study does recognise the } \\
\text { intangible benefits that were delivered in the } \\
\text { execution of the project. } \\
\text { This study does add further weight to the argument } \\
\text { that outstanding VfM can be achieved from the } \\
\text { adoption of a project alliance model, However, it } \\
\text { does not provide any particular insights into the } \\
\text { manner in which this outcome might be transferred } \\
\text { to other projects delivered by the same procurement } \\
\text { method. }\end{array}$ \\
\hline $\begin{array}{l}\text { Do Alliance } \\
\text { Projects offer } \\
\text { Value for Money? } \\
\text { Survey Report }\end{array}$ & 2004 & $\begin{array}{l}\text { Currie and Brown } \\
\text { Pty Ltd }\end{array}$ & $\begin{array}{l}\text { Following the release of the NSWAG's Report } \\
\text { on the Northside Storage Tunnel Project, the } \\
\text { Sewerfix Pumping Station Programme } \\
\text { Alliance, which also involved Sydney Water as } \\
\text { the owner participant, commissioned Currie } \\
\text { and Brown to undertake a comparative study }\end{array}$ & $\begin{array}{l}\text { The study measured project performance against } \\
\text { the stakeholder's expectations, } 61 \% \text { of alliance } \\
\text { projects exceeded expectations compared with } \\
17 \% \text { of non-alliance projects. When the } \\
\text { commercial outcome was taken into account, } 72 \% \\
\text { of alliance projects achieved a lower actual cost }\end{array}$ & $\begin{array}{l}\text { This study was the first and remains the most } \\
\text { substantive attempt to date, to the knowledge } \\
\text { of the researcher, to investigate the } \\
\text { background to a range of projects both alliance } \\
\text { and non-alliance in order to make comparative } \\
\text { comment in the respective approaches to }\end{array}$ & $\begin{array}{l}\text { It is not clear that the definition of an alliance used in } \\
\text { this study is consistent with the accepted definition of } \\
\text { a project alliance in Australia i.e. that all risks are } \\
\text { shared by the project parties and all costing is } \\
\text { addressed on a purely open book basis. } \\
\text { The population canvassed in the study was small and }\end{array}$ \\
\hline
\end{tabular}




\begin{tabular}{|c|c|c|c|c|c|c|}
\hline \multirow[t]{2}{*}{ VfM Study } & \multirow[t]{2}{*}{ Date } & \multirow[t]{2}{*}{ Author } & \multirow[t]{2}{*}{ Rationale } & \multirow[t]{2}{*}{ Conclusions } & \multicolumn{2}{|l|}{ Critique } \\
\hline & & & & & Contributions & Deficiencies \\
\hline & & & $\begin{array}{l}\text { between alliances and conventionally } \\
\text { procured projects to address the question 'Do } \\
\text { alliance projects offer value for money'? } \\
\text { The study was carried out by means of a } \\
\text { detailed questionnaire that was intended to } \\
\text { determine the performance of projects } \\
\text { against set criteria which included the } \\
\text { complexity of the project, the risks and } \\
\text { opportunities, time for completion, quality } \\
\text { and the requirement for technical innovation. } \\
\text { Information on } 48 \text { projects was collected, of } \\
\text { which } 33 \text { were based in Australia and the } \\
\text { balance in the UK, Brazil, Indonesia, Portugal } \\
\text { and Spain. The number of 'alliance' projects } \\
\text { reviewed was } 15 \text { and the balance of } 33 \\
\text { projects were 'non-alliances'. }\end{array}$ & $\begin{array}{l}\text { than the initial target/budget compared with } 43 \% \\
\text { of non-alliance projects. In relation to schedule, } \\
36 \% \text { of alliance projects were ahead of schedule } \\
\text { compared to } 10 \% \text { in non-alliance projects. } \\
\text { The study suggested that alliance and non-alliance } \\
\text { projects have distinct ways of demonstrating VfM. } \\
\text { Non-alliance projects use the market to determine } \\
\text { the 'right price' although this can sometimes be } \\
\text { distorted due to a particularly buoyant market. } \\
\text { Alliances by contrast, determine a price for the } \\
\text { work which embraces the softer issues of project } \\
\text { delivery and remove barriers which allow the team } \\
\text { to operate in a less adversarial environment which } \\
\text { may produce innovations and better risk } \\
\text { minimisation. } \\
\text { The study concluded with the statement that when } \\
\text { a project is complex, there are significant risks in } \\
\text { delivery, certainty of cost is important and time is a } \\
\text { major constraint, then there is a greater } \\
\text { probability of the alliance procurement process } \\
\text { providing VfM for the project initiator and meeting } \\
\text { the project objectives. }\end{array}$ & $\begin{array}{l}\text { deliver VfM. } \\
\text { There are a number of analytical shortcomings } \\
\text { in the approach adopted as outline in the } \\
\text { criticisms of the study detailed opposite. }\end{array}$ & $\begin{array}{l}\text { only one party was approached for each project. } \\
\text { Furthermore, as discussed above, the term 'alliance' } \\
\text { was used broadly adopted i.e. not all the projects } \\
\text { considered were project alliances. } \\
\text { The analysis of the results obtained was purely } \\
\text { comparative and no rigorous statistical techniques } \\
\text { were adopted to address any postulated hypotheses. } \\
\text { Consequently, it is not possible to consider the } \\
\text { conclusions drawn to be definitive in relation to the } \\
\text { issue of VfM relating to project alliances. However, } \\
\text { they do suggest that hat alliance type projects can } \\
\text { achieve superior results compared to more } \\
\text { traditional means of procurement. }\end{array}$ \\
\hline $\begin{array}{l}\text { Northside Storage } \\
\text { Tunnel Project- } \\
\text { Post } \\
\text { Implementation } \\
\text { Review }\end{array}$ & 2004 & $\begin{array}{l}\text { Evans and Peck } \\
\text { Consulting Pty Ltd }\end{array}$ & $\begin{array}{l}\text { As result of receiving the NSW Auditor } \\
\text { General's Report in 2003, Sydney Water } \\
\text { Corporation (SWC) engaged Evans and Peck } \\
\text { Consulting (E\&P) to undertake a post } \\
\text { implementation cost review of the Northside } \\
\text { Storage Tunnel Project (NSST). This } \\
\text { commission resulted from the observations by } \\
\text { the Auditor General that there was } \\
\text { insufficient evidence to judge whether the } \\
\text { cost of the tunnel represented value for } \\
\text { money and that a post implementation review } \\
\text { should be undertaken. } \\
\text { sWC requested that that E\&P develop an } \\
\text { estimate based on using a Design and } \\
\text { Construct (D\&C) delivery method for the } \\
\text { project. This comparison was then to form } \\
\text { part of the assessment as to whether Sydney } \\
\text { Water had received VfM by proceeding with } \\
\text { the NSST project under an alliance delivery } \\
\text { method. } \\
\text { E\&P used the alliance Target Cost Estimate } \\
\text { (TCE) as the basis for producing a D\&C tender } \\
\text { estimate. This D\&C tender estimate was then } \\
\text { revised to include additional costs for the } \\
\text { actual scope changes and delays, which } \\
\text { impacted on the project. This revised estimate } \\
\text { could then be compared to the Alliance actual } \\
\text { cost at completion to indicate whether or not } \\
\text { a D\&C delivery method would have delivered }\end{array}$ & $\begin{array}{l}\text { The results of the analysis indicated that the } \\
\text { increase in the budget requirement for the D\&C } \\
\text { budget from the approved Alliance budget would } \\
\text { be approximately } \$ 44 \text { M. This significant difference } \\
\text { was ascribed to the different risk transfer and the } \\
\text { additional SWC costs that would be incurred in } \\
\text { procuring a D\&C contractor. } \\
\text { The probable increase between the Alliance cost } \\
\text { at completion and the D\&C cost at completion } \\
\text { could be as high as } \$ 105 \mathrm{M} \text {. Again this significant } \\
\text { difference was considered to be due to the } \\
\text { different risk transfer and the additional SWC costs } \\
\text { involved in administering and settling major } \\
\text { contract variations. The results indicated that the } \\
\text { Alliance delivery method chosen by SWC for the } \\
\text { delivery of the NSST project offered a significantly } \\
\text { lower final cost than would have resulted if a D\&C } \\
\text { delivery method had been chosen. } \\
\text { E\&P concurred with the findings of the NSWAG } \\
\text { and agreed that had a D\&C delivery method been } \\
\text { adopted the costs due to claims would have been } \\
\text { significantly higher and delays would most likely } \\
\text { have been increased. } \\
\text { The cost-saving initiatives and innovations would } \\
\text { also have been unlikely to be achieved through a } \\
\text { D\&C delivery method where the D\&C contractor's } \\
\text { and the client's interests are not aligned. } \\
\text { It was also probable that the NSST would not have } \\
\text { been available to receive overflows during the }\end{array}$ & $\begin{array}{l}\text { This study was limited to an analysis of purely } \\
\text { financial outcomes although the intangible } \\
\text { benefits of delivering the project before the } \\
\text { Olympic opening deadline were acknowledged. } \\
\text { Whilst such an analysis is necessarily based on } \\
\text { a series of judgements of how matters would } \\
\text { have unfolded in a D\&C environment these } \\
\text { judgements were made by people who are } \\
\text { highly experienced in the delivery of major } \\
\text { works and can realistically be relied upon to } \\
\text { represent what would happened if the D\&C } \\
\text { procurement model had been adopted. }\end{array}$ & $\begin{array}{l}\text { Whilst such single project retrospective reviews are } \\
\text { instructive, in themselves, they are of limited value in } \\
\text { developing a model which will allow us to ensure that } \\
\text { future alliance projects do deliver VfM. However, a } \\
\text { number of such studies in combination can provide } \\
\text { some useful insights into the organisational } \\
\text { arrangements and behaviours that might be } \\
\text { necessary to ensure success in delivering VFM. }\end{array}$ \\
\hline
\end{tabular}




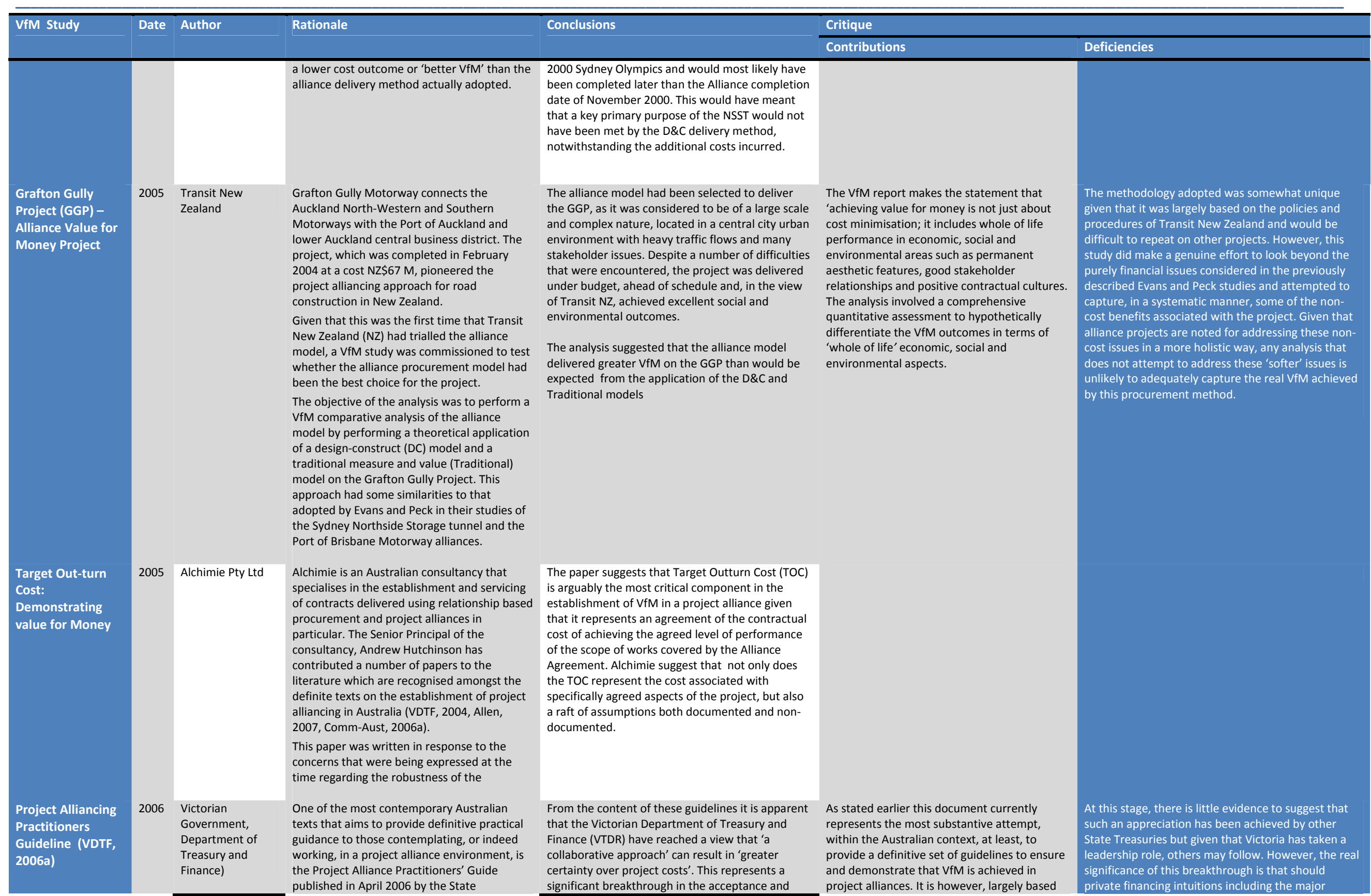




\begin{tabular}{|c|c|c|c|c|c|c|}
\hline \multirow[t]{2}{*}{ VfM Study } & \multirow[t]{2}{*}{ Date } & \multirow[t]{2}{*}{ Author } & \multirow[t]{2}{*}{ Rationale } & \multirow[t]{2}{*}{ Conclusions } & \multicolumn{2}{|l|}{ Critique } \\
\hline & & & & & Contributions & Deficiencies \\
\hline & & & $\begin{array}{l}\text { Government of Victoria (VDTF, 2006a). This } \\
\text { document was produced with significant input } \\
\text { from Jim Ross from Project Control } \\
\text { International who is another prominent } \\
\text { project alliance facilitator and the author of } \\
\text { one of the most definitive texts on the } \\
\text { mechanisms employed in establishing project } \\
\text { alliances in Australia and New Zealand } \\
\text { (Rapoport, 1970). }\end{array}$ & $\begin{array}{l}\text { adoption of project alliances in Australia. } \\
\text { Previously Treasuries, particularly at the State } \\
\text { level, have been very sceptical about the value that } \\
\text { could be obtained from a procurement procedure } \\
\text { that selects a contractor and designer by a method } \\
\text { that does not involve price competition and then } \\
\text { seeks to negotiate a price for the project. } \\
\text { Furthermore, under the typical project alliance } \\
\text { painshare/gainshare model, the Client then } \\
\text { accepts liability for all additional costs should the } \\
\text { out-turn cost exceed the point at which the Non- } \\
\text { Owner participants have surrendered their margin } \\
\text { and head office overhead. The VTDR have clearly } \\
\text { satisfied themselves, presumably form observing } \\
\text { the outcome of project alliance elsewhere, given } \\
\text { the relatively small numbers in Victoria, that } \\
\text { dynamics of the alliance are much more likely to } \\
\text { result in the out-turn cost being less than the } \\
\text { target than in a traditional contract the out-turn } \\
\text { cost will invariably exceed the agreed contract } \\
\text { value. }\end{array}$ & $\begin{array}{l}\text { on an intuitive approach to what is required, } \\
\text { albeit that the intuition concerned is based on } \\
\text { a now substantive body of experience in } \\
\text { Australia. The researcher suggests that this } \\
\text { document represents a very good starting } \\
\text { point but that more developed, quantitative } \\
\text { and verified techniques need to be added in } \\
\text { order to make this a more useful and widely } \\
\text { accepted model. }\end{array}$ & $\begin{array}{l}\text { merchant banks come to a similar conclusion as the } \\
\text { VTDR, the delivery of Private Public Partnership (PPP) } \\
\text { through a project alliance model may become } \\
\text { acceptable to these financial institution and this } \\
\text { would present the prospect of significant expansion } \\
\text { of project alliance activity in Australia given the very } \\
\text { substantial extent of public infrastructure that is likely } \\
\text { to be delivered through PPP's in the next decade and } \\
\text { potentially beyond. }\end{array}$ \\
\hline $\begin{array}{l}\text { Method for } \\
\text { demonstrating } \\
\text { value for money }\end{array}$ & 2007 & $\begin{array}{l}\text { SRD Consulting Pty } \\
\text { Ltd }\end{array}$ & $\begin{array}{l}\text { SRD, a Perth based consultancy that } \\
\text { specialises in the establishment of project } \\
\text { alliances and the coaching of participants in } \\
\text { alliances, have recently developed an } \\
\text { approach to the demonstration of value for } \\
\text { money in alliances. } \\
\text { The Senior Principal of SRD, Malcolm } \\
\text { Washbourne first presented a methodology } \\
\text { for demonstrating value for money in alliances } \\
\text { during an Alliancing Conference held in } \\
\text { Brisbane in August } 2007 \text { and a detailed paper } \\
\text { outlining the approach in further detail was } \\
\text { released in November } 2007 \text { (Gordon, 2009a). } \\
\text { The method adopts the following definitions; } \\
\text { - Value: Value = Benefits - Price } \\
\text { - VfM is achieved when the alliance } \\
\text { achieves Minimum Conditions of } \\
\text { Satisfaction (MCOS) in the owners Key } \\
\text { Result Areas (KRA's) for a 'value assured' } \\
\text { TOC }\end{array}$ & $\begin{array}{l}\text { SRD conclude that the debate as to whether, } \\
\text { alliancing as a contract delivery strategy, delivers } \\
\text { VfM outcomes without commercial competition } \\
\text { will continue to be heard at all levels of project } \\
\text { governance until a robust yet simple model and } \\
\text { practiced methodologies for the demonstration of } \\
\text { VfM are established, adopted and driven by the } \\
\text { owners of organisations that deliver projects, } \\
\text { programs and service provision through alliances. } \\
\text { SRD suggest that the model described above } \\
\text { addresses these requirements and allows: } \\
\text { - Owners to demonstrate that target costs are } \\
\text { value assured; } \\
\text { - Alliance participants to collectively monitor } \\
\text { and display their performance against the } \\
\text { defining purposes of their alliance and act } \\
\text { accordingly; and } \\
\text { - Alliance participants to report and } \\
\text { demonstrate categorically to their parent } \\
\text { organisation and other stakeholders how they } \\
\text { are progressed against VfM both during the } \\
\text { job and after its completion. }\end{array}$ & $\begin{array}{l}\text { The suggestion that the TOC be 'value assured' } \\
\text { to ensure that it is rigorously justified is } \\
\text { consistent with the views expressed by } \\
\text { Alchimie the Victorian Department of Treasury } \\
\text { and Finance and others but the means by } \\
\text { which this assurance will be achieved are not } \\
\text { entirely clear. }\end{array}$ & $\begin{array}{l}\text { The model attempts to reduce the analysis of VFM to } \\
\text { a single value and whilst the methodology proposed } \\
\text { does seek to include the non-cost KRA's it is felt their } \\
\text { consideration is somewhat simplistic. } \\
\text { The approach appears to commence with the process } \\
\text { of establishing the TOC when, in the view of the } \\
\text { researcher, the 'VfM destiny' of the project is likely to } \\
\text { be largely influenced by decisions made much earlier } \\
\text { in project life cycle, such as the business case } \\
\text { development and procurement method selection. } \\
\text { Consequently, any model that seeks to } \\
\text { comprehensively address the VfM issue needs to } \\
\text { include a consideration of these earlier stages. }\end{array}$ \\
\hline $\begin{array}{l}\text { Performance of } \\
\text { PPPs and } \\
\text { Traditional } \\
\text { Procurement in } \\
\text { Australia }\end{array}$ & 2007 & $\begin{array}{l}\text { Allen Consulting } \\
\text { Group Pty Ltd }\end{array}$ & $\begin{array}{l}\text { Infrastructure Partnership Australia (IPA) } \\
\text { engaged the Allen Consulting Group in } \\
\text { conjunction with the University of Melbourne } \\
\text { to undertake a study of the efficiency of Public } \\
\text {-Private partnerships (PPP's) relative to } \\
\text { traditional procurement approaches to : }\end{array}$ & $\begin{array}{l}\text { Having studied } 21 \text { PPP projects and } 33 \text { traditional } \\
\text { projects the conclusions included; } \\
\text { - PPP's provide superior performance in both } \\
\text { cost and time dimensions and that the PPP } \\
\text { advantage increases (in absolute terms) with } \\
\text { size and complexity of projects. }\end{array}$ & $\begin{array}{l}\text { Whilst there may be some doubt regarding the } \\
\text { real contribution that this study makes to the } \\
\text { analysis of the value delivered by various } \\
\text { procurement models it does provide a } \\
\text { relatively contemporary listing of recent } \\
\text { projects including project alliance projects }\end{array}$ & $\begin{array}{l}\text { There are, however, some issues that cause the } \\
\text { researcher to have concern about the validly of these } \\
\text { rather strongly expressed conclusions. These include; } \\
\text { The term 'traditional' was used somewhat } \\
\text { indiscriminately and included all procurement } \\
\text { methods other than PPP's. Consequently, the more }\end{array}$ \\
\hline
\end{tabular}




\begin{tabular}{|c|c|c|c|c|c|c|}
\hline \multirow[t]{2}{*}{ VfM Study } & \multirow[t]{2}{*}{ Date } & \multirow[t]{2}{*}{ Author } & \multirow[t]{2}{*}{ Rationale } & \multirow[t]{2}{*}{ Conclusions } & \multicolumn{2}{|l|}{ Critique } \\
\hline & & & & & Contributions & Deficiencies \\
\hline \multirow{9}{*}{$\begin{array}{l}\text { Review of South } \\
\text { East Water's } \\
\text { Works Alliance } \\
\text { Agreement }\end{array}$} & \multirow{9}{*}{2008} & & $\begin{array}{l}\text { test the notion that PPP's provide } \\
\text { infrastructure with reduced cost over- } \\
\text { runs compared to traditional } \\
\text { procurement; } \\
\text { to examine factors that account for the } \\
\text { relative success of PPP's }\end{array}$ & $\begin{array}{l}\text { A major source of PPP advantage over } \\
\text { traditional procurement approaches that de- } \\
\text { couple the management/construction and } \\
\text { operation phases, creating additional sources } \\
\text { of inefficiency. }\end{array}$ & $\begin{array}{l}\text { undertaken in Australia in recent years. } \\
\text { It is believed that some of the advantages } \\
\text { described for the PPP model are also } \\
\text { applicable to the project alliance model. }\end{array}$ & $\begin{array}{l}\text { conventionally defined traditional procurement } \\
\text { model (design then tender and build) is bundled with } \\
\text { design and construct projects and project alliances. } \\
\text { The relative performance of Ppp's versus other } \\
\text { procurement models might have been better } \\
\text { illustrated if the performance of each model had } \\
\text { been considered separately. This may not have been } \\
\text { feasible, however, due to the relatively small sample } \\
\text { sizes involved. }\end{array}$ \\
\hline & & \multirow[t]{8}{*}{$\begin{array}{l}\text { Victorian Auditor } \\
\text { General }\end{array}$} & \multirow{8}{*}{$\begin{array}{l}\text { This report related to a audit a long term } \\
\text { (12year) 'service alliance' between South East } \\
\text { Water(SEW) and two companies to provide } \\
\text { utility services established in } 2005 \text {. The } \\
\text { estimated value of the works concerned is } \\
\text { estimated to be approximately } \$ 850 \text { million in } \\
2008 \text { NPV terms. } \\
\text { The audit objectives were to assess the } \\
\text { planning and management of the alliance } \\
\text { agreement and to determine whether the } \\
\text { alliance was achieving SEW's objectives and } \\
\text { the expected benefits }\end{array}$} & \multirow{5}{*}{$\begin{array}{l}\text { The audit findings stated that SEW had achieved } \\
\text { the cost savings that were forecast a consequence } \\
\text { of the alliance but had concerns under three main } \\
\text { headings: } \\
\text { Procurement options: } \\
\text { SEW did not rigorously assess the alliance option } \\
\text { against other procurement options and did not } \\
\text { consider other alliance models or develop a } \\
\text { business case. SEW was, therefore, unable to } \\
\text { demonstrate that it had achieved the best } \\
\text { procurement option. } \\
\text { Alliance objectives; } \\
\text { Despite the cost savings achieved it was not clear } \\
\text { that SEW had achieved the best VfM outcome } \\
\text { available from the alliance. I had not applied the } \\
\text { same commercial rigour in determining the } \\
\text { commercial participant's margin as it applied to } \\
\text { other parts of the alliance development process. } \\
\text { This margin was considered to be high and was } \\
\text { 'locked in' for the duration of the alliance. } \\
\text { A significant percentage of the gain-share } \\
\text { payments paid to the Non Owner participants } \\
\text { resulted from capital works risks that had not } \\
\text { eventuated. SEW had since risk allocations from } \\
\text { gain-share calculations. }\end{array}$} & \multirow{8}{*}{$\begin{array}{l}\text { The report makes a number of positive findings } \\
\text { about the alliance methodology adopted and } \\
\text { offers a number of constructive suggestions as } \\
\text { to how the business case development could } \\
\text { be improved. } \\
\text { It dwells on the need to demonstrate that the } \\
\text { alliance approach is adopted following a } \\
\text { careful consideration of the other available } \\
\text { options and not simply based on a positive } \\
\text { experience in the past }\end{array}$} & \multirow{8}{*}{$\begin{array}{l}\text { The report appears to give less credit than might be } \\
\text { due to the alliance for the achievement of savings in } \\
\text { excess of TOC. } \\
\text { It even suggests that the achievement of these } \\
\text { savings should result in an annual review of the } \\
\text { commercial framework and not just the KPI's. } \\
\text { This comment is typical of those who appear to see } \\
\text { the success of the alliance as an indication that the } \\
\text { commercial framework was 'generous' to the Non } \\
\text { Owner participants and not a direct reflection of the } \\
\text { 'win-win' culture which is an essential feature of } \\
\text { alliances. As the MD of SEW put it in his responses to } \\
\text { the report 'It appears that the Auditor General has a } \\
\text { different expectation of the 'annual review', including } \\
\text { that a review must result in changes to practices } \\
\text { rather than simply endorse the current situation as } \\
\text { being still appropriate for the purposes of SEW' }\end{array}$} \\
\hline & & & & & & \\
\hline & & & & & & \\
\hline & & & & & & \\
\hline & & & & & & \\
\hline & & & & $\begin{array}{l}\text { The alliance had generated significant revenue by } \\
\text { offering services to external parties. This had } \\
\text { benefited SEW and increased competition in the } \\
\text { industry. }\end{array}$ & & \\
\hline & & & & $\begin{array}{l}\text { Anecdotal evidence suggested that staff had more } \\
\text { interesting and diverse jobs with greater } \\
\text { opportunities for new experiences and learning. }\end{array}$ & & \\
\hline & & & & $\begin{array}{l}\text { Management and review: } \\
\text { The alliance development process was conducted } \\
\text { with probity, however, threw re lapses in } \\
\text { documentation and although a probity advisor was } \\
\text { appointed there was no probity auditor. }\end{array}$ & & \\
\hline $\begin{array}{l}\text { In Pursuit of } \\
\text { Additional Value }\end{array}$ & 2009 & $\begin{array}{l}\text { Evans and Peck } \\
\text { Consulting Pty Ltd } \\
\text { and the University } \\
\text { of Melbourne } \\
\end{array}$ & See Chapter 7 & See notes at the foot of table 3.1. & See Chapter 7 & See Chapter 7 \\
\hline
\end{tabular}


Having completed the review described in Table 3.2 above, the following points are apparent to the researcher regarding the current status of this issue:

- Whilst there have been several retrospective studies of projects which appear to support the view that the alliance model has delivered a better outcome than would have achieved in a 'design and construct' or 'traditional' environment these studies provide limited insight into what actually contributes to success. Further, analysis of each project to demonstrate 'after the event' whether it achieved an acceptable VfM outcome is not considered to be a practical or sustainable working approach.

- The initiatives proposed in the 2006 Edition Victorian Government's 'Project Alliancing Practitioners' Guide' (VDTF) through some 19 tangible, practical, common sense measures, are seen to represent a start to addressing the issue of demonstrating $\mathrm{VfM}$ in project alliances. However, these measures tend to focus on the later stages of the project life cycle and have little emphasis on the earlier project development stages.

- The model proposed by SRD Consulting offers an approach which appears to determine in a quantitative manner whether VfM has been achieved and then seeks to monitor VfM as the project proceeds. Whilst this concept is appealing, the model, as proposed starts with the determination of a 'value assure' TOC. In the view of the researcher, the 'VfM destiny' of the project is likely to be largely influenced by decisions made much earlier in project life cycle, such as the business case development and procurement method selection. Consequently, any model that seeks to comprehensively address the $\mathrm{VFM}$ issue needs to include a consideration of these earlier stages.

- Despite the work that has been done to date it appears to be clear that the need to determine and demonstrate VfM in project alliances remains. It is also apparent that there is no model or methodology currently identified that provides a full 'life-cycle' approach to determining and demonstrating VfM.

\subsection{Obtaining VfM under the Alliance Procurement Model}

It is natural and appropriate for owners and/or their financial advisor's ask how they can be satisfied that they are getting VfM and as importantly, how can they demonstrate to themselves and the community, or their shareholders that VfM is being achieved.

An unusual feature of the use of the project alliance model, compared to most other procurement models, is that there have been very few, if indeed any, examples of significant failures of this procurement method. The Hot Briquetted Iron (HBI) project undertaken by BHP in Western Australia during the late 1990's is sometimes quoted as an example of such a failure but it is questionable 
whether this project truly fulfilled the definition of a project alliance and was rather an amalgam of three separate fabrication/construction contracts termed alliances (Ross, 2000).

Nevertheless, there remains to be some scepticism, particularly in public sector treasury agencies, regarding the apparent achievement by alliances of successful outcomes, represented by completing projects for less than the Turn Out Cost (TOC), as developed by the Alliance, and meeting or exceeding further non-cost performance targets.

The sceptics have questioned the veracity and robustness of the development of the TOC's and performance targets and suggested that the commercial arrangements of the single TOC approach, in particular, encourage the non owner participants (NoPs) to seek a higher TOC and more achievable performance targets(VDTF, 2006a).

Consequently, it could be argued that the need to demonstrate that project alliances truly deliver $\mathrm{VfM}$ is not a consequence of the failure of the model in the past, but is the result of the apparently very high rate of success of the model. This success causes some observers to be concerned that this success is being predetermined by the inherent nature of the commercial arrangements in the model which may be presenting 'soft' targets to the participants.

In the last fifteen years since the Wandoo and the East Spar alliances in the private sector and the first bold step by the public sector in the Northside Storage Tunnel alliance, the use of project alliancing has become quite widespread in Australia as was described in Chapter 2. In particular the year 2006 saw a rapid increase in the establishment of project alliances in Australia as a means to effectively deliver infrastructure in the public sector, with well over $\$ 10$ billion of projects being delivered or planned under an alliance model (Ross, 2007). This increase was almost exclusively the public sector even though it is generally considered that there is greater pressure on public sector than private bodies to demonstrate $\mathrm{VfM}$ in procurement.

Some of the large public sector works procurement authorities such as the RTA in New South Wales, who were initially sceptical about the benefits of the single TOC project alliance model have initially selected a 'competitive' TOC approach to the selection of NoPs but have later proceeded to adopt a 'single' TOC model. This is illustrated by the history of the RTA experience with project alliances. Initially, for the Windsor Road Alliance, they chose to pursue a 'price competition' form, seemingly as a consequence of their reservation about securing VfM with a form that did not involve competitive pricing. However, subsequently they chose to adopt the single TOC model for the Lawrence Hargraves Drive Alliance and a number of the Pacific Highway Upgrade projects. This could suggest that, given a free choice, public sector agencies may prefer to adopt the single TOC approach. 
In any procurement process, comparison needs to be made between suppliers and there should be competition between the parties seeking to undertake the work. Without competition, efficiencies and innovation will not be driven and this will conspire against VfM. However, competition does not automatically mean a process that drives suppliers to offer the lowest price. If it is possible to fully quantify the required attributes of a good or service and it becomes, in effect, a commodity. If that is the case, price competition alone may be a reasonable and legitimate basis on which to base the procurement decision. However, in the case of complex infrastructure delivered through construction contracts, selection of parties based solely on price grossly over simplifies the procurement decision, indeed the adoption of such a simplistic attitude on the part of the body undertaking such procurement could be characterised as unprofessional or even negligent and is specifically contrary to the requirements of many procurement guidelines including Commonwealth Procurement guidelines(Comm-Aust, 2008).

As suggested above, the use of project alliancing in Australia, by public sector clients in particular, has grown significantly in recent years. It would appear to be self evident that such bodies would be unlikely to enthusiastically embrace such a procurement model if they believed that the outcomes were unsatisfactory and that VfM was not being achieved. However, the continued growth of the model as described in Chapter 2 is believed to have been stimulated by both the perceived success of the previous uses of the method and a sense, within some public sector clients, that in the buoyant market experience in Australia, in recent years, traditional procurement models including document/tender/build and design and construct (D\&C) lost their attractiveness due to a shortage of resources and general lack of capacity to deliver projects within the construction industry. It has been remarked by government agencies that there has been little interest by contractors to bid for $D \& C$ contracts which allocate all significant risks to the contractor, when there was an abundant supply of work available as project alliances or other forms of relationship contracting, with risk sharing regimes which they viewed as much more equitable (Skinner, 2006). Such a shortage of resources also makes contractors reluctant to commit large teams of personnel to preparing long and detailed tenders for D\&C contracts when alliance selection procedures are much shorter and more direct, even though they may involve the time of more senior members of the respective organisations.

This conundrum did reach the point in 2007, prior to the effect of the so-termed Global Financial Crisis (GFC) of 2008 where some requests for D\&C tenders were reportedly attracting a very limited number of responses. Clearly this impacts on the opportunity to develop competition between bidders and as a consequence, the cost of undertaking work under a price based procurement strategy, such as D\&C, has risen substantially in recent times (Karpin, 1995). These increases are 
thought to have arisen for several reasons including increasing costs of labour in a buoyant market and high material costs for commodities such as steel and cement which result from world demand. This situation provides an interesting illustration of the outcome of trying to follow a 'price based' procurement process in circumstances where a 'cost based' procurement approach such as project alliancing would provide a much more transparent process that would enable clients to better understand, and then better justify, whether the investment involved offered best value.

This represents an ironical change of circumstances. Previously alliances, particularly the single TOC model, have been criticised for as not providing real competition compared to the 'free market'. The competitive forces present in traditionally tendered 'price based' contracts have been proclaimed as the only objective means of demonstrating the achievement of a 'value for money' outcome. Putting aside for a moment that value is much more than lowest price, when the free market fails to offer sufficient numbers of responses then price competition offers no correlation to value and only 'cost based' procurement provides a means of transparently determining whether VfM is being achieved.

In the early days of project alliance contracting in Australia (1997-2004) there were a number of issues that inhibited the adoption of alliancing as a 'mainstream' procurement method that could be used on a regular basis to secure infrastructure projects. These concerns included some reservations about a number of issues including the following:

- The policy of 'no disputation' whereby the parties surrendered any right to take action against each other on the basis that they were in effect one virtual organisation and nobody can take legal action against itself.

- The absence of professional indemnity insurance. Because the responsibility for all matters is shared between the parties it was not possible for the owner or contractor to seek damages, which would be covered by insurance.

- Concern was sometimes expressed regarding the adequacy of the selection process in identifying the truly best alliance team rather than 'best presenting' team.

Experience of project alliances has developed and the procurement method has matured to the point where most of these issues have now been successfully resolved. However, one issue that remains a relatively controversial matter is the demonstration that alliances truly offer $\mathrm{VfM}$ outcomes. Concern that this matter is yet to be successfully addressed is a view held broadly by both individuals and organisations associated with project alliancing. This is confirmed by the fact that this issue is a particular focus of the Alliancing Association of Australasia (AAA), an industry group formally 
constituted in 2006 to represent the interests of owners, contractors, designers, lawyers and other professionals involved in alliance contracting.

\subsection{The VfM message from the Early Contractor Involvement (ECI) Model}

Further forms of relationship contracts have emerged in recent times which are not described earlier in this thesis. These forms include Early Contractor Involvement (ECI). ECI developed initially as an extension to the partnering model favoured in the UK and has subsequently been adopted in Australia, notably by public sector clients in South Australia and Queensland.

$\mathrm{ECl}$ is in fact a hybrid form which consists of a project alliance front end (up to the development of the target out-turn cost (TOC)) and then a D\&C delivery phase in which the contractor takes all delivery and cost risk.

At first glance, this may be seen as an odd combination of approaches and could be seen as placing at risk all the goodwill that should have been built up during the initial phases of the project, by adopting an adversarial mode during delivery. Experience with this model, particularly in Australia, is more limited than is the case for alliances, but such concerns do not appear to have materialised in practice. However, the mere existence of this model and certainly the nature of its adoption in Australia appears to act as a metaphor for the fact that VfM concerns remain, particularly within some public sector treasuries. Such bodies can seemingly be persuaded that early consultation with a constructor can drive better solutions for construction related projects and that this should make a contribution to improved VfM prior to the development of the TOC. An apparent difficulty occurs, however, when the parties come to jointly accept risk for the final cost of the works. If such a joint ownership of risk is embraced the price for the project is, seemingly, seen not to be fully determined and the owner carries price risk, albeit that this risk can result in either downside or upside exposure i.e. the final cost of the project could be less than the TOC and the owner would benefit from these circumstances.

Anecdotal evidence, supported by the adoption of $\mathrm{ECl}$, suggests that treasury agencies would actually prefer to commit to a fixed price at the time that the TOC is developed rather than endure any exposure to price risk even though experience to date with project alliances suggests that a shared risk regime is more likely to actually increase $\mathrm{VfM}$ as a consequence of the whole project team working together to deliver further cost savings during the delivery phase.

If this is the case, then concerns often expressed about VfM in alliancing are perhaps not genuinely about best value at all but are really concerns about certainty of price. Given that most project alliances in Australia complete the project for a sum less than the TOC (See Chapter 2) it could be 
claimed that such an approach actually sacrifices a likely increase in VfM in order to purchase certainty of price. This position might be seen as even more illogical as one considers that the adversarial D\&C delivery mode often leads to the development of a 'claims mentality' that invariably results in the final price for the works being higher than the original contract value (in this case the TOC) and more than occasionally, substantially higher.

\subsection{Recent relevant post-graduate research relevant to VfM in Project Alliances}

The Application of Relationship Marketing to Construction - PhD Thesis, Davis (2005)

Relationship Marketing (RM), which is a well understood concept outside the construction industry, involves the attraction of new clients and ensures that existing clients are looked after in a collaborative engagement where objectives are identified and mutual goals set.

More typically, in the construction industry a more traditional transactional marketing approach applies which focuses on price and fails to recognise the interrelationship between key elements of the marketing mix. The relationship model provides: integral linkages to keep clients for the long term, adds value to the project and reduces emphasis on price.

Research undertaken by Davis and reported in his PhD Thesis (2005) identified that in RM has many attributes that should be applied to construction whilst noting that several aspects are already applied in alliance projects, particularly in the form of relationship development between stakeholders. These stakeholders, who form the virtual organisation that manage the project, develop trust, commitment and mutual goals that closely parallel similar constructs in RM.

Davis developed a number of construction relationship marketing models and found that traditional procurement models focus in discrete projects; process features, short time scales with little emphasis in client service. They operate in an environment of low commitment and contact, producing negligible vertical integration. Alternatively, the adoption of an RM procurement approach reduces the emphasis of price, focussing instead on demonstrated commitment, trust, confidence building and performance satisfaction. Through the project life cycle, supply chain collaboration and vertical integration are developed and enhanced. Project trust, commitment, satisfaction and value are increased, whilst at the same time stress, for the project team and associated delivery stakeholders, decreases. The outcome is that transactions are likely to increase creating a long span for life for relationships and overall enhanced organisational achievement.

Davis also concluded the following: 


\section{Alliancing}

Project Alliancing is a manifestation of the RM approach that delivers successful projects with high levels of client and project team delivery satisfaction. Further, from a procurement perspective, the RM approach and RM outcome relating to a project alliance, seek to deliver greater understanding between project participants and hence great customer focus. Davis concludes that the benefits and opportunities that RM offers as a business development strategy should be now widely adopted in the construction industry.

\section{Social Capital}

Relationship based procurement systems are based upon the development of effective use of social capital, and deliver win-win outcomes for project participants throughout the project supply chain. This provides a framework for understanding the underlying process that leads to project success using a relationship based procurement approach. Social capital and the positive impact upon supply chain management influenced the outcome of projects that were reviewed.

Davis investigated whether an RM approach had the ability to add value to construction projects and whether 'construction actors' endeavour to add value to the projects that they carry out. This research indicated that the relationship development process in alliance projects enables value creation via the principal components of trust development and maintenance and commitment to mutual goals. Trust and trusting behaviours provided value to clients in both the process and the final project. The value to the project was derived from trust that enabled the parties involved to work with people on the issues that were important as opposed to concerning themselves solely with monetary considerations. Value was also identified through the identification of organisational learning. Often, however, the value created in the relationship development process would not be captured in a tangible way through reporting, for example. This failure caused several respondents, mainly clients, to miss the worth of the value and presume that the relationships development offered little net gain to the overall project. The respondents indicated that VfM deliverables occur in many shapes and forms throughout the project's whole life and for impact to new projects, these should be captured and reviewed. Davis observed that post-implementation reviews and close out reports from recent alliance projects are becoming more accessible and these would provide a valuable source of information.

Davis also sought to determine the principal factors which influenced the selection of particular partners to an alliance and concluded that: The relationships the respondents in the research were striving toward were likened to personal relationships. They endeavoured to identify suitable 
partners they could work with and trust. Individuals were more important than the respective organisations.

The themes from this work that are considered to be relevant to this research are:

- The importance of moving beyond a transactional relationship to a collaborative model in order to create an environment in which value can be significantly increased;

- The failure to adequately record the capture of additional value throughout the project lifecycle which reduced the opportunity for organisational learning and transfer of knowledge between projects;

- The importance of trust and personal, rather than organisational behaviours in the selection of partners to undertake a project.

\section{Alliance, Public Sector Governance and Value for Money - PhD Thesis, Davies (2007)}

Davies sought to address the research question of whether alliances comply with the governance framework of the public sector and how whether these procurement options are suitable for delivering public works. The results of this research are reported in his PhD thesis (2007).

Davies concluded that alliances fail to comply with both the performance and compliance aspects of public governance. In particular, he reports that price alliances, despite their popularity, fail to adequately demonstrate VfM for the public sector and contribute to diminished accountability, integrity and transparency in procurement. His research also suggested that there was no precise definition of VfM provided by any level of government in Australia.

However, despite this rather damning view of alliances, Davies also concedes that many of the criticisms that he levels upon alliances are also equally applicable to conventional procurement options. Additionally, he makes a number of recommendations from reform to address the alliance governance shortcomings that he identifies.

Davies expressed concerns that alliances have the potential to be adopted as either, the last refuge of the incompetent project manager or specification developer or to mitigate against poor drafting. However, he also acknowledges that his research confirmed that alliances can be, and are often, successful noting that the definition of success needs to be carefully formulated. In making this statement he also states that alliances do not succeed simply on the basis they are alliances but because they force participants to define project requirements robustly and to treat risks sensibly. Further, alliances develop target costs and schedules after considerable time and money is expended and, he argues, conventionally developed bids are not provided with these luxuries. 
Davies concludes that given his view that alliances are significantly less likely to satisfy the governance objectives of the public sector than conventional contract delivery mechanisms, the situation can only be remedied by changing either the governance arrangement of alliances or the governance rules of the public sector.

The latter category includes improvements to the manner in which governments define VfM and select decision making rules. Without a robust and reportable framework for measuring the value of competing procurement options and tenderers, then any attempts to develop project business cases are fraught with risks of abuse.

Alliances also need to evolve to better demonstrate VfM, retain accountability for outcomes and achieve fairness in tender evaluations.

Davies concedes that despite his concerns there is a legitimate niche for the use of the alliance process to procure high-risk projects that are subject to variable scope.

The themes from this work that are relevant to this research are:

- That the promotion of alliances, particularly pure alliances, need to recognise that alliances must be seen to respect appropriate governance requirements;

- That a robust and repeatable framework for measuring the value of competing options to be developed;

- Alliances need to develop a systematic means of demonstrating VfM.

\section{Addressing Market Failure: Using Transaction Cost Economics to Improve the Construction Industry's Performance - Sweeney, PhD thesis (2009)}

Sweeney sought to investigate why there is no widely accepted method for deeming which project delivering methodology would be most appropriate for a given project. The results of this research are reported in his PhD Thesis (2009)

The research involved a comprehensive review of the state of the construction industry which concluded that the industry was performing poorly. The characteristics of the industry were then compared to the principles of market contracting which confirmed that the predominant approach of the industry closely matches the market contracting approach. This conclusion aligned with the work of Davis (2003) The principles underpinning the market contracting approach were then assessed and shown to be invalid in the modern construction setting for complex projects. These principles include the assumptions that there is perfect information and perfect rationality, litigation/enforcement is effortless and costless, perfect competition exists and there are no 
transaction costs. The lack of validity of these assumptions is portrayed as representing a clear example of market failure.

The theory of Transactional Cost Economics (TCE) is then introduced and outlined. This approach which is essentially a behavioural framework embraces such concepts as Bounded Rationality, Asset Specificity and Opportunism which it is argued move accurately reflect the real world behaviour of the industry. Sweeney argues that the adoption of such an approach would result in much better contracting performance and therefore much improved efficiency and would deal with the market failure conditions that result from the market contracting approach based on neo-classical economic theory.

Sweeney then proceeds to test whether contracting approaches that show more positive recognition of and response to the issues raised by TCE theory will show superior project delivery performance and therefore demonstrate that TCE can be used productively to provide more accurate guidance about what may occur within a specific setting. The analysis is applied to the dominant market contracting traditional delivery approach and two newer forms being project alliancing and Public Private Partnerships (PPP). Each procurements approach was analysed using a TCE schema to enable predictions of performance to be made and this is compared to the actual results of 234 traditional delivery projects, 40 project alliances and 5 PPP projects. The results indicated that project alliances and PPPs showed more positive responses to the issues arising in the TCE and exhibited superior project performance as a result. Additionally, TCE can be used to predict and improve project contracting performance.

The themes of this work that are relevant to this research are:

- That the neo-classical economic theory regularly used to support the position that alliances cannot demonstrate $\mathrm{VfM}$, in the same manner as the traditional procurement approach, as they do not involve standard price competitive procedures, has a number of practical flaws;

- That the performance of project alliances correlates well to an alternative economic approach which recognises real-world behaviour.

\section{Achieving Value for Money in Infrastructure Projects delivered through an Alliance Contract - McIntyre, Master in Project Management (2009)}

McIntyre (2009) sought to address the following research question - Can value for money be achieved in infrastructure Projects delivered through alliance contracts? In addressing this question his research sought to address the following issues:

- What is value for money (VfM) and why is it so important? 
- What is an alliance contract and what rare these benefits and concerns for their application to the delivery of infrastructure projects?

- How does an alliance contract attempt to achieve value for money?

McIntyre found that there was no commonly adopted definition of $\mathrm{VfM}$ and support the view formed by others that $\mathrm{VFM}$ depends upon the point of view of the individual organisation making the determination (Cosby and Tyson, 1993, Morwood et al., 2008, Henneveld, 2006).

McIntyre suggests that a full understanding of $\mathrm{VFM}$ requires a broader approach to the definition as proposed by Price Waterhouse (1990) and Permain (1992). The work of these authors seeks to define 3 dimensions of $\mathrm{VFM}$ being:

Economy: the practiced of thrift and good housekeeping/obtaining the right things at the right time at the right cost;

Efficiency: ensuring that the maximum useful output is gained for resources;

Effectiveness: ensuring that the output from any given activity is achieving the desired result.

These 3 aspects of $V f M$ are seen to be interrelated in a similar manner to the project management knowledge areas of costs, time and quality. A change in one aspect of VfM will impact on one or both of the other aspects.

McIntyre then analyses a number of definitions of VfM existing in the literature and identifies the existence of all 3 aspects in a number of the more broadly accepted definitions including that promoted by HM Treasury: - 'VfM is defined a the optimum combination of whole of life costs and quality (or fitness for purpose) of the goods or serve to meet the user's requirements. VfM is not the choice of goods or services based on the lowest cost bid'.

This work emphasises the multidimensional nature of VfM and the importance of avoiding a purely monetary perspective in considering the matter.

McIntyre also refers to a statement from the National Audit Office (2001) which also assists in defining $V f M$ by identifying outcomes characteristic of projects not achieving VfM:

- Users' expectations not met;

- Poor quality public services;

- Adverse effects in economic competiveness;

- Adverse social or environmental consequences; 
- Little or no benefit delivered or not sustainable in the longer term;

- Sections of society excluded from benefits.

Using a questionnaire based survey of industry participants (67 responses) McIntyre demonstrated that $99 \%$ of alliance participants placed a high level of importance on achieving VfM. Further, no responded believed that alliance contacts could not deliver VfM. However, the findings of the survey did illustrate a need to investigate how the three aspects of VfM identified can be translated into actions and activities that can be incorporated in regular practice.

The themes of this work that are relevant to this research are:

- It emphases the multi-dimensional nature of VfM that it is not well addressed in current practice;

- It supports the position that tangible actions and activities need to be identified to ensure and demonstrate VfM.

\subsection{Strengths and weaknesses analysis to determine the required attributes of the VfM/BV Model}

\subsubsection{Strengths and weakness of current practice}

In seeking to define the required attributes of a model suitable for ensuring and demonstrating VfM, it is important to establish what is currently well addressed and what is clearly inadequately addressed in current alliance procurement practice. To achieve this, a strengths and weaknesses analysis of current practice was undertaken.

In order to perform this analysis the Gateway ${ }^{\mathrm{TM}}$ Process was used as a temporal framework and the results are presented in Table 3.3 below. The particular 'Gateway ${ }^{\top \mathrm{M} \text { ' }}$ terminology used in this table is taken from the process developed by the Commonwealth of Australia (2006b) and shown in Figure 3.1 below. It should be noted that this differs, to a minor degree, from the terminology adopted by the OGC and indeed the models adopted by each of the State Governments in Australia. The reasons for adopting the framework of the Gateway process are described further in Section 3.6 below.

The review as described in Table 3.3 provided a comprehensive analysis of the strengths and weaknesses of the current approach to alliance procurement. It also identified the issues that needed to be addressed at each stage of the project lifecycle if $\mathrm{VfM} /$ best value was to be achieved in an alliance project.

This review was valuable in identifying both what was done well in current practice and what was not done well, However, it also provided insights into issues that were not addressed in the literature i.e. 
identified gaps. Additionally, it also considered the VfM questions that needed to be addressed at each stage of the project lifecycle if $\mathrm{VfM} / \mathrm{BV}$ is to be achieved in an alliance project.

\subsubsection{Required attributes of a VfM/BV Model}

Further to the analysis as reported in Table 3.3, it was considered that a number of issues needed to be addressed in a VfM/BV model and that this demanded particular requirements of the model. To capture these requirements a specification was developed which described the issues that needed to be addressed by the model. This specification is described in Table 3.4 below and includes a description of;

- the objective of the model,

- the boundaries of applicability of the model,

- the target audience of the model,

- the benefits of an alliance that needed to be captured by the model,

- other dimensions of $\mathrm{VFM}$ that the model was required to address,

- $\quad$ required attributes of the model;

- $\quad$ other benefits anticipated from the development of the model.

In summary, the research question to be addressed by the proposed research was 'What is the optimum configuration of a model that will assist all participants in a project alliance to both ensure and demonstrate the achievement of VfM or best value'? 


\section{GATE 0 - BUSINESS NEED}

This review focuses on the strategic assessment of the business need of the agency proposing the project or programme. Areas of assessment include:

- Stakeholder buy-in.

- Contribution to organisational business strategy and to high-level policy objectives, strategies and initiatives.

- Review of arrangements for leading and managing the project or programme.

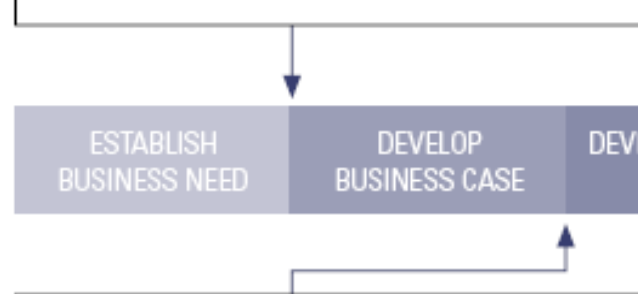

\section{GATE 1 - BUSINESS CASE}

This review focuses on a project's business justification and whether the proposed approach has been adequately researched and can be delivered. Areas assessed include:

- Does the project contribute to the agency's business strategy?

- Are the scope, scale and requirements realistic, clear and unambiguous?

- Have major risks been identified and a management plan outlined?

- Have critical success factors been agreed with stakeholders?

\section{GATE 2 - PROCUREMENT STRATEGY}

This review focuses on the project's viability, its potential for success and whether the project is ready to invite proposals or tenders.

Areas assessed include:

- Does the business case still meet the

business need?

- Have all procurement options been explored?

- Is the project plan through to completion realistic, with the appropriate resources in place?

- Does the project team have enough expertise to understand the supplier market?
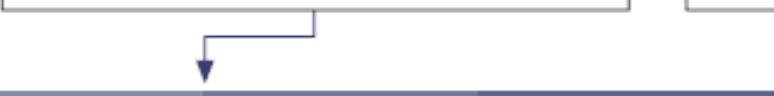

\section{$\checkmark$} COMPETITIVE
PROCUREMENT STRATEGY CONTRACT 4

\section{GATE 3 - INVESTMENT DECISION}

This review assesses the appropriateness of the supplier selection process, whether the business needs are being met and whether processes are in place for contract delivery. Areas assessed include:

- Has the specified procurement plan been followed and conducted properly?

- Will the recommended procurement deliver what is required, on time and achieve value for money?

- Does the project team have contract management expertise, if required?

\section{GATE 4 - READINESS FOR SERVICE}

This review focuses on whether the service solution is ready for delivery, as well as whether the agency is adequately prepared to receive and utilise the solution. It also examines the robustness of the basis for evaluating ongoing performance. Areas assessed include:

- Is the business case still valid?

- Are the plans for managing implementation and operation achievable?

- Does the project team have plans for managing the relationship?

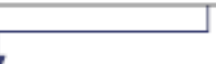

$\begin{array}{ll}\text { MPLEMENT } & \text { MANAGE } \\ \text { CONTRACT }\end{array}$

\section{GATE 5 - BENEFITS REALISATION}

This review, scheduled 6-12 months after the project is delivered, focuses on ensuring that the project is delivering the identified benefits. Areas assessed include:

- Was the business case realistic and are the expected benefits being delivered?

- Are sufficient resources in place to manage the project?

- Is the project team actively seeking to improve the project's value for money performance?

- Is an exit strategy in place for this project?

\section{Figure 3.1 - GatewayTM Review Process and the Procurement Lifecycle, Commonwealth Government of Australia (Comm-Aust, 2006b)}




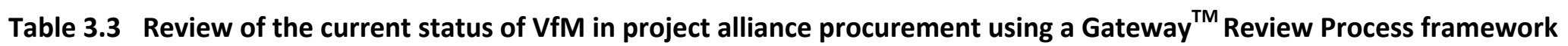

\begin{tabular}{|c|c|c|c|c|c|c|c|}
\hline Issue/Question & $\begin{array}{l}\text { Business Case } \\
\text { Development ( } \\
\text { Gateway }{ }^{\mathrm{TM}} \text { Reviews } 0 \text { and } \\
\text { 1) }\end{array}$ & $\begin{array}{l}\text { Selection of Procurement } \\
\text { Strategy (Gateway }{ }^{\text {TM }} \\
\text { Review 2, Construction } \\
\text { Gate 2) }\end{array}$ & $\begin{array}{l}\text { Brief- EOI (Alliances) } \\
\text { (Construction Gate 2) }\end{array}$ & $\begin{array}{l}\text { Selection and } \\
\text { establishment of } \\
\text { risk/reward model } \\
\text { (Construction Gate 3) }\end{array}$ & $\begin{array}{l}\text { Finalisation of TOC ( } \\
\text { Gateway }{ }^{\mathrm{TM}} \text { Review 3, } \\
\text { Investment decision) and }^{\mathrm{T}} \\
\text { Gateway }{ }^{\mathrm{TM}} \text { Review } 4 \\
\text { (Construction Decision } \\
\text { Point 1) }\end{array}$ & $\begin{array}{l}\text { Completion of Detailed } \\
\text { Design (Construction } \\
\text { Decision Point 2) }\end{array}$ & $\begin{array}{l}\text { Completion and Close out } \\
\text { (Gateway }{ }^{\mathrm{TM}} \text { Review 5) } \\
\text { (Construction Gates 4\&5) }\end{array}$ \\
\hline $\begin{array}{l}\text { Currently at this stage, } \\
\text { What is well done? }\end{array}$ & $\begin{array}{l}\text { - Recognition that this } \\
\text { needs to be addressed } \\
\text { - Increased use of } \\
\text { processes such as } \\
\text { Gateway }\end{array}$ & $\begin{array}{l}\text { Increasing trend to } \\
\text { consider alternative } \\
\text { procurement models } \\
\text { (i.e. other than } \\
\text { traditional, D\&C and } \\
\text { BOOT) }\end{array}$ & $\begin{array}{l}\text { Some standard } \\
\text { models have emerged } \\
\text { which results in the } \\
\text { industry being able to } \\
\text { respond rapidly to EOI } \\
\text { requests }\end{array}$ & $\begin{array}{l}\text { In Australia a well } \\
\text { developed procedure } \\
\text { has been established } \\
\text { for the selection of } \\
\text { alliance teams } \\
\text { Overall cost of } \\
\text { tendering less than } \\
\text { other methods such } \\
\text { as D\&C or BOOT. }\end{array}$ & $\begin{array}{l}\text { Involves Owner, } \\
\text { constructor and often } \\
\text { Operator to produce } \\
\text { optimum result }\end{array}$ & $\begin{array}{l}\text { Procedures for the } \\
\text { management of the } \\
\text { design process are } \\
\text { generally improving }\end{array}$ & $\begin{array}{l}\text { - Alliances embrace the } \\
\text { process of risk and } \\
\text { reward which } \\
\text { provides a tangible } \\
\text { measure of success } \\
\text { versus the TOC at the } \\
\text { end of the project }\end{array}$ \\
\hline $\begin{array}{l}\text { Currently at this stage, } \\
\text { What is not well done? }\end{array}$ & $\begin{array}{l}\text { - Accuracy of scope } \\
\text { definition is typically } \\
\text { poor. } \\
\text { - Consequent accuracy } \\
\text { of estimates is poor } \\
\text { and this reduces } \\
\text { confidence in the } \\
\text { process. } \\
\text { - Prioritisation and } \\
\text { selection of options } \\
\text { not well addressed. }\end{array}$ & $\begin{array}{l}\text { - Rarely based on a } \\
\text { truly rational process } \\
\text { - In the present } \\
\text { buoyant market, often } \\
\text { based on the need for } \\
\text { early delivery } \\
\text { - Still an overemphasis } \\
\text { on price rather than } \\
\text { value }\end{array}$ & $\begin{array}{l}\text { - } \text { Timeframe for } \\
\text { considered responses } \\
\text { Is often realistically } \\
\text { short } \\
\text { - Selection criteria } \\
\text { weightings are often } \\
\text { not well addressed } \\
\text { - Can simply be a } \\
\text { 'beauty parade' }\end{array}$ & $\begin{array}{l}\text { Supplies have learnt } \\
\text { how to manipulate } \\
\text { the established } \\
\text { process } \\
\text { - Enormous amount of } \\
\text { senior management } \\
\text { time is tied up during } \\
\text { the selection process }\end{array}$ & $\begin{array}{l}\text { - Can lead to estimate } \\
\text { being too } \\
\text { conservative } \\
\text { - Quality of auditing } \\
\text { processes very } \\
\text { variable }\end{array}$ & $\begin{array}{l}\text { - Completion of DD } \\
\text { process should } \\
\text { provide opportunity } \\
\text { to review and monitor } \\
\text { the TOC estimate and } \\
\text { make changes if } \\
\text { necessary. This } \\
\text { opportunity is rarely } \\
\text { seized. }\end{array}$ & $\begin{array}{l}\text { - Formal completion or } \\
\text { close out reviews are } \\
\text { not often undertaken } \\
\text { - No commonly } \\
\text { established } \\
\text { methodology applies } \\
\text { to all alliances }\end{array}$ \\
\hline $\begin{array}{l}\text { What are the gaps in the } \\
\text { literature }\end{array}$ & $\begin{array}{l}\text { Established process } \\
\text { for business case } \\
\text { development } \\
\text { (Gateway } \\
\text { the exception here) }\end{array}$ & $\begin{array}{l}\text { Established process } \\
\text { for procurement, } \\
\text { selection are not well } \\
\text { documented } \\
\text { - Advantages of } \\
\text { relationship based } \\
\text { procurement not well } \\
\text { documented but } \\
\text { becoming better } \\
\text { appreciated partly } \\
\text { because of buoyant } \\
\text { market in which } \\
\text { traditional 'hard } \\
\text { nosed' approaches } \\
\text { are unlikely to attract } \\
\text { competent suppliers }\end{array}$ & $\begin{array}{l}\text { - Little quantitative or } \\
\text { qualitative research to } \\
\text { establish how } \\
\text { effective EOI } \\
\text { processes are }\end{array}$ & & $\begin{array}{l}\text { The issue of the } \\
\text { significance of the } \\
\text { TOC is not well } \\
\text { addressed in the } \\
\text { literature. } \\
\text { - There is some } \\
\text { discussion regarding } \\
\text { the relative merits of } \\
\text { the competitive and } \\
\text { non-competitive } \\
\text { alliance model i.e. } 1 \\
\text { versus } 2 \text { TOC's but } \\
\text { little considered } \\
\text { analysis }\end{array}$ & $\begin{array}{l}\text { Not sure whether this } \\
\text { addressed at all in the } \\
\text { literature. }\end{array}$ & $\begin{array}{l}\text { Reporting of success } \\
\text { and failures of alliance } \\
\text { is largely anecdotal } \\
\text { with little quantitative } \\
\text { analysis }\end{array}$ \\
\hline
\end{tabular}




\begin{tabular}{|c|c|c|c|c|c|c|c|}
\hline Issue/Question & $\begin{array}{l}\text { Business Case } \\
\text { Development (Gateway }{ }^{\mathrm{TM}} \\
\text { Reviews } 0 \text { and 1) }\end{array}$ & $\begin{array}{l}\text { Selection of Procurement } \\
\text { Strategy ( Gateway }{ }^{\mathrm{TM}} \\
\text { Review 2, Construction } \\
\text { Gate 2) }\end{array}$ & $\begin{array}{l}\text { Brief- EOI (Alliances) } \\
\text { (Construction Gate 2) }\end{array}$ & $\begin{array}{l}\text { Selection and } \\
\text { establishment of } \\
\text { risk/reward model } \\
\text { (Construction Gate 3) }\end{array}$ & $\begin{array}{l}\text { Finalisation of TOC ( } \\
\text { Gateway }{ }^{\mathrm{TM}} \text { Review } 3 \text {, } \\
\text { Investment decision) and } \\
\text { Gateway }{ }^{\mathrm{TM}} 4 \\
\text { (Construction Decision } \\
\text { Point 1) }\end{array}$ & $\begin{array}{l}\text { Completion of Detailed } \\
\text { Design (Construction } \\
\text { Decision Point 2) }\end{array}$ & $\begin{array}{l}\text { Completion and Close out } \\
\text { ( Gateway }{ }^{\mathrm{TM}} \text { Review 5) } \\
\text { (Construction Gates 48.5) }\end{array}$ \\
\hline $\begin{array}{l}\text { What are the value for } \\
\text { money questions at } \\
\text { each stage? }\end{array}$ & $\begin{array}{l}\text { - Is this the best project } \\
\text { to address the } \\
\text { perceived need? } \\
\text { - Is the Owners budget } \\
\text { rigorous and based on } \\
\text { a realistic risk analysis } \\
\text { i.e. Monte carol } \\
\text { simulation? } \\
\text { Does the Owner have } \\
\text { the } \\
\text { capability/leadership } \\
\text { to deliver the project? } \\
\text { - Does the Owner } \\
\text { understand the scope } \\
\text { and d what will } \\
\text { constitute success, } \\
\text { and is this supported } \\
\text { by the users and } \\
\text { stakeholders? } \\
\text { - Have the critical } \\
\text { success factors and } \\
\text { benefits been agreed } \\
\text { with the key } \\
\text { stakeholders? } \\
\text { Has there been any } \\
\text { independent advisor } \\
\text { been involved in the } \\
\text { development of the } \\
\text { business case? }\end{array}$ & $\begin{array}{l}\text { - Have all possible } \\
\text { procurement options } \\
\text { been considered? } \\
\text { - Is the selected } \\
\text { procurement strategy } \\
\text { legal, robust, } \\
\text { appropriate and } \\
\text { understood by the } \\
\text { potential suppliers? } \\
\text { - Does the Owner have } \\
\text { adequate financial } \\
\text { controls, funding and } \\
\text { resourcing? }\end{array}$ & $\begin{array}{l}\text { Does the EOI } \\
\text { adequately describe } \\
\text { what the objectives of } \\
\text { the project are } \\
\text { including the } \\
\text { approach to VfM? }\end{array}$ & $\begin{array}{l}\text { - Is the preferred } \\
\text { proponent selected } \\
\text { on their clear } \\
\text { understanding of VfM } \\
\text { issues? } \\
\text { - Are the Owners and } \\
\text { the preferred } \\
\text { proponent aligned on } \\
\text { VfM strategy and } \\
\text { deliverables when the } \\
\text { alliance commences? } \\
\text { - Have the appropriate } \\
\text { KRA's and KPI's been } \\
\text { developed to ensure } \\
\text { VfM? } \\
\text { - Have appropriate } \\
\text { measures for } \\
\text { monitoring VfM } \\
\text { during the TOC period } \\
\text { and construction been } \\
\text { agreed and } \\
\text { documented? } \\
\text { Has the proponent } \\
\text { demonstrated a } \\
\text { commitment to } \\
\text { continuous } \\
\text { improvement? }\end{array}$ & $\begin{array}{l}\text { Does the output of } \\
\text { the TOC process } \\
\text { confirm the original } \\
\text { business case } \\
\text { assumptions } \\
\text { - Will proceeding with } \\
\text { alliance be likely to } \\
\text { deliver what is } \\
\text { needed on time } \\
\text { within budget and } \\
\text { achieve VfM? } \\
\text { - Has the issue of } \\
\text { buildability been } \\
\text { adequately } \\
\text { addressed? } \\
\text { Is the business case } \\
\text { still valid and } \\
\text { unaffected by internal } \\
\text { and external events or } \\
\text { changes? } \\
\text { Is there an agreed } \\
\text { plan for managing } \\
\text { risks during the } \\
\text { construction phase? }\end{array}$ & $\begin{array}{l}\text { - Is there a process for } \\
\text { taking advantage of } \\
\text { improvements that } \\
\text { may emerge during } \\
\text { the DD phase? } \\
\text { - Are value } \\
\text { management and } \\
\text { value engineering } \\
\text { techniques being used } \\
\text { to optimise the design } \\
\text { outcome? }\end{array}$ & $\begin{array}{l}\text { - Is a post- completion } \\
\text { review stipulated in } \\
\text { the contract } \\
\text { documentation? } \\
\text { - Are key lessons from } \\
\text { the project being used } \\
\text { to improve } V f M \text { and } \\
\text { performance of other } \\
\text { projects? }\end{array}$ \\
\hline
\end{tabular}




\section{Table 3.4 Specification for a VfM/BV Model for Project Alliances}

\begin{tabular}{|c|c|}
\hline \multicolumn{2}{|c|}{ Specification for a VfM/BV Model for Project Alliances } \\
\hline \multicolumn{2}{|c|}{$\begin{array}{l}\text { Objective; } \\
\text { It should be a prescriptive model, adopting a systematic methodology which combines quantitative and qualitative tools to } \\
\text { demonstrate, in a structured manner, how VfM in alliances can be addressed, developed and monitored. This model would } \\
\text { facilitate, through data capture and compelling evidence how the issue of VfM in alliances can be verified. }\end{array}$} \\
\hline \multicolumn{2}{|c|}{$\begin{array}{l}\text { Boundaries; } \\
\text { The model should address the complete life-cycle of alliance from concept development through project execution to operation. } \\
\text { The model would specifically address single alliances rather than on-going program/strategic alliances in the infrastructure sector. }\end{array}$} \\
\hline \multicolumn{2}{|c|}{$\begin{array}{l}\text { Target Audience; } \\
\text { The model is intended to be of use to Owners at the initial stages of the project development and the later operational or post } \\
\text { construction phase. Once the Non-owner participants (NOP's) are engaged the model can be used by all the participants in the } \\
\text { alliance to measure and demonstrate VfM. }\end{array}$} \\
\hline $\begin{array}{l}\text { Issues that are often described as being benefits of an alliance } \\
\text { based approach that need to be addressed or captured by the } \\
\text { model included; } \\
\text { - Potential improvements due to an alliance } \\
\text { environment. } \\
\text { - Design innovation Constructability - reduced } \\
\text { construction durations, less re-work } \\
\text { - Knowledge sharing/access to information leading to a } \\
\text { - } \text { reduced number of queries, simpler documentation } \\
\text { - Accelerated decision making } \\
\text { - Improved estimates, reliable TOC } \\
\text { - Removal of duplication of roles, reduced complexity of } \\
\text { - organisational structure } \\
\text { - Measurement of behavioural aspects } \\
\text { - } \text { trust and respect (through understanding of the whole } \\
\text { - Enhanced social and environmental benefits } \\
\text { - Improved relationships client/community } \\
\text { - Innovation related - Need to capture these issues pre } \\
\text { and post TOC to demonstrate where savings have come } \\
\text { from. If not documented post TOC > leads to suggestion } \\
\text { that the TOC was 'fat' }\end{array}$ & $\begin{array}{l}\text { The model also needed to address or accommodate all the } \\
\text { dimensions of VfM - 'best value' including; } \\
\text { - Financial } \\
\text { - Increased return for same expenditure (improved IRR) } \\
\text { - Improved shareholder outcomes } \\
\text { - Fitness for purpose with lowest consumption of resources } \\
\text { - Functional facility with improved quality } \\
\text { - Industry maturity - Broader benefits to the industry } \\
\text { - Enhancement of skills } \\
\text { - Knowledge transfer } \\
\text { - Value Engineering } \\
\text { - Execution strategy analysis } \\
\text { - Project Controls } \\
\text { - Team selection } \\
\text { - Fitness for purpose } \\
\text { - Design issues } \\
\text { - Quantities measurement } \\
\text { - Constructability reviews } \\
\text { - Design appropriateness } \\
\text { - Technology selection } \\
\text { - Design change process } \\
\text { - Design for maintainability }\end{array}$ \\
\hline $\begin{array}{l}\text { This model is required to have the following attributes; } \\
\text { - Address the whole project life cycle in detail from } \\
\text { business case to execution. } \\
\text { - Defines the key stages or gates along the life cycle that } \\
\text { would require review of the project. } \\
\text { - Provide checklists and a combination of measurement } \\
\text { tools for the establishment of VfM at each gate. }\end{array}$ & $\begin{array}{l}\text { Other benefits anticipated; } \\
\text { - Standardise alliance life-cycle definition } \\
\text { - Standardise terminology } \\
\text { - Provide ability to benchmark future projects } \\
\text { - Act as a tool for auditors and independent reviewers of } \\
\text { - } \text { alliances } \\
\text { Potentially remove the inability to measure } \mathrm{VfM} \text { as an } \\
\text { impediment to the further uptake of the alliance model } \\
\text { where it appropriate }\end{array}$ \\
\hline
\end{tabular}




\subsection{Preliminary VfM/BV Model}

As discussed in Sections 3.2 and 3.3 above the issue of VfM in project procurement broadly has been extensively addressed in the literature even though the field of $\mathrm{VFM}$ in relationship based contracts was, at least until late 2009, relatively immature and undeveloped. At that time the Victorian Department of Treasury and Finance (VDTF) issued the first of a series of publications specifically addressing this matter. The post, late 2009 situation is addressed in some detail in Chapters 7 and 9. The question, however, arose at the time that this research was commenced i.e. late 2008, as to whether the existing body of knowledge and practice could be used to provide any insight into the manner in which the issue could be addressed in relationship based contracts.

The researcher considered that there were some specific documents in the literature at that time that provided a sound foundation for the development of a model that would address the requirements as specified in Table 3.4 above and these are discussed in further detail below.

\subsubsection{Applicability of the GatewayTM Process}

The Gateway ${ }^{\mathrm{TM}}$ Review process described earlier in Chapter 2 was developed by the Treasury in the UK and launched in 2001 as a tool for reviewing the viability of a project at various stages of its life cycle from concept development through the business case to execution. This process is primarily a tool for the owner to regularly check, using a series of reviews or 'gates', that there is clear justification to proceed to the next step of the project life cycle. The principles of this process have been taken further by the Office of Government Commerce (at that time, a branch of the UK Treasury) who also developed a Managers checklist (OGC, 2007e) which contains a series of questions that the person responsible for the administration of a project should address, at each of a number of identified critical decisions points, to best ensure that the project will succeed. The OGC has also developed a further document 'Construction Projects- a manager's checklist'(OGC, 2007g) in a similar format suited to construction projects.

The researcher formed the view that this flowchart approach, which followed the natural lifecycle of a project, was well suited to the development of a specific model or business tool that would be capable of addressing all aspects of the specification requirements as described in Table 3.4. The Gateway ${ }^{\mathrm{TM}}$ Review model is generic and is based around a traditional procurement process. It also focused heavily on the earlier stages of project cycle. Consequently, the Gateway ${ }^{\mathrm{TM}}$ process, as it stood, it was not considered directly applicable to task required but provided a platform for the development of a model that could address VfM in project alliances. 
The development of the Gateway ${ }^{\mathrm{TM}}$ Review process by the Office of Government Commerce in the UK resulted from the recognition by the public sector that there needed to be improvements of the manner in which government procurement was managed in order to ensure that 'best value' is achieved. The Gateway ${ }^{\mathrm{TM}}$ Process is described by the following quotation from an OGC document addressed to senior civil servants entitled, somewhat invitingly , 'OGC Gateway ${ }^{\mathrm{TM}}$ Review Process Designed to make you successful'(OGC, 2005), p2:

'The OGC Gateway ${ }^{T M}$ Process is based on well-proven management techniques that lead to more effective delivery of benefits, together with more predictable costs and outcomes. The process examines a programme or project at critical stages in its lifecycle to provide assurance that it can progress successfully to the next stage. There are five OGC Gateway ${ }^{T M}$ Reviews (Gates 1-5) during the life cycle of a project, with three addressing the stages before contract award and two looking at service implementation and confirmation of the operational benefits. The process emphasises early review for maximum added value' (emphasis added).

Given these objectives the Gateway ${ }^{\mathrm{TM}}$ Process is considered to be closely aligned to the objective of developing a systematic approach for determining and demonstrating VfM in alliance projects.

\subsubsection{Achieving Excellence in Construction}

OGC are also responsible for another initiative in public sector procurement entitled 'Achieving Excellence in Construction'. This initiative originally launched in 1999 and was directed at improving the performance of central government departments, their executive agencies and nondepartmental public bodies as clients of the construction industry, following major failures in time and cost overruns(Latham, 1994, Egan, 1998). It aimed to provide a step change in construction procurement performance and in the value for money achieved by government on construction projects, including maintenance and refurbishment. The Achieving Excellence initiative set out a route map with challenging targets for government performance under four headings Management, Measurement, Standardisation and Integration. Targets included the use of partnering and the development of long-term relationships, the reduction of financial and decision-making approval chains, increased training and empowerment, the adoption of performance measurement indicators, the use of integrated procurement routes and the use of tools such as value management, risk management and whole-life costing.

Quoting from the OGC's documentation describing the initiative(OGC, 2007a), p5: 
'The key thrust of Achieving Excellence is the delivery of value for money (emphasis added). This is not the lowest cost but the optimum combination of whole-life cost and quality to meet the user's requirements'.

Whilst the use of a project alliance procurement model does not specifically feature in this description of the Achieving Excellence initiative it can be seen that one of the purposes of the initiative was to establish the use of a relationship based approach to procurement which encouraged long-term associations, an integrated approach and the adoption of performance measurement indicators which are all consistent with an alliance approach.

In 2003 the OGC released an Achieving Excellence suite of procurement guides which were updated in 2007. These guides are closely aligned with the OGC Gateway ${ }^{\mathrm{TM}}$ process, the emerging lessons learned from Gateway ${ }^{\mathrm{TM}}$ reviews and the Successful Delivery Toolkit, of which the suite forms a key component.

The suite consisted of three core and eight supporting documents together with two high level documents. One of these high level documents was entitles Achieving Excellence in Construction: checklist for managers (OGC, 2007d) which supplemented an earlier publication entitled Gateway ${ }^{\mathrm{TM}}$ Checklist for Managers (OGC, 2007e) It provides a checklist of the key questions that investment decision makers and senior responsible owners should ask before approving a project and during its implementation. The Achieving Excellence in Construction Pocketbook (OGC, 2007c) provides a stepby-step outline of the procurement process for construction projects, together with summaries of essential tools and techniques.

It is believed that these documents provide a firm foundation for the development of a model that would be suitable for determining and demonstrating whether a project alliance project, as has developed in the Australian context. Given that they are primarily produced for government agencies to use in the establishment of the need for a project and the selection of a procurement method they are focused on the early stages of the procurement cycle. The researcher believed, however, that they could be readily adapted to the alliance model by increasing the number of review points in the delivery stage of a project.

In particular, the OGC publication 'Project procurement lifecycle' (2007b) describes an integrated procurement process which detailed all the measures associated with comprehensively verifying that 'best value' was being delivered at every point of the life cycle. This 'model' is seen as providing a good foundation for the development of a model for a project alliance. However, as it primarily 
focussed on the front end of projects up to the award of a construction contract and is seen to be somewhat lacking in the necessary detail for the 'contractor selection and post - award' phases.

\subsubsection{Project Alliancing Practioners' Guide (VDTF, 2006a)}

The Victorian Government 's Practitioners' Guide for project alliancing described earlier in Section 3.2 was seen to provide some very useful and practical guidance regarding VfM/BV, particularly in Chapter 5 which specifically addressed VfM. The document concentrated on the later phases of the project life cycle and was somewhat deficient in the earlier phases. Consequently, the two approaches were seen to be complimentary and in combination provided good coverage of the whole project lifecycle. A flowchart illustrating the preliminary model that was developed based on the above described documents, the literature more widely and the experiences of the researcher as an established practitioner in the field is shown in Figure 3.2 below.

\subsubsection{Structure of the Preliminary VfM/BV Model}

The legend for this preliminary model is depicted below:

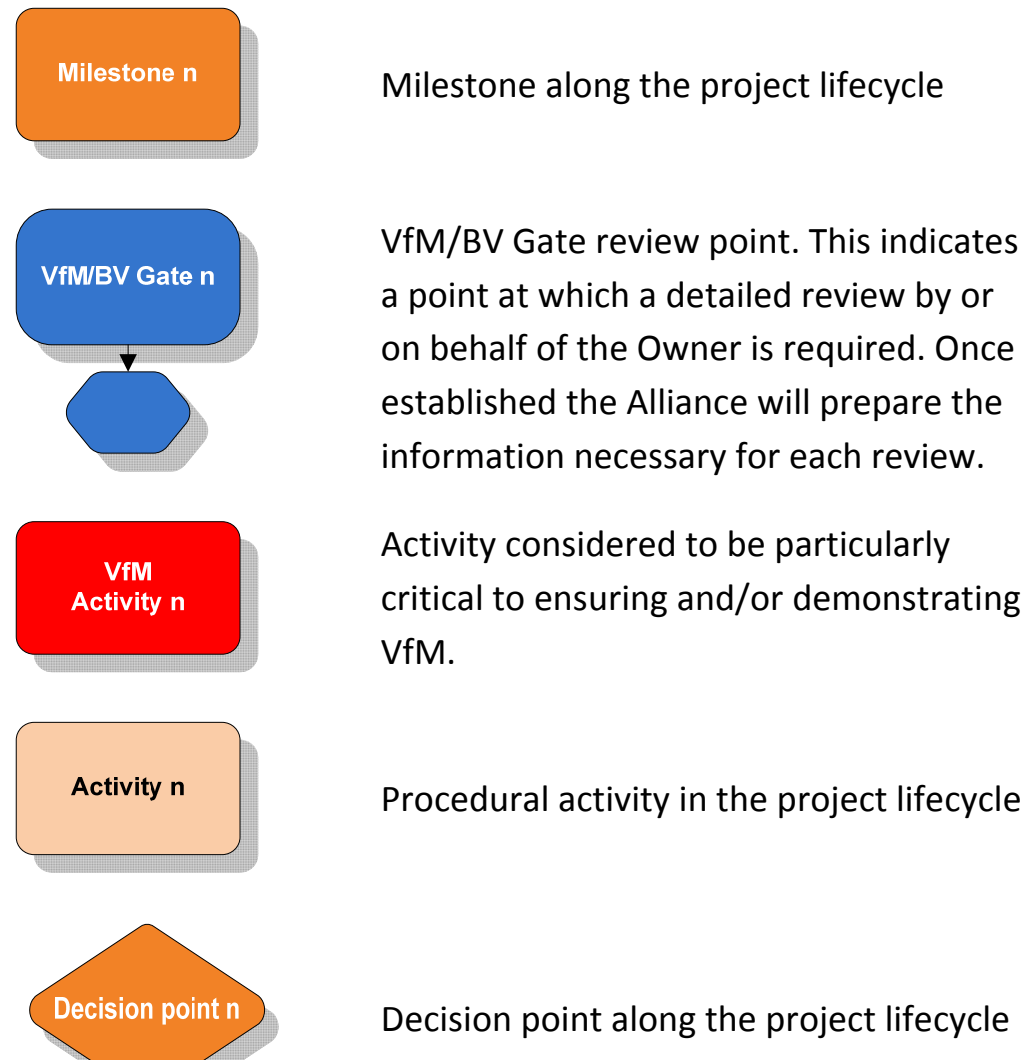

The lifecycle of a project is depicted by seven stages which are based on the stages described in the Gateway $^{\mathrm{TM}}$ Process as shown in Figure 3.2. 
At the end of each stage a VfM Gate is described which comprises a review of the issues that are a critical to establishing and demonstrating VfM in the procurement of the project concerned.

The Gateway ${ }^{\mathrm{TM}}$ Review process consists of some six Gates. However, to address the particular requirements of project alliances it was felt to be necessary to introduce and additional stage and two additional gates. The additional stage recognised that the 'Investment Decision' stage of the original Gateway ${ }^{\mathrm{TM}}$ Review process needed to be separated into two components being, the 'selection of NOP's' and the 'TCE Approval ' stages. The additional gates reflected the increase in the number of stages plus the perceived need to introduce an 'Ongoing Benefits Evaluation' gate as well as a 'Final Benefits Evaluation' gate.

A comparison between the gates identified in the generic Gateway ${ }^{\mathrm{TM}}$ Process, the Gateway Review process developed by the Commonwealth Government of Australia (Comm-Aust, 2006b), the OGC Framework for Construction Procurement (2007b) and the gates that were felt to be necessary for alliance procurement, is presented in Table 3.9. This table describes the purpose of each gate, the general Gateway ${ }^{\mathrm{TM}}$ Review issues normally identified at that point in the lifecycle and the specific $\mathrm{VfM}$ issues that were considered to be important to ensure and demonstrate VfM. 


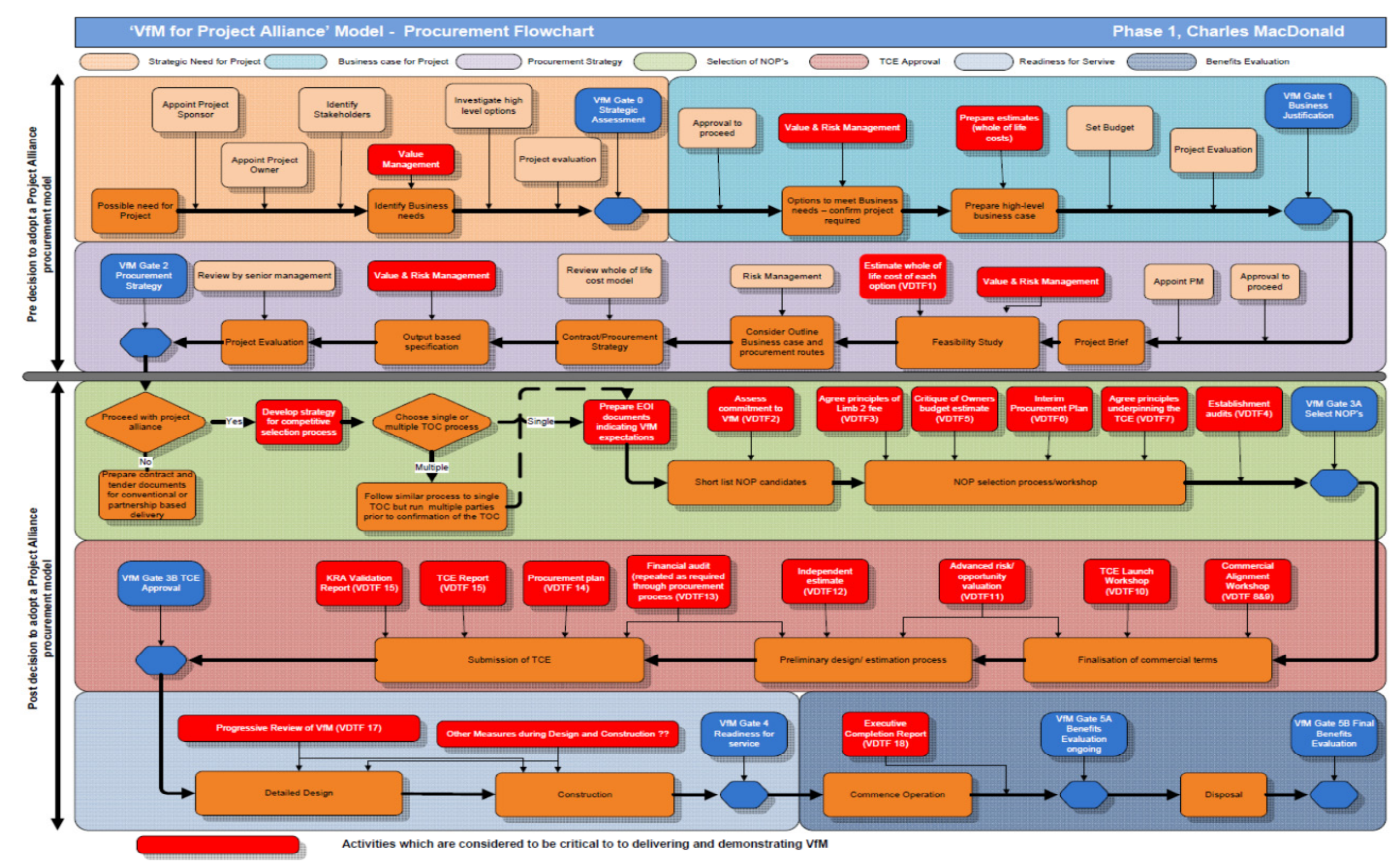

Figure 3.2 Flowchart for VfM/BV Procurement Model (based on the Gateway ${ }^{\mathrm{TM}}$ Review Process, procurement Guide 03 and $0 G \mathrm{C}$ model (OGC, $2007 \mathrm{~b}$ ) and VDTF Project Alliancing Practitioners" Guide (2006a) 


\section{Table 3.5 Comparative Review of Gateway ${ }^{\mathrm{TM}}$ Review Process}

\begin{tabular}{|c|c|c|c|c|c|c|c|c|c|}
\hline \multicolumn{2}{|c|}{$\begin{array}{l}\text { The generic UK Gateway }{ }^{\mathrm{TM}} \\
\text { Process }\end{array}$} & \multicolumn{2}{|c|}{$\begin{array}{l}\text { Commonwealth } \\
\text { Generic }^{\text {GatewayTM }} \\
\text { Process }\end{array}$} & \multicolumn{2}{|c|}{$\begin{array}{l}\text { OGC Model } \\
\text { Gateway }{ }^{\mathrm{TM}} \text { Process } \\
\text { for Construction }\end{array}$} & \multicolumn{4}{|c|}{ Gate in 'Vfm for Project Alliance' Model } \\
\hline Gate description & Gate & $\begin{array}{l}\text { Gate } \\
\text { description }\end{array}$ & Gate & $\begin{array}{l}\text { Gate } \\
\text { description }\end{array}$ & Gate & Gate description & Purpose & General GatewayTM Review Issues & Specific VfM issues \\
\hline $\begin{array}{l}\text { Strategic Assessment } \\
\text { for Programmes only }\end{array}$ & 0 & 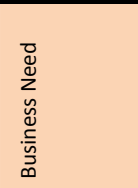 & 0 & 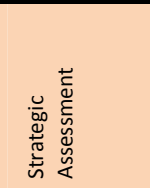 & 0 & Strategic need for project & $\begin{array}{l}\text { Assessment of the business need } \\
\text { for the proposed project or } \\
\text { programme }\end{array}$ & $\begin{array}{l}\text { - Stakeholder by-in } \\
\text { Contribution to organisational business } \\
\text { strategy and to high-level policy objectives, } \\
\text { strategies and initiatives } \\
\text { - Review of arrangements for leading and } \\
\text { managing the project or programme }\end{array}$ & $\begin{array}{l}\text { Has a thorough value management process been } \\
\text { undertaken in identifying the business needs for the } \\
\text { project? Without such a process to clearly identify the } \\
\text { primary needs there is no foundation for value to be } \\
\text { determined. }\end{array}$ \\
\hline Business Justification & 1 & 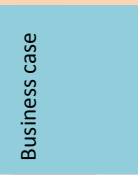 & 1 & 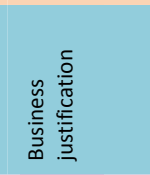 & 1 & Business case for project & $\begin{array}{l}\text { Considers the project's business } \\
\text { justification and whether the } \\
\text { proposed approach has been } \\
\text { adequately researched and can } \\
\text { be delivered }\end{array}$ & $\begin{array}{l}\text { - Does the project contribute to the } \\
\text { organisational business strategy? } \\
\text { - Are the scope and, scale and requirements } \\
\text { realistic, clear and unambiguous? }\end{array}$ & $\begin{array}{l}\text { - Have major risks been identified and a management plan } \\
\text { outlined? } \\
\text { - Have critical success factors been agreed with stakeholders? } \\
\text { - Have estimates been prepared on a truly 'whole of life } \\
\text { 'basis? }\end{array}$ \\
\hline Delivery Strategy & 2 & 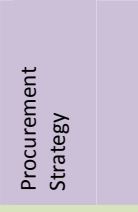 & 2 & 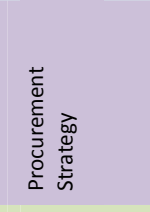 & 2 & Procurement Strategy & $\begin{array}{l}\text { Focus on the viability of the } \\
\text { project the potential for success } \\
\text { and whether the project is ready } \\
\text { to invite proposals or tenders. }\end{array}$ & $\begin{array}{l}\text { - Have all feasible procurement options been } \\
\text { explored? } \\
\text { Is the project plan through to completion } \\
\text { realistic with the appropriate resources in } \\
\text { place? }\end{array}$ & $\begin{array}{l}\text { Does the business case still meet the business need? } \\
\text { - Does the team have enough expertise to understand the } \\
\text { supplier market? } \\
\text { Have the procurement options been subjected to thorough } \\
\text { risk and value management analyses? } \\
\text { Is the Project Alliance model the best option for this } \\
\text { project? }\end{array}$ \\
\hline \multirow[t]{2}{*}{ Investment Decision } & 3 & 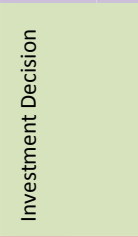 & 3 & 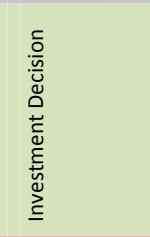 & 3A & Selection of NOP's & $\begin{array}{l}\text { To ensure that the best and most } \\
\text { appropriate NOP's been selected } \\
\text { for the TCE phase of the project }\end{array}$ & $\begin{array}{l}\text { - Was the supplier selection process } \\
\text { appropriate? } \\
\text { - Are the business needs still being met? } \\
\text { Are processes now in place for as successful } \\
\text { project delivery? }\end{array}$ & $\begin{array}{l}\text { - Has the importance of VfM been adequately communicated } \\
\text { to the Owner and NOP members of the team? } \\
\text { - Have the appropriate commercial arrangements been put in } \\
\text { place to ensure that appropriate behaviour, conducive to } \\
\text { VfM, will result? } \\
\text { - Have appropriate audits been undertaken? } \\
\text { - Are the principles underpinning the TCE process clear to all } \\
\text { parties? }\end{array}$ \\
\hline & & & 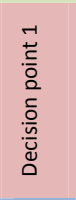 & 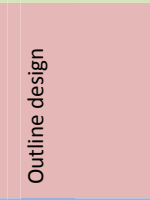 & 3B & TCE Approval & $\begin{array}{l}\text { Formal review of the Turn-out } \\
\text { Cost Estimate which is necessary } \\
\text { for the Investment decision to be } \\
\text { confirmed and the project to } \\
\text { proceed to final design and } \\
\text { construction. }\end{array}$ & $\begin{array}{l}\text { - Has alliance procurement selection process } \\
\text { been followed and conducted properly and } \\
\text { the best team for the project selected? } \\
\text { Do the project team (Owner and Non- } \\
\text { Owner participants) have project } \\
\text { management expertise necessary? }\end{array}$ & $\begin{array}{l}\text { - Is the TCE acceptable } \\
\text { - Has the final TCE been reconciled with the original } \\
\text { estimate? } \\
\text { - Has an Independent estimate been undertaken? } \\
\text { Does the business case still warrant proceeding with the } \\
\text { project? }\end{array}$ \\
\hline Readiness for Service & 4 & 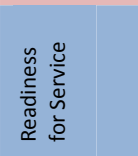 & 4 & & 4 & Readiness for service & & $\begin{array}{l}\text { - Has the construction been successfully } \\
\text { completed? } \\
\text { - Are the plans for operation complete and } \\
\text { achievable? }\end{array}$ & $\begin{array}{l}\text { - Was the TCE achieved? } \\
\text { - Have the KRA's been monitored and targets achieved? } \\
\text { - Did the Project Alliance approach delver innovations? }\end{array}$ \\
\hline \multirow[t]{2}{*}{$\begin{array}{l}\text { Operations review and } \\
\text { benefits realisation }\end{array}$} & 5 & & 5 & & $5 A$ & $\begin{array}{l}\text { Benefits evaluation } \\
\text { ongoing }\end{array}$ & & $\begin{array}{l}\text { Is the project successfully addressing the } \\
\text { original business objectives }\end{array}$ & $\begin{array}{l}\text { - Is the project efficiently addressing the original business } \\
\text { objectives? }\end{array}$ \\
\hline & & & & & $5 B$ & Final benefits evaluation & & $\begin{array}{l}\text { Did the project successfully deliver the } \\
\text { 'whole of life' benefits predicted? }\end{array}$ & $\begin{array}{l}\text { - Did the project successfully deliver the 'whole of life' } \\
\text { benefits predicted? }\end{array}$ \\
\hline
\end{tabular}




\subsection{Summary of Chapter}

This chapter has closely examined the status of the literature as represented by procurement guidelines and procedures specifically relating to VfM in project alliances as it existed at the time the research reported in this thesis commenced. Later development in the literature particularly the work published by the VDTF since late 2009 is described in Chapters 7 and 9.

A detailed review of the various VfM reports and guidelines in existence at that time is described. This review identifies what are perceived to be the contributions and deficiencies of each of these publications. This is followed by a description of the various Government publications describing $\mathrm{VFM}$ in procurement more generally.

A review of the strengths and weaknesses of the current status of $\mathrm{VFM}$ determination/demonstration for project alliances is then undertaken. This analysis adopts the chronology of all project lifecycle described in the Gateway ${ }^{\top \mathrm{M}}$ Review Process. The analysis confirms that there is a clear gap or deficiency in current knowledge and then defines the research question to be addressed by this thesis as "what is the optimum configuration of a model that will assist all participants in a project alliance to both ensure and demonstrate the achievement of VfM or best value".

An explanation is then provided of the perceived applicability of the Gateway ${ }^{\mathrm{TM}}$ Review process and the 'Framework for Construction' developed by the OGC in their publication - Project Procurement Lifecycle: the integrated process (OGC, 2007b) to the development of a model designed to address the research question. The relevance of the specific measures described in the VDTF 2006, Practitioners Guide is also identified.

Finally the chapter concludes with a description of the preliminary model that was developed. This description outlines the basic architecture of the model and also identifies the linkage that exists to the rationale developed in the Gateway ${ }^{\mathrm{TM}}$ process, OGC framework for construction as adopted to suit the circumstances of the project alliance procurement methodology.

This model was then 'tested' by seeking comment from practitioners in the construction industry to establish whether the model would address the identified need. The research methodology adopted for this approach is described in Chapter 4 and the findings that resulted are described in Chapter 5. 


\section{Chapter 4 - Research Design}

'Not everything that counts can be counted and not everything that can be counted counts'

(Poster in Albert Einstein's office at Princeton University)

\subsection{Introduction}

Chapter 3 provided a detailed description of the gap that was perceived to exist in the literature regarding a reliable and repeatable process for ensuring and demonstrating VfM or best value in project alliances.

Chapter 3 also described the development of a preliminary model designed to address this need.

Section 4.2 of this chapter discusses how the actual research question being considered should be addressed. This question is 'what is the optimum configuration of a model that will assist all participants in a project alliance to both ensure and demonstrate the achievement of $\mathrm{VfM}$ or best value.

In considering the research design i.e. the rationale and structure of the approach to be adopted in addressing this research question, it is necessary to carefully contemplate the theoretical basis of such an approach. Consequently, this chapter commences with a consideration of the alternative research philosophies that could be employed.

Section 4.3 then proceeds to provide a detailed consideration of holistic nature of the research process and alterative research strategies available. This then leads to a description of the actual strategy selected and an exploration of why this is considered to be the methodology best suited to the research task.

Section 4.4 moves from a discussion of the selected methodology to a description of the mechanics that were adopted in engaging with practitioners in the field of alliancing to obtain commentary upon the preliminary model as initially conceived by the researcher and to determine how it could be developed and refined to address the research question.

\subsection{Research Philosophy}

Research in the field of management is a complex matter that presents number of challenges to any researcher. This is particularly the case, however, for a researcher who has spent an 
extended career in the engineering world where there is generally a strongly held view that a scientific approach is the only means to establish rigour in the research process or indeed any logical endeavour. However, through the process of preparing for and undertaking the research task described in this thesis, the researcher has been persuaded that such an approach is not only often poorly suited to research in the social/business fields, but can actually be inappropriate.

At the commencement of any significant research exercise a wide range of approaches need to be considered before the methodology best suited to the research at hand can be determined. These approaches range from qualitative to quantitative, inductive to deductive, experimental to methods based on archival analysis.

As noted by Yin (1994), some researchers distinguish between quantitative and qualitative research, not on the basis of type of evidence but on the basis of wholly different philosophical beliefs. Such distinctions produce sharp debate and whilst some believe that the philosophical beliefs are irreconcilable, the counter argument can still be posed that regardless of whether one favours qualitative of quantitative research there is a strong and essentially common ground between the two (Yin, 1994).

The classic scientific, positivist, deductive approach involves a research design which includes (Gill and Johnson, 2002):

- a priori hypothesis;

- a priori criterion that can be used to measure the acceptability of those hypotheses;

- isolation and control of the variables under investigation; and

- methods of measuring and verifying the variables in the investigation.

However from a 'management science' or operations perspective there is a view that the extreme complexity of managerial problems and the misguided attempts to apply natural scientific methodology to real world, essentially social problems, have resulted in the somewhat limited success of management science (Checkland, 1981, Checkland, 1991).

Bygrave (1989) has suggested that many of the key contributors to business strategy have a scientific education and he makes a plea for less 'physics envy' in approaches to management research. Van Maanen (1995)has also commented that 'we display more than a little physics envy when we reach for covering laws, causes, operational definitions, testable hypothesis 
and so forth'. Flyvberg (2001) also cautions against 'physics envy' in describing what he terms 'the science wars' debate regarding the validly of social science research.

Gill and Johnson (2002) quote the old proverb 'for he who has but one tool, the hammer, the whole world looks like a nail' as an argument to suggest that a broad range of research methodology should be considered to ensure that the method best suits the research being contemplated. The selection of the appropriate research strategy is clearly critical to the success of the endeavour.

Gill and Johnson (2002), also suggest that whatever research philosophy is adopted, a seven step sequence as proposed by Howard and Sharp (1983)) building on work by Rummel and Bellane (1963) is relevant and useful. This sequence is shown in Figure 4.1 below.

Gill and Johnson (2002) recommend that each step of the sequence needs to be given equal attention if the overall research program is to be optimised. As will be explained in further detail later, the researcher has followed this sequence in developing and executing the research task. However, before deciding on the approach selected it was necessary to fully understand the interactive nature of the relationship between the research process and the issue of interest.

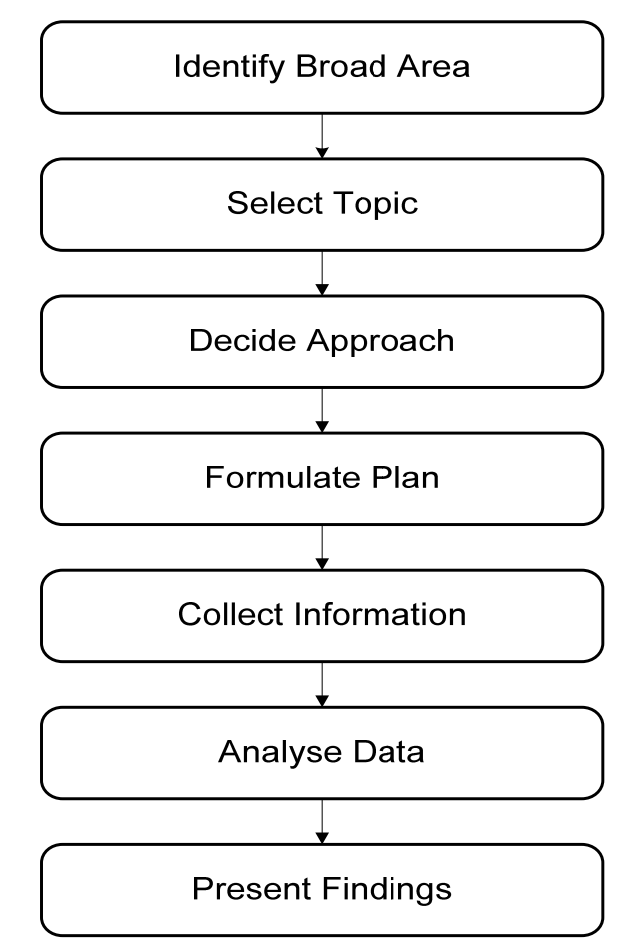

Figure 4.1 - The Research Sequence (Gill and Johnson, 2002), p 4 


\subsection{Research Approach}

Much of the literature concerning management research addresses the relationship between the research process and the nature of knowledge created in the process (Cicmil, 2006).

Figure 4.2 below is an interpretation by Cicmil (2006) of the interconnectedness of the elements in the process of management research. It involves an assertion made by multiple authors (Alvesson and Deetz, 2000, Arbnor and Bjerke, 1997, Calori, 2002, Cicmil and Hodgson, 2006, Easterby-Smith et al., 1991, Introna, 1997, Johnson and Duberley, 2000, Mitroff and Linstone, 1993, Seale, 1999, Silverman, 2001, Stacey, 2003, Weick, 2002) that the decision to study a management related topic in a particular way involves a philosophical choice by the researcher about what is important and that this choice is made simultaneously and not in isolation from the researcher's understanding of the phenomenon or issues of interest and area s of study within which it is situated.

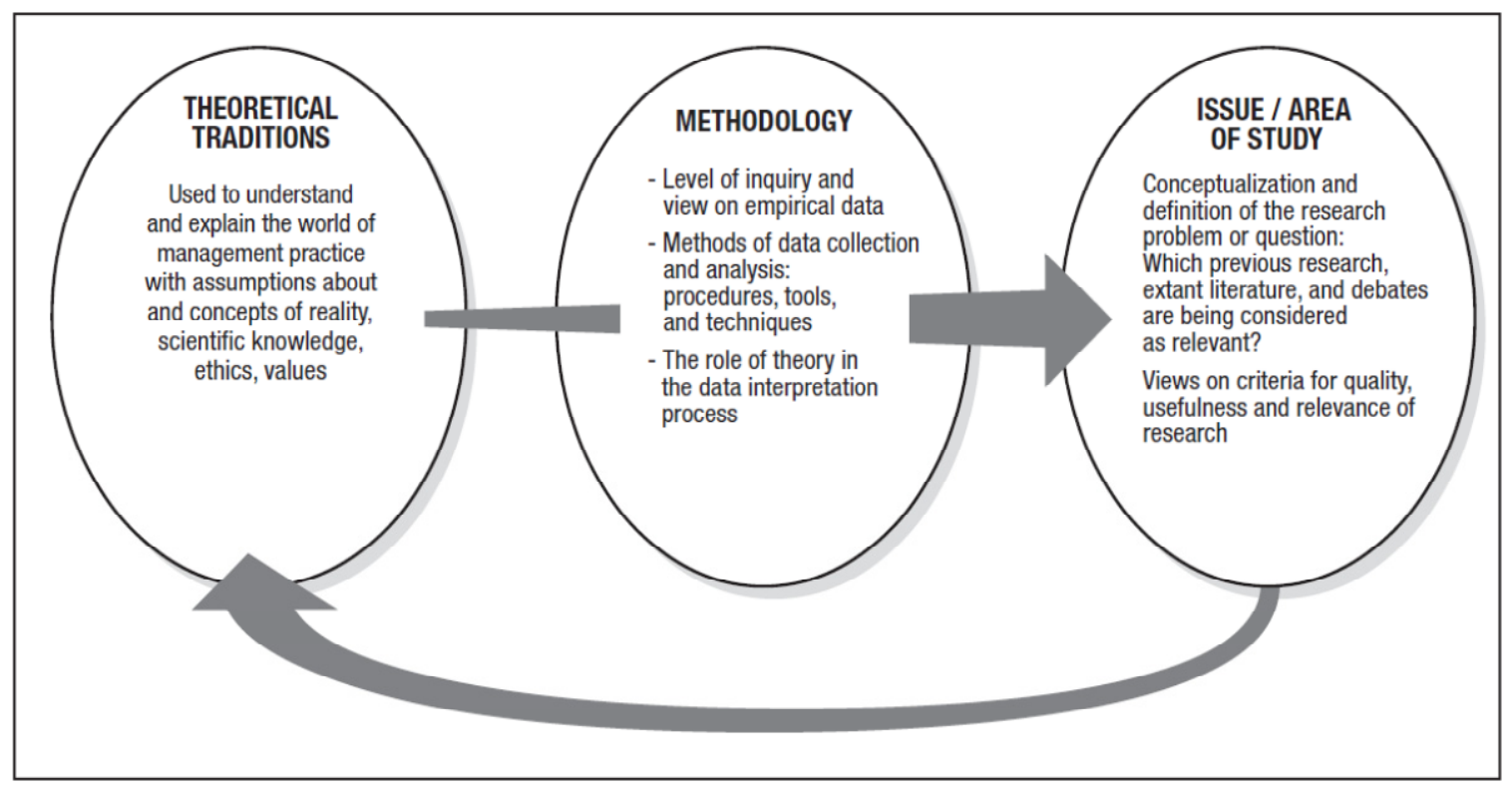

Figure 4.2 - A representation of the research activity as a knowledge creation process and the interconnectedness between its key elements (Cicmil, 2006), p 29.

Figure 4.2 represents research as a holistic intellectual activity spanning all three elements of theoretical traditions, methodology and issue/area of study. This emphasises the intrinsic link between research methodology and the nature of the knowledge created in the process (Cicmil, 2006).

During the course of this research process, particularly the earlier stages during the preparation of reflective Learning and thesis preparation papers, which are a specific requirement of the DPM course, the nature of the proposed research question mutated 
somewhat. The original intention was to demonstrate that the project alliance procurement approach could deliver VfM and by inference was a superior model to convention to convention or 'traditional' procurement methods. However, it soon became clear that such an approach would require access to a very broad range of projects at a very detailed level.

Additionally, during the gestation period of this research, which was somewhat extended, the industry knowledge and understanding of alliancing developed significantly. The growth of the use of this procurement approach was documented in some detail earlier in Chapter 2.

Consequently by the time that a final focus was required to confirm the nature of the research topic, it was felt that establishing that project alliances could deliver VFM was somewhat unnecessary and would not provide a substantive contribution to the knowledge of the industry. Work undertaken by others including Keys (2004) and VDTF (2006a) as described earlier in Table 3.2 had already addressed this issue. However, it was evident that whilst many involved in the industry accepted that, in the right circumstances, alliances could deliver VFM there was still an absence of an appropriate procedure or model for ensuring and demonstrating that VFM was achieved for a given alliance.

Consequently, given that the practice of alliance contracting and this research program have been developing in parallel and it has been necessary to adjust the focus of the research from establishing that alliance can offer $\mathrm{VFM}$ to a model for ensuring and demonstrating that $\mathrm{VFM}$ has been achieved in the procurement process.

Having established that the nature of the research question is fundamentally linked to the most appropriate research method it is clear that the careful definition of the research question is vitally important.

The following characteristics of the research question were seen as critical to the selection of research methodology;

- The matter being investigated is a newly emergent and rapidly changing field at the leading edge of procurement practice in the construction industry. Consequently, such strategies as historical or archival analysis, have limited application to this research.

- The researcher is heavily involved in the issues being investigated as a practitioner in the alliance contracting, a Director of the relatively newly established Industry body in the field (AAA) and is recognised within the Australian Industry as a commentator on the development of alliance contracting as a procurement approach. Consequently, the researcher is not examining the subject from a distance as a detached observer. 
This fact needed to be recognised and addressed in both the selection of the research approach and the execution of the research task.

- The research question is a matter to which there is not necessarily a definitive answer but is best addressed by seeking to access the collective views of the industry on the best process or procedures to address VfM.

- It is not a question which lends itself to a quantitative approach but a more qualitative methodology which seeks to aggregate the views of the industry using a collegiate or consultative framework.

Further, as described earlier, the researcher is effectively 'embedded' in the forefront of the issue of VfM in project alliances and this provided the opportunity to use this position and knowledge, in combination with an extensive review of industry practice and the literature, to develop a initial model which could be reviewed and commented upon by the industry. Additionally, through the researcher's knowledge and close involvement with industry it was possible to gain access to interview key personnel in some five alliances in order to seek comments from experienced practitioners on the merit of this initial model. This offered the opportunity to both understand how VfM had been addressed on those projects (case study approach) and effectively 'market test' this initial VfM model to determine whether it suited the circumstance of those alliances and might have more universal merit for project alliances generally.

(Yin, 1994) suggests that there are three conditions relating to the choice of research strategy being:

- The type of research question posed.

- The extent of control an investigation has over actual behavioural events.

- The degree of focus on contemporary as opposed to historical events.

In Table 4.1 below these conditions are related to the five major research strategies in the social sciences; experiments, surveys, archival analysis, histories and case studies. This table includes a column indicating the researchers view on whether each strategy is suited to the proposed research question.

Further, based on the matrix developed by Gill \& Johnson (2002) for the selection of a research strategy, these characteristics of the research question, see Figure 4.3 below, suggested that the question resided in the upper right hand box of the model and an action research focus was appropriate. 
Table 4.1 - Relevant situations for different research strategies, adapted from Yin (1994), p6.

\begin{tabular}{|c|c|c|c|c|}
\hline Strategy & $\begin{array}{l}\text { Form of } \\
\text { research } \\
\text { question }\end{array}$ & $\begin{array}{l}\text { Requires control } \\
\text { over behavioural } \\
\text { events? }\end{array}$ & $\begin{array}{l}\text { Focuses on } \\
\text { contemporary } \\
\text { events? }\end{array}$ & $\begin{array}{l}\text { Suited to } \\
\text { proposed } \\
\text { research question }\end{array}$ \\
\hline experiment & how, why & yes & yes & no \\
\hline survey & $\begin{array}{l}\text { who, what, } \\
\text { where, how } \\
\text { many, how } \\
\text { much }\end{array}$ & no & yes & yes \\
\hline archival analysis & $\begin{array}{l}\text { who, what, } \\
\text { where, how } \\
\text { many, how } \\
\text { much }\end{array}$ & no & yes/no & $\begin{array}{l}\text { Yes - to develop } \\
\text { research question }\end{array}$ \\
\hline history & how, why & no & no & $\begin{array}{l}\text { Yes - to develop } \\
\text { research question }\end{array}$ \\
\hline case study & how, why & no & yes & yes \\
\hline
\end{tabular}

The theoretical principles underlying an action research approach are presented in more detail below.

Having reached this view it was apparent that the industry knowledge and network of the researcher could be used to take such an applied approach even further. Once the model had been 'market tested' on five 'case study' alliances the refined model could then be given an even more rigorous review by seeking comment from a range of people who were acknowledged experts in the field. This was achieved using a Delphi Survey approach, a technique which is intended to enhance informed decision making by gaining access to a wider reservoir of knowledge in a given field. This technique is discussed in more detail in later in this chapter.

\section{Action Research}

As described above, given the nature of the research question being investigated, the professional background of the researcher (practicing professional engineer with 35 years experience in the construction industry, including more than 10 years involvement with relationship based contracting), and the practical nature of the outcome sought, the most appropriate choice of research methodology was considered appeared to be an action research approach. This was selected over other approaches which might be termed pure or 
applied (Bowyer, 2003). It is apparent, however, that the chosen strategy also fulfils many of the characteristics of the approach defined as applied research.

\begin{tabular}{|c|c|c|}
\hline $\begin{array}{l}\text { Prescriptive, } \\
\text { deductive, } \\
\text { obtrusive } \\
\text { 'from the outside' }\end{array}$ & $\begin{array}{l}\quad \quad \text { I } \\
\text { ANALYTICAL } \\
\text { SURVEYS AND } \\
\text { EXPERIMENTAL } \\
\text { RESEARCH DESIGN } \\
\text { (concerned with } \\
\text { precision) }\end{array}$ & $\begin{array}{c}\| \\
\text { ACTION RESEARCH }\end{array}$ \\
\hline \multirow[t]{2}{*}{$\begin{array}{l}\text { Descriptive, } \\
\text { inductive, } \\
\text { unobtrusive } \\
\text { 'from the inside' }\end{array}$} & $\begin{array}{l}\quad \text { III } \\
\text { DESCRIPTIVE } \\
\text { SURVEY RESEARCH } \\
\text { DESIGN } \\
\text { (concerned with } \\
\text { generality) }\end{array}$ & \begin{tabular}{l}
\multicolumn{1}{c}{ IV } \\
ETHNOGRAPHY \\
(concerned with \\
character of \\
context)
\end{tabular} \\
\hline & $\begin{array}{l}\text { General } \\
\text { extensive }\end{array}$ & $\begin{array}{l}\text { Particular } \\
\text { intensive }\end{array}$ \\
\hline
\end{tabular}

Figure 4.3 Choosing research strategies, from Gill \& Johnson (Gill and Johnson, 2002),p196.

The primary distinction of action research is that the research does not purport to maintain a distance and separation from the thing that is being researched. Indeed the aim of the research is to have a direct and immediate impact and hence it is accepted that change should be incorporated into the research process itself (Easterby-Smith et al., 2002).

Rapoport (1970) has provided the following definition; 'Action Research aims to contribute both to the practical concern of people in an immediate problematic situation and to the goals of social science by joint collaboration within a mutually accepted ethical framework'. Action Research (AR) has also been described (Pedler et al., 2005) as not so much a research approach, but an educational process that makes extensive use of action research methods. $A R$ is seen to be an approach which is best suited to open-ended problems, rather than puzzles with an unidentifiable solution (Revens, 1980). It was concluded that the particular research question being addressed falls firmly into this classification.

A key benefit of action research is that it can directly assist organisational learning. Whilst there are several definitions of the concept of organisational learning and the learning organisation the definition offered by Zuber-Skerrit and Perry (2002) is considered particularly relevant to this research exercise. They describe organisational learning, in the context of academic research, as a process of collaborative active learning and action research in an 
organisation with the aims of solving complex problems and achieving change and improved performance at the individual, team and organisational levels. They go on to suggest the learning organisation is an as ideal form of organisation that is defined by five disciplines Senge (1990) : personal mastery, mental models, shared vision, team learning and systems thinking.

Whilst AR appears to provide an appropriate approach to management issues that require active participation or collaboration to enable the researcher to 'penetrate' the intricacies of the issue, this approach is not without critics or those who reject some of the paradigmatic assumptions embodied in AR and maintain that AR is little more than consultancy. These suggested failings include (Baskerville and Wood-Harper, 1996):

- it is impossible to establish causal relationships;

- it is difficult to generalise from AR studies;

- risk of researcher bias; and

- generally lacks the key qualities normally associated with rigorous research.

However, such shortcomings have been address by the work of MacKay and Marshall, in particular, as discussed below. Consequently the researcher was persuaded that such an approach remained relevant to this research.

Having determined the nature of the methodology to be adopted, it was necessary to further reflect on the knowledge creation process developed by Cicmil (2006) and described earlier in this Chapter. In order to articulate the interconnectedness described earlier in Figure 4.2, a further figure was developed, see Figure 4.4 below. This depicts the same diagram but it is populated with the specifics of the research exercise being described in this thesis.

Criticisms have been made of the relevance of graduate research to management practice including the Karpin Report, commissioned by the Australian Commonwealth Government (Karpin, 1995). This provides a further stimulus to consider research approaches such as action research which are 'in tune' with the actual needs and requirements of management practice.

AR can be differentiated from traditional research as representing a different paradigm. According to Bawden (1991), 'We can talk of systematic methods of experimental, positivist, 
reductionist, deterministic natural science. We can refer to the methods of post positivist, empirical, constructivist, interpretative social science'. (emphasis added)

The traditional approach is well suited and highly successful in the physical sciences where 'hard' boundaries separate the researcher from the system being researched. However, investigation of social systems, such as managerial practice even in the relatively objective environment of the construction industry involves 'soft' systems without clearly defined boundaries between the researcher and the system.

As summarised by and Perry and Zuber-Skerritt (1994), traditional and action research both have roles to play in social science research but action research can be particularly appropriate for soft systems of management and organisational learning.

As with much AR this particular research task is attempted to address two objectives; to enhance learning within an organisation or more broadly the construction industry and also to make a contribution to a body of knowledge that fulfils the requirements of the DPM program. These two goals or imperatives are acknowledged by McKay and Marshall (2001) as the need to address a practical problem within an organisation and the simultaneous need to generate new knowledge and understanding.

Perry and Zuber-Skerritt (1992) have actually distinguished between core and thesis research for a given AR exercise suggesting that there is sufficient distinction between the two objectives to warrant a separate reflection on the field work or action component of the research including consideration of professional and organisation practices. They suggested that these findings are reported and verified by the participants. By comparison the academic thesis analyses and evaluates the results of action (content and process) in the light of the literature review before reflecting on the conclusions of the research. This distinction is shown in Figure 4.5 below. 


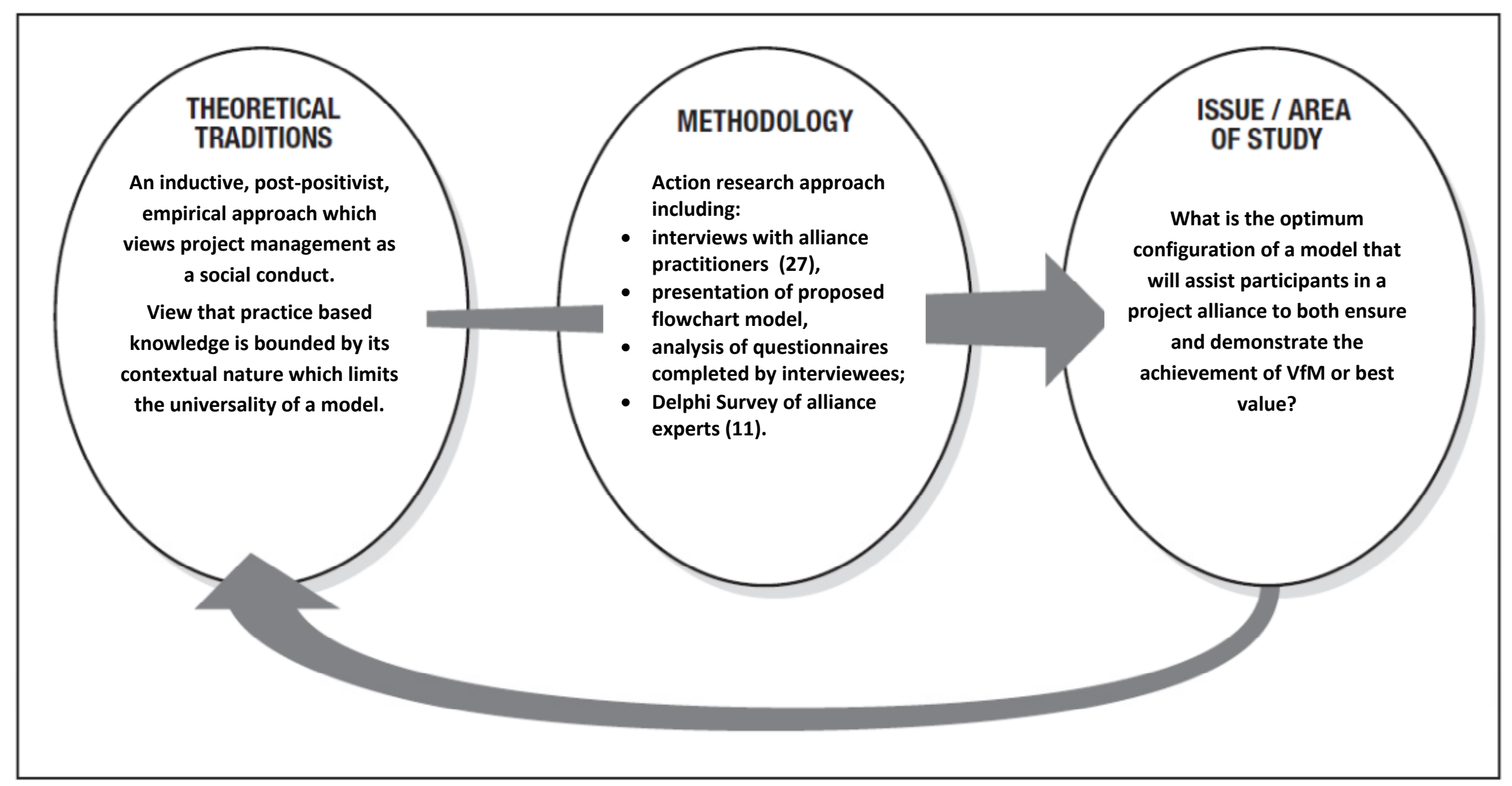

Figure 4.4 An amended version of Figure 4.2 from Cicmil (2006), p29, adapted to the specifics of this research 


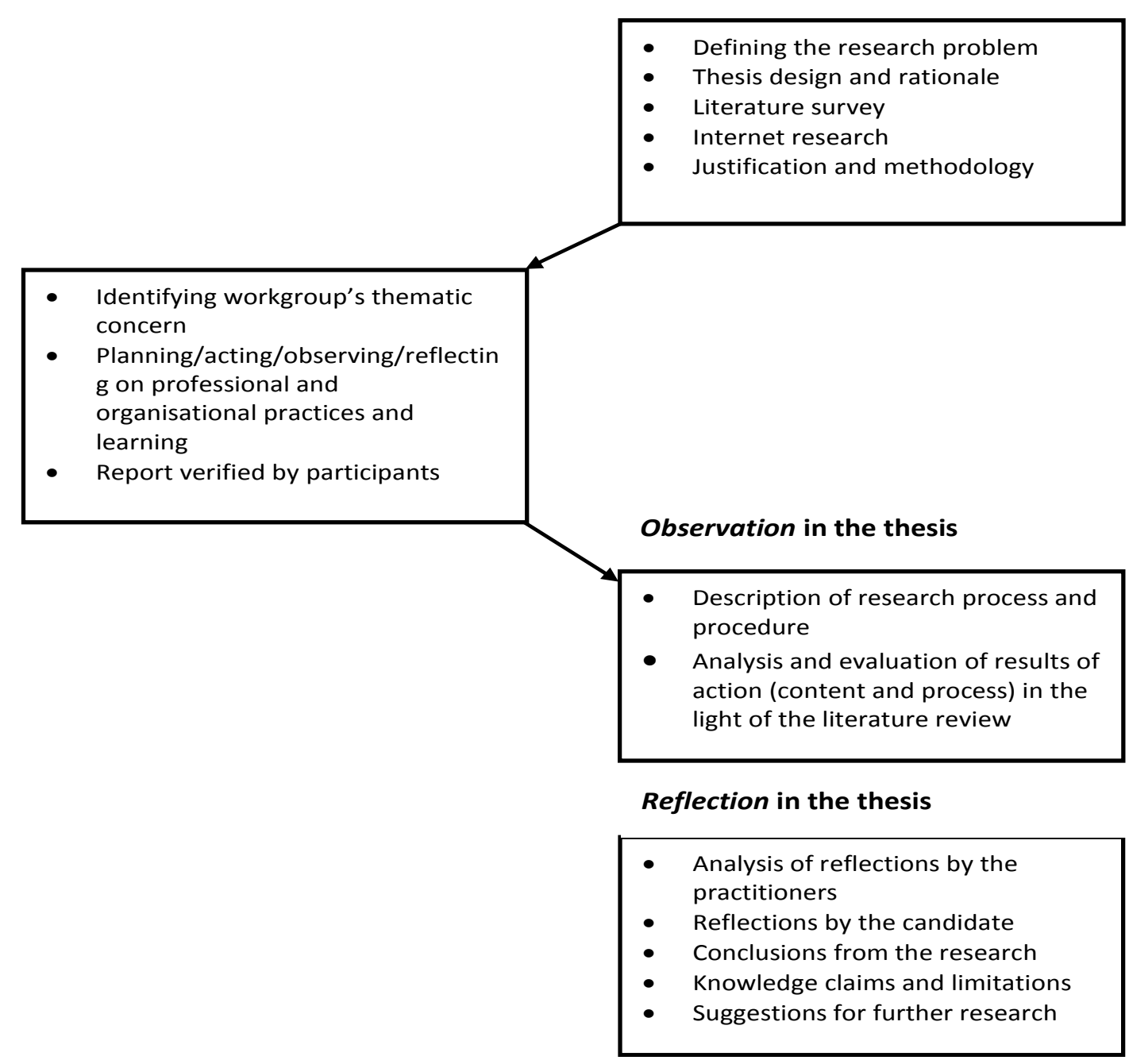

Figure 4.5 Relationships between core and action research projects, adapted from Perry Zuber-Skerritt (1992), p203.

Zuber-Skerritt and Perry (2002) depict the relationship between the thesis research, core action research and thesis writing. This process as adapted for the research is shown in Figure 4.6 below.

As mentioned earlier, this approach was seen to represent a very close match to the requirements of the research proposed and consequently was adopted and the guiding strategy for the research task. In particular the core AR research element of the model was 
structured as three elements which sought to address the thematic concern of refining a VfM/BV Model for project alliances. These three elements were comprised of;

- interviews with alliance participants;

- the distribution and analysis of questionnaires; and

- a Delphi survey of a group of experts in the alliancing field.

Each element is described in further detail later in this Chapter. The actual adaption of the Zuber-Skerritt and Perry model to the circumstances of the research is shown in Figure 4.7 below.

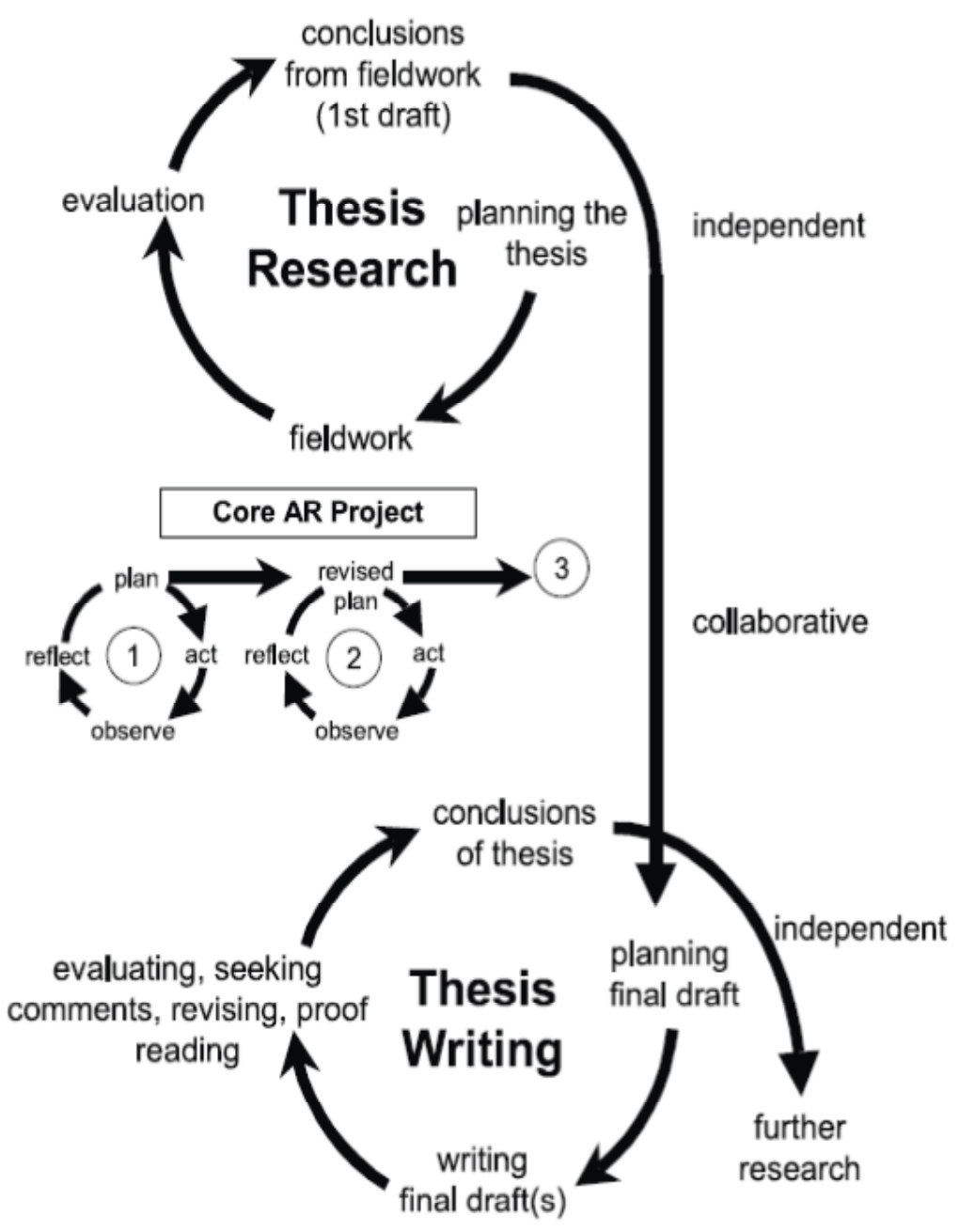

Figure 4.6 The relationship between thesis research, core action and thesis writing, Zuber-Skerritt and Perry (2002), p177, as adapted from Perry and ZuberSkerritt (1992). (A modified version of this figure is shown in Figure 4.7 which illustrates this research program) 


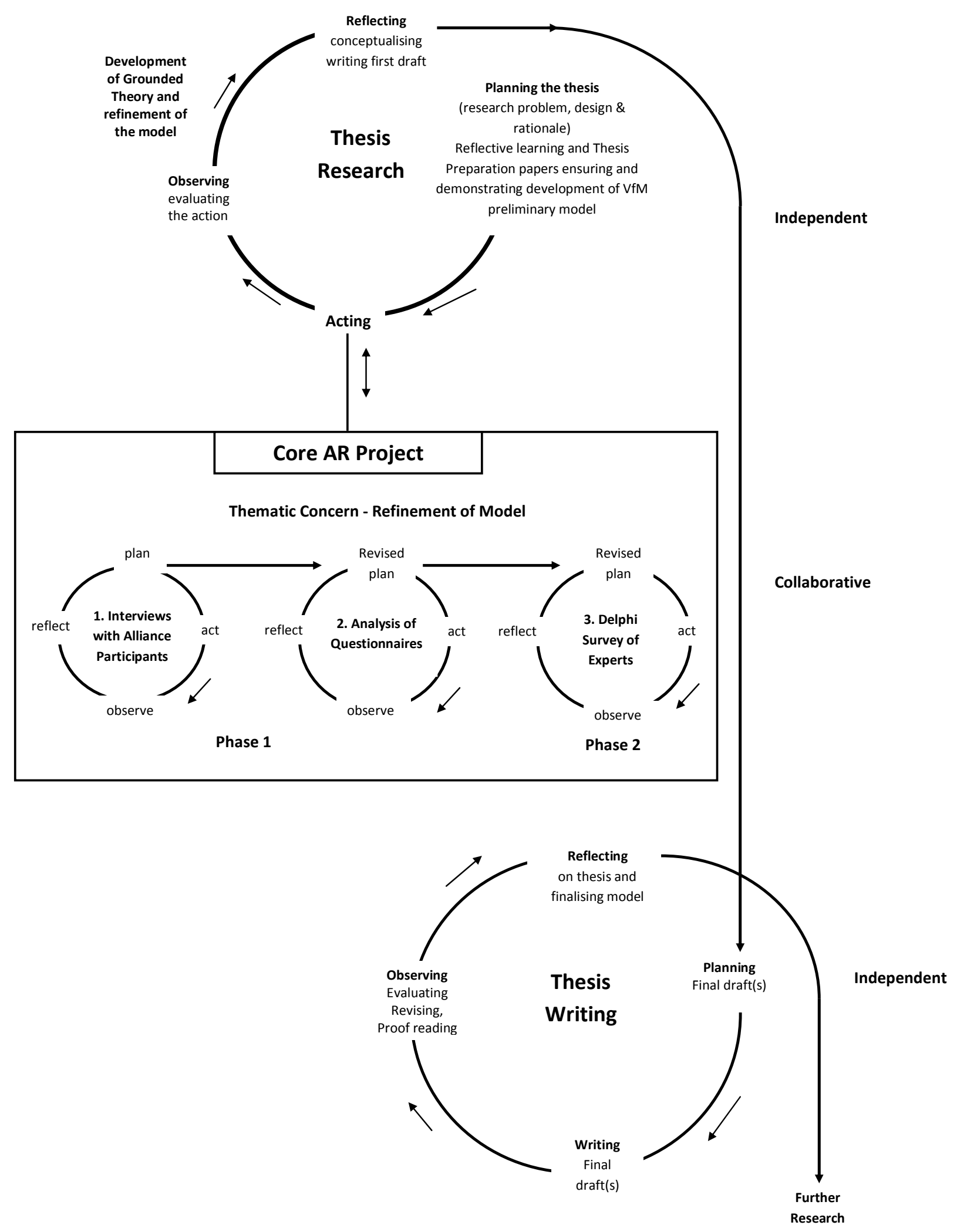

Figure 4.7 The relationship between thesis research, core action research and thesis writing for this research, adapted from Zuber-Skerritt and Perry (2002), p177. 


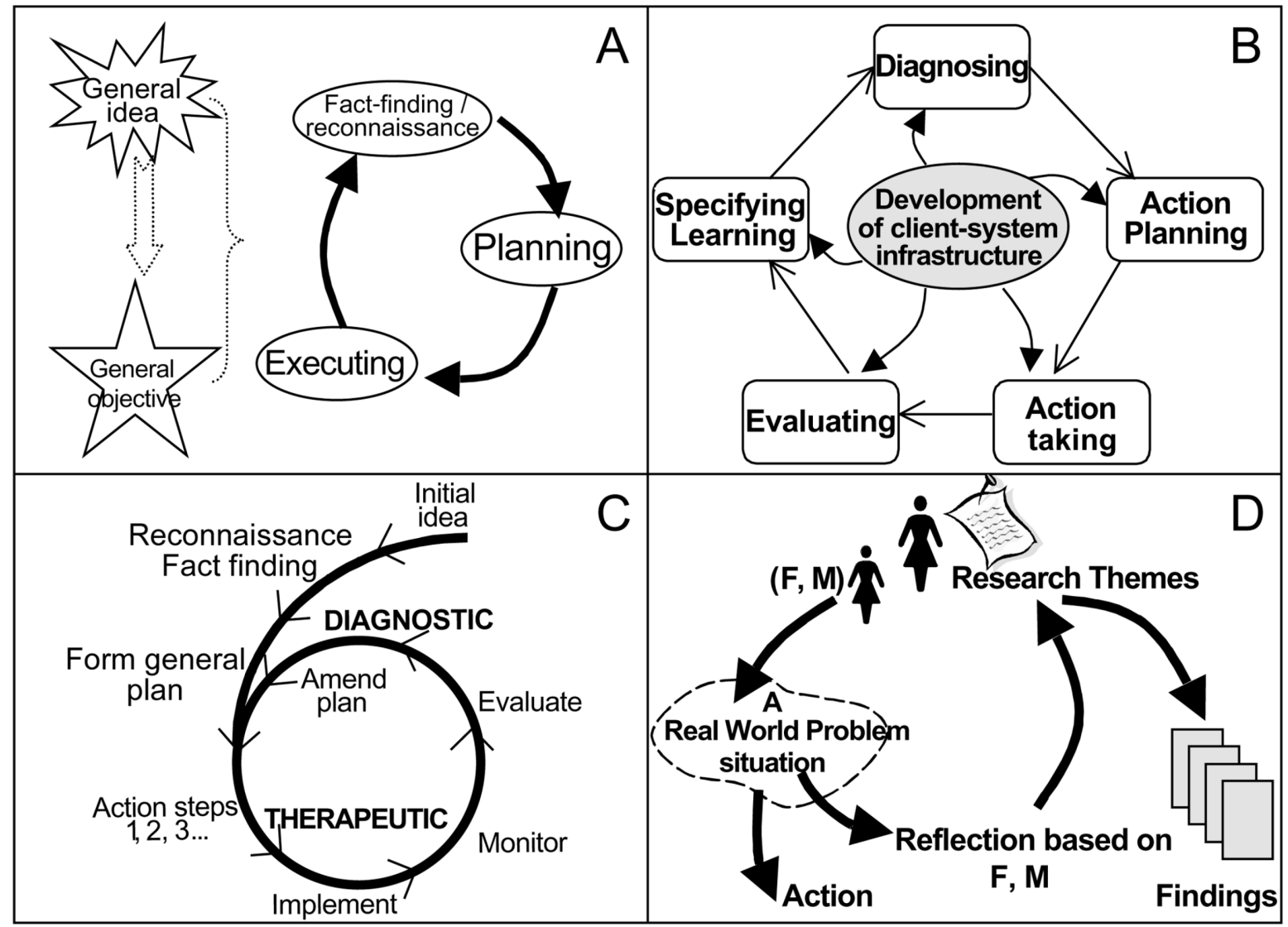

Figure 4.8 Representations of the Action Research Cycle as a single cycle, from McKay and Marshall (2006) - (A: (Morwood et al., 2008); B: (McKay and Marshall, 2001); C: (OCG, 2007); D: (ANAO, 2003))

As referred to above, McKay and Marshall (2001), have responded to the criticisms levelled at $A R$. They suggest that such concerns, which may have some merit in poorly conducted AR, result largely from the manner in which AR is conceptualised. Reflecting on the observations presented above, McKay and Marshall (2001) suggest that many of these issues can be addressed if AR is conceptualised as two, interlinked cycles of problem solving interest and research interest, rather than the more common perception of AR being a single cycle process, with possible iterations. This single cycle view of action research has been described by several authors in the past and a number of such models are depicted in Figure 4.8 above.

The juxtaposition between action and research and of theory and practise is illustrated in Figure 4.9 below. McKay and Marshall (2001) suggest that these cycles should not be conducted independently but are highly interlinked and somewhat contingent upon each other. Consequently action researchers need to think and act more deeply and more reflectively than the simple models in Figure 4.8 suggest. Such an approach assists in overcoming the criticisms listed above by addressing the suggestion that AR does not contain 
the degree of rigour necessary to generate significant research outcomes. Specifically the emergence of the research interest cycle distinguishes action research from activities which are simply consultancy.

A specific practical application of this approach is provided by Nogeste (2008) who adopted a dual cycle action research approach in undertaking a professional doctorate case study which considered how to improve the way in which project stakeholders define and align intangible project outcomes with tangible project outputs. Nogeste reached the conclusion that a dual cycle AR model provides academic researchers and reflective practitioners of project management with an effective and efficient means of addressing the dual imperatives of research and problem solving. This dual cycle approach was adopted within the research strategy described in Figure 4.7 above.
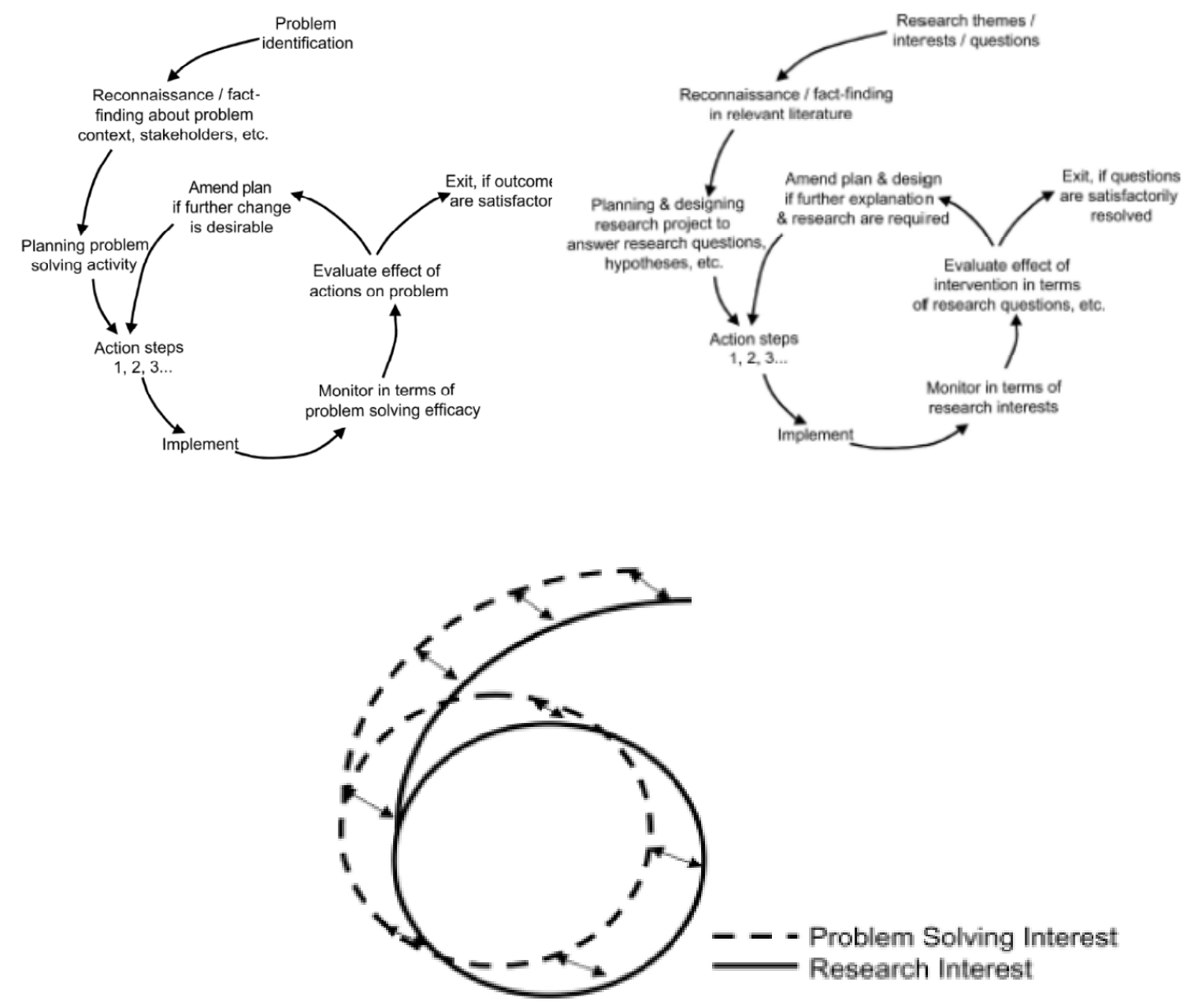

Figure 4.9 Concurrent cycles of problem solving and research interests - adapted from McKay and Marshall (2001), p50-52. 


\section{Delphi Technique}

Having described the general rational for the adoption of an action research approach the theoretical basis of the Delphi Technique used in Phase 2 of this research is now described.

The Delphi Technique is an iterative process which collects and distils the judgement of a group of experts using a series of questionnaires interspersed with feedback. Each questionnaire, or round, is developed based on the results of the previous round (Berrata, 1996, Green et al., 1999, Hasson et al., 2001, Powell, 2003). The process concludes when the question is answered or the problem addressed i.e. consensus has been achieved or when sufficient information has been exchanged to establish a clear range of opinions on the subject. The technique has been extensively used in graduate research and is considered to be well suited as a research instrument when there is incomplete knowledge about a problem or phenomenon (Skulmoski et al., 2007).

The Delphi technique was developed at the Rand Corporation in the 1960's (Dalkey, 1969). The technique draws upon the concept of the Delphi oracle of ancient Greece, the function of which was to foretell the future for those who sought its counsel. The Rand Corporation employed a group of advisors for modelling likely scenarios for future events (particularly war scenarios). Consequently the term should technically speaking be reserved only for techniques that involve scenario modelling or forecasting (Northcote et al., 2008). However, it is used extensively to support judgemental or heuristic decision making, or more colloquially, creative or informed decision making (Ziglio, 1996).

The Delphi technique has had its critics as a research methodology. Criticisms are largely based on the fact that 'scientific' procedures for sampling and testing of results through conventional experimental control are not adopted. The most strident criticism of the Delphi technique was made by Sackman (Sackman, 1974) who stated that 'The future is far too important for the human species to be left to fortune tellers using new version of old crystal balls. It is time for the oracle to move out and science to move in'.

Sackman's criticisms were largely addressed by Goldschmidt (1975) who also acknowledged that many Delphi questionnaires were poorly constructed but pointed out that there should be a distinction between criticising and 'technique and the application of the technique'.

In a somewhat more strident response Linstone (1975) offered the following comment regarding Sackman's suggestion that the Delphi technique is unscientific. 'Science to Sackman means psychometrically trained social scientists.... it is the same vein' as the illusion that 
science is 'objective', that only Lockean or Leibnizian inquiring systems are legitimate and subjective or Bayesian probability is heretical. Orthodoxy faced with new paradigms often responds with sweeping condemnations and unwitting distortions'.

The mechanics of the Delphi technique, as they have been adopted in this research, are summarised in Figure 4.10 below, although they are also explained in some detail later.

As described by Dick (1999) the researcher decides which questions to ask, most commonly ones that can be answered numerically. The panel is recruited, presented with the question that the researcher wishes to ask and they then respond. This is the first round. On subsequent rounds, panel members have a choice to vary their position in the direction of the emerging consensus or offer reasons for retaining their position. By the final round, panel members are better informed that they were at the beginning of the process. Consequently Dick (Dick, 2002) suggests that the Delphi process might be described as an activity characterised by mutual education, a pooled data base of the most relevant information having been developed.

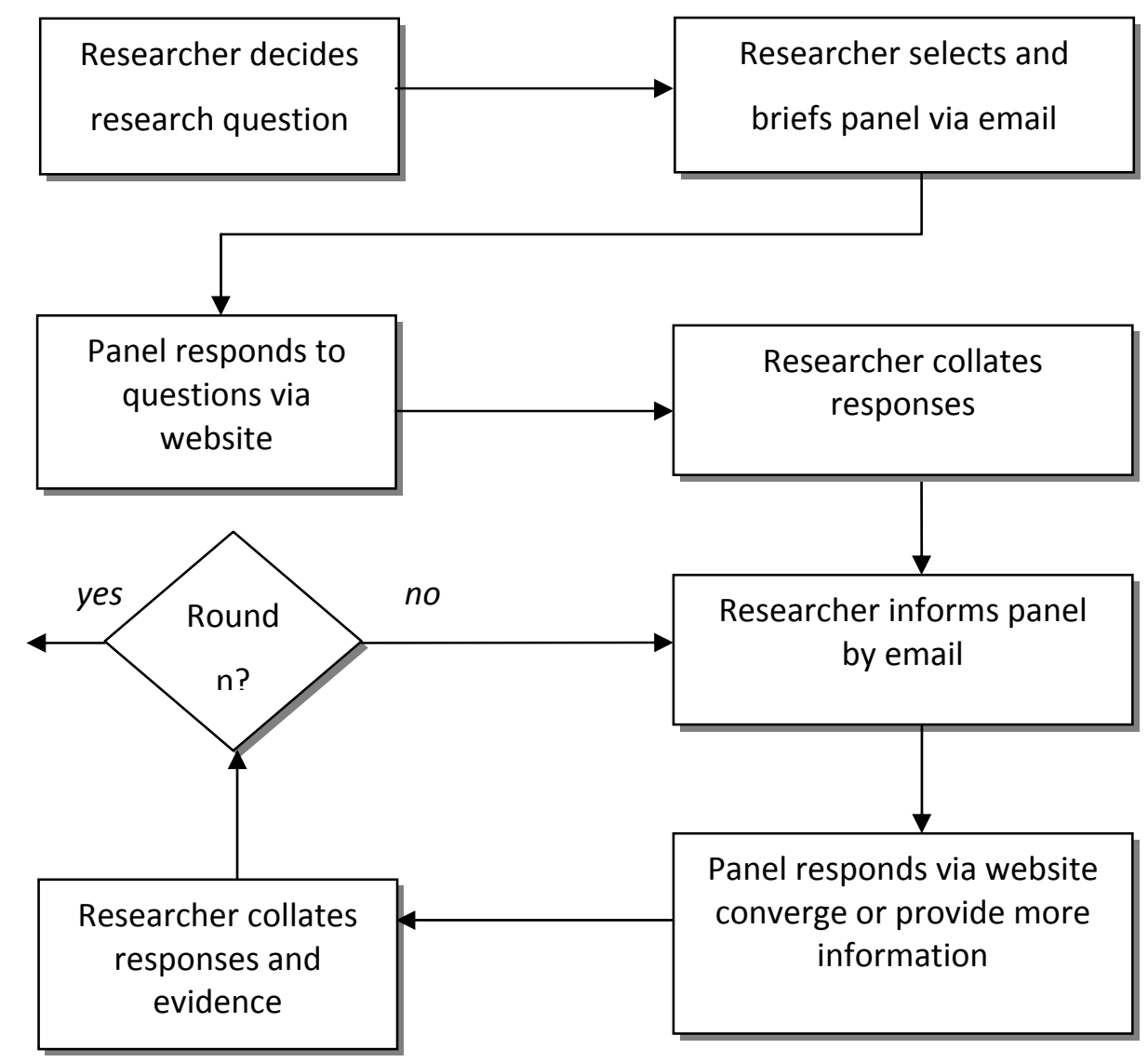

Figure 4.10 The stages of the Delphi process adapted from Dick (2002) 
The merits of the technique that have direct relevance to this research as summarised by Adler and Ziglio (1996) as follows:

- It focuses attention directly on the issue under investigation;

- it provides a framework within which individuals with diverse backgrounds or in remote locations can work together on the same problem;

- it minimises the tendency to follow the leader and other psychological and professional barriers to communication;

- it provides equal opportunity for all experts involved in the process; and

- it provides precise documented records of the distillation process through which informed judgement has been achieved.

These same conclusions are supported by a number of more contemporary references (Brown, 2007, Gordon, 2009a, Gordon, 2009b, Keeney et al., 2006).

\subsection{Research Methodology Adopted}

The research sought to test the validity of an approach, based on a model, to demonstrate and document VfM in project alliances.

The original conception of such a model emerged from the initial Reflective Learning and Thesis Research papers prepared in the earlier stages of the DPM Program.

However, to lay the foundations for the development of such a model and to more accurately identify the actual gap in existing knowledge that was to be addressed a detailed review of the literature was required. This review took place in two stages;

- The general literature review described in Chapter 2.

- A more specific review of relevant reports, guidelines and other VfM related material.

These reviews led to the development of the preliminary VfM/BV model which was described in Chapter 3.

Given that the model is intended to be a 'working tool' that can be used by practitioners, it was considered to be important that the model was exposed to the scrutiny and comment of such practitioners as early as possible, to ensure that the work remained grounded and not simply a theoretical document which would be of limited real life application. 
To achieve this end the action research approach that was developed consisted of two data gathering stages which were entitled Phase 1 and Phase 2. The scope of these stages of the research was as follows;

Phase 1 - A series of interviews (27 No.) with participants in five alliances in which the VfM practices in the respective alliance was discussed. The initial VfM model which had been developed by the researcher was presented and a detailed questionnaire was left with each participant to complete. Following receipt of the questionnaires (21 No.) the model was updated to reflect the comments received through both the interviews and questionnaire.

Phase 2 - A three round Delphi Survey of experts (12 No.) in the field of project Alliancing who commented on the content and merit of the VfM model. The model was updated both during and at the completion of the survey process.

Following completion of the data gathering stages the information gathered was carefully analysed and comparisons made with other contemporary research, as described in Chapter 7. Further to consideration of all this information the model was than finalised and is presented in Chapter 8.

A flowchart illustrating the overall staging of the research process is contained in Figure 4.9 Summary Flowchart of DPM Research Process for VfM/BV Model for Project Alliancing is shown below and this is followed by a more detailed description of the data gathering stages of the research. 


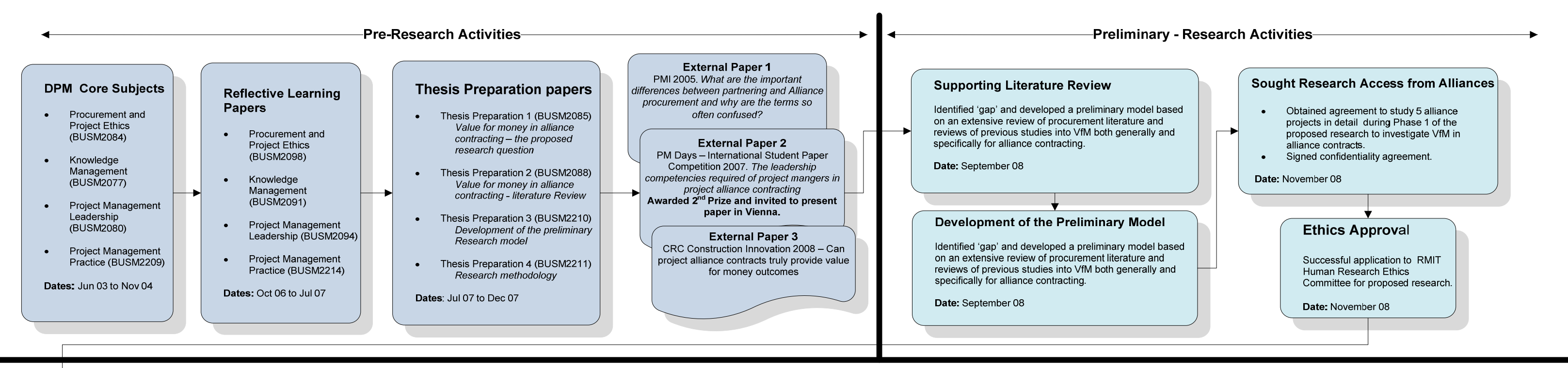

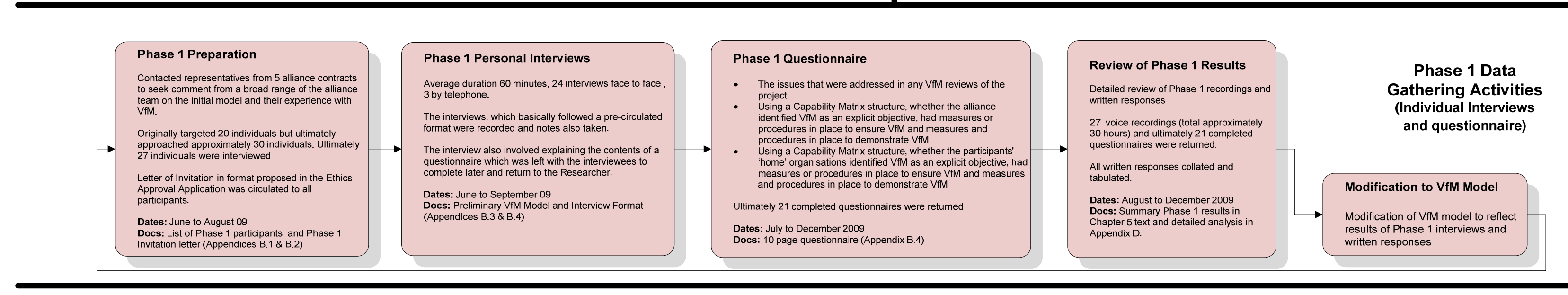

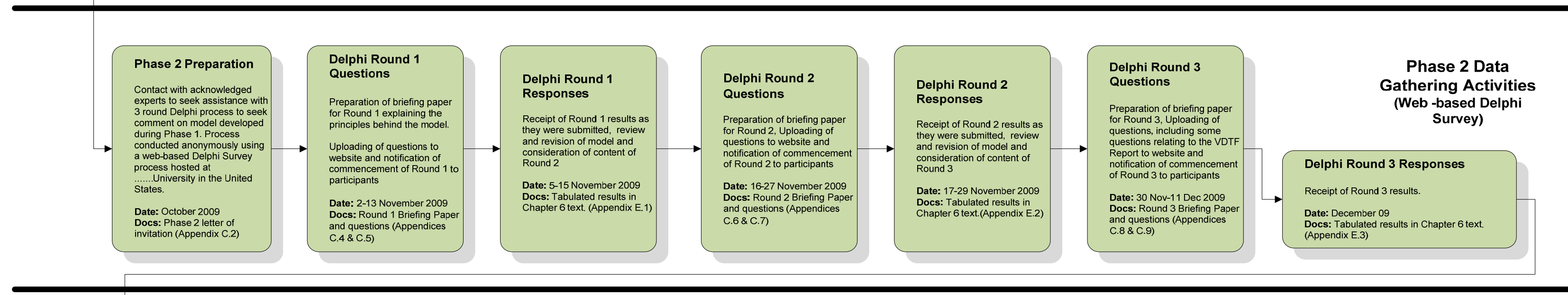

Analysis of data,
finalisation of model
and comparison with
IASCNDDTF WOrk

Figure 4.11 Summary Flowchart of DPM Research Process for VfM/ BV Model for Project Alliancing 


\section{Phase 1}

The first phase of the research involved discussions with parties involved in five separate project alliances. Access to parties working in such contracts is not easy to obtain given that they are primarily focussed on the job at hand of delivering the respective projects concerned. However, through the researcher's broad industry knowledge and professional network, agreement was obtained to hold detailed discussions with five alliances which were in various stages of development to speak to a broad range of participants i.e. representatives of the Owner, the Constructor (Contractor) and other Non-Owner Participants (NOPs).

Agreement was reached initially, with the organisation that was the Constructor in all the projects concerned. This involved the researcher signing a confidentiality agreement which was designed to ensure that anonymity was preserved in the research process and that commercially sensitive information was not revealed in the public domain. The organisations and individuals approached, with very few exceptions, were eager to participate in research into the issue of VFM which they acknowledged as being of importance to both themselves and the industry more broadly.

The detailed discussions involved a series of 'one on one' interviews in which the VfM model, as developed at that stage, was presented to each individual to seek initial comment. The researcher then proceeded to explain the purpose and format of a questionnaire (10 pages) (see Appendix B.4) which sought to obtain comments on the manner in which VfM had been approached on the particular alliance concerned, and within the 'home' organisation of each participant in the research.

A Capability maturity model (CMM) tabulated matrix response approach was adopted for a number questions in the questionnaire. Five levels of maturity were specified for each question at each stage of the project lifecycle. This approach was selected for several reasons. It provided a clear means of communicating the context of the questions. It accommodated the anticipated broad range of understanding and sophistication in the manner in which VfM was addressed both at the project and organisational levels and it also providing a simple and efficient means for the respondents to reply to the questions. The CMM matrix developed was based largely on the approach described by Walker and Nogeste (2008) in the development a modelling tool developed to understand how organisations create competitive advantage through the efficient use of knowledge. The questionnaire concluded with a number of open questions which sought the participant's view of the likely usefulness of the proposed model and any deficiencies or obvious failings of the approach proposed. 
The format of the interviews was standardised by largely following a predetermined script (see Appendix B.4). However, the purpose of the interviews was to generate conversations which uncovered the areas of interest of the participant and to respond to specific questions that they had regarding either the model, as tabled or the content of the questionnaire.

Consequently this format was not followed in a strictly regimented fashion.

Whilst it was initially intended that only 20 people would be interviewed, being four participants from each of 5 alliances, eventually some 27 people were interviewed with two participants having a role in two of the alliances considered. As these two participants commented separately on each alliance there were effectively 29 interviews held in this Phase 1 of the research. All but three of the interviews were held in an individual face to face basis. One of three telephone interview participants was involved in two alliances. Consequently of the 29 total interviews, some 25 were 'face to face' and 4 were telephone based.

The alliances involved are not individually identified in this thesis, due to confidentiality reasons, although the nature of the works undertaken is described. A table listing the parties contacted in each alliance, the timing of the interviews and the date that the questionnaires were returned is contained in Appendix B.1. Some 21 returned questionnaires were received and the responses to the questions posed are detailed in Chapter 5.

Table 4.2 Phase 1 Interviews and Responses to Questions

\begin{tabular}{|c|c|c|c|c|c|c|c|c|}
\hline \multirow[b]{2}{*}{ Alliance } & \multicolumn{2}{|c|}{ Constructor } & \multicolumn{2}{|c|}{ Other NOPs } & \multicolumn{2}{|c|}{ Owners } & \multicolumn{2}{|c|}{ Total } \\
\hline & Interviews & Responses & Interviews & Responses & Interviews & Responses & Interviews & Responses \\
\hline Blue & 4 & 3 & 1 & 1 & 1 & 1 & 6 & 5 \\
\hline Red & 3 & 1 & 2 & 1 & 0 & 0 & 5 & 2 \\
\hline Green & 3 & 3 & 2 & 2 & 1 & 1 & 6 & 6 \\
\hline Purple & 3 & 2 & 1 & 0 & 2 & 1 & 6 & 3 \\
\hline Black & 2 & 2 & 2 & 2 & 1 & 1 & 6 & 5 \\
\hline Total & 16 & 11 & 8 & 5 & 5 & 4 & 29 & 21 \\
\hline $\begin{array}{l}\text { Response } \\
\text { rate }\end{array}$ & \multicolumn{2}{|c|}{$69 \%$} & \multicolumn{2}{|c|}{$63 \%$} & \multicolumn{2}{|c|}{$80 \%$} & \multicolumn{2}{|c|}{$72 \%$} \\
\hline $\begin{array}{l}\% \text { of } \\
\text { responses }\end{array}$ & $55 \%$ & - & $28 \%$ & - & $17 \%$ & - & $100 \%$ & - \\
\hline $\begin{array}{l}\% \text { of } \\
\text { responses }\end{array}$ & - & $52 \%$ & - & $24 \%$ & _ & $19 \%$ & & $100 \%$ \\
\hline
\end{tabular}

Table 4.2 above summarises the constitution of the interviews and the response rate received regarding the questionnaire. 
All interviews were recorded, using a digital voice recorder, with the agreement of the participants and copies of the recording were forwarded to each participant after the interview. The length of each meeting is noted in the table in Appendix B.1. However, the average interview duration was 60 minutes.

\section{Phase 1 analysis}

The full details of the results collected in Phase I and the analysis undertaken is reported in Chapter 5. Results of Phase 1 were carefully considered before proceeding to Phase 2 of the research and the VfM model was modified in recognition of some of the points made by parties who participated in Phase 1.

The preliminary model was generally well received and considered to be useful in identifying the stages of the project life cycle and the specific VfM issues that were relevant at each stage. However some difficulties with the model were identified including the following:

- The legibility of the model required improvement

- The model appeared to be rather complex even though it was acknowledged that VfM merited a detailed model to address the issues concerned at each stage.

Having received this general feedback and following careful digestion of the recordings of each interview the preliminary model was modified prior to the commencement of Phase 2.

However, as well as leading to a documentary change of the model, the Phase 1 responses which were quite comprehensive comprising some 30 hours of recordings and 21 detailed questionnaire responses, informed the preparation for Phase 2 of the research which involved consultation with a group of identified experts in Alliance Contracting.

\section{Phase 2}

The rational for adopting a Delphi Survey of selected group of experts for the second phase of this research is described earlier in this chapter from a theoretical perspective. This section will describe the procedure adopted from a more practical perspective of how the process was actually managed.

\section{Selection of Experts}

As explained earlier, the researcher has been closely involved in alliance contracting since the early adoption of this procurement approach in Australia. This included occasional involvement in the first public sector alliance in Australia, the North Side Storage Tunnel Alliance in Sydney, which incidentally is now generally considered to be the first Public Sector project alliance in the world. 
During the extended period, now some 13 years, the researcher has had contact with many of the senior professional in the field including Owners, Contractors, Lawyers, Consultants and facilitators who normally engage to both established alliance arrangements and their participants regarding their conduct in project alliances.

Based largely upon the researcher's established contact with the industry, a group of 25 established experts in the field of alliancing were contacted to determine whether they would be prepared to participate in a Delphi process which would comment on the model developed in Phase 1 of the research. A total of 21 experts responded in the affirmative confirming that they would be willing to participate. As might be expected from a group of experts, their availability to participate in such an exercise was limited by their work commitments which were generally substantial. This was a significant factor in determining the timing of the rounds of the Delphi Process as is discussed further below.

It was considered to be important to ensure that there was a broad mix of backgrounds of the experts. The backgrounds, profile (extent of recognition as an expert in the field) and ultimate participation in the Delphi Process are shown in Appendix C.1.

Ultimately, 12 of the experts who agreed to participate actually did so. Whilst this represents a relatively small panel of experts, it is believed that this represents a satisfactory response, based on established Delphi process practice (Dick, 1999).

\section{Procedure for the Delphi Process}

As described earlier the VfM model was revised following the Phase 1 interview/questionnaire process and this formed the baseline version for the Phase 2 process. In order to brief the Phase 2 participants prior to commencement of Round 1 of the Delphi Process a briefing paper was prepared which was circulated with the revised model. This paper, which is contained in Appendix C.4, expanded upon the original letter of invitation that had been sent to the prospective experts to seek their participation. This letter is contained in Appendix C.2. In the briefing paper the development of the model, to date, was described in some detail to explain the context of the comments that were being sought. The mechanics of the proposed process were also described explaining that comments were being sought and received through the web-based service (forecastingprinciples.com) which would communicate with each expert to forward the questions, inform the participants of the times for responses and other administrative details. This website was also the medium through which responses were submitted. Once each of the three rounds of the research was completed the collated views of 
all the participants were then be shared, albeit anonymously, with the rest of the group in the next round of the process.

The program for the three rounds of the process was shown in the table below:

Table 4.3 Timing of the Delphi Survey Process

\begin{tabular}{llll}
\hline & Round 1 & Round 2 & Round 3 \\
\hline Start date & Monday 2 & Monday 16 & Monday 30 \\
& November 2009 & November 2009 & November 2009 \\
\multirow{2}{*}{ End Date } & Friday 13 & Friday 27 & Friday 11 \\
& November 2009 & November 2009 & December 2009 \\
\hline
\end{tabular}

This timing represented a relatively 'fast track' timetable for a Delphi Process which would typically be undertaken over a number of months. However, this was largely dictated by the fact that the experts were very busy and that there was a limited 'window of time' available to obtain the active participation of the experts.

It was emphasised that it was important that responses were received by the end date of each round so that they could be included in the collated response document which would inform the next round of questions.

The website used was a free service operated through the Wharton School at the University of Pennsylvania. The software was originally developed by J. Scott Armstrong and was funded, in part, by the International Institute of Forecasters. The website was considered to be particularly suited to this particular research task for the following reasons:

- It dealt with a significant proportion of the administrative tasks associated with contacting a number of experts over 3 rounds of the Delphi Process;

- It provided an 'independent' portal that demonstrated a rigorous and professional approach to the Delphi Review Process;

- It offered services, albeit limited, for collating and reporting the responses received to the survey questions; and

- It enabled the anonymity of the experts to be preserved, which was considered to be helpful in ensuring that the participants expressed their views freely.

Examples of some of the pages of the website are contained in Appendix C.3. 
Following the circulation of the Phase 2 base line model and the Round 1 Briefing Paper the questions being posed to the experts in Round 1 were 'loaded' into the website. These questions are contained in Appendix C.5. Once this was completed the Delphi Round was initiated and the Delphi website communicated with the experts by email confirming that Round 1 had commenced. The website also later issued reminder emails to the participants who had not responded at that time indicating that the closing date for the round was approaching.

Once Round 1 closed, the complete set of responses to the questions was available to the researcher on the website and these were reviewed. This led to some revisions to the model and a new briefing paper was drafted for circulation by email prior to the commencement of Round 2. This process was then repeated for Round 3. The documents relevant to the respective rounds are all contained in Appendix C. Their respective locations are confirmed in list of Appendices provided in the Table of Contents to this thesis.

\subsection{Summary of Chapter}

This Chapter commenced with a detailed consideration of the philosophical options that were available to the researcher in designing a research methodology suited to the task being considered.

This led the researcher to consider and then select an approach which was primarily based on 'action research' orientation which was felt to be well aligned with the applied nature of the research question being considered and the 'reflective practitioner' status of the researcher.

Section 4.4 described the mechanics of the research task undertaken including the procedures adopted in both Phase I comprising interviews with 2 alliance practitioners and the receipt of 21 completed questionnaires) and Phase 2 (comprising a 3 round Delphi Survey with 12 recognised experts in alliance procurement.

Table 4.4, which follows this summary, lists the key tasks in the execution of the methodology selected and then describes the 'actions required', 'inputs', 'expected outputs' and linkage between these stages as contemplated in the design of the research process. The table also contains notes describing the documentation produced at each stage of the process.

The data gathered during Phase $1 \& 2$ is presented and discussed in Chapters 5 and 6 respectively. 
Table 4.4

Planned sequence for the Research Exercise - (actual sequence of documents generated are noted at foot of table)

\begin{tabular}{|c|c|c|c|c|c|c|c|}
\hline & $\begin{array}{l}\text { Phase } 1 \text { letter and VfM model } \\
\text { distributed to Phase } 1 \\
\text { participants }\end{array}$ & $\begin{array}{l}\text { Phase } 1 \text { Interviews with } \\
\text { participants in } 5 \text { Alliances(case } \\
\text { studies) }\end{array}$ & $\begin{array}{l}\text { Collation of Phase } 1 \text { responses } \\
\text { and refinement of model }\end{array}$ & $\begin{array}{l}\text { Phase 2, Selection } \\
\text { and invitation of } \\
\text { Delphi participants. }\end{array}$ & Phase 2, Delphi Round 1 & $\begin{array}{l}\text { Phase 2, Delphi Round } 2 \text { and } \\
\text { possibly Round } 3\end{array}$ & $\begin{array}{l}\text { Collation of Delphi } \\
\text { responses }\end{array}$ \\
\hline $\begin{array}{l}\text { Actions } \\
\text { Required }\end{array}$ & $\begin{array}{l}\text { Following final identification of } \\
\text { the parties to be interviewed for } \\
\text { each of the five alliance projects } \\
\text { selected - forward letter } \\
\text { describing Phase } 1 \text { interviews. }\end{array}$ & $\begin{array}{l}\text { - Speak with each of the } \\
\text { participants (estimated number } \\
20 \text { ) for approx } 45 \text { mins each. } \\
\text { - Speak to Alliance Manager to } \\
\text { obtain qualitative data and some } \\
\text { quantitative information } \\
\text { regarding the performance of } \\
\text { each alliance including actual } \\
\text { cost } v \text { TCE } v \text { Original estimate or } \\
\text { current cost } v \text { TCE budget } \\
\text { original budget. Time to } \\
\text { complete v programme. } \\
\text { CMM model matrix needs to be } \\
\text { developed posing discrete } \\
\text { questions to draw experience } \\
\text { from the projects being studied } \\
\text { in this Phase. }\end{array}$ & $\begin{array}{l}\text { Undertake collation and } \\
\text { possible statistical analysis of } \\
\text { feedback both oral and via the } \\
\text { questionnaire. }\end{array}$ & $\begin{array}{l}\text { - Selection of } \\
\text { suitable Delphi } \\
\text { response sample. } \\
\text { Currently } \\
\text { contemplating } \\
\text { about } 8 \text { to } 10 \\
\text { participants. } \\
\text { - Invitations need to } \\
\text { be circulated by } \\
\text { late April 2009. } \\
\\
\text { - The panel } \\
\text { participants will be } \\
\text { contacted } \\
\text { individually and } \\
\text { their identity will } \\
\text { not be revealed to } \\
\text { the other } \\
\text { participants. }\end{array}$ & $\begin{array}{l}\text { Circulate model and CMM } \\
\text { based questionnaire to Delphi } \\
\text { participants by email. } \\
\text { (Consider using a web based } \\
\text { tool here). }\end{array}$ & $\begin{array}{l}\text { Re -circulate model and } \\
\text { questionnaire to Delphi expert } \\
\text { panel. }\end{array}$ & $\begin{array}{l}\text { Analyse results of Round } \\
\text { and } 2 \text { if considered } \\
\text { necessary Round } 3 \text {. }\end{array}$ \\
\hline Inputs & $\begin{array}{l}\text { - Letter based on draft supplied at } \\
\text { the time of Ethics Approval. } \\
\text { - Outline of ' } V f M \text { for Project } \\
\text { Alliance' Model. } \\
\text { - Explanation of the context and } \\
\text { purpose of the model }\end{array}$ & $\begin{array}{l}\text { - Prepared list of questions to be } \\
\text { used in order to guide the } \\
\text { interviews and ensure that } \\
\text { consistent structure is used in all } \\
\text { the interviews held during this } \\
\text { phase of the research. } \\
\text { - Use CMM matrices to pose a } \\
\text { series of questions regarding the } \\
\text { approach to VfM on the project. } \\
\text { These questions will include } \\
\text { questions about the specific } \\
\text { measures adopted on the } \\
\text { project to address VfM. } \\
\text { Leave a questionnaire with the } \\
\text { interviewees for them to fill in } \\
\text { after the interview. This will } \\
\text { provide a series questions asking } \\
\text { for ratings on performance of } \\
\text { project in VfM performance and } \\
\text { documentation. }\end{array}$ & $\begin{array}{l}\text { Review } 20 \text { responses to } \\
\text { identify common themes and } \\
\text { to develop further measures } \\
\text { that can be added or removed } \\
\text { from the model following } \\
\text { feedback from the } \\
\text { participants. }\end{array}$ & $\begin{array}{l}\text { - Invitations need to } \\
\text { be circulated by } \\
\text { late early May } \\
\text { 2009. Developed } \\
\text { model. } \\
\text { - Refine CMM } \\
\text { questions for } \\
\text { consideration by } \\
\text { the Experts in the } \\
\text { Phase } 2 \text { stage }\end{array}$ & $\begin{array}{l}\text { The panel will be provided } \\
\text { with: } \\
\text { - A detailed explanation of } \\
\text { the model and its } \\
\text { development including an } \\
\text { explanation of the } \\
\text { specific issues that } \\
\text { emerged during phase } 1 \\
\text { of the research. } \\
\text { A revised series of CMM } \\
\text { matrices which will seek } \\
\text { comment on the general } \\
\text { level of maturity of the } \\
\text { industry rather than the } \\
\text { individual project focus of } \\
\text { the Phase } 1 \text { research. }\end{array}$ & $\begin{array}{l}\text { The panel will be provided with; } \\
\text { - A detailed report on the } \\
\text { outcome of the first round of } \\
\text { the Delphi process } \\
\text { identifying common themes } \\
\text { and particular differences. } \\
\text { A further series of questions } \\
\text { that explore the differences } \\
\text { in particular to understand } \\
\text { whether these differences } \\
\text { are real and the impact that } \\
\text { this might have in the } \\
\text { development of a general } \\
\text { model for the better } \\
\text { management of } \mathrm{VfM} \text {. }\end{array}$ & $\begin{array}{l}\text { The results for Round } 2 \text { and } \\
\text { Round } 3 \text {, if considered to be } \\
\text { necessary. }\end{array}$ \\
\hline
\end{tabular}


Figure 4.4 (continued) Planned sequence for the Research Exercise - (actual sequence of documents generated are noted at foot of table)

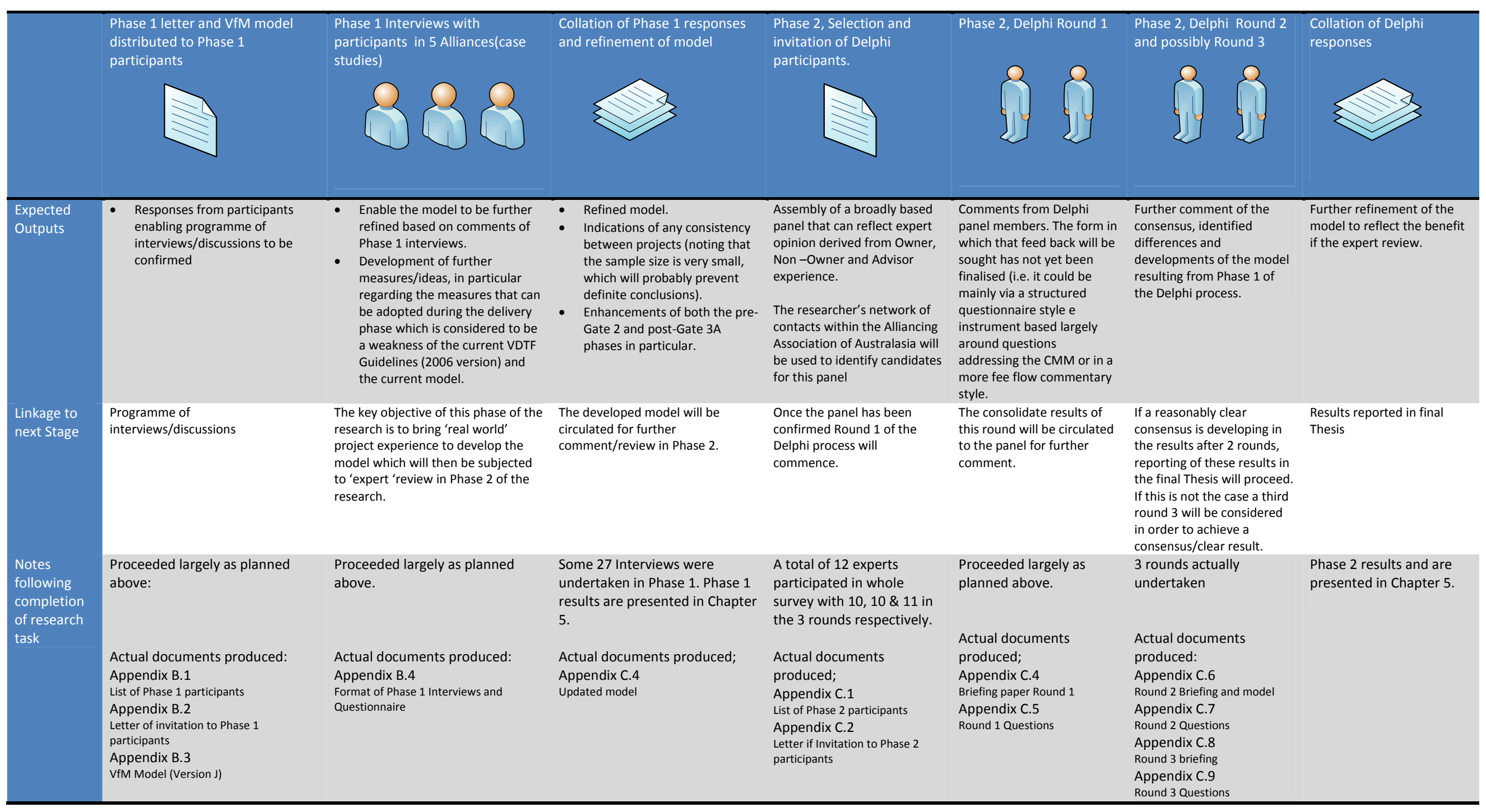




\section{Chapter 5 - Phase 1 Research Findings}

'Research is to see what everybody else has seen, and to think what nobody else has thought'.

Albert Szent-Gyorgyi

\subsection{Introduction to this Chapter}

This chapter presents the findings of Phase 1 of the research undertaken based on the methodology described in some detail earlier in Chapter 4. The research undertaken was actually divided into two phases, the content of which are briefly summarised below to refresh the context of the findings. The purpose of this Chapter is to report the data collected in Phase 1 and to discuss the interpretation if this data.

In order to clearly distinguish between factual information and the interpretative content of this chapter, the latter is presented in italicised blue coloured text.

Phase 1 involved twenty seven interviews with representatives of four project alliances plus one program alliance which consisted of three projects. These interviews sought the views of the participants on;

- the meaning of the term VfM;

- their views on whether $\mathrm{VFM}$ had been achieved in the alliance in which they were participating; and

- their comments on the manner in which VfM had been documented.

At the conclusion of each of these interviews the participants were asked to complete a questionnaire which posed a series of questions regarding

- the treatment of VfM in the particular alliance in which the individual was involved;

- the VfM 'culture' of the organisation from which the participant originated; and

- the respondent's comments on the preliminary 'VfM/BV for Project Alliance' model that had been developed by the researcher.

Phase 2 of the research involved using a three round Delphi Survey process to obtain comments of a panel of experts on the VFM model which was updated following completion of Phase 1. The findings of this phase of the research are presented in Chapter 6. 
As indicated above, this chapter presents both the data collected during Phase 1 and an interpretation of this material. The table below distinguishes between sections of the text which present either the data collected, or provide a discussion which interprets the perceived meaning of this data.

Further details regarding the breakdown of the responses gathered through the questionnaire are contained in a series of charts in Appendix D.

\section{Table 5.1 Data/Discussion coverage for Chapter 5}

\begin{tabular}{|c|c|c|}
\hline Section & Data & Discussion \\
\hline Phase 1 Interviews & 5.2 & 5.3 \\
\hline Issues addressed in VfM Reviews (Question A). & 5.4 .1 & 5.4 .2 \\
\hline $\begin{array}{l}\text { Level of Maturity (LOM) in the consideration of VfM through the } \\
\text { project lifecycle (Questions B to G). }\end{array}$ & 5.4 .3 & \\
\hline $\begin{array}{l}\text { Level of Maturity (LOM) in the consideration of VfM through the } \\
\text { project lifecycle (Questions B, C and D). }\end{array}$ & & 5.4 .4 \\
\hline $\begin{array}{l}\text { General conclusions from feedback relating the consideration of } \\
\text { feedback by alliance. }\end{array}$ & & 5.4 .5 \\
\hline $\begin{array}{l}\text { Level of Maturity (LOM) in the consideration of VfM through the } \\
\text { project lifecycle (Questions E, F and G). }\end{array}$ & & 5.4 .6 \\
\hline $\begin{array}{l}\text { General conclusions from feedback relating the consideration of } \\
\text { feedback by home organisation. }\end{array}$ & & 5.4 .7 \\
\hline $\begin{array}{l}\text { Responses to open questions regarding the preliminary VfM } \\
\text { Framework/model }\end{array}$ & 5.4 .8 & 5.4 .8 \\
\hline
\end{tabular}

Section 5.5 contains a summary of the findings of Phase 1 and Section 5.6 summarises the content of this Chapter.

\subsection{Phase 1 Interviews}

As explained earlier in Chapter 4, Phase 1 represented the first of two data gathering stages of the research and involved a series of some twenty-seven interviews with participants in three alliances (four project alliances and one program alliance, which in turn involved three separate projects). A listing of the interviews undertaken is summarised in Appendix B.1, although the identity of the individuals is not revealed for reasons of confidentiality. The format of the interview was as described in the documents contained in Appendix B.4. This document was distributed to each participant. 
During the interviews the participants were asked to explain whether they believed VfM was achieved in the alliance in which they were participating or had participated in and whether VfM had been demonstrated. A number of these oral responses are listed in Tables 5.2 to 5.6 below which respectively address the five alliances studied.

In providing such responses a number of the participants provided a description of what they believed constituted VfM and these included some interesting and varied definitions of the concept of value and VfM. Some of these observations and other comments that were relevant to the treatment of VfM in the specific alliance are also contained in Tables 5.2 to 5.6.

The interviews fulfilled two functions, firstly they presented an opportunity for an in-depth conversation with key members of a range of alliance projects. These conversations explored the concept of VfM in some depth and the manner in which the issue had been addressed on the projects concerned. Secondly, they enabled the researcher to brief the participants prior to the subsequent completion of the questionnaire including an explanation of the philosophy and structure of the preliminary VfM model.

Both the preliminary VfM Model and the questionnaire were presented to the participants during the course of the interview. The structure of the preliminary model is summarised in Table 5.7 below and the main questions posed on the model are listed in Table 5.8 below. 


\section{Table 5.2 Alliance Blue (Railway works) - Comments from Phase 1 Participants (At the time of the interview this project/s were still under construction)}

\begin{tabular}{|c|c|c|c|c|}
\hline Participants & Organisation & $\begin{array}{l}\text { Do you believe that VfM was } \\
\text { achieved? }\end{array}$ & Was VfM demonstrated/documented? & Definitions of VfM and other comments \\
\hline Blue 1 & Constructor & $\begin{array}{l}\text { VfM was certainly achieved in the } \\
\text { Alliance. } \\
\text { Situation varies between the various } \\
\text { projects in the program alliance. }\end{array}$ & $\begin{array}{l}\text { A best value report was prepared for each TOC to be } \\
\text { submitted to the Owner. This was prepared by economist } \\
\text { who considered the broader benefits of each project. }\end{array}$ & $\begin{array}{l}\text { VFM not necessarily the same thing as best value. VfM assumes a rather narrow financial } \\
\text { base of assessment whist best value takes a more global approach. }\end{array}$ \\
\hline Blue 2 & Constructor & $\begin{array}{l}\text { Yes, things have been done that } \\
\text { would not have happened through a } \\
\text { D\&C approach }\end{array}$ & $\begin{array}{l}\text { The demonstration of VfM has been a struggle. } \\
\text { The alliance approach was suited to an environment in } \\
\text { which resources were scarce when the work started. } \\
\text { The rate of delivery could not have been achieved by } \\
\text { traditional models. }\end{array}$ & $\begin{array}{l}\text { Independent estimates have been of very limited value in demonstrating VfM. They simply } \\
\text { check unit rates and do not assess whether the 'right' project has been developed for } \\
\text { construction. Alliances have the flexibility to change the project to suit the Owners } \\
\text { requirements in a way that other procurement approaches are rarely able to match. }\end{array}$ \\
\hline Blue 3 & Other NOP & $\begin{array}{l}\text { Yes, in comparison to the outcome } \\
\text { that would have been achieved by } \\
\text { other models. }\end{array}$ & $\begin{array}{l}\text { Reported monthly on best value when relevant. } \\
\text { Final Best Value report under preparation. Best value } \\
\text { approach gives stronger consideration of whole of life costs } \\
\text { rather than focus solely on capital costs. } \\
\text { A number of problems arose and were 'fixed' as 'value-adds' } \\
\text { that would not have been 'included' under any other } \\
\text { procurement model. }\end{array}$ & $\begin{array}{l}\text { Rail project TOC } \$ 230 \mathrm{~m} \text {, brownfields project yet to be determined at the time of the } \\
\text { interview. } \\
\text { Major innovations occurred prior to settling TOC which made a major contribution to VfM } \\
\text { and saving passed to Owner alone. } \\
\text { The alliance approach has the flexibility to deliver the best solution whilst the D\&C model } \\
\text { can proceed with the 'wrong' solution due the contractual positions created within the } \\
\text { contract. }\end{array}$ \\
\hline Blue 4 & Constructor & $\begin{array}{l}\text { Yes, if this had been a D\&C project } \\
\text { each change would have had a } \\
\text { significant time impact. }\end{array}$ & $\begin{array}{l}\text { A best value register was maintained. } \\
\text { A best value report will be produced at the end of the } \\
\text { project. } \\
\text { Through the alliance model a total realignment, two new } \\
\text { stations, additional roadwork's, power upgrade and the } \\
\text { elimination of a level crossing were agreed. It is very unlikely } \\
\text { that this would have been accommodated in any other } \\
\text { delivery model. }\end{array}$ & $\begin{array}{l}\text { Rail Project initial TOC } \$ 240 \mathrm{~m} \text {, final TOC } \$ 280 \mathrm{~m}, A O C \text { yet to be determined at the time of the } \\
\text { interview. } \\
\text { Legacy issues and options for the future are also important matters to be considering in } \\
\text { assessing best value. } \\
\text { Such complex projects delivered under the D\&C model have, in the past, often resulted in the } \\
\text { parties being tied up for two years in claims. Have we all forgotten this? }\end{array}$ \\
\hline Blue 5 & Owner & $\begin{array}{l}\text { How do you measure it? } \\
\text { Have we achieved what we w } \\
\text { The alliance should deliver: } \\
\text { - Value for program } \\
\text { - Learning process } \\
\text { - Development of relationships } \\
\text { - Mature behaviour in relationship } \\
\text { - Extend the relationship concept } \\
\text { anted from the program? }\end{array}$ & $\begin{array}{l}\text { Best value was included in regular reporting. However, there } \\
\text { was no regular format and there was a tendency to report } \\
\text { good news stories around innovation. }\end{array}$ & $\begin{array}{l}\text { The Industry has not got it right yet! Are we achieving the same or better outcomes than } \\
\text { other delivery methods? } \\
\text { We choose the alliance method due to risk profile, uncertainty in scope, stakeholder } \\
\text { issues/complexity. However, we then judge success by conventional cost comparison against } \\
\text { another delivery method and do not assess the success of the project based on the criteria } \\
\text { that were the justification for establishing the alliance in the first place! } \\
\text { Such an analysis will then verify whether the alliance was selected for the right reason. }\end{array}$ \\
\hline Blue 6 & Constructor & Yes & $\begin{array}{l}\text { Monthly report incorporated section of Best Value, a term } \\
\text { preferred to VfM. } \\
\text { Final report being prepared prior to completion of the } \\
\text { works. }\end{array}$ & $\begin{array}{l}\text { Rail Project initial TOC } \$ 166 \mathrm{~m} \text {, final TOC, AOC yet to be determined at the time of the } \\
\text { interview. } \\
\text { The primary contribution to VfM of the Alliance model is the ability to respond to radical } \\
\text { changes of scope. }\end{array}$ \\
\hline
\end{tabular}


Table 5.3 Alliance Red (Water treatment works) - Comments from Phase 1 Participants (At the time of the interview construction of this project was complete)

\begin{tabular}{|c|c|c|c|c|}
\hline Participants & Organisation & $\begin{array}{l}\text { Do you believe that VfM } \\
\text { was achieved? }\end{array}$ & Was VfM demonstrated/documented? & Definitions of VfM and other comments \\
\hline Red 1 & Constructor & Absolutely, Yes! & $\begin{array}{l}\text { There was a date determined by legislation when domestic supply } \\
\text { could not be used for industrial purposes and this drove the program. } \\
\text { Water had to be delivered from the plant within twelve months and } \\
\text { this date was non-negotiable. }\end{array}$ & $\begin{array}{l}\text { Extreme necessity of delivery of water by due date. } \\
\text { Benchmark costs high but requirement was for the earliest possible date. }\end{array}$ \\
\hline Red 2 & Constructor & $\begin{array}{l}\text { Yes - in the context of what } \\
\text { value represented in that } \\
\text { project. The project was not } \\
\text { cheap but was very valuable } \\
\text { to the Owner for the project } \\
\text { to be delivered as quickly as } \\
\text { possible. }\end{array}$ & $\begin{array}{l}\text { A close out report was produced after completion of the project. The } \\
\text { cost of the project was less than the combined TOC's for both phases } \\
\text { of the project. }\end{array}$ & $\begin{array}{l}\text { If this project had been bid conventionally the price would have been very high (much higher } \\
\text { that the TOC) due to the extreme time risk. } \\
\text { The political value for having the project completed in the shortest possible time was huge. } \\
\text { This was effectively a cost reimbursable EPCM contract. }\end{array}$ \\
\hline $\operatorname{Red} 3$ & Other NOP & $\begin{array}{l}\text { In the circumstances, Yes! } \\
\text { Could have been better VfM } \\
\text { in different circumstances. }\end{array}$ & $\begin{array}{l}\text { Overall both stages of the project were delivered under the combined } \\
\text { TOC. Based on this criterion, VfM was achieved. } \\
\text { There was little contemporary documentation of VfM as the job } \\
\text { proceeded }\end{array}$ & $\begin{array}{l}\text { In this project, value was represented by getting the job done on time. } \\
\text { VfM does not emerge in the later stages if it is not laid down in the foundations of the } \\
\text { project. } \\
\text { After the event, when the project was not actually needed to address the emergency } \\
\text { situation anticipated, the Owner felt that they had paid more than they needed to. }\end{array}$ \\
\hline Red 4 & Other NOP & $\begin{array}{l}\text { Yes - but value needs to be } \\
\text { carefully defined. } \\
\text { In the available time, } \\
\text { market conditions and } \\
\text { other circumstances. VfM } \\
\text { was achieved }\end{array}$ & $\begin{array}{l}\text { The focus of the project was delivery and little contemporary VfM } \\
\text { documentation was produced. } \\
\text { Alliance team produced a close out report addressing value at the } \\
\text { need of the project. }\end{array}$ & $\begin{array}{l}\text { When dealing with suppliers the question 'by how much can the price be reduced' was not } \\
\text { asked. The question asked was 'by how much can the delivery time be reduced'? }\end{array}$ \\
\hline Red 5 & Constructor & Yes & $\begin{array}{l}\text { Projects are not as well documented these days. } \\
\text { The risk register was used as a VFM tool but there was little recording } \\
\text { of VfM matters. }\end{array}$ & $\begin{array}{l}\text { VfM could have been better but project was well suited to an alliance as the scope was not } \\
\text { well defined. } \\
\text { Alliances were previously more 'fluffy' and used too many times i.e. for projects not really } \\
\text { suited to alliances. However, they now have a sharper more commercial (VfM) edge. } \\
\text { The important issued were time and safety. Waste and to a degree quality were not primary } \\
\text { concerns. }\end{array}$ \\
\hline
\end{tabular}




\section{Table 5.4 Alliance Green (Interurban road works) - Comments from Phase 1 Participants (At the time of the interview this project was still under construction)}

\begin{tabular}{|c|c|c|c|c|}
\hline Participants & Organisation & $\begin{array}{l}\text { Do you believe that VfM } \\
\text { was achieved? }\end{array}$ & Was VfM demonstrated/documented? & Definitions of VFM and other comments \\
\hline Green 1 & Constructor & Yes - but demonstrated, No & $\begin{array}{l}\text { Clarity had been sought from the owner regarding reporting } \\
\text { requirements but little direction had been given. } \\
\text { Client did not reveal budget until after the TOC was tabled. There was } \\
\text { a substantial difference between the two figures } \$ 390 \mathrm{~m} \text { versus } \$ 520 \mathrm{~m} \\
\text { and a radical reduction in scope was required. }\end{array}$ & $\begin{array}{l}\text { The project was relatively straight forward other than the timeframe which was dictated by } \\
\text { funding arrangements i.e. if delivered after a certain date some of the funding would not be } \\
\text { guaranteed. } \\
\text { Substantial difference between the TOC and original budget which was apparently old and } \\
\text { had not been adequately updated. Scope reduction required before job could proceed. }\end{array}$ \\
\hline Green 2 & Owner & $\begin{array}{l}\text { Well Yes, were heading } \\
\text { there! }\end{array}$ & $\begin{array}{l}\text { Documentation is still in progress. Collecting together information. } \\
\text { Outputs from workshops and changes documented. } \\
\text { Incentives for good ideas - useful at site level. }\end{array}$ & $\begin{array}{l}\text { What constitutes VfM - normal thing to seek improvement but VfM is to be distinguished } \\
\text { from simply improvement which is 'normal practice'. } \\
\text { The RTA used a Peer Review team who were separate from the alliance to assess technical } \\
\text { issues. } \\
\text { Job not complex but the timeframe was the challenge. Weather exceptionally inclement. } \\
\text { Savings on TOC available to performance pool. }\end{array}$ \\
\hline Green 3 & Constructor & $\begin{array}{l}\text { Yes, are there things that } \\
\text { could have been done } \\
\text { better-yes! }\end{array}$ & $\begin{array}{l}\text { Started the process of documenting VfM during project as it was } \\
\text { known that a VfM Report required at the end of job. } \\
\text { A VfM Champion recorded issues that were seen as representing VfM } \\
\text { earlier in the project but the Champion left. } \\
\text { The Client did not seem to know what they wanted in the final report, } \\
\text { as they did not necessarily understand what represented VfM. }\end{array}$ & $\begin{array}{l}\text { VfM - where we bring our skills to bear to do things better than before. VfM - things that } \\
\text { are done to improve the TOC position. } \\
\text { There have been innovations both pre and post TOC but there was no holding back pre TOC } \\
\text { with people who had lost of experience. } \\
\text { Ideas should be taken from any source 'Steal with Pride!' }\end{array}$ \\
\hline Green 4 & Other NOP & $\begin{array}{l}\text { Greater than BAU was } \\
\text { achieved but nothing } \\
\text { outstanding1 }\end{array}$ & $\begin{array}{l}\text { Documentation of VfM has been relatively limited. } \\
\text { A weekly innovation award was offered early in the project (gift } \\
\text { voucher but this drooped off over time. } \\
\text { The Client did not reveal the budget until after the TOC had been } \\
\text { developed which did not assist in building trust and mutual respect. }\end{array}$ & $\begin{array}{l}\text { The ALT has been relatively uninvolved in the conduct of the alliance. The Owner has } \\
\text { retained most of the decision making power and has given limited delegation to the ALT. } \\
\text { Many members of the Alliance, Owner, Constructor and NOP representatives were relatively } \\
\text { inexperienced in alliances. }\end{array}$ \\
\hline Green 5 & Constructor & $\begin{array}{l}\text { Yes, I think it has, but } \\
\text { recording is another thing! }\end{array}$ & $\begin{array}{l}\text { There is relatively little VfM documentation despite KPI for a VfM } \\
\text { document. There will be a report produced after the event but } \\
\text { documentation of the design process and VfM justification for changes } \\
\text { is minimal. }\end{array}$ & $\begin{array}{l}\text { Primary reason for approaching as an alliance was the tight time frame due to funding } \\
\text { timetable, otherwise the scope and nature of the project would have been suited to a D\&C } \\
\text { model. } \\
\text { The project has been affected by exceptionally inclement weather which is a joint risk under } \\
\text { the alliance but would have been the Contractor's risk under a D\&C contract. }\end{array}$ \\
\hline Green 6 & Other NOP & $\begin{array}{l}\text { Hard to tell as no specific } \\
\text { measures of VfM were } \\
\text { developed. }\end{array}$ & $\begin{array}{l}\text { There was a substantial difference between the budget, not declared } \\
\text { by the Owner and the initial TOC. A more open approach to releasing } \\
\text { the budget prior to the development of the TOC would have allowed } \\
\text { the two to be reconciled and VFM. }\end{array}$ & $\begin{array}{l}\text { The adverse weather resulted in close to } 50 \% \text { of the time being lost rather than } 25 \% \text { as } \\
\text { expected. In a D\&C contract, this would have resulted in contractual claims and negotiations } \\
\text { even if the adverse weather had been allocated as a risk to the Contractor. } \\
\text { It was a shared risk under an alliance. }\end{array}$ \\
\hline
\end{tabular}


Table 5.5 Alliance Purple (Dam works) - Comments from Phase 1 Participants (At the time of the interview this project was still under construction)

\begin{tabular}{|c|c|c|c|c|}
\hline Participants & Organisation & Do you believe that VfM was achieved? & Was VfM demonstrated/documented? & Definitions of VFM and other comments \\
\hline Purple 1 & Constructor & $\begin{array}{l}\text { Yes, I do! } \\
\text { The project had many uncertainties and a tight } \\
\text { program which made it well suited to the } \\
\text { alliance model. }\end{array}$ & $\begin{array}{l}\text { Yes, a value and Innovations Register was being } \\
\text { maintained. } \\
\text { A final VfM report would be produced. }\end{array}$ & $\begin{array}{l}\text { Early involvement of the Contractor due to the need to complete at an early date to secure a } \\
\text { proportion of the funding. } \\
\text { Full team involved in the feasibility study and EIS. } \\
\text { The alliance model allowed the contractors best people to focus on delivering the project } \\
\text { and not be distracted by preparing contractual arguments. } \\
\text { Very complex geotechnical conditions that would have led to extensive claims in a more } \\
\text { conventional contract. }\end{array}$ \\
\hline Purple 2 & Constructor & Ido! & $\begin{array}{l}\text { Project had to address three criteria: } \\
\text { - Flood mitigation } \\
\text { - Increase water supply } \\
\text { Alliance Innove current safety register } \\
\text { Expectations of a close out VfM Report. }\end{array}$ & VfM - value used interchangeably \\
\hline Purple 3 & Other NOP & $\begin{array}{l}\text { Definitely, the challenge is selling that } \\
\text { message! }\end{array}$ & $\begin{array}{l}\text { An Innovations Report is being developed which } \\
\text { will tell the story. }\end{array}$ & $\begin{array}{l}\text { The project was committed at a low level of design }(30 \%) \text { and issues found in the field would } \\
\text { have resulted in parties being in court under a D\&C model. } \\
\text { Change of Owner organisation during delivery has resulted in some history being lost. }\end{array}$ \\
\hline Purple 4 & Owner & Yes- as a perception. & $\begin{array}{l}\text { Ability to demonstrate is poor, no established } \\
\text { framework to track innovations - discussing but } \\
\text { no-one interested. }\end{array}$ & $\begin{array}{l}\text { Why perceived VfM? - high quality work, good people, independent technical panel } \\
\text { assessing, good safety culture, non-cost KPI's going well. }\end{array}$ \\
\hline Purple 5 & Owner & $\begin{array}{l}\text { Yes! This was a single TOC which rings alarm } \\
\text { bells for some members of the Owners } \\
\text { organisation, but was done for timing reasons. }\end{array}$ & $\begin{array}{l}\text { We followed an established procedure to } \\
\text { systematically analysis the most suitable } \\
\text { procurement process. This helps to document the } \\
\text { reasons why an alliance was selected. } \\
\text { Governance review undertaken by external } \\
\text { consultant. } \\
\text { Risk and Opportunity Register and Innovations } \\
\text { Register both maintained by the alliance. }\end{array}$ & $\begin{array}{l}\text { In the discussion about VfM in alliance contracts people have forgotten about all the costs } \\
\text { that were previously involved in adversarial behaviours. } \\
\text { The model was sufficiently flexible to accommodate change of Owner. Not many models } \\
\text { would have been able to do this. }\end{array}$ \\
\hline Purple 6 & Constructor & Yes & $\begin{array}{l}\text { Unless we can demonstrate that VfM has been } \\
\text { achieved we will be compelled to go back to the } \\
\text { old ways i.e. adversarial behaviours which were } \\
\text { never priced. }\end{array}$ & $\begin{array}{l}\text { There was a change of Owner organisation during the course of the project. However, } \\
\text { Owners have participated fully in the delivery of the project. } \\
\text { Funding of the project was linked to a very tight time frame. } \\
\text { TOC approximately } \$ 400 \mathrm{~m} \text { with an original budget of approximately } \$ 100 \mathrm{~m} \text {. }\end{array}$ \\
\hline
\end{tabular}


Table 5.6 Alliance Black (Public transport infrastructure) - Comments from Phase 1 Participants (At the time of the interview construction of this project was complete)

\begin{tabular}{|c|c|c|c|c|}
\hline Participants & Organisation & Do you believe that VfM was achieved? & Was VfM demonstrated/documented? & Definitions of VfM and other comments \\
\hline Black 1 & Constructor & To a certain extent-Yes & $\begin{array}{l}\text { VfM was an agenda item for all meetings and } \\
\text { mentioned regularly in the early stages of the } \\
\text { project but not as frequently in the later part of } \\
\text { the project, } \\
\text { A specific VfM Champion was active in the early } \\
\text { stages. } \\
\text { Drawing review comment sheets had a VfM } \\
\text { column. } \\
\text { VfM report was being produced following } \\
\text { completion of the project but focus during the } \\
\text { project had been on doing rather than recording. }\end{array}$ & $\begin{array}{l}\text { VfM for Treasury is represented by a low price. } \\
\text { VfM for the Agency is represented by quality of work, lower maintenance costs/whole of life } \\
\text { costs. } \\
\text { The project had consisted of } 3 \text { stages (total value } \$ 306 \mathrm{M} \text { ). First two stages delivered under } \\
\text { TOC but third stage over TOC. In aggregate very close to total TOC. } \\
\text { TOC for third stage had been prepared in haste and without the same level of review. }\end{array}$ \\
\hline Black 2 & Constructor & $\begin{array}{l}\text { Depends on your perspective. I call it value for } \\
\text { Client. It is the Client who is sending the money } \\
\text { and they achieved value on this project. }\end{array}$ & $\begin{array}{l}\text { Draft VfM report has been compiled following } \\
\text { completion of the project. Report has tracked } \\
\text { differences between budget and final TOC. }\end{array}$ & $\begin{array}{l}\text { Demonstration of value includes cost value (Treasury interest) plus the quality of the product } \\
\text { that has been delivered. } \\
\text { Need to establish non-cost value using appropriate KRA's. }\end{array}$ \\
\hline Black 3 & Other NOP & VfM for the Owner, yes absolutely! & $\begin{array}{l}\text { Risk and Opportunity Register was maintained } \\
\text { during the project. This was a strong discipline } \\
\text { initially but not necessarily maintained through } \\
\text { the whole project. } \\
\text { However, very complex stakeholder issues were } \\
\text { addressed well. It is unclear that they could have } \\
\text { been handled as well by any other approach. }\end{array}$ & $\begin{array}{l}\text { The final product developed by the alliance was of very high quality. } \\
\text { The alliance was able to address a number of very complex interface issues that would have } \\
\text { very difficult to accommodate within a traditional delivery approach. } \\
\text { Stages } 1 \text { and } 2 \text { were particularly successful. Stage } 3 \text { was less successful but still delivered a } \\
\text { very good outcome for the Owner. }\end{array}$ \\
\hline Black 4 & Owner & Yes - but proving it is another matter. & $\begin{array}{l}\text { Report produced as an afterthought through a } \\
\text { series of workshops }\end{array}$ & $\begin{array}{l}\text { VfM is being able to demonstrate how much the job has cost and benchmark but also } \\
\text { capturing information about components representing VfM. } \\
\text { Alliances can rapidly react to a changing environment. The flexibility to respond and } \\
\text { accurately price changing circumstances in an open book manner is priceless! }\end{array}$ \\
\hline Black 5 & Constructor & $\begin{array}{l}\text { Yes - The project was ideally suited to the } \\
\text { alliance model i.e. scope relatively undefined }\end{array}$ & $\begin{array}{l}\text { A detailed VfM Report was produced at the end of } \\
\text { the project. }\end{array}$ & $\begin{array}{l}\text { Stages } 1 \text { and } 2 \text { were below the TOC but Stage } 3 \text { exceeded the TOC. There was less innovation } \\
\text { in Stage } 3 \text {. } \\
\text { Contractual letters are not necessary, this allows people to get on with the job and direct } \\
\text { their energy to positive outcomes. }\end{array}$ \\
\hline Black 6 & Other NOP & $\begin{array}{l}\text { I believe that VfM was achieved, but } \\
\text { demonstration is the challenge! }\end{array}$ & $\begin{array}{l}\text { Minimal and there are ongoing discussions in the } \\
\text { industry on how it should be done. } \\
\text { Design changes were well documented which } \\
\text { assists in monitoring the likely AOC. }\end{array}$ & $\begin{array}{l}\text { The real strength of the alliance was the ability to 'work around' changes in political } \\
\text { conditions and new interface issues without contractual claims ensuing. } \\
\text { Less time was available for detailed scrutiny of the TCE for Stage } 3 \text {. }\end{array}$ \\
\hline
\end{tabular}




\subsection{Phase 1 Interviews (Discussion)}

The interviews were time consuming to arrange and hold but provided considerable insight into the thoughts of a broad range of practitioners in the alliance field. Each interview was recorded and subsequently played back, in some cases several times, in order to digest the feedback provided. This material has proved to be very valuable in immersing the researcher in the issues that concern practitioners in the conduct of project alliances. Transcripts were not produced but some of the key messages for each interview are presented in Tables 5.2 to 5.6 relating to each of the alliances approached.

Most practitioners were confident that VfM was being achieved in their respective alliance, although, the majority of respondents indicated that the demonstration and/or documentation of VfM was either poor or at least limited.

The definitions of VfM offered by individuals were quite varied, pointing to the need for a better understood and more universally applied definition in the industry. Additionally, a number of interesting general comments were made regarding the conduct of alliances. The following quotes were seen to be particularly insightful.

- Independent estimates have been of very limited value in demonstrating VfM. They simply check unit rates and do not assess whether the 'right' project has been developed for construction'.

- 'We choose the alliance method due to risk profile, uncertainty in scope, stakeholder issues/complexity. However, we then judge success by conventional cost comparison against another delivery method and do not assess the success of the project based on the criteria that were the justification for establishing the alliance in the first place'!

- In the discussion about VfM in alliance contracts people have forgotten about all the costs that were previously involved in adversarial behaviours'.

- 'Alliances can rapidly react to a changing environment. The flexibility to respond and accurately price changing circumstances in an open book manner is priceless'!

The responses received during the interviews are believed to support the researchers' premise that there needed to be a better established and more methodical approach to addressing VfM in project alliances. 
Table 5.7 Structure of the preliminary VfM/BV Model - (See Appendix B.3 for details)

\begin{tabular}{l|r|l}
\hline STAGE & $\begin{array}{l}\text { VfM/BV } \\
\text { GATE }\end{array}$ & TITLE \\
\hline Strategic need for project & 0 & Strategic Assessment \\
Business case for project & 1 & Business Justification \\
\hline $\begin{array}{l}\text { Procurement strategy } \\
\text { Selection of NoPs }\end{array}$ & 2 & Procurement Strategy \\
\hline TCE approval & 3 A & Select NoPs \\
\hline Readiness for Service & $3 B$ & TCE approval \\
\hline Benefits Evaluation & 4 & Readiness for Service \\
\hline
\end{tabular}

Note:

The terminology described above applied to the preliminary model issued in Phase 1 (see Appendix B.3). This terminology was revised following the feedback obtained in Phases 1 and 2 of the research. The final terminology is described in Chapter 8.

Table 5.8 Questions posed in the Phase 1 Questionnaire (See Appendix B.4 for details)

\begin{tabular}{cl}
\hline Question & Text \\
A & $\begin{array}{l}\text { Were the following issues addressed in a review of VfM at these stages of the } \\
\text { project? (see Table } 5.5 \text { for a listing of these issues) }\end{array}$ \\
B & Is VfM an explicit project objective for the Alliance? \\
C & Are specific measures or procedures in place to ensure that VfM is achieved? \\
D & $\begin{array}{l}\text { Are specific measures in place to ensure that VfM has been demonstrated to } \\
\text { have been achieved? }\end{array}$ \\
E & $\begin{array}{l}\text { Is VfM an explicit project objective for your organisation? } \\
\text { F }\end{array}$ \\
Are specific measures normally in place (within your organisation) to ensure that \\
VfM is achieve?
\end{tabular}


Table 5.9 Issues which were listed in Question A (were the following issues addressed in a review of $\mathrm{VfM}$ at these stages of the project)

\section{CATEGORY}

Social
- Occupational Safety and Health (internal \& community)
- Industry capacity
- Enhance and involve the community

\section{ISSUES}
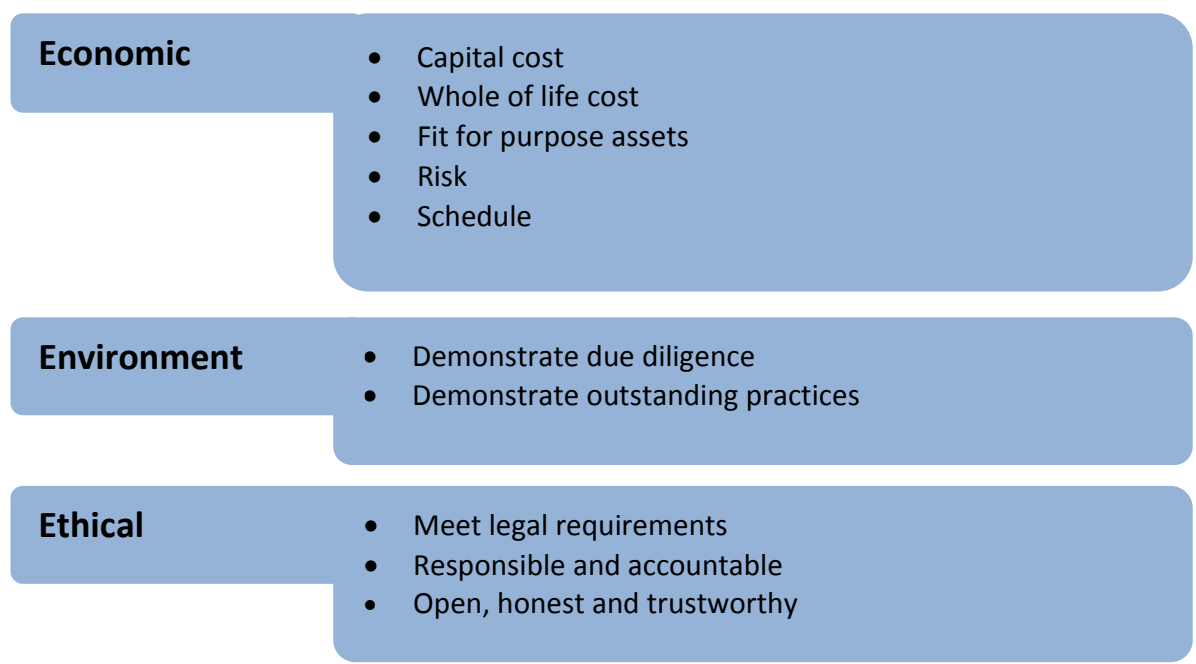

Stakeholder
- Understanding and managing the community

- Understanding and managing customers

- Understanding and managing external stakeholders

- Understanding and managing internal stakeholders

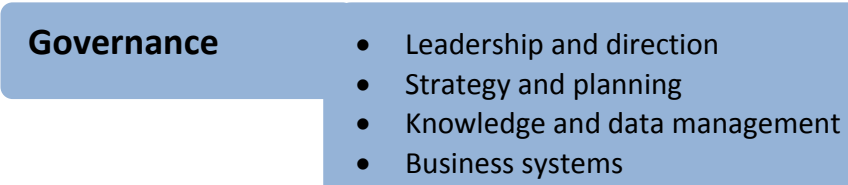

- Knowledge and data management

- Business systems

Source: West Australian Water Corporation Water Scores Guidebook.(WAWC, 2007) 


\subsection{Phase 1 Questionnaire}

The questionnaire (see Appendix B.4) was designed to further investigate the degree to which VfM was a focus of the alliances concerned at each stage of the project lifecycle. Additionally, comments were sought on the preliminary VfM Model. The questions posed in the questionnaire, as listed in Table 5.8 above, related to a number of different matters. Consequently the reporting of the responses obtained and the associated discussion is divided into a number of sub-sections as presented below.

\subsubsection{Issues addressed in VfM Reviews (Question A)}

The first question posed in the questionnaire (Question A) was a general enquiry to determine whether a range of issues had been addressed in any review of VfM at each of the stages of the project lifecycle identified in the model. The respondents were asked to indicate, by circling the appropriate box, whether or not each issue had been considered or alternatively whether the issue was not considered to be applicable.

The issues identified were drawn from a list of twenty two Sustainability Business Principles that had been previously developed by the Water Corporation of Western Australia (WAWC) (2007). These principles had been structured in six dimensions which included outcome and process matters. To access performance against these principles, a series of twenty two benchmarks or 'water scores', as they were termed, were developed by WCWA (see Table 5.9 above).

These benchmarks were adopted as the relevant issues for Question A as they were seen to represent a comprehensive listing of matters that needed to be addressed in delivering a successful alliance and hence providing value to the Owner.

This first question was intended to act as an 'ice breaker' which would introduce the survey and provide a context for the balance of the questions. However, this question provided an abundant source of data, which upon subsequent analysis has yielded some interesting insights into the nature of alliance procurement.

Figure 5.1 shows the overall results for question A. This figure shows the frequency of responses indicating that an issue had been considered in a review of $\mathrm{VFM}$ (positive response) against each of the 22 issues grouped into 6 discrete categories (dimensions), for each of the 7 stages of the project lifecycle identified in the preliminary VfM/BV model. This figure depicts the absolute number of responses (by number), whilst Figure 5.2 presents a 'normalised' response (percentage of respondents). This recognises that there are different numbers of respondents for each stage of the lifecycle. Whilst this is a relatively complex diagram it does provide an overall impression of the 
results for Question A and enables some general findings to be drawn. However, in order to assess the results in more detail, figures are contained within Appendix D (Appendices D.1.1 to Appendix D.1.13) break down these results in 2 distinct ways. Firstly, the results are presented by grouping issues for each VfM Gate. Secondly, the results are presented by the category of issues. It is believed that by presenting these results in the two formats, greater clarity and insight is provided.

Not all respondents have replied to each question. In the case of Question A, this reflects the fact that a number of participants were unable to make comment on earlier stages of the lifecycle given that they were not personally involved at that point. This was particular the case for the Non Owner Participants (NOP's) who would not typically be involved in the project until VfM/BV Gate 2 (Procurement Strategy) had been completed. By contrast, questions relating to Gates 3B (TCE Approval) and 4 (Readiness for Service) have much higher response rates reflecting the fact that all participants in the project are engaged in these later stages of the project. Nevertheless, notwithstanding the number of responses is limited for some of the review points considered, it is believed that the responses obtained provide some valuable insights into VfM issues from parties actively participating in the practice of alliance project delivery. Figures 5.3 and 5.4 below present the positive responses received regarding each issue; both in absolute numbers, and as a percentage of respondents, respectively, grouped by a category of issues. 


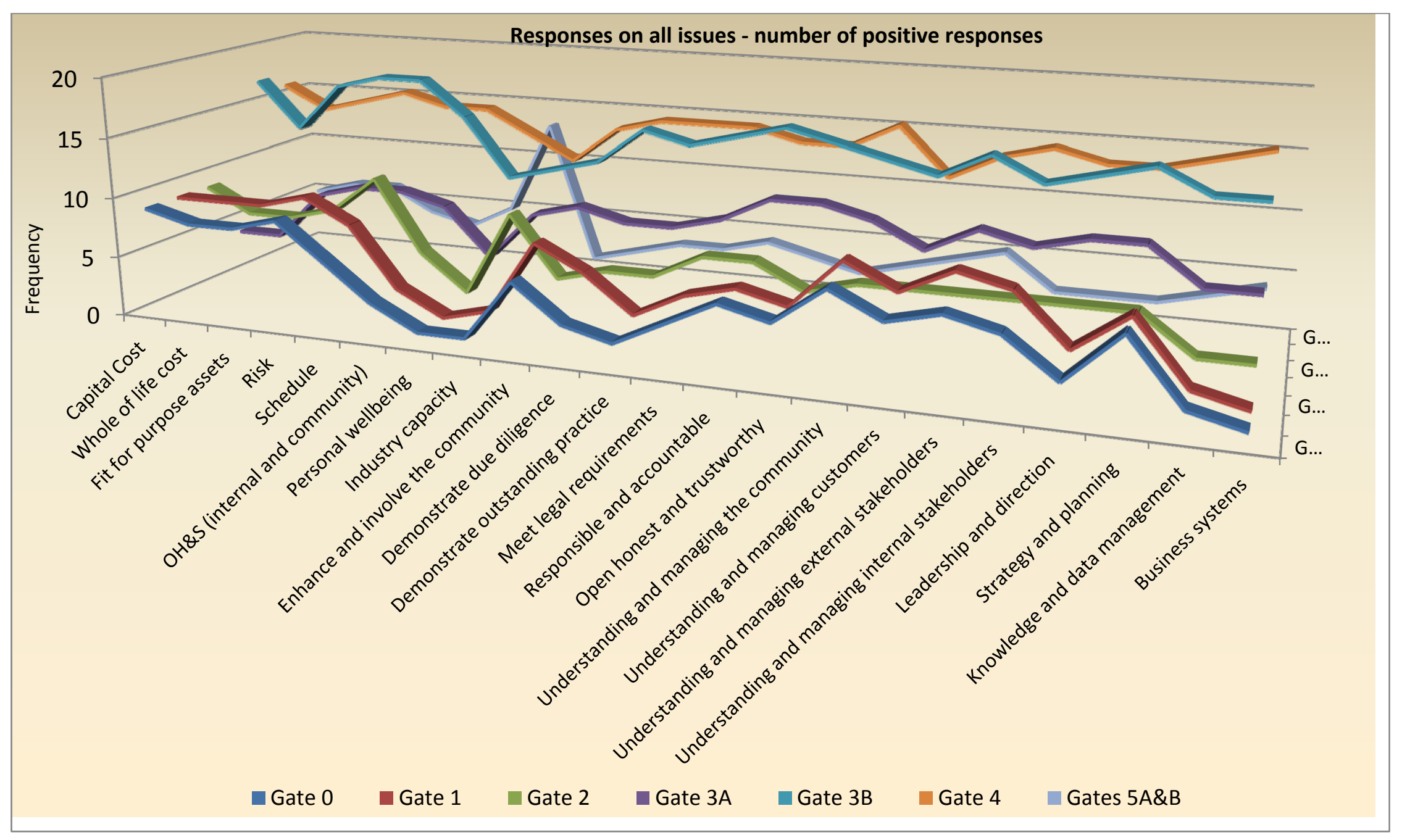




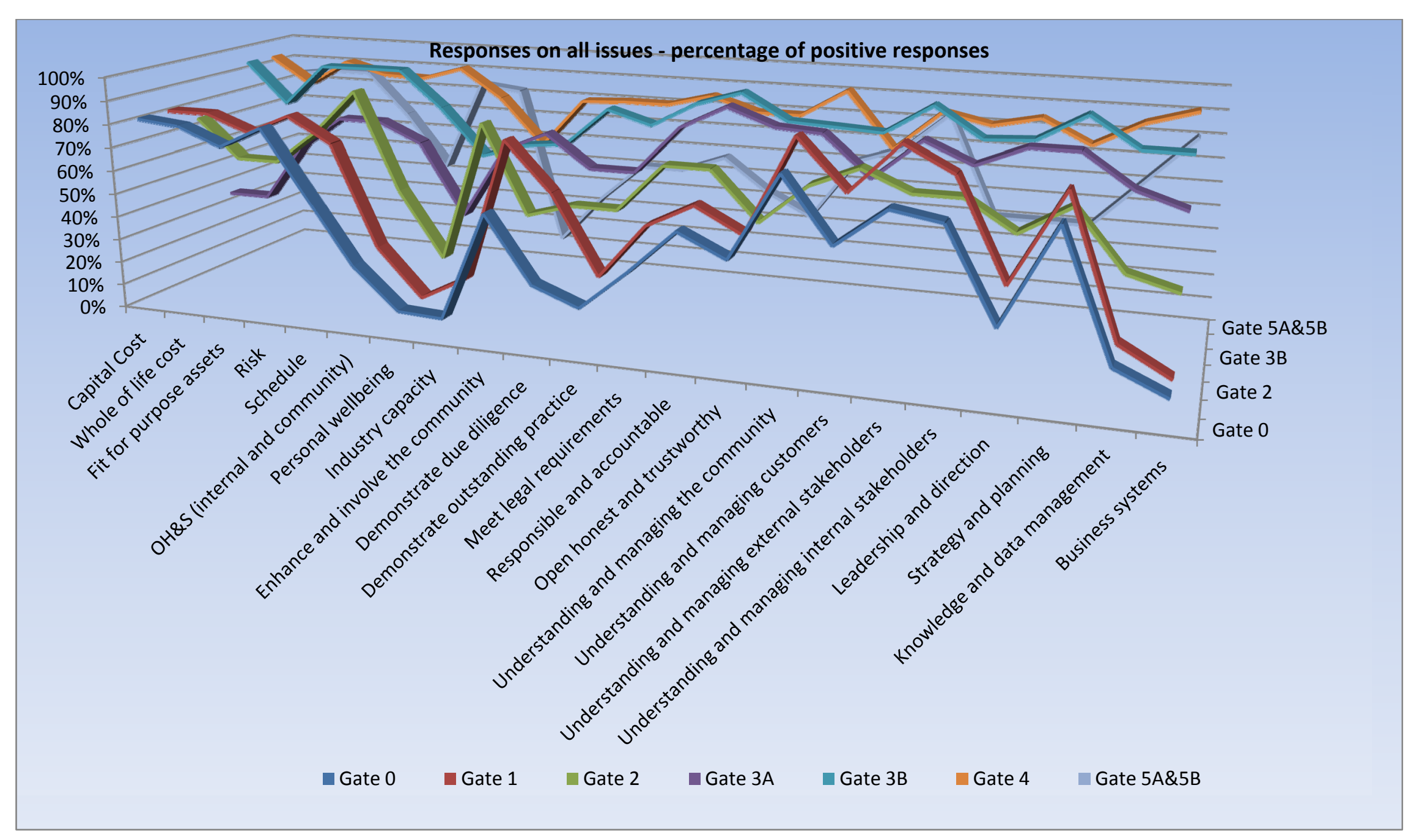

Figure 5.2

Phase 1, Consolidated response: issues considered in VfM reviews, percentage of positive responses 

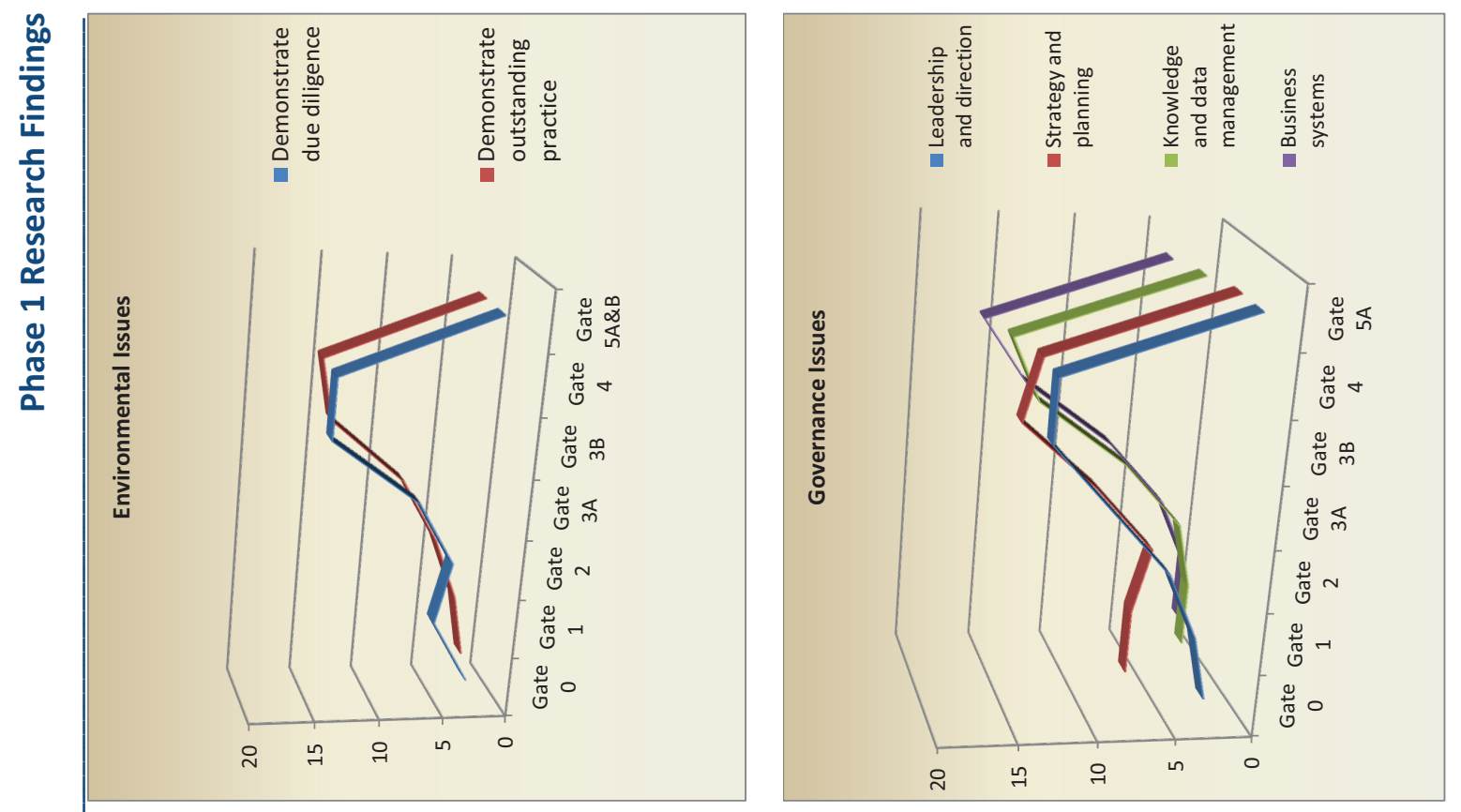

ฐ
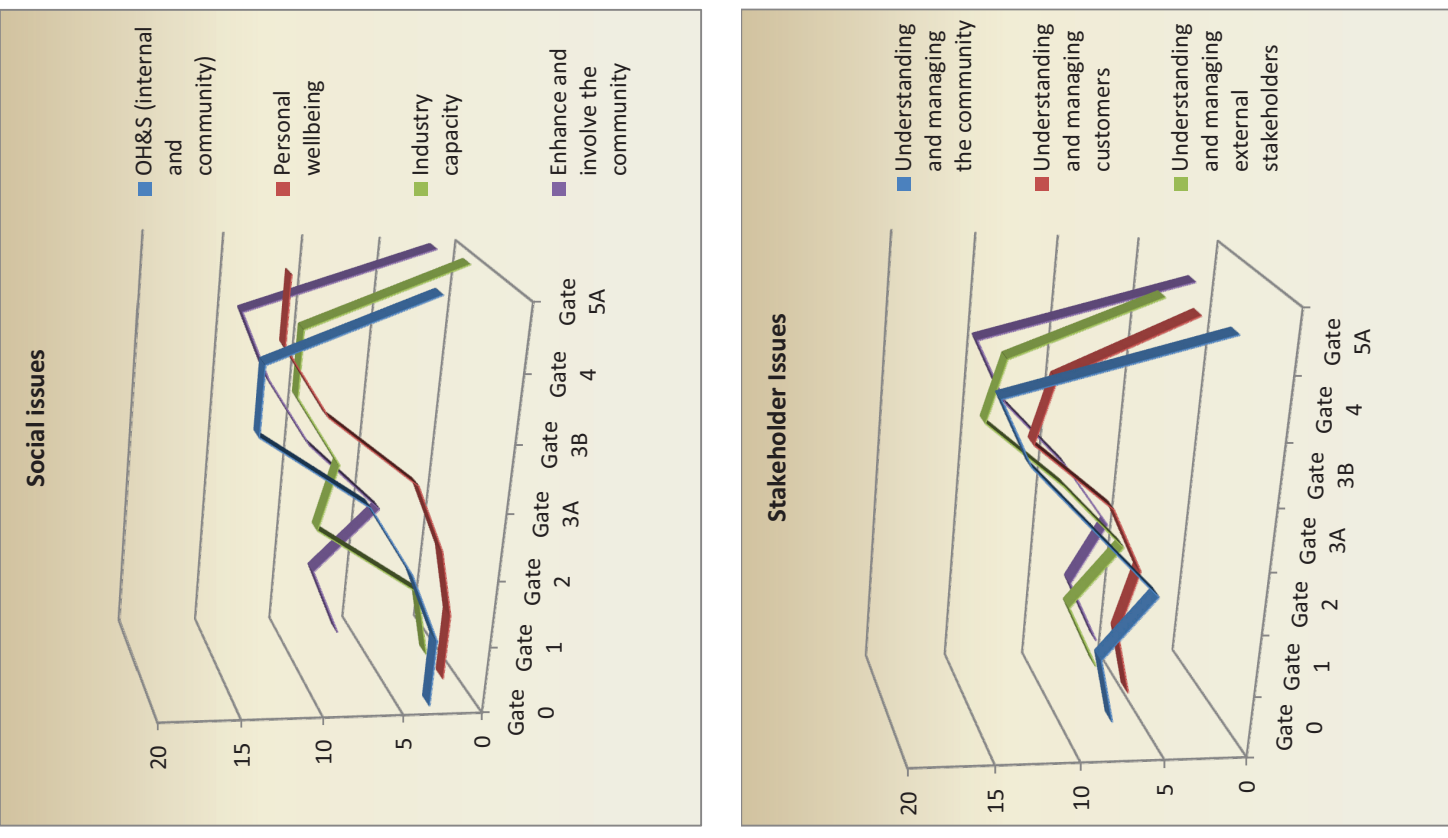

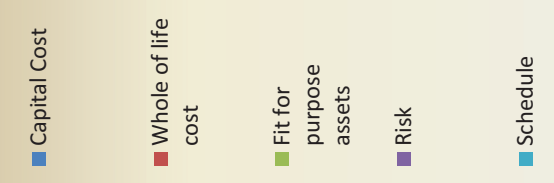

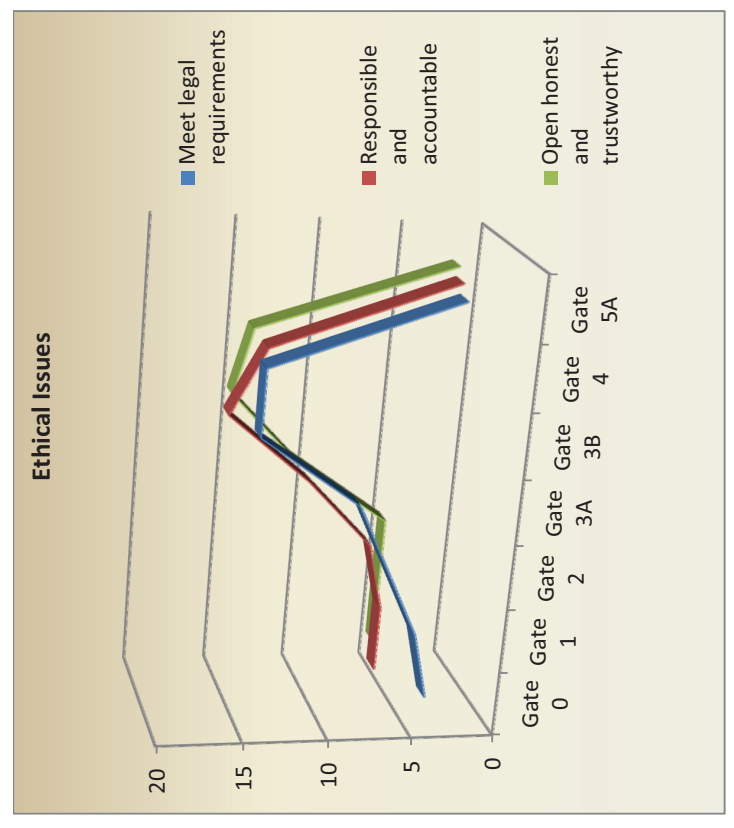

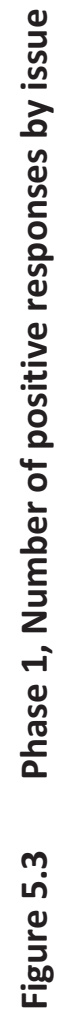



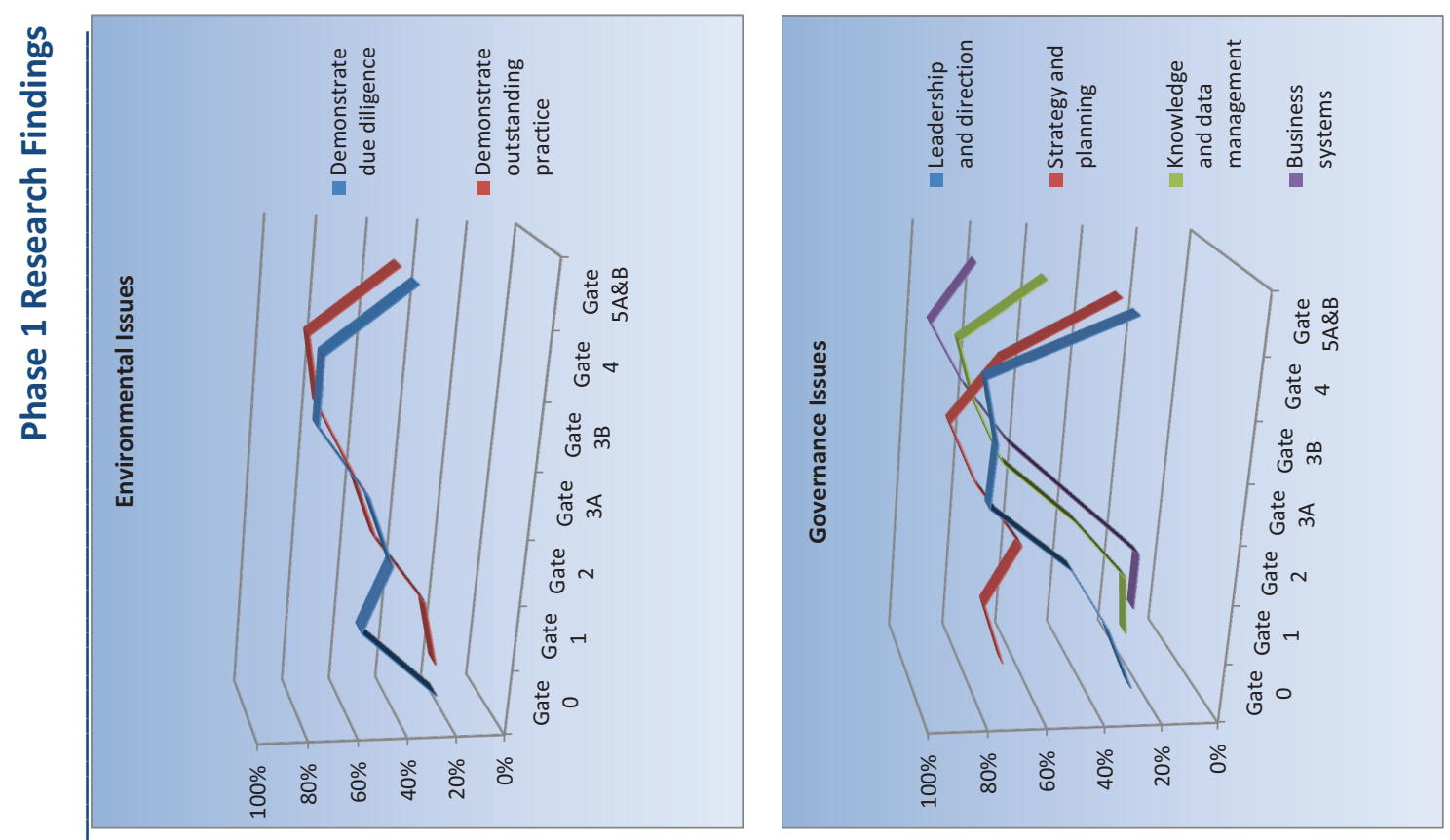

욤
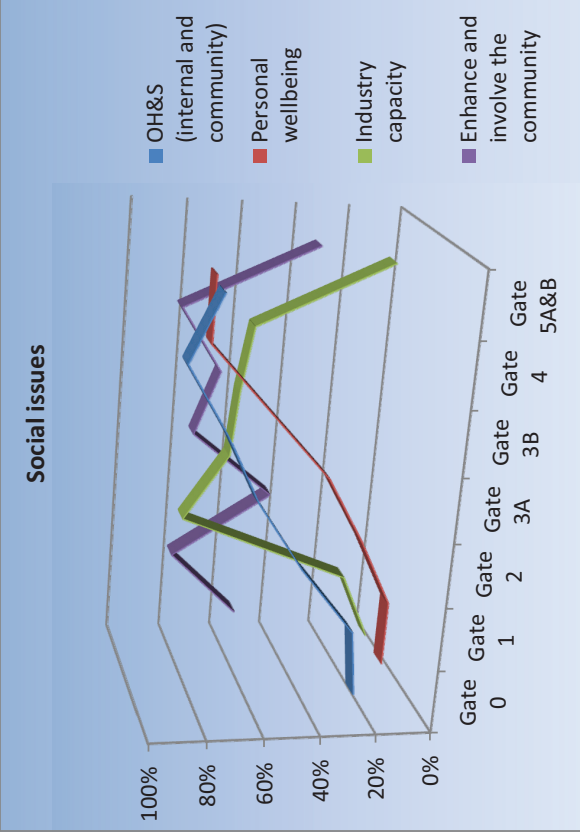

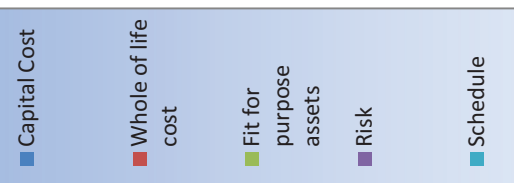

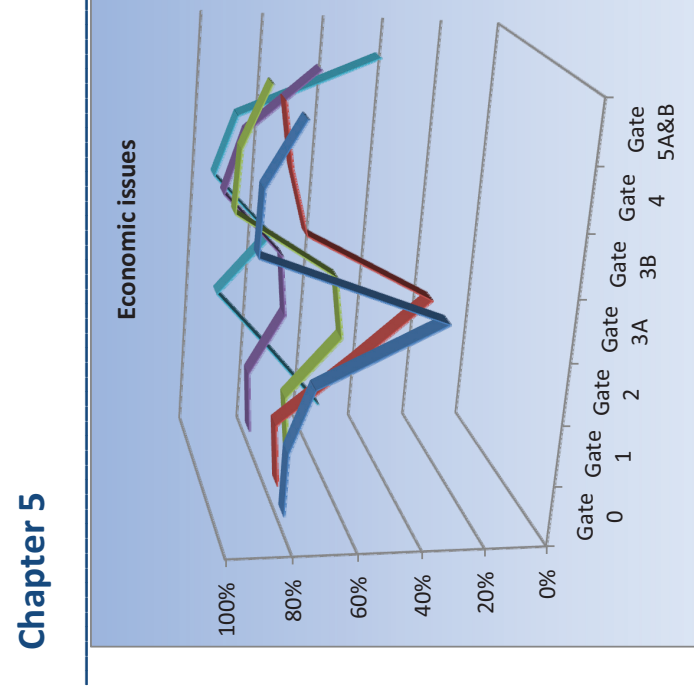

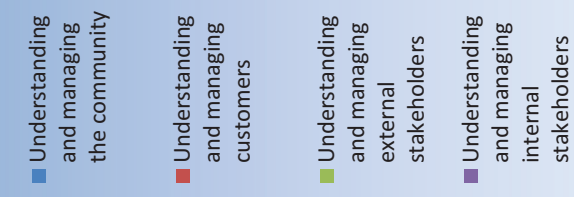

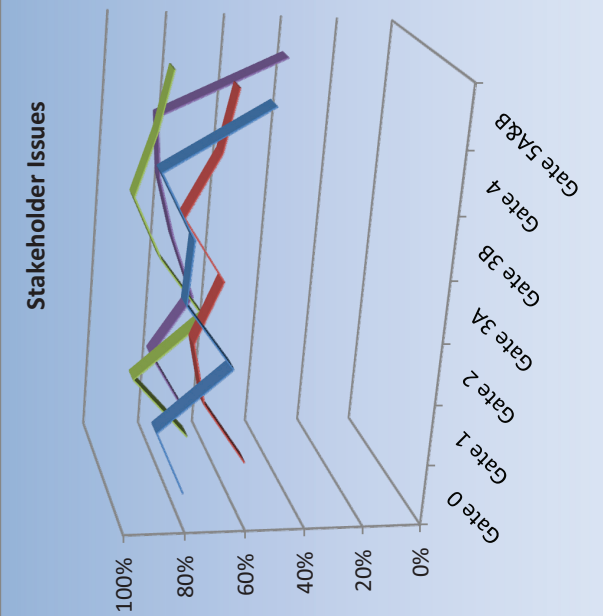

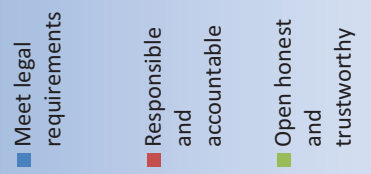

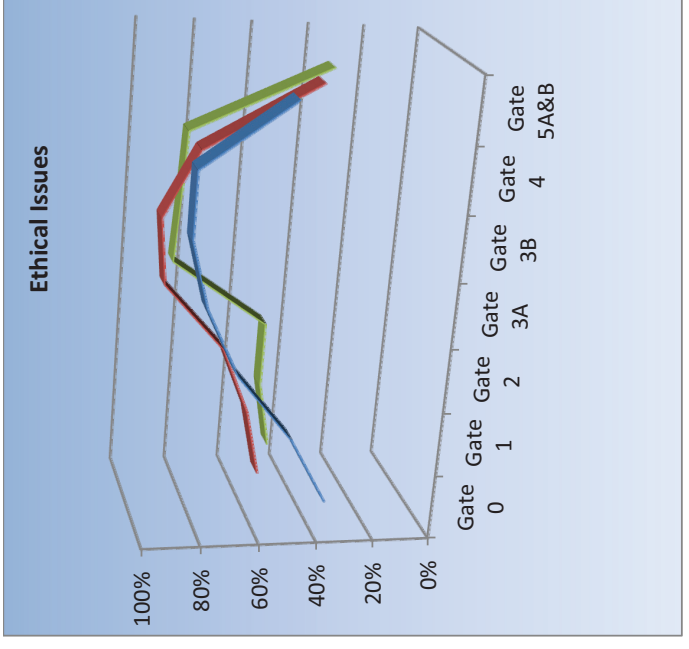

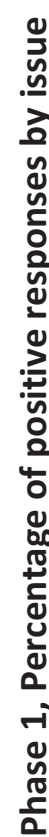

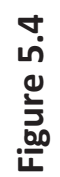




\subsubsection{Issues addressed in VfM Reviews (Question A), (Discussion)}

Examination of these figures confirms that the general trend of responses across the lifecycle is consistent for issues within each category, although the trend is seen to be different between categories. The notable exceptions to this trend are the category of social issues, and to lesser degree, the category of governance issues. For the social category the issue of 'personal wellbeing' is not 'aligned' with other issues across lifecycle of the project. Similarly for governance category, the 'strategy and planning' issue is not 'aligned' in the earlier stages of the lifecycle. The main distinctions between the patterns of responses for each category of issues are described in Table 5.10 below.

\section{Table 5.10 Summary of responses regarding issues considered in VfM Reviews (Question A)}

\begin{tabular}{|c|c|}
\hline Category & Character of Response \\
\hline Economic & $\begin{array}{l}\text { Notable decline of positive responses at VfM/BV Gate } \\
3 A \text { (Selections NoPs) excepting schedule }\end{array}$ \\
\hline Social & $\begin{array}{l}\text { Relatively diverse pattern of responses } \\
\text { Strong increase in positive responses for } \mathrm{OH} \& S \text { and } \\
\text { 'personal well-being' later in the lifecycle }\end{array}$ \\
\hline Environmental & $\begin{array}{l}\text { Few positive responses initially with strongest } \\
\text { response at Gates } 3 B \text { and Gate } 4 \text { (TCE Approval and } \\
\text { Readiness for Service) }\end{array}$ \\
\hline Ethical & $\begin{array}{l}\text { Similar patterns to Environmental but also stronger } \\
\text { responses at Gate } 2\end{array}$ \\
\hline Stakeholder & $\begin{array}{l}\text { All issues are seen to be relatively important } \\
\text { throughout the project lifecycle. }\end{array}$ \\
\hline Governance & $\begin{array}{l}\text { Generally more positive responses at Gates } 3 B \text { and } 4 \\
\text { ('TCE approval' and 'readiness for service') } \\
\text { 'Strategy and Planning' has strong response through } \\
\text { the lifecycle }\end{array}$ \\
\hline
\end{tabular}

In order to more clearly determine whether there were any distinct messages in the data collected in this initial question, the number of positive responses received for each of the 22 issues at each stage of the lifecycle is presented graphically. The results of this analysis are shown in Figure 5.5 which effectively represents a form of 'league table' of the perceived importance of issues at each stage of the project lifecycle. Some quite interesting trends can be observed concerning the relative ranking of issues in respective stages of the lifecycle. In particular, it is evident that the ranking of particular issues in the economic and ethical categories vary quite significantly through the project lifecycle. 


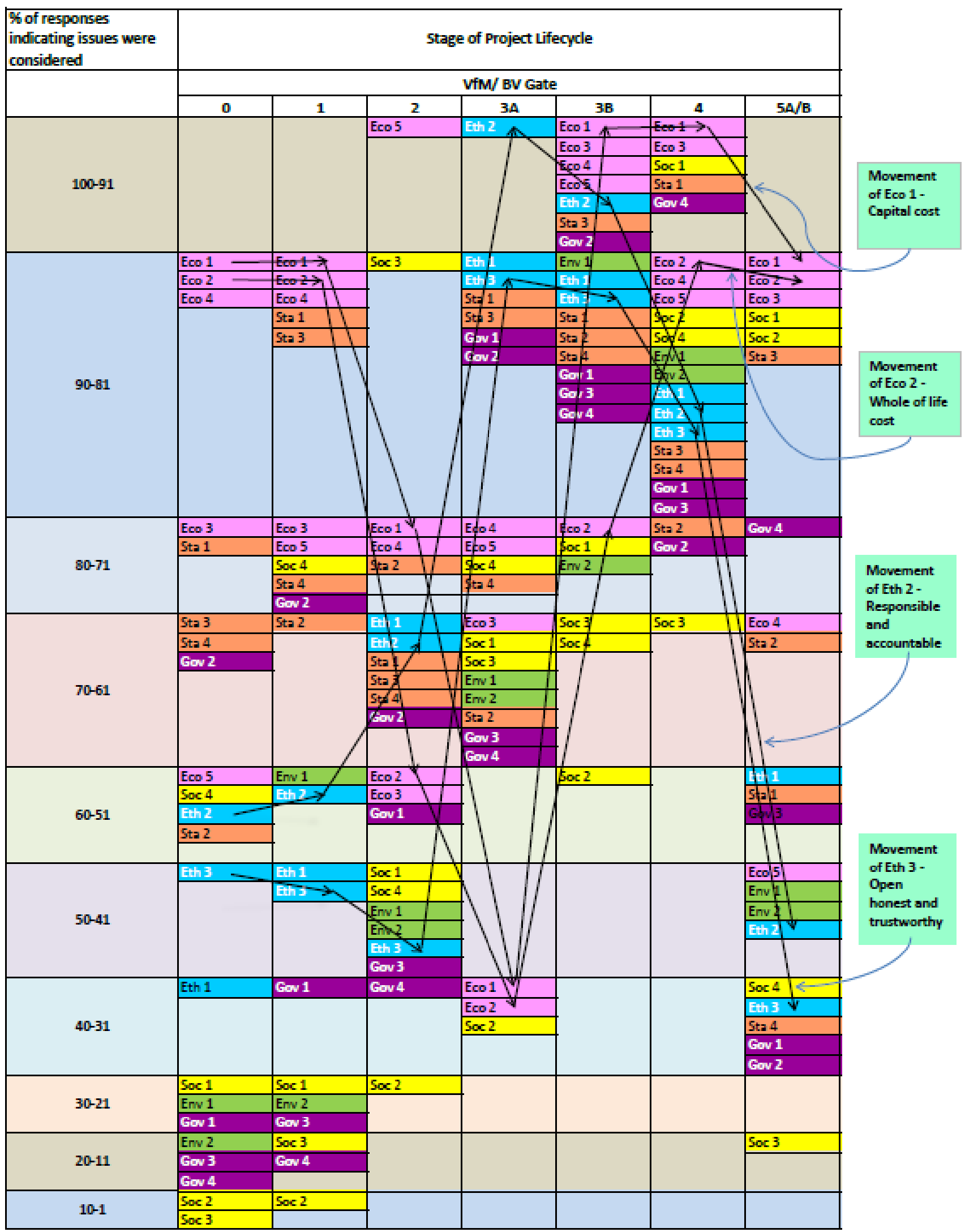

Figure 5.5 Movement of issues considered during the lifecycle of a project 


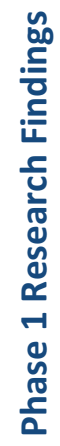

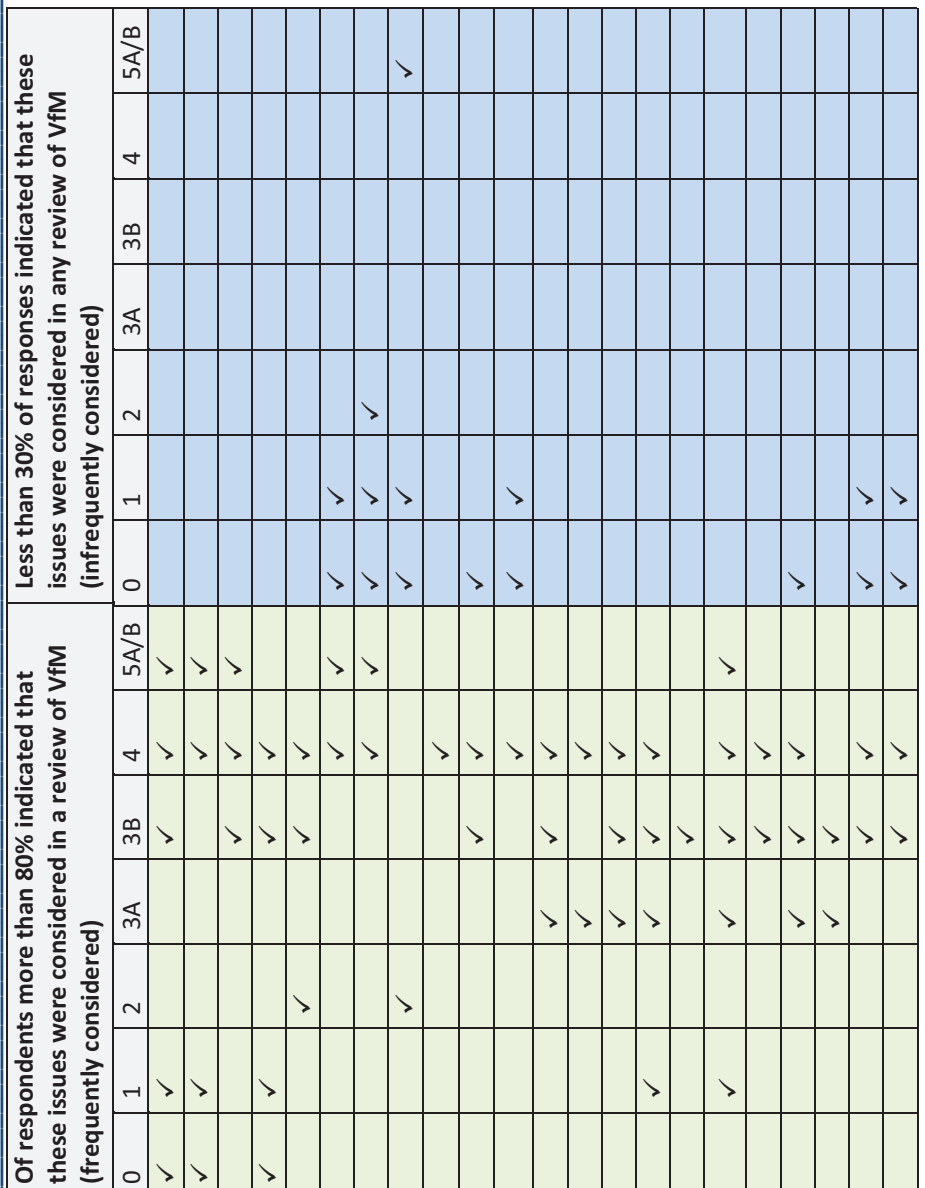

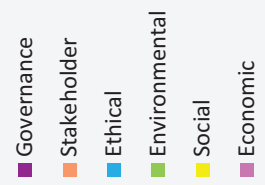
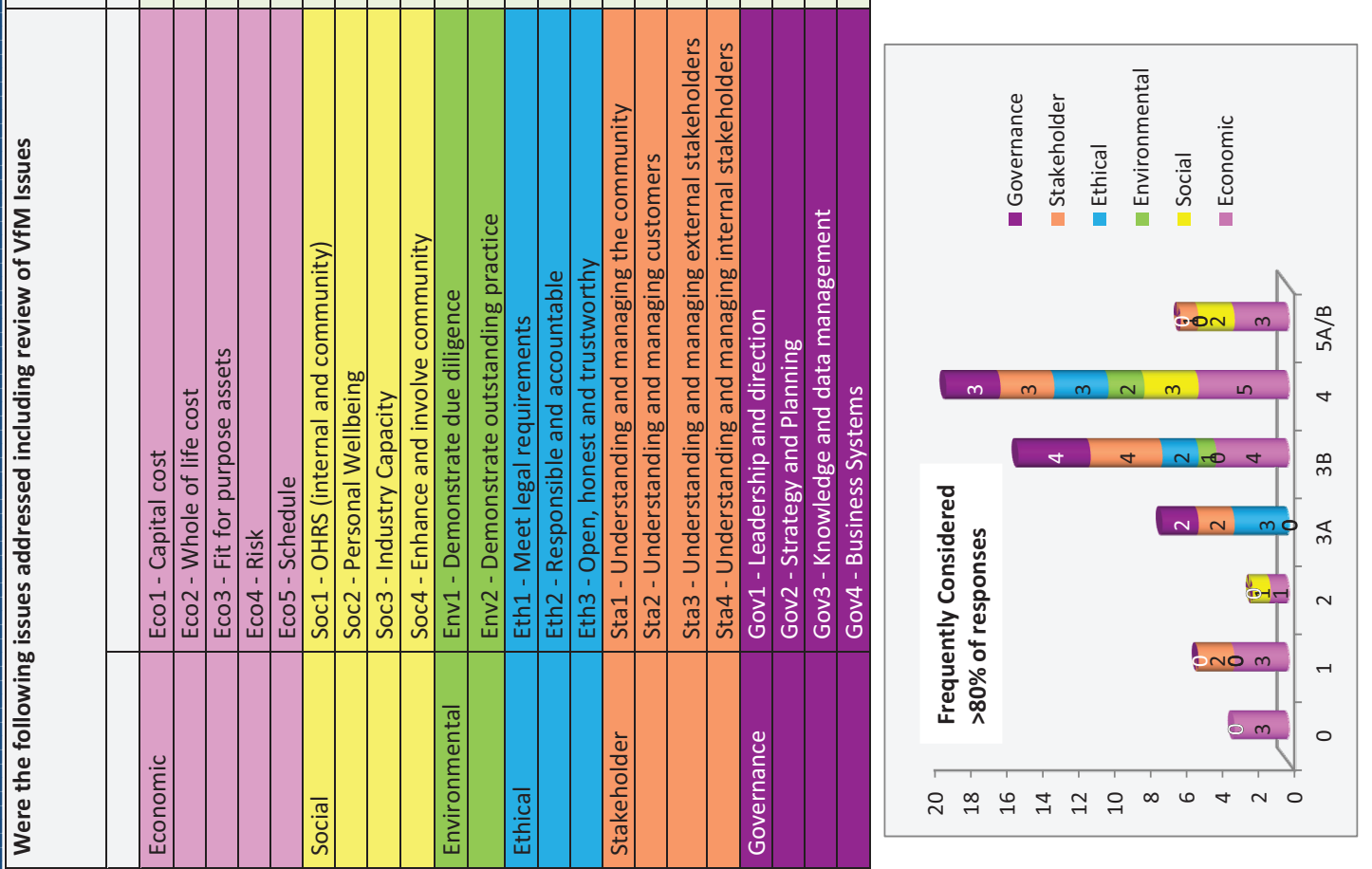

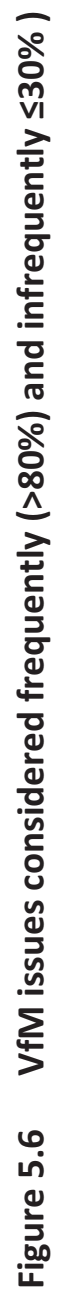


Notably, the economic issues of 'Capital Cost' and 'Whole of Life' costs are amongst the highest ranked issues in all reviews with lifecycle with the marked exception of VfM Gate 3A (Selection of NOPs). Conversely the ethical issues of 'Responsible and accountable' and 'Honest and trustworthy' are lowly ranked during the earlier review points in the lifecycle but are considered to be of the utmost importance at VFM Gate 3A (Selection of NOPs). In Figure 5.5 the relative movement of the ranking of these specific economic and ethical issues is tracked to illustrate these statements.

This juxtaposition of the importance of economic and ethical issues, at the point of selecting the NOPs, is seen to be key finding that can be drawn from the data gathered in response to Question $A$.

The message that is evident here is that when the alliance partners are being confirmed, it is the perceived personal and ethical behaviours of the prospective participants that is critical to the final VfM outcome and the economic issues related to cost are of the least relevance.

This touches upon a fundamental issue in alliance contracting. If the project is one that is suited to a collaborative or relationship based procurement method, the success of the project will be largely dependent on the strength of the relationship between the parties. Consequently, it would be inappropriate to adopt economic issues as the primary criterion at the point of selecting the alliance parties. If it felt that such criterion should be pre-eminent at that point and should govern the selection decision it should also be apparent that the wrong procurement model is not the method best suited to the delivery of the project.

It needs to be recognised that all of the alliances considered in the survey were 'pure' rather than 'competitive' alliances. That is, as discussed earlier in Chapter 2, the selection of the NOPs was in each case based on 'non-price' selection criteria and consequently it might be expected that cost issues would not be represented as being of the highest priority at the point of selecting the NOPs i.e. $V F M / B V$ Gate 3A. However, the pronounced ascent of the ethical issues identified to the highest ranking does emphasise that the selection of the NOPs is primarily a relationship based decision when issues of trust and accountability are much more relevant to the ability of the parties involved to establish a sustainable ongoing alliance than are the issues of cost.

This supports the position that should such cost related issues constitute the predominant selection criteria at this critical point, then the alliance procurement approach is not suited to the task at hand. It then follows that a more conventional delivery methodology based on the selection of the lowest price would be more appropriate and should be adopted.

Figure 5.6 identifies the issues either considered frequently (81\% or more) and infrequently (30\% or less) being the opposite ends of the spectrum of responses. This information is shown for each review 
point or VfM Gate of the project lifecycle. This figure also illustrates the point that economic issues featured in the 'frequently' considered band, as described above, in all reviews of the lifecycle with the sole and notable exception of Gate $3 A$ (Selection of NOPs). This figure also emphasises that all issues are considered more frequently in later reviews in the lifecycle (i.e. VfM Gate 3A (TCE approval) and VfM Gate 4 (Readiness for Service)).

Examination of the lower band of 'infrequently' considered issues, also shown in Figure 5.6, illustrates that social, environmental and governance issues are seen as less important in the earlier reviews (i.e. VfM/BV Gate 0 (Strategic Assessment) and VfM/BV Gate 1 (Business Justification)). However, only two social issues being 'Personal Wellbeing' at VfM/BV Gate 2 (Procurement Strategy) and 'Industry Capacity' at a VfM/BV Gate 5A/B (Benefits Evaluation), respectively, feature as being infrequent in later reviews during the project lifecycle.

Given the significant change of the relative priority of issues observed at the point of VfM Gate $3 \mathrm{~A}$ (Selection of NOPs), the data was further interrogated. Specifically the responses attributable to each of the respective types of organisations involved in the alliances, i.e. Owners, Constructors and other NOPs, was examined. The results of this analysis are shown in Table 5.7 below:

Table 5.11

Percentage of responses received indicating that issues were considered at $\mathrm{VFM} / \mathrm{BV}$ Gate 3A (Selection of NOPs)

\begin{tabular}{ll|cccc}
\hline \multicolumn{1}{c}{ Issue } & \multicolumn{3}{c}{ Organisation } \\
\cline { 3 - 6 } & Owner & Constructor & Other NOPs & $\begin{array}{c}\text { Overall } \\
\text { Score (as } \\
\text { per Figure } \\
5.5)\end{array}$ \\
\hline Eco 1 & Capital Cost & & & $50 \%$ & $40 \%$ \\
\hline Eco 2 & Whole of Life Cost & $0 \%$ & $50 \%$ & $50 \%$ & $40 \%$ \\
\hline Eth 2 & Responsible \& Accountable & $100 \%$ & $100 \%$ & $66 \%$ & $92 \%$ \\
\hline Eth 3 & Open, Honest \& Trustworthy & $75 \%$ & $100 \%$ & $75 \%$ & $84 \%$ \\
\hline
\end{tabular}

This table illustrates that Owners considered the economic issues of 'Capital Cost' and 'Whole of Life Cost' (both 0\%) to be of no importance at this critical decision point. However, they did consider the ethical issues of being 'Responsible and accountable' (100\%) and 'Open, honest and trustworthy' 
(75\%) as being very important matters at the same decision point. This result makes it clear that the Owners concerned placed much greater emphasis on ethical conduct than cost at the point of selecting the NOPs, bearing in mind that this is a decision that only the Owner can make.

Interestingly, the Contractor took a similar view regarding ethical issues but still believed that economic issues would carry significant weight in the selection process. The other NOPs took a similar view to the Contractor regarding economic issues but placed less emphasis on the ethical issues than the Contractor or the Owner. The lack of alignment between the respective organisations is quite marked. The Owners took the strongest view that only ethical issues were considered and the Constructors and the NOPs adopted positions of increasing ambivalence between ethical and economic issues being most frequently considered.

To summarise this discussion regarding the response to Question A, the flowing question is addressed;

What do these responses to Question A reveal about the relative importance of the 22 issues presented?

The results obtained showed that economic issues were dominant in reviews of VfM through the project lifecycle. This is an outcome that should be expected; particularly in Public Sector procurement where the issues of contestability and competition are very important to the bureaucracy in ensuring appropriate probity is observed. However, despite this clear result a further message emerged, namely that:

- At the point of selection the alliance partners, the issues of ethical conduct were paramount and this is a view held particularly strongly, in fact, universally in responses received by the Owner respondents;

- Whilst economic and stakeholder issues dominate in the early 'strategic need' and 'business case' stages of the project, a broader range of issues become more relevant to VfM in the later stages of the lifecycle up to and including the delivery of the project;

- Interestingly, once the project is in operation the priority of issues reverts to a similar pattern to that pertaining to the earlier stages although some social issues, namely OH\&S and personal wellbeing attain higher importance. 


\subsubsection{Level of Maturity (LOM) in the consideration of VfM through the project lifecycle (Questions B to G)}

Questions B to $G$ in the questionnaire adopted a different format to Question A which, as discussed earlier, related to issues that were considered during reviews of $\mathrm{VFM}$ at the conclusion of each stage. In these later questions the respondents were asked to assess the level of maturity (LOM) displayed regarding ensuring and demonstrating VfM at the end of each stage of the project lifecycle in both the alliance in which they were involved and their own home organisation. Questions B, C and D addressed the LOM in the alliance, whilst Questions E, F and G, related to the LOM of their own home organisation.

The concept of a LOM relating to the manner in which VfM was approached, was adapted from earlier work by Walker and Nogeste (2008) and briefly outlined in Chapter 4. The advantage of such an approach, using a Capability Maturity Model (CMM) matrix or table, is that it allows the respondent to be presented with a series of scenarios in 'word pictures' described varying levels of sophistication of approach that might apply to the circumstances of the relevant project. The respondent is then able to consider these word pictures and relate their own experience to the spectrum of scenarios presented. Whilst this approach does add to the length and complexity of the questionnaire it is designed to minimise the time necessary to complete the questionnaire which assists in encouraging a higher response rate. In this case, of the twenty-seven questionnaires circulated, twenty-one were retuned corresponding to a $78 \%$ response rate.

As is described above, for each question, the respondents were presented with a matrix describing what typified each of five levels of maturity at each stage of the project lifecycle. They then were asked to circle the description which they believed to most accurately reflect the situation in either their alliance or home organisation. The responses relating to LOM in each alliance are presented in Figures 5.7 to 5.9 which show the frequency of responses, in a histogram form, for each of the five levels of maturity identified in the matrix. Similarly, the results relating to LOM in each organisation are presented in Figures 5.11 to 5.13. These LOM range from 'inactive awareness' through to 'embedded, routinisation and infusion'. This terminology is adopted from Walker and Nogeste (2008) who developed the earlier work of Walker (2004). The statistics presented in these figures represent the aggregate assessment of all respondents and do not distinguish between the alliances or organisations considered. The breakdown of the relative responses for individual alliances is contained in Appendices D.2 to D.4, whilst those relating to LOM in each organisation are contained in Appendices D.5 to D.7. As was discussed earlier for Question A, the number of responses relating to the earlier VfM/BV Gates, are less than those relating to the later VfM/BV Gates, where all participants would be involved in each alliance considered. 


\section{Question B - Is VfM an explicit project objective for the Alliance?}

'Strategic Need' Stage - VfM/BV Gate 0

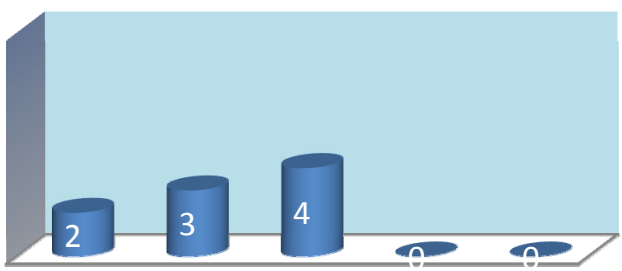

1
2
4

$\mathrm{n}=6$, active adoption with distinct towards lower LOM

\section{VfM/BV Gate 2 - 'Procurement Strategy' Stage}

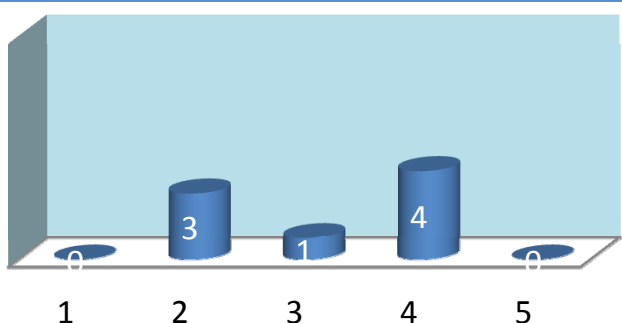

$\mathrm{n}=8$, bipolar response, pre-active initiation and pro-active acceptance

\section{'TCE Approval' Stage - VfM/BV Gate 3B}

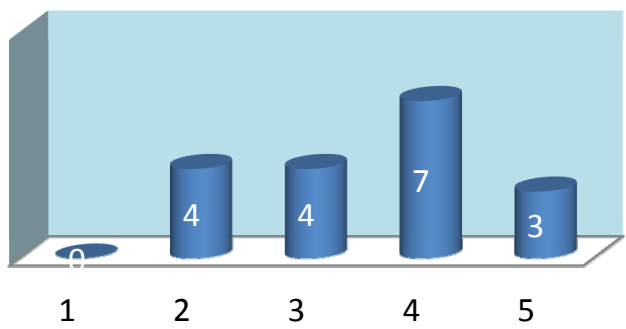

$\mathrm{n}=18$, broad response with slight leaning towards higher LOM

\section{'Benefits Evaluation' Stage - VfM/BV Gates 5A\&5B General comments}

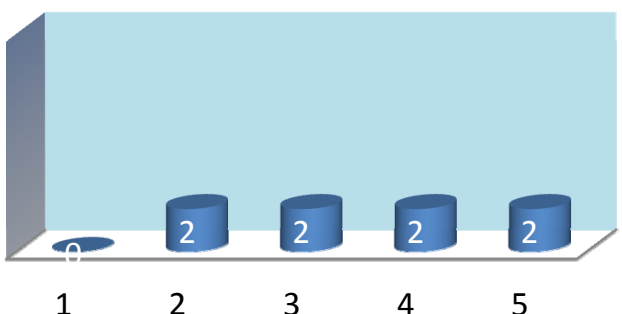

$\mathrm{n}=8$, broad range with leaning towards lower LOM

\section{'Business Case' Stage - VfM/BV Gate 1}

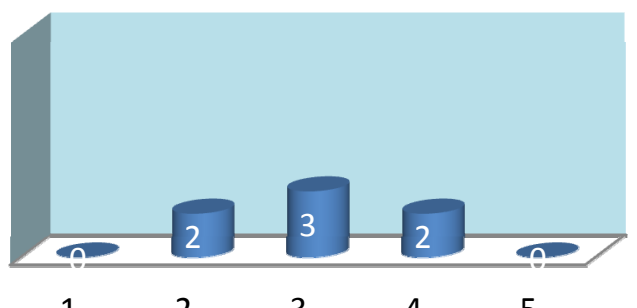

$\mathrm{n}=7$, mean/mode of active adoption with symmetrical distribution

\section{'Selection of NOPs' Stage - VfM/BV Gate 3A}

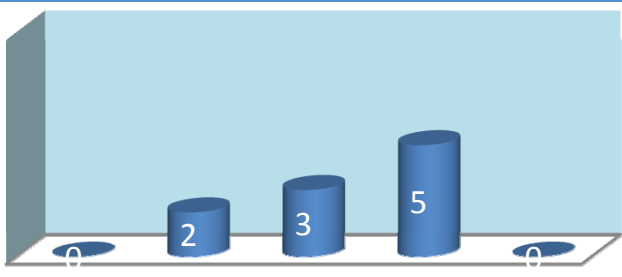

$\begin{array}{lllll}1 & 2 & 3 & 4 & 5\end{array}$

$n=10$, range of responses with slight leaning towards higher LOM, proactive acceptance

\section{'Readiness for Services' Stage - VfM/BV Gate 4}

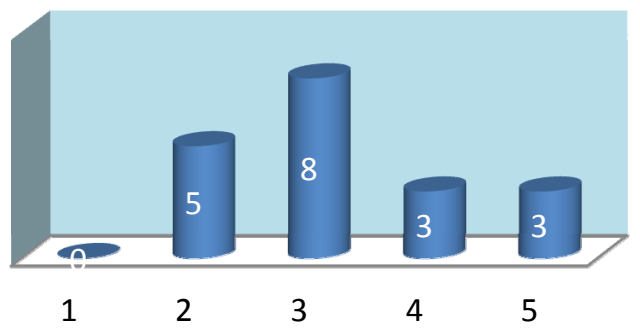

$\mathrm{n}=19$, broad response with slight leaning towards higher LOM

Lower response rate for earlier stage of the project lifecycle which is to be expected given that this is typically the province of the Owners alone.

Generally centred on active adoption or slightly higher LOM.

Legend:

1 - Inactive awareness,

2 - Pre-active initiation,

3 - Active adoption,

4 - Pro-active acceptance + adoption,

5 - Embedded routinisation + infusion

Figure 5.7 Phase 1, Question B, Frequency v LOM for each stage of the project lifecycle - All participants 
Question C - Are specific measures or procedures in place to ensure that VfM is achieved?

'Strategic Need' Stage - VfM/BV Gate 0 -

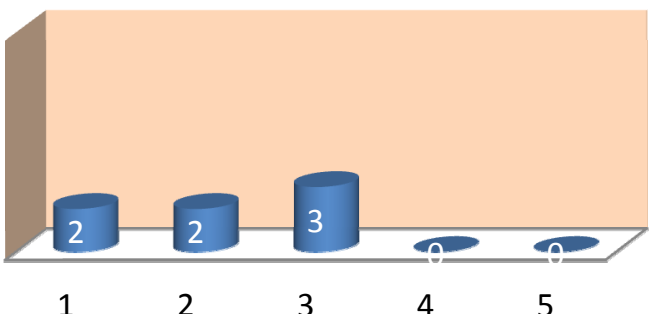

$\mathrm{n}=7$, active adoption leaning towards lower LOM

\section{'Business Case' Stage - VfM/BV Gate 1 -}

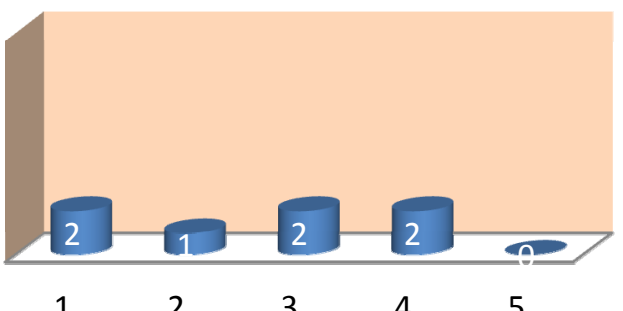

$\mathrm{n}=7$, broad range with slight leaning to lower LOM

\section{'Procurement Strategy' Stage - VfM/BV Gate 2 -}

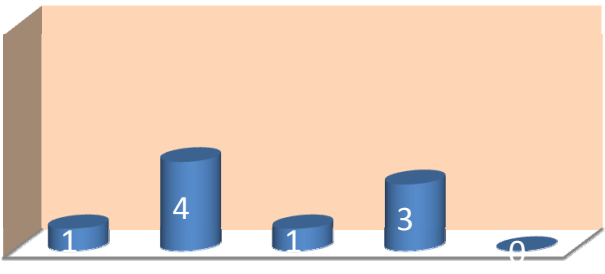

12

3

4

5

\section{'Selection of NOPs' Stage - VfM/BV Gate 3A -}

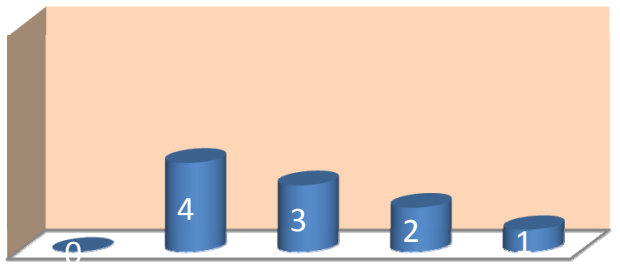

$\begin{array}{lllll}1 & 2 & 3 & 4 & 5\end{array}$

$n=9$, polarised response with tendencies to either pre- $n=10$, leaning towards higher LOM active initiation of pro-active acceptance

\section{'TCE Approval' Stage - VfM/BV Gate 3B -}

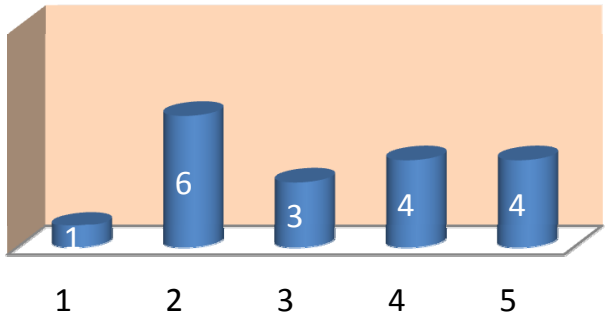

$\mathrm{n}=18$, very broad response, full range of LOM

\section{'Benefits Evaluation' Stage - VfM/BV Gates} $5 \mathrm{~A} \& 5 \mathrm{~B}$

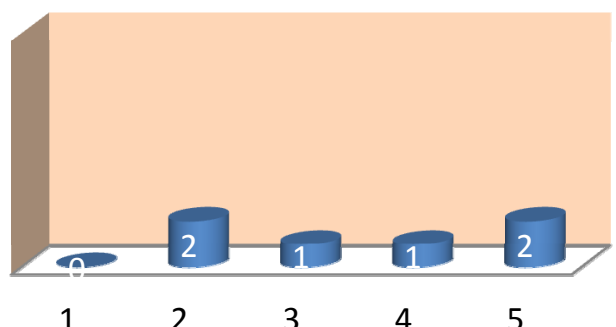

$\mathrm{n}=6$, broad range with leaning towards higher LOM

\section{'Readiness for Service' Stage - VfM/BV Gate 4}

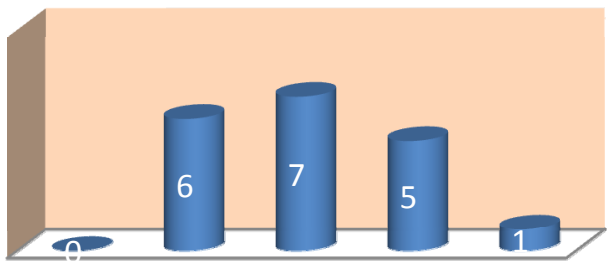

$\begin{array}{lllll}1 & 2 & 3 & 4 & 5\end{array}$

\section{General comments}

Lower response rate for earlier stage of the project lifecycle which is to be expected given that this is typically the province of the Owners alone.

Generally active adoption or less rather than higher LOM.

Legend:

1 - Inactive awareness,

2 - Pre-active initiation,

3 - Active adoption,

4 - Pro-active acceptance + adoption,

5 - Embedded routinisation + infusion

Figure 5.8 Phase 1, Question C, Frequency v LOM for each stage of the project lifecycle - All participants 
Question D - Are specific measures in place to ensure that VfM is demonstrated to have been achieved?

\section{'Strategic Need' Stage - VfM/BV Gate 0 -}

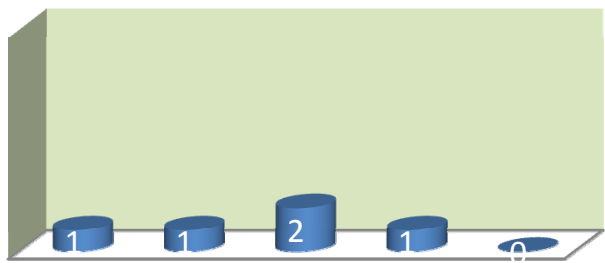

1

3

4

5

$n=5$, active adoption with slight leaning to lower LOM

$\mathrm{n}=8$, broad range with slight leaning to higher LOM

\section{'Procurement Strategy' Stage - VfM/BV Gate 2 -}

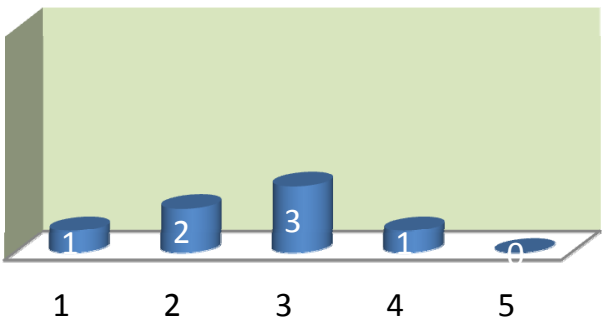

$\mathrm{n}=7$, broad range with slight leaning to lower LOM

\section{'Selection of NOPs' Stage - VfM/BV Gate 3A -}

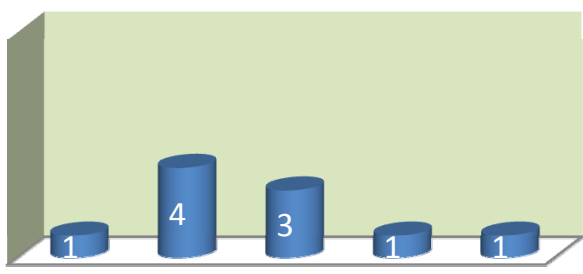

$\begin{array}{lllll}1 & 2 & 3 & 4 & 5\end{array}$

$\mathrm{n}=10$, broad range with leaning towards lower LOM

\section{'TCE Approval' Stage - VfM/BV Gate 3B -}

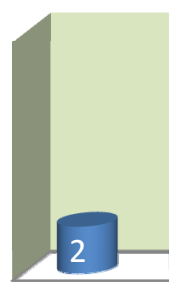

1

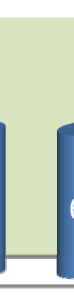

2

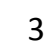

3

$\mathrm{n}=17$, broad range with leaning towards lower LOM

\section{'Benefits Evaluation' Stage - VfM/BV Gates} $5 \mathrm{~A} \& 5 \mathrm{~B}-$

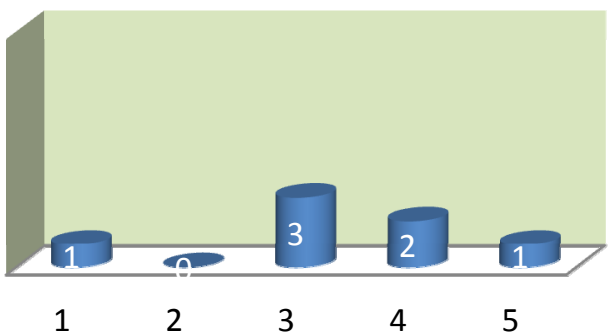

$\mathrm{n}=7$, broad range with leaning towards higher LOM

\section{'Readiness for Service' Stage - VfM/BV Gate 4}

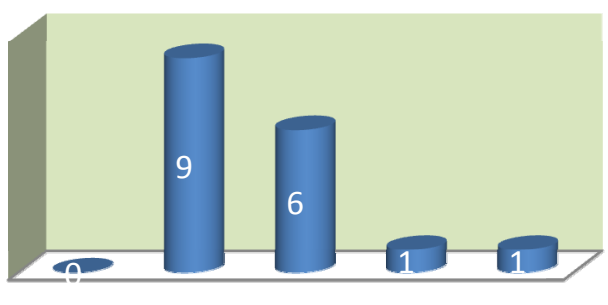

1

2

5 $\mathrm{n}=17$, broad response with strong leaning towards lower LOM

\section{General comments}

Lower response rate for earlier stage of the project lifecycle which is to be expected given that this is typically the province of the Owners alone.

Generally active adoption or less rather than higher LOM.

Legend:

1 - Inactive awareness,

2 - Pre-active initiation,

3 - Active adoption,

4 - Pro-active acceptance + adoption,

5 - Embedded routinisation + infusion

Figure 5.9 Phase 1, Question D, Frequency v LOM for each stage of the project lifecycle - All participants 


\subsubsection{Level of Maturity (LOM) in the consideration of VfM through the project lifecycle. (Questions B, C and D), (Discussion)}

As is explained above, Questions B to D sought feedback from the participants on the consideration of $\mathrm{VFM}$ in the respective alliance that they were participating in.

The responses obtained are first examined at the level of the individual questions and then as a group to determine if there are any patterns that emerge when the responses are considered in combination.

\section{Question:}

Is VfM an explicit project objective for the alliance? (Question B).

\section{Response/Discussion:}

The results are presented in Figure 5.7 above and in further detail by alliance in Appendix D.2. Generally the LOM at each of the stages of the project lifecycle is in the mid-range of the scenarios presented to the respondents, with a few exceptions which are noted below. At the early stage of the project lifecycle (i.e. the 'Strategic Need' stage) the LOM is relatively low. In the 'Business Case' stage mid-range, although for the 'Selection of NOPs' and 'TOC Approval' stages a tendency to a higher LOM was observed. For the 'TCE Approval' stage, the level of maturity ranges from an intermediate value to a higher level of maturity. There was a significant range of results for the 'D\&C phase' although the median value still remains fairly central. The response rate for the 'Benefits Evaluation' stage was significantly less which was not surprising given that a number of the projects were still in progress and consequently had not yet reached the point at which the benefits were being critically evaluated.

The general pattern is low LOM at the commencement of the project lifecycle which increases during the lifecycle. Appendix D.2 indicates that there is no readily discernable difference between the responses for the respective alliances.

\section{Question:}

Are specific measures or procedures in place to ensure that VfM is achieved? (Question C)

\section{Response/Discussion}

Reference Figure 5.8, with full details in Appendix D.3.

The results were similar to those obtained in Question B in that the LOM at the 'Strategic Need' stage is considered to be at an intermediate level of maturity or lower. Interestingly whilst the result is not significantly different for the 'Procurement Strategy' stage, the 'Selection of NOPs' stage appears to suggest that the maturity of the measures in place to ensure VfM has occurred are lagging behind the importance of the objective of VfM being achieved as revealed in question B. A similar result is noted at the 'TCE Approval' stage where 
again the measures and procedures would appear to lag behind the importance of achieving VfM identified in the earlier question.

A similar pattern is observed to that in the previous question (i.e. a lower LOM initially which increases during the lifecycle. As noted above, for some of the stages the measures and procedures in place do not match the importance of VfM as confirmed in the question $B$. Appendix D.3 also indicates that there is no readily discernable difference between the responses for the respective alliances.

\section{Question:}

Are specific measures in place to ensure that value for money is demonstrated to have been achieved? (Question D).

\section{Response/ Discussion:}

Reference Figure 5.9, with full details in Appendix D.4.

The responses to this question yielded a broader range of LOM in response to this question. Interestingly, at the 'Selection of NOPs' stage, the result appears to mirror the response obtained in Question C (i.e. there appears to be a strong correlation between the maturity of the measures or procedures in place to ensure that value for money has been achieved and the demonstration of that objective). By contrast in the 'TCE Approval' stage, the results suggest that the LOM of the measures to demonstrate VFM lag behind the measures or procedures in place to ensure that the VfM has been achieved. This result is consistent with a number of remarks made during the interview process in which several respondents indicated that there was a dearth of tools available to demonstrate that VfM had occurred at various stages of the lifecycle even though there were some specific measures in place to ensure that this objective was achieved. Similarly during the 'D\&C phase' there is a notable difference between the responses to Questions $C$ and $D$, again indicating that the measures in place to demonstrate VfM are generally at a lower LOM.

As already noted above the results suggest a discernable difference in the LOM observed between ensuring and demonstrating VfM, particularly for the later stages of the lifecycle. As in the case of Questions $B$ and $C$ there appears to be no discernable difference between the respective alliances in the breakdown presented in Appendix D.4. 


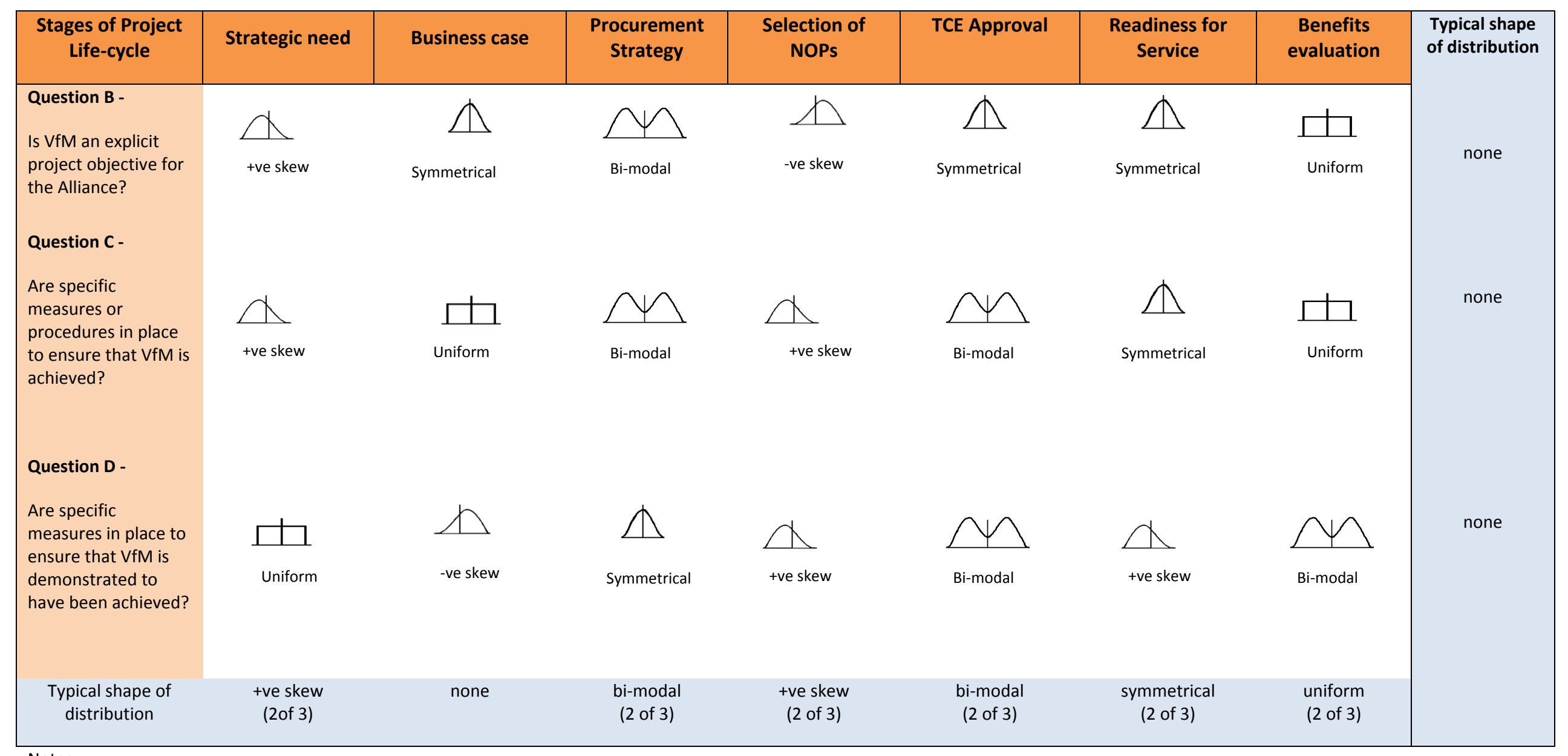

Notes:

- No consistent trend to -ve skew in any question at any Stage i.e. no tendency towards higher LOM.

- Leaning towards +ve skew (2 of 3) in both Strategic need Stage and Selection of NOPs Stage

\section{Figure 5.10 Responses to Questions regarding Level of Maturity (LOM) within the alliances considered}




\subsubsection{General conclusions from feedback relating to the consideration of VfM in each alliance.}

To determine whether there are any distinct trends in the data that might be observed when the responses to these three questions regarding VfM in the project alliances were considered in aggregate, a consolidated format was produced.

In Figure 5.10 above the general form of the distribution of responses for each stage of the project lifecycle in each question has been depicted by a stylised icon. By examination of the content of this figure the following conclusions can be drawn:

There was no consistent trend to a -ve skew in any question at any stage of the lifecycle i.e. there is no tendency towards higher LOM indicative that the degree of sophistication or LOM in addressing VfM is relatively low. This confirms that there is considerable scope for improvement in ensuring and demonstrating that VfM has been achieved.

There were some observed leanings towards +ve skew (2 of 3) at both VfM/BV Gate 0 (Strategic Assessment) and VfM/BV Gate 3A (Select NOPs) indicating that both of these points in the project lifecycle there was distinct tendency towards a lower LOM indicating that at these Gates the LOM in addressing VfM was least developed. The identification of the 'Strategic Need for a Project' and the 'Selection of the NOPs' constitute two crucial stages of any project and a noted trend towards a low LOM regarding VfM matters at the conclusion of these stages is a cause for some concern. This illustrates need for the development of measures to improve the process of ensuring and demonstrating VfM throughout the project lifecycle and particularly at these stages. 


\section{Question E - Is VfM an explicit project objective for your Organisation?}

'Strategic Need' Stage - VfM/BV Gate 0 -

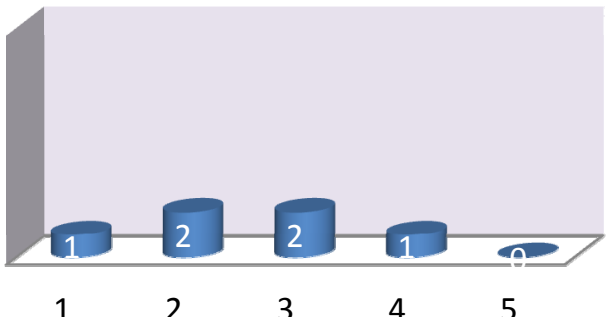

$\mathrm{n}=6$, active adoption with slight leaning to lower LOM

\section{'Business Case' Stage - VfM/BV Gate 1 -}

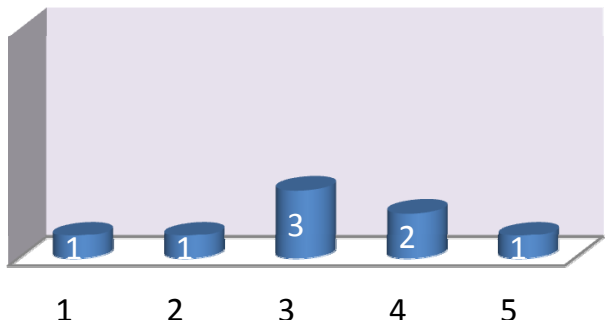

$\mathrm{n}=8$, active adoption with slight leaning towards higher LOM

\section{'Procurement Strategy' Stage - VfM/BV Gate 2 -}

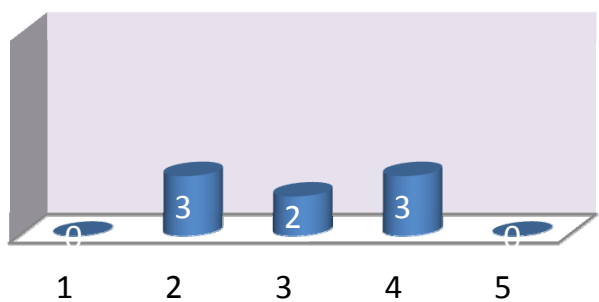

$\mathrm{n}=8$, slightly bi-polar centred around active adoption

\section{'Selection of NOPs' Stage - VfM/BV Gate 3A -}

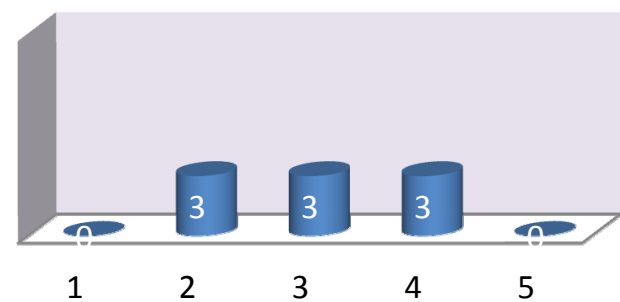

$n=9$, range centred around active adoption

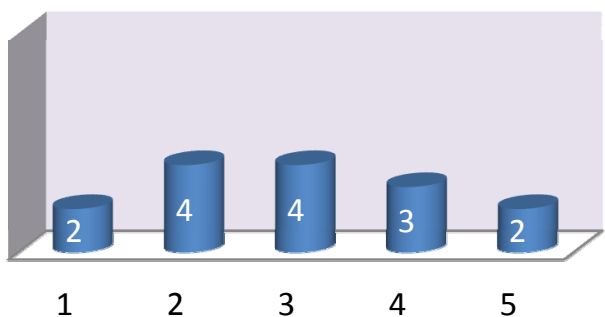

$\mathrm{n}=15$, very broad response with slight leaning towards lower LOM

\section{'Benefits Evaluation' Stage - VfM/BV Gates 5A\&5B-}

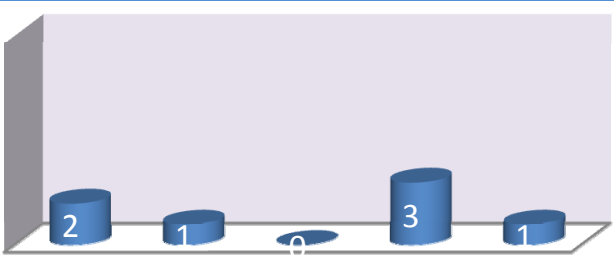

1

2

3

4

$\mathrm{n}=7$, bi-polar response, slight leaning towards higher LOM

Figure 5.11 Phase 1, Question E, Frequency v LOM for each stage of the project lifecycle - All participants

\section{'Readiness for Service' Stage - VfM/BV Gate 4}

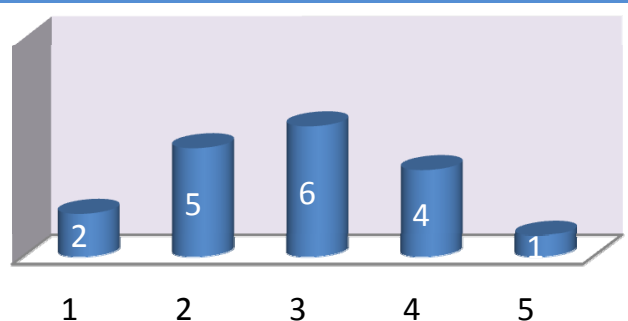

$\mathrm{n}=18$, very broad response, active adoptions with slight leaning towards lower LOM

\section{General comments}

Lower response rate for earlier stage of the project lifecycle which is to be expected given that this is typically the province of the Owners alone.

Generally active adoption or less rather than higher LOM.

Legend:

1 - Inactive awareness,

2 - Pre-active initiation,

3 - Active adoption,

4 - Pro-active acceptance + adoption,

5 - Embedded routinisation + infusion 
Question F - Are specific measures normally in place (within your organisation) to ensure that VfM is achieved?

'Strategic Need' Stage - VfM/BV Gate 0

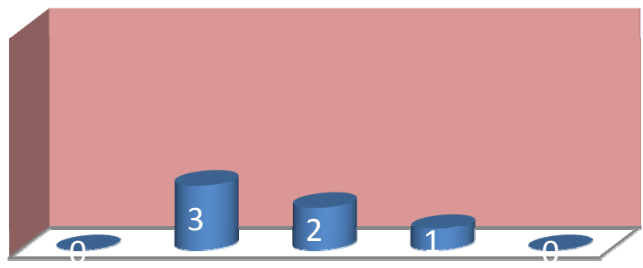

1

45

$\mathrm{n}=6$, active adoption with slight leaning towards lower LOM

\section{'Procurement Strategy' Stage - VfM/BV Gate 2}

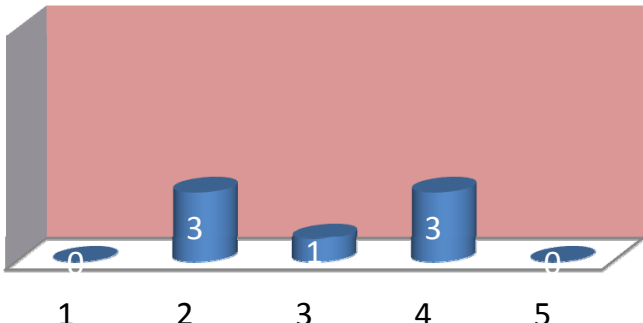

$\mathrm{n}=7$, bipolar response centred around active adoption

\section{'TCE Approval' Stage - VfM/BV Gate 3B}

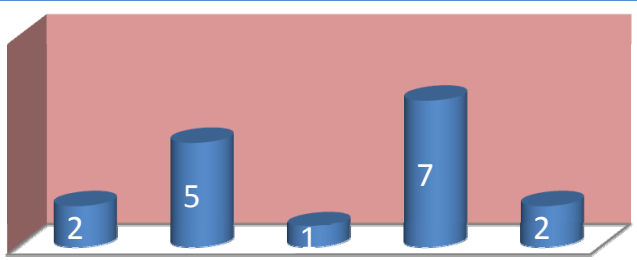

1

23

4

5

\section{'Business Case' Stage - VfM/BV Gate 1}

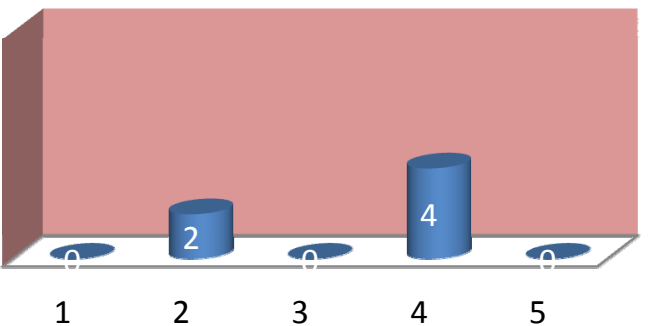

$\mathrm{n}=6$, bi-polar response with learning to higher LOM bimodal

\section{'Selection of NOPs' Stage - VfM/BV Gate 3A}

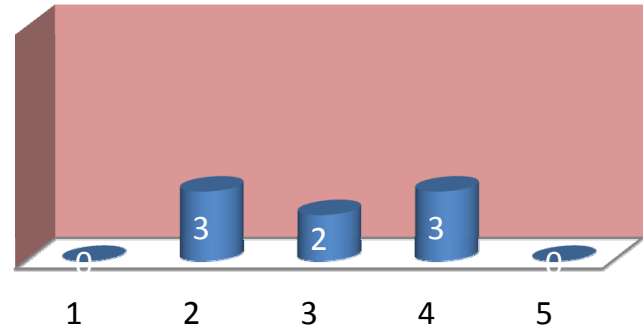

$\mathrm{n}=8$, response centred around active adoption

\section{'Readiness for Service' Stage - VfM/BV Gate 4}

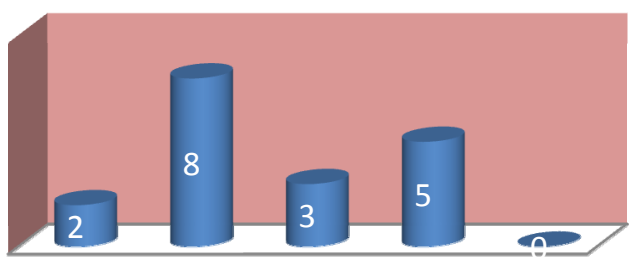

1

5

$n=17$, full range of LOM, slight leaning towards higher LOM $n=18$, broad response with leaning towards low LOM

\section{'Benefits Evaluation' Stage - VfM/BV Gates 5A\&5B General comments}

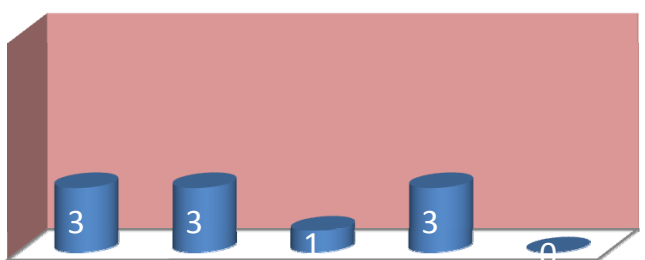

1

2

3

4

5

$\mathrm{n}=10$, broad range with leaning towards lower LOM

Lower response rate for earlier stage of the project lifecycle which is to be expected given that this is typically the province of the Owners alone.

Generally active adoption or less rather than higher LOM.

Legend:

1 - Inactive awareness,

2 - Pre-active initiation,

3 - Active adoption

4 - Pro-active acceptance + adoption,

5 - Embedded routinisation + infusion

Figure 5.12 Phase 1, Question F, Frequency v LOM for each stage of the project lifecycle - All participants 
Question G - Are specific measures normally in place (within your organisation) to ensure that VfM is demonstrated to have been achieved?

\section{'Strategic Need' Stage - VfM/BV Gate 0}

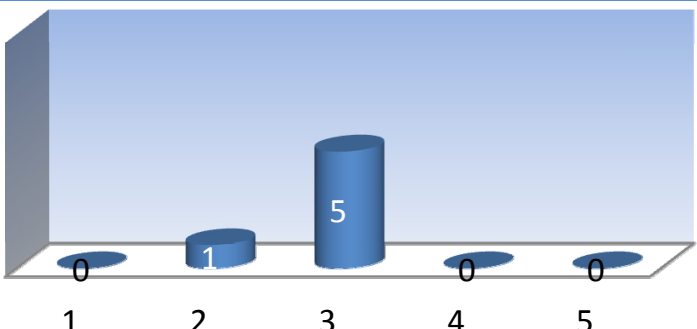

$n=6$, active adoption with slight leaning to lower LOM

\section{'Procurement Strategy' Stage - VfM/BV Gate 2}

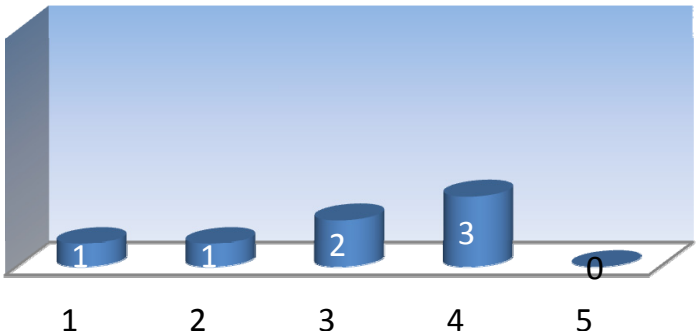

$n=7$, very broad response ranging to lower LOM

\section{'TCE Approval' Stage - VfM/BV Gate 3B}

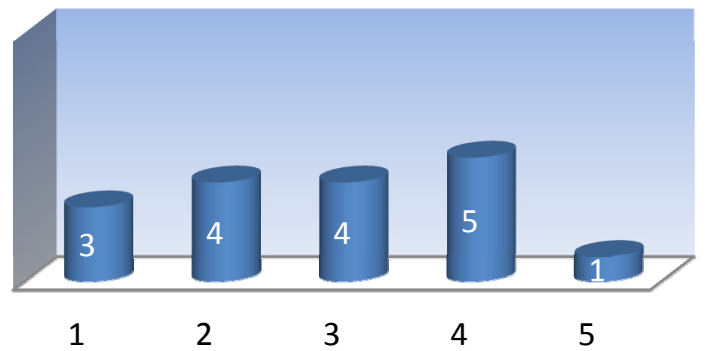

$\mathrm{n}=17$, very broad response, full range of LOM

\section{'Benefits Evaluation' Stage - VfM/BV Gates 5A\&5B}

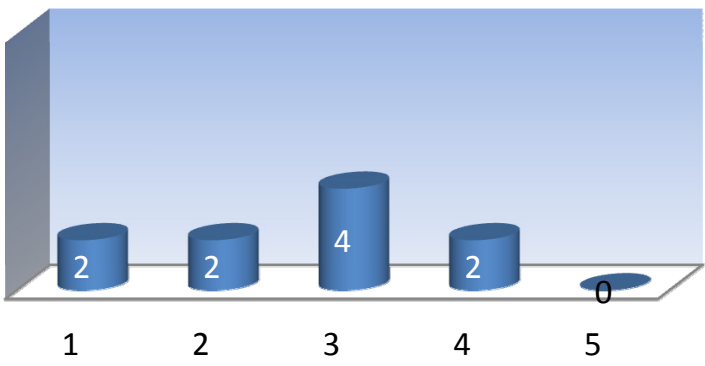

$\mathrm{n}=10$, broad range with leaning towards lower LOM

\section{'Business Case' Stage - VfM/BV Gate 1}

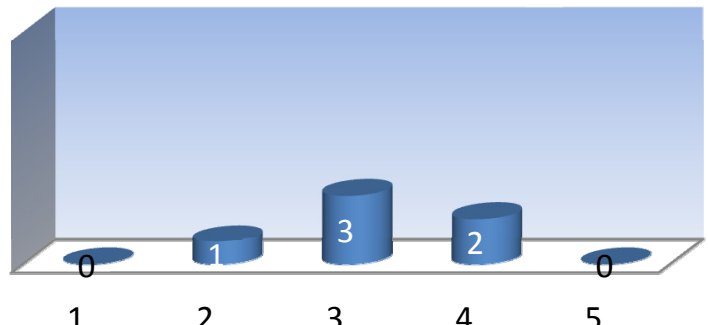

$n=6$, active adoption with slight leaning to pro-active acceptance

\section{'Selection of NOPs' Stage - VfM/BV Gate 3A}

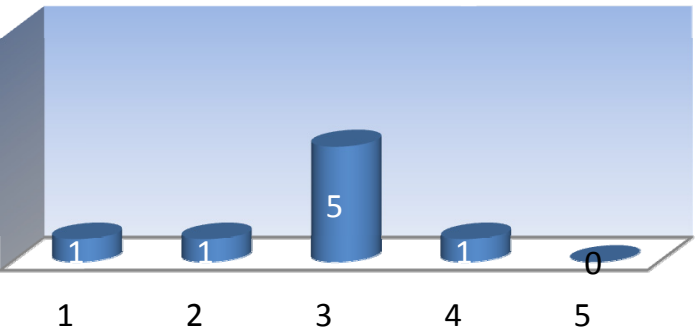

$\mathrm{n}=8$, active adoption with slight leaning towards lower LOM

\section{'Readiness for Service' Stage - VfM/BV Gate 4}

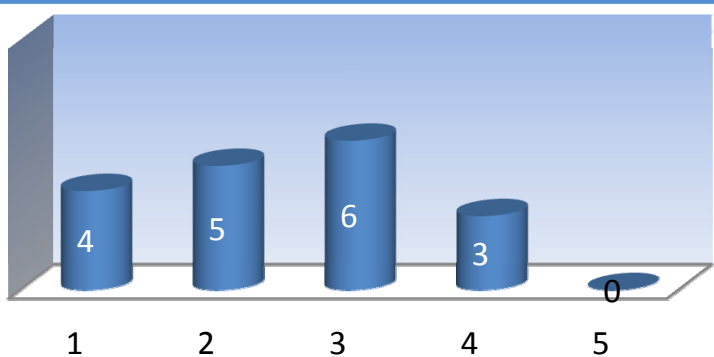

$\mathrm{n}=18$, broad response with leaning towards low LOM

\section{General comments}

Lower response rate for earlier stage of the project lifecycle which is to be expected given that this is typically the province of the Owners alone.

Generally active adoption or less rather than higher LOM.

Legend:

1 - Inactive awareness,

2 - Pre-active initiation,

3 - Active adoption,

4 - Pro-active acceptance + adoption,

5 - Embedded routinisation + infusion

Figure 5.13 Phase 1, Question G, Frequency v LOM for each stage of the project lifecycle - All participants 


\subsubsection{Level of Maturity (LOM) in the consideration of VfM through the project lifecycle. (Questions E, F and G), (Discussion)}

The next three questions, being Questions $E, F$ and $G$ sought feedback from respondents about the manner in which their home organisation addressed VfM matters, in contrast to the manner in which such issues had been addressed in the respective alliances they were involved in. As in the case of the consideration of $\mathrm{VfM}$ in each alliance, the responses obtained are first presented in aggregate (see Figures 5.11 to 5.13). The results are also reported by the three organisational groups being Owner participants, Constructor participants and Other NOP participants being primarily design consultants. (See Appendices D.5 to D.7)

As was the case for the earlier questions relating to specific alliances, the results are first examined at the level of the individual question and then as a group to determine if there are any patterns that emerge when the responses are considered in combination.

\section{Question:}

Is VfM and explicit project objective for your Organisation? (Question E).

\section{Reasons/Discussion:}

Summarised results are presented in Figure 5.11 below and in further detail by organisation in Appendix D.5

In the case of this particular question comparison between Figure 5.11 and Appendix D.6 reveals an interesting difference between the responses of different organisations. The response as a whole as shown in Figure 5.11 which shows a +ve skew i.e. lower LOM for the 'Strategic Need' stage and the corresponding division by organisation as shown in Appendix D.6 indicates that Owner participants generally report a lower LOM than the Construction participants. In the 'Business Case' stage there is some evidence of a higher LOM generally with the Constructor participants again tending to report higher LOM scores. Through the 'Procurement Strategy', 'Selection of NOPs' and 'TCE Approval' stages, the median score for LOM is mid range. However, for the later two stages of 'Readiness for Service' and 'Benefits Evaluation' it is again notable that Constructor participants report higher LOM scores than either Owners with Other NOP participants.

The responses to these questions indicate that a Constructor holds the view that they achieve a higher LOM regarding VIM as an explicit objective. 


\section{Question:}

Are specific measures normally in place (within your organisation) to ensure that VfM is achieved? (Question F)

\section{Response/Discussion:}

Reference Figure 5.12 with full details in Appendix D.6

As was the case in the previous question, a +ve skew i.e. lower LOM, is reported for the 'Strategic Need' Stage with Owners indicating lower scores than Construction participants. Thereafter, for all of the subsequent stages of the lifecycle there appears to be bi-modal distribution with results clustered in two groups either side of a central value. There appears, however, to be no distinct pattern of particular organisations reporting in each of these clusters. Rather, it suggests that respondents simply consider their organisation to have either a high or low LOM at each stage with relatively few respondents considering that they were mid-range.

The polarised responses at each stage of the lifecycle excepting the 'Strategic Need' are difficult to interpret. As discussed above the responses do not appear to be characteristic of organisations but rather represents individual views. It does confirm, however, that at least half the respondents believe that there is scope for improvement in the LOM at each stage.

\section{Question:}

Are specific measures normally in place (within your organisation) to ensure that VfM is demonstrated to have been achieved? (Question $\mathrm{G}$ ).

\section{Response/Discussion:}

Reference Figure 5.13 with full details in Appendix D.7

Again at the 'Strategic Need' stage a +ve skew is noted although this is a more 'normal' response than that obtained to the equivalent question for ensuring VfM in alliances (Question B). At the 'Business Case' stage a symmetrical distribution around a central median was observed but at the 'Procurement Strategy' stage a more developed LOM was reported. Interestingly, when this question was presented by type of organisation in Appendix D.7, Owner's responses were evenly distributed around a central value whilst responses from Construction participants recorded either very low or high LOM. For the 'Selection of NOPs' stage, the responses from Owners was very consistent at a central range value with Constructor and other NOP participants providing more divergent scores.

For the final three stages of lifecycle there were slight tendencies towards a +ve skew i.e. lower LOM. Notably Owner participants reported scores that were consistently mid-range. 
Other NOPs reported lower LOM scores and Construction participants provided scores across the range.

For most stages of the lifecycle a +ve skew to the responses was noted indicating lower LOM. The responses from Owners were generally more consistent than others and centred around a central value of LOM. These results again suggest significant scope for improvement in demonstrating $V f M$.

\subsubsection{General conclusions from questions relating to the VfM approach by each home} organisation.

In a similar manner to that explained earlier in relation to the responses to questions relating to VfM issues in each alliance, a grouping of responses was produced for the questions that related to the attitude to VfM in each organisation. (See Figure 5.14 below)

Whilst the overall picture that emerges is not dissimilar to the responses by each Alliance i.e. there is little evidence to suggest a consistent trend towards higher LOM scores at any stage of the project lifecycle there are some notable differences being:

- The pattern of a +ve skew (i.e. lower LOM) at the Strategic Need Stage (3 of 3) is even more pronounced than in the grouping by alliance.

- There is a very consistent trend towards a bi-modal distribution in response to the question relating to ensuring VfM (Question F). The reasons for this are unclear but this polarisation indicates that there is scope to improve the performance of at least half the sample.

- $\quad$ There is a notable leaning towards +ve skew distribution (4 of 7) i.e. lower LOM in response to the question relating to the demonstration of VfM (Question G), again suggesting that the demonstration of VfM lags behind ensuring that VfM is achieved. 


\begin{tabular}{|c|c|c|c|c|c|c|c|c|}
\hline $\begin{array}{l}\text { Stages of Project } \\
\text { Life -cycle }\end{array}$ & Strategic need & Business case & $\begin{array}{l}\text { Procurement } \\
\text { strategy }\end{array}$ & $\begin{array}{l}\text { Selection of } \\
\text { NOPs }\end{array}$ & TCE Approval & $\begin{array}{l}\text { Readiness for } \\
\text { service }\end{array}$ & $\begin{array}{l}\text { Benefits } \\
\text { evaluation }\end{array}$ & $\begin{array}{c}\text { Typical } \\
\text { shape of } \\
\text { distribution }\end{array}$ \\
\hline $\begin{array}{l}\text { Question E - } \\
\text { Is VfM and explicit } \\
\text { project objective for } \\
\text { your Organisation? }\end{array}$ & $\underset{\text { +ve skew }}{\searrow}$ & -ve skew & $\bigcap_{\text {Bi-modal }}$ & Symmetrical & Symmetrical & $\prod_{\text {Symmetrical }}$ & $\bigwedge_{\text {Bi-modal }}$ & none \\
\hline Question F - & & & & & & & & \\
\hline $\begin{array}{l}\text { Are specific } \\
\text { measures normally } \\
\text { in place (within your } \\
\text { organisation) to } \\
\text { ensure that VfM is } \\
\text { achieved? }\end{array}$ & $\underset{\text { +ve skew }}{\nwarrow}$ & $\bigwedge_{\text {Bi-modal }}$ & $\bigwedge_{\text {Bi-modal }}$ & $\bigwedge_{\text {Bi-modal }}$ & $\bigwedge_{\text {Bi-modal }}$ & $\bigwedge_{\text {Bi-modal }}$ & $\bigwedge_{\text {Bi-modal }}$ & $\begin{array}{l}\text { Bi-modal } \\
\text { (6 of } 7 \text { ) }\end{array}$ \\
\hline Question G- & & & & & & & & \\
\hline $\begin{array}{l}\text { Are specific } \\
\text { measures normally } \\
\text { in place (within your } \\
\text { organisation) to } \\
\text { ensure that VfM is } \\
\text { demonstrated to } \\
\text { have been } \\
\text { achieved? }\end{array}$ & $\underset{\text { +ve skew }}{\searrow}$ & $\bigwedge$ & -ve skew & $\bigwedge_{\text {symmetrical }}$ & $\underset{\text { +ve skew }}{\nwarrow}$ & $\underset{\text { +ve skew }}{\searrow}$ & $\underset{\text { +ve skew }}{\varnothing}$ & $\begin{array}{l}\text { +ve skew } \\
\text { (4 of } 7 \text { ) }\end{array}$ \\
\hline $\begin{array}{l}\text { Typical shape of } \\
\text { distribution }\end{array}$ & $\begin{array}{c}\text { +ve skew } \\
(3 \text { of } 3)\end{array}$ & none & $\begin{array}{l}\text { bi-modal } \\
(2 \text { of } 3)\end{array}$ & $\begin{array}{l}\text { symmetrical } \\
(2 \text { of } 3)\end{array}$ & none & none & $\begin{array}{l}\text { bi-modal } \\
(2 \text { of } 3)\end{array}$ & \\
\hline
\end{tabular}

Notes: -

- No consistent trend to -ve skew in any question at any stage i.e. no tendency towards higher LOM.

- Consistent leaning towards +ve skew (3 of 3) in Stage 0 (Strategic need) i.e. low LOM

- Consistent bi-modal response (6 of 7) to Question F i.e. distinct division in LOM but no clear reason identified for this polarisation of responses in organisational spread - See Appendix D.5

- Leaning towards +ve skew (4 of 7) for question $\mathrm{G}-$ i.e. tendency towards lower LOM

\section{Figure 5.14 Responses to Questions regarding Level of Maturity (LOM) within each 'home' organisation}




\subsubsection{Responses to open questions regarding the preliminary VfM Framework/model.}

As described earlier, one function of the interviews was to explain the format and function of a preliminary model which had been developed by the researcher and presented in the form of a flowchart. This model was based on a combination of the findings, a detailed literature review and the researcher's personal experience of project alliances. Having presented the model to the participants a number of open questions were posed in the questionnaire which sought to obtain feedback from each of the participants regarding their views on the possible use and effectiveness of this model.

A detailed listing of the responses related to each question is provided in Appendix D.8. However the question posed and a brief summary of the response and discussion is provided below:

\section{Question:}

Do you think that such a model would be a valuable tool to those seeking to achieve and demonstrate VfM?

\section{Response/Discussion:}

There was generally a positive response suggesting that such a structured methodology was of value in introducing a systematic approach to the issue of VfM. Some believed that the model would primarily be of benefit to Owners as they would be involved in all stages of an alliance. Some comments suggested that the model rather complex and not easy to follow.

\section{Question:}

Do you see any obvious disadvantages or difficulties with the model?

\section{Response/Discussion:}

Whilst there was a range of comments to this question, the main points that were made included:

- $\quad$ The model was somewhat complicated and could be simplified.

- It could be considered as providing a structure for what was already done in practice but not systematically documented. This should ensure that it was not viewed as representing yet further work but rather collating work that was, in many cases, already undertaken.

- $\quad$ The model needed to be presented as an aid to the process of ensuring and demonstrating VfM and not simply a procedure that would involve further work without yielding any benefits. 


\section{Question:}

Any suggestions for VfM activities in the 'Readiness for Service' (Design and Construct) Stage of the model?

\section{Response/Discussion:}

This question generated a broad range of responses. Three typical responses are noted below:

- VfM process could include - VfM champion to be recognised in the organisational structure.

- Regular VfM reports on design changes - a more formal approach to be required in this phase of the project.

- An innovation register should be maintained that demonstrates value added by the alliance.

- Key Result Areas (KRA's) and Key Performance Indicators (KPI's) need to be developed which match the Client's original value proposition.

\section{Question:}

Do you have any specific suggestions regarding any of the other 6 stages of the model?

\section{Response/Discussion:}

A number of practical suggestions were received in response to this question, including:

- $\quad$ Each stage should be presented in a separate sheet for clarity.

- Should be a guide rather than too structured.

- The 'Benefit Evaluation' Stage is underdeveloped.

- VfM needs to be driven by what the customer wants rather than alliance 'selling' back to client.

\section{Question:}

Any other comments?

\section{Response/Discussion:}

Naturally this provided a wide range of responses which are fully reported in Appendix D.8. Some examples are as follows;

- I have worked with well defined \& disciplined stage gate process in a previous role \& can attest to the benefits in cost /time/quality achieved relative to earlier projects that did not have the well defined, disciplined gate approval process. Initial reaction to introduction of stage gate was perceived additional workload but the results were there at the end, both in completed and aborted projects. 
- A client will always want to achieve VfM and question if an alliance can achieve the same or better VfM when compared with other procurement models. It is, therefore, key for clients to be able to measure the effectiveness of alliance and be able to make this comparison. There have been a number of alliances where the client's budget has been a long way short of the TOC developed by the alliance. Client's budget needs to be developed and maintained to reflect costs more closely. A model would help stimulate achieving and documenting VFM, and assist in comparison of projects and procurement methods.

- The following areas could be improved in demonstrating VfM on any project:

- Key is to agree upfront (at TCE stage) the criteria of measurement and goals with client/Treasury re. VfM demonstration on any particular project.

- These criteria could be reviewed, and the (Outcomes could be measured against these criteria) Final Report can demonstrate VfM against those agreed upfront.

- Understanding of client Budget and Estimate prior to TCE process

- Nominate Champion to facilitate the process. This is pretty much a dedicated role and need to be agreed and allocated at TCE stage.

- Project RFI (Request for Information) register, Innovations register and VfM registers could be managed together as these are interrelated.

- Regular Reporting on VfM outcome to ALT \& AMT (on a monthly basis).

- Final project Report to include VfM as an important output.

These responses and the others contained in Appendix D. 8 were taken into account in further refining the model that was then circulated for comment in Phase 2. 


\subsection{Summary of Phase 1 findings}

During Phase 1 of this research some twenty-seven responses were received in the form of recorded interviews and this was then supplemented by twenty-one participants subsequently submitting completed questionnaires. This provided the researcher with a rich source of data relating to the views of participants in a number of areas being:

- Issues considered relevant to reviews of VfM at each stage of the project lifecycle (Question A)

- The perceived Level of Maturity (LOM) of VfM in the Alliances studied at each stage of the project lifecycle (Questions B, C and D)

- The perceived Level of Maturity (LOM) of VfM in the Organisations participating in these alliances at each stage of the project lifecycle (Questions E, F and G)

- Comments on the perceived value of the proposed VfM model (Open Questions)

- Comments on disadvantages and difficulties with the model (Open Questions)

- Suggestions regarding improvement and development of the model (Open Questions)

Whilst the detailed findings in each of these areas are reported in detail in the earlier text or in the various Figures contained in Appendix $D$, the following comments summarise the key finding of this phase of the research:

- Whilst a broad range of issues were noted as being relevant to $V f M$, at the point of selecting alliance partners, ethical issues (including 'Responsible and Accountable' (Eth 2) and 'Open, Honest and Trustworthy' (Eth 3)) assumed the highest status. This was particularly noteworthy given that at that the same review point, economic issues such as 'Capital Cost' and 'Whole of Life Cost' were seen as the least relevant issues. For all review points before and after the selection of the NOPs, such cost issues were seen as the pre-eminent issues. This is considered to be a fundamental finding of this research which is all the more striking when the breakdown between types of organisation is considered. Notably the Owner respondents all indicated that economic issues were not considered at that point but rather the ethical issues identified. This contrasted with the views expressed by the NOPs that economic issues carried some weight in the selection process. This outcome is seen to strongly support a theme the selection of the most appropriate partners for a project alliance should be non-price based and that experienced Owners are very conscious of this point.

- The perceived LOM regarding the assessment of each stage of the project lifecycle for both the alliances and home organisations was generally low to mid-range suggesting substantial 
scope for development to higher levels of maturity. This response confirmed the view promoted by the researcher that there was a need to develop a more systematic and methodical approach to both ensuring and demonstrating VfM in project alliances.

- Comments on the preliminary VfM model developed by the researcher were generally positive and a number of constructive suggestions were received on how the model could be improved and made clearer to potential users. This lead to a revision of the model which was subjected to further review and comment in Phase 2 of the research.

- As a result of the feedback received from this stage of the research the $\mathrm{VFM} / \mathrm{BV}$ model was modified and this updated version is presented in Appendix C.4.

\subsection{Summary of Chapter}

This chapter has described in some detail the actual research procedure that was adopted in Phase 1 subsequent to the development of the research methodology that was described in Chapter 4.

The results of Phase 1 of the research which included twenty seven interviews and the receipt of twenty one completed questionnaires were presented in detail and a number of findings are drawn following consideration of the data collected in this Phase. These include:

- The need for a tool to assist in ensuring and demonstrating VfM in project alliance was strongly supported.

- Evidence gathered supported the proposition that at the time of selecting partners for an alliance, the key issues relating to $\mathrm{VfM}$ were ethical rather than economic. Significantly this view was held most strongly by Owner participants.

- It was established that the level of maturity with the industry in assessing and recording VfM during the lifecycle of a project was generally low.

- The format of the model presented was seen as being appropriate and of value in providing structure and discipline to current practice without necessarily representing a break through development.

This chapter has documented the considerable volume of general feedback and practitioner comment that was gathered through the face to face interviews and questionnaire processes In particular the response received informed the revision to the VfM/BV Model that was undertaken prior to seeking comment for the experts who agreed to participate in the Delphi Survey which is described in Chapter 6. . 


\section{Chapter 6 - Phase 2 Research Findings}

\subsection{Introduction to Chapter}

This chapter presents the findings of Phase 2 of the research undertaken based on the methodology described in some detail earlier in Chapter 4.

During Phase 1 the researcher had undertaken some 27 hours of interview discussion with alliance practitioners and received 21 questionnaire responses which addressed the performance of actual alliances in achieving VFM. Additionally detailed feedback was received on the Preliminary VfM/BV Model that had been developed by the researcher.

Consequently, by the time that Phase 2 commenced the model had been 'road tested' and modified to reflect a number of changes and improvements that had emerged during Phase 1 . This revised model is contained in Appendix C.4.

Given the more iterative nature of the Delphi process, the responses received during Phase 2 are presented in a somewhat different manner than the 'data followed by discussion' format adopted in Chapter 5. In this case the very considerable amount of feedback received from the experts, both quantitative and qualitative, during each round is presented in a summarised form within section 6.2 of the chapter. The full date set is available in Appendices E.1 to E.3.

A discussion of the findings of Phase 2 is provided in section 6.3 and the chapter is summarised in section 6.4.

\subsection{Phase 2 Survey}

As was explained in some detail in Chapter 4, Phase 2 of the research involved a Delphi survey process which was conducted through an established externally administered web page designed specifically for such surveys. This survey took the form of 3 rounds of discussion involving 10 or 11 experts per round. Initially some 21 experts (identities protected) were contacted to seek their commitment to participate in the survey. A listing of the experts contacted is contained in Appendix C.1 which also identifies the generic backgrounds of the experts and the extent of their participation over the 3 rounds. Figure 6.1 below contains a summary of the responses obtained to each of the questions posed in Round 1 of the process. Figures 6.2 and 6.3 contain summaries of the responses received during Rounds 2 and 3 respectively. Each boxed section within these figures displays the results of a single question. Additionally, qualitative responses to each question are also summarised. The full responses to all questions are contained in Appendices E.1 to E.3 for Rounds 1 to 3 respectively. The findings for each of the three rounds are presented in sequence below. For questions which sought a qualitative response, a histogram displaying the distribution of responses is presented. 


\subsubsection{Delphi Round 1 Feedback}

Round 1 consisted of 8 questions as listed in Appendix 4.10. Questions 2, 3, 4, 7 contain both quantitative and qualitative assessments with the remaining questions being solely qualitative. It should be noted that Question 1 is absent from this table. This is a consequence of Question 1 being used as the vehicle for explaining the nature of the questions to be answered in the round. This practice was adopted in all three rounds. Full details of the responses obtained in Round 1, including the information provided in Question 1 is contained in Appendix E.1. A review of the results of Round 1 is provided below in section 5.4.1.1 and this is also provided in Appendix C. 6 which contains the briefing document circulated to the participants of Round 2. 
Round 1 Question 2

The objective of developing the framework/model is to ensure the achievement and demonstration of VfM/BV. Do you think the framework/model achieves this objective?

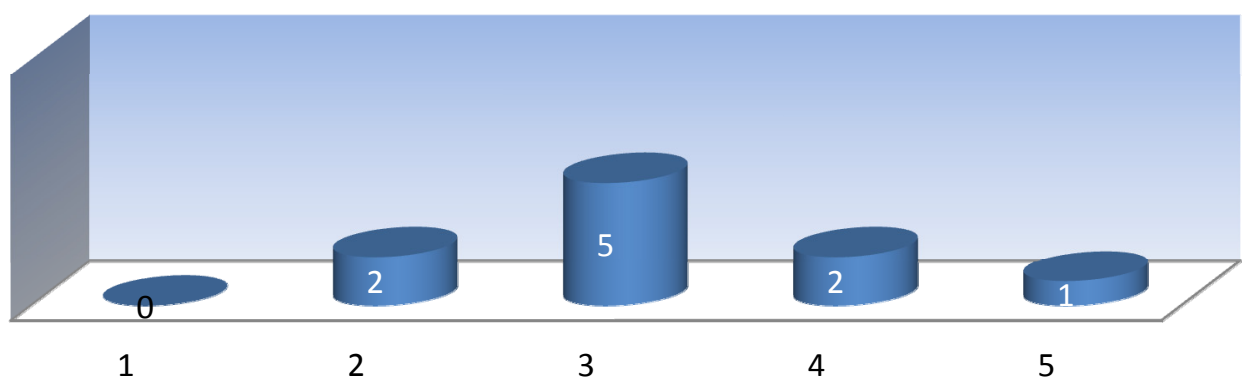

Scale: 1 (The Model fails to achieve the objective)

Scale: 5 (The Model clearly achieves the objective)

Responses: $10 \quad$ Ave $=3.20 \quad$ SD $=0.87 \quad$ Median $=3.00$

Summary of results

Quantitative

The classic 'bell shaped' response around a central mean suggesting neither a strong endorsement nor rejection of the proposition that the model is achieving the stated objective.

Qualitative

A number of respondents made the point that the model largely summarised information from existing sources but did not necessarily provide a new approach to the assessment of VFM/BV.

\section{Round 1 Question 3}

Do you think the framework/model could be a valuable tool to Owners in seeking to ensure the achievement and demonstration of VfM/BV?

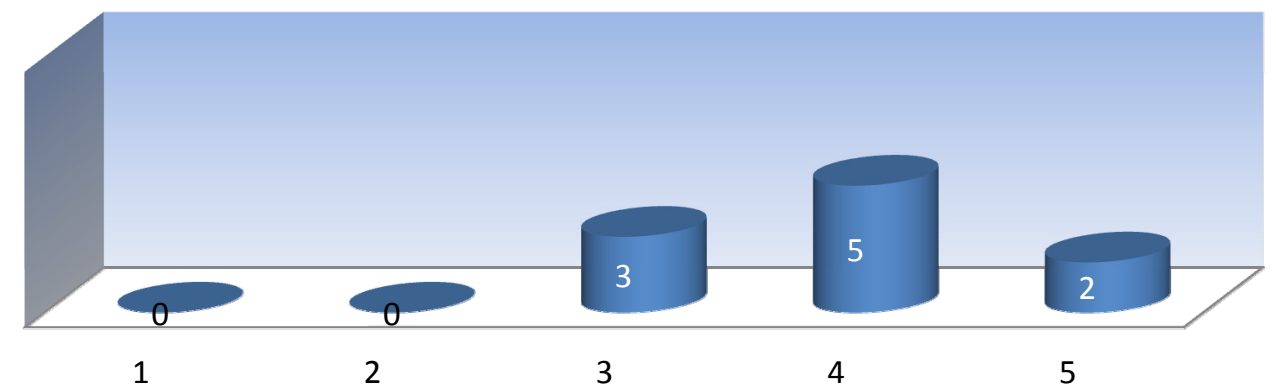

Scale: 1 (Not at all valuable)

Scale: 5 (Highly valuable) Responses: $10 \quad$ Ave $=3.90 \quad \mathrm{SD}=0.70 \quad$ Median $=4.00$

\section{Quantitative:}

A more positive response than that received to Question 2 suggesting that the model was seen as being of value to Owners.

Qualitative:

The model was seen as providing a useful 'roadmap' and standardised process for Owners which would bring discipline to the process. However, it was not seen as representing a fundamental breakthrough in the understanding or VfM/BV.

\section{Figure 6.1 Phase 2, Delphi Survey, Summarised results for Round 1}




\section{Round 1 Question 4}

Do you think the framework/model could be a valuable tool to NOPs in seeking to ensure the achievement and demonstration of $\mathrm{VfM} / \mathrm{BV}$ ?

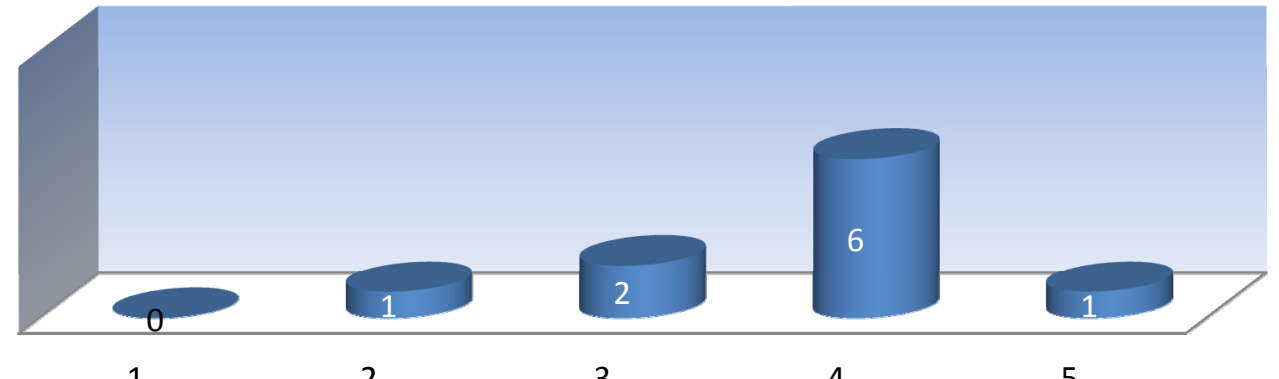

1

2

5

Scale: 1 (Not at all valuable)

Scale: 5 (Highly valuable)

Responses: $10.00 \quad$ Ave $=3.60 \quad \mathrm{SD}=0.80 \quad$ Median $=4.00$

\section{Summary of results}

Quantitative:

A slightly more positive response than that received to question 3 suggesting that the model might be seen as being of greater value to NOPs than Owners. VfM/BV.

Qualitative:

The model would enable NOPs to better understand the context in which Owners operate and seek to establish VfM/BV.

The model was seen as providing a good outline of a thorough process.

\section{Round 1 Question 5}

Do you see any particular disadvantages or difficulties with the framework/model?

\section{Summary of results}

\section{Quantitative: n/a}

Qualitative:

The disadvantages of the model which were identified included:

- The model appeared to be complex and the format was a little cumbersome. The model could benefit from redrafting as a single page 'simpler' document with 'backup' pages for each of the 7 stages.

- $\quad$ The model as drafted suited the single TOC model but did not appear to address the different sequence that was necessary if a multiple TOC approach was adopted.

- The model was largely focussed on process rather than the core issue of measuring VfM and by whom.

\section{Round 1 Question 6}

The table identifies specific VfM/BV issues that should be addressed at the end of each stage of the project lifecycle. Do you have any comments regarding the issues listed e.g. are any inappropriate or have any important issues been overlooked?

\section{Summary of results}

\section{Quantitative: n/a}

Qualitative:

The issues that were seen as inappropriate or having been overlooked included:

- $\quad$ Some of the 'red box' processes were seen as purely process and did not represent key steps in obtaining VfM/BV.

- $\quad$ As commented in the responses to Question 5, the model did not really suit a multiple TOC process and given the likely increase of such an approach in the future This could be seen a significant oversight, particularly by those critical of the degree of VfM achieved through the alliance procurement method.

- The 'Readiness for Service' stage is too 'high level' and requires further detail to drive real VfM/BV.

- The point that was made hat following a process to demonstrate that the original objective had been reached was not enough alone to demonstrate $\mathrm{VfM} / \mathrm{BV}$. The level of innovation and creativity developed by the alliance needed to be compared quantitatively and quantitatively with similar projects delivered by other procurement methods.

- Several detailed improvements to the drafting/structure of each stage were suggested.

Figure 6.1 (Continued) Phase 2, Delphi Survey, Summarised results for Round 1 


\section{Round 1 Question 7}

In the Procurement Strategy Phase of the model it is proposed that a detailed review of procurement options is undertaken progressively considering Traditional, D\&C and EOI options before considering Project Alliance options, either single or multiple TOC. The purpose of this particular activity is to clearly establish that a project alliance is the best procurement option to deliver VfM/BV for a particular project. Do you agree that this process of elimination would assist in arriving at the most appropriate procurement strategy?

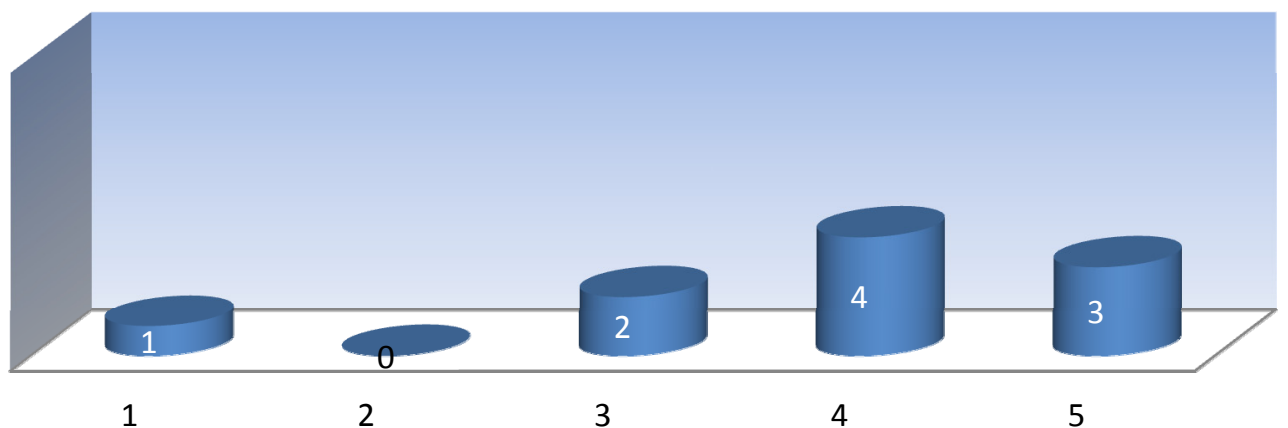

Scale: 1 (Disagree)

Responses: 10

Ave=3.80 SD=1.17 Median=4.00

Scale: 5 (Strongly Disagree)

\section{Summary of results}

\section{Quantitative:}

- There was a positive response, with one firm exception, to the suggestion that a selective elimination process would have merit.

Qualitative:

- There was general consensus that the discipline of such a process would ensure that all procurement options were systematically considered before a project alliance was adopted and that this would test the real suitability of the project to this procurement approach.

- Such a process would, however, require some sophisticated analysis and this presents a challenge to Owners who might currently use relatively 'ad hoc' decision processes.

- As commented in the responses to Question 5, the model did not really suit a multiple TOC process and given the likely increase of such an approach in the future This could be seen a significant oversight, particularly by those critical of the degree of $\mathrm{VfM}$ achieved through the alliance procurement method.

- The 'Readiness for Service' stage is too 'high level' and requires further detail to drive real VfM/BV.

- The point that was made that following a process to demonstrate that the original objective had been reached was not enough alone to demonstrate VfM/BV. The level of innovation and creativity developed by the alliance needed to be compared quantitatively and quantitatively with similar projects delivered by other procurement methods.

- Several detailed improvements to the drafting/structure of each stage were suggested.

\section{Round 1 Question 8}

The Readiness for Service (Design and Construct) Phase of the project lifecycle currently contains two activities: 1) the progressive preparation of a VfM/BV Report and 2) the continuous review of KPA's/KPI's. What specific comments do you have on the contents of these activities and are there other activities that should be adopted in this phase of the project lifecycle?

\section{Summary of results}

\section{Quantitative: n/a}

\section{Qualitative:}

A number of comments and suggestions were received including the following:

- $\quad$ These are good concepts but rarely done well. Alliances could benefit from a template but this not core business for construction professionals and they need help.

- Within the progressive VfM Report there should be a requirement to record any movements in the TOC from initial TOC to final TOC. There should also be an explanation of the reasons for any difference between the final TOC and the AOC.

- $\quad$ As commented in the responses to Question 5, the model did not really suit a multiple TOC process and given the likely increase of such an approach in the future This could be seen a significant oversight, particularly by those critical of the degree of $\mathrm{VfM}$ achieved through the alliance procurement method.

- The 'Readiness for Service' stage is too 'high level' and requires further detail to drive real VfM/BV.

- The point that was made that following a process to demonstrate that the original objective had been reached was not enough alone to demonstrate VfM/BV. The level of innovation and creativity developed by the alliance needed to be compared quantitatively and quantitatively with similar projects delivered by other procurement methods.

- Several detailed improvements to the drafting/structure of each stage were suggested.

Figure 6.1 (Continued) Phase 2, Delphi Survey, Summarised results for Round 1 
Quantitative responses for Round 1

Table 5.11 below presents the results that were obtained for the questions that sought a quantitative (scaled) response.

Table 6.1 Quantitative results from Delphi Survey, Round 1

\begin{tabular}{|c|c|c|c|c|}
\hline No. & Question & mean & $\sigma$ & Researchers Comments \\
\hline 2 & $\begin{array}{l}\text { The objective of developing the } \\
\text { framework/model is to ensure the } \\
\text { achievement and demonstration of } \\
\text { VfM/BV. Do you think the } \\
\text { framework/model achieves this } \\
\text { objective? }\end{array}$ & 3.22 & 0.92 & $\begin{array}{l}\text { A result which suggest that the } \\
\text { model, at this stage, is not seen to } \\
\text { be strongly addressing the objective } \\
\text { although it did provide a useful } \\
\text { checklist of matters that need to be } \\
\text { reviewed. }\end{array}$ \\
\hline 3 & $\begin{array}{l}\text { Do you think the framework/model could } \\
\text { be a valuable tool to Owners in seeking } \\
\text { to ensure the achievement and } \\
\text { demonstration of VfM/BV? }\end{array}$ & 3.78 & 0.63 & $\begin{array}{l}\text { The model was seen as being of } \\
\text { use to both Owners and NOPs. The } \\
\text { comments suggested that the }\end{array}$ \\
\hline 4 & $\begin{array}{l}\text { Do you think the framework/model could } \\
\text { be a valuable tool to NOPs in seeking to } \\
\text { ensure the achievement and } \\
\text { demonstration of VfM/BV? }\end{array}$ & 3.56 & 0.83 & $\begin{array}{l}\text { model was of more use to Owners } \\
\text { than NOPs but the statistics, based } \\
\text { on a small sample, suggest there is } \\
\text { little real difference. }\end{array}$ \\
\hline 7 & $\begin{array}{l}\text { In the Procurement Strategy Phase of } \\
\text { the model it is proposed that a detailed } \\
\text { review of procurement options is } \\
\text { undertaken progressively considering } \\
\text { Traditional, D\&C and EOI options } \\
\text { before considering Project Alliance } \\
\text { options, either single or multiple TOC. } \\
\text { The purpose of this particular activity is } \\
\text { to clearly establish that a project } \\
\text { alliance is the best procurement option } \\
\text { to deliver VfM/BV for a particular } \\
\text { project. Do you agree that this process } \\
\text { of elimination would assist in arriving at } \\
\text { the most appropriate procurement } \\
\text { strategy? }\end{array}$ & 4.11 & 0.74 & $\begin{array}{l}\text { A strong response that indicates } \\
\text { that the respondents considered } \\
\text { that such a process has merit. }\end{array}$ \\
\hline
\end{tabular}

\section{Qualitative responses for Round 1}

- A number of people made that point that the model largely summarised information from existing sources but did not necessarily provide a new approach to the assessment of VfM/BV.

- It was acknowledged that the model did aggregate a number of approaches in a systematic way that had not been done before and that this was seen as useful step. 
- There was a view that the model was rather complex and included too many measures, although others felt that a number of elements were missing and/or needed to be expanded. In particular, the need to address the adoption of price competition in the selection of NOPs was raised and this is discussed further below.

- The suggestion was made that there was rather too much information on a single flowchart and accompanying table and that a simpler, 7 stage, model with back-up pages conveying the detail would be easier to digest.

- It was suggested, by several experts that the model did not really address the multiple TOC process and that it should be amended to do so give the increasing use of this approach.

- It was also suggested that the model was 'loaded' towards the early stages of the project lifecycle and as a consequence might be of more value to Owners rather than NOPs (a statement not supported by the statistics shown in Table 6.1 above.)

- There was a very clear view, as confirmed in the answer to Question 7 in Table 1, that it was important to adopt a process in the procurement strategy phase of the project lifecycle that would critically analyse which procurement process was best suited to the project with a view that more conventional processes should be considered before an alliance was contemplated.

\section{Changes made to the flowchart/ model as consequence of the feedback through Round 1}

Further to these comments the following changes were made to the framework/model:

- Rather than presenting the full detail of the framework/model on one flowchart, all the VfM/BV measures from the main for 'head' flowchart were transferred to separate flowchart/tables that related to each of the seven stages of the lifecycle. This was designed to make it easier to follow the logic of the model and minimise any confusion that may have been resulting from the apparent complexity of the framework/model. The flowchart/tables for each stage of the lifecycle would also include the VfM/BV Gate issues that were previously detailed in the 'VfM/BV Reviews Table' that was attached to the original framework/model in Round 1. These lifecycle flowcharts would take a little time to develop. However, a flowchart for the 'Procurement Strategy' stage of the lifecycle that had been developed as a prototype and was attached to the Round 2 briefing paper.

- The 'head' framework/model was amended to provide a clear distinction between the single and multiple TOC processes. 
- The lifecycle flowchart/tables were intended to provide more useful benchmarks which would assist in demonstrating that VfM had been achieved at each stage of the project lifecycle.

\subsubsection{Delphi Round 2 Feedback}

Following the receipt and processing of the Round 1 responses, the results and the analyses of which is described in the preceding section, a briefing paper was prepared to be sent to all participants in advance of Round 2 (see Appendix C.6). This paper contained the analysis presented above, and a copy of a revised 'Head' framework/model, a framework/model for the 'Procurement Strategy' stage of the project lifecycle and some guidance regarding the structure and timing of the ongoing Delphi process.

The turnaround time between receipt of the Round 1 results and start of Round 2 was very short (Round 1 closed 15 November 2009, Round 2 commenced 17 November 2009). This necessitated a focussed effort by the researcher but this was required due to limited time in which the participants were available to participate and the desire to maintain the momentum of the process.

The questions posed in Round 2 were intended to gauge the respondent's reaction to:

- The results obtained from their co-respondents in Round 1

- The changes made to the model following the feedback in Round 1

- Further feedback on specific measures designed to ensure and demonstrate VfM that could be incorporated into the model.

The results obtained in Round 2 which closed on 28 November 2009, after a period of 11 days, are summarised in Figure 6.2 below. The full details of the responses gathered in Round 2 are contained in Appendix E.2. 


\section{Round 2 Question 2}

The objective of developing the framework/model is to ensure the achievement and demonstration of VfM/BV. Do you think the Revised Round 2 framework/model achieves this objective?

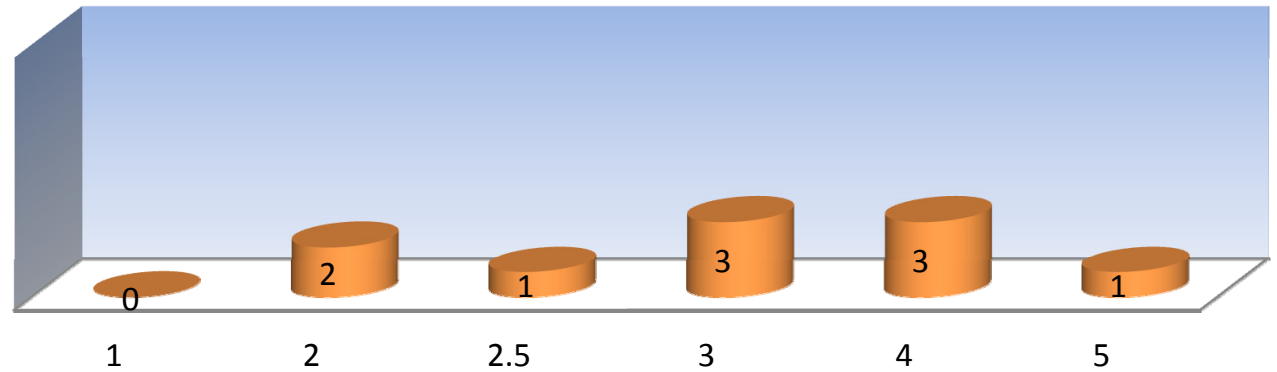

Scale: 1 (The model fails to achieve the objective)

Scale: 5 (The model clearly achieves the objective)

Responses: $10.00 \quad$ Ave $=3.25 \mathrm{SD}=0.93$ Median=3.00

\section{Quantitative:}

The average value increased from 3.2 in Round 1 to 3.25 in Round 2. However, the standard deviation increased from 0.87 to 0.93 . This represents a very slightly positive movement to support the view that the revised model better addressed the objective.

Qualitative:

The comments made by the respondents suggest a clear view that the revised model represents an improvement, particularly in terms of clarity and understanding. The recognition of the different process for the multiple TOC approach was also recognised.

\section{Round 2 Question 3}

Do you think the Revised Round 2 framework/model could be a valuable tool to Owners in seeking to ensure the achievement and demonstration of VfM/BV?

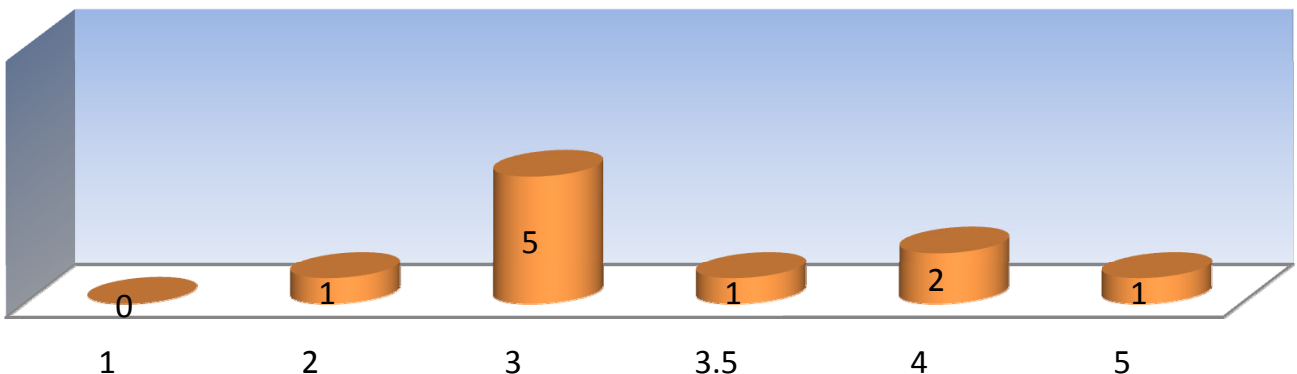

Scale: 1 (Not at all valuable)

Scale: 5 (Highly Valuable)

Responses: 10.00

Ave $=3.35 \quad \mathrm{SD}=0.78 \quad$ Median $=3.00$

\section{Summary of results}

\section{Quantitative:}

The average value declined from 3.9 in Round 1 to 3.35 in Round 2. The standard deviation increased from 0.70 .78 . This represents a tangible decline in the success of the model being of value to Owners.

\section{Qualitative:}

Despite the quantitative decline reported above the comments made by the respondents generally supported the changes made in the revised model, particularly in relation to the recognition of need to address a multiple TOC approach in a manner which addressed the Owner's requirements in relation to this matter. This apparent conflict between the quantitative and qualitative feedback would appear to be paradoxical.

Figure 6.2 Phase 2, Delphi Survey, Summarised results for Round 2 


\section{Round 2 Question 4}

Do you think the Revised Round 2 framework/model could be a valuable tool to NOPs in seeking to ensure the achievement and demonstration of VfM/BV?

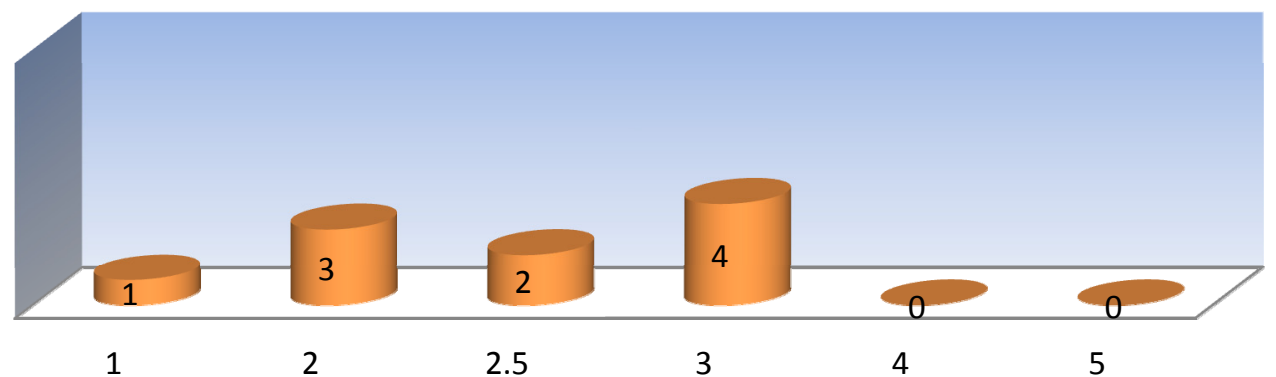

Scale: 1 (Not at all valuable)

Scale: 5 (Highly Valuable)

Responses: $10 \quad$ Ave $=2.40 \mathrm{SD}=0.68 \quad$ Median=2.50

\section{Summary of results}

\section{Quantitative:}

The average value declined from 3.6 in Round 1 to 2.4 in Round. The standard deviation decreased from 0.80 .62 . This represents a significant decline in the success of the model being of value to NOPs.

Qualitative:

Several comments reflected the view that the model was of greater value to Owners than NOPs, The changes to the model were considered by some to bring clarity but confirmed it was a an Owner's tool to others.

\section{Round 2 Question 5}

\section{Do you see any particular disadvantages or difficulties with the Revised Round 2 framework/model?}

\section{Summary of results}

\section{Quantitative:}

n/a

Qualitative:

A number of suggestions were made regarding improvements to the redrafting of the model. Some comments suggested that a critical review of the revised model was hampered by the fact that only one supporting diagram had been produce at that time. There was, however, a consistent view that the model may be best suits to the needs of Owners with the primary benefit to NOPs being an understanding and appreciation of the issues that might be important to Owners.

\section{Round 2 Question 6}

Does the Round 2 flowchart/table for the specific stage of the project lifecycle (Procurement Strategy) adequately address the VfM/BV issues that need to be addressed at this stage?

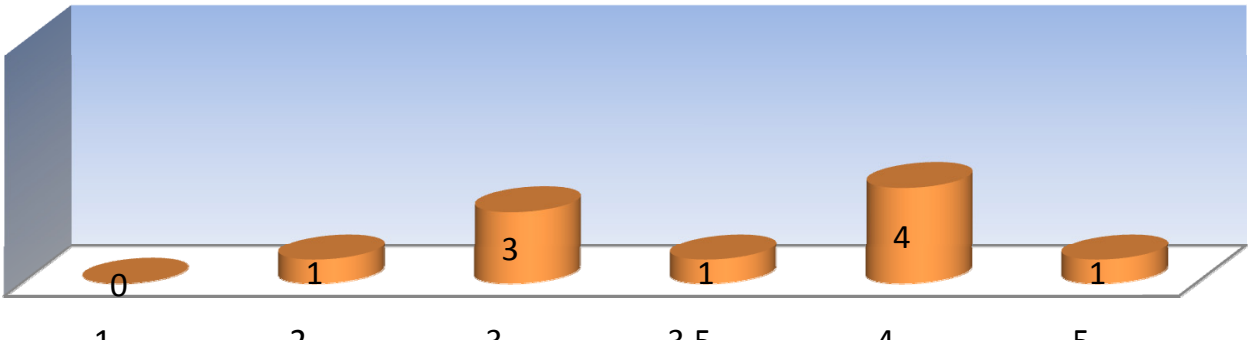

12

3.5

Scale: 5 (Highly valuable)

Scale: 1 (Not at all valuable)

Responses: 10

Ave $=3.55 \mathrm{SD}=0.79 \quad$ Median=3.75

\section{Summary of results}

Quantitative:

Whilst the mean value for the distribution was 3.55.the mode was 4 suggesting that there was a generally positive response to the question.

Qualitative:

The responses received were generally positive about the development of the flowchart/table for this stage of the project lifecycle. The structured approach was supported although comment was made that the diagram provided a series if reminders and prompts rather than offering any ground breaking developments. Others suggested that further detail or 'how to' guidance was required if VfM/BV was to be adequately addressed. 


\section{Round 2 Question 7}

In the responses to Round 1, there was strong agreement that there should be a process for progressively considering Traditional, D\&C and EOI options before considering Project Alliance options (either single or multiple TOC) in the Procurement Strategy stage. Do you think that the Round 2 flowchart/table addresses the objective of arriving at the most appropriate procurement strategy?

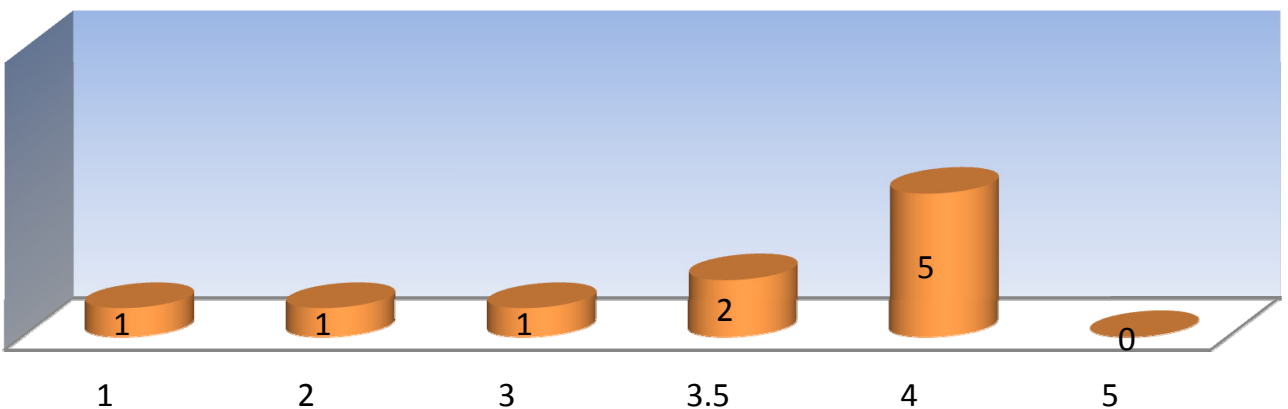

Scale: 1 (The flowchart does not address the objective) Scale: 5 (The flowchart clearly address the objective)

Responses: 10

Ave $=3.30 \quad S D=0.98 \quad$ Median $=3.75$

\section{Summary of results}

\section{Quantitative:}

Whilst a direct comparison with the result of Question 7, Round 1 is not entirely valid, the reduction in the average and median scores suggests that support for a progressive procedure to select a procurement strategy was not necessarily assisted by the revised layout.

Qualitative:

Several responses questioned whether a progressive approach was necessary which is reflected in some of the lower scores in the distribution, although, the mode of the distribution suggested that half of the respondents strongly supported the proposition that the revised flowchart addressed the objective of arriving at the most appropriate procurement strategy.

\section{Round 2 Question 8}

The 'head' flowchart (Revised Round 2 framework/model) now separately addresses a multiple TOC approach as well as the single TOC approach. Do you think this section of the flowchart adequately addresses the distinction between these options?

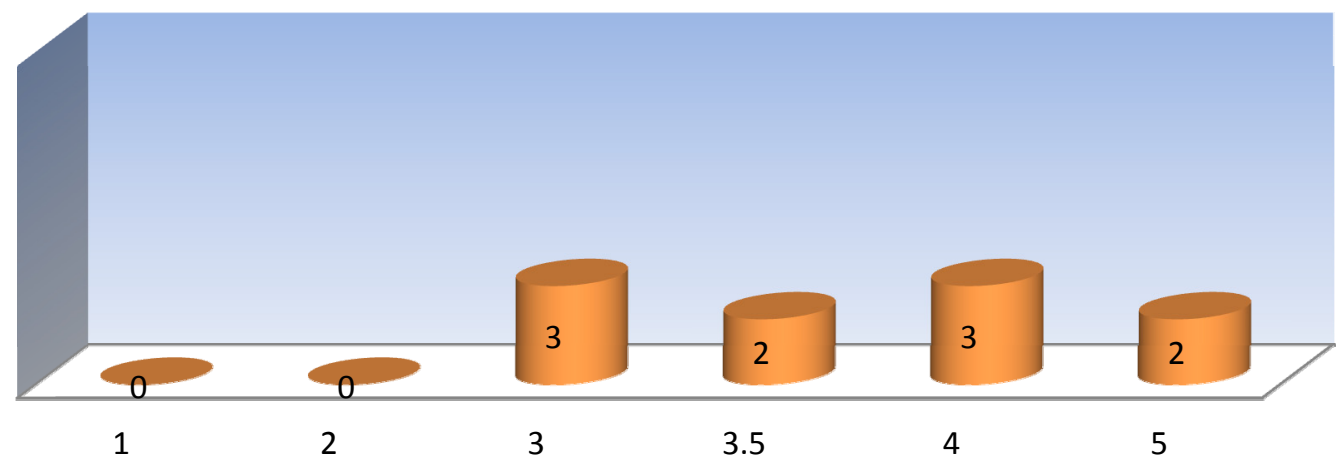

Scale: 1 (The flowchart does not adequately address the distinction) Scale: 5 (The flowchart clearly addresses the distinction)

Responses: 10

Ave=3.80 SD=0.71 Median=3.75

\section{Summary of results}

\section{Quantitative:}

The Distribution has a -ve skew indicating a tendency towards a higher score with a median value of 3.75 .

Qualitative:

Generally it was felt that the revisions to the 'head' flowchart regarding the multiple TOC approach were of value. However, some responses suggested that the distinction from a single TOC process could be clearer or that full comment was not possible until the 'stage' level flowchart had been produced.

Figure 6.2 (continued) Phase 2, Delphi Survey, Summarised results for Round 2 


\section{Round 2 Question 9}

In the responses to Round 1 (Question 8), a number of comments were received regarding the lack of detail provided for the Readiness for Service (Design and Construct) Phase of the project lifecycle. Do you have any comments additional to those provided in Round 1 (view on website) regarding activities that should be adopted in this phase of the project lifecycle?

\section{Summary of results}

\section{Quantitative: n/a}

Qualitative:

A number of commends were received including:

- $\quad$ Articulating the VFM process to be used during design and construct phases would be a good start. Readiness for service as a VFM gate could mean the project is ready for service but did/didn't achieve VFM?

- How do you show/report VfM during this phase? Suggest that NOP reports on VFM during project should link reports to Client's stated VFM values, i.e. just cost, innovation reports, issues avoided etc.

- Too many times requirements are unaligned to the opportunities that an Alliance can provide. Functional briefs and concept designs need to be challenged early in pre commencement workshops to really tease out what is possible or acceptable by the client.

- $\quad$ The AMT should be undertaking monthly reviews of the VfM Criteria (VfM Proposition produce by the Owner).

\section{Round 2 Question 10}

What other comments or suggestions do you have for improving either the Round 2 Revised Framework/model or the Round 2 flowchart/table?

\section{Summary of results}

\section{Quantitative: n/a}

Qualitative:

A number of comments were received including;

- $\quad$ Better definition of what the project was supposed to deliver would help in defining VfM and might help to address the distinction between a healthy project in VfM terms and VfM

- $\quad$ Reference is made in the flowchart to 'output based specifications. Too many clients have very prescriptive specifications. Alliances require a different approach to D\&C contracts in this regard if innovation is to be allowed to develop.

- As early as possible in the Business case development the Owner to employ specialists who can develop credible programs and cost plans.

Figure 6.2 (continued) Phase 2, Delphi Survey, Summarised results for Round 2 
Quantitative responses for Round 2

Further to some comments in Round 1 that the flowchart was too busy and rather hard to follow. The format was changed to comprise a 'head' flowchart' with separate flowcharts for each stage of the life cycle. Based on the qualitative comments on this revision, most respondents appeared to find this change of format useful although one respondent specifically indicated that the original format was preferred. This generally acknowledged 'improvement' is quantitatively reflected in the small increase in the mean response from 3.2 to 3.25 for Question 2 as shown on the table below. However, when Questions 3 and 4 were raised again in Round 2 the responses indicated a lower level of agreement that the framework/model could be a valuable tool to the Owner and NOPs respectively, compared to the model provided in Round 1. The quantitative results for Questions 3 and 4 are shown in the table below.

These results suggest that whilst the revised model was seen as marginally more successful in addressing the original objective of ensuring an demonstrating $\mathrm{VfM} / \mathrm{BV}$, the value of the revised model was seen as somewhat less to Owners and significantly less for NOPs. This feedback was considered to be a little confusing and consequently in Round 3 some further questions were posed to clarify whether the separation of the 'Head' and 'Stage' model was perceived to be an advantage or disadvantage in addressing VfM/BV issues.

\section{Table 6.2 Quantitative results from Delphi Survey, Round 2}

\begin{tabular}{|c|c|c|c|}
\hline $\begin{array}{l}\text { Question } \\
\text { no. }\end{array}$ & Question raised in Round 1 and Round 2 & $\begin{array}{l}\text { Score in Round } \\
1 \\
\text { mean, }(\sigma) \\
\text { median }\end{array}$ & $\begin{array}{l}\text { Score in Round } \\
2 \\
\text { mean, }(\sigma) \\
\text { median }\end{array}$ \\
\hline 2 & $\begin{array}{l}\text { The objective of developing the } \\
\text { framework/model is to ensure the } \\
\text { achievement and demonstration of VfM/BV. } \\
\text { Do you think the framework/model achieves } \\
\text { this objective? }\end{array}$ & $3.2,(0.87), 3$ & $3.25,(0.93), 3$ \\
\hline 3 & $\begin{array}{l}\text { Do you think the framework/model could be a } \\
\text { valuable tool to Owners in seeking to ensure } \\
\text { the achievement and demonstration of } \\
\text { VfM/BV? }\end{array}$ & 3.9, $(0.70), 4$ & $3.35,(0.78), 3$ \\
\hline 4 & $\begin{array}{l}\text { Do you think the framework/model could be a } \\
\text { valuable tool to NOPs in seeking to ensure the } \\
\text { achievement and demonstration of VfM/BV? }\end{array}$ & 3.6, $(0.80), 4$ & $2.4,(0.62), 2.5$ \\
\hline
\end{tabular}


Qualitative responses for Round 2 (researcher's responses in italics)

- A comment was made that only one of the 'supplementary' flowcharts addressing the particular stages of the life cycle had been included in the revised framework/model presented in Round 2 and this made it difficult to evaluate the overall framework. This point was acknowledged in the briefing paper for Round 3 indicating that further supplementary flowcharts would be developed.

- As commented upon in Round 1, a view was expressed by some respondents that whilst the framework/model presented current practice in a systematic manner that might not have been done before, it did not take 'a new step forward' at this point. This point was also acknowledged in the Briefing Paper to Round 3 indicating that in completing the research task new insights or approaches may emerge.

- It was suggested by several respondents that the framework/model was a tool that would be of greater value to Owners' than NOPs and this was perhaps reflected to a degree in the responses to Questions 3 and 4. It was noted, however, that the framework/model might enhance NOPs' understanding of the issues that an Owner faces in contemplating a project alliance. This point was noted.

- The specific identification of a separate route for multiple TOC alliances was seen to be positive step although the view was expressed that the steps identified were too similar to the single TOC route. This comment was addressed in later changes to the model.

- The comment was made that the 'flow' of the 'supplementary' flowcharts should run in the same direction as the 'master flowchart'. This comment was subsequently addressed.

- Some comments were made regarding measures that could be adopted during the Design and Construction phase of a project but this phase continued to be 'lightly populated' in terms of specific VFM/BV initiatives. A number of specific measures were specifically added to the model to address this comment.

Changes made to the flowchart/ model as result of feedback in Round 2 No specific changes were made to the model which was circulated in Round 3 of the process, although it was indicated to the participants in Round 3 that further changes were likely to be made following a more comprehensive review of the detailed feedback from both Round 1 and 2 . 


\subsubsection{Delphi Round 3 Feedback}

In similar fashion to the procedure followed earlier, a paper summarising the results of Round 2 was circulated to each participant (see Appendix C.8). This paper acted as a briefing paper for Round 3. Whilst no revised framework/model was attached to this paper, a brief document summarising the key findings of the recently produced 'In Pursuit of Additional Value' publication published by the Victorian Department of Treasury and Finance (VDTF) in November 2009 was attached. This intention of circulating this document was to gain some feedback on the key findings. Such a measure had been proposed in the briefing paper to Round 1 (Appendix C.4) as coincidentally the VDTF document, which was considered to be highly relevant to questions posed in this Delphi Survey, was actually published on the same date that Round 1 commenced.

Consequently in Round 3 some questions were posed regarding the previously discussed material whilst other questions focused on the content of the VDTF report.

The turnaround time between receipt of the Round 2 results and start of Round 3 was again very short (Round 2 closed 28 November 2009, Round 3 commenced 4 December 2009). This necessitated a focussed effort by the researcher but this was required due to limited time in which the participants were available to participate and the desire to maintain the momentum of the process.

The questions posed in Round 3 were intended to gauge the respondent's reaction to:

- The results obtained from their co-respondents in Round 2

- Some specific questions regarding apparent anomalies between the responses received in Rounds 1 and 2.

- Feedback on some of the specific measures presented in the Key Findings of the recent VDTF research report 'In Pursuit of Additional Value'. These findings were considered to be of particular relevance to the proposed BV/VfM model.

The results obtained in Round 3 which closed on 13 December 2009 are summarised in Figure 6.3 below. The full details of the responses gathered in Round 2 are contained in Appendix E.3. 


\section{Round 3 Question 2}

In both Round 1 and Round 2 the question was asked whether the framework/model could be valuable to the Owner in seeking to ensure the achievement and demonstration of VfM/BV (Question 3 in both rounds). Following the revision of the framework/model in Round 2, which was intended to clarify the content, satisfaction with the framework/model decreased (3.9 to 3.25 ).

In order to further test this outcome the following question is posed - Compared with the Round 1 framework/model, to what extent do you agree that the Revised Round 2 framework/model is more useful to Owners?

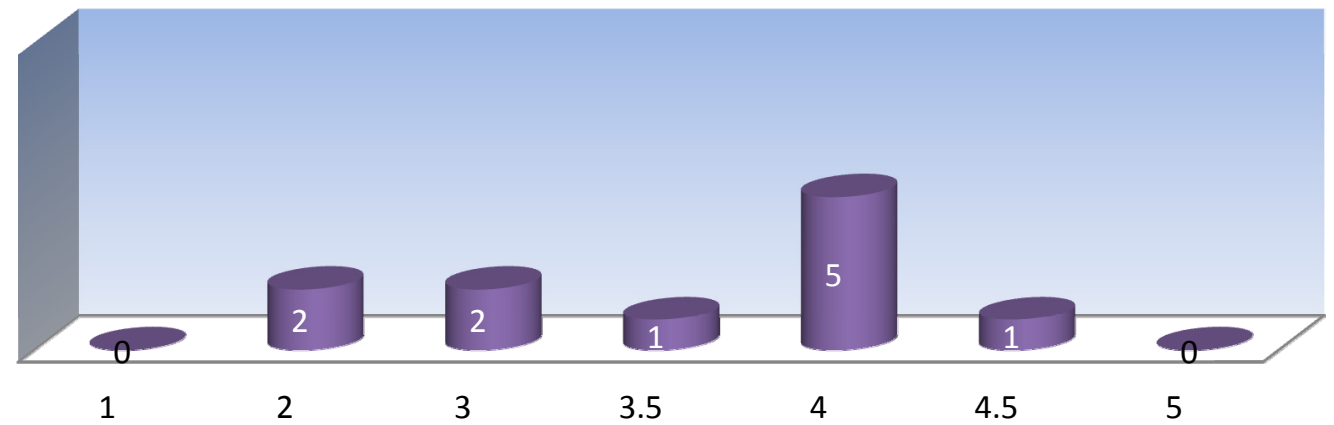

Scale: 1 (The flowchart does not adequately address the distinction) Scale: 5 (The flowchart clearly addresses the distinction)

Responses: 11

Ave $=3.45 \quad \mathrm{SD}=0.81 \quad$ Median $=4.00$

\section{Summary of results}

Quantitative:

The distribution has a -ve skew i.e. leaning towards an improvement for Owners.

Qualitative:

Whilst there is general consensus that the revised framework/model represents an improvement two respondents in particular remain unconvinced.

\section{Round 3 Question 3}

In both Round 1 and Round 2 the question was asked whether the framework/model could be valuable to the NOPs in seeking to ensure the achievement and demonstration of VfM/BV (Question 4 in both rounds). Following the revision of the framework/model in Round 2, which was intended to clarify the content, satisfaction with the framework/model substantially decreased (3.6. to 2.4). In order to further test this outcome the following question is posed - Compared with the Round 1 framework/model, to what extent do you agree that the Revised Round 2 framework/model is more useful to NOPs?

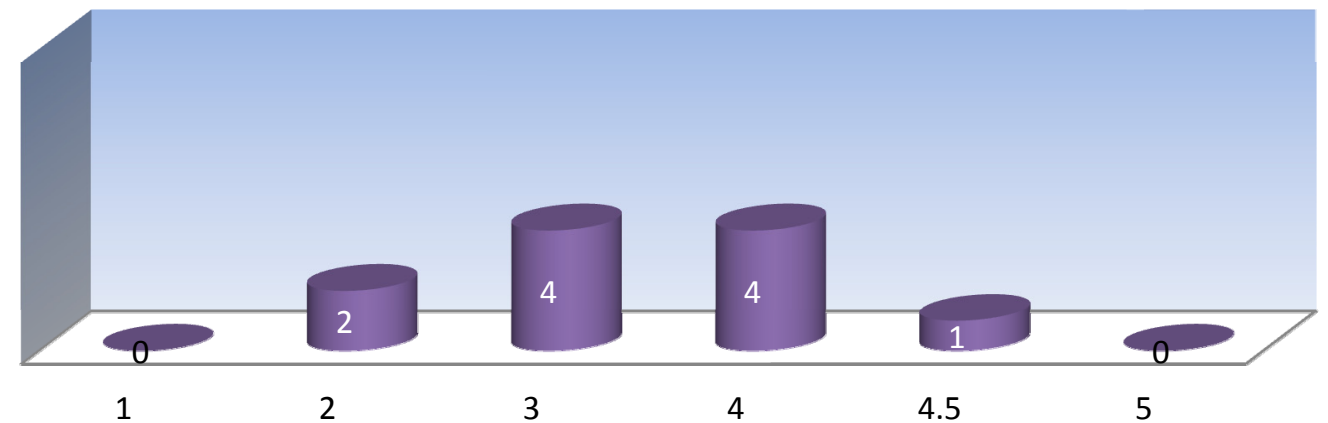

Scale: 1 (Strongly disagree)

Scale: 5 (Strongly agree)

Responses: $11 \quad$ Ave $=3.32 \mathrm{SD}=0.81$ Median=3.00

Summary of results

Quantitative:

The distribution is essentially symmetrical with a slight +ve skew i.e. slight leaning towards a negative response

Qualitative:

In contrast to the response to Round 3, Question 2 concerning the benefit to Owners, the response to this question suggests that whilst the revised model has some advantage it is less obvious.

Figure 6.3 Phase 2, Delphi Survey, Summarised results from Round 3 


\section{Round 3 Question 4}

The VDTF Report comments that 'Alliance projects are often associated with uncertainty and complexity. This requires greater, not less, rigour in the business case to ensure that adequate anchoring, benchmarking and guidance is provided to the alliance team as the project progresses. As a minimum the business case should include the value proposition which incorporates the project objectives, agreed funding of 'externalities' (for example environmental works, stakeholder relations) and a robust cost plan. It should (barring sections subject to confidentiality) be made available to the alliance team'. To what extent do you agree with this statement?

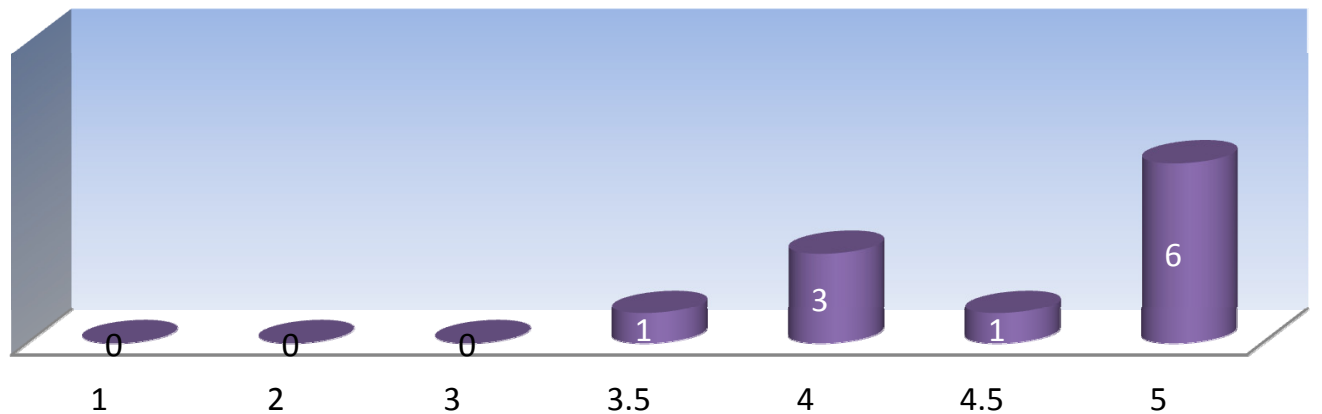

Scale: 1 (Strongly disagree)

Scale: 5 (Strongly agree)

Responses: $11 \quad$ Ave $=4.55 \mathrm{SD}=0.54 \quad$ Median $=5.00$

\section{Summary of results}

Quantitative:

The distribution represents a strong -ve skew i.e. a strong trend towards positive agreement to the question posed Qualitative:

Some comments make the point that this question asks respondents to agree with what is almost a 'truism' and consequently any other result would have been most unexpected.

\section{Round 3 Question 5}

The VDTF report comments that 'Current alliance procurement guidelines recommend selecting NOPs using predominately non-price criteria. This does not always reflect good government procurement practice which requires price to be included as a significant criterion. Whilst price competition is not appropriate in all circumstances, it should be required as a default position'. To what extent do you agree with this statement?

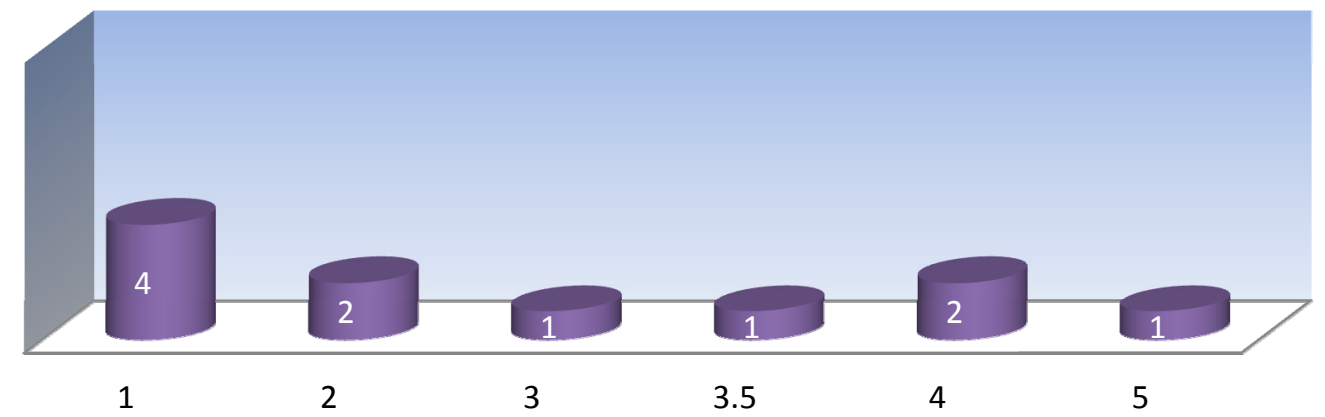

Scale: 1 (Strongly disagree)

Scale: 5 (Strongly agree)

Responses: $11 \quad$ Ave $=2.50 \quad \mathrm{SD}=1.40 \quad$ Median=2.00

\section{Summary of results}

Quantitative:

Whilst the mode of the distribution represents a strong disagreement with the proposition of the question this is a very diverse distribution suggesting a lack of consensus.

Qualitative:

Of all the questions asked during this Delphi process, this question and the succeeding question regarding outstanding outcomes in project alliances resulted in the widest spectrum of responses with a bimodal patter emerging i.e. two camps emerging. One camp strongly disagreed that 'price competition' should be the default strategy and another agreed that is should be, albeit not as strongly.

Figure 6.3 (continued) Phase 2, Delphi Survey, Summarised results for Round 3 


\section{Round 3 Question 6}

The VDTF Report comments that 'Outstanding outcomes ('paradigm shift', 'not been done before') are often sought by Owners when selecting the alliance delivery method and they are generally a requirement in the PAA. However, there was little evidence that outstanding outcomes are being achieved despite significant investment in 'high performance teams'. To what extent do you agree with this statement?

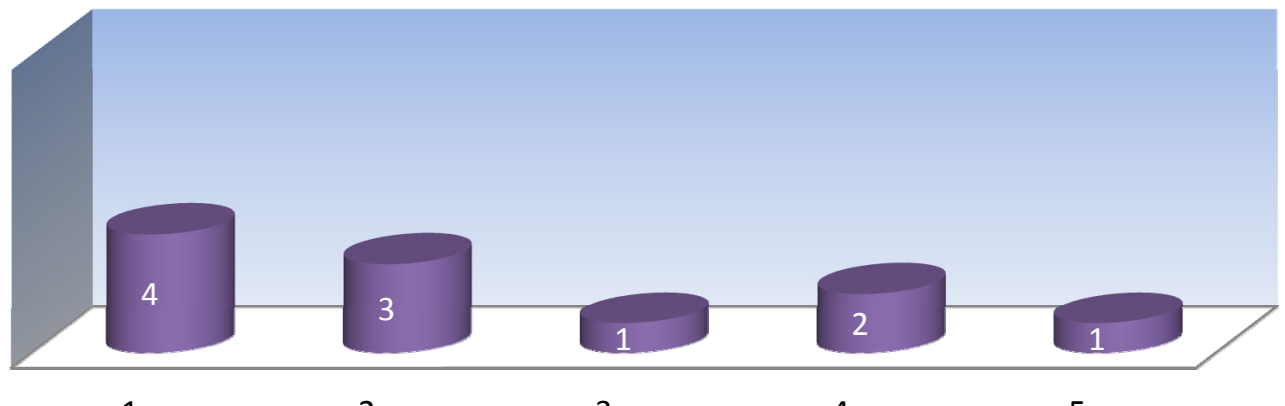

1

2

3

4

5

Scale: 1 (Strongly disagree)

Scale: 5 (Strongly agree)

Responses: $11 \quad$ Ave=2.36 SD=1.37 Median=2.00

Summary of results

Quantitative:

As per Question 5 above, whilst the mode of the distribution represents a strong disagreement with the proposition of the question, this is a very diverse distribution suggesting a lack of consensus.

Qualitative:

Of all the questions asked during this Delphi process, this question and the proceeding question concerning the mandatory adoption of a multiple TOC approach resulted in the widest spectrum of responses with a bimodal pattern emerging i.e. two camps emerging. One camp strongly disagreeing that 'outstanding outcomes' are achieved in project alliances and another agreeing that there little evidence to support the proposition that such outcomes are achieved, albeit not as strongly.

\section{Round 3 Question 7}

Following the suggestion of one of your fellow research participants, would you willing to participate in a telephone conference hook-up with the other Delphi survey participants (to be scheduled for late January 2010) to further discuss the current status of the framework/model and its effectiveness in achieving and demonstrating VfM/BV?

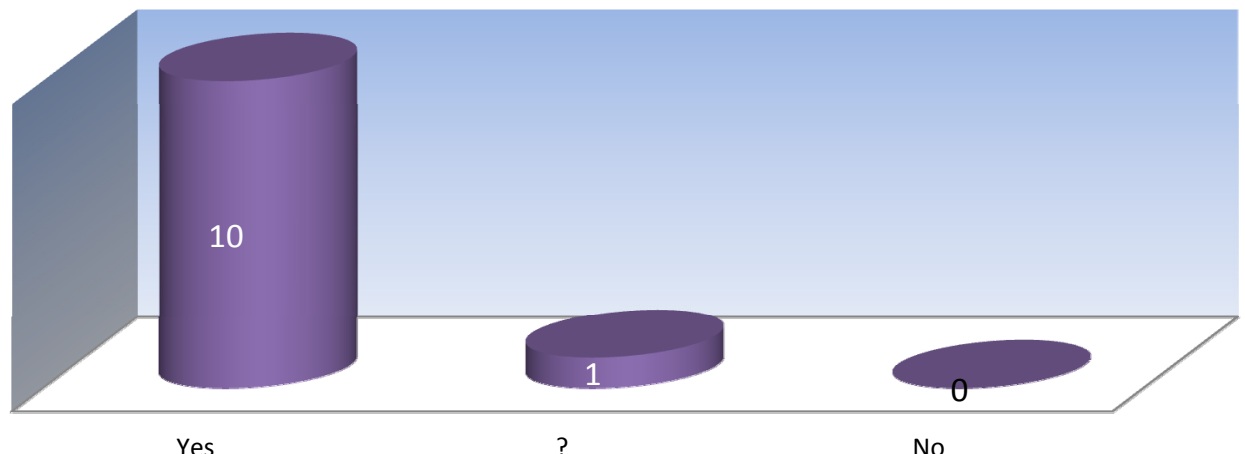

Responses: $11 \quad$ Ave=1.05 SD=0.14 Median=1.00

\section{Summary of results}

Quantitative:

There is a very substantial majority answering yes to this question with only one respondent expressing any doubt.

Qualitative:

Whilst there was a strong support to the proposition of organizing a telephone hook up with one respondent expressing concerns about the likelihood of achieving consensus and concerns about the loss of anonymity. Respecting that comment regarding anonymity which was a basic condition of approaching the experts involved and given that it took much longer to process and analysis the results of the research than was first anticipated the January 2010 was unrealistic.

\section{Figure 6.3 (continued) Phase2, Delphi Survey, Summarised results for Round 3}




\section{Quantitative responses for Round 3}

As described above, Round 3 consisted of two distinct parts. Questions 2, 3 and 4 sought to clarify some apparent anomalies between the results obtained in Rounds 2 and 3 whilst the later questions 4, 5 and 6 sought to obtain some feedback on some specific findings in VDTF publication 'in Pursuit of Additional Value' which had recently been released, in draft form, and related to matters being investigated by this research.

The responses to the questions (Questions 2 and 3) asked regarding the relative value of the respective measures of the framework/model in Rounds 2 and 3 are shown in the Table 6.3 below. The responses indicate that the revised model, as presented in Round 2, is seen to be of increased value to both Owners and NOPs. However, the framework/model is seen to be inherently of more value to Owners. This result is supported by the qualitative comments made by participants in both Phase 1 and Phase 2 of this research.

Question 4 asked participants to comment on the extent they agreed with the finding that 'Business cases should be improved and made available to the alliance team'. This question met with a very positive response (mean $=4.55, \sigma=0.54$, median $=5$ ). Such a response was perhaps not surprising given that it was unlikely that the sentiment of the finding would be objected to, and again, was consistent with the feedback obtained throughout both Phase 1 and Phase 2 of the research.

Question 5 asked participants to comment on the finding that 'Whilst price competition was not appropriate in all circumstances it should be required as the default position in selecting NOPs. This question met with a negative response ( mean $=2.5, \sigma=1.4$, median $=2$ ) although there was some spread in the results with 4 of 11 responses being higher than mid value suggesting a minority do agree with the VDTF position on this issue.

Question 6 asked participants to comment on the finding that 'There was little evidence that outstanding outcomes are being achieved despite significant investments in high performance teams'. This also received a negative response (mean $=2.36, \sigma=1.37$, median $=2)$. The histogram of this response as shown on Figure 6.3 indicates seven of the eleven participants polled disagreed or strongly disagreed with this statement. Consequently, whilst the result was not unanimous, a significant majority take an alternative view to the position seemingly established by the VDTF Research. 
Finally, respondents were asked whether they would be prepared to participate in a telephone hookup with the other participants. Whilst there was a strong support to the proposition of organizing a telephone hook-up with only one respondent expressing concerns about the likelihood of achieving consensus and the loss of anonymity. Respecting that comment regarding anonymity which was a basic condition of approaching the experts involved and given that it took much longer to process and analysis the results of the research than was first anticipated the January 2010 telephone hookup did not take place.

\section{Table 6.3 Quantitative results regarding reflective value of framework/model}

\begin{tabular}{c|ll}
\hline $\begin{array}{l}\text { Question } \\
\text { no. }\end{array}$ & Question raised in Round 3 & $\begin{array}{l}\text { Score in Round 3 } \\
\text { mean, }(\sigma), \text { median }\end{array}$ \\
\hline 1 & $\begin{array}{l}\text { Compared with Round 1 framework/model, to } \\
\text { what extent do you agree that the Revised } \\
\text { Round 2 model is more useful to Owners? }\end{array}$ & $3.45,(0.81), 4$ \\
\hline 2 & $\begin{array}{l}\text { Compared with the Round 1 framework/model } \\
\text { to what extent do you agree that the Revised } \\
\text { Round 2 model is more useful to NOPs? }\end{array}$ & $3.32(0.81), 3$ \\
\hline
\end{tabular}

Changes made to the flowchart/ model as result of feedback in Round 3

Extensive changes were made to the model following Round3. These changes primarily related to the development of a separate flowchart/table for each stage of the lifecycle. These changes are shown in the final version of the framework/model presented in Chapter 8.

\subsection{Discussion of Phase 2 findings}

An objective when adopting the Delphi method of research is to obtain a degree of consistency, or at least a clear understanding of the groupings of opinions that might exist within the subject group of experts. It was felt that after 3 rounds a reasonably clear understanding of the views of the experts had emerged and that a further round would not add further insights.

The comments offered by the group of experts during the Delphi Survey were particularly useful in developing the VfM/BV model in that they were frank, informed and in many instances quite detailed. Many of the comments were supportive of the model as drafted whilst others were more critical and suggested changes that might be contemplated to improve the function and usefulness of the model. 
These comments can be divided into a number of specific categories. Table 6.4 below defines these categories and indicates how those comments, which suggested improvements, were addressed in the further development of the model.

As described above, Round 3 of the Delphi Survey included some questions regarding some of the findings of the recently published research by the VDTF into VfM in project alliances which were considered to particularly relevant to the proposed model. The responses received from the experts, particularly Question 5 regarding the use of price based selection criteria for the selection of NOPs indicated that there was a wide range of views on this issue. It became apparent to the researcher that the publication of the VDTF research was such a significant event in the development of project alliance procurement in Australia, it would be necessary to carefully consider the impact of this document on the model that had been developed to that point. This realisation was further confirmed by the release of subsequent publications by the VDTF, particularly Guidance Note No. 4 'Reporting VfM Outcomes in Alliance Contracting'. The content of the VfM publications is outlined in Chapter 7. The degree of alignment of the BV/VfM model developed through this research and the outcomes of the VDTF research is also explored in Chapter 7. 


\section{Table 6.4 Response to the expert comments received through the Delphi Survey process}

\begin{tabular}{|c|c|c|}
\hline Category of comment & Specific points raised & $\begin{array}{l}\text { Response in the development of the } \\
\text { BV/VfM Model }\end{array}$ \\
\hline $\begin{array}{l}\text { Purpose and function } \\
\text { of the model }\end{array}$ & $\begin{array}{l}\text { - The purpose of the model needed } \\
\text { to be clearer. } \\
\text { - The model did not appear to } \\
\text { break 'new ground'. }\end{array}$ & $\begin{array}{l}\text { The purpose and function of the model } \\
\text { are now clearly addressed in the 'Cover } \\
\text { Sheet 'of the model. } \\
\text { The ordered, structured and more } \\
\text { methodical and repeatable approach } \\
\text { suggested by the model is the } \\
\text { contribution that it makes to alliance } \\
\text { procurement practice. } \\
\text { The degree of 'alignment' of the model to } \\
\text { the IASC/VDTF VfM publications as } \\
\text { discussed later in this thesis is considered } \\
\text { to provide further evidence of the } \\
\text { contribution that the model offers to } \\
\text { alliance practitioners (see Chapter } 7 \text { ). }\end{array}$ \\
\hline $\begin{array}{l}\text { Layout and legibility } \\
\text { of the model }\end{array}$ & $\begin{array}{l}\text { - The model appeared to be } \\
\text { complex and cumbersome. } \\
\text { - Several suggested drafting } \\
\text { changes were identified. }\end{array}$ & $\begin{array}{l}\text { The architecture of the model was } \\
\text { radically changed to provide a 'Summary } \\
\text { level flowchart' and separate charts for } \\
\text { each stage of the project lifecycle. } \\
\text { These changes improved the legibility and } \\
\text { ease of use of the model. }\end{array}$ \\
\hline $\begin{array}{l}\text { Failure to address } \\
\text { price competitive } \\
\text { selection process }\end{array}$ & $\begin{array}{l}\text { - The model only considered a } \\
\text { single TOC approach. } \\
\text { - The model needed to address the } \\
\text { increasing use of a multiple TOC } \\
\text { approach. }\end{array}$ & $\begin{array}{l}\text { The model was amended to specifically } \\
\text { address the use of price completion in the } \\
\text { section of NOPs. A specific chart for the } \\
\text { 'Development of the project proposal and } \\
\text { TOC approval - Multiple TOC' approach } \\
\text { was produced (see Stage E, Chapter } 8 \text { ). }\end{array}$ \\
\hline $\begin{array}{l}\text { Coverage of the } \\
\text { model }\end{array}$ & $\begin{array}{l}\text { - The model dwelt on the early } \\
\text { stages of the project lifecycle and } \\
\text { need to address the later stages in } \\
\text { more detail. } \\
\text { - Given the 'front end' focus of the } \\
\text { model it was seen to be more of } \\
\text { an Owner's tool. }\end{array}$ & $\begin{array}{l}\text { It was considered important to maintain } \\
\text { the level of content relating to the early } \\
\text { stages of the lifecycle on the basis that } \\
\text { the foundation of VfM needs to be } \\
\text { created in these early stages. However, } \\
\text { the content of the model relating to the } \\
\text { later stages of the lifecycle was expanded } \\
\text { and developed in the final model (see } \\
\text { Chapter 8). } \\
\text { These changes are believed to make the } \\
\text { model equally useful to all parties and not } \\
\text { just the Owner. }\end{array}$ \\
\hline $\begin{array}{l}\text { Details of VfM } \\
\text { questions }\end{array}$ & $\begin{array}{l}\text { The model needed to provide } \\
\text { more specific guidance re VfM } \\
\text { questions in each stage of the } \\
\text { lifecycle. } \\
\text { - Practical suggestions for VfM } \\
\text { during the construction stage } \\
\text { were not well addressed. }\end{array}$ & $\begin{array}{l}\text { As discussed above in relation to } \\
\text { coverage of the model, each chart } \\
\text { corresponding to a specific stage of the } \\
\text { project life cycle was developed to pose } \\
\text { the relevant VfM questions to be } \\
\text { addressed at the major milestones and } \\
\text { during the VfM/BV Gate Review at the } \\
\text { end of each stage. }\end{array}$ \\
\hline
\end{tabular}




\subsection{Summary of Chapter}

This chapter has described in some detail the actual research procedure that was adopted in Phase 2 subsequent to the development of the research methodology that was described in Chapter 4.and the outcome of Phase 1 of the research as described earlier in Chapter 5.

The primary findings from Phase 2 were;

- The experts (with some qualifications) also supported the model as being a way of summarising and formalising current best practice.

- A number of constructive suggestion were made to improve the model and this resulted in a substantial re drafting of the model to incorporate a 'head' flowchart and supplementary flowchart/tables for each of the seven stages of the project lifecycle.

Additionally, this chapter described the feedback that was obtained to questions in Round 3 of the Delphi process that were posed regarding some of the key findings of the VDTF publication 'In Pursuit of Additional Value'. Whilst such questions may be seen as being unconnected with the VfM model developed by the researcher, it was considered that they were, in fact, of direct relevance to some of the findings that emerged from Phase 1 and particularly Phase 2 of the research i.e. accessibility to the original Business Case for the project, the advantages and disadvantages of adopting of a multiple TOC approach in the selection of alliance partners and the evidence of outstanding performances in alliances.

This chapter, and the associated appendices (E.1 to E.3), have documented the considerable volume of feedback that was obtained from the experts who kindly participated in the Delphi survey process. A number of general findings have been developed from this material and are documented within the chapter. They are also reflected in the detail of the final VfM/BV Model that is described in presented in Chapter 8. 


\section{Chapter 7 - The work of the Inter- jurisdictional Alliancing Steering Committee (IASC)}

'There is nothing more difficult to take in hand, more perilous to conduct or more uncertain in its success than to take the lead in the introduction of a new order of thing'.

Niccolo Machiavelli

\subsection{Introduction}

The research described in this thesis was contemplated over an extended period. The timing of the process can be summarised as follows (also see Figure 4.9 which details the chronology of the research task):

- Background, 'Reflective Learning' and 'Thesis Preparation' papers which were used to develop the theme of this research were produced between late 2006 and late 2007.

- The consent of the parties concerned to allow access to a number of alliance projects, during Phase 1 of the research, was obtained in November 2008.

- The necessary RMIT Human Research Ethics Committee approval was also obtained in November 2008.

- The data gathering process, including both Phase I and Phase 2 as described in Chapter 4, occurred in the second half of 2009 followed by processing and review of the data in 2010.

As with most fields of management science, the literature in the field has been active during this period with work being undertaken by a number of parties who have contributed to the collective knowledge and understanding in the field of Value for Money (VfM) generally and in project alliance procurement in particular. The work considered to most relevant is identified and reviewed in both Chapter 2, which provides a general literature review, and Chapter 3 which presents the background to the development of a Preliminary Research Model.

However, due to significant developments in the field that have taken place during the data gathering phase of this research, the researcher believes that is necessary describe to the work concerned to ensure the currency of this thesis.

The work being referred to is a very substantial program, initially of research and then publication of new policy, procedural and guidance documents, undertaken by the Inter-jurisdictional Alliancing Steering Committee (IASC) or its members. This committee was formed in 2009 by the Treasuries of the States of Victoria, New South Wales, Western Australia and Queensland. This committee has 
been chaired by a representative of the Victorian Department of Treasury and Finance (VDTF) who have been the main driving force behind the body. The Commonwealth Government subsequently joined the IASC in August 2010 (DOIT, 2010). This committee, in turn, engaged the University of Melbourne to assist in the research component of this work and engaged Evans and Peck Pty Ltd (E\&P), a management consultancy practice specialising in construction procurement, to assist in both the research phase of this work and the later development of policy and procedure.

In this chapter the work, which will be referred to as IASC Research, will be briefly described and comparisons made between the outcomes that research and the work described in his thesis.

Additionally, a review is provided of the publications that largely resulted from the IASC Research, for which the lead sponsor and publisher has primarily been the VDTF. These documents will be referred to as the IASC/VDTF Publications.

This chapter concludes with a direct comparison of the approaches proposed to address VfM in project alliances as result of the two research activities. This includes the identification of the characteristics which they have in common and were they differ. The aspects, in which both approaches may be considered to be deficient, and capable of further development, are also briefly discussed.

\subsection{IASC Research and Publications}

The timeframe of the research work extended from the commencement of data gathering, in May 2009 , to the formal release of results from both phases of this research, in late 2009. As briefly described above, various policies, procedural and guidance materials were published subsequent to this work during 2010 and early 2011, primarily by the VDTF. A detailed listing of the documents that have been published both during and following the IASC Research is presented in Table 7.1 below. This table also outlines the content of these documents and incorporates some brief comments regarding this content of each publication. Some of these documents have been commented upon in further detail elsewhere in this thesis and the locations of such comments are also referenced in Table 7.1.

Given that the outputs of this work amount to joint statements from the central finance agencies of the four largest states (by public sector expenditure) in Australia, the findings are considered to be likely to represent the future policy position of these states regarding public sector project alliances. This in turn means that these findings and the guidance documents subsequently published, based on these findings, are of major significance to all parties involved in project alliance procurement. 
In a foreword to the final report of the IASC Research, 'In Pursuit of Additional Value' (2009), pviii, it was stated that:

'The number and value of government projects delivered through alliancing is significant and increasing. The output of this study is an opportunity for jurisdictions to learn from each other and ensure that they can continually improve both the decision criteria, when to use the alliance delivery method and the decisions on the structuring of that alliance, so that VfM for taxpayers is delivered' (emphasis added).

This statement confirms that VfM was a central tenant of the research.

\subsubsection{IASC Research Brief}

In May 2009 Evans and Peck and the University of Melbourne circulated an invitation to selected members of the Australian construction industry to participate in the proposed research (Evans\&Peck and UOM, 2009).

In this document it was stated that the study would (p2) 'investigate the incremental value of the Alliance procurement methodology over other alternatives and will be used to inform the development of new alliancing policies, revise current Alliancing guidelines and to develop training programs'.

It was also confirmed that the purpose of the study was (p2) 'to measure whether Alliancing delivers incremental value for money (VFM) to Government (taxpayer) against other procurement methods'.

Additionally, it was also claimed that $(\mathrm{p} 4)$ 'the ultimate aim of the research was to provide for industry to better understand the concept of value for money from the Governments' perspective and under what circumstances Alliances are the preferred project implementation methodology'.

It was later stated in the report produced at the conclusion of this research 'In Pursuit of Additional Value' (IASC, 2009) that, following the literature review stage of the research, gaps were uncovered in the then current body of knowledge which together with the findings of the survey in the first phase of this research, resulted in the study question being expanded to: 'How can VFM (Value for Money) be enhanced in the alliance delivery method'.

As was acknowledged in the research report, in order to address the aims described above it was first necessary to define VfM in infrastructure projects from a government perspective. In doing this the report considered a number of public sector definitions of VfM before confirming that the study had been guided by the definition devised by the VDTF (VDTF, 2006b) being: 
Table 7.1 Publications emanating for the work of the Inter-jurisdictional Alliancing Steering Committee (IASC) - IASC/VDTF Publications

\begin{tabular}{|c|c|c|c|c|}
\hline Date & Title & $\begin{array}{l}\text { Lead } \\
\text { Sponsor/Advisor }\end{array}$ & Content & Researcher's comments \\
\hline May 2009 & $\begin{array}{l}\text { In Pursuit of Additional Value } \\
\text { Benchmarking Study into } \\
\text { Alliancing }\end{array}$ & VDTF & $\begin{array}{l}\text { Outline of proposed research in two phases } \\
\text { Phase } 1 \text { - Investigate of a broad range of } \\
\text { alliance by electronic questionnaire } \\
\text { Phase } 2 \text { - In depth study of targeted alliances } \\
\text { through confidential information and access to } \\
\text { alliance documentation }\end{array}$ & $\begin{array}{l}\text { This document outlines the aim, scope and methodology of the study proposed by VDTF. The initial purpose of the } \\
\text { study was to measure whether alliancing delivers incremental VfM to Government (the tax payer) against other } \\
\text { procurement methods. }\end{array}$ \\
\hline August 2009 & $\begin{array}{l}\text { Alliance Participants Self } \\
\text { Evaluation - Phase } 1 \text { Report }\end{array}$ & $\begin{array}{l}\text { VDTF/Evans \& } \\
\text { Peck; University } \\
\text { of Melbourne }\end{array}$ & $\begin{array}{l}\text { Draft of Phase I Report and issued to Alliancing } \\
\text { Association of Australia (AAA) and others for } \\
\text { comment }\end{array}$ & $\begin{array}{l}\text { This report described the results of the Phase } 1 \text { survey of } 46 \text { alliances ( } 82 \text { responses). The results indicated that } \\
\text { these alliances had performed well, exceeding requirements. The report expressed concerns about a very optimistic } \\
\text { views being expressed by the respondents plus other findings. }\end{array}$ \\
\hline $\begin{array}{l}\text { November } 2009 \text { (Rev A) } \\
\text { (Originally issued October } \\
\text { 2009) }\end{array}$ & $\begin{array}{l}\text { In Pursuit of Additional Value - } \\
\text { A benchmarking study into } \\
\text { Alliancing in the Australian } \\
\text { Public Sector }\end{array}$ & $\begin{array}{l}\text { VDTF/ Evans \& } \\
\text { Peck; University } \\
\text { of Melbourne }\end{array}$ & $\begin{array}{l}\text { Study report describing outcomes of both Phase } \\
1 \& 2 \\
\text { Subsequently revised in November } 2009\end{array}$ & $\begin{array}{l}\text { Report produced at the end of Phase } 2 \text { of the Study. This report also contained the Phase } 1 \text { findings, plus } 14 \text { key } \\
\text { findings, } 20 \text { discussion points, and } 8 \text { recommendations. These outcomes are commented upon in detail in } \\
\text { Appendices 7.1 to 7.4. A conclusion that VfM can be enhanced in the alliance delivery method. (TOC reduced by 5- } \\
\text { 15\%). }\end{array}$ \\
\hline $\begin{array}{l}\text { December } 2009 \\
\text { (Exposure draft issued August } \\
\text { 2009) }\end{array}$ & $\begin{array}{l}\text { Guidance Note No } 1 \text { - } \\
\text { Language in Alliance } \\
\text { Contracting - a Short Analysis } \\
\text { of Terminology }\end{array}$ & VDTF/Freehills & $\begin{array}{l}\text { Document aimed at standardising and } \\
\text { explaining alliance terminology }\end{array}$ & $\begin{array}{l}\text { This document provides some useful explanations of concepts such as 'no blame', 'best for project', 'Gamebreaking } \\
\text { performances', 'Risk/reward' and, 'We will agree'. }\end{array}$ \\
\hline $\begin{array}{l}\text { December } 2009 \\
\text { (Exposure draft issued August } \\
\text { 2009) }\end{array}$ & $\begin{array}{l}\text { Guidance Note No } 2 \text { - } \\
\text { Insurance in Alliance } \\
\text { Contracting; Selling Insurable } \\
\text { Risks }\end{array}$ & $\begin{array}{l}\text { VDTF/Ernst \& } \\
\text { Young; Freehills }\end{array}$ & $\begin{array}{l}\text { Overrun of key insurance related issues for all } \\
\text { alliance participants }\end{array}$ & $\begin{array}{l}\text { This document provides a well researched review of the insurance issues as they relate to alliancing. This includes a } \\
\text { description of the challenges in obtaining insurance for a contract arrangement which includes principles of 'no } \\
\text { blame' and 'collective assumption of risk'. }\end{array}$ \\
\hline March 2010 & $\begin{array}{l}\text { Guidance Note No } 3 \\
\text { Key Risk Areas and Trade Offs } \\
\text { (The lead sponsor for this } \\
\text { document was the Department } \\
\text { of Treasury and Finance WA.) }\end{array}$ & WADTF/Freehills & $\begin{array}{l}\text { Note prepared to provide public sector } \\
\text { participants greater clarity regarding the value } \\
\text { proposition of using alliance contracting. }\end{array}$ & $\begin{array}{l}\text { This document was not circulated for external comment. It provides an interesting insight in its statement that 'A } \\
\text { fundamental cornerstone of alliancing is that traditional contractual legal protections are traded by the State in } \\
\text { exchange for non-owner participants bringing their 'good faith' in acting with 'integrity' for the 'best interest' of the } \\
\text { project. }\end{array}$ \\
\hline $\begin{array}{l}\text { March } 2011 \text { (Updated } 1^{\text {st }} \\
\text { Edition) } \\
\text { (Exposure draft issued } \\
\text { February 2010, } 1^{\text {ts }} \text { Edition - } \\
\text { June 2010) }\end{array}$ & $\begin{array}{l}\text { Guidance Note No } 4 \\
\text { Reporting VfM Outcomes in } \\
\text { Alliance Contracting }\end{array}$ & $\begin{array}{l}\text { VDTF/Graeme } \\
\text { Joyce }\end{array}$ & $\begin{array}{l}\text { Note to clarify the VfM concept in Government } \\
\text { investment decisions and provide guidance on } \\
\text { management and reporting VfM outcomes }\end{array}$ & $\begin{array}{l}\text { This is a document with direct relevance to the content of this research task. Consequently a detailed review of this } \\
\text { document which was actually submitted to the VDTF during the review process is contained in Appendix } 7.5 \\
\text { See also discussion of Section } 7.5 \text { of this thesis }\end{array}$ \\
\hline July 2010 & $\begin{array}{l}\text { Policy for Alliance contracting } \\
\text { - July } 2010\end{array}$ & *VDTF & $\begin{array}{l}\text { Policy document aimed at establishment policy } \\
\text { of principles for governance and the approval } \\
\text { framework to be applied by agencies using the } \\
\text { alliance delivery method. }\end{array}$ & $\begin{array}{l}\text { This is a relatively short and simple policy document outlining the approval necessary for alliance projects. The three } \\
\text { sections headings elegantly summarise the content: Public accountability and public interest, value for money, } \\
\text { efficient and effective market management. }\end{array}$ \\
\hline $\begin{array}{l}\text { March } 2011 \\
\text { (Exposure draft issued } \\
\text { October 2010) }\end{array}$ & $\begin{array}{l}\text { Guidance Note No } 5 \\
\text { Developing the TOC in Alliance } \\
\text { contracting }\end{array}$ & $\begin{array}{l}\text { VDTF/Evans \& } \\
\text { Peck }\end{array}$ & $\begin{array}{l}\text { Notes to assist public officials to ensure VfM } \\
\text { outcomes during TOC development in } \\
\text { accordance with the Practitioners Guide to } \\
\text { Alliance Contracting }\end{array}$ & $\begin{array}{l}\text { A detailed guide regarding the mechanics of TOC development and approval process for price and non-price based } \\
\text { methods. Describes the content of the Business Case Alignment Report (BCAR). The final version of this document is } \\
\text { due to be issued in March } 2011 \text {. }\end{array}$ \\
\hline $\begin{array}{l}\text { October } 2010 \\
\text { (Exposure draft issued July } \\
\text { 2010) }\end{array}$ & $\begin{array}{l}\text { The Practitioners Guide to } \\
\text { Alliance Contracting }\end{array}$ & $\begin{array}{l}\text { VDTF/ Evans \& } \\
\text { Peck }\end{array}$ & $\begin{array}{l}\text { Definitive document intended to provide } \\
\text { consistent and leading practice guidance to WA, } \\
\text { Qld, NSW and Vic Government departments } \\
\text { and agencies that develop and own } \\
\text { infrastructure assets. }\end{array}$ & $\begin{array}{l}\text { This document replaced the original Practitioners Guide issued in 1996. It contains a well presented introduction to } \\
\text { project alliancing. The later text reflects the findings, conclusions and recommendations of 'In Pursuit of Value' as } \\
\text { issued in November } 2009 \text {. }\end{array}$ \\
\hline
\end{tabular}


'Value for money denotes, broadly, a balanced benefit measure covering quality levels, performance standards, risk exposure, other policy or special interest measures (e.g. environmental impacts), as well as price [of inputs and outputs]. Generally, value for money is assessed on a "whole of life" or "total cost or ownership" basis, which includes the transitioningin, contract period and transitioning-out phases of a contractual relationship. It is often used in the sense of the "long-term sustainability of Value for Money", denoting that the state focuses on choices that ensure value for money outcomes are promoted and protected in successive anticipated contracts'.

Whilst this definition is somewhat more elaborate than the version favoured in Chapter 2 , the intent of the definitions appear to be aligned i.e. both advocate a broad based assessment of value and consider a 'whole of life' perspective.

The methodology of the IASC Research employed both quantitative and qualitative approaches to address the questions being considered and comprised the following stages:

- Literature Review to identify existing research in order to refine the study approach.

- Phase 1: A review of current alliance performance in Australia through a self evaluation survey of 46 alliances ( 82 responses).

- Phase 2: A detailed analysis of 14 alliances through a case study approach.

- Analysis of the research findings resulting in conclusions and recommendations.

Discussions that the researcher has held directly with members of the IASC and personnel from the actual research team undertaking the research have confirmed that this work was commissioned by the Treasuries further to concerns held that project alliances were not seen to be adequately demonstrating the achievement of VfM. During these discussions it also became apparent that there was a view held in central government agencies that alliancing, as a procurement method, has been adopted and developed by public sector agencies and departments prior to the active involvement of the central agencies. Consequently, the practice of alliance procurement has not been initially reviewed and endorsed by the central government agencies being the respective Treasuries and relevant Premier's Departments. This is in marked contrast to the other significant development in public sector procurement for major infrastructure projects in the last fifteen years being Public Private Partnerships (PPP's). Treasuries had been responsible for the development of policies and guidelines for PPPs in each state jurisdiction and had ensured that they were satisfied that VfM issues were being addressed to their satisfaction before the procurement method was promoted and adopted by the relevant departments and agencies of government. 
It is also apparent from the content of 'In Pursuit of Additional Value' that the State Treasuries have held concerns regarding how a procurement approach, that did not include clear and open price competition in the selection of the participants, could be seen to demonstrate VfM. Further, it would also appear to be the case, based on the researcher's discussions with representatives of the State Treasuries, the content of the IASC Research documentation and subsequent IASC/VDTF publications, that central agencies have developed a view that the personnel from the departments or agencies participating in project alliances as the Owners Representative (OR) should not able to also exercise the role of an Owner in the procurement process. This concern, seemingly, has two themes. Firstly, given that Alliance Leadership Teams (ALT's) normally operate on a unanimous basis for decision making, the OR could be seriously disadvantaged by the 'asymmetry of commercial capability' deemed to exist between the OR and the NOP representatives (IASC, 2009), p xvii. Secondly, that too many issues are seen to be determined at the ALT level and more matters should be referred back to the Owner for determination.

\subsection{Findings of the IASC Research}

The study was led by the VDTF on behalf of the IASC. However, the State Treasuries of New South Wales, Queensland and Western Australia were also involved in the initiative as co-sponsors. This offered the prospect of the future approach to alliance procurement being consistent between these states. In the past the respective approaches of these states have been quite different and the move to greater consistency, and the possibility of national approach to alliance procurement, was widely welcomed by the construction industry at large.

The IASC Research program was a very substantial undertaking and involved a significant analysis of performance outcomes, particularly through the review of the data collected during the Phase I survey. The quantitative findings of this phase of the study were initially contained a draft document which was issued on a limited circulation in August 2009. These findings were then subsequently presented in Appendix A to the research report 'In Pursuit of Additional Value' issued in October 2009 (IASC). These results indicated that for the 46 Alliances surveyed:

- $85 \%$ met or bettered the TOC for the alliance;

- Only $2.7 \%$ of NOPs believed that their alliance did not meet the performance requirements (aggregated) compared with $4.5 \%$ of owners;

- In excess of $93 \%$ met or bettered the target project duration. 
These results were largely consistent with those obtained from a much smaller scale study to examine the performance of project alliances in Australia, commissioned by the Alliancing Association of Australasia (AAA) and undertaken by RMIT in 2008 (Blismas and Harley).

'In Pursuit of Additional Value' contains a detailed and comprehensive discussion of the outcomes of the IASC Research, including both Phase 1 and 2, under the headings of 'key findings', 'discussion points', 'conclusions' and 'recommendations'. Comments by the researcher, regarding each of the issues raised under these headings, are contained in Appendices 7.1 to 7.4, respectively. These comments were originally forwarded to the AAA who formulated a consolidated a response from their membership to the initial release of 'In Pursuit of Additional Value' as issued by VDTF in October 2009.

When the results of the research were first released some of the findings, conclusions and recommendations contained in the report were seen to be somewhat controversial. Such a view was expressed by a broad cross-section of the industry including public and private sector parties. The concerns being expressed related primarily to the fact that a number of definitive statements were being made about the conduct of alliances, based on relatively information and apparently without the necessary scientific/methodological rigour to justify such strongly expressed conclusions.

Specific points that were raised included:

- Concerns about the statistical validity of some of the conclusions drawn from very small sample sizes. This was a particular issue concerning a statement that a price based selection of the NOPs delivered a lower Turn-out Cost (TOC);

- The broad statement that for project alliances the average increase from the Business Case estimate to Actual Outcome Cost (AOC) was of the order of 45-55\%. Further explanations of the distribution of such increases or insights regarding why the projects considered might have resulted in such a variance were not provided;

- The recommendation that Owners should adopt a multiple TOC or price based selection process, by default, when selecting NOP's with a non-priced based or single TOC selection process only being used when specifically justified. This, particular recommendation, has led to a considerable amount of debate with concerns being expressed by a broad range of industry participants that such a position will make alliances much less effective in both attracting suitable alliance partners to compete for projects and in generating the appropriate team dynamic in either the TOC preparation period or the actual delivery of the project. 
Given the brief of the IASC Research, as described above, it was clearly intended that the research findings might lead to a definitive position being adopted regarding a number of matters that had been the subject of extended 'debate' regarding the optimal delivery of projects through the alliance procurement model. In particular the seemingly perennial issue of whether a client is best advised to pursue a single or multiple TOC approach was considered by the study. The research report makes a firm recommendation (Policy Recommendation 6) that, in the future, a multiple TOC or 'price competitive' strategy should be adopted as the default position and a single TOC or 'pure' alliance methodology should only be considered where a specific case can be made and approved. Interestingly, this is a total reversal of the recommendation of the earlier Project Alliancing Practitioners' Guide (VDTF, 2006a) which specifically recommended that the single TOC was the preferred, or default, arrangement.

Whilst it is not a unique situation for an owner body, either public or private sector, to change procurement policy, this reversal of an approach has led to considerable debate and discussion within the industry.

Policy Recommendation 6 is particularly controversial for several reasons:

- As described earlier in Chapter 3 of this thesis, the decision to follow a 'price competitive' selection process has been a matter of rigorous debate since the publication of the NSW Auditor General's report on the Northside Storage Tunnel Project. The discussion on the matter has been somewhat polarised with the single TOC argument being very strongly advocated by some members of the industry including a particular school of procurement consultancies active in the project alliancing field. Alternatively, other members of the industry, including an alternative school of procurement consultancies strongly advocate that the multiple TOC approach should be preferred. This latter school has advised clients on a number of the major project alliances which have adopted this approach.

- Interestingly an advisor from the former school assisted the VDTF when they published their Project Alliancing Practitioners' Guide (2006a) which recommended a single TOC approach and an advisor from the latter school were part of the research team that recommended that this policy be reversed to favour a multiple TOC approach as the default position. In making this point no improper behaviour is being suggested or implied. Rather, it is argued that the disposition of the parties providing advice may tend to influence the outcome of the review. In making this statement, the researcher declares a preference for the single TOC approach based on direct personal experience of both approaches and acknowledges that, despite every effort being made 
to view matters objectively, a degree of bias may be inherent in some of the statements or conclusions made in this thesis.

- Whilst such outcomes may in fact be purely coincidental a number of participants in the industry including client bodies, constructors, design consultants, procurement consultants and coaches have voiced their concern, either directly or through industry bodies such as the AAA, that such a significant policy reversal should have been made seemingly on the basis of very limited data. Phase 2 of the study considered fourteen alliances of which two were alliances established adopting a multiple TOC approach. The key findings of the study, as listed in Appendix 7.1, make very strident comment about the respective performance of single and multiple TOC selection processes. Additionally, the research report offers little or no quantitative data to support Recommendation 6.

- This recommendation in particular, which appears to represent a philosophical belief, rather than being a conclusion derived from the data gathered during the research, has led a number of industry participant being reluctant to accept the premise that the finding of this research should be broadly embraced.

\subsection{Comparison between VDTF Research and this Research}

As indicated above it is believed that the program of work undertaken by the Inter-jurisdictional committee under the leadership of the VDTF constitutes a landmark commitment by the public sector to examine in detail a newly emerging procurement approach. In fact, at least in the Australian context, such a commitment to research a particular procurement model and then issue a practitioners guide and supplementary guidance notes over a relatively short period is very unusual. The only other example of a similar level of documentation, although not necessarily research, is the introduction of Public Private Participation (PPP) procurement and the publication of guidance documentation from the Commonwealth and several states in the early 2000's which were referenced earlier in Section 7.2.

A brief comparison of the structure of the IASC Research and the research described in this thesis is provided in Table 7.2 below. It should be noted that the timing of the respective data gathering phases actually overlapped.

Both initiatives were seeking to better understand the issue of VfM in project alliancing and both have recommended a more systematic approach to ensuring and demonstrating VfM for Project Alliances. 
Other similarities between the outcomes of the initiatives are listed below and this is followed by an identification of some of the key differences between the findings reached and the actions recommended.

\subsubsection{Similarities}

- Both studies involved extensive data gathering from, and discussions with, practitioners in alliance procurement.

- Both studies identified a strongly held view by those participating in alliances that the respective projects were delivering VfM, even though VfM was not explicitly defined to the participants in either study at the time of data gathering. Both studies concluded that a more systematic and better documented process should be adopted to ensure and demonstrate VfM and proposed methodologies to address this matter. This research proposes the adoption of structured model, based on the project timeline. The documents published as a consequence of the IASC Research (discussed later in Section 7.4) also follow an approach based on the project timeline although in a less structured manner.

- Both studies concluded that the VfM outcome is highly dependent on the degree of rigour applied in the early stages of a project and that the original business case is fundamentally important in that regard.

\subsubsection{Differences}

In contrast to the similarities and synergies discussed above there are a number of differences in outcomes of the research:

- The IASC Research concluded that the Owner should adopt a 'price based' approach, by default, in selecting alliance partners. In contrast, this research provided evidence that economic criteria are not considered to be the best means of selecting alliance partners.

- The IASC Research concluded that 'commercial asymmetry' exists between public sector owner or client bodies and private sector NOP's. No such suggestion emerged in this research.

- This research indicated that the success of the alliance depended upon complete trust and sharing of the decision making process. The IASC research recommended that the Owner should seek to reserve more decision making powers and allow the Alliance Leadership Team (ALT) less autonomy. 


\section{Table 7.2 Comparison of the findings/outcomes of IASC Research and this Study}

\begin{tabular}{|c|c|c|}
\hline & In Pursuit of Additional Value & This Research \\
\hline Objective & $\begin{array}{l}\text { Undertaken as benchmark study to investigate whether alliancing } \\
\text { delivers incremental VfM to Government against other } \\
\text { procurement methods. } \\
\text { Later developed to 'How can VfM be enhanced in the alliance } \\
\text { delivery method'? }\end{array}$ & $\begin{array}{l}\text { The research objective was to determine the optimum } \\
\text { configuration of a model that will assist participants in a project } \\
\text { alliance to both ensure and demonstrate the achievement of VfM } \\
\text { or best value. }\end{array}$ \\
\hline Research Methodology & $\begin{array}{l}\text { - Phase } 1 \text { - A high level quantitative analysis of } 46 \text { alliances } \\
\text { (outcome based). } \\
\text { - Phase } 2 \text { - A quantitative and qualitative confidential case study } \\
\text { analysis of } 4 \text { alliances selected from Phase } 1 .\end{array}$ & $\begin{array}{l}\text { - Phase } 1 \text { - Interviews with } 27 \text { participants in Alliances (7 actual } \\
\text { projects) } \\
\text { - Questionnaire completed by } 21 \text { of the participants. } \\
\text { - Phase } 2 \text { - Three-round Delphi Survey involving } 12 \text { industry } \\
\text { experts not involved in Phase } 1 .\end{array}$ \\
\hline \multirow{3}{*}{$\begin{array}{ll}\text { Time Frame } \\
-\quad \text { Data collection } \\
-\quad \text { Report on research } \\
-\quad \text { Subsequent } \\
\quad \text { documentation }\end{array}$} & - (May to August 2009) & (June to December 2009) \\
\hline & - (October 2009) & (April 2011) \\
\hline & - $\quad$ (December 2009 to October 2010), see Table 7.1 & See Chapter 8 \\
\hline Key Findings & See Appendix F.1 & See Chapter 5 \\
\hline Discussion points & See Appendix F.2 & See Chapter 6 \\
\hline $\begin{array}{l}\text { Conclusions and } \\
\text { Recommendations }\end{array}$ & See Appendix F.3 (Conclusions), Appendix .4 (Recommendations) & See Chapter 9 \\
\hline \multirow[t]{3}{*}{ Key Outcomes } & $\begin{array}{l}\text { - Confirmed that alliances can lead to enhanced VfM for } \\
\text { particular projects }\end{array}$ & $\begin{array}{l}\text { - Supported a commonly held view that alliances were } \\
\text { achieving but not effectively demonstrating VfM }\end{array}$ \\
\hline & $\begin{array}{l}\text { - Statement that 'to extract optimum VfM alliances a number of } \\
\text { changes need to be made at both alliance and whole of } \\
\text { government (Page 93) levels. This includes improved rigour in } \\
\text { the documentation of the procurement process }\end{array}$ & $\begin{array}{l}\text { - Achieved a strong consensus that the VfM model developed } \\
\text { would be valuable in bringing discipline to the documentation } \\
\text { of VfM }\end{array}$ \\
\hline & $\begin{array}{l}\text { - Made a specific recommendation that a price based selection } \\
\text { process should be the default position in selecting alliance } \\
\text { partners }\end{array}$ & $\begin{array}{l}\text { - Provided evidence that economic criteria are not seen as the } \\
\text { best means of selecting alliance participants }\end{array}$ \\
\hline
\end{tabular}




\subsubsection{Relevance of IASC Research to development of the VfM/BV Model}

Having identified similarities and differences between the two research exercises the question arises: 'What is the particular relevance of the IASC Research findings to the development of the VfM Model that results from this research'?

This question can be answered by the following points:

- The recommendations of the IASC Research generally advocate greater discipline in the alliance procurement process. This is particularly the case for the development and documentation of the business case and the selection of the procurement strategy. The 'whole of project' timeline approach and the disciplined structure of the VfM/BV model proposed in this thesis is believed to be consistent with these recommendations;

- The IASC Research recommendations call for a consistent approach across agencies and governments. This will require the development of a consistent approach or model or format for justifying the procurement process and the development of established procedures for the selection of the procurement strategy and thus the ongoing demonstration of VFM.

- The researcher has a concern a that Recommendation 6 of the IASC Research, in particular, will result in an attitude that relies upon a price competitive process for the selection of NOPs as the sole means of demonstrating VFM. Such a simplistic attitude would greatly underestimate the potential benefit of an alliance and reduce the whole debate regarding VfM to purely a pricedriven agenda. The model proposed in this thesis adopts an approach which seeks to address the demonstration of VfM throughout the project lifecycle. The IASC Research also advocates a 'whole of project lifecycle approach. However, the emphasis placed on the default adoption of price based selection is, in the view of the researcher, likely to reduce the demonstration of VfM to the lowest common denominator of price.

In short, whilst there are some points of differences between the outcomes of the two exercises, it is believed that the most of the recommendation of the IASC Research support the thrust of the $\mathrm{VFM} / \mathrm{BV}$ model developed in this research. This point is further illustrated in Section 7.6 of this chapter which compares some of the procedural recommendations of the documents published by IASC/VDTF subsequent to the IASC Research, with the structure of the VfM/BV model.

\subsection{IASC/VDTF Publications issue post IASC Research}

Following the publication of 'In Pursuit of Additional Value', the VDTF, assisted by various consultants, proceeded to release a series of publications on behalf of the IASC, including a number 
of guidance notes. In most cases these were initially released in exposure draft form and then as final documents further to industry comment.

A full listing of all the publications issued both during and subsequent to the IASC Research is provided in Table 7.1 above. This table also briefly describes the content of these documents and, consequently, such information will not be repeated here. However, given that the content of Guidance Note No. 4, 'Reporting VfM Outcomes in Alliance Contracting' is considered to be directly relevant to the content of this thesis, this particular document is specifically addressed in further detail in Section 7.6 below.

Prior to the IASC Research and subsequent publications there was relatively little factual data available regarding the adoption of project alliances in Australia. The work commissioned by the Alliancing Association of Australia (AAA) and undertaken by the RMIT (Blismas and Harley, 2008) is the only notable exception. Consequently, the IASC Research has significant increased the body of data available regarding the performance of project alliances. Additionally, the subsequent publications have considerably expanded the documentation of project alliance practice in Australia which previously relied heavily on a few landmark papers; Ross (2003a), Hutchinson and Gallagher (2003), the work of some prominent authors (Walker and Hampson, 2003, Walker and Rowlinson, 2008) and the original edition of the Practitioners' Guide to Alliancing Published by VDTF(2006a) .

Further to the IASC Research, the Practitioners' Guide to Alliance Contracting (VDTF, 2010b) was issued to replace the Project Alliance Practitioners' Guide (VDTF, 2006a) which was generally accepted as the primary guide to public sector practice in the conduct of project alliances. It is interesting to note that, however, that whilst this new publication has been formally adopted in both Victoria and Queensland, the other states involved in the research have yet to do so.

Additionally, as of April 2011, only Victoria appears to have formally adopted the Guidance Notes issued ( see table 7.1) subsequent to the publication of the Research Report (IASC, 2009), suggesting that, at least to date, the objective of having a formally adopted, common approach to alliance procurement across all the states supporting in the IASC Research, has yet to be achieved.

\subsubsection{Industry reaction to the VDTF publications}

In the view of the researcher, the whole exercise IASC exercise, incorporating the initial research and subsequent stream of subsequent publications including a revised Practitioners Guide and a series of guidance notes represents a definitive body of work in the field of alliance procurement in Australia. 
Additionally, most of the material (probably in excess of 95\%) contained in the publications issued by the VDTF, either on behalf of the IASC or on its own behalf, has been viewed by the industry as providing well needed and balanced documentation of established processes in alliance practice, as it has developed over the 10 to 15 years in Australia.

However, the issues of NOP selection and autonomy of the alliance are two particular issues which have been addressed by the publications in a manner which has caused a broad cross-section of the industry, including public sector agencies, industry associations, contractors, consultants and individuals to voice significant concerns.

Further, based on the feedback which was collated by the AAA, there are concerns that the adoption of some of the procedures now enshrined in the VDTF publications may undermine the dynamics that allow project alliances to be successful and deliver VfM.

\subsection{VDTF Guidance Note No 4 - Reporting VfM Outcomes in Alliance Contracting (GN4)}

In the introduction to this guidance note the point is made that whilst it is not difficult to develop a definition of $\mathrm{VfM}$, it is more challenging to fully articulate how the $\mathrm{VfM}$ concept is applied to in order to plan and practically assess VfM outcomes for an alliance project.

The stated purposes of the guidance note are to:

- $\quad$ Align the understanding and use of VfM concept in alliancing with general government processes and practices;

- Provide a framework for appreciating, reporting and measuring VfM that is shared by the State, the Owner and the alliance;

- Identify how/where alliance arrangements can be improved to further demonstrate their value to the State;

- Propose the inclusion of an 'Owners VfM Statement' in each contract that is aligned to the Business Case;

- Provide a VfM Report template to promote reporting on Alliances in a manner that is comparable between Projects and meets a consistent standard that is accessible to the State.

Figure 7.1 below, which is based on material contained in GN4, illustrates the proposed hierarchy of five steps for planning and reporting VfM in an alliance and the role that each party during these steps. . This figure references specific documents which are considered to be particularly relevant to reporting of VfM being; the Business Case, the Owner's VfM Statement and finally a VfM Report submitted by the Owner to the State. The figure provides a concise summary of the content and apparent intent of the guidance note. 
Three of the five steps are represented by milestones i.e. discrete events in time whilst the remaining two are actually processes that occur over a period of time. In turn they are:

- $1^{\text {st }}$ step, milestone, Business Case - submitted by the Owner for approval by the State;

- $\quad 2^{\text {nd }}$ step, milestone, Owners VfM Statement - communicating the Owner's vision and directions to the proposed alliance;

- $\quad 3^{\text {rd }}$ Step, process, Tender Process - the Owners VfM Statement informs the tender documents including the tender selection criteria;

- $\quad 4^{\text {th }}$ Step, process, Alliance - delivers on the Owners VfM Statement and other tender documents;

- $5^{\text {th }}$ Step, milestone, The VfM Report - Report back to the State by the Owner on the VfM achieved by the Alliance compared to the approval Business Case.

Based on the feedback obtained in the research reported in this thesis, the researcher has the following comments on the approach advocated in Guidance Note 4.

1) The establishment of an Owner's VfM Statement is an attempt to articulate the Business Case in the form of project parameters, objectives and budget. In contrast to the Business Case itself, which includes expected social and economic benefits arising from the new community services being enabled by the infrastructure, the Owner's VfM Statement is designed to be specifically relevant to and applied by the Alliance. GN4 indicates that the Business Case is just the starting point for the VfM Statement which needs to detail all the Owner's expectations that impact VfM outcomes. This initiative is very much in line with the feedback obtained during this research when it was repeatedly stated to greater exposure to the basis of the Business Case and the objectives of the Owner would assist an Alliance in delivering VfM.

Consequently, the third step, advocated by GN4, of using the Owner's VfM Statement to inform the tender documents, including the tender selection process, followed by the fourth step of using the VfM Statement to guide the delivery of the Alliance, appears to be well aligned with the view of practitioners and experts in the alliancing field. This is also consistent with the architecture of the VfM/BV model developed during this research.

2) The fifth step of a VfM Report being prepared by the Owner regarding the VfM achieved by the Alliance compared to the Business Case is, however, not seen to be consistent with the feedback obtained during the research reported in this thesis. The concept of the Owner preparing this report rather than the Alliance appears to be indicative of a distinct theme in the documentation produced by the IASC/VDTF suggesting that the Owner should adopt a more distinct identity which is entirely separate from the Alliance. Whilst there is clearly a need to 
ensure that there is a distinct contractual role for the Owner, the alliance model requires that the full skills and talent of the Owner are contributed to the Alliance in the same way that the NOPs are expected to contribute to the best of their skills and talent. Further, the Owner working alone is unlikely to have the knowledge and resources necessary to produce a comprehensive and meaningful VfM Report that will both assess the performance of the Alliance and also capture lessons learned. Certainly, based on examination of the template for the VfM Report provided in Appendix B of GN4, it would appear that a large amount of detailed information will be required, which only the alliance can really supply.

GN4 emphasises that the State, or in this case the central agencies of the State particularly Treasury are more than simply 'bankers' for the project and the State ultimately accepts the risk of delivering capital assets which are fit for purpose. However, it is still unclear to the researcher why it is not the responsibility of the Alliance to justify to the Owner that VfM has been achieved. If the Owner (agency) is empowered to commission the project, should they not also be empowered to ensure and demonstrate that VfM has been achieved? Clearly the necessary auditing processes should be in place (i.e. Auditor General Review) to check, as necessary, that this is the case. Presumably, the Auditor General may do this anyway, even if the VfM Report is submitted by the Owner to the State. The researcher believes that the exclusion of the Alliance from the responsibility to prepare the VfM Report is not in accordance with the principles underlying the alliance model and suggests a lack of trust. It is suggested that it would be more appropriate for the Owner to employ advisers to independently review the report prepared by the Alliance. This would appear to be more efficient and effective approach for demonstrating whether or not VfM has actually been achieved. 


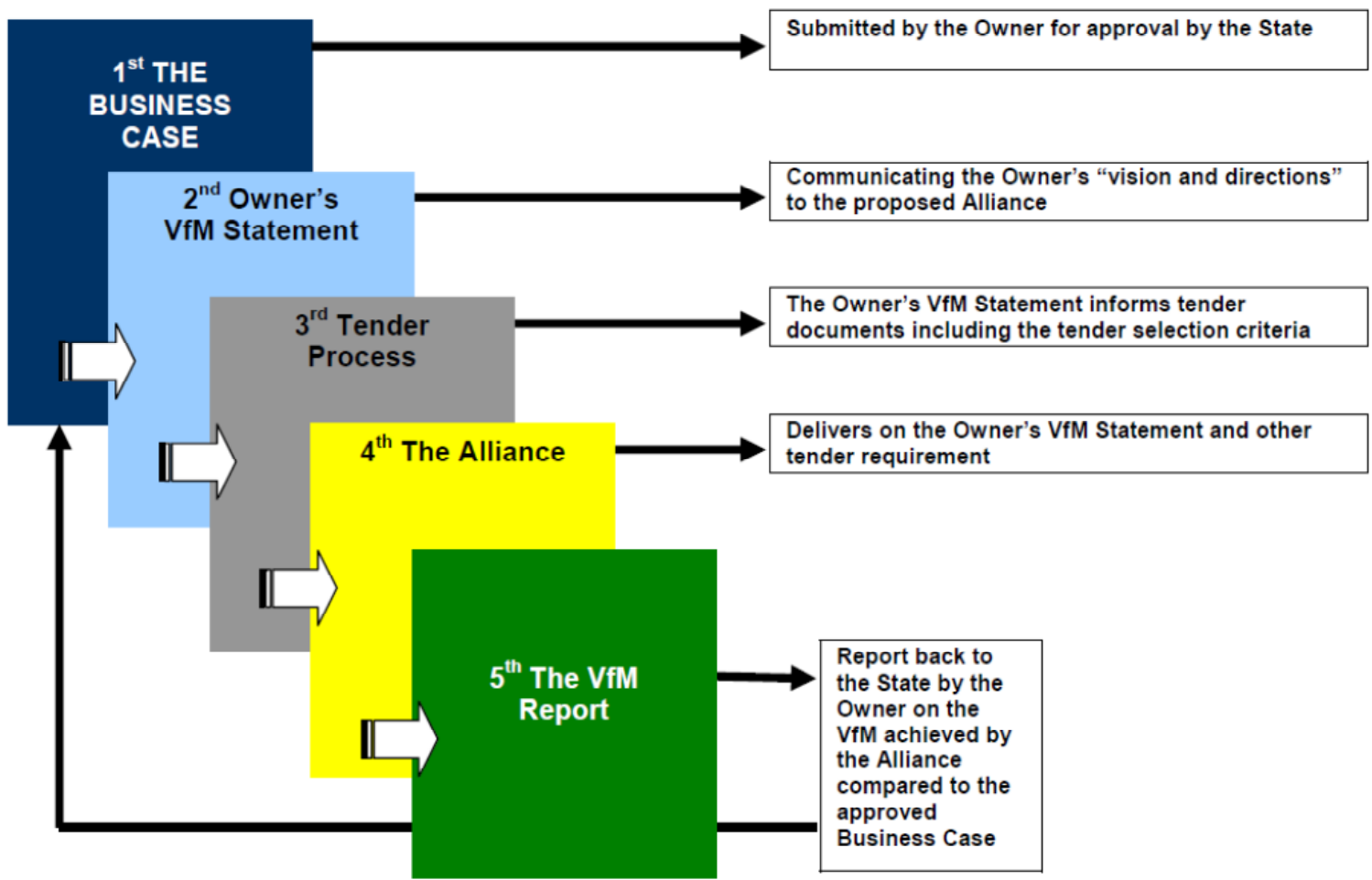

\begin{tabular}{|c|c|c|c|c|c|}
\hline \multirow[b]{2}{*}{$\begin{array}{l}\text { Role in } \\
\text { project } \\
\text { lifecycle }\end{array}$} & \multicolumn{5}{|c|}{ Selected planning and delivery steps } \\
\hline & $\begin{array}{l}\text { 1. Business } \\
\text { Case }\end{array}$ & $\begin{array}{l}\text { 2. Owner's VfM } \\
\text { Statement }\end{array}$ & $\begin{array}{l}\text { 3. Tender Processes \& } \\
\text { PAA }\end{array}$ & $\begin{array}{l}\text { 4. The Alliance } \\
\text { (Project Delivery) }\end{array}$ & $\begin{array}{l}\text { 5. VfM Report } \\
\text { (Project } \\
\text { implementation review) }\end{array}$ \\
\hline State & $\begin{array}{l}\text { Determines } \\
\text { investment } \\
\text { priorities and } \\
\text { approves funding } \\
\text { for selected } \\
\text { business cases }\end{array}$ & $\begin{array}{l}\text { Provides funding } \\
\text { (and/or underwrites } \\
\text { risks) }\end{array}$ & $\begin{array}{l}\text { Provides funding (and/or } \\
\text { underwrites risks). } \\
\text { May have approval role for } \\
\text { specified tender milestones }\end{array}$ & $\begin{array}{l}\text { Provides funding } \\
\text { (and/or underwrites } \\
\text { risks) } \\
\text { Receives progress } \\
\text { reports from Owner } \\
\text { (against approved } \\
\text { Business Case) }\end{array}$ & $\begin{array}{l}\text { Receives formal VfM } \\
\text { Report from Owner } \\
\text { which assesses VfM } \\
\text { outcomes against } \\
\text { approved Business } \\
\text { Case. }\end{array}$ \\
\hline Owner & $\begin{array}{l}\text { Identifies } \\
\text { community need } \\
\text { and possible } \\
\text { solutions for } \\
\text { funding by State } \\
\text { Prepares } \\
\text { Business Case } \\
\text { for approval by } \\
\text { State }\end{array}$ & $\begin{array}{l}\text { Finalises the } \\
\text { Owner's VfM } \\
\text { Statement (which is } \\
\text { aligned with the } \\
\text { business case } \\
\text { approvals), clearly } \\
\text { articulates project } \\
\text { parameters, } \\
\text { objectives and } \\
\text { budget. }\end{array}$ & $\begin{array}{l}\text { Attaches and incorporates } \\
\text { the VfM Statement into } \\
\text { Tender documents }{ }^{1} \text {. } \\
\text { Finalises the Tender } \\
\text { Selection Criteria for NOP } \\
\text { evaluation and selection. } \\
\text { Prepares RFP (including } \\
\text { draft PAA). Develops TOC. }\end{array}$ & $\begin{array}{l}\text { Maintains active } \\
\text { informed commercial } \\
\text { role as part of the } \\
\text { Alliance. } \\
\text { Provides suitable } \\
\text { participants to be part } \\
\text { of the Alliance }\end{array}$ & $\begin{array}{l}\text { Prepares a post } \\
\text { implementation review of } \\
\text { the Alliance project (ie } \\
\text { the VfM Report for the } \\
\text { State) }\end{array}$ \\
\hline $\begin{array}{l}\text { Alliance } \\
\text { (Proponents } \\
\text { and then } \\
\text { Participants) }\end{array}$ & No role & No role & $\begin{array}{l}\text { Develops TOC, aligns and } \\
\text { agrees to PAA to deliver } \\
\text { on Owner's VfM Statement } \\
\text { and other tender } \\
\text { requirements }\end{array}$ & $\begin{array}{l}\text { Provides regular } \\
\text { project progress } \\
\text { reports to Owner }\end{array}$ & $\begin{array}{l}\text { Project documentation } \\
\text { available to support post } \\
\text { implementation review } \\
\text { process }\end{array}$ \\
\hline
\end{tabular}

${ }^{1}$ Figure 7.1 Hierarchy of steps for planning and reporting VfM outcomes in an Alliance and the role of parties in planning for, and reporting, VfM Outcomes (from VDTF Guidance Note No. 4 - Reporting VFM Outcomes in Alliance contracting) p6, Figure 1 and Table 1.

\footnotetext{
${ }^{1}$ Footnote from GN4: Some of the Business Case content lends itself being incorporated in the Project Alliance Agreement (PAA) (e.g. functionality of the infrastructure asset to be constructed); however, most of the content may not be associated with the work of the Alliance (e.g. the expected social and economic benefits arising from the new community services being enabled by the infrastructure). The Owner's VfM Statement is designed to be relevant to, and applied by, the Alliance. It informs the drafting of the PAA and the full VfM Statement should be incorporated as part of the PAA.
} 
3) A similar issue is apparent from the content of the table embedded in Figure 7.1 which defines the respective roles of the parties, as proposed by VDTF, in the planning and reporting of VfM outcomes. The roles and responsibilities attributed to the Alliance in this table are seen to be of a support nature to the Owner or State rather than those appropriate for the body charged with the task of delivering the project. The model proposed by the researcher places the responsibility of delivering the VfM Report with the Alliance. If the Alliance parties cannot be 'trusted ' to provide an objective report, they should not have be appointed to undertake the work under an arrangement fundamentally founded on a relationship of trust.

Whilst the model developed by the researcher and represented in detail in Chapter 8 also suggests that the State and primarily the Owner have the major role to play in the early Business Case and Owner's VfM Statement steps, the role of the Alliance is considered to be much more central in the demonstration of VfM in the later steps detailed in Figure 7.1.

Additionally, the researcher believes that the responses received in Phase 1 of the research reported in this thesis, in particular, illustrate that the NOPs can have a significant role to play in developing the Business Case and informing the development of the Owner's VfM Statement.

The point in the lifecycle at which NOPs are introduced into the project, will naturally depend on the circumstances of the particular project. However, the advantage of earlier involvement of NOPs is that they can bring specialist technical and commercial skills (rather than 'commercial asymmetry') to the project which is likely to lead to a more accurate assessment of project outcomes and costs. Consequently, the Business Case and Owner's VfM Statement are more likely to align with the final AOC which addresses one of the issues raised in the IASC Research i.e. AOC costs for projects which are delivered as Alliances have higher variance to Business Case costs than others forms of procurement. In fact, the VDTF documentation actively discourages such early involvement, apparently on the basis that the State should ensure that the VfM objectives are fully defined before the private sector becomes involved. This view appears to be counter to increasing practice of Early Contractor Involvement (ECI) or Early Tender Involvement (ETI) being adopted by government agencies, often as an alternative to project alliances.

4) GN4 provides some very useful guidance on reporting VfM outcomes in alliance contracting, which is what the title of the document purports to provide. However, what the document does not do, nor does it claim to do is to ensure that VfM is actually achieved. This is the main difference between the model developed by the researcher and GN4 in particular. While some of the other VDTF publications in this series do provide considered and sound advice on how to 
approach alliance contracting they provide limited advice regarding any detailed processes and procedures to enable Alliances to both ensure and demonstrate VfM.

When the exposure draft for this publication was issued in February 2010, the researcher made a formal submission in April 16, 2010 to the VDTF commenting on the content. This submission, which is attached in Appendix F.5, reflects a number of the points made above. 


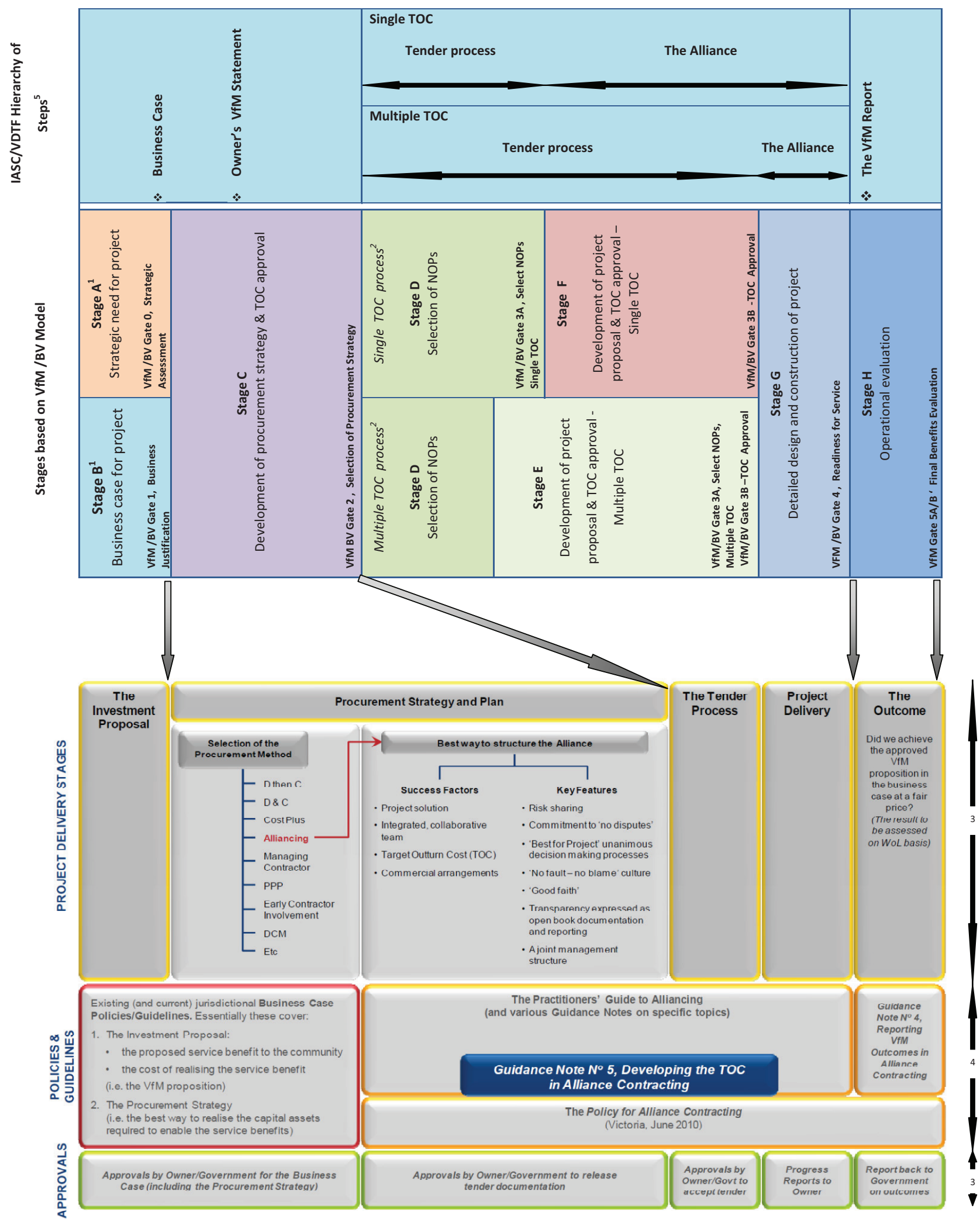

\section{Figure 7.2 Alignment of the VfM/BV Model to IASC/VDTF hierarchy of planning and delivery steps}

This diagram seeks to align the structure of the VfM/BV model with the IASC hierarchy of steps for planning and reporting VfM outcomes as described in Guidance Note No. 5 (Ref), p5

Notes: $\quad$ 1: In the VfM/BV Model as developed, Stages A 'Strategic need for project' and Stage B 'Business case for project' combined are equivalent to 'The Investment Proposal' section in the IASC hierarchy of planning and delivery steps diagram

2: $\quad$ For detailed differences between the single and multiple TOC processes see Chapter 8.

3: The Project Delivery Phases are directly addressed by the VfM/BV Model.

4: The VfM/BV Model is consistent with the requirements of these documents.

5: Hierarchy of steps for planning reporting VfM outcomes as depicted in Figure 
Table 7.3 Comparison between the VfM/BV Model with the IASC/VDFT Approach to VfM

\begin{tabular}{|c|c|c|c|c|}
\hline $\begin{array}{l}\text { Stages of IASC/VDTF } \\
\text { Approach }\end{array}$ & \multicolumn{2}{|l|}{ Stages of VfM /BV Model } & Alignment between Approaches & Difference between Approaches \\
\hline The Investment Proposal & \multicolumn{2}{|l|}{$\begin{array}{l}\text { Stage } B \\
\text { Business case for project }\end{array}$} & $\begin{array}{l}\text { Both approaches stress the importance of ensuring an adequate } \\
\text { focus is given to the generation of a soundly based Business Case } \\
\text { estimate. } \\
\text { A clear outcome of both the IASC Research, and the research } \\
\text { reported in this thesis, is that thorough preparation of a carefully } \\
\text { considered and well documented Business Case was an essential } \\
\text { foundation to ensure that VfM could be created and measured } \\
\text { during the lifecycle of a project. }\end{array}$ & $\begin{array}{l}\text { The Investment Proposal stage described in the IASC/VDTF approach } \\
\text { is broken down into Stage A, Strategic need for project and Stage B, } \\
\text { Business case for project in the VfM/VB Model. This distinction is } \\
\text { seen to be important and reflects the particular attention given in } \\
\text { the VfM/BV model to distinguishing between the strategic need and } \\
\text { possible project solutions to ensure that actual need is identified } \\
\text { before project options are considered. This is considered to be } \\
\text { necessary to identify the real 'values' that are being pursued. }\end{array}$ \\
\hline $\begin{array}{l}\text { Procurement Strategy \& } \\
\text { Plan }\end{array}$ & \multicolumn{2}{|c|}{$\begin{array}{l}\text { Stage } \mathrm{C} \\
\text { Development of procurement strategy }\end{array}$} & $\begin{array}{l}\text { Stage } \mathrm{C} \text { of the VfM/BV Model aligns well with the Procurement } \\
\text { Strategy and Plan stage of the IASC/VDTF Approach. This alignment } \\
\text { includes a similar understanding that the project alliance } \\
\text { procurement route should be consciously selected from the various } \\
\text { procurement options available. Additionally, both approaches } \\
\text { recognise that the success factors required and the optimal structure } \\
\text { of the alliance need to be considered at this point. }\end{array}$ & $\begin{array}{l}\text { The primary difference between the two approaches is the level of } \\
\text { documentation prescribed by the VfM/BV Model in relation to the } \\
\text { selection of the preferred procurement methodology (see Chapter } 8 \text {, } \\
\text { Sheet } 5 \text { of } 10 \text {. The VfM/BV Model actually advocates a project } \\
\text { alliance as the last option to consider on the basis that no other } \\
\text { method suits the circumstances of the project. This last option } \\
\text { approach is not specifically articulated in the IASC Approach } \\
\text { although it is not inconsistent with such a process. }\end{array}$ \\
\hline The Tender Process & $\begin{array}{l}\text { Single TOC } \\
\text { Stage D } \\
\text { Selection of NOPs } \\
\text { Stage F } \\
\text { Development of project } \\
\text { proposal \& TOC approval } \\
\text { Stage G } \\
\text { Detailed design and } \\
\text { construction of project }\end{array}$ & $\begin{array}{l}\text { Multiple TOC } \\
\text { Stage D } \\
\text { Selection of NOPs } \\
\text { Stage E } \\
\text { Development of project } \\
\text { proposal and TOC approval } \\
\text { Stage G } \\
\text { Detailed design and } \\
\text { construction of project }\end{array}$ & $\begin{array}{l}\text { These respective stages of the lifecycle are the least aligned. } \\
\text { Both approaches are able to address a Single or Multiple TOC } \\
\text { methodology but the IASC/VDTF Approach appears to assume that a } \\
\text { Multiple TOC methodology will be adopted. } \\
\text { During the course of the Tender Process and Project Delivery, as they } \\
\text { are defined in GN4, the NOPs are selected and the works are } \\
\text { delivered. However, the Single and Multiple TOC methodologies } \\
\text { address this sequence in quite different ways which require a } \\
\text { different approach to the documentation of VfM. This is illustrated } \\
\text { by examination of the respective processes for the two } \\
\text { methodologies as detailed in the VfM/BV Model described in } \\
\text { Chapter } 8 \text {. }\end{array}$ & $\begin{array}{l}\text { Within the IASC/VDTF approach the Tender Process and Project } \\
\text { Delivery are depicted as distinct stages. The VfM/BV model, } \\
\text { however, recognises a somewhat different structure to the stages of } \\
\text { the lifecycle required to address either a Single or Multiple TOC } \\
\text { methodology. } \\
\text { The respective durations of the Tender Process and The Alliance, as } \\
\text { they are defined in GN4, are actually quite different between the } \\
\text { two methodologies. This statement is premised on the principle that } \\
\text { The Alliance does not truly commence until the NOPs are formally } \\
\text { selected. Consequently, the single TOC methodology has a longer } \\
\text { period in which true alliance behaviours and philosophical alignment } \\
\text { are likely to exist. } \\
\text { In the personal experience of the researcher, this constitutes a } \\
\text { major difference between the approaches and represents a } \\
\text { significant advantage of the single TOC approach. }\end{array}$ \\
\hline The Outcome & $\begin{array}{l}\text { Stage } \mathrm{H} \\
\text { Operational evaluation }\end{array}$ & & $\begin{array}{l}\text { The Outcome stage of the IASC/VDTF approach aligns well with the } \\
\text { Operational evaluation stage of the VfM/BV Model, }\end{array}$ & $\begin{array}{l}\text { The major difference between the approaches is the part responsible } \\
\text { for writing The VfM Report. The IASC/VDTF Approach insists that the } \\
\text { Owner should be the author whilst the VfM/BV Model strongly } \\
\text { recommends that the Alliance produce this document. }\end{array}$ \\
\hline
\end{tabular}




\subsection{Comparison of VfM/BV model with the IASC/VDTF Approach to VfM}

Whilst this chapter has provided a critical review of the IASC Research and the subsequent documentation published by the IASC/VDTF, the researcher believes that there is a good deal of alignment between the approach described in the IASC/VDTF documentation addressing VfM for project alliances and the VfM/BV Model proposed in this thesis.

To illustrate this alignment, Figure 7.2 above presents a compilation of a diagram taken from one of the IASC/VDTF publications and a table which characterises the structure of the VfM/BV model described in more detail in Chapter 8. The diagram selected, which illustrates the hierarchy of planning and delivery steps in a project alliance, is taken from Guidance Note No 5, 'Developing the TOC in Alliance Contracting' (VDTF, 2010a), although a very similar diagram also features in 'The Practitioners' Guide to Project Alliancing' (VDTF, 2010b). This diagram is intended to illustrate the wider policy and approvals context in which the various IASC/VDTF documents exist.

The lower table contained within Figure 7.2 represents a schematic characterisation of the VfM/BV Model described in detail on Chapter 8. This table illustrates the relative timing and purpose of the stages of the model and the various reviews or gates that take place at the end of the respective stages.

It is believed that Figure 7.2 demonstrates the complementary nature of the VfM/BV model to the wider policy and approvals context defined by the IASC/VDTF Approach to VfM. However, there are also differences between the two approaches. Figure 7.2 also incorporates a further table above the representation of the VfM/BV Model which illustrates the hierarchy of five steps as contemplated in Guidance Note No.4 and presented earlier in Figure 7.1. This table illustrates that the respective durations of the 'Tender Process' and 'The Alliance', as they are defined in Figure 7.1, are actually quite different between the two approaches. The researcher suggest that, on the basis that 'The Alliance', does not truly commence until the NOPs are selected, the single TOC approach has a longer period in which true alliance behaviours and philosophical alignment are likely to exist. In the personal experience of the researcher, this constitutes a significant difference between the approaches and represents a significant advantage of the single TOC approach.

Table 7.3 above describes, by stage of the project lifecycle, the nature of the similarities or alignment between the approaches and also identifies the differences between them. 


\subsection{Summary of Chapter}

The IASC/VDTF body of work has included a major research study and the subsequent production of a number of publications, which will undoubtedly be the definitive texts for the management and administration of public sector project alliances in Australia.

The objectives of this chapter were to;

- recognise that during the period of the research reported in this thesis this very significant and highly relevant body of work was undertaken, in parallel, by the IASC/VDTF;

- critically review the IASC Research and the series of IASC/VDTF publications that have been published as a result of this work;

- compare the outcomes of the IASC Research with the outcomes of the research reported in this thesis; and

- compare the VfM/BV model developed during this research with the approach that has been advocated by the IASC/VDTF in the publications issued following their research.

It is believed that these objectives have been addressed in turn through the chapter.

Some differences were identified between the outcomes of the respective research exercises being primarily:

- The insistence within the IASC/VDTF approach that NOPs should be selected using a price based process by default.

- A trend within the IASC/VDTF approach to transfer authority and decision-making from the hands of the Alliance Leadership Team to the Owner.

However, the similarities between the two approaches were much more marked than these differences. In particular, both advocate the adoption of a disciplined and systematic framework which tracks the progress of a project through the various stages of the life-cycle. The VfM/ BV model employs many of the techniques developed in the Gateway ${ }^{\odot}$ Review process and whist this process has not been explicitly embraced by the IASC/VFM documentation issued to date, the need to do so is specifically stated in Guidance Note No.4. Consequently, it is believed that the outcomes of this research are largely complimentary to the IASC/VDTF Approach. 


\section{Chapter 8 - VfM/BV framework/model}

'The purpose of science is not to analyse or describe but to make useful models of the world. A model is useful if it allows us to get use out of it'

(Edward de Bono)

\subsection{What this Chapter will cover}

This chapter is included in this thesis to specifically outline the development of the VfM/BV framework/model that was created, to present the final form of the model and to explain its use. The creation of the model was considered to be central to addressing the research question posed earlier in Chapter 5. (i.e. What is the optimum configuration of a model that will assist all participants in a project alliance to both ensure and demonstrate the achievement of VfM or best value?). The framework/model is designed to be of use to all parties involved in the delivery of project alliances including Owners, Constructors, Design Consultants and other NOP's and is intended to mutually inform all participants of the issues that are critical to VfM/BV throughout the whole lifecycle of a project.

During the course of the research process, the model developed from a one-page flowchart which was initially based on a format originally developed by the Office of Government Commerce (OGC) in the suite of procurement guidance documents that they issued as part of the 'Achieving Excellence in Construction' initiative which followed the Egan Report (1998). The document that was particularly relevant here was the third in 'Procurement Guide' series entitled 'Project procurement cycle - the integrated process' (OGC, 2007b). As a consequence of the research undertaken, including the Phase1 interviews and questionnaire followed by the Phase2 Delphi Survey process, the model went through a number of updates and revisions.

This model is believed to successfully address the research question described above and consequently it is believed that it makes a significant contribution to the practice of alliance procurement by providing a structured and disciplined approach to the establishment and documentation of $\mathrm{VFM}$ in the procurement of projects using the project alliance methodology.

\subsection{The development of the VfM/BV Model}

The purpose of creating a VfM/ BV Model was to provide a systematic and repeatable process for both ensuring and demonstrating $\mathrm{VFM} / \mathrm{BV}$ if the project alliance procurement model is selected as 
the most appropriate means of delivering a given project. The model is specifically designed for use in the delivery of construction related projects.

The original form of the model was based on the architecture described in the OGC Procurement Guide (2007b) described above. This guide used a flowchart format to depict the various activities and milestones that define the lifecycle of a project and nominates a number of review points or gates which needed to occur at critical points along the lifecycle. The concept of review points or gates is the principle behind the Gateway ${ }^{\mathrm{TM}}$ Review Process advocated by the OGC as a formalised procedure for external review of projects (OCG, 2004, OGC, 2005, OGC, 2007f, OGC, 2007e). In the Gateway ${ }^{\top \mathrm{M}}$ Review process such gates are designed to subject the progress of a project to critical review to ensure that projects remain 'on track' and only proceed to the next stage of the lifecycle once the gates have been seen to be successfully traversed and there has been a clear demonstration that the project remains relevant to the original project objectives, budget and timeline. The poor performance of many projects in the past, as discussed at some length in both the Latham (1994) and Egan (1998) Reports, set the scene for the development of such a process .

As explained earlier in Chapter 3, the Gateway ${ }^{\top \mathrm{M}}$ Process described above was originally developed by the OGC in the UK but has subsequently been adopted by the Australian Federal Government and most Australian States. Consequently, the Gateway ${ }^{\mathrm{TM}}$ process represents a now familiar approach to public sector clients in particular, although a similar approach is also used by a number of larger private sector clients.

Interestingly, in their February 2010 'Exposure draft' publication entitled 'Guidance Note No 4, Reporting VfM Outcomes in Alliance contracting', the Victorian Department of Treasury and Finance (VDTF) (p25) reported that 'The Government's risk profile under alliance contracts means that Alliances are regularly subject to the Gateway Review Process. The Gateway Review Process will be specifically tailored to take the unique characteristics of alliancing into consideration'. However, the first edition of this publication issued in June 2011 and the current version, being the updated first edition issued in March 2011 (VDTF, 2011)revised this statement to indicate that 'The Gateway Review Process may be specifically tailored to take the unique characteristics of alliancing into consideration'. In either event, these comments were made after the conception of the model now being presented, but support the approach adopted. The model also adopted a number of the VfM measures recommended in the original version of the 'Project Alliancing Practitioners' Guideline' produced by the VDTF(2006a). This publication included a specific chapter which provided a series of practical suggestions regarding how VfM might be both ensured and demonstrated to have been achieved. These measures, which spanned the project lifecycle were inserted into the model, 
although in doing so it became apparent that the measures were focussed on the later stages of the lifecycle commencing at Stage D (see final version of model in Section 8.3) when the NoPs were selected. The lack of earlier measures, particularly at the time of producing the 'Business Case for the Project' (Stage B), was seen as significant weakness in practice to date.

During the course of the Phase 1 Interviews and questionnaire process, which is described in some detail earlier in Chapters 4 and 5, the original model was presented to the 27 alliance practitioners who agreed to participate in the research. Based on the feedback obtained at that time, a number of changes were made to the model which were relatively minor but aimed primarily at increasing the legibility of what was seen by a number of people as a rather 'busy' diagram that was difficult to follow. The original model is shown in Appendix B. 3 and the revised format at the end of Phase 1 is shown in Appendix C.4.

During the Phase 2 Delphi Survey process the revised model was again subjected to comment, in this case from the 12 'experts' who participated in this anonymous consultative Delphi process which, again, is described in detail in Chapters 4 and 5. A range of comments were received including a number that suggested a substantially revised approach would improve both the legibility and function of the model. This resulted in further revisions to the format including the introduction of a simpler Summary Level Flowchart or 'road map' accompanied by a series of separate flowcharts which addressed each stage the lifecycle of an alliance project. Feedback was also received during Round 1 of the Delphi Survey process that the model needed to address the use of a multiple TOC development process, rather than simply focus on a single TOC approach, if it was to be real value to practitioners. Respondents indicated that this was particularly important given the apparently increasing use of such an approach in the selection of NoPs to participate in project alliances. This multiple TOC approach was seen to be primarily be driven by concerns, in the public sector, that it was becoming increasingly difficult to promote the single TOC model due to concerns regarding VfM as a consequence of a lack of price completion in the selection of NOPs. The findings of the research undertaken by the VDTF and the University of Melbourne (IASC, 2009) published in October 2009 further supported the need to address the multiple TOC approach given that this work included a clear recommendation that this should now become the default methodology, for public sector clients.

The model was amended to adopt the revised format described above between Rounds 1 and 2 of the Delphi Process and whilst some respondents were concerned about the increased size of the model most were of the view that greater clarity and functionality were achieved. The model issued during Round 2 of the Delphi Survey process is shown in Appendix C.6. 
Since completion of the Delphi Survey process the model has been further developed. Initially this development involved the creation of separate flowcharts for each of the seven stages of the lifecycle identified in the Summary Level Flowchart. Only one such flowchart, for the Procurement Strategy Stage had been prepared at the time of Round 2 of the Delphi Survey. In fact, eight flowcharts were required given that an extra chart was created to address the combined selection of NOPs/TOC Approval stage involved in a multiple TOC process.

The VDTF research referred to above has spawned a series of subsequent VDTF publications concerning alliance practice. Consideration of the content of these publications also led to a number of further changes to the model. These VDTF publications are discussed in some detail in Chapter 7 but two of the recommendations that are particularly relevant to the development of the VfM/BV Model are the specific provision of an Owner's VfM Statement, prior to seeking the involvement of NOPs and a Value for Money Report produced at the completion of construction. Most of these measures contained within these two documents were in fact already addressed in the model but were described and named using different terms. Given the likely widespread adoption of the terminology proposed in the various recent VDTF publications it was considered to be sensible to adopt the same terms and the model has been amended accordingly.

Whilst the model presented in this thesis was initially developed before the VDTF commenced their now extensive process of research and publication of guidelines and guidance notes, it is interesting to note that the VDTF has adopted a similar timeline approach in describing the matters necessary to best ensure that VfM is achieved. VDTF have, in fact, identified only five stages given that they do not distinguish between the Strategic Need and Business Case stages and also have not included an Operational Evaluation Stage.

The overall philosophy of the approach proposed by the VDTF for reporting VFM Outcomes in Guidance Note No. 4 (2011) is very closely aligned with the approach adopted by the researcher in developing the VfM/BV described in this thesis. The two approaches are seen as being totally complimentary. The primary difference between them is that the VfM/BV seeks to outline a more detailed process using a Gateway ${ }^{\mathrm{TM}}$ based approach. Additionally, the VfM/BV model seeks to guide practitioners to proactively ensure that $\mathrm{VfM}$ is actually achieved as well as recording outcome to demonstrate that this has or has not occurred.

\subsection{Presentation of the final version of the Model}

The ten page final model is presented below. The document is structured in a manner which addressed the temporal sequence of any project starting with the consideration of a business and 
community needs through the selection of the procurement approach, the design and construction, physical completion, operations and ultimately decommissioning of the project.

The model includes a cover page (Sheet 1 of 10) which provides a brief description of the purpose, basis and development of the model. This page also lists a table of contents of the model explaining what stage of the lifecycle each page addresses. The cover page also lists a brief bibliography of some of the documents that were influential in the drafting of the model following by a legend which explains the symbols used in the various flowcharts which define the structure of the model. Finally, the cover sheet defines the acronyms used in the document.

The second page of the model is the Summary Level Flowchart (Sheet 2 of 10) which depicts the whole lifecycle of a project divided into seven discrete stages (plus another for the multiple TOC approach) and proposes that at the end of each stage a structured review of progress is undertaken (VfM/BV Gate Review). As explained earlier, the model adopts the approach, and where directly applicable, the terminology of the Gateway ${ }^{\mathrm{TM}}$ Review process. The researcher has noted that each Australian Government jurisdiction appears to have somewhat varied terminology and specifically the numbering system of the original Gateway ${ }^{\mathrm{TM}}$ Review. This is unfortunate, although not altogether unexpected given the history of such a divergence of approach between Australian jurisdictions. The model has generally followed the original UK terminology and numbering of the Gates except where changes have been specifically required by the particular characteristics of alliance procurement.

What is now termed the Summary Level Flowchart was originally the model itself but, due to feedback received and the further consideration by the researcher, it was determined that a separate page for each stage would enable the specifics of each stage to be better explained. The specific feedback that gave rise to this change is described in some detail in Chapter 5.

Consequently, the individual pages for each stage contain a flowchart (Sheet 3 of 10 to Sheet 10 of 10), which specifically identifies the activities and milestones applicable to that stage, and a corresponding table which poses the particular questions applicable to the milestones within the stage. The table also nominates the purpose of the VfM/BV Gate review/s that need to be traversed, during or at the conclusion of each stage.

Whilst the approach and format are conceptually similar to the Gateway ${ }^{\mathrm{TM}}$ Review process, the content of the model is firmly focussed on issues that are particular to the achievement and demonstration of VfM or best value hence the adoption of the term VfM/BV Gate. The model is aimed at ensuring projects do not proceed to the next stage without critical review. 
It is not proposed that the VfM/BV Gate review be undertaken by an independent third party team which would specifically be the case for the Gateway Review process. It is, however, important that the representatives of the Owner, as opposed to the Owner participants in the Alliance, are either directly involved in the review process or appoint representatives to do so. The preparation of documentation for the review would, however, is seen as the responsibility of the alliance team once this is established (i.e. from Stage D onwards). This discipline will ensure that the alliance team maintains a constant and consistent focus on $\mathrm{VFM}$ and also generates the documentary evidence that will be necessary to include in a final VfM Report (VDTF, 2006a, VDTF, 2011, VDTF, 2010b) that will need to be assembled and presented at the conclusion of the delivery of the project.

\subsection{Proposed use of the model}

The model has been designed to address VfM from the very start to the end of the lifecycle of the project rather than leaving this with post project completion. Consequently, the parties making use of the model will vary through the lifecycle of the project. Initially only the Owner will be involved but others, being designers or constructors, will participate during the later stages once the alliance is formed. The optimum point of involvement of Non-Owner Participants (NOPs) in the development of the project is a subject of some debate. Some, notably including the VDTF in their recent publications, believe that NOPs should not be involved in the project until the business case is completed and the procurement approach has been determined. Others, the researcher included, would argue that such an approach prevents the Owner from gaining insights into how the project that can be best delivered by those experienced in the practical aspects of such projects and that a delay in their involvement may result in the business case being unrealistic and/or a sub-optimal solution being selected.

One of the key benefits of the adoption of the model being proposed is that it would give all participants a clear understanding of the type of questions that need to be addressed and their timing of $\mathrm{VFM} / \mathrm{BV}$ is to be achieved. A consistent theme that emerged during Phase 1 of the research undertaken, in particular, was that participants believed that VFM/BV had been achieved in most alliance projects completed to date and the basic statistics presented in Chapter 2 appear to support this premise. However, the deficiency in current practice that was regularly identified was the failure to adequately record and demonstrate such success.

The actual use of the model by practitioners is a simple matter which involves a methodical and progressive movement through each stage of the lifecycle addressing the questions posed by the model and end in a systematic manner to relevant responses. As is noted in the model, the 
questions posed at each milestone should be addressed and responded to in the affirmative and then recorded.

Importantly, as per the original Gateway ${ }^{\mathrm{TM}}$ Review process each VfM/BV gate needs to be adequately addressed or traversed before the project can proceed to the next stage. To use a term that is common in the practice of construction, these gates represent 'hold points' at which progress of the project must be literally held until the sponsor of the project, the Owner, has been satisfied that there is satisfactory evidence to support the proposition that the project will result in a best value outcome and should proceed further.

The first few stages of the model as presented, (i.e. Stages A to C) concern the selection of the procurement approach and are consequently applicable to all projects. The researcher would also suggest that the model would be readily adapted so that the later stages were drafted to suit the circumstances of the $D \& C$ or traditional procurement approach to ensure that $V f M / B V$ was similarly documented through the development and delivery of projects prosecuted under these procurement regimes. Such an approach, it is suggested, would provide a more substantial demonstration of $\mathrm{VfM} / \mathrm{BV}$ that the simple reliance on the premise that a project secured under a 'lowest price' or price competitive framework must, by definition, represent VfM. Such documentation through the lifecycle of such projects would also capture the actual cost of delivery compared to the tendered price. Historically (Ross, 2003b, Rapoport, 1970, Sweeney, 2009) there has been a substantial difference between the two with claims and contract disputes leading to often substantial increases in the actual cost of delivery. This growth in the cost of delivering projects through these nonrelationship based procurement approaches has received little considering in the recent writings of the VDTF and others when assessing whether alliances can deliver better cost outcomes compared to traditional procurement approaches. 


\section{Purpose of Model}

The purpose of the VfM/ BV Model is to provide a systematic and repeatable process for both ensuring and demonstrating that $\mathrm{VFM} / \mathrm{BV}$ is obtained if the project alliance procurement model is selected as the most appropriate means of delivering a given project. The model is specifically designed for use in the delivery of construction related projects.

\section{Basis of the mode}

The model draws upon a number of previous approaches including the lifecycle procurement flowchart ${ }^{1}$ developed by the Office of Government Commerce (OGC) a division of HM Treasury, UK. This, in turn, drew upon the rationale of the Gateway ${ }^{\mathrm{TM}}$ Review Process also developed by the OGC and subsequently adopted by most Australian Governments. Additionally, the model references the original 'Project Alliancing Practitioners' Guideline ${ }^{2}$, produce by the Victorian Department of Treasury and Finance (VDTF) and the more recent publications 'Reporting VfM outcomes in Alliance Contracting (Guidance Note $\left.\mathrm{N}^{0} 4\right)^{3 \text { ' }}$ and 'The Practitioners' Guide to Alliance Contacting ${ }^{4}$ ' both issued by the same agency.

\section{Development of the mode}

The model has been developed initially from the above specific references ( 1 to 3 ), the literature more broadly and the professional experience of the researcher. The model was further refined following discussions and comments received from some twenty seven practitioners participating in five alliance projects which were studied in some detail in mid 2009. Additionally, comments were also obtained from some twelve parties, regarded as 'experts' in the field of project alliancing in Australia through a Delphi Survey process conducted in late 2009. The model was further informed by the VDTF publications issued in 2010 as noted below.

\section{Contents of Mode}

\section{Cover Sheet for framework/model}

Sheet 1 of 10

Summary Level Flowchart

Strategic Need for Project Stage - VfM/BV Gate 0

Sheet 2 of 10

Sheet 3 of 10

Sheet 4 of 10

Business case for Project Stage - VfM/BV Gate 1

Sheet 5 of 10

Sheet 6 of 10

Sheet 7 of 10

Development of Project Proposal and TOC Approval Stage

(Multiple TOC) - VfM/BV Gates 3A\&B

Development of Project Proposal and TOC Approval Stage

(Single TOC) - VfM/BV Gates 3B

Detailed Design and Construction of Project Stage - VfM/BV Gate 4

Operational Evaluation Stage - VfM/BV Gates 5A\&B

Sheet 9 of 10

Sheet 10 of 10

\section{Use of Model}

The framework/model is designed to be of use to all parties involved in the delivery of project alliances including Owners, Constructors, Design Consultants and other NOP's and is intended to mutually inform all participants of the issues that are critical to VfM/BV throughout the whole lifecycle of a project.
Bibliography:

1 OGC, 'Project procurement cycle - the integrated process',

Procurement Guide 3, 2007

VDTF, 'Project Alliancing Practitioners' Guide', April 200

3 VDTF, 'Reporting VfM outcomes in Alliance Contracting (Guidance Note $\left.\mathrm{N}^{0} 4\right)^{\prime}$, June 2010

4 VDTF, 'The Practitioners' Guide to Alliance Contacting',

October 2010

\section{Legend:}
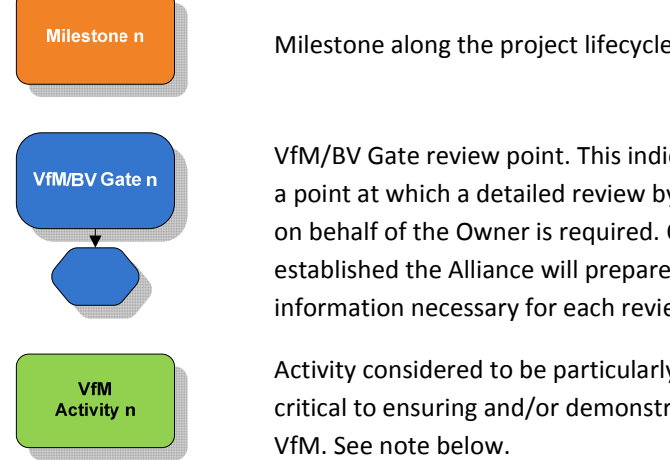

$\mathrm{VfM} / \mathrm{BV}$ Gate review point. This indicates a point at which a detailed review by or on behalf of the Owner is required. Once established the Alliance will prepare the information necessary for each review.

Activity considered to be particularly critical to ensuring and/or demonstrating $\mathrm{VfM}$. See note below.

Procedural activity in the project lifecycle

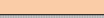

Decision point along the project lifecycle

Acronyms

\begin{tabular}{lllll}
\hline ALT & Alliance Leadership Team & NOP & Non Owner Participant \\
\hline AMT & Alliance Management Team & TCE & Target Cost Estimate \\
\hline AOC & Actual Out-turn Cost & TOC & Target Out-turn Cost \\
BV & Best value & VfM & Value for Money \\
ECI & Early Contractor Involvement & & \\
EOI & Expressions of Interest & & \\
KPA & Key Performance area & & \\
KPI & Key Performance Indicator & & \\
\hline
\end{tabular}

Notes: A number of VfM activities have been identifies as VDTF ' $x$ ' where $x$ refers to the VfM item identified in Chapter 5 of Bibliography reference no. 3 . This model is best printed at A3 page size but has been designed to be legible at A4 page size using a high quality printer. 


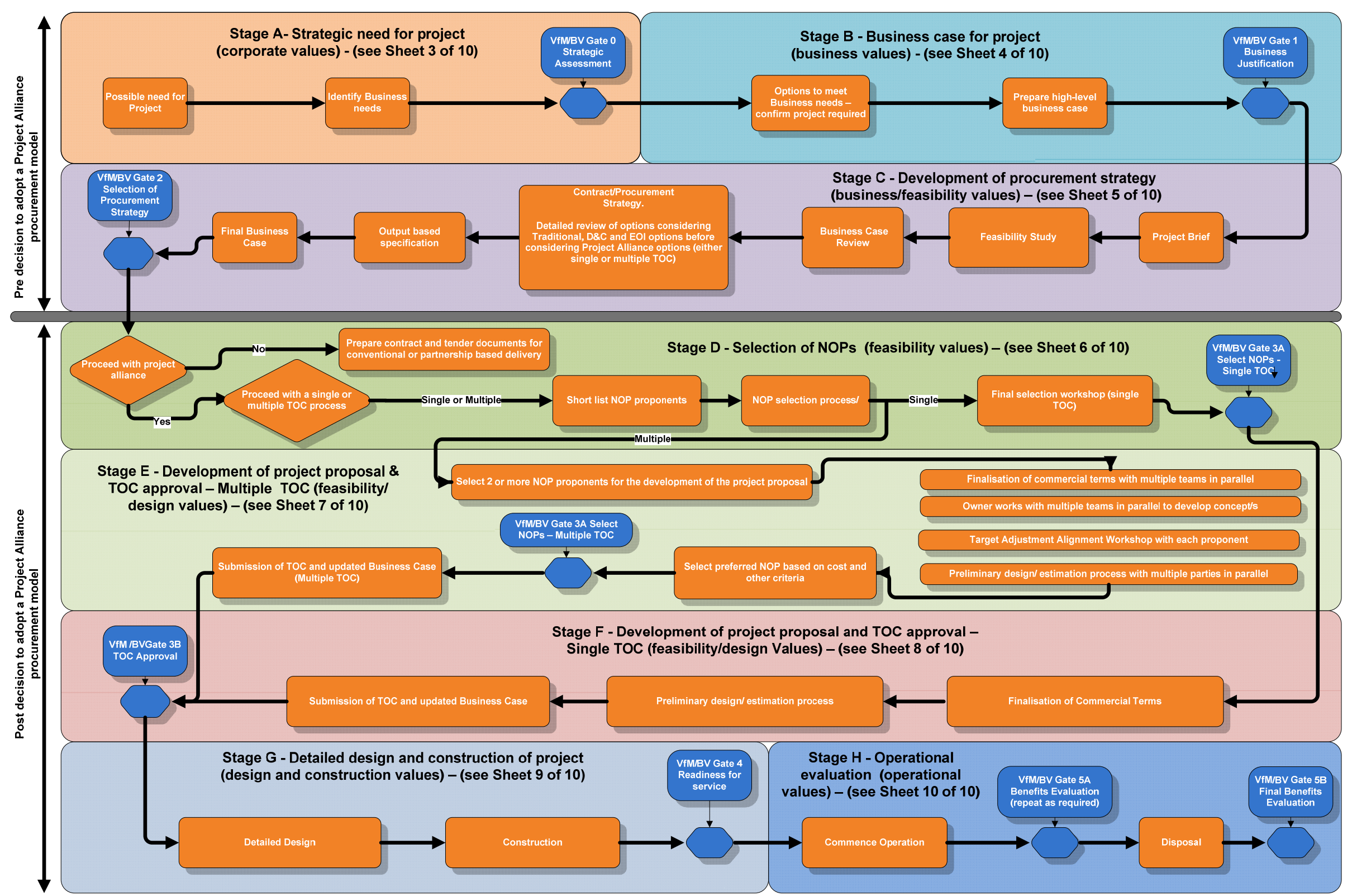




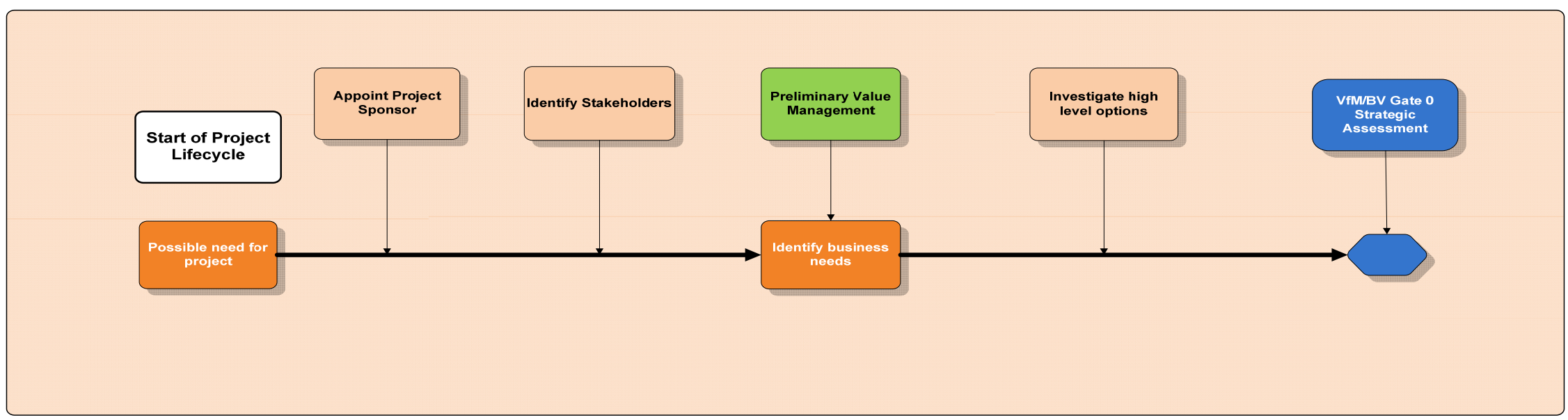

Significant milestones in the Stage A - Strategic Need for Project of the project lifecycle

(In this stage, the high level business needs that might lead to a project or program are identified and evaluated)

\begin{tabular}{|c|c|c|}
\hline \multicolumn{3}{|c|}{$\begin{array}{l}\text { Significant milestones in the Stage A - Strategic Need for Project of the project lifecycle } \\
\text { (In this stage, the high level business needs that might lead to a project or program are identified and evaluated) } \\
\text { BUSINESS VALUES }\end{array}$} \\
\hline Possible need for Project & Identify Business Needs & VfM/BV Gate 0 -Strategic Assessment \\
\hline $\begin{array}{l}\text { Has a possible corporate need or goal been } \\
\text { identified that could necessitate the delivery of a } \\
\text { project or programme of projects to address this } \\
\text { need or goal? }\end{array}$ & $\begin{array}{l}\text { - Has there been a review of arrangements for leading and } \\
\text { managing a project or programme including the appointment of } \\
\text { a project sponsor? } \\
\text { - Has a project sponsor been appointed? } \\
\text { - Have the stakeholders been identified and contacted? } \\
\text { - Are the stakeholders supportive of the business needs } \\
\text { identified i.e. are corporate values being addressed? } \\
\text { - Do the needs identified contribute to the organisational } \\
\text { business strategy and to high-level policy objectives, strategies } \\
\text { and initiatives? } \\
\text { - Has a preliminary value management study been undertaken? } \\
\text { Note: All of the above questions need to be responded to in the } \\
\text { affirmative and documented for this milestone to be achieved. }\end{array}$ & $\begin{array}{l}\text { Have the business needs that might lead to the need for a project been } \\
\text { identified and evaluated at a strategic level? } \\
\text { - Has a thorough value management process been undertaken in } \\
\text { identifying the business needs that might be addressed by a project or } \\
\text { program of projects? } \\
\text { Without such a process to clearly identify the primary needs there } \\
\text { is no foundation for value to be determined. } \\
\text { - Have high level options been considered which address the identified } \\
\text { business needs? } \\
\text { Has a preliminary Owners' Value Proposition }\left(\mathrm{VDTF}^{2}\right) \text { been developed } \\
\text { which defines the service benefits to be delivered to the community? } \\
\text { Note: This VfM/BV Gate which concludes the Strategic Need for a Project } \\
\text { stage the lifecycle must be successfully traversed before the next stage } \\
\text { can commence. }\end{array}$ \\
\hline
\end{tabular}




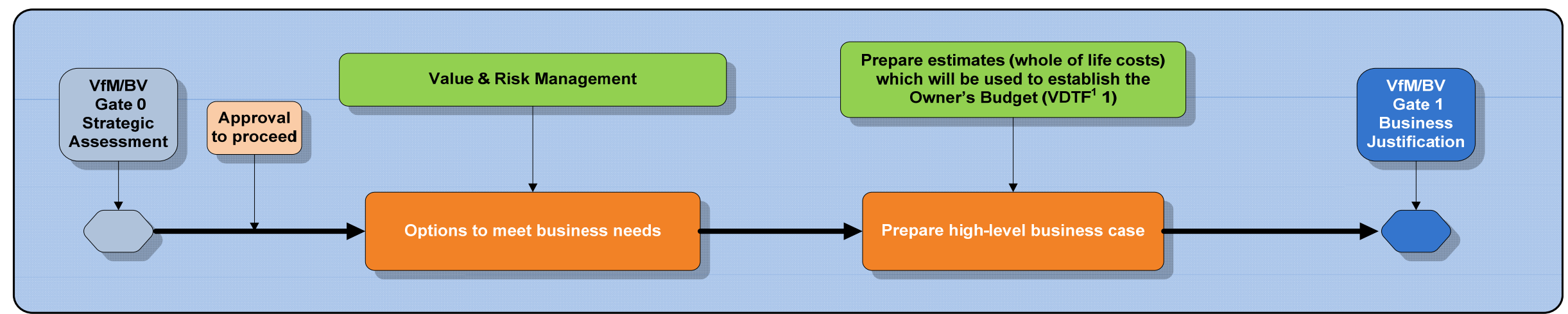

Strategic Need for a Project Stage
VfM/BV Gate 0 - Strategic Assessment
Have the business needs that might lead to the
need for a project been identified and evaluated
at a strategic level?
- Has a thorough value management process been
undertaken in identifying the business needs that
might be addressed by a project or program of
projects?
Without such a process to clearly identify the
primary needs there is no foundation for value
to be determined.
- Have high level options been considered which
address the identified business needs?
Note: This VfM/BV Gate which concludes the
Business Case for Project Stage of the lifecycle
must be successfully traversed before the next
stage can commence.

Significant milestones in Stage B - Business Case for Project of the project lifecycle

(In this stage project options that might address the Identified business needs are investigated and a business case is developed which includes the

(In this stage project options that might address the Identified business needs are investigte
'Owner's Value Proposition'

BUSINESS VALUES
BUS Value Proposition

\begin{tabular}{|c|c|c|}
\hline Options to meet business needs & Prepare high level business case & VfM/BV Gate 1- Business Justification \\
\hline $\begin{array}{l}\text { - Have range of possible solutions which } \\
\text { address the identified business needs been } \\
\text { considered } \\
\text { - Have appropriate value management and risk } \\
\text { management processes been undertaken? } \\
\text { - Does the project contribute to the } \\
\text { organisational business strategy? } \\
\text { - Are the scope and, scale and requirements } \\
\text { realistic, clear and unambiguous? }\end{array}$ & $\begin{array}{l}\text { - Have major risks been identified and a } \\
\text { management plan outlined? } \\
\text { - Have critical success factors been agreed with } \\
\text { stakeholders? } \\
\text { - Have estimates been prepared on a truly 'whole } \\
\text { of life 'basis and appropriately checked and } \\
\text { reviewed? } \\
\text { - Has the Owner's Value Proposition been clearly } \\
\text { articulated i.e. the initial Owner VfM Statement } \\
\text { (VDTFF') been developed which articulates the } \\
\text { service benefits to be delivered to the } \\
\text { community weighted against the costs and risks } \\
\text { of delivery? }\end{array}$ & $\begin{array}{l}\text { What is the value context within which project } \\
\text { development is taking place and what are the } \\
\text { implications for the project development process? } \\
\text { - Has an appropriate project solution been developed to } \\
\text { pre-feasibility stage } \\
\text { - Have major risks been identified and a management plan } \\
\text { outlined? } \\
\text { - Have the values and critical success factors been agreed } \\
\text { with stakeholders? } \\
\text { - Have preliminary estimates been prepared on a truly } \\
\text { 'whole of life' basis? (Getting the Owners budget estimate } \\
\text { right!) } \\
\text { - Has a realistic pre-feasibility budget been produced and } \\
\text { documented in a form that can be revisited at a later stage } \\
\text { of the project? } \\
\text { - Has the Owners Value Proposition been clearly } \\
\text { articulated? }\end{array}$ \\
\hline \multicolumn{2}{|c|}{$\begin{array}{l}\text { Note: All of the above questions need to be responded to in the affirmative and documented } \\
\text { for this milestone to be achieved. }\end{array}$} & $\begin{array}{l}\text { Note: This VfM/BV Gate which concludes the Business } \\
\text { Case for Project Stage of the lifecycle must have been } \\
\text { successfully traversed before this stage can commence. }\end{array}$ \\
\hline
\end{tabular}




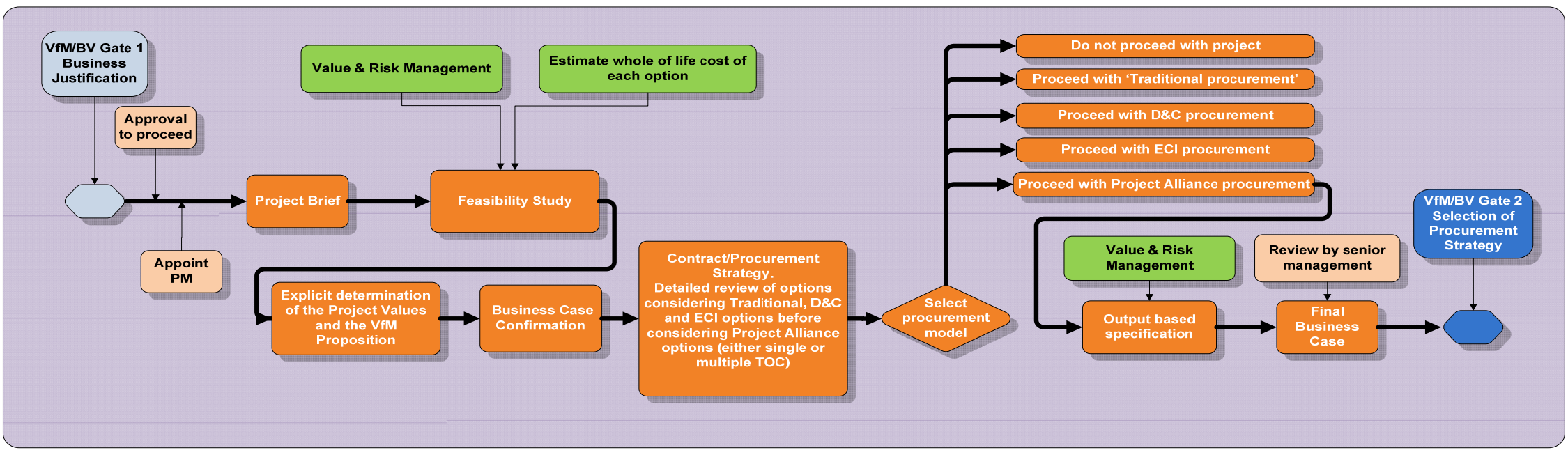

Business Case for Project Stage

VfM/BV Gate 1 - Business Justification

What is the value context within which project development is taking place an what are the implications for the proje development process?

- Have major risks been identified and a management plan outlined?

- Have the values and critical success factors been agreed with stakeholders?

- Have estimates been prepared on a truly 'whole of life' basis? (Get the owners budget estimate right!)

- Has a realistic budget been produced and documented in a form that can be revisited at a later stage of the project?

Note: This VfM/BV Gate review, which concludes the Business Case for Project Stage, must have been successully trage, must have been successfully raversed before the next stage can commence.
Significant milestones in Stage C - Development of Procurement Strategy of the project lifecycle

(In this stage, the high level Business Case previously developed is expanded to facilitate the selection of the most appropriate procurement mode)

\section{BUSINESS/FEASIBILITY VALUES}

\begin{tabular}{|c|c|c|c|c|}
\hline Feasibility Study & $\begin{array}{l}\text { Explicit determination of the Project } \\
\text { Values and the ViM Proposition }\end{array}$ & Business Case Confirmation & Contract/Procurement Strategy & $\begin{array}{l}\text { VfM/BV Gate 2-Selection of Procurement } \\
\text { Strategy }\end{array}$ \\
\hline $\begin{array}{l}\text { - Has the functionality of the } \\
\text { project been fully defined? } \\
\text { - Have all credible options been } \\
\text { fully considered for the project? } \\
\text { - Have detailed whole of life costs } \\
\text { been considered for each option? } \\
\text { - Has a thorough value } \\
\text { management process been } \\
\text { undertaken? } \\
\text { - Has a thorough risk assessment } \\
\text { been undertaken? }\end{array}$ & $\begin{array}{l}\text { - Have the values for the project } \\
\text { been clearly articulated and } \\
\text { documented? } \\
\text { - Do the values reflect the interests } \\
\text { of all key stakeholders? } \\
\text { - Has the Owner's VfM Proposition } \\
\text { (VDTF2) been fully developed and } \\
\text { confirmed for the project? } \\
\text { - Has the VfM Proposition been } \\
\text { clearly articulated i.e. are the } \\
\text { costs/risks of the balanced } \\
\text { against the service benefits of the } \\
\text { proposal? } \\
\text { Is certainty of final outturn cost a } \\
\text { key issue? }\end{array}$ & $\begin{array}{l}\text { - Has the budget been firmly } \\
\text { established? } \\
\text { Has a program for the project } \\
\text { been confirmed? } \\
\text { - Is the Value Proposition } \\
\text { compelling? } \\
\text { - Has the appropriate allocation of } \\
\text { risk between parties been } \\
\text { considered? } \\
\text { - Has the complexity of the } \\
\text { political/stakeholder issues been } \\
\text { adequately assessed? }\end{array}$ & $\begin{array}{l}\text { The following options should be } \\
\text { considered in this sequence: } \\
\text { - Is the project suited to the } \\
\text { adoption of a 'Traditional' design, } \\
\text { tender, build model? If not: } \\
\text { - Is the project suited to the } \\
\text { adoption of a 'Design and } \\
\text { Construct (D\&C)' model? If not: } \\
\text { - Is the project suited to the } \\
\text { adoption of an 'Early Contractor } \\
\text { Involvement' Model (ECI) model? } \\
\text { If not: } \\
\text { - Given that the above models are } \\
\text { not suited to the project - would } \\
\text { an alliance model be appropriate } \\
\text { for this project? } \\
\text { - Has the Owner's VfM Statement } \\
\text { (VDTF2) been completed } \\
\text { including project level details that } \\
\text { expand the Business Case? }\end{array}$ & $\begin{array}{l}\text { What is the procurement route that best } \\
\text { addresses the Owners' value parameters? } \\
\text { - Have the criteria that will define VfM/BV } \\
\text { for the project been explicitly determined? } \\
\text { Does the business case still meet the } \\
\text { business need? } \\
\text { - Does the Owner's team have the expertise } \\
\text { to understand the supplier market? } \\
\text { - Have the procurement options been } \\
\text { subjected to thorough risk and value } \\
\text { management analyses? } \\
\text { - Has a methodical approach been adopted } \\
\text { to select the most appropriate } \\
\text { procurement model, or would other } \\
\text { approaches offer a similar or better } \\
\text { outcome? } \\
\text { Note: This VfM/BV Gate which concludes the } \\
\text { Development of Procurement Strategy stage } \\
\text { the lifecycle must be successfully completed } \\
\text { before the next stage can commence. }\end{array}$ \\
\hline
\end{tabular}




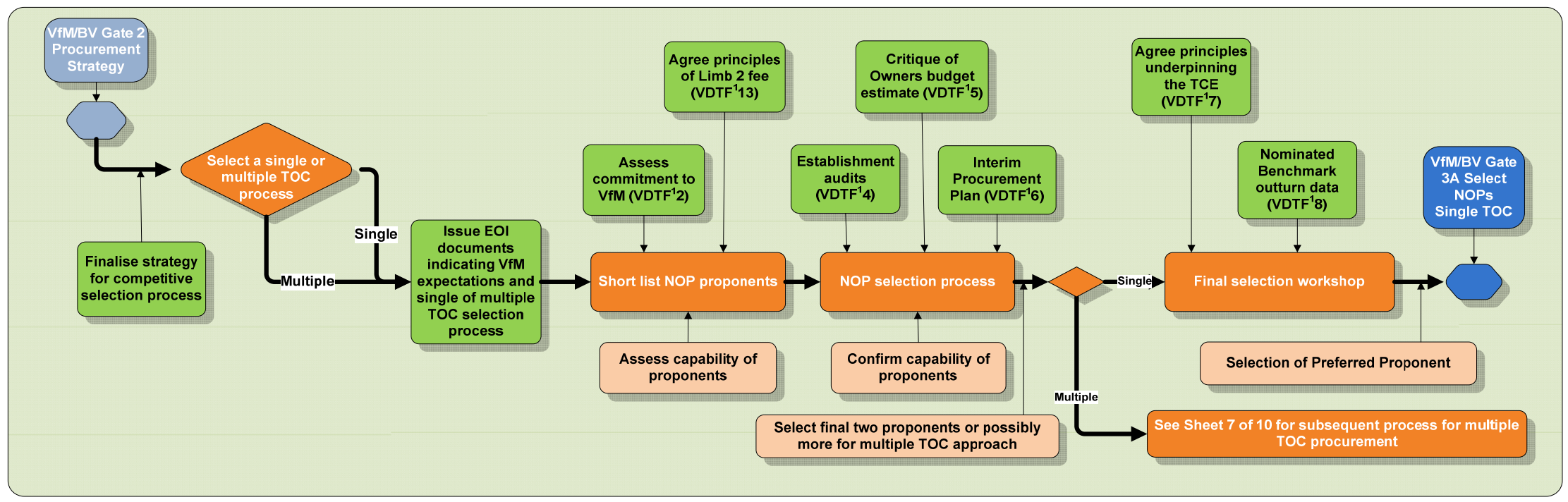

Development of Procurement Strategy Stage

VfM/BV Gate 2 - Selection of Procurement Strategy

What is the procurement route that best addresses the Owners' value parameters?

- Have the criteria that will define VFM/BV for the project been explicitly determined?

Does the business case still meet the business need?

- Does the Owner's team have the expertise to understand the supplier market?

- Have the procurement options been subjected to thorough risk and value management analyses?

- Has a methodical approach been adopted to select the most appropriate

procurement model, or would other approaches offer a similar or better outcome?

Note: This VfM/BV Gate which concludes the Procurement Strategy stage the lifecycle must be successfully traversed before the next stage can commence.

\begin{tabular}{|c|c|c|c|}
\hline \multicolumn{4}{|c|}{$\begin{array}{l}\text { Significant milestones in Stage D - Selection of NOPs (Single TOC) of the project lifecycle } \\
\text { (In this stage, it is vital to ensure that the best and most appropriate NOP's are selected) } \\
\text { FEASIBILITY VALUES }\end{array}$} \\
\hline Select single or multiple TOC process & Short list NOPs/ NOP selection process & $\begin{array}{l}\text { Final selection workshop for single } \\
\text { TOC }\end{array}$ & VfM/BV Gate 3A-Select NOPs \\
\hline $\begin{array}{l}\text { The selection of single or multiple } \\
\text { TOC approach is a fundamental } \\
\text { decision. This may, however, be } \\
\text { predetermined by the Owner's } \\
\text { procurement policy. } \\
\text { - If a choice is available it should be } \\
\text { necessary to have good reasons not } \\
\text { to proceed with a single TOC } \\
\text { approach. This position is supported } \\
\text { by the results of the Authors } \\
\text { research which suggest that at the } \\
\text { point NOP's are selected non cost } \\
\text { based 'ethical' criteria are seen as } \\
\text { being the issues most critical to VfM }\end{array}$ & $\begin{array}{l}\text { - Has the commitment of the proponents } \\
\text { to VfM outcomes and documentation } \\
\text { been seriously addressed? } \\
\text { - Have the principles behind the Limb } 2 \text { fee } \\
\text { been openly and candidly discussed and } \\
\text { locked in before proceeding further? } \\
\text { - Have the proponents demonstrated that } \\
\text { they understand and accept the Value } \\
\text { Proposition prepared by the Owner? } \\
\text { - Have the necessary establishment audits } \\
\text { been undertaken by an appropriately } \\
\text { qualified financial auditor? } \\
\text { - Has there been total transparency of the } \\
\text { owner's estimate and has this been } \\
\text { openly critiqued? } \\
\text { - Has an interim procurement plan been } \\
\text { prepared and if so, how much work and } \\
\text { materials will be procured through } \\
\text { competitive tender? }\end{array}$ & $\begin{array}{l}\text { - Are the principles underpinning } \\
\text { the TCE agreed? } \\
\text { Has the benchmark date from } \\
\text { other projects been provided by } \\
\text { the proponents and adequately } \\
\text { assessed? } \\
\text { - Has a Variation Alignment } \\
\text { Workshop been undertaken with } \\
\text { the preferred proponent to } \\
\text { ensure alignment on events that } \\
\text { will justify an adjustment to the } \\
\text { TOC? } \\
\text { - Has a thorough and sufficiently } \\
\text { exacting process been adopted } \\
\text { in the conduct of the final } \\
\text { selection workshop? } \\
\text { Is there complete confidence } \\
\text { that the team most able to } \\
\text { deliver the Owner's Value } \\
\text { Proposition been selected? }\end{array}$ & $\begin{array}{l}\text { To ensure that the best and most appropriate NOP's been selected for } \\
\text { the project. } \\
\text { - Has the importance of VfM been adequately communicated to the } \\
\text { Owner and NOP members of the team? } \\
\text { - Has the preferred proponent demonstrated that they understand } \\
\text { and accept the Value Proposition prepared by the Owner? } \\
\text { - Have the appropriate commercial arrangements been put in place to } \\
\text { ensure that appropriate behaviour, conducive to VfM, will result? } \\
\text { - Have appropriate audits been undertaken? } \\
\text { - Are the principles underpinning the TCE process clear to all parties? } \\
\text { Note: This VfM/BV Gate which concludes the Procurement Strategy } \\
\text { stage the lifecycle must be successfully traversed before the next stage } \\
\text { can commence. }\end{array}$ \\
\hline
\end{tabular}




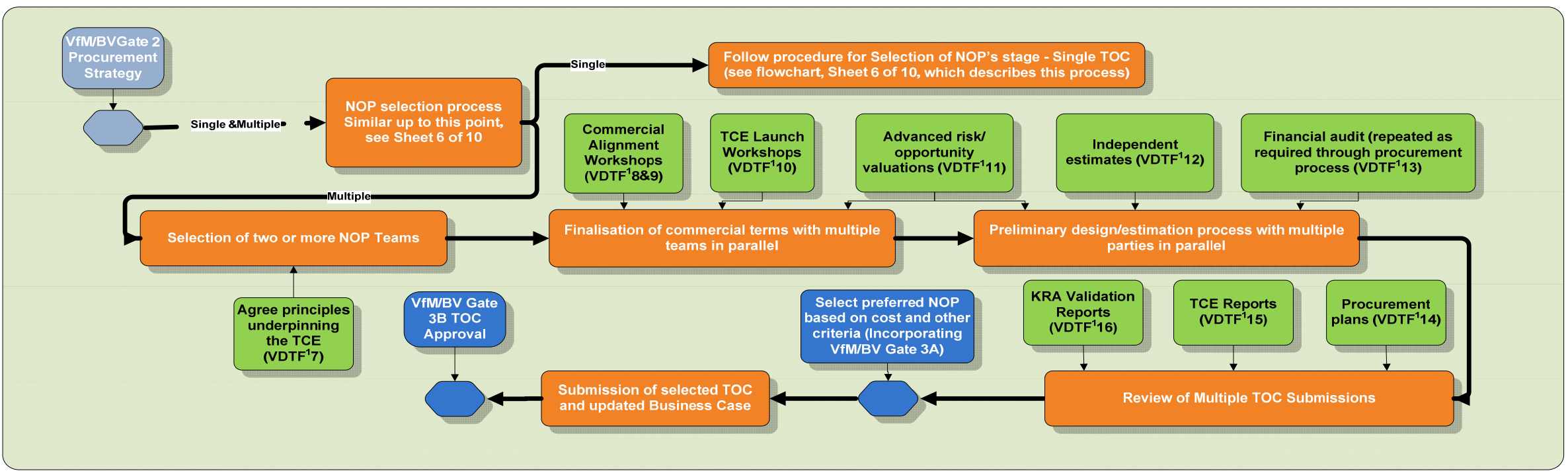

Development of Procurement Strategy Stage

VfM/BV Gate 2 - Selection of Procurement Strategy

What is the procurement route that best addresses the Owners' value parameters?

- Have the criteria that will define $\mathrm{VFM} / \mathrm{BV}$ for the project been explicitly determined?

- Does the business case still meet the business need?

- Does the Owner's team have the expertise to

understand the supplier market?

- Have the procurement options been subjected to thorough risk and value management

analyses?

dical approach been adopted to select the most appropriate procurement model, or would other approaches offer a similar or better outcome?

Note: This VfM/BV Gate, which precedes the Procurement Strategy stage, must have been successfully traversed before this stage can commence.

\section{Significant milestones in Stage E - Selection of NOP's and TOC Approval of the project lifecycle for Multiple TOC Selection Process}

(In this stage, the high level Business Case previously developed is expanded to facilitate the selection of the most appropriate procurement model)

\section{(In this stage, the high level Business Case previously developed is expanded to facilitate the
FEASIBILITY AND DESIGN VALUES}

\section{Finalisation of commercial terms and} preliminary design/estimation proces paralle. to ensure that a clear assessment can be made the relative VfM of competing bids:

- What measures are in place to ensure equal availability of Owner resources personnel in the respective teams?

- Is frank advice being given to the NOPs regarding the acceptability of their emerging solution to the Owner?
A number of issues should be monitored A number of issues should be monitored

\begin{tabular}{|c|c|}
\hline $\begin{array}{l}\text { Review of multiple TOC Submissions } \\
\text { Preferred NOP selected (effectively } \\
\text { incorporating VfM/BV Gate 3A) } \\
\end{array}$ & ubmission of TOC and updated Business Case \\
\hline $\begin{array}{l}\text { To ensure that the best and most } \\
\text { appropriate NOP's been selected for the } \\
\text { TCE phase of the project? } \\
\text { - Has the importance of VfM been } \\
\text { adequately communicated to the } \\
\text { Owner and NOP members of the team? } \\
\text { - Has the importance of VfM been } \\
\text { adequately communicated to the } \\
\text { Owner and NOP members of the team? } \\
\text { - Have the appropriate commercial } \\
\text { arrangements been put in place to } \\
\text { ensure that appropriate behaviour, } \\
\text { conducive to VfM, will result? } \\
\text { - Have appropriate audits been } \\
\text { undertaken? } \\
\text { Are the principles underpinning the TCE } \\
\text { process clear to all parties? }\end{array}$ & $\begin{array}{l}\text { - Has a procurement plan been developed to } \\
\text { expand on the interim plan developed } \\
\text { earlier? } \\
\text { - Has a process for achieving best value been } \\
\text { determined including price competition for } \\
\text { procurement of 'commodity' services and } \\
\text { materials? } \\
\text { - Has a TCE Report been produced which } \\
\text { includes: } \\
\text { A A detailed reconciliation between the } \\
\text { original Owner's Budget and the proposed } \\
\text { TOC? } \\
\text { Details and valuation of all significant } \\
\text { improvements and innovations embedded } \\
\text { in the TCE? } \\
>\text { A third party verification of the contents of } \\
\text { the report? } \\
\text { Have appropriate KRA's and KPI's been } \\
\text { developed which address the requirements } \\
\text { of the Owner's Value Proposition? }\end{array}$ \\
\hline
\end{tabular}

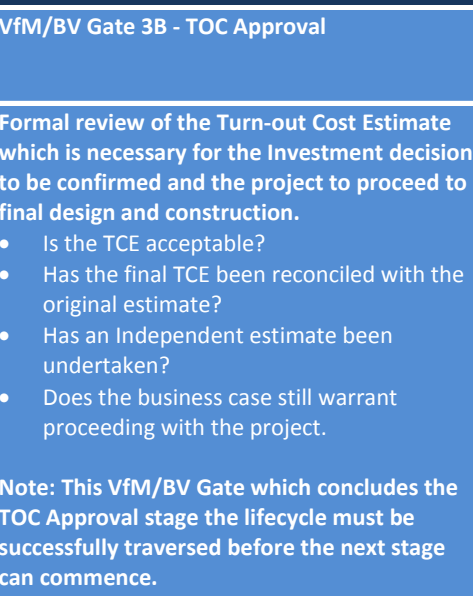

Note: This VfM/BV Gate which concludes the TOC Approval stage the lifecycle must be

successfully traversed before the next stage

can commence. 


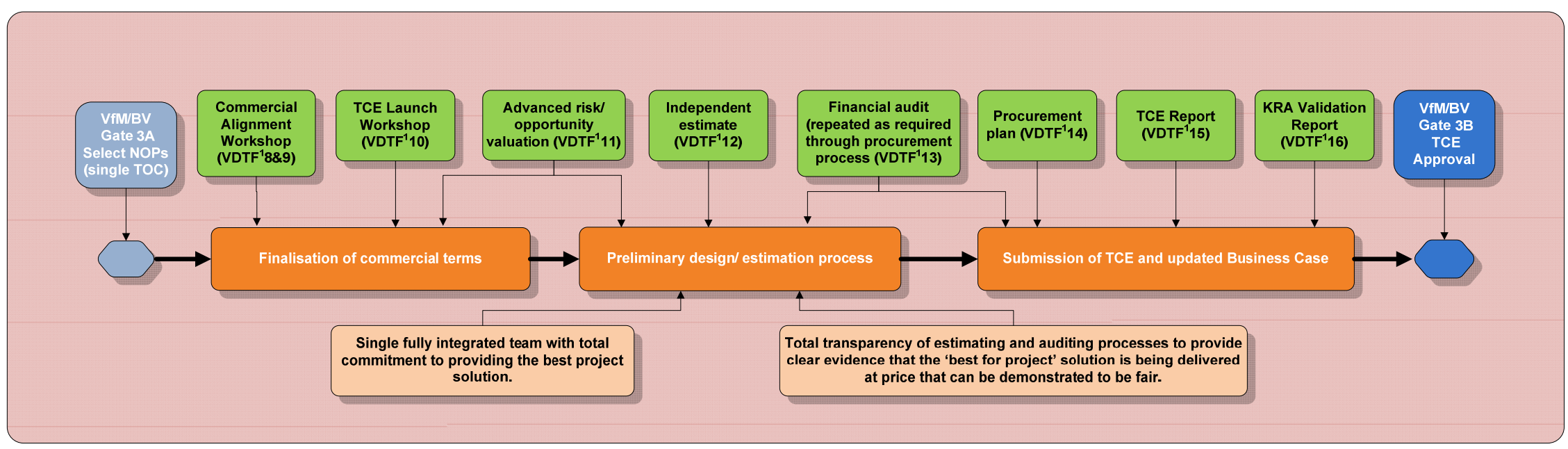

\section{Selection of NOPs Stage}

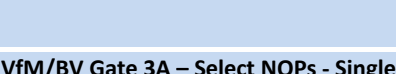
TOC

To ensure that the best and most appropriate NOP's been selected for the TCE phase of the project?

- Has the importance of VfM been adequately communicated to the Owner and NOP members of the team?

- Have the appropriate commercial arrangements been put in place to ensure that appropriate behaviour, conducive to VfM, will result?

- Have appropriate audits been undertaken?

- Are the principles underpinning the TCE process clear to all parties? Note: This VfM/BV Gate, which precedes the Procurement Strategy Stage, must have been successfully traversed before this stage can commence.

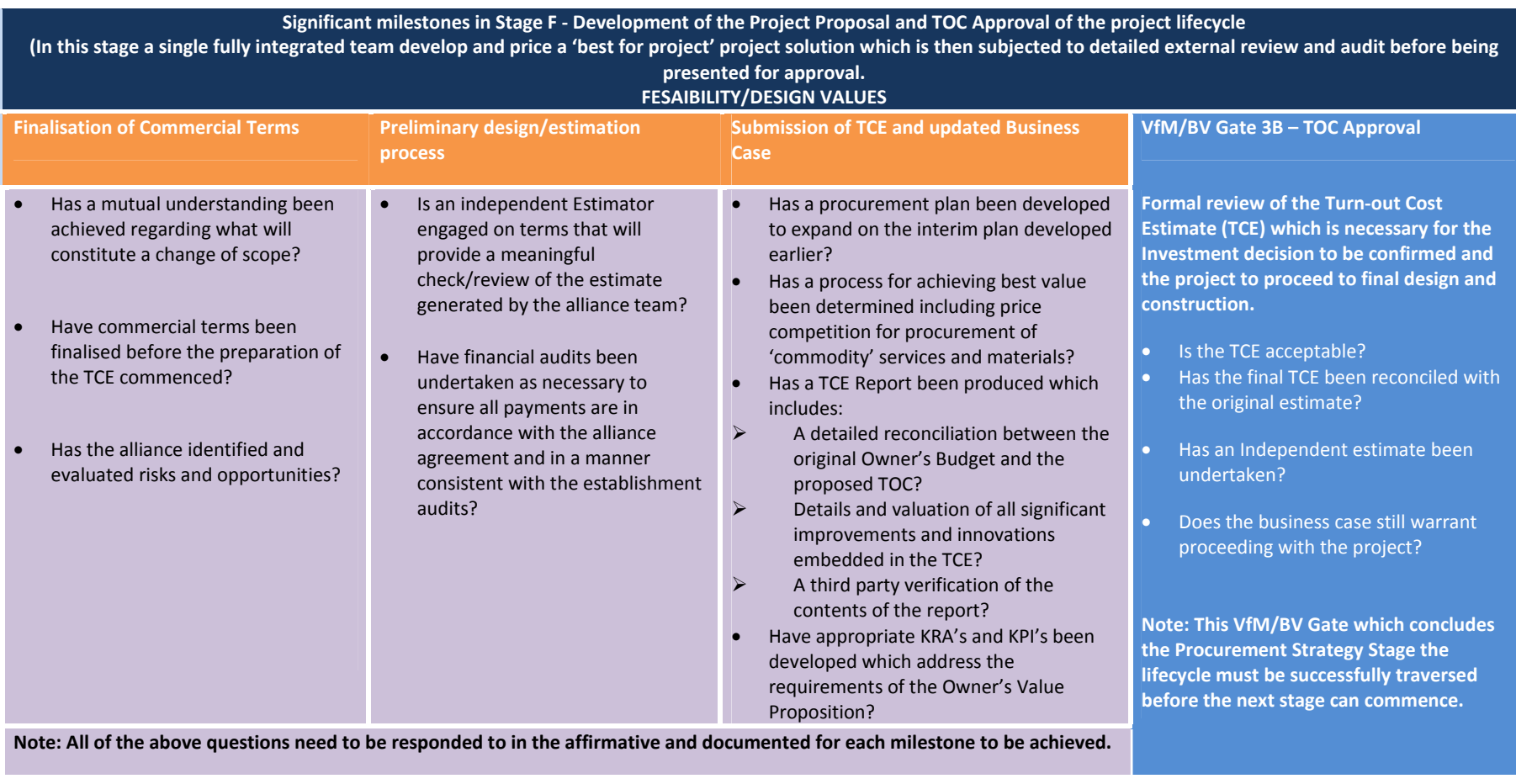




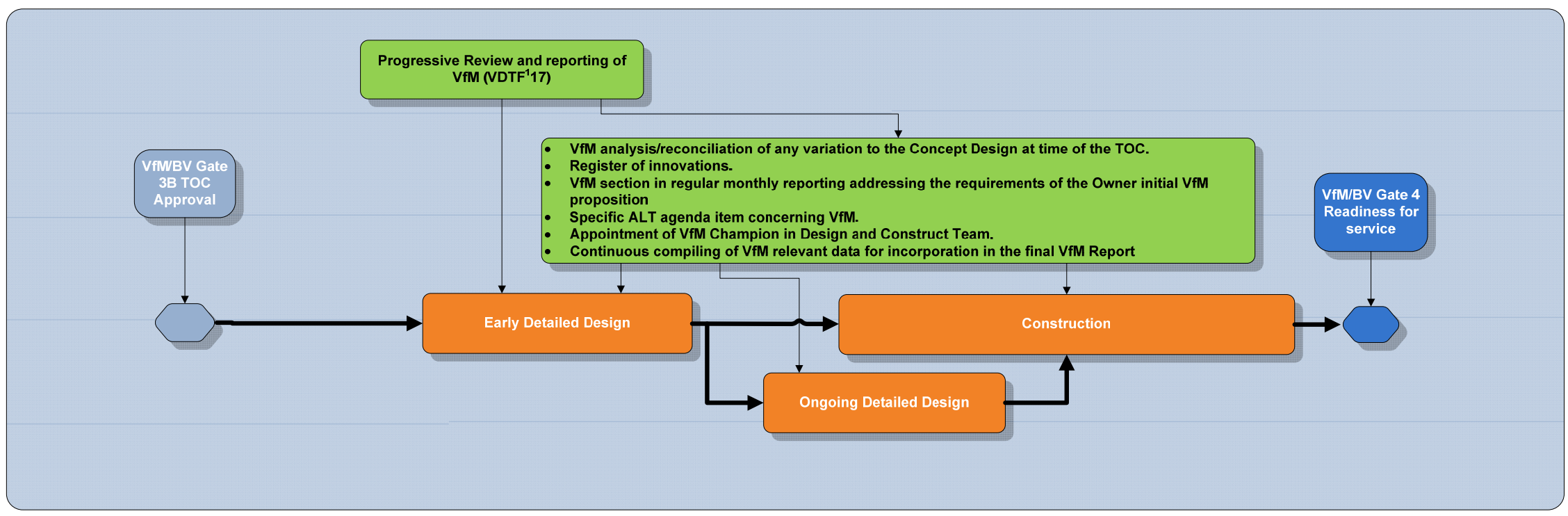

Development of Project Proposal and TOC Approval - Single or Multiple TOC

\section{VfM/BV Gate 3B - TOC Approval}

Formal review of the Turn-out cost Estimate (TCE) which is necessary for the Investment decision to be confirmed and the project to proceed confirmed and the project to procer

- Is the TOC acceptable?

- Has the final TOC been reconciled with the original estimate?

- Has an Independent estimate been undertaken?

- Does the business case still warrant proceeding with the project?

Note: This VfM/BV Gate, which precedes the Readiness for Service (Design and Construction) stage, must have been successfully traversed before this stage can commence.
Significant milestones in Stage G - Detailed Design and Construction Readiness for Service of the project lifecycle

(In this stage, the project solution that has been developed and priced (TOC) is further developed through detailed design and then constructed DESIGN AND CONSTRUCTION VALUES

Detailed Design

Continuous monitoring and recording during the Detail

address the Value Proposition whilst looking for

Continuous monitoring and recording during Construction

Design process to ensure that construction continues to

address the Value Proposition whilst looking for

ddress the Value Proposition whilst looking for

- VfM andysis/reconciliation of any variation to the $\quad$ VfM analysis/reconciliation of any variation during Concept Design

- Register of design innovations.

construction.
cin analysis/reco

- Register of construction innovations.

- VfM section in regular monthly reporting addressing the requirements of the Owner initial VfM proposition

- Specific ALT agenda item concerning VfM.

- VfM section in regular monthly reporting addressing the requirements of the Owner initial VfM proposition

- Specific ALT agenda item concerning VfM.

- Appointment of VfM Champion in Design and Construct Team.

- Continuous compiling of VfM relevant data for

- Appointment of VfM Champion in Design and Construct Team.

- Continuous compiling of VfM relevant data for incorporation in the final VfM Report

incorporation in the final VfM Report

Note: All of the above questions need to be responded to in the affirmative and documented for this milestone to be achieved.
VfM/BV Gate 4 - Readiness for Service

Has VfM been delivered during the Design and

Construction Stage of the project lifecycle?

Was the TOC achieved?

Have the KRA's been monitored and target s achieved?

Did the project alliance approach deliver innovations?

Was a comprehensive set of procedures adopted to monitor and document VfM during this phase of the project?

Note: This VfM/BV Gate which concludes the Design and Construction Stage the lifecycle must Design and Construction Stage the Iffecycle must can commence. 


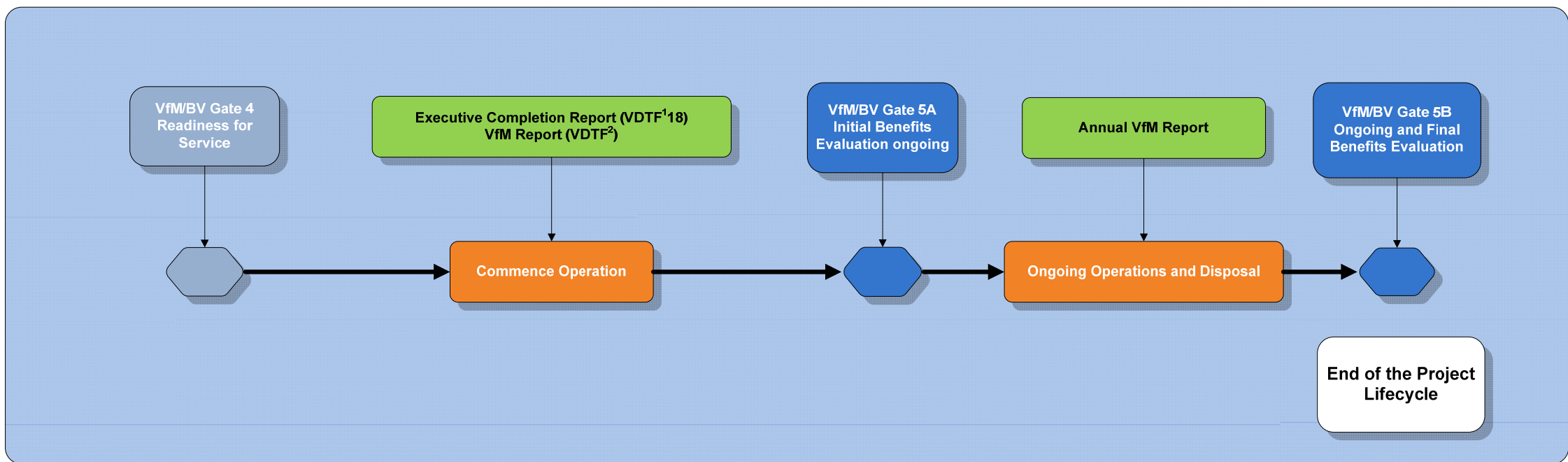

Detailed design and construction of the project Stag

\section{VfM/BV Gate 4 - Readiness for Service}

Has VfM been delivered during the Design and Construction Stage of the project lifecycle?

- Was the TOC achieved?

- Have the KRA's been monitored and target $s$ achieved?

- Did the project alliance approach deliver innovations?

- Was a comprehensive set of procedures adopted to monitor and procedures adopted to monitor and the project?

Note: This VfM/BV Gate which concludes the Readiness for Service (Design and Construction) stage the lifecycle must successfully traversed before the next stage can commence
Significant milestones in Stage $\mathrm{H}$ - Benefits Evaluation of the project lifecycle

(In this stage, the performance of the alliance in delivering the through the operational life of the project.

\begin{tabular}{|c|c|c|c|}
\hline Commence Operation & $\begin{array}{l}\text { VFM/BV Gate 5A-Initial Benefits } \\
\text { Evaluation }\end{array}$ & Ongoing Operations and Disposal & $\begin{array}{l}\text { VFM/BV Gate 5B - Ongoing and Final Benefits } \\
\text { Evaluation }\end{array}$ \\
\hline $\begin{array}{l}\text { - Has a VfM or Completion Report } \\
\text { been written to provide a post } \\
\text { implementation review of } \\
\text { outcomes compared to the } \\
\text { approved Business case? }\end{array}$ & $\begin{array}{l}\text { Is the project efficiently addressing } \\
\text { the original business objectives? }\end{array}$ & $\begin{array}{l}\text { - Report prepared initially on an } \\
\text { annual basis and then at intervals } \\
\text { appropriate to the project. }\end{array}$ & $\begin{array}{l}\text { Did the project successfully deliver the 'whole } \\
\text { of life' benefits predicted? }\end{array}$ \\
\hline $\begin{array}{l}\text { Does the report ensure that the } \\
\text { alliance process can be subject to } \\
\text { continuous improvement? }\end{array}$ & & & \\
\hline $\begin{array}{l}\text { - Does the VfM Report address all } \\
\text { the matters listed in VDTF }\end{array}$ & & & \\
\hline (Section 7.5)? & $\begin{array}{l}\text { Note: This VfM/BV Gate which } \\
\text { characterises the Benefits Evaluation } \\
\text { stage the lifecycle must be repeated } \\
\text { until the project reaches the end of } \\
\text { the operational phase and the Final }\end{array}$ & & \\
\hline $\begin{array}{l}\text { Note: All of the above questions need } \\
\text { to be responded to in the affirmative } \\
\text { and documented for this milestone to } \\
\text { be achieved. }\end{array}$ & $\begin{array}{l}\text { Benefits Evaluation review is } \\
\text { concluded which marks the end of the } \\
\text { project lifecycle. }\end{array}$ & $\begin{array}{l}\text { Note: All of the above questions need } \\
\text { to be responded to in the affirmative } \\
\text { and documented for this milestone to } \\
\text { be achieved. }\end{array}$ & $\begin{array}{l}\text { Note: This VfM/BV Gate which concludes the } \\
\text { Benefits Evaluation stage the lifecycle must be } \\
\text { successfully traversed before the whole project } \\
\text { lifecycle is concluded. }\end{array}$ \\
\hline
\end{tabular}




\subsection{Summary of Chapter}

The purpose of this chapter was to outline the development of the VfM/BV model and to present the final version of the document.

During the course of the research task the model developed from a single page, albeit rather busy chart, to a ten page document which seek to address the specific $\mathrm{VfM} / \mathrm{BV}$ requirements of each stage of the project lifecycle. This evolution resulted from a number of suggestions made by the industry experts who were consulted during the Delphi Survey process undertaken during Phase 2 of the research task. This 'exposure' of the model facilitated a detailed focus on the particular questions that were relevant to each phase of the project lifecycle.

Whilst it has not been produced, it would be possible to develop a companion spreadsheet to the model that would list each question from each stage and act as a depository for recording of the response to each question. Such a document would provide very useful reference when compiling the VfM Report at the end of the delivery of the project and could actually be appended to the final $\mathrm{VfM}$ report illustrating the manner in which VfM was addressed at each significant milestone as well as at each of the VfM/BV Gates along the Project lifecycle. 


\section{Chapter 9 -Conclusions and Recommendations}

'Please be good enough to put your conclusions and recommendations on one sheet of paper in the very beginning of your report, so I can even consider reading it'.

Winston S Churchill

\subsection{What this Chapter will address}

This chapter presents that the conclusions that the researcher believes can be drawn from the research that has been described in this thesis. These conclusions were informed by each stage of the research process undertaken which included:

1. The general literature review described in Chapter 2.

2. The more specific literature review which led to the development of the preliminary VfM/BV model as described in Chapter 3.

3. The personal interviews with 27 participants from the 5 alliances that were investigated in detail. The results of these interviews are reported in Chapter 5.

4. The detailed questionnaire which was responded to by 21 participants. The results of this process are also reported in Chapter 5.

5. The three rounds of the Delphi Survey process that obtained the feedback of 12 experts in the project alliancing field. The results of the survey are presented in Chapter 6

6. The finalisation of the model with the final version being presented in Chapter 8 .

7. The review of the research and other publications published by the IASC/VDTF which also considered the delivery of $\mathrm{VFM}$ in project alliance contracts. This review included a direct comparison between the findings of the IASC study and this research. This is reported in Chapter 7.

These conclusions are also informed and fashioned by the researcher's own industrial experience both generally as a practitioner in the infrastructure construction field for a period approaching forty years, a participant in a number of project alliances and as a previous Director of the Alliancing Association Australasia.

This chapter also includes a number of recommendations. These have been divided into recommendations which relate to practice in project alliance procurement and areas in which future research could be usefully undertaken to develop a deeper understanding of the issue of VfM within the field of relationship contracting. 


\subsection{Conclusions from the research}

The delivery of value is not just an essential requirement of good project management it actually defines what project management is. Consequently, the identification of the project values, at the earliest juncture and their preservation through the 'project value chain' defines the success or failure of a project.

The lack of consistency in the definition of value for money $(V f M)$ is quite striking. This results from two aspects of $\mathrm{VfM}$ which can be interpreted quite differently being; the dimensions of value and the timeframe of evaluation. The more considered definitions of $\mathrm{VfM}$ recognise that value has many dimensions beyond the conventional economic perspective including social and environmental objectives plus intangible deliverables including quality of relationships, leadership, learning, reputation and trust. The more sophisticated approaches to VfM look at the whole lifecycle of a project and do not focus wholly on the benefits delivered during the construction phase.

The association between $\mathrm{VfM}$ and lowest cost is considered to be almost inevitable given the specific reference to the word 'money' within the term. It was noted that in the recent UK literature, in particular, there appears to be a conscious move away from the term VfM to the expression 'best value' to convey the message that there is a broader meaning to the concept of value. This alternative term appeals to the researcher for that reason. However, whilst the term 'best value' has been introduced into the model/documentation as developed, due to the established nature of the term $\mathrm{VfM}$ in the construction industry the term has not been abandoned in this thesis. Nevertheless, when used, the terms are considered to be synonymous.

The construction industry has a poor record in delivering value and traditional procurement methods which are price based and seek to transfer rather than address risk, often lead to adversarial relationships between the contract parties.

Whilst traditional methods suit a narrow definition of value, relationship based procurement methods, which are 'cost' based, open book and seek to share responsibility for risks, are better suited to the delivery of complex projects which have multiple project values extending beyond purely economic considerations and invariably include intangible deliverables.

Because relationship based approaches are cost based and, in their 'pure form' select participants based on capability, they have been criticised for not demonstrating VfM. This criticism comes from the 'price based' perspective that holds that price competition is the only economically supportable model for ensuring the best price, and consequently that VfM has been achieved. It is believed that this argument is flawed for two fundamental reasons; 
- The assumption that price is a metric of value. This is challenged within this thesis.

- The validity of the concept of the 'perfect market', which is used to justify relying wholly on price completion to guarantee value VfM. The Australian industry fails to meet virtually all of the tests required by such a theoretical construct.

It can be argued that project alliances, a specific form of relationship based contracting, are being required to demonstrate $\mathrm{VFM}$ in a manner that traditional methods have never been asked to do because of the absolute reliance on price competition to support the establishment of $\mathrm{VFM}$ for the traditional approach.

In fact, price completion alone, is an inadequate measure of $\mathrm{VFM}$ for any procurement method and responsible project management requires the rigourous measurement of performance, quantitative performance targets, transparent pricing and demanding arrangements for the selection of partners. Project alliances are required to comply with such conditions in direct contrast to the normal requirements for traditional contracts. VfM is best achieved by balancing competition with cooperation, ethics and corporate governance, in order to drive behaviours which are consistent with the reasonable objectives of all parties to the contract.

There is much debate in the industry about the relative merits of price completion in the selection of alliance participants and this point has been discussed at some length in the thesis. Both those who believe in such an approach and those who advocate the non-price based or 'pure' approach do so with some conviction. However, both camps would subscribe to the view that the Non-Owner participants' (NOPs') profit should be earned by performance and not on their ability to make and win claims which, unfortunately, is a regular outcome of traditional procurement approaches. Profit based on performance is much more likely in a relationship based procurement methodology.

The specific literature that related to $\mathrm{VfM}$ in project alliances, as discussed in Chapter 3, included a number of project specific performance reports and some earlier guidelines regarding the achievement of $\mathrm{VfM}$. These documents were critically reviewed to identify their respective contribution to the determination of VfM in project alliances and this assisted in identifying the 'gaps' existing in the current state of knowledge in the field.

Additionally, a number of recent academic theses relating to the topic were reviewed in Chapter 3 . This material was particularly valuable in confirming the 'gaps' in the current knowledge and refining the specification of a model that could address these deficiencies. A number of the themes emerging from the review of these theses, that are considered relevant to the research, are repeated below as 
they are considered to represent a listing of matters that this research has considered and addressed through the methodology adopted.

- The importance of moving beyond a transactional relationship to a collaborative model in order to create an environment in which value can be significantly increased.

- The failure to adequately record the capture of additional value throughout the project lifecycle which reduced the opportunity for organisational learning and transfer of knowledge between projects.

- The importance of trust and personal, rather than organisational behaviours in the selection of partners to undertake a project.

- That the promotion of alliances, particularly pure alliances, needs to recognise that alliances must be seen to respect appropriate governance requirements.

- That a robust and repeatable framework for measuring the value of competing options should be developed.

- Alliances need to develop a systematic means of demonstrating VfM.

- That the neo-classical economic theory regularly used to support the position that alliances cannot demonstrate $\mathrm{VFM}$, in the same manner as the traditional procurement approach, as they do not involve standard price competitive procedures, has a number of practical flaws.

- That the performance of project alliances correlates well to an alternative economic approach which recognises real-world behaviour.

- The multi-dimensional nature of VfM that it is not well addressed in current practice.

In considering a suitable framework for a preliminary VfM/BV model it became apparent that it would be necessary to address the whole lifecycle of the project and that the work undertaken by the Office of Government Commerce (OGC) in the UK in developing the Gateway ${ }^{\mathrm{TM}}$ Review process and associated document 'Construction Projects - a manager's checklist' would be provide a suitable platform for such a model. It was also apparent that the most developed Australian approach to VfM, at that time, was the Project Alliancing Practitioners' Guide, published by the Victorian Department of Treasury and Finance in 2006. By considering these documents and the themes that had emerged from the earlier research, a preliminary model was constructed by the researcher. However, to ensure that this model would be of genuine use and value to the industry it was necessary to verify this model through review by a range of practitioners. This led to the 'action research' orientated consultation stage of the research which comprised of interviews, a detailed questionnaire and a Delphi survey process. 
In the interviews with practitioners all were confident that $\mathrm{VfM}$ was being achieved in their respective alliances although the majority of respondents indicated that the demonstration and/or documentation of VfM was either poor or limited.

A number of quotes from the participants regarding the achievement and demonstration of $\mathrm{VFM}$ are reported in Chapter 5. However, three quotes which are considered to characterise the tenor of the feedback received and capture some important findings of this research are as follows:

- 'We choose the alliance method due to risk profile, uncertainty in scope, stakeholder issues/complexity. However, we then judge success by conventional cost comparison against another delivery method and do not assess the success of the project based on the criteria that were the justification for establishing the alliance in the first place'.

- In the discussion about VfM in alliance contracts people have forgotten about all the costs that were previously involved in adversarial behaviours'.

- 'Alliances can rapidly react to a changing environment. The flexibility to respond and accurately price changing circumstances, in an open book manner, is priceless'.

The first quote addresses a particularly important point being that the success of an alliance needs to be judged based on criteria that are appropriate to the circumstances of selecting that procurement method.

The questionnaire presented to the participants covered a wide range of issues and generated a large volume of data which is described and discussed in Chapter 5.

Two principal conclusions drawn from the feedback provided through the questionnaire are:

- Evidence gathered supported the proposition that at the time of selecting partners for an alliance, the key issues relating to VfM were ethical rather than economic. Significantly this view was held most strongly by Owner participants who are the parties responsible for making such selection decisions. This outcome was seen to provide further support to the position that a much broader view of value was required when considering VfM for the type of projects that are best suited to the alliance delivery model.

- The format of the model presented was seen as being appropriate and of beneficial in providing structure and discipline to current practice without necessarily representing a breakthrough development. However, suggestions were made to improve the model and a number of these were adopted in revising the model prior to the next round of the research being the Delphi Survey process. 
The Delphi Survey process was conducted using a web based service which proved to be a very efficient means of managing the administration of this process. Three survey rounds were completed after which it was considered that a clear response had been received from the group of experts consulted. A number of constructive suggestions were made to improve the model and this resulted in a substantial re-drafting of the model to incorporate a 'head' flowchart and supplementary flowchart/tables for each of the seven stages of the project lifecycle which represent the final form of the model as presented in Chapter 8. The third round of the Delphi Survey also posed three questions regarding some specific findings that were contained in the IASC Research that were considered to be relevant to this research.

Given that the IASC/VDTF body of work, which included a research study and the subsequent production of a number of publications, had taken place in parallel with this research it was considered to be important to critically review this work and compare the findings of the IASC Research with outcomes of this research. This review is presented in Chapter 7. Whilst there are some differences in findings, particularly in relation to the procedure for selecting NOPs and the appropriate authority of the Alliance leadership Team (ALT), both initiatives advocate the adoption of a disciplined and systematic framework which tracks the progress of a project through the various stages of the project life-cycle. Consequently, it is believed that the outcomes of this research are largely complimentary to the IASC/VDTF approach.

\subsection{Has the research question been addressed?}

The research question developed was:

'What is the optimum configuration of a model that will assist all participants in a project alliance to both ensure and demonstrate the achievement of VfM or best value'?

It is considered that the model presented in Chapter 8, which was subjected to extensive external review during the research, does successfully address this question.

Whether the configuration is truly optimal for everyday use in an ongoing project can only be adequately demonstrated through adoption and use in such circumstances. However, the researcher is confident that the model does consider the issues that have been identified through the research as critical to $\mathrm{VFM}$ and represents a genuine step forward from the unstructured status of current practice. 


\subsection{Current State of Alliancing}

During the currency of this research the project alliancing scene in Australia has changed significantly. When the research commenced the number of alliance contracts being commenced was continuously increasing, on a year on year basis, and some sections of the industry held a view, albeit mistakenly in the view of the researcher, that any project could be delivered through an alliance arrangement.

Since those 'halcyon days' a number of circumstance have arisen which have changed the outlook. These include:

- The Global Financial Crisis (GFC), which whilst not affecting Australia as badly as other parts of the world, has substantially, reduced the number of projects being commenced by any delivery method.

- It is arguable that an over commitment to alliancing had occurred in a manner not dissimilar to many 'new' ideas which when initially introduced are seen as the answer to everyone's problems. Consequently it was natural for the industry to become more reflective regarding whether an alliance is the most appropriate methodology for a given set of project circumstances and a decline in the, year on year, adoption rate was always likely. This is not to relegate project alliances to the status of a management 'fad' which might rapidly decline and potentially be never seen again once the 'fashion' moved on. The change of attitude represented by alliancing and other forms of relationship contracting is considered to be reflective of a 'quantum shift' in the delivery of infrastructure projects. Whilst there may be a smaller proportion of projects delivered through project alliances in the future, the methodology is now firmly established in the suite of procurement option available to Owners.

The substantial volume of work recently completed by the IASC under the leadership of the VDTF (as discussed in Chapter 7) clearly represents a landmark in the development of alliancing in Australia. This level of cooperation between the treasuries of the four most significant procurement states, recently joined by the Commonwealth, is unprecedented. It is significant that these organisations felt sufficiently motivated to undertake such an extensive program of initially research, followed by the publication of a number of documents each substantial in their own right. The new Practitioners' Guide to Alliance contracting, as published by the VDTF describes the merits of alliancing in enthusiastic terms and clearly the opportunity continues to exist for suitable projects to be promoted 
as candidates for delivery by the project alliance methodology. The researcher, based on the findings of this study, and personal experience, believes that such projects will continue to emerge.

However, despite this optimism the new documentation issued by the IASC and the VDTF also raises some concerns about the future conduct of alliances. One of the strengths of project alliancing has been the liberating influence that it has had on the industry that has been burdened by process, procedure and contractual conflict. The new paradigm of alliancing has enabled parties, who were previously conditioned to act in an adversarial manner, to work cooperatively and openly. In this environment trust and increased professional respect has grown between Owners, Constructors and other NOPs. This has, in turn, convinced many who were previously cynical about such 'warm and fuzzy' concepts as 'win-win', 'no-blame' and 'best for project' ' to become strong advocates of a methodology which channels all talent and energy within a project team to the best possible project outcome rather than diverting effort to contractual posturing.

This tendency for people to fully embrace the philosophy of the alliance approach, once they have been involved in an alliance project, is seen to be both a strength and weakness and has polarised opinion regarding alliancing. For the 'believers' this outcome is a demonstration that the approach overcomes all the suspicions and mistrust of conventional procurement approaches. The 'nonbelievers' see this reaction as 'proof positive' that alliancing is tantamount to an 'evangelical movement' where those involved abandon reason and logic to the adoption of an altruistic faith. In fact, neither position is supportable.

A conservative reaction to some of the 'almost too good to be true' achievements and 'inspirational' capacity of alliancing is not surprising and it is perfectly reasonable to expect that alliancing should be subjected to the same level of critical review that any other procurement methodology might be exposed to. However, it is also important to ensure that the spontaneity and motivational dynamics of alliancing are not lost by attempts to codify and 'proceduralise' the conduct of alliancing to the point where the positive energy generated by the approach, which can achieve such desirable behaviours and attitudes, is dampened to a point where any advantage is lost.

Additionally, it is clear from this research, and this point was strongly expressed in many of the interviews conducted, that maintenance of the autonomy and authority of the alliance, particularly through the Alliance leadership Team ALT, who are effectively the Board of this virtual organisation, is vital to the success of the project alliance approach. Consequently, the researcher has concerns about the implications of some measures suggested by the IASC/VDTF work which appear to reduce 
the authority of the ALT and reserve greater control over the project by the Owner, as distinct from the Owner's representative on the ALT.

\subsection{The future of project alliancing}

As indicated above, the researcher believes that there continues to be a place for project alliancing in the future. However, this future is likely to involve less projects being delivered by this methodology.

Within the VFM/BV model produced through this research a process is recommended that compels Owners to consider all other procurement options before selecting a project alliance approach. This reflects a view that the project alliance approach is best suited to a select list of projects and Owners do a disservice to themselves and the industry by promoting a project as an alliance when other approaches are more appropriate. Projects which suit the approach will have a complex value proposition which will include a number of important issues beyond price. Having selected this approach, it then makes little sense to apply a price based approach to the selection of the NOPs. However, whilst the IASC/VDTF recommended approach does contemplate 'non-price' based selection of NOP's, this has to be specifically justified and formally accepted. Only the future will see whether such justifications are, in fact, accepted.

\subsection{Recommendations}

As described in the introduction to this chapter recommendations have been divided into two sections as follows:

\section{Practice in alliance procurement}

- It is recommended that the use of the project alliance procurement model is considered more carefully in the future. There have been examples of the approach being selected when it is inappropriate to the circumstance of the project. This represents a disservice to both the Owners concerned and the broader industry.

\section{Further research}

- It is recommended that there be further research to better substantiate whether there are substantial differences in the likely commercial and performance outcomes between alliances that select NOPs based on either a 'pure' and 'price competitive' process.

- It is recommended that there be further research into the managements skills required for alliance leaders. 


\section{References}

ABRAMSON, M. W. 1979. Engineering Law and the ICE Contracts, 4th Edition, London, Applied Science Publishing.

ACA 1999. Relationship Contracting - Optimising Project Outcomes, Sydney, Australian Constructors Association.

ACA/BDW 2006. Scope for Improvement - A survey of pressure points in Australian construction and infrastructure projects, Australian Constructor's Association and Blake Dawson Waldron.

ADAM, E. 1993. Value management - cost reduction strategies for the 1990's, Longman Professional.

ADLER, M. \& ZIGLIO, E. (eds.) 1996. Gazing into the Oracle: The Delphi Method and its Application to Social Policy and Public Health, London and Philadelphia: Jessica Kingsley Publishers

ALCHIMIE 2004. Target Outturn Cost: Demonstrating and Ensuring Value for Money. Alchime Pty Ltd.

ALLEN 2007. Performance of PPP's and Traditional Procurement in Australia - Report to Infrastructure Partnerships Australia. The Allen Consulting Group.

ALVESSON, M. \& DEETZ, S. 2000. Doing critical management research, London, Sage.

ANAO 2000. Report on the Acton Peninsula Alliance, Australian National Audit Office.

ANAO 2003. Public Sector Governance and the Individual Officer. Australian National Audit Office.

ARBNOR, I. \& BJERKE, B. 1997. Methodology of creating business knowledge, Thousand Oaks, CA, Sage.

BARRETT, P. 2005. Revaluing Construction - A Global CIB Agenda.

BARTON, R. 2000. Soft value management methodology for use in project initiation - a learning journey. Journal of Construction Research, 1, 102-122.

BASKERVILLE, R. L. \& WOOD-HARPER, A. T. 1996. A critical perspective on action research as a method for information systems research. Journal of Information Technology, 7, 90-107.

BAWDEN, R. (ed.) 1991. Towards action research systems, Aldershot: Gower-Avebury.

BERRATA, R. 1996. A critical review of the Delphi technique: characteristics and sequence model. Nurse Researcher, 3, 79-89.

BLISMAS, N. \& HARLEY, J. 2008. Alliance Performance in Public Sector Infrastructure - A survey on alliance performance in public sector infrastructure across Australia. Melbourne RMIT University and Alliancing Association of Australasia. 
BLOCKLEY, D. \& GODFREY, P. 2000. Doing it Differently: systems for rethinking construction, London, Thomas Telford.

BOWYER, D. 2003. Management of Procurement, London, Thomas Telford.

BROOME, J. 2002. Procurement Routes for Partnering - A practical Guide, London, Thomas Telford.

BROWN, C. A. 2007. The opt-in /opt-out feature in a multi-stage delphi method study. International Journal of Social Research Methodology, 10, 135-144.

BSI 1997. BS EN 1325-1:1997 Value manangement, value analysis, functional analysis vocabulary. British Standard Institution.

BYGRAVE, W. D. 1989. The entrepreneurship paradigm: a philosophical look at its research methodologies. Entrepreneurship: Theory and Practice, 14, 7-26.

CALORI, R. 2002. Real-time/real-space research: Connecting action and reflection in organization studies. Organizational Studies, 23, 877-883.

CHECKLAND, P. 1981. Systems Thinking, Systems Practice, Chichester, Wiley.

CHECKLAND, P. (ed.) 1991. From framework through experience to learning; the essential nature of action research, North Holland: Elsevier Publishers.

CHENG, E. W. L., LI, H., LOVE, P. E. D. \& IRANI, Z. 2001. Network Communication: A Mechanism for Construction Alliances Corporate Communications: An International Journal, 6, 61-70.

CHRISTENSEN, D. \& WALKER, D. H. T. 2004. Understanding the Role of "Vision" in Project Success. Project Management Journal, 35, 39-52.

CIB 2007. CIB Priority Theme - Revaluing Construction: A W065 'Organisation and Management of Construction' Perspective. In: SEXTON, M., KAHKONEN, K. \& SHU-LING, L. (eds.).

CICMIL, S. 2006. Understanding project management practice through interpretative and critical research perspectives. Project Management Journal, 37, 27-37.

CICMIL, S. \& HODGSON, D. (eds.) 2006. Making project critical: An introduction: Palgrave, NY.

CLEGG, S., PITSIS, T., RURA-POLLEY, T. \& MAROSSZEKY, M. 2002. Govenmentality Matters: Designing an Alliance Culture of Inter-organisational Collaboration for Managing Projects. Organization Studies, 23, 317-337.

COMM-AUST 1997. Financial Management and Accountability Act (Cmth).

COMM-AUST 2005. Commonwealth Procurement Guidelines (2005). Department of Finance and Adminsitration. 
COMM-AUST 2006a. Australian Government Policy Principles for the use of Public Private Partnerships. Finance and Administration.

COMM-AUST 2006b. Gateway Review Process, A Handbook for Conducting Gateway Reviews. Department of Finance and Administration

COMM-AUST 2008. Commonwealth Procurement Guidelines. Department of Finance and Deregulation.

COSBY, S. \& TYSON, W. 1993. Value for money in accessible transport. PTRC Summer Annual Meeting, 21st, University of Manchester, UK. London: PTRC Education and Research Services Ltd and Computation (International) Co Ltd.

COWAN, C. 1990. Partnering: a strategy for excellence. In: TRANSPORT, A. D. O. (ed.).

CRC 2004. Construction 2020 - A vision for Australia's Property and Construction Industry, Brisbane, CRC for Construction Innovation.

DALKEY, N. C. 1969. An experimental study of group opinion: the Delphi Method. Futures, 1, 408-426.

DAVIES, J. 2007. Alliances, Public Sector Governance and Value for Money. PhD Thesis, Griffith University Law School, Queensland.

DAVIS, P. R. 2005. The Application of Relationship Marketing to Construction. PhD Thesis, RMIT.

DICK, B. 1999. Rigour without numbers: the potential of dialectic processes as qualitative research tools. third ed. Chapel Hill, Queensland: Interchange.

DICK, B. 2002. Building agreement from disagreement: the anatomy of dialectic processes. Chapel Hill, Queensland: Interchange.

DISR 1999. Building for Growth - An Analysis of the Australian Building and Construction Industries, Canberra, Department of Industry, Science and Resources, Commonwealth Government of Australia.

DOIT 2010. Infrastructure Planning and Delivery: Best Practice Case Studies. Canberra: Department of Infrastructure and Planning.

EASTERBY-SMITH, M., THORPE, R. \& LOWE, A. 1991. Management Research - An Introduction, London, Sage.

EASTERBY-SMITH, M., THORPE, R. \& LOWE, A. 2002. Management Research: An Introduction, Sage Publications Ltd.

EGAN, J. 1998. Rethinking Construction. London: Department of the Environment, Transport and the Regions. 
EVANS\&PECK 2003. Port of Brisbane Motorway Alliance - Alliance Learning Experience.

EVANS\&PECK 2004. Northside Storage Tunnel Project - Post Implementation Cost Review, Final Report. Sydney.

EVANS\&PECK \& UOM 2009. In Pursuit of Additional Value: Benchmark Study into Alliancing. Victorian Department of Treasury and Finance.

FEEHELY, J. 2007. Dealing with legal issues between mining alliance participants \& stakeholders. Brisbane: DLA Phillip Fox.

FLYVBJERG, B. 2001. Making Social Science Matter, Cambridge, Cambridge University Press.

GILL, J. \& JOHNSON, P. 2002. Research Methods for Managers, London, Sage Publications.

GOLDSCHMIDT, P. 1975. Scientific inquiry or political critique? Remarks on the Delphi assessment, expert opinion, forecasting and group process by H Sackman. Technological Forecasting and Social Change, 7, 195-213.

GORDON, T. J. 2009a. The Delphi Method. Futures Research Methodology. Washington , DC: The Millenium Project.

GORDON, T. J. 2009b. Real-time Delphi. Futures Research Methodology [Online], Version 3.0.

GREEN, B., JONES, M., HUGHES, D. \& WILLIAMS, A. 1999. Applying the Dephi technique in the study of GP's information requirements. Health and Social Care in the Community, 7, 198-205.

GREEN, S. \& LENARD, D. 1999. Organising the project procurement process. In: ROWLINSON, S. \& MCDERMOTT, P. (eds.) Procurement Systems: A guide to best practice in construction. London: E\&FN Spon.

GUNN, J. 2002. The Effective Use of partnering and Alliancing. Sydney: Minter Ellison, Lawyers.

HASSON, F., KEENEY, S. \& MCKENNA, H. 2001. Research guidelines for the Delphi survey technique. Journal of Advanced Nursing, 32, 1008-1015.

HENDERSON, A. \& CUTTLER, R. 1999. Northside Storage Tunnel Project. 10th Australian Tunnelling Conference. Melbourne.

HENNEVELD, M. 2006. Alliance Contracting: Removing the Boundaries for Infrastructure Delivery. Charlottetown, Prince Edward Island: Commissioner of Main Roads, Western Australia.

HENSHER, D. 2006. Delivering Value for Money to Government through Efficient and Effective Public Transit Service Continuity: Some Thoughts. Sydney: University of Sydney, Institute of Transport and Logistics Studies. 
HOLT, G. D., LOVE, P. E. D. \& LI, H. 2000. The Learning Organisation: A Paradigm for Mutually Beneficial Strategic Construction Alliances. International Journal of Project Management, 18, 415-423.

HOWARD, K. \& SHARP, J. A. 1983. The Management of a Student Research Project, Aldershot, Gower.

HUTCHINSON, A. 2004. Target Outturn Cost: Demonstrating and Ensuring Value for Money. Alchime Pty. Ltd.

HUTCHINSON, A. \& GALLAGHER, J. 2003. Project Alliances: An Overview. Centre for Advanced Engineering. Auckland and Christchurch, New Zealand: Alchimie Pty Ltd and Phillips Fox

IASC 2009. In Pursuit of Additional Value - A bencmarking study into Alliancing in the Australian Public Sector - Report Rev A. In: FINANCE, V. D. O. T. A. (ed.). Melbourne.

INTRONA, L. D. 1997. Management, information and power, London, Macmillan Press.

JOHNSON, P. \& DUBERLEY, J. 2000. Understanding management research - An introduction to epistemology, London, Sage.

JOHNSTON, R. 2004. Towards a Better Understanding of Service Excellence. Managing Service Quality, 14, 129-133.

KARPIN, D. 1995. Enterprise nation; Renewing Australia's Managers to Meet the Challenges of the Asia Pacific Century. Canberra: Australian Government Publishing Service.

KEENEY, S., HASSON, F. \& MCKENNA, H. 2006. Consulting the oracle: ten lessons from using the Delphi technique in nursing research. Journal of Advanced Nursing, 53, 205-279.

KELLY, J., MORLEDGE, R. \& WILKINSON, S. (eds.) 2002. Best Value in Construction Blackwell Science.

KEYS, J. 2004. Do Alliance Projects Offer Value for Money? - A Study comparing procurement routes. Currie \& Brown.

KNOTT, T. 1996. No Business as Usual, London, The British Petroleum Company PIc.

LANGFORD, D. 2007. Revaluing Construction - Hard and Soft values. In: SEXTON, M., KAHKONEN, K. \& SHU-LING, L. (eds.) CIB Priority Theme - Revaluing Construction: A W065 'Organisation and Management of Construction' Perspective. CIB General Secreteriat.

LATHAM, M. 1994. Constructing the Team, London, HMSO.

LINSTONE, H. L. (ed.) 1975. Eight basic pitfalls: a check list, Reading, MA: Addison-Wesley. 
LOVE, P. E. D., DAVIS, P. R. \& CHEVIS, R. 2011. Risk/Reward Compensation Models in Alliances for the Delivery of Civil Engineering Infrastructure Projects. ASCE Journal of Construction Engineering and Management, 137, 127-136.

LOVE, P. E. D., DAVIS, P. R. \& MISTY, D. 2010. Price Competitive Alliance Projects: Identification of Success Factors fo Public Clients. ASCE Journal of Construction Engineering and Management, 136, 947-956.

LOVE, P. E. D., IRANI, Z., CHENG, E. W. L. \& LI, H. 2002. A Model for Supporting Inter-Organizational Relations in the Supply Chain. Engineering Construction and Architectural Management, 9, 215.

MACDONALD, C. C. 2001. Allocation of risk in major infrastructure projects - why do we get it so wrong? International Construction Law Review, 18.

MACDONALD, C. C. 2005. What are the important differences between partnering and alliance procurement models and why are terms so often confused? Australian Institute of Project Management. Melbourne.

MACDONALD, C. C. 2007. The leadership competencies required of project managers in project alliance contracting. $p m$ days '07. Vienna, Austria.

MACDONALD, C. C. 2008. Can Project Alliance Contracts Truly Provide Value for Money Outcomes? CRC Construction Innovation. Brisbane: CRC: Construction Innovation.

MALE, S. 2002. Building the Business Value Case. In: KELLY, J., MORLEDGE, R. \& WILKINSON, S. (eds.) Best Value in Construction. Oxford: Blackwell.

MALE, S. \& KELLY, J. 1992. Value management as a strategic management tool. In: PALMER, A. (ed.) Value and the Client, A comparison of US Value Engineering with British Cost Control Procedures. RICS.

MALLESONS 2003. Alliancing. Asian Projects and Construction Update.

MARX, K. 1867. Das Kapital, London, Penguin.

MASTERMAN, J. W. E. 2002. An Introduction to Building Procurement Systems, London, E \& FN SPON.

MCINTYRE, S. A. 2009. Achieving Value for Money in Infrastructure Projects delivered through an Alliance Contract. Master in Project Management Thesis, Queensland University of Technology.

MCKAY, J. \& MARSHALL, P. 2001. The dual imperatives of action research. Information Technology \& People, 14, 46-59.

MILLS, A. \& HARLEY, J. 2010. Alliance Performance and Perception Survey in Public Sector Infrastructure. Melbourne: RMIT University and Alliancing Association of Australasia. 
MITROFF, I. I. \& LINSTONE, H. L. 1993. The unbounded mind: Breaking the chains of traditional business thinking, New York, Oxford University Press.

MORWOOD, R., SCOTT, D. \& PITCHER, I. 2008. Alliancing: a participant's guide, Brisbane, Maunsell AECOM.

MURRAY, M. \& LANGFORD, D. 2003. Construction Reports 1944-98, Oxford, Blackwell Science.

NAO 2001. Modernising Construction, Report by the Comptroller and Auditor General. National Audit Office.

NOGESTE, K. 2008. Dual cycle action research: a professional doctorate case study. International Journal of Managing Projects in Business, 1, 566-585.

NOGESTE, K. \& WALKER, D. H. T. 2005. Project Outcomes and Outputs: Making the Intangible Tangible. Measuring Business Excellence, Emerald, UK, 9, 55-68.

NORTHCOTE, J., LEE, D., CHOK, S. \& WEGNER, A. 2008. An Email-based Delphi Approach to Tourism Program Evaluation: Involving Stakeholders in Research Design. Current Issues in Tourism, 11, 269-279.

NSW-TREASURY 2005. Code of Practice for Procurement. In: NSW GOVERNMENT, D. O. T. (ed.).

NSWAG 2003a. NSW Auditor General's Report, Performance Audit, 'Sydney Water Corporation Northside Storage Tunnel Project'. NSW Auditor General.

NSWAG 2003b. NSW Auditor General's Report, Performance Audit, 'The Millenium Train Project'. In: GENERAL, N. A. (ed.).

OCG 2004. OCG Gateway Review 2 - Procurement strategy. In: COMMERCE, O. O. G. (ed.).

OCG 2007. Inititiative into Action, Achieving Excellence in Construction Procurement Guide. Achieiving Excellence in Construction Procurement Guide. HM Treasury.

OGC 2005. OGC Gateway ${ }^{\mathrm{TM}}$ Review Process Designed to make you Successful

OGC 2007a. Achieving Excellence in Construction, Guide1, Initiative into action.

OGC 2007b. Achieving Excellence in Construction, Guide 3, Project procurement lifecycle - the integrated process.

OGC 2007c. Construction Process Pocketbook V.2. In: COMMERCE, U. O. O. G. (ed.).

OGC 2007d. Construction Projects - A manager's checklist. www.ogc.gov.uk.

OGC 2007e. Gateway process - A manager's checklist V.2. www.ogc.gov.uk. 
OGC 2007f. Gateway Review Workbooks, (Stages 0 to 5), V.2. www.ogc.gov.uk.

OGC 2007g. A Manager's Checklist - Construction Projects V.2.

PEDLER, M., BURGOYNE, J. \& BROOK, C. 2005. What has action research learning learned to become? Action Learning: Research and Practice, 2, 49-68.

PERMAIN, N. 1992. Value for Money (VFM) auditing in local government. Local Government Engineers Association of Western Australia State Conference. Perth: Local Government Engineers Association of Western Australia.

PERRY, C. \& ZUBER-SKERRITT, O. 1992. Action reserach in graduate management research programs. Higher Education, 23, 195-208.

PERRY, C. \& ZUBER-SKERRITT, O. 1994. Doctorates by Action Research for Senior Practising Managers. Management Learning, 25, 341.

PERRY, R. 1914. The Definition of Value. Journal of Philosophy, Psychology and Scientific Methods, 12, 141-162.

PORTER, M. E. 1985. Competitive Advantage: Creating and Sustaining Superior Performance, New York, The Free Press.

POWELL, C. 2003. The Delphi technique: myths and realities. Journal of Advanced Nursing, 41, 376382.

PRICE-WATERHOUSE 1990. Value for Money Auditing: The Investigation of Economy, Efficiency, Effectiveness. London: Gee \& Co Publishers.

QLD-DPW 2000. Better Purchasing Guide-Value for Money. Queensland Goverment, Department of Public Works.

QUICK, R. 2007. Queensland's ECI Contract. The International Construction Law Review, 11.

RAPOPORT, R. N. 1970. Three dilemmas in action research. Human Relations, 23, 499-513.

REVENS 1980. Action Learning: New Techniques for Management, London, Blond and Briggs.

RICARDO, D. 1817. Theory of the Principles of Political Economy, London, John Murray.

RMIT 2007. Higher Degrees by Research: Policy \& Procedures Information Booklet. RMIT University.

ROSS, J. 2000. Introduction to Project Alliancing. Presentation to the Institution of Engineers, Australia. Brisbane. 
ROSS, J. 2003a. Introduction to Project Alliancing (on engineering and construction projects). Alliance Contracting Conference, April 2003. Sydney.

ROSS, J. 2003b. Project Alliancing - A Strategy for Avoiding and Overcoming Adversity. World Project Management Week. Gold Coast: Project Control International P/L.

ROSS, J. 2007. Alliancing - Fad or Fixture? Leighton Contractors Magazine.

ROSS, J. \& PURCELL, J. 2005. Alliancing is Not a Universal Panacea. Engineers Australia, 77, 24-25.

RUMMEL, R. W. \& BALLAINE, W. C. 1963. Research Methodology in Business, New York, Harper \& Row.

RUSKIN, J. 1849. The Seven Lamps of Architecture, New York, The Noonday Press.

SACKMAN, H. 1974. Delphi Critique: Expert Opinion, Forecasting and Group Process, Lexington, MA, D. C. Heath.

SEALE, C. 1999. The quality of qualitative research, London, Sage.

SENGE, P. 1990. The fifth discipline, New York, Basic Books.

SILVERMAN, D. 2001. Interpreting qualitative data: Methods for analysing talk and text interaction, London, Sage.

SKINNER, D. 2006. Delivering VFM in an Overheated Market. ARF National Roads Summit. Sydney: Queensland Department of Main Roads.

SKULMOSKI, G. J., HARTMAN, F. T. \& KRAN, J. 2007. The Delphi Method for Graduate Research. Journal of Information Technology in Education, 6, 1-21.

SMITH, A. 1776. The Wealth of Nations (1999 edition), London, Penguin.

STACEY, R. 2003. Strategic management and organisational dynamics - the challenge of complexity, Harlow: FT-Prentice hall, Pearson.

STANDING, N. 1999. Value engineering and the contractor. Unpublished PhD Thesis, University of Leeds.

SWEENEY, S. 2009. Addressing Market Failure: Using Transaction Cost Economics to Improve the Construction Industry's Performance. PhD Thesis, University of Melbourne.

TRANSIT-NZ 2005. Grafton Gully Project Alliance Value for Money, Results Report, . V2.1 ed.: Tranzit New Zealand. 
TRENCH, D. 1991. On target; A Design and manage target Cost Procurement System, London, Thomas Telford.

UK-TREASURY 2006. Value for Money Assessment Guidance, HM Treasury.

USCII 1989. Partnering Task Force - Interim Report. US Construction Industry Institute.

VAN MAANEN, J. 1995. Style as Theory. Organisational Science, 7, 158-177.

VDTF 2004. Gateway Review Process, Leadership Guide. Victorian Government Department of Treasury and Finance.

VDTF 2006a. Project Alliancing Practitoners' Guide. Victorian Department of Treasury and Finance.

VDTF. 2006b. Strategic Sourcing Policy [Online]. Available: http://www.procurement.vic.gov.au/CA2575BA0001417C/pages/procurement-practitionersstage-1---planning-step-3---develop-the-procurement-strategy-strategic-sourcing-policy [Accessed April 2011].

VDTF 2010a. Guidance Note No 5: Developing the TOC in Alliance Contracting. Victorian Department of Treasury and Finance.

VDTF 2010b. The Practitioners' Guide to Alliance Contracting. Victorian Department of Treasury and Finance.

VDTF 2011. Guidance Note No.4: Reporting VfM Outcomes in Alliance Contracting. 1st Edition with updates, March 2011 ed. Melbourne: Victorian Department of Treasury and Finance.

WALKER, D. H. T. 2004. The Knowledge Advantage (K-Adv) Unleashing Creativity and Innovation. Unpublished report draft manuscript. Melbourne.

WALKER, D. H. T. \& HAMPSON, K. D. 2003. Procurement Strategies: A relationship-based approach, Blackwell Science.

WALKER, D. H. T. \& LLOYD-WALKER, B. 2011. Profiling Professional Excellence in Alliance Management. Alliancing Association of Australasia.

WALKER, D. H. T. \& NOGESTE, K. 2008. Project measures and project procurement. In: WALKER, D. H. T. \& ROWLINSON, S. (eds.) Procurement Systems: A cross-industry project management perspective. Abingdon, Oxon: Taylor \& Francis.

WALKER, D. H. T. \& ROWLINSON, S. (eds.) 2008. Procurement Systems: A cross-industry project management perspective, Abingdon, Oxon: Taylor and Francis. 
WALKER, D. H. T., ROWLINSON, S. \& STARK, J. 2008a. Preface. In: WALKER, D. H. T. \& ROWLINSON, S. (eds.) Procurement Systems: A cross-industry project management perspective. Abingdon, Oxon: Taylor and Francis.

WALKER, D. H. T., STARK, J., ARLT, M. \& ROWLINSON, S. 2008b. Introduction and Fundemantals. In: WALKER, D. H. T. \& ROWLINSON, S. (eds.) Procurement Systems: A cross-industry project management perspective. Abingdon, Oxon: Taylor and Francis.

WASHBOURNE, M. 2007. Measuring Value for Money in an Alliance SRD Consulting Pty Ltd.

WAWC 2007. Water Scores Benchmarking Program. In: AUSTRALIA, W. C. O. W. (ed.).

WEICK, K. 2002. Real-time reflexivity prods to reflection. Organizational Studies, 23, 893-898.

WILLIAMS, S. 2008. Review of South East Water's Works Alliance Agreement. In: OFFICE, V. A.-G. S. (ed.). Melbourne: Victorian Government.

YIN, R. K. 1994. Case Study Research: Design and Methods, Sage Publications.

YUKL, G. A. 1999 A evaluative essay on current conceptions of effective leadership. European Journal of Work and Organisational Psychology, 8, 33-48.

ZIGLIO, E. (ed.) 1996. The Delphi Method and its Contribution to Decision-Making, London and Philadelphia: Jessica Kingsley Publications.

ZUBER-SKERRITT, O. \& PERRY, C. 2002. Action research within organisations and university thesis writing. The Learning Organization, 9, 171-179. 


\section{Appendices}

\section{A Confidentiality Agreement}

A.1 Confidentiality Agreement (not included in final version to preserve anonymity)

B Phase 1 Research Documents

B.1 List of Phase 1 Participants

B.2 Letter of Invitation to Phase 1 Participants

B.3 Documents forwarded to Phase 1 Participants prior to interview

- Preliminary VfM Model.

- Comparative Table of GatewayTM Reviews

B.4 Documents tabled at Phase 1 interviews

- Format of Phase 1 interviews

- Phase 1 questionnaire

\section{Phase 2 Research Documents}

C.1 List of Phase 2 Participants

C.2 Letter of Invitation to Phase 2 Participants

C.3 Sample pages of the Delphi Process website

\section{Round 1}

C.4 Documents forwarded to participants prior to the commencement of Round 1

- $\quad$ Briefing Paper for Phase 2, Round 1 Participants

- VfM Model

C.5 Round 1 Questions as posted to the Delphi Website to be addressed by participants

\section{Round 2}

C.6 Documents forwarded to participants prior to the commencement of Round 2

- $\quad$ Briefing paper for Phase 2, Round 2 participants

- VfM model

C.7 Round 2 Questions as posted to the Delphi Website to be addressed by the participants

\section{Round 3}

C.8 Documents forwarded to participants prior to the commencement of Round 3

- Briefing paper for Phase 2, Round 3

C.9 Round 3 Questions as posted to the Delphi Website to be addressed by the participants 
D Phase 1, Detailed results

D.1 Question A - Were the following issues addressed in any review of $\mathrm{VfM}$ at these stages of the project?

D.1.1 Issues addressed at the 'Strategic Need' Stage of the project lifecycle (VfM/BV Gate 0)

D.1.2 Issues addressed at the 'Business Case' Stage of the project lifecycle (VFM/BV Gate 1)

D.1.3 Issues addressed at the 'Procurement Strategy' Stage of the project lifecycle (VfM/BV Gate 2)

D.1.4 Issues addressed at the 'Selection of NOPs' Stage of the project lifecycle (VfM/BV Gate 3A)

D.1.5 Issues addressed at the 'TCE Approval' Stage of the project lifecycle (VFM/BV Gate 3B)

D.1.6 Issues addressed at the 'Readiness for Service' Stage of the project lifecycle (VfM/BV Gate 4)

D.1.7 Issues addressed at the 'Benefits Evaluation' Stage of the project lifecycle (VfM/BV Gate 5A\&B)

D.1.8 Economic Issues at each stage of the project lifecycle

D.1.9 Social Issues at each stage of the project lifecycle

D.1.10 Environmental Issues at each stage of the project lifecycle

D.1.11 Ethical Issues at each stage of the project lifecycle

D.1.12 Stakeholder Issues at each stage of the project lifecycle

D.1.13 Governance Issues at each stage of the project lifecycle

D.2 Question B - Is VfM an explicit project objective for the Alliance?

Frequency $v$ LOM for each stage of the project lifecycle

D.3 Question C - Are specific measures or procedures in place to ensure that VfM is achieved?

Frequency $v$ LOM for the each stage of the project lifecycle

D.4 Question D - Are specific measures in place to ensure that VfM is demonstrated to have been achieved?

Frequency $v$ LOM for the each stage of the project lifecycle

D.5 Question E - Is VfM an explicit project objective for your Organisation?

Frequency $v$ LOM for the each stage of the project lifecycle

D.6 Question F - Are specific measures normally in place (within your Organisation) to ensure that $\mathrm{VfM}$ is achieved?

Frequency $v$ LOM for the each stage of the project lifecycle 
D.7 Question G - Are specific measures normally in place (within your Organisation) to ensure that VfM is demonstrated to have been achieved? Frequency $v$ LOM for the each stage of the project lifecycle

\section{D.8 Open Questions}

Appendix 5.7.8 - Phase 1 Open Questions - Detailed Responses

E Phase 2: Detailed Results

\section{E.1 Delphi Survey, Round 1}

Consolidated Responses

E.2 Delphi Survey, Round 2

Consolidated Responses

\section{E.3 Delphi Survey, Round 3}

Consolidated Responses

\section{F Comments on IASC Documents}
F.1 In Pursuit of Additional Value - Key Findings
F.2 In Pursuit of Additional Value - Discussion Points
F.3 In Pursuit of Additional Value - Conclusions
F.4 In Pursuit of Additional Value - Recommendations
F.5 Guidance Note No. 4, Reporting VfM Outcomes in Alliance Contracting 


\section{Appendix A.1}

\section{Confidentiality Agreement}

(Agreement not included in final version to

preserve anonymity of parties) 


\section{Appendix B.1}

\section{List of Phase 1 Participants}




\section{Appendix B.1 - List of Phase 1 Participants}

Alliance Blue (Railway works)

\begin{tabular}{|c|c|c|c|c|c|c|c|}
\hline Name & Position (Organisation) & Organisation & Contacted & Interview & Forms returned & Comment & Time (m) \\
\hline Blue 1 & Alliance Manager (program) & Constructor & $1 / 6 / 09$ & $16 / 7 / 09$ & & Form not returned. & 51.34 \\
\hline Blue 2 & $\begin{array}{l}\text { Program Controls Manager and } \\
\text { "Create Client Value" KRA Leader }\end{array}$ & Constructor & $1 / 6 / 09$ & 19/6/09 & $8 / 9 / 09$ & & 72.33 \\
\hline Blue 3 & $\begin{array}{l}\text { Construction Manager for program } \\
\text { previously Project manager for one } \\
\text { of the projects in the program }\end{array}$ & Other NOP & $1 / 6 / 09$ & $7 / 8 / 09$ & $10 / 9 / 09$ & & 67.52 \\
\hline Blue 4 & $\begin{array}{l}\text { Project Manager one of the } \\
\text { projects in the program }\end{array}$ & Constructor & $1 / 6 / 09$ & 4/09/09 & $8 / 12 / 09$ & & 69.41 \\
\hline Blue 5 & $\begin{array}{l}\text { Program Director for Owner, and } \\
\text { ALT Rep }\end{array}$ & Owner & $2 / 6 / 09$ & $15 / 7 / 09$ & 21/7/09 & & 54.45 \\
\hline Blue 6 & $\begin{array}{l}\text { Project Manager one of the } \\
\text { projects in the program }\end{array}$ & Constructor & $22 / 7 / 09$ & $12 / 8 / 09$ & $16 / 9 / 09$ & & 75.17 \\
\hline
\end{tabular}

\section{Alliance Red (Water treatment works)}

\begin{tabular}{|c|c|c|c|c|c|c|c|}
\hline Name & Organisation & Organisation & Contacted & Interview & Forms returned & Comment & Time (m) \\
\hline Red 1 & Alliance Manager & Constructor & $1 / 6 / 09$ & $7 / 8 / 09$ & $18 / 9 / 09$ & & 81.47 \\
\hline Red 2 & ALT Member & Constructor & $24 / 8 / 09$ & $2 / 9 / 09$ & & Form not returned. & 47.24 \\
\hline Red 3 & Design/Technology Manager & Other NOP & $24 / 8 / 09$ & $4 / 9 / 09$ & & $\begin{array}{l}\text { Form not returned, } \\
\text { Telephone interview }\end{array}$ & 47.42 \\
\hline Red 4 & Deputy Alliance Manager & Other NOP & $24 / 8 / 09$ & $4 / 9 / 09$ & $4 / 9 / 09$ & Telephone interview & 34.20 \\
\hline Red 5 & Construction manager & Constructor & $17 / 6 / 09$ & $21 / 8 / 09$ & & Form not returned. & 50.14 \\
\hline
\end{tabular}

Alliance Green (Interurban road works)

\begin{tabular}{|l|l|l|l|l|l|l|l|}
\hline Name & Organisation & Organisation & Contacted & Interview & Forms returned & Comment \\
\hline Green 1 & Alliance Manager & Constructor & $1 / 6 / 09$ & $6 / 7 / 09$ & $13 / 7 / 09$ & 60.59 \\
\hline Green 2 & $\begin{array}{l}\text { Project Development Manager, } \\
\text { AMT }\end{array}$ & Owner & $1 / 6 / 09$ & $7 / 7 / 09$ & $29 / 7 / 09$ & 72.23 \\
\hline Green 3 & Zone Manager and VFM reporting & Constructor & $1 / 6 / 09$ & $6 / 7 / 09$ & $24 / 7 / 09$ & \\
\hline Green 4 & Design Manager & Other NOP & $1 / 6 / 09$ & $2 / 7 / 09$ & $19 / 3 / 10$ & \\
\hline Green 5 & Interface Manager & Constructor & $1 / 6 / 09$ & $21 / 7 / 09$ & $4 / 1 / 10$ & Telephone interview \\
\hline Green 6 & Design Manager up to TOC & Other NOP & $7 / 6 / 09$ & $30 / 6 / 09$ & $10 / 7 / 09$ & 60.02 \\
\hline
\end{tabular}

Alliance Purple (Dam works)

\begin{tabular}{|l|l|l|l|l|l|l|l|}
\hline Name & Organisation & Organisation & Contacted & Interview & Forms returned & Comment \\
\hline Purple 1 & Alliance Manager & Constructor & $7 / 6 / 09$ & $24 / 7 / 09$ & $29 / 7 / 09$ & 76.16 \\
\hline Purple 2 & Project Manager, Concrete & Constructor & $7 / 6 / 09$ & $24 / 7 / 09$ & $29 / 7 / 09$ & 53.02 \\
\hline Purple 3 & Design Manager & Other NOP & $7 / 6 / 09$ & $7 / 8 / 09$ & & Form not returned. \\
\hline Purple 4 & Owner's Representative & Owner & $7 / 6 / 09$ & $31 / 7 / 09$ & & Form not returned. \\
\hline Purple 5 & $\begin{array}{l}\text { Owner's Representative - Local } \\
\text { Govt }\end{array}$ & Owner & $17 / 6 / 09$ & $30 / 7 / 09$ & $22 / 12 / 09$ & \\
\hline Purple 6 & ALT Member & Constructor & $24 / 8 / 09$ & $2 / 9 / 09$ & & Form not returned. \\
\hline
\end{tabular}

Alliance Black (Public transport infrastructure)

\begin{tabular}{|l|}
\hline Name \\
\hline Black 1 \\
\hline Black 2 \\
\hline Black 3 \\
\hline Black 4 \\
\hline Black 5 \\
\hline Black 6 \\
\hline
\end{tabular}

Organisation

Alliance Manager

VfM Coordinator Mechanical \& Electrical Manager

Integration Manager

Construction Manager

ALT member \begin{tabular}{|l|l|l|l|l}
\hline Organisation & Contacted & Interview & Forms returned & Comment
\end{tabular}

$4 / 12 / 09$

$25 / 8 / 09$

\begin{tabular}{l|l|l} 
Constructor & $7 / 6 / 09$ & $19 / 8 / 09$ \\
\hline
\end{tabular}

\begin{tabular}{l|l}
\hline Other NOP & $7 / 6 / 09$
\end{tabular}

Owner $\quad 7 / 6 / 09$

Constructor $7 / 6 / 09$

Other NOP $17 / 6 / 09$

$21 / 8 / 09$

$7 / 8 / 09$

$21 / 8 / 09$

$21 / 8 / 09$

$11 / 12 / 09$

$17 / 8 / 09$

$25 / 11 / 09$




\section{Appendix B.2}

\section{Letter of Invitation to Phase 1 Participants}




\section{DRITUniversity}

\section{INVITATION TO PARTICIPATE IN A RESEARCH PROJECT \\ PROJECT INFORMATION STATEMENT}

\section{Project Title: The development of a model to facilitate the achievement and demonstration of value for money in project alliances}

\section{Investigators:}

- Mr. Charles MacDonald (Project Management Doctoral degree student) 0412250638

- Professor Derek Walker (Project Supervisor: Professor of Project Management, RMIT University, derek.walker@rmit.edu.au, (03) 99253908

\section{School of Property, Construction and Project Management}

Building 8, Level 8

360 Swanston Street

Melbourne VIC 3001

Australia

GPO Box 2476V

Melbourne VIC 3001

Australia

$\mathrm{Tel}+61399252230$

Fax +61399251939

www.rmit.edu

Dear (to be completed),

You are invited to participate in a research project being conducted by RMIT University with the cooperation and assistance of Thiess Pty Ltd. This information sheet describes the project in straightforward language, or 'plain English'. Please read this sheet carefully and be confident that you understand its contents before deciding whether to participate. If you have any questions about the project, please contact the Investigator.

\section{Who is involved in this research project? Why is it being conducted?}

- The Investigator is Charles MacDonald ......(text deleted to preserve anonymity). The supervisor of the research project is Derek Walker, Professor of Project Management at RMIT.

- The research is being conducted as part of a Doctorate of Project Management Degree.

- This project has been approved by the RMIT Human Research Ethics Committee and (Company X) has agreed to the investigator gaining access to details of an number of project alliances in which it has participated on the strict understanding that appropriate confidentiality provisions are adhered to.

\section{Why have you been approached?}

- You have been approached as party that has been identified as a key participant in a recent project alliance project that Thiess has been involved in.

- Great value is placed on your comments and views on the manner in which 'value for money (VFM) was addressed on that project. Additionally your comments are being sought regarding a model that is being developed to address VfM in future projects.

\section{What is the project about?}

- The project is aimed at the development of a model to facilitate the achievement and demonstration of value for money in project alliances for infrastructure works.

- In this first of two phases of the research, approximately 20 key parties from five project alliances are being contacted to seek their comments on VfM in these alliances (case studies) and the 
applicability of a model that has been developed by the researcher to address value for money through the full life cycle of a project. All these project alliances involveld (Company X) as the constructor within the alliance team.

- In a second stage a smaller group of people involved in other alliance projects will be asked to comment on the model following modifications or refinements that result from comments received in this first stage. This second stage is being conducted using the 'Delphi Method' which involves the views of each participant being shared, anonymously, with the rest of the group consulted prior to a further round of individual comment.

If I agree to participate, what will I be required to do?

- If you agree to participate in the research you will be asked a series of questions about the manner in which the issue of value for money was addressed within the particular alliance in which you were involved. These questions will seek your views on what was done well and what could have been better addressed. Your comments will then be sought on the merits and possible failings of a model that the researcher has developed which seeks to ensure that value for money occurs in project alliances. Details of this model will be forwarded to you prior to the interview.

- The questions that will be asked are expected to take no longer than 45 minutes to complete. Typical questions would include:

- Please describe whether or not VfM was achieved in the (to be completed) alliance?

- If not, why do you believe this was the case?

- If VfM was addressed well in the alliance where do you believe that it could have been improved?

- Do you believe that there were satisfactory measures and controls regarding VfM?

- If not, please indicate why the measures that did exist were satisfactory.

- If satisfactory measures were in place, please indicate how you feel they could have been improved.

\section{What are the risks or disadvantages associated with participation?}

- Participation will require you to make some time available to respond. Whilst the research project has been designed to minimise this time it is appreciated that you are likely to be very busy and finding this time may be difficult

- You may be concerned that you are being asked to reveal information or insights which you believe to be confidential. As is described in further detail below a number of safeguards will be implemented to ensure that the information that you provide will be treated confidentially and your identity will remain anonymous.

\section{What are the benefits associated with participation?}

- The Investigator believes that VfM in project alliances is a matter that is not adequately addressed at present and that the construction industry as a whole (owners, constructors, designers etc.) would benefit greatly from a verified model that ensures and demonstrates VFM. Your participation would be a major contribution to this goal.

\section{What will happen to the information I provide?}

- Your contribution to the proposed research will remain anonymous thorough the adoption of pseudonyms

- Data provided will be treated confidentially and seen only by the investigator, supervisors and examiner. These parties will all be required to sign a confidentiality agreement.

- At the request of (Company $X$ ) the thesis produced as consequence of this research will be embargoed for a period 3 years. This means that the thesis will not be available through the RMIT Library during this period. It is intended, however, that the parties participating in this research will be prioy to the key findings and conclusions of the thesis once it is finalized. (Requirement later withdrawn)

- Research data will be kept securely for a period of 5 years before being destroyed. 


\section{What are my rights as a participant?}

Your participation in this research would be entirely voluntary and your rights would include:

- The right to withdraw your participation at any time, without prejudice.

- The right to have any unprocessed data withdrawn and destroyed, provided it can be reliably identified, and provided that so doing does not increase the risk to yourself.

- The right to have any questions answered at any time.

\section{Whom should I contact if I have any questions?}

○ Please contact Charles MacDonald on 0412250638.

What other issues should I be aware of before deciding whether to participate?

- The proposed research activities will be undertaken between June 20092008 and August 2009.

- The first phase interviews will be held in June/July 2009.

- The second phase 'Delphi' rounds will occur in September/October 2009.

\section{How do I confirm that I am prepared to participate?}

If you are willing to participate please forward a brief response to the email which covered this letter, Once this is received the researcher will contact you to arrange an interview time that is convenient to you.

Yours Sincerely

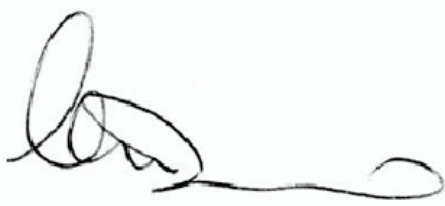

Charles MacDonald

BSc, MSc, MBA, CPEng, FIEAust, MICE, MIHT,, MIAMA, RPEQ

Doctor of Project Management candidate

RMIT University

Mobile 0412250638 
Appendix B.3

Documents forwarded to Phase 1 Participants prior to interview

- Preliminary VfM Model

- Comparative Table of Gateway Reviews 


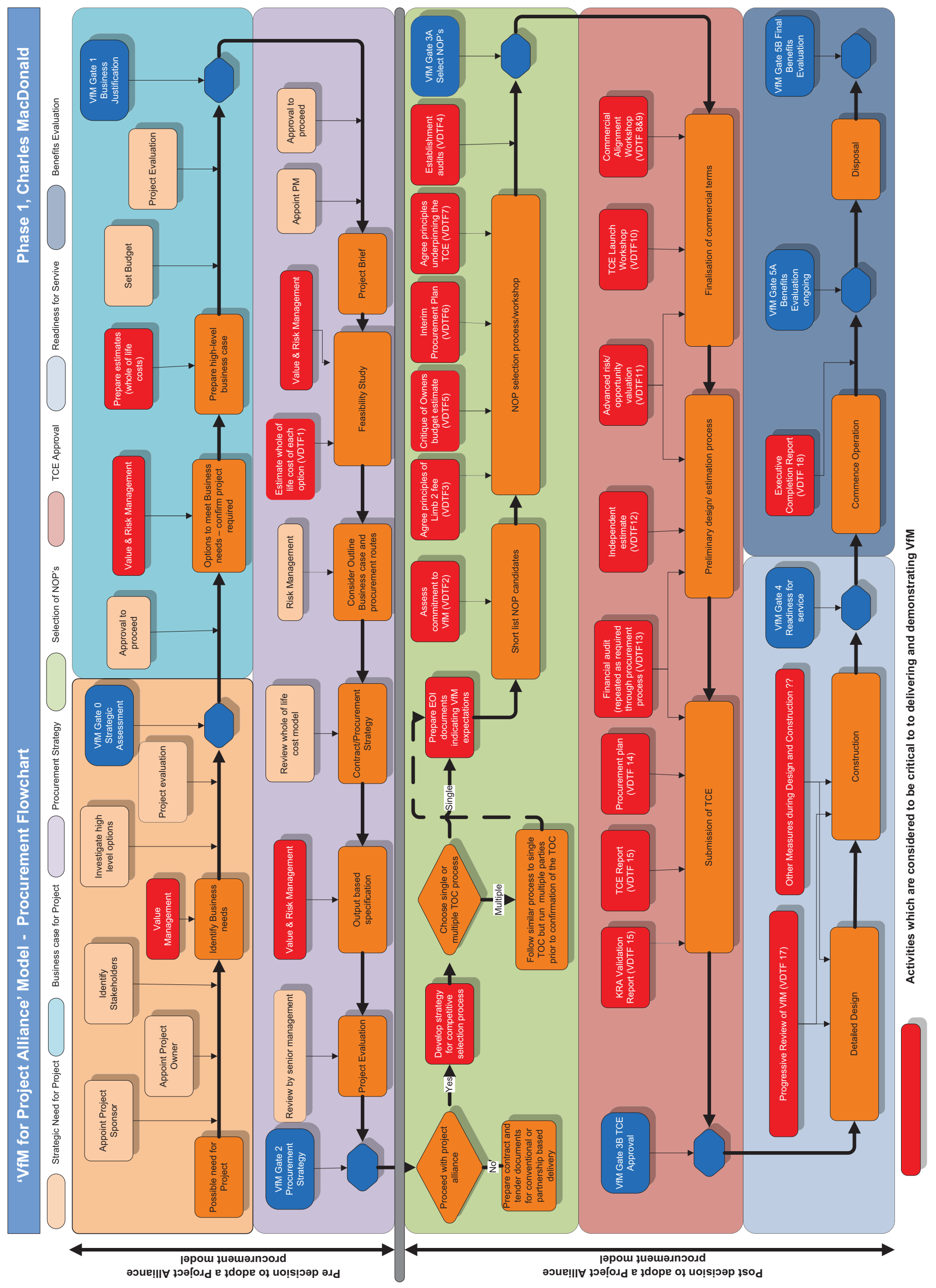




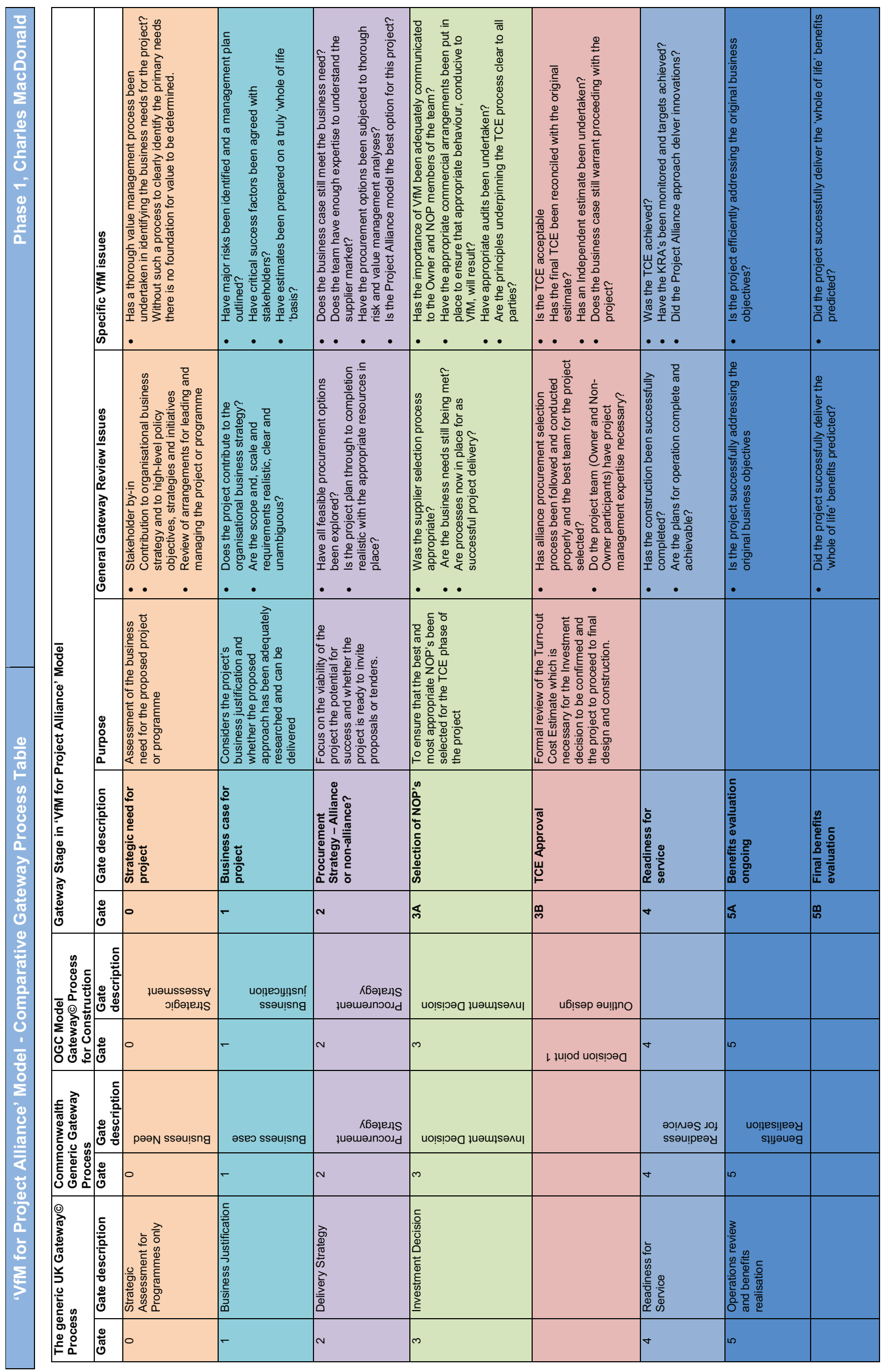


Appendix B.4

Documents tabled at Phase 1 Interviews

- Format of Phase 1 interviews

- Phase 1 questionnaire 


\section{Introduction}

This interview is part of a research project designed to develop a tool which will enable optimal VfM to be achieved and demonstrated in project alliances.

The purpose of the interview is to:

1. Gain an understanding of the practices adopted in the $x x x x$ Alliance in relation to ensuring and demonstrating VfM in project alliances.

2. Briefly outline a proposed model for formalising a standard approach to addressing VfM.

3. Seek feedback on how the model can be developed or expanded to be a comprehensive and practical tool.

The 'face to face' interview will be in a 'conversational' format and you will then be requested to answer a series of questions in a questionnaire format following the interview. A detailed explanation of the questions will be provided during the interview. An addressed and prepaid Express Post envelope is provided to enable you to return your responses to the Investigator.

\section{Discussion regarding VfM practices in the $x x x x$ Alliance}

This will be a discussion based around the following questions aimed at ascertaining the manner in which VfM has been addressed in the $x x x x$ Alliance.

Please describe whether or not you believe that VfM has been achieved in the xxxx Alliance?

- If not, why do you believe this is the case?

- If VfM was addressed well in the alliance what were the factors or reasons for this success?

- What are the issues that you believe could be improved

Do you believe that there were satisfactory measures and controls regarding VfM?

- If not, please describe why the measures that id exist were not satisfactory.

- If satisfactory measures were in place, what were the factors or reasons for this?

- What improvements would you identify to the measures and controls adopted?

\section{Proposed Model}

Following an extensive review of the literature on VfM in Project Alliances and the based on the experiences of the researcher, a model has been created which attempts to identify the specific measures that should be put in place to both ensure and demonstrate VfM during each of 7 identified stages of the life cycle of a project. These stages are;

- The identification of a Strategic Need.

- The development of the Business Case for a project

- The selection of a Procurement Strategy for the project.

Then assuming that a project alliance procurement model is selected:

- The Selection of the NOP's (Non-Owner participants).

- The process leading to the Approval of the TCE (Target Cost Estimate).

- The design and construction phase which leads to Readiness for Service.

- The Benefits Evaluation stage during operations and finally completion/decommissioning of the project. 
These stages, which each have intermediate or sub-stages, have been selected as the primary and distinct episodes that occur for any project with the completion of each corresponding to the gates in the Gateway ${ }^{\circ}$ review process as developed by the UK Treasury. These gates, which are often used by public sector organisations, provide an opportunity to review the progress of the project and check that the original objectives, in this case the VfM objectives, continue to be addressed in the delivery of the project.

The model takes the form of a flowchart that was previously forwarded to you but a further copy is attached for ease of reference.

Question A as attached seeks to identify whether a procedure akin to the Gateway ${ }^{\odot}$ review process has been adopted in the xxxx alliance.

\begin{tabular}{|cll|}
\hline Question & Wording & Context of the question \\
A & Have a comprehensive series of reviews been & This question seeks to identify \\
& $\begin{array}{l}\text { undertaken on the project at the stages } \\
\text { described in an attached table? }\end{array}$ & $\begin{array}{l}\text { whether a procedure akin to the } \\
\text { Gateway review process has been } \\
\text { adopted in the xxxx Alliance. }\end{array}$ \\
\hline
\end{tabular}

\section{Gathering an understanding of current practice}

The specific alliance you have been involved with will have addressed VfM, at each stage of the project, in a manner which could range from poorly to very well. It is suggested that the sophistication of the approach taken will represent a level of maturity in relation to VfM for each stage of the lifecycle. Attached are Questions B to G contain as series of Capability Maturity Models (CMM's) which describe, using a simple 'word picture' five levels of maturity for each of the life cycle stages described above and illustrated in the flowchart in Figure 1.

Each $\mathrm{CMM}$ relates to specific question that is being posed in relation to $\mathrm{VfM}$ being:

\begin{tabular}{|c|c|c|}
\hline Question & Wording & Context of the question \\
\hline B & $\begin{array}{l}\text { Is VfM an explicit project objective for the } \\
\text { Alliance? }\end{array}$ & \multirow{3}{*}{$\begin{array}{l}\text { These questions relate to the } \\
\text { treatment of VfM within the specific } \\
\text { project alliance being considered. }\end{array}$} \\
\hline C & $\begin{array}{l}\text { Are specific measures or procedures in place to } \\
\text { ensure that VfM is achieved? }\end{array}$ & \\
\hline D & $\begin{array}{l}\text { Are specific measures or procedures in place to } \\
\text { ensure that VfM is demonstrated to have been } \\
\text { achieved? }\end{array}$ & \\
\hline $\mathbf{E}$ & $\begin{array}{l}\text { Is VfM an explicit project objective for your } \\
\text { Organisation? }\end{array}$ & \multirow{3}{*}{$\begin{array}{l}\text { These questions relate to the } \\
\text { treatment of VfM within your own } \\
\text { Organisation rather than the } \\
\text { specific project alliance addressed in } \\
\text { questions A to C above. }\end{array}$} \\
\hline $\mathbf{F}$ & $\begin{array}{l}\text { Are specific measures or procedures normally in } \\
\text { place (within your Organisation) to ensure that } \\
V f M \text { is achieved? }\end{array}$ & \\
\hline G & $\begin{array}{l}\text { Are specific measures or procedures normally in } \\
\text { place (within your Organisation) to ensure that } \\
\text { VfM is demonstrated to have been achieved? }\end{array}$ & \\
\hline
\end{tabular}

For each question you are requested to circle the 'word picture' that best describes the level of maturity for each stage of the project lifecycle. For some individuals not all questions will be relevant. For example a representative from an NOP organisation may not be able to provide meaningful comment on the treatment of VfM during the Strategic Need phase of the particular project, in which case the response would be (n/a). 
However, participants in the research are encouraged to answers as many questions as they feel they are able to.

Additionally for Questions B, C and D you are requested respond to the question 'was a Gateway ${ }^{\odot}$ style review undertaken' at the conclusion of each stage of the project life cycle? In some cases the answer may be unknown, and the response would be (?) or the project may not yet have reached that point of the project life cycle.

For Questions $\mathrm{E}, \mathrm{F}$ and $\mathrm{G}$ the question addresses whether such reviews are routinely undertaken by the organisation at the conclusion of each phase of the life cycle.

3. Further feedback on how the model can be developed.

- Do you think that such a model would be a valuable tool to those seeking to achieve and demonstrate VfM?

- Do you see any obvious disadvantages or difficulties with model?

- The design and construct phases in the Readiness for service phase of the model is currently the least developed section of the model. Given that you have experience in this stage, do you have any particularly suggestions for specific VfM activities in this phase based on your experience on the specific project alliance under discussion or indeed any other project alliance?

- Do you have any specific suggestions regarding any of the other 6 phases of the model?

Your cooperation in this process is much appreciated.

Charles MacDonald

0412250638

macdonald@optusnet.com.au 


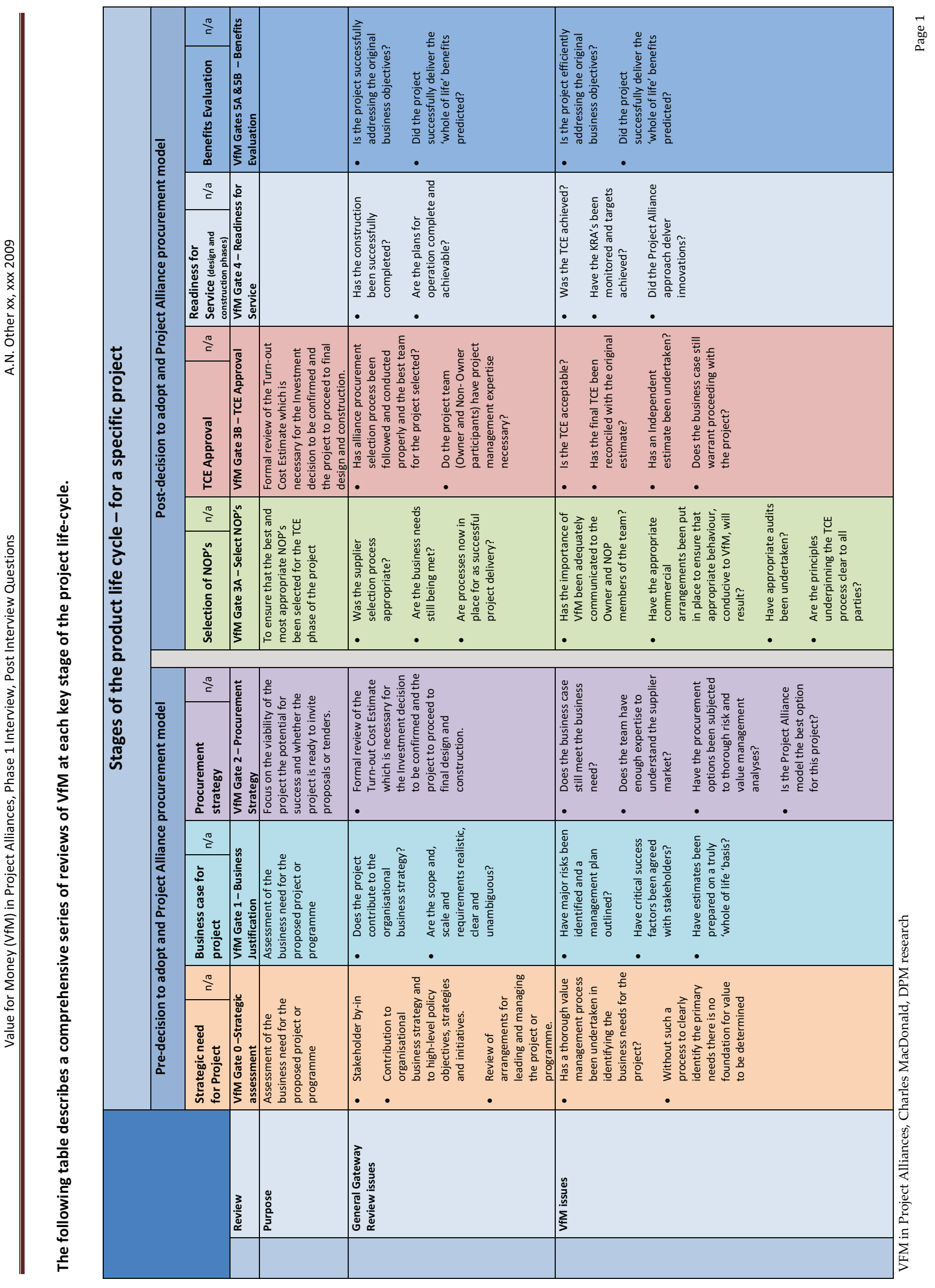




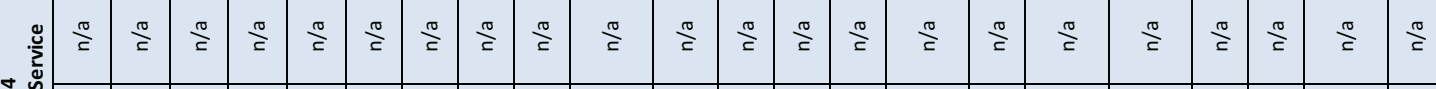

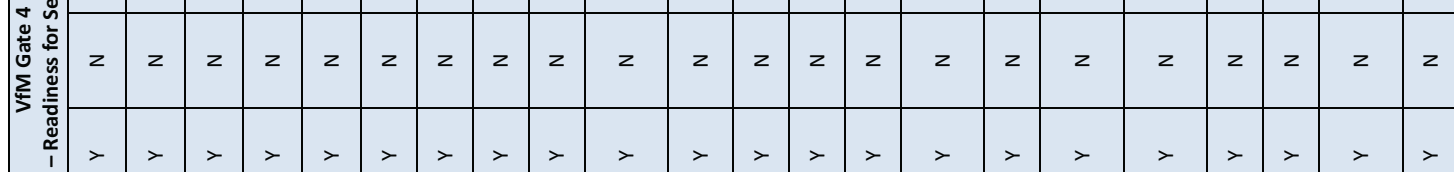

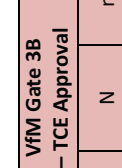

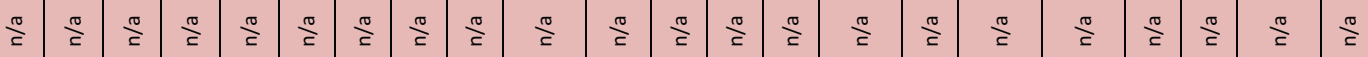

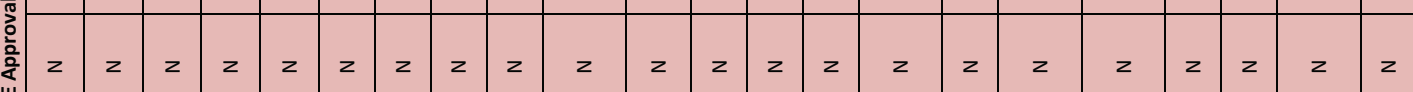

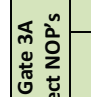

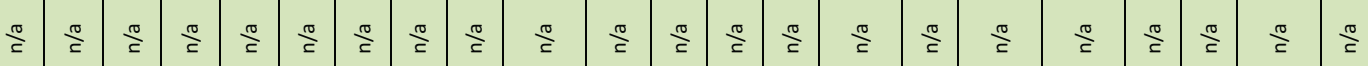

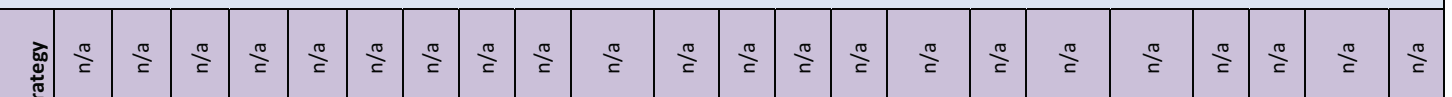

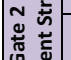

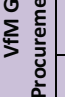

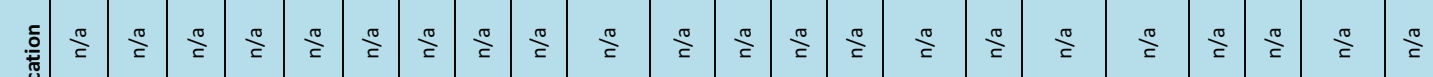
心

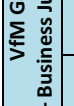

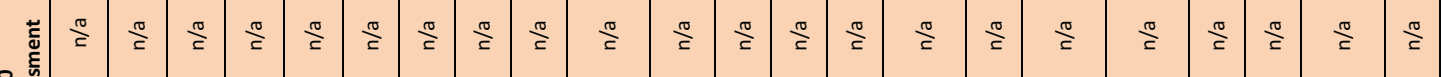

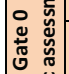

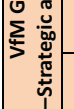

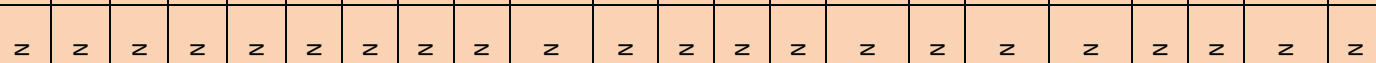
$>>$

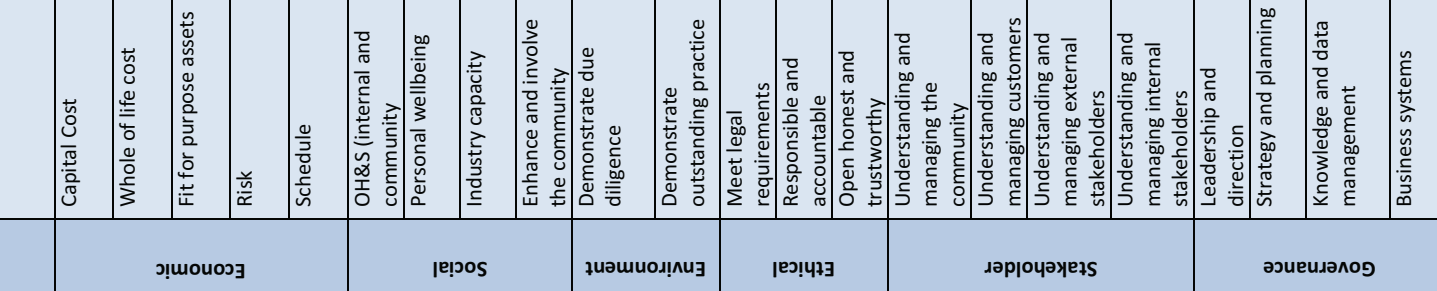




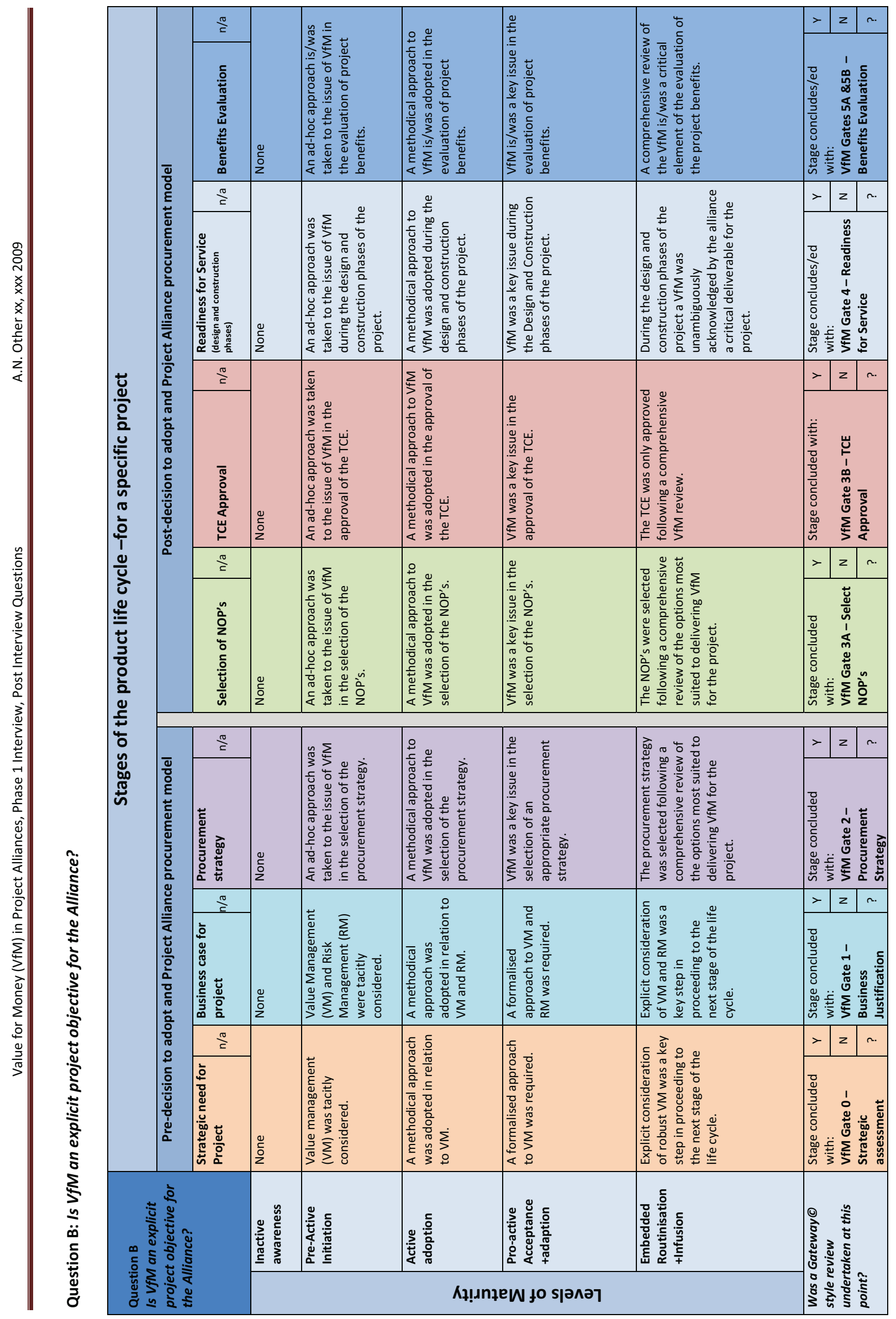

$m$
0
0
0
0
0 


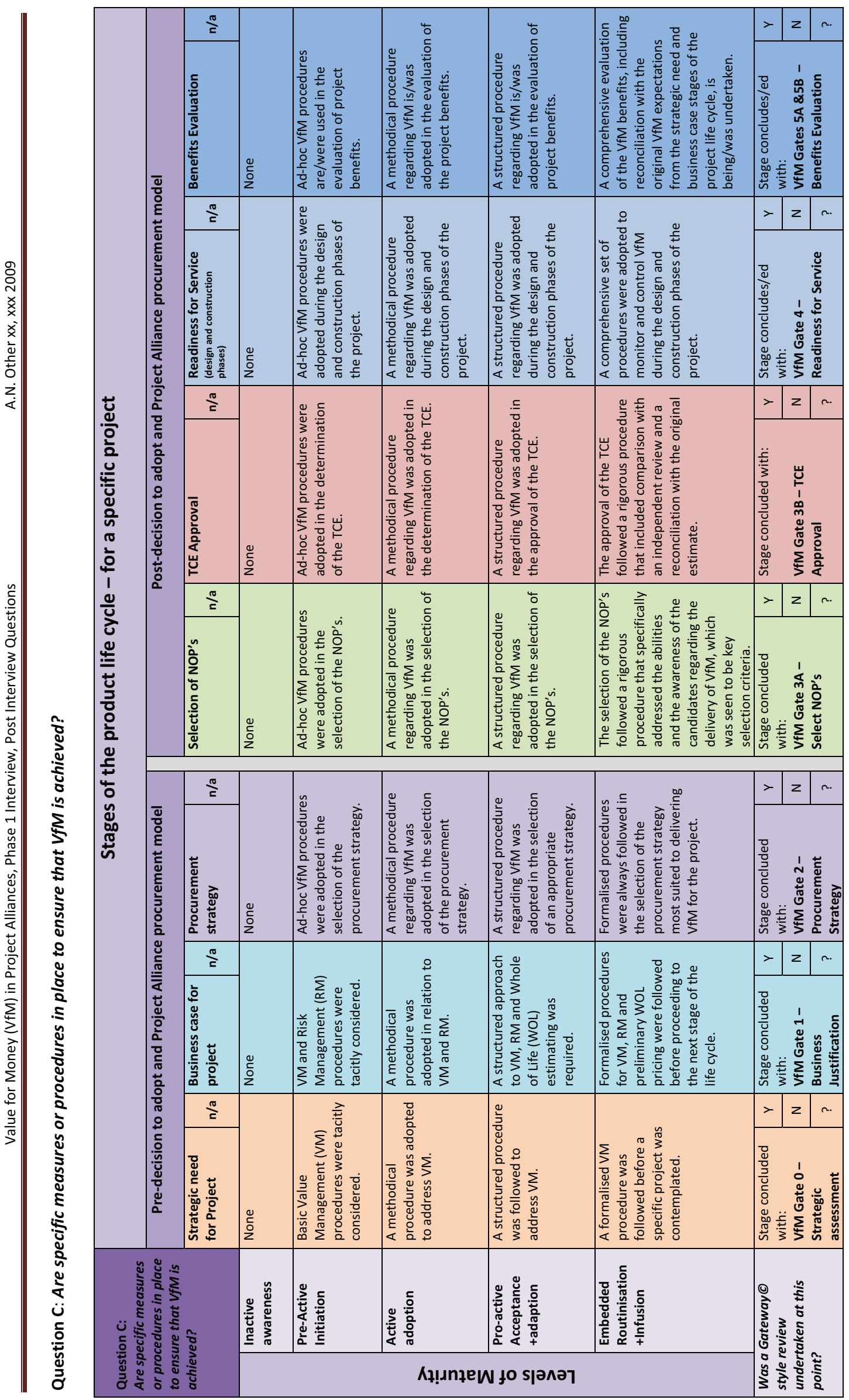




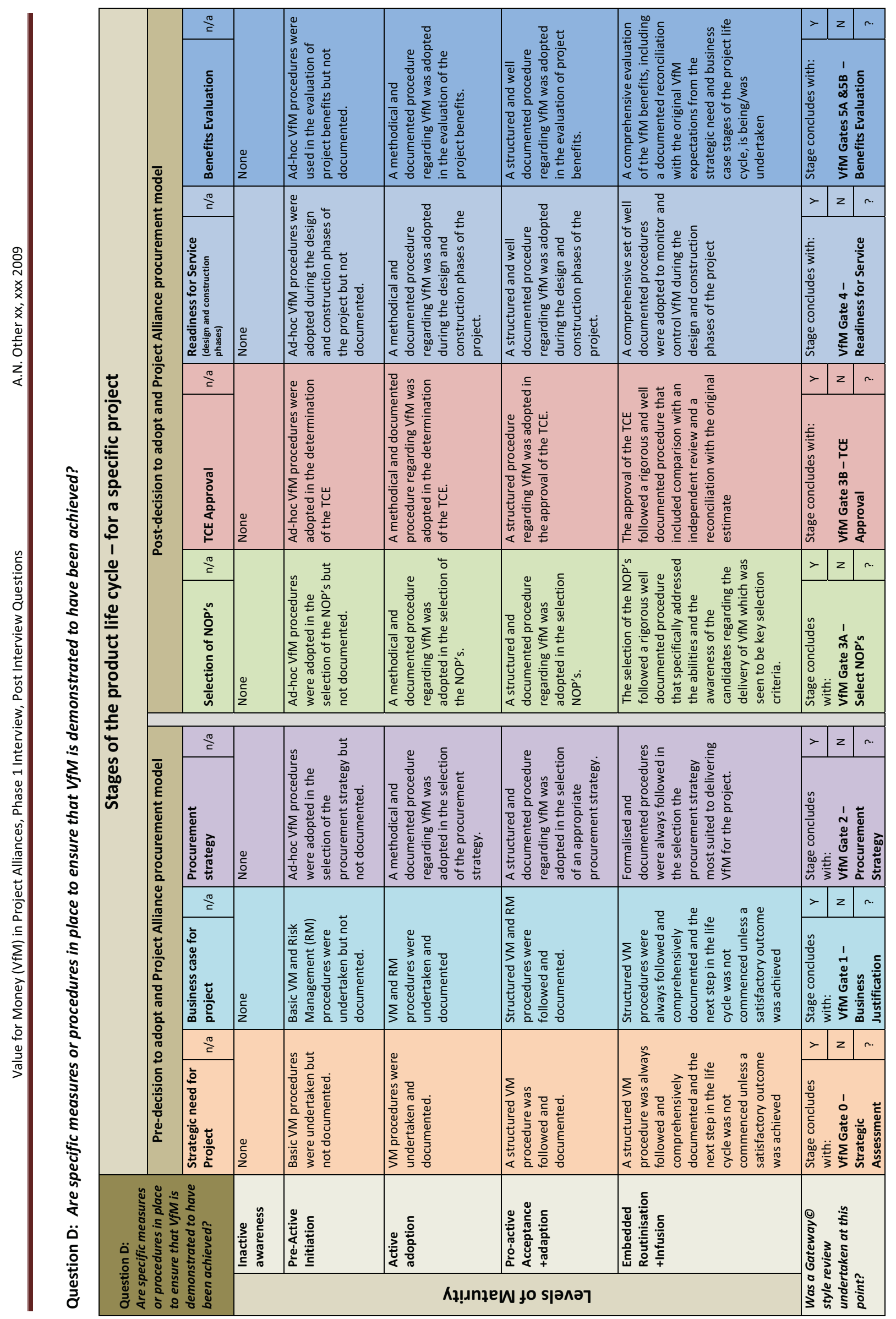

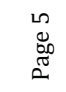




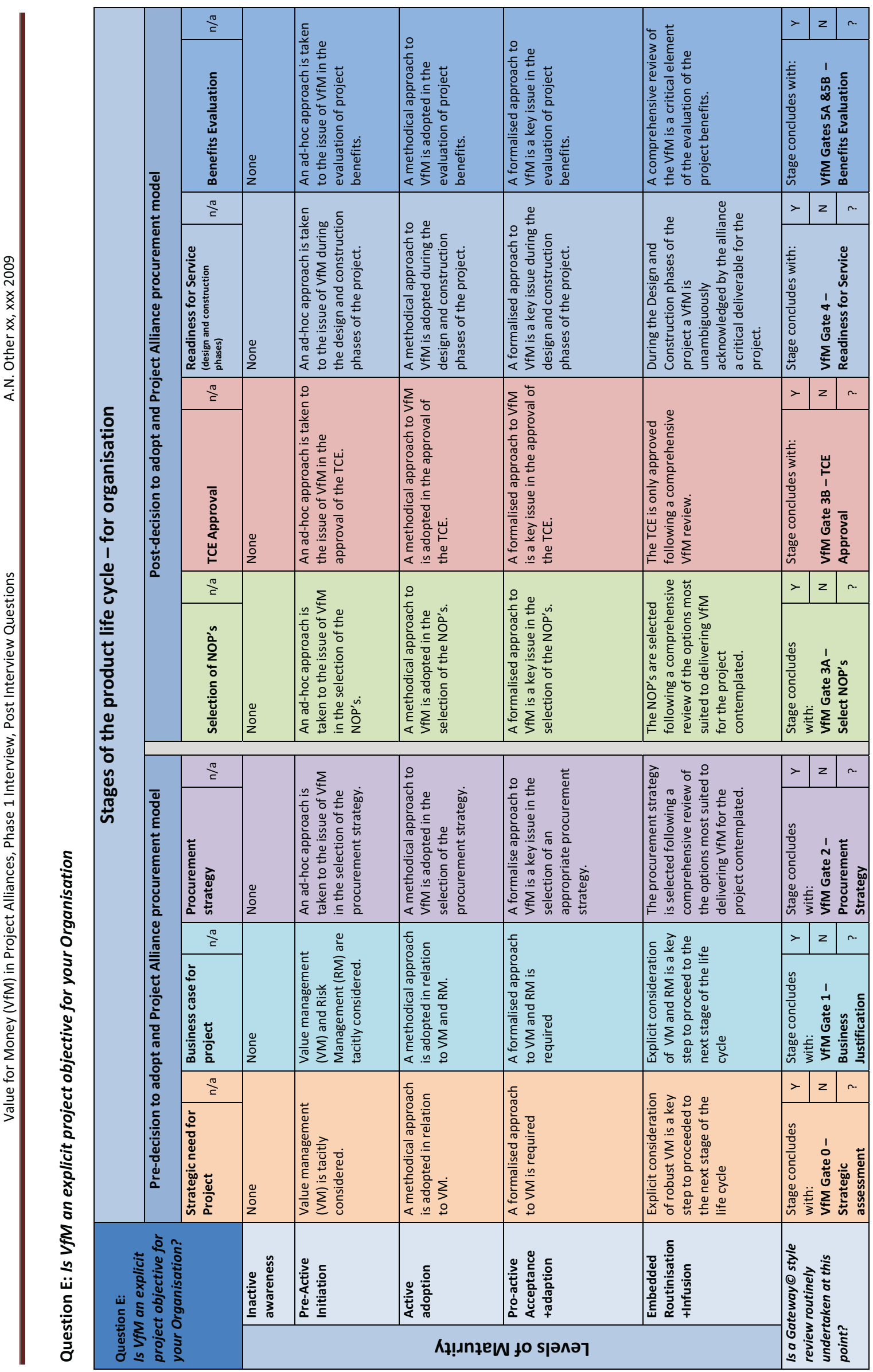

0
0
0
0
0
0 


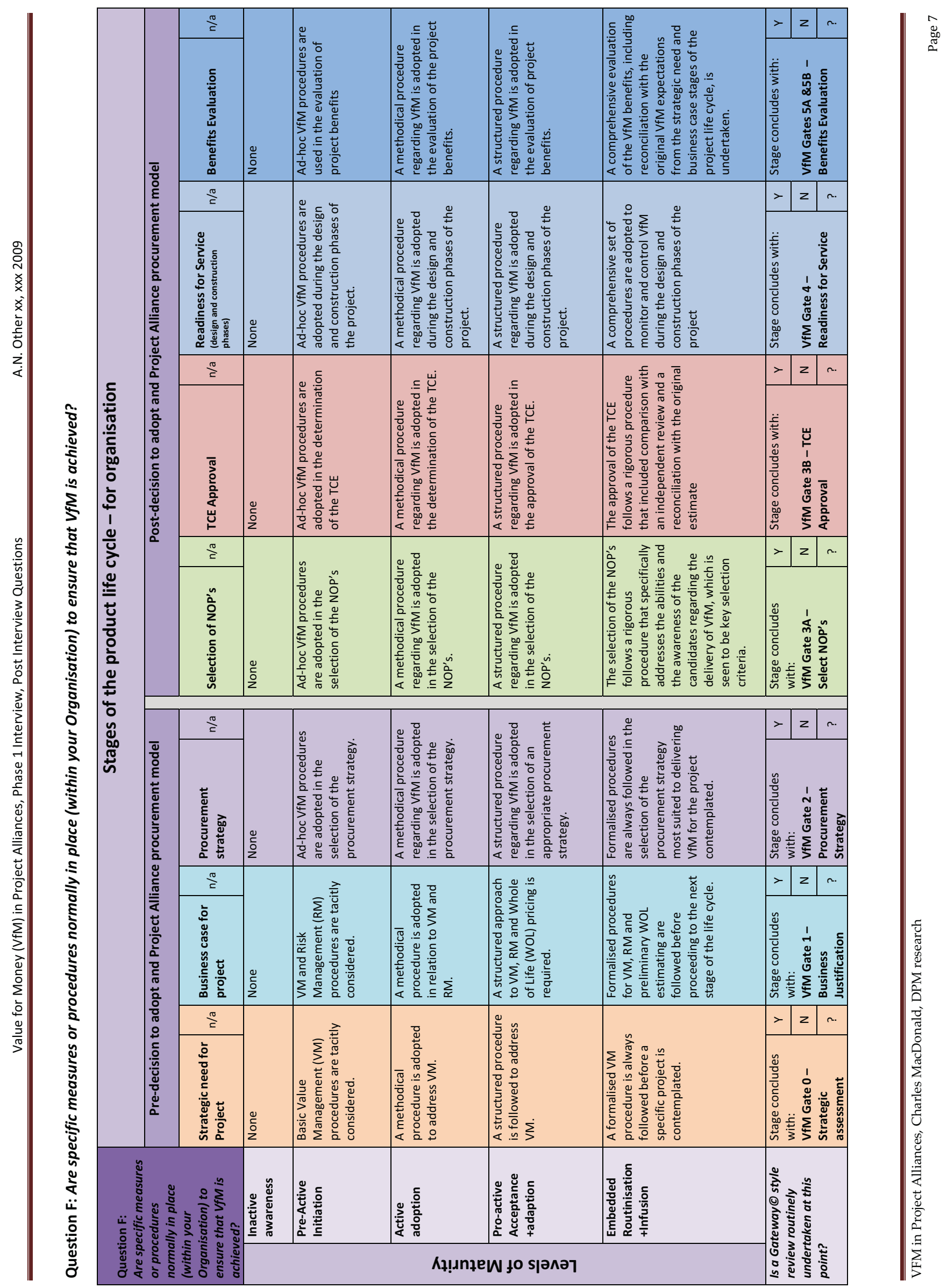




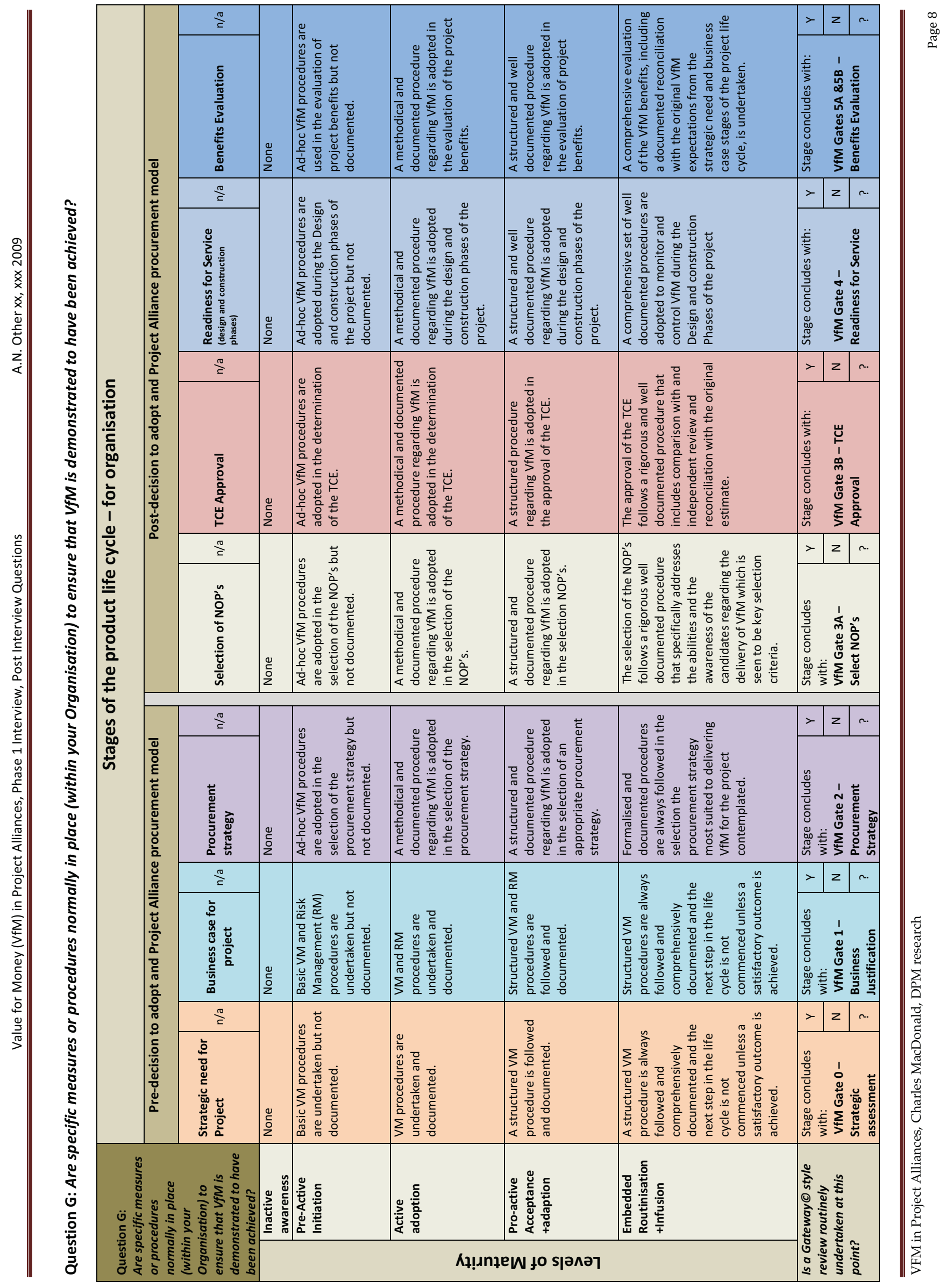




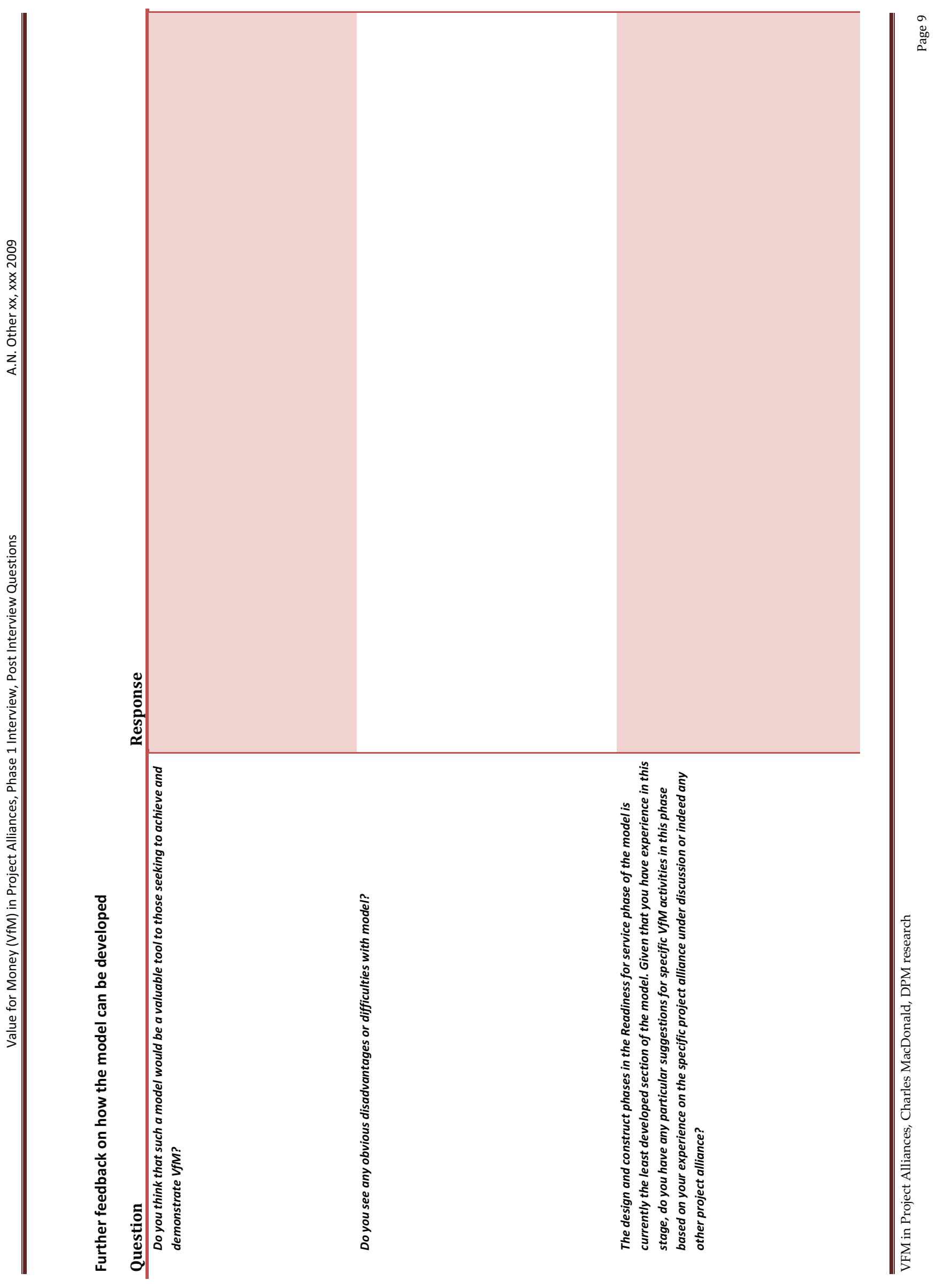




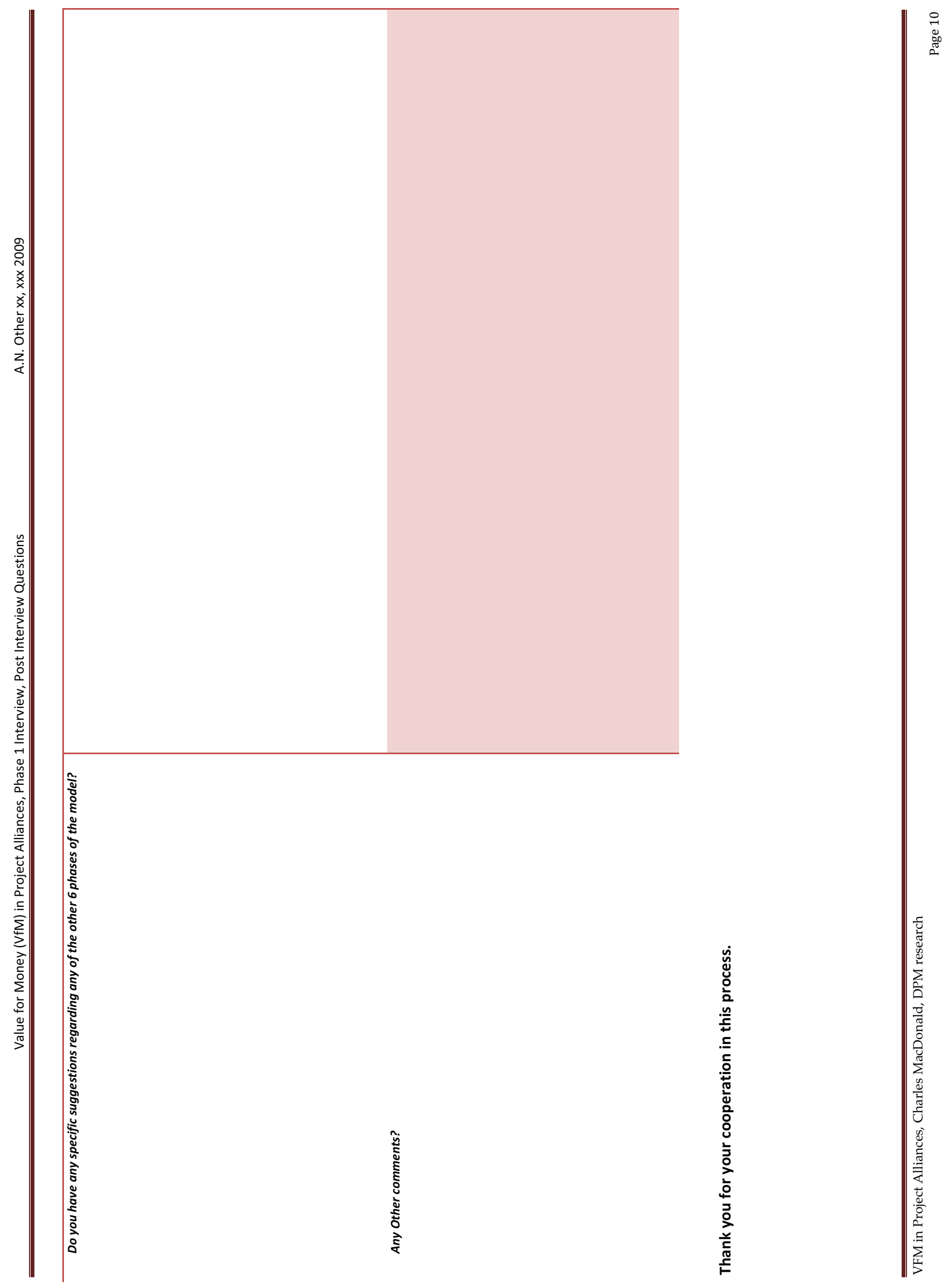




\section{Appendix C.1}

\section{List of Phase 2 Participants}




\section{Appendix C.1 List of Phase 2 Participants}

\begin{tabular}{|c|c|c|c|c|c|c|}
\hline \multirow[t]{2}{*}{ Expert } & \multicolumn{3}{|c|}{ Profile } & \multicolumn{3}{|c|}{ Participation } \\
\hline & International & National & State & $\begin{array}{l}\text { Round } 1 \\
(2-13 / 11 / 09)\end{array}$ & $\begin{array}{l}\text { Round } 2 \\
(17-28 / 11 / 09)\end{array}$ & $\begin{array}{l}\text { Round3 } \\
(4-13 / 12 / 09)\end{array}$ \\
\hline \multicolumn{7}{|l|}{ Consultants } \\
\hline 1 & $\checkmark$ & $\checkmark$ & $\checkmark$ & $\checkmark$ & $\checkmark$ & $\checkmark$ \\
\hline 2 & & $\checkmark$ & $\checkmark$ & $\checkmark$ & $\checkmark$ & $\checkmark$ \\
\hline 3 & $\checkmark$ & $\checkmark$ & $\checkmark$ & & & $\checkmark$ \\
\hline 4 & & $\checkmark$ & $\checkmark$ & $\checkmark$ & $\checkmark$ & $\checkmark$ \\
\hline 5 & & & $\checkmark$ & & & \\
\hline 6 & $\checkmark$ & $\checkmark$ & $\checkmark$ & & & \\
\hline $7^{1}$ & & $\checkmark$ & $\checkmark$ & & & \\
\hline & & & Total & 3 & 3 & 4 \\
\hline \multicolumn{7}{|l|}{ Lawyers } \\
\hline$\overline{1}$ & $\checkmark$ & $\checkmark$ & $\checkmark$ & $\checkmark$ & & \\
\hline $2^{2}$ & & $\checkmark$ & $\checkmark$ & & & \\
\hline 3 & & $\checkmark$ & $\checkmark$ & & & \\
\hline & & & Total & 1 & 0 & 0 \\
\hline \multicolumn{7}{|l|}{ Owners } \\
\hline $1^{3}$ & 3 & $\checkmark$ & $\checkmark$ & $\checkmark$ & $\checkmark$ & $\checkmark$ \\
\hline $2^{4}$ & 4 & & $\checkmark$ & $\checkmark$ & $\checkmark$ & $\checkmark$ \\
\hline $3^{5}$ & 5 & $\checkmark$ & $\checkmark$ & & & \\
\hline & & & Total & 2 & 2 & 2 \\
\hline \multicolumn{7}{|l|}{ Contractors } \\
\hline 1 & & & $\checkmark$ & $\checkmark$ & $\checkmark$ & $\checkmark$ \\
\hline 2 & & $\checkmark$ & $\checkmark$ & & $\checkmark$ & $\checkmark$ \\
\hline 3 & & $\checkmark$ & $\checkmark$ & $\checkmark$ & $\checkmark$ & $\checkmark$ \\
\hline 4 & & $\checkmark$ & $\checkmark$ & & & \\
\hline 5 & & $\checkmark$ & $\checkmark$ & & & \\
\hline 6 & & & $\checkmark$ & $\checkmark$ & $\checkmark$ & $\checkmark$ \\
\hline 7 & & & $\checkmark$ & & & \\
\hline 8 & & $\checkmark$ & $\checkmark$ & $\checkmark$ & $\checkmark$ & $\checkmark$ \\
\hline & & & Total & 4 & 5 & 5 \\
\hline \multicolumn{4}{|r|}{ Grand Total } & 10 & 10 & 11 \\
\hline Notes 1, 2 & \multicolumn{6}{|c|}{$\begin{array}{l}\text { Consultant } 7 \text { and Lawyer } 2 \text { were unavailable for the period of the Delphi Survey but agreed to } \\
\text { act as reviewers of the final findings. }\end{array}$} \\
\hline Notes 3, 4 & \multicolumn{6}{|c|}{$\begin{array}{l}\text { Owners } 1 \text { and } 2 \text { had recently untaken their own research in the area of } \mathrm{VfM} \text { and were } \\
\text { particularly motivated to participate in this research exercise. }\end{array}$} \\
\hline Note 5 & \multicolumn{6}{|c|}{$\begin{array}{l}\text { Owner } 3 \text { was unavailable to participate in the Delphi Survey but met with the researcher in } \\
\text { December } 2009 \text { to be briefed on the results available at that time and to explain their view on } \\
\text { the manner in which VfM can be captured in alliance contracts. }\end{array}$} \\
\hline
\end{tabular}


Appendix C.2

Letter of Invitation to Phase 2 Participants 


\section{DRITUniversity}

\section{INVITATION TO PARTICIPATE IN A RESEARCH PROJECT \\ PROJECT INFORMATION STATEMENT}

\section{Project Title: The development of a model to facilitate the achievement and demonstration of value for money in project alliances}

\section{Investigators:}

- Mr. Charles MacDonald (Project Management Doctoral degree student), macdonald@optusnet.com.au, Mob:0412 250638

- Professor Derek Walker (Project Supervisor: Professor of Project Management, RMIT University, derek.walker@rmit.edu.au (03) 99253908

\section{Potential Participant:}

A. N. Other, XYZ Corp.

Dear $x \boldsymbol{x x}$,
School of Property, Construction and Project Management

Building 8, Level 8 360 Swanston Street Melbourne VIC 3001 Australia

GPO Box 2476V

Melbourne VIC 3001

Australia

$\mathrm{Tel}+61399252230$

Fax +61399251939

www.rmit.edu

18 October 2009

Further to earlier informal contact, you are invited to participate in the second and final phase of a research project being conducted by RMIT University with the cooperation and assistance of (Company X). This information letter describes the project in straightforward language, or 'plain English'. Please read this letter carefully and be confident that you understand its contents before deciding whether to participate. If you have any questions about the project, please contact the Investigator, Charles MacDonald.

\section{Who is involved in this research project? Why is it being conducted?}

- The Investigator is Charles MacDonald (Text removed to preserve anonymity).

- The senior supervisor of the research project is Derek Walker, Professor of Project Management at RMIT.

- The research is being conducted as part of a Doctorate of Project Management Degree.

\section{Why have you been approached?}

- You have been approached because you are considered to be an expert in the development and execution of project alliances.

- Great value is placed on your comments and views on the manner in which VfM can be achieved and demonstrated in the performance of such project alliances.

\section{What is the research project about?}

- The research project is aimed at the development of a model/framework to facilitate the achievement and demonstration of VfM in project alliances for infrastructure works.

- In the first of two phases of the research, some 27 key parties from five project alliances were interviewed and completed a questionnaire to seek their comments on VfM in these alliances (case studies) and the applicability of a preliminary model that was developed by the researcher to address VfM through the full life cycle of a project. 
- In this second stage, a smaller group of approximately 16 people, all viewed as experts, are being asked to comment on the model following modifications and refinements that have result from comments received in the first stage. This second stage will be conducted using the 'Delphi Technique' which involves each participant commenting on material which will be forwarded to them by email. The collated views of all the participants will then be shared, albeit anonymously, with the rest of the group in the next round of the process. It is currently anticipated that there will be three rounds of the process.

- The Delphi process will be administered through a website service entitled 'Delphiforecastingprinciples.com'. The Delphi Round will commence following the distribution of the VfM Framework and a brief tutorial on the use of the website software.

\section{If I agree to participate, what will I be required to do?}

- If you agree to participate in this second stage of the research, you will be forwarded a document which will describe the model that has been developed during the first stage of the research and you will be asked to comment on the merits and possible failings of the proposed approach. The purpose of seeking comment individually and then sharing the collated feedback on an anonymous basis is to enable each participant to express their views freely and for their comments to be considered on their merits during later rounds of the process. It is expected that at the end of three rounds, a reasonable degree of convergence should occur in the position of the experts following the sharing of views as described above.

- Your input is expected to take no longer than 30 to 45 minutes to complete for each round of the process.

\section{What are the risks or disadvantages associated with participation?}

- Participation will require you to make some time available to respond. Whilst the research project has been designed to minimise this time it is appreciated that you are likely to be very busy and finding this time may be difficult.

- You may be concerned that you are being asked to reveal information or express views that you would not wish to be attributed directly to you. A number of safeguards will be implemented to ensure that your identity will remain anonymous.

\section{What are the benefits associated with participation?}

- The Investigator believes that VfM in project alliances is a matter that is not adequately addressed at present and that the construction industry as a whole (owners, constructors, designers etc.) would benefit greatly from a verified model/framework that ensures and demonstrates VfM. Your participation would be a major contribution to this goal.

\section{What will happen to the information I provide?}

- Your contribution to the proposed research will remain anonymous with even the researcher being unable to associate comments provided with the author of the comments.

- At the request of (Company $X$ ) the thesis produced as a consequence of this research will be embargoed for a period of 3 years. This means that the thesis will not be available through the RMIT Library during this period. It is intended, however, that the parties participating in this research will be privy to the findings and conclusions of the thesis once it is finalised. (requirement later withdrawn)

- Research data will be kept securely for a period of 5 years before being destroyed.

\section{What are my rights as a participant?}

Your participation in this research would be entirely voluntary and your rights would include:

- The right to withdraw your participation at any time, without prejudice.

- The right to have any unprocessed data withdrawn and destroyed, provided it can be reliably identified, and provided that so doing does not increase the risk to yourself. 
- The right to have any questions answered at any time.

\section{Whom should I contact if I have any questions?}

- Please contact Charles MacDonald on 0412250638 or by email, macdonald@optusnet.com.au.

\section{What other issues should I be aware of before deciding whether to participate?}

- The first phase interviews were held in June to August 2009.

- The second phase 'Delphi' rounds will occur in late October to early December 2009.

\section{How do I confirm that I am prepared to participate?}

It is understood that you are willing to participate in this research and you are not required to respond further if that remains the case. If, however, having read this letter, you wish to withdraw please forward a brief response to the email which accompanied this letter.

Thank you for taking the time to read this letter and I look forward to receiving your comments through the Delphi process.

Yours sincerely,

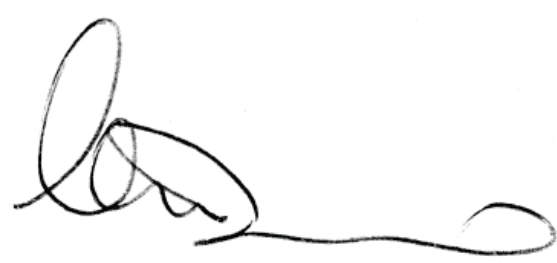

Charles MacDonald

BSc, MSc, MBA, CPEng, FIEAust, MICE, MIHT, MIAMA, RPEQ

Doctor of Project Management candidate

RMIT University

Mobile 0412250638

Any complaints about your participation in this project may be directed to the Secretary, Portfolio Human Research Ethics Sub Committee, Business Portfolio, RMIT, GPO Box 2476V, Melbourne, 3001. The telephone number is (03) 99255594 or email address rdu@rmit.edu.au. Details of the complaints procedure are available from http://www.rmit.edu.au/rd/hrec_complaints 


\section{Appendix C.3}

Sample pages from the Delphi Survey website 

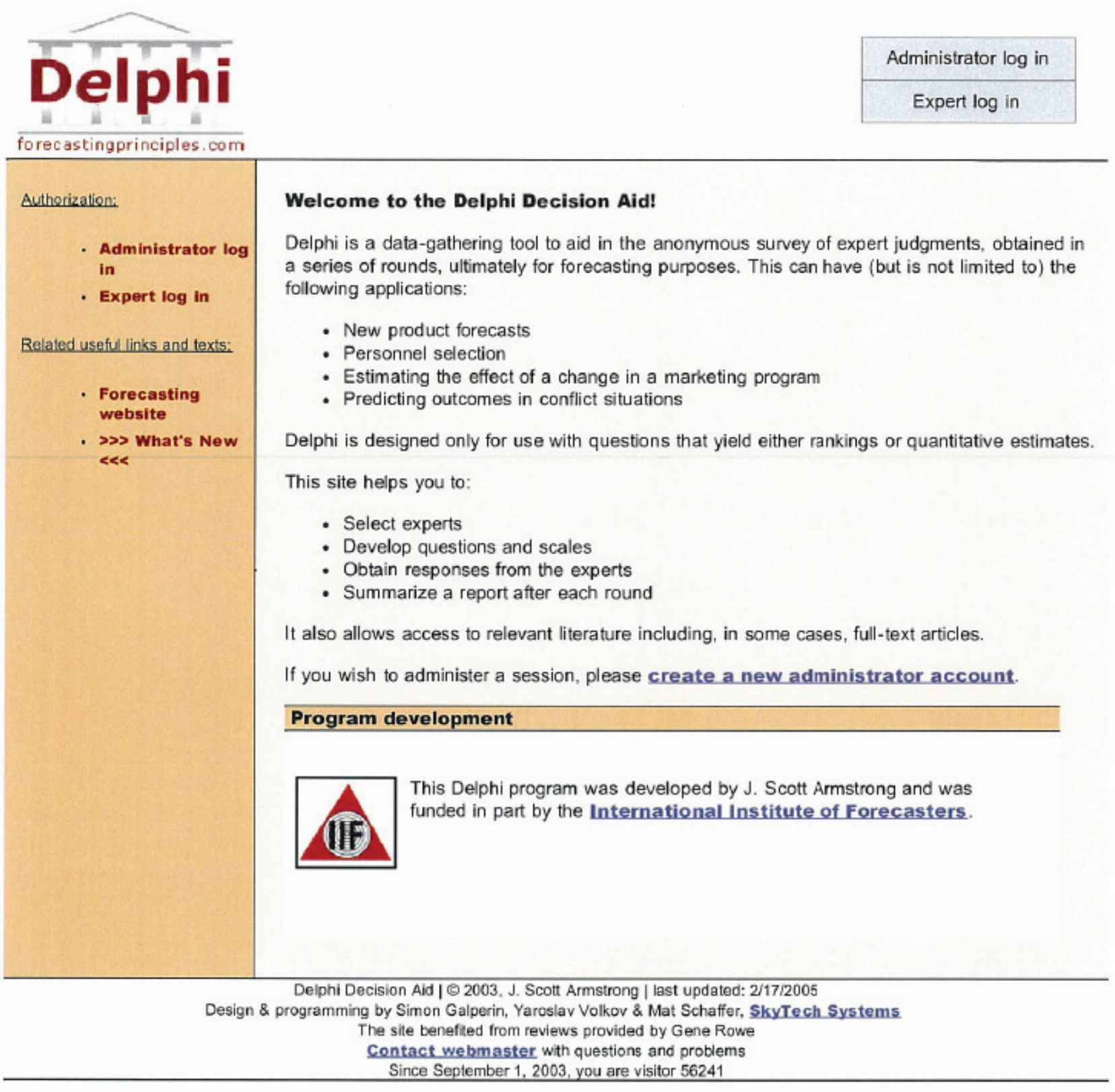


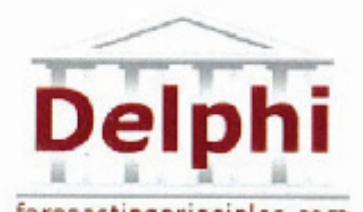

forecastingprinciples,com

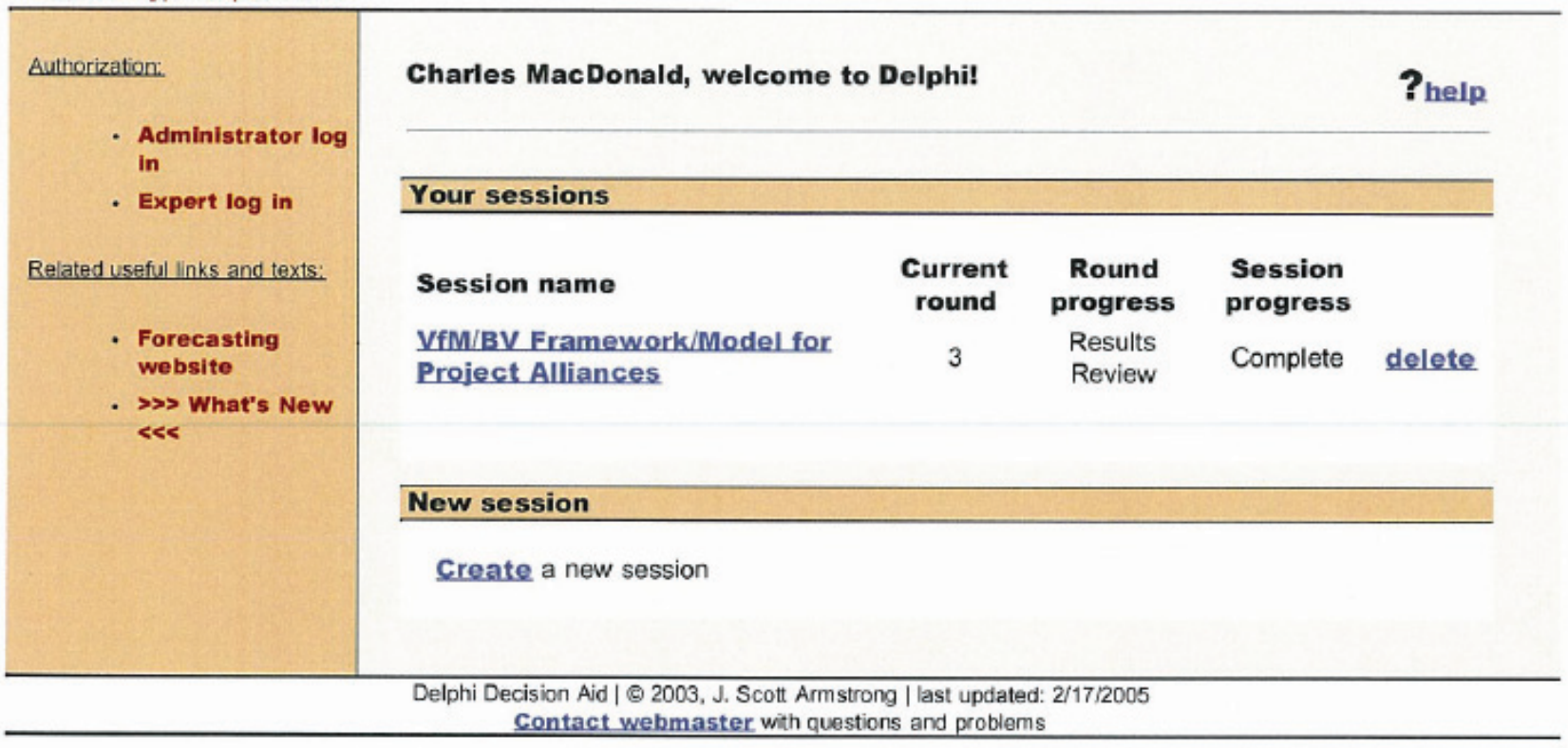




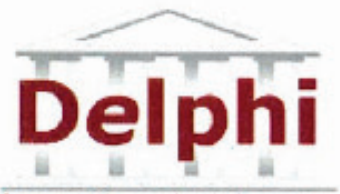

Authorization:

- Administrator log

- Expert log in

Related useful inks and texts:

Forecasting website

> W What's New «

\section{VfM/BV Framework/Model for Project Alliances: overall ?help}

\section{results}

Delphi research survey re proposed VfM/BV framework/model for project alliances.

View other rounds:

[Round 1] [Round 2] [Round 3]

Overall session results

This page represents summarized statistics for every question used in the session.

- If a question was used in several rounds throughout the session, you will see the summary that takes into account all of the answers received in different rounds.

- If a question was used in a single round, the statistics here will be identical to those for that round.

\section{Data results: Question \#4}

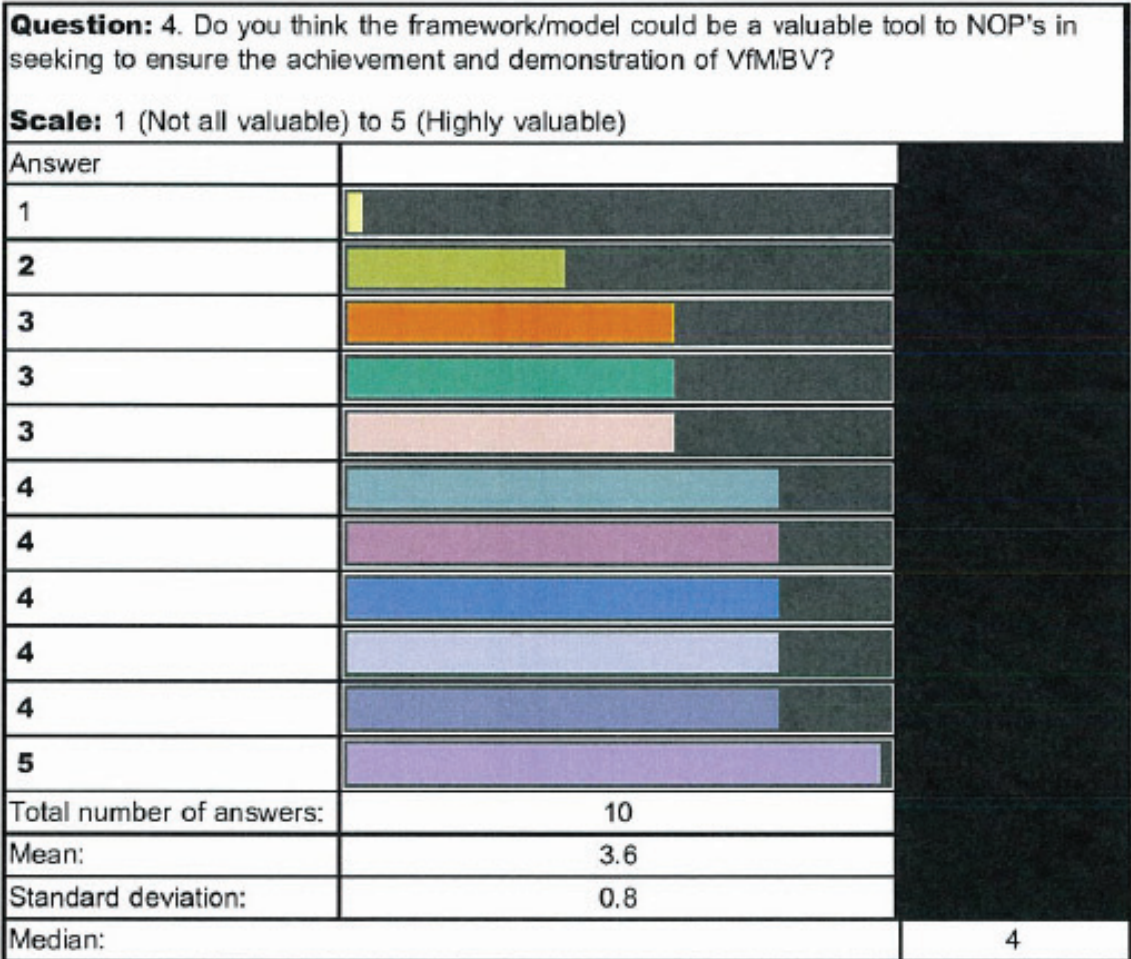

\section{Results display options}

You are currently viewing detailed results 


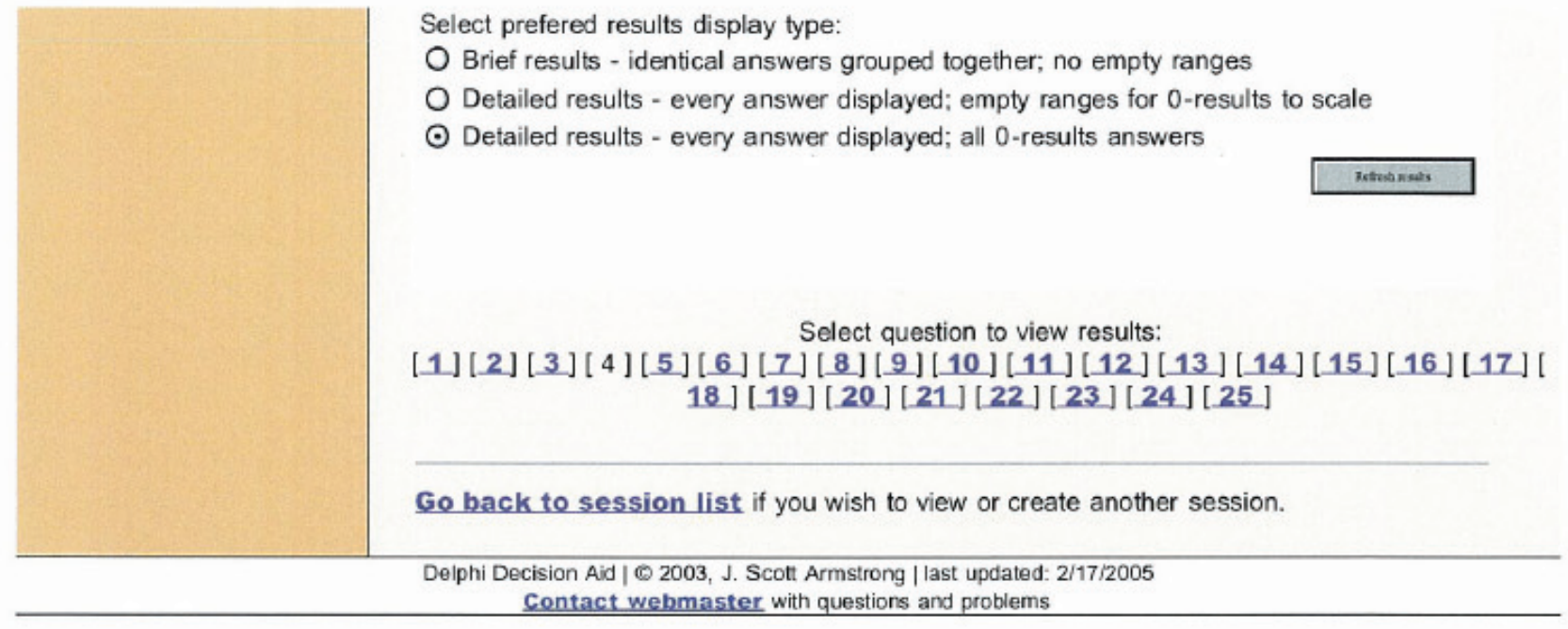


Appendix C.4

Documents forwarded to participants prior to the commencement of Round 1

- Briefing Paper for Phase 2, Round 1 participants

- VfM Model 


\section{Briefing Paper for Phase 2 participants}

\section{Dear xxx}

\section{Introduction}

Thank you once again for agreeing to participate in this Delphi research process which addresses the issue of value for money (VfM) or best value (BV) in project alliances. You are one of approximately 16 experts who have kindly agreed to participate in this exercise and I hope you will find involvement in the research a rewarding and even enlightening experience.

Both those who are generally supportive of alliancing, in the single TOC or 'pure' form, and those who are doubtful about the benefit of this procurement approach use VfM as the justification for their argument. Those critical of this form of alliancing argue that a lack of price competition in the selection process removes the only real opportunity to demonstrate, objectively, that $\mathrm{VfM}$ has been achieved. Those supportive of this form of alliancing claim that the results consistently achieved by alliances provide ample evidence that when parties work as a team in a non-adversarial, risk sharing environment, outstanding outcomes can and do occur and these are considered to clearly represent $\mathrm{VfM}$. This has been referred to as the 'VfM paradox'.

It is the view of the researcher that this a relatively narrow argument which somewhat misses the point as VfM is a much more fundamental issue that needs to be addressed throughout the whole lifecycle of a project and not simply or solely at the time the cost estimate is finalised.

During the course of this research, I have developed a preference for the use of the term best value (BV) rather than VFM as it immediately removes the whole focus of the discussion from purely financial issues and acknowledges a broader context of the term value. However, for the present I have adopted the expression VfM/BV to emphasise this broader context.

\section{Purpose of the research}

The main objective of this research is to try to develop a framework or model that will facilitate the achievement and demonstration of VfM/BV for project alliances. The driver for this objective is the desire to place the issue of VfM/BV in alliances in its true context. All procurement methodologies need to demonstrate their worth and alliancing is no different. However, alliances have been placed under a huge amount of scrutiny regarding their ability to deliver VfM/BV. I believe it is now time to firmly establish a systematic methodology which will allow all participants in a particular procurement process to readily identify whether alliancing represents the best option and then adequately demonstrates VfM/BV to a no lesser standard that applies to other procurement options. Once this has been achieved the industry might then be able to 'move on' in the knowledge that this important issue is satisfactorily addressed and the collective energies of the industry can then be re-focussed on other, perhaps more challenging issues that continue to exist in the delivery of successful projects.

\section{The broader context of value}

VfM/BV in projects is a multi-dimensional concept. Not only are project values divided between financial and non-financial utilities, they also have temporal context i.e. as a project progresses through its lifecycle the values that are critical at that time will change as new participants influence the collective judgement of the project team. The sequence of changing values transitions from corporate to business, feasibility, design, construction, commissioning to operational values and is sometimes referred to as the 'project value chain'. Each value transition should be adding value for the Owner until the complete project forms an asset for the Owner's organisation that meets a corporate need. 
The choice of procurement route is a strategic decision made by the owner and/or advisors that has a fundamental impact on delivering best value and has the capacity to either hinder or enhance the transfer of value through the procurement process. Procurement approaches which involve the project participants at the earliest possible stage and establish a fully integrated team, such as a project alliance, are arguably best able to ensure that a 'value thread' is preserved through the procurement lifecycle to deliver the best value outcome.

\section{Overview of the VfM/BV framework/model as developed to date}

As I described in the formal invitation letter sent earlier, this exercise is the second of two stages of my research. During the first phase I interviewed some 27 parties involved in alliance projects to seek their comments on a preliminary framework/model that I had developed to address VFM/BV in project alliances.

This framework/model, as developed to this point, does not necessarily represent a 'breakthrough' document which provides some form of 'silver bullet' that addresses the VfM/BV question in a totally new light - sorry to dash your hopes there! On the contrary, the framework seeks to gather together a whole series of different initiatives that have taken place in recent years in the procurement field, both traditional and relationship based, and integrates them into a 'timeline' or 'roadmap' which traces the development of a project through the chronology or life-cycle that all projects experience. The framework, which beyond the procurement strategy phase is specific to project alliances, recommends a series of actions that should be followed to best ensure:

- That the need for a given project is clearly and firmly established

- The values that are important for the project are identified at an early stage of the project lifecycle

- That the best procurement method is chosen for a given project

- That reviews are taken at the end of each stage of the lifecycle (VfM Gates) to critically examine whether $\mathrm{VFM} / \mathrm{BV}$ is being truly considered/addressed as the project proceeds.

The VfM/BV framework/model, which is attached as a separate file entitled 'Flowchart for Procurement Model Phase 2 RevC.PDF', presents the project lifecycle in a flowchart format. The lifecycle is divided into seven stages which run from the 'Strategic Need for Project' through to 'Benefits Evaluation'. For the first three stages of the lifecycle the flowchart attempts to document the various processes which apply to any project. The subsequent four stages have been customised to specifically address the characteristics of a project alliance.

As described earlier, recent initiatives in the project procurement literature have been incorporated in the framework/model including:

- The UK Treasury, Office of Government Commerce (OGC), Procurement Guide - Project Procurement Lifecycle.

- The Gateway ${ }^{\odot}$ Review process approach originally developed by the UK Treasury (OGC) and subsequently adopted by the Commonwealth and most State Governments in Australia.

- The VfM initiatives described in the Victorian Department of Treasury and Finance, Project Alliancing Practitioners' Guide.

The flowchart identifies a number of measures (coloured red) which are considered to be critical to delivering and demonstrating VfM/BV and also describes a series of VfM Gates which correspond to the Gates mandated in the Gateway ${ }^{\odot}$ Review process. A further document being a table, also attached as a separate file entitled 'VfM/BV Gate Review Matrix Rev C.PDF', describes the VfM Gates in more detail and identifies the specific VfM/BV issues that should be addressed in a formal review at the end of each stage of the project lifecycle. 
These attachments are both single page documents that contain a lot of detail and need to be printed out on A3 size paper in colour in order to be legible. Please note that the stages of the project lifecycle follow the same colour coding in both documents.

\section{The Delphi Process - What will happen, timeframes and what you need to do}

In this second stage of this research program, as one of a group of experts you are being asked to comment on the model following modifications and refinements that have result from comments received in the first stage. This second stage will be conducted using the 'Delphi Technique' which involves each participant responding to questions which are being posed based on the framework/model which is attached to this briefing paper. These comments will be sought and received through the web-based service 'Delphi-forecastingprinciples.com' which will communicate with you to forward the questions, inform you of the times for responses and other administrative details. This will also be the medium through which responses are submitted. Once each of the three rounds of the research is completed the collated views of all the participants will then be shared, albeit anonymously, with the rest of the group in the next round of the process.

The program for the three rounds of the process is shown in the table below:

\begin{tabular}{|l|l|l|l|}
\cline { 2 - 4 } \multicolumn{1}{c|}{} & Round 1 & Round 2 & Round 3 \\
\hline Start date & Monday 2 & Monday 16 & Monday 30 \\
& November 2009 & November 2009 & November 2009 \\
\hline End Date & Friday 13 & Friday 27 & Friday 11 \\
& November 2009 & November 2009 & December 2009 \\
\hline
\end{tabular}

This represents a relatively 'fast track' timetable for a Delphi Process which would typically be undertaken over a number of months. However, I am conscious that you are very busy and that there is a limited 'window of time' available to obtain your active participation.

It is important that your responses are received by the end date of each round so that they can be included in the collated response document which will inform the next round of questions.

The first round will be used to ensure that the framework/model is clear to you, as a means of seeking initial comment and testing the web-based communication process. The subsequent rounds will pose more detailed questions which will be informed by the feedback/responses received during Round 1.

\section{Victorian Department of Treasury and Finance research}

As you will be aware, the VFM debate regarding alliances has been running for some years and has become particularly topical since the Victorian Department of Treasury and Finance (VDTF) recently commissioned a detailed benchmarking study into project alliances with a particular focus on the delivery of VfM. The final report of this study has coincidentally been released today. Given that the report's findings are expected to be highly relevant to this research, I will prepare a brief summary of these findings and will forward this to further inform your comments during this Delphi process. The full version of the VDTF Report can be accessed via the following link: 


\title{
Conclusion
}

Your commitment to participate in this process is greatly appreciated and I look forward to receiving your responses through the web-based communication process. However, if you would like to clarify the content of this briefing paper or the attached documents I would be happy to respond either by email or phone.

A tutorial (Delphi software user guide) regarding the use of the Delphi website is available by following the following URL;

http://www.forecastingprinciples.com/index.php?option=com content\&task=view\&id=9\&ltemid=9

This tutorial, which is a series of PowerPoint slides, relates to a sample survey concerning the Amtrack rail system and the questions discussed are primarily quantitative. The questions that I wish to pose will be text based and largely qualitative in nature.

You will receive an email from the Delphi website shortly indicating that Round 1 has commenced. Please note the Round 1 will commence on Monday 2 November and close on Friday 13 November 2009.

Attachments (Print A3 size, colour)

\section{- 'Flowchart for Procurement Model Phase 2 RevC.PDF' \\ - 'VfM/BV Gate Review Matrix Rev C.PDF'}

Thank you once again for your valuable input to this research

\author{
Charles MacDonald \\ General Manager Construction \\ BrisConnections Pty Ltd \\ RMIT Student No. 3037138 \\ macdonald@optusnet.com.au \\ 0412250638
}

2 November 2009

Tip: The Delphi website has little or no text editing functionality. You may wish to prepare your responses to questions in Word and then post them into the website form. This is the way the questions were created. 


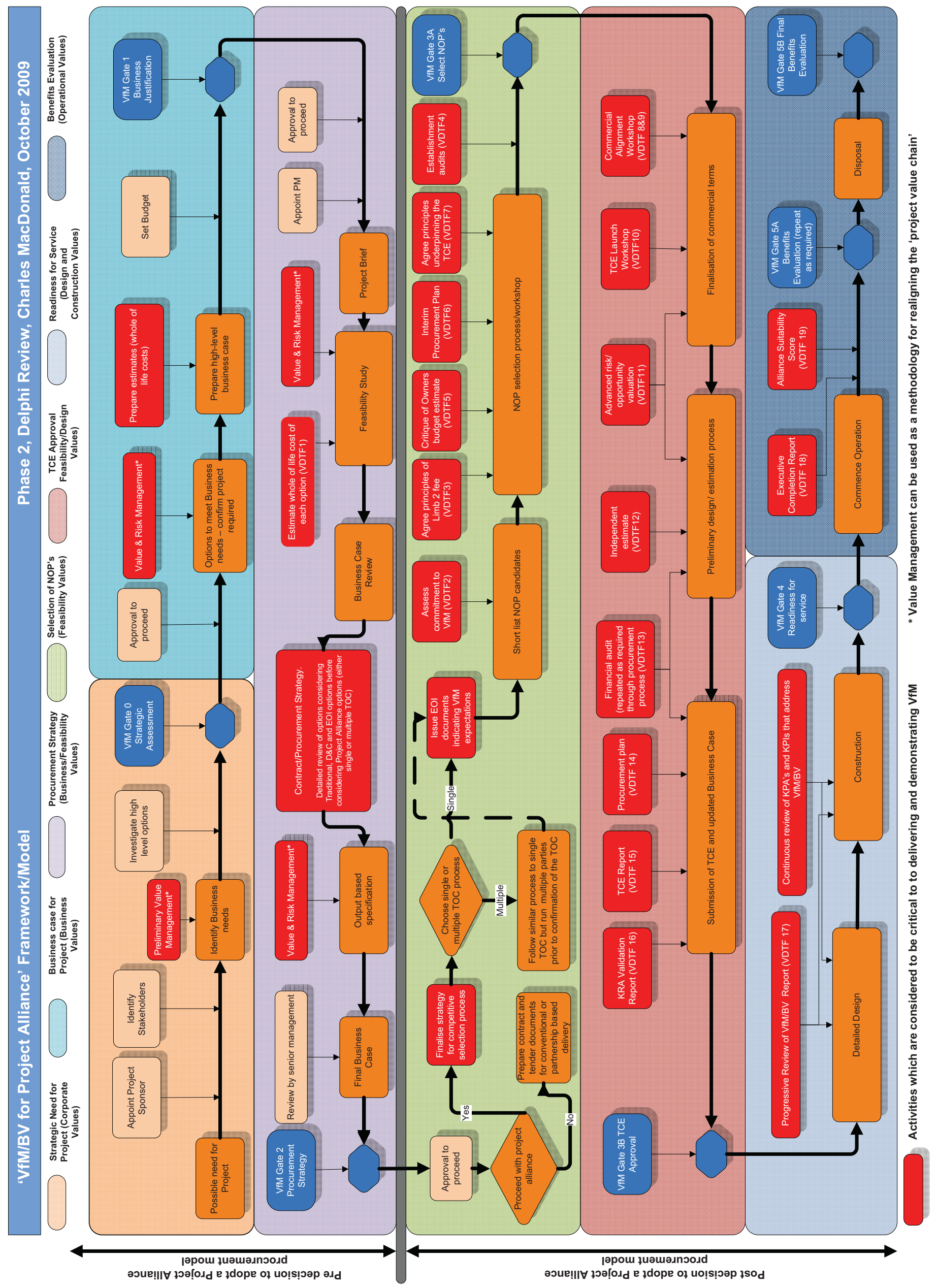




\section{Appendix C.5}

Round 1 Questions as posted on the Delphi website to be addressed by the participants 


\section{VfM Delphi Survey, Phase 2, Round 1 Questions}

1. You should have received an email from the researcher (Charles MacDonald) with the following attachments:

- a briefing paper which describes the research and the details of your participation,

- the VfM/BV framework/model in the form of a flowchart and

- a table associated with the framework/model which describes the issues to be addressed at each VfM/BV Gate.

If you have not received this email, or if you have any queries following receipt of this material please contact Charles MacDonald by email or phone

(macdonald@optusnet.com.au or 0412250 638) - Text only

2. The objective of developing the framework/model is to ensure the achievement and demonstration of VfM/BV. Do you think the framework/model achieves this objective? Scaled question plus room for comment

3. Do you think the framework/model could be a valuable tool to Owners in seeking to ensure the achievement and demonstration of VfM/BV? - Scaled question plus room for comment

4. Do you think the framework/model could be a valuable tool to NOP's in seeking to ensure the achievement and demonstration of VfM/BV? - Scaled question plus room for comment

5. Do you see any particular disadvantages or difficulties with the framework/model?

6. The table identifies specific VfM/BV issues that should be addressed the end of each stage of the project lifecycle. Do you have any comments regarding the issues listed e.g. are any inappropriate or have any important issues been overlooked?

7. In the Procurement Strategy Phase of the model it is proposed that a detailed review of procurement options is undertaken progressively considering Traditional, D\&C and EOI options before considering Project Alliance options, either single or multiple TOC. The purpose of this particular activity is to clearly establish that a project alliance is the best procurement option to deliver VfM/BV for a particular project. Do you agree that this process of elimination would assist in arriving at the most appropriate procurement strategy? Scale

8. The Readiness for Service (Design and Construct) Phase of the project lifecycle currently contains two activities: 1 ) the progressive preparation of a VfM/BV Report and 2) the continuous review of KPA's/KPI's. What specific comments do you have on the contents of these activities and are there other activities that should be adopted in this phase of the project lifecycle? 
9. What comments do you have regarding the measures identified in the other 5 stages of the Project Lifecycle (Strategic Need for the Project, Business Case, Selection of NOP's, TCE Approval and Benefits Evaluation)? 
Appendix C.6

Documents forwarded to participants prior to the commencement of Round 2

- Briefing Paper for Phase 2, Round 2 participants

- VfM Model 


\section{Briefing Paper for Delphi Survey participants}

Dear Colleague,

\section{Introduction}

Firstly, thank you to all those who responded to Round 1. I appreciate that others may not have been able to find the time to respond but hope you will be able to participate in the subsequent rounds.

The times available for each round are relatively short, at less than two weeks, but I am reluctant to extend the periods as I am conscious that participants only have a limited amount of time available for the whole process which I expect to run over three rounds and last six weeks from start to finish.

By now the results of Round 1 can be viewed on the website with responses aggregated for each question. The round closed off at $6.00 \mathrm{pm}$ (Brisbane time) on Sunday 15 November 2009. This was earlier than I planned, even though the deadline was extended, as I accidentally terminated the round on the website at that time. Consequently, it is possible that some people may have been unable to submit their response on Sunday evening. If that is the case, I apologise and confirm that I would be happy to receive any Round 1 comments by email (macdonald@optusnet.com.au).

The full details of the responses received in Round 1 can be viewed on the website. However, I have listed below some of the key points that were made.

\section{Results of Round 1}

The comments received during Round 1 contain some very detailed feedback which will be carefully considered in attempting to further develop the VfM/BV Model/framework. However, the main thrust of these comments is summarised as follows:

Quantitative results:

Table 1 below presents the results that were obtained to the questions that sought a quantitative (scaled) response.

Qualitative comments:

- A number of people made that point that the model largely summarised information from existing sources but did not necessarily provide a new approach to the assessment of VfM/BV. This was acknowledged in the original briefing paper. However, it is hoped that as a consequence of this current process additional insights will be gained which will promote 'new thinking'.

- It was acknowledged that the model did aggregate a number of approaches in a systematic way that had not been done before and that this was seen as a useful step.

- There was a view that the model was rather complex and included too many measures, although others felt that that a number of elements were missing and/or needed to be expanded. 
Value for Money/Best Value in Project Alliances, Phase 2, Round 2

Delphi Review - 16 November 2009

\begin{tabular}{|c|c|c|c|c|}
\hline No. & Question & mean & $\sigma$ & Researchers Comments \\
\hline 2 & $\begin{array}{l}\text { The objective of developing the } \\
\text { framework/model is to ensure the } \\
\text { achievement and demonstration of } \\
\text { VfM/BV. Do you think the } \\
\text { framework/model achieves this objective? }\end{array}$ & 3.22 & 0.92 & $\begin{array}{l}\text { A result which suggest that the model, } \\
\text { at this stage, is not seen to be strongly } \\
\text { addressing the objective although it did } \\
\text { provide a useful checklist of matters } \\
\text { that need to be reviewed. }\end{array}$ \\
\hline 3 & $\begin{array}{l}\text { Do you think the framework/model could } \\
\text { be a valuable tool to Owners in seeking to } \\
\text { ensure the achievement and demonstration } \\
\text { of } V f M / B V ?\end{array}$ & 3.78 & 0.63 & \multirow{2}{*}{$\begin{array}{l}\text { The model was seen as being of use to } \\
\text { both Owners and NOP's. The } \\
\text { comments suggested that the model } \\
\text { was of more use to Owners than NOP's } \\
\text { but the statistics, based on a small } \\
\text { sample, suggest there is little real } \\
\text { difference. }\end{array}$} \\
\hline 4 & $\begin{array}{l}\text { Do you think the framework/model could } \\
\text { be a valuable tool to NOP's in seeking to } \\
\text { ensure the achievement and demonstration } \\
\text { of } V f M / B V \text { ? }\end{array}$ & 3.56 & 0.83 & \\
\hline 7 & $\begin{array}{l}\text { In the Procurement Strategy Phase of the } \\
\text { model it is proposed that a detailed review } \\
\text { of procurement options is undertaken } \\
\text { progressively considering Traditional, D\&C } \\
\text { and EOI options before considering Project } \\
\text { Alliance options, either single or multiple } \\
\text { TOC. The purpose of this particular activity } \\
\text { is to clearly establish that a project alliance } \\
\text { is the best procurement option to deliver } \\
\text { VfM/BV for a particular project. Do you } \\
\text { agree that this process of elimination would } \\
\text { assist in arriving at the most appropriate } \\
\text { procurement strategy? }\end{array}$ & 4.11 & 0.74 & $\begin{array}{l}\text { A strong response that indicates that } \\
\text { the respondents considered that such } \\
\text { a process of elimination has merit. }\end{array}$ \\
\hline
\end{tabular}

Table 1. Quantitative results from Round 1

- The suggestion was made that there was rather too much information on a single flowchart and accompanying table and that a simpler framework/model with back-up pages conveying the detail for each of the seven stages of the project lifecycle, would be easier to digest.

- It was suggested that the framework/model did not really address the multiple TOC process and that it should be amended to do so.

- It was also suggested that the framework/model was 'loaded' towards the early stages of the project lifecycle and as a consequence might be of more value e to Owners rather than NOP's (a statement not necessarily supported by the statistics shown in Table 1 above.)

- There was a very clear view, as confirmed in the answer to Question 7 (see Table 1 above), that the adoption of a process for the progressive elimination of procurement approaches in the Procurement Strategy phase of the project lifecycle would be of assistance in demonstrating that other procurement approaches had been adequately considered before an alliance was contemplated. If the alliance is not consciously selected as the best approach to address the values required from the project at this early stage, it will be very difficult to demonstrate that the alliance is subsequently delivering VfM/BV. 
- A number of respondents felt that the Design and Construction phase of the framework/model needed further development and that documentation of VfM/BV at this stage remained a key issue.

\section{Changes made to the framework/ model}

Further to these comments the following changes have been made to the framework/model:

- Rather than presenting the full detail of the framework/model on one flowchart, I have now removed all the VfM/BV measures from the main for 'head' flowchart and transferred these details to separate flowchart/tables that relate to each of the seven stages of the lifecycle. This will hopefully make it easier to follow the logic of the model and minimise any confusion that may be resulting from the apparent complexity of the framework/model. Later I hope to add an automatic link that will provide direct access to the flowchart/tables associated with each lifecycle stage. However, this is just a convenience and it is more important that the respective content of the flowchart/tables is appropriate and achieves the original objective of ensuring and demonstrating VfM//BV.

- The lifecycle flowchart/tables will also include the VfM/BV Gate issues that were previously detailed in the 'VfM/BV Reviews Table' that was attached to the original framework/model in Round 1. These lifecycle flowcharts will take a little time to develop. However, a flowchart for the 'Procurement Strategy' stage of the lifecycle has been developed as a prototype and is attached to this paper.

- The 'head' framework/model has been amended to provide a clear distinction between the single and multiple TOC processes.

- The lifecycle flowchart/tables are intended to provide more useful benchmarks which will assist in demonstrating that VfM has been achieved at each stage of the project lifecycle.

As in Round 1, the attachments contain a good deal of detail and need to be printed out on A3 size paper, in colour, in order to be legible.

\section{The Delphi Process - What happens now and what you need to do}

As advised in the briefing paper circulated prior to the commencement of Round 1, the 'Delphi Process' involves each participant responding to questions which, for Round 2, will be based on the revised framework/model which is attached to this briefing paper. These responses will be sought and received through the web-based service 'Delphi-forecastingprinciples.com' which will communicate with you to forward the questions, inform you of the times for responses and other administrative details. This will also be the medium through which responses are submitted. The collated views of all the participants for Round 1 are now shared, albeit anonymously, with the rest of the group and the results of the subsequent rounds will be added as the survey proceeds.

The program for the three rounds of the process is shown in the table below:

\begin{tabular}{|l|l|l|l|}
\cline { 2 - 4 } \multicolumn{1}{c|}{} & Round 1 & Round 2 & Round 3 \\
\hline Start date & Monday 2 November & Tuesday 17 & Monday 30 \\
& 2009 & November 2009 & November 2009 \\
\hline & $\begin{array}{l}\text { Friday 13 (later } \\
\text { amended to 15 }\end{array}$ & $\begin{array}{l}\text { Saturday 28 } \\
\text { November 2009 } \\
\text { Novem }\end{array}$ & $\begin{array}{l}\text { Saturday 12 } \\
\text { December 2009 } \\
\text { (noon) }\end{array}$ \\
\hline & Now complete & & \\
\hline
\end{tabular}


It is important that your responses are received by the end date of each round so that they can be included in the collated response document which will inform the next round of questions.

\section{Victorian Department of Treasury and Finance research}

As described previously, a brief paper summarising the key conclusions of the research into delivery of VfM as recently completed by the Victorian Department of Treasury and Finance (VDTF) recently commissioned, will be forwarded shortly. The full version of the VDTF Report can be accessed via the following link:

\section{www.dtf.vic.gov.au/project-alliancing}

\section{Conclusion}

Your commitment to participate in this process is greatly appreciated and I look forward to receiving your responses through the web-based communication process. However, if you would like to clarify the content of this second briefing paper or the attached documents I would be happy to respond either by email or phone.

You will receive an email from the Delphi website shortly indicating that Round 2 has commenced. Please note the Round 2 will commence on Tuesday 17 November and close on Saturday 28 November 2009 (noon).

Attachments (Print A3 size, colour)

- 'Procurement Framework Model_Delphi, Round 2.pdf'

- 'Round 2 Flowchart Table_Procurement Strategy.pdf'

Thank you once again for your valuable input to this research

\section{Charles MacDonald}

General Manager Construction

BrisConnections Pty Ltd

RMIT Student No. 3037138

macdonald@optusnet.com.au

0412250638

16 November 2009

Tip: The Delphi website has little or no text editing functionality. You may wish to prepare your responses to questions in Word and then post them into the website form. This is the way the questions were created. 


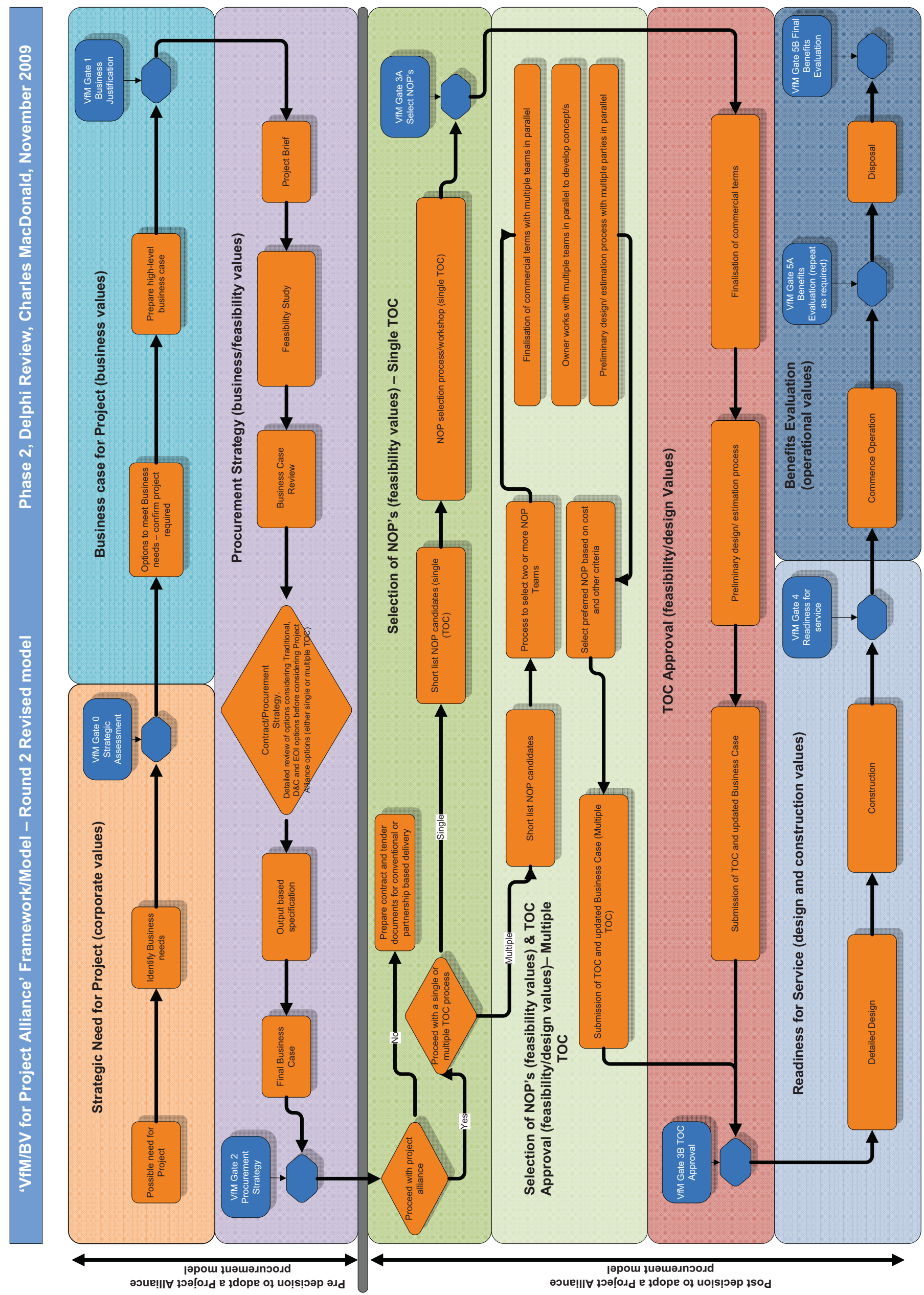




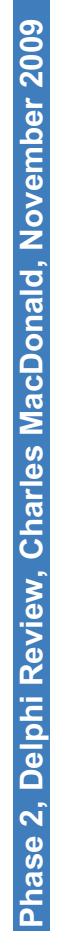

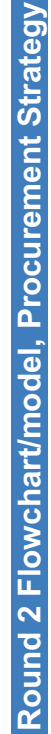

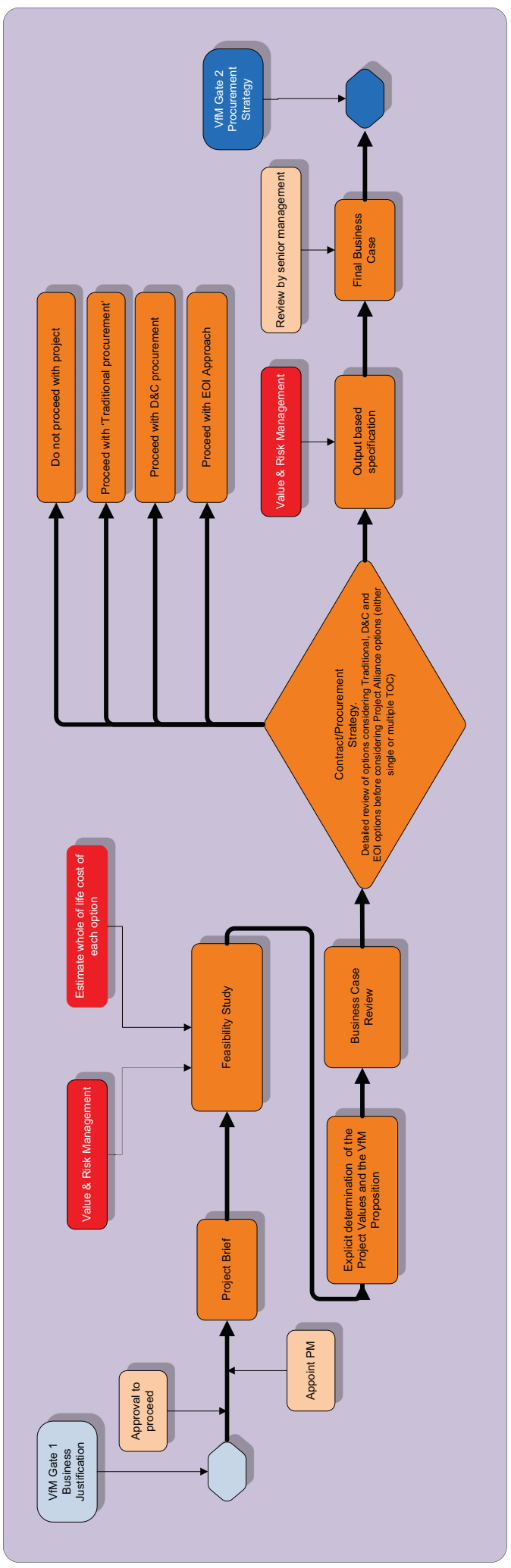

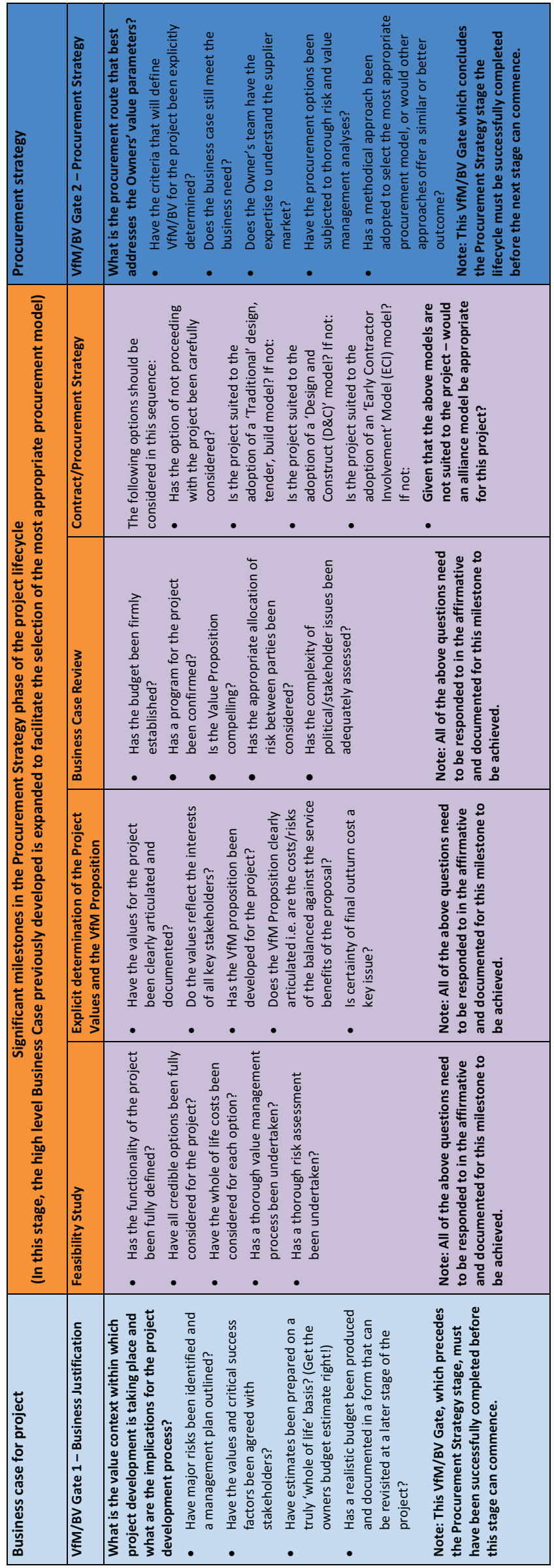




\section{Appendix C.7}

Round 2 Questions as posted on the Delphi website to be addressed by the participants 


\section{VfM Delphi Survey, Phase 2, Round 2 Questions}

1. You should have received an email from the researcher (Charles MacDonald) with the following attachments:

- a new briefing paper (dated 16 November 2009) which describes the results of Round 1 and the changes that have been made to the VFM/BV framework/model to address a number of the comments that were made

- Revised Round 2 framework/model - this is described in the briefing paper as the 'head' flowchart. This is now a much simplified flowchart which outlines the structure of framework/model and removes the detail of VfM/BV measures to supplementary flowchart/tables for each stage of the lifecycle.

- Round 2 flowchart/table - this describes VfM/BV considerations for the Procurement Strategy stage of the project lifecycle. Similar flowchart/tables will later be produced for each stage of the project lifecycle

Questions 2, 3, 4 and 5 are a repeat of the questions posed in Round 1. They are being asked again to measure the extent to which the revised model ensures the achievement and demonstration of VfM/BV.

If you have not received this email, or if you have any queries following receipt of this material please contact Charles MacDonald by email or phone

(macdonald@optusnet.com.au or 0412250 638)

This 'Question 1'is not a real question and no response is required-Text only

2. The objective of developing the framework/model is to ensure the achievement and demonstration of VfM/BV. Do you think the Revised Round 2 framework/model achieves this objective? - Scaled question plus room for comment

3. Do you think the Revised Round 2 framework/model could be a valuable tool to Owners in seeking to ensure the achievement and demonstration of VfM/BV? - Scaled question plus room for comment

4. Do you think the Revised Round 2 framework/model could be a valuable tool to NOP's in seeking to ensure the achievement and demonstration of VfM/BV? - Scaled question plus room for comment

5. Do you see any particular disadvantages or difficulties with the Revised Round 2 framework/model?

6. Does the Round 2 flowchart/table for the specific stage of the project lifecycle (Procurement Strategy) adequately address the VfM/BV issues that need to be addressed at this stage? Scaled question plus room for comment 
7. In the responses to Round 1, there was strong agreement that there should be a process for progressively considering Traditional, D\&C and EOI options before considering Project Alliance options (either single or multiple TOC) in the Procurement Strategy stage. Do you think that the Round 2 flowchart/table achieves the objective of arriving at the most appropriate procurement strategy? Scale

8. The 'head' flowchart (Revised Round 2 framework/model) now separately addresses a multiple TOC approach as well as the single TOC approach. Do you think this section of the flowchart adequately addresses the distinction between these options? Scaled question plus room for comment

9. In the responses to Round 1 (Question 8), a number of comments were received regarding the lack of detail provided for the Readiness for Service (Design and Construct) Phase of the project lifecycle. Do you have any comments additional to those provided in Round 1 (view on website) regarding activities that should be adopted in this phase of the project lifecycle?

10. What other comments or suggestions do you have for improving either the Round 2 Revised Framework/Model or the Round 2 flowchart/table? 
Appendix C.8

Documents forwarded to participants prior to the commencement of Round 3

- Briefing Paper for Phase 2, Round 3 participants 


\section{Briefing Paper for Delphi Survey participants}

Dear Colleague,

\section{Introduction}

Firstly, thank you for responding to one or both of the earlier rounds. I have received some very useful and constructive feedback and this has been most helpful in advancing my thought and ideas on the proposed framework/model.

I closed off Round 2 at midnight on Saturday 28 November 2009 and I believe that I now need to spend some further time to reflect on the detailed content of the responses from both rounds in finalising the framework /model. However, I would still like to complete a Round 3 to 'close out' this Delphi survey process. As promised earlier this week this final Round will be relatively short and take less time to consider and complete than the previous two rounds.

By connecting to the Delphi website and selecting each of the two rounds to date it is possible to view the full details of the responses received in Rounds 1 and 2 and you may find it interesting to do this. However, in order to enable you to more easily learn what was said in Round 2, I have listed below some of the key points that were made by those who responded.

\section{Results of Round 2}

Quantitative results:

Further to some comments in Round 1 that the flowchart was too busy and rather hard to follow, I changed the format to have a 'master flowchart' and separate flowcharts for each stage of the life cycle. Based on the qualitative comments on this revision, most respondents appeared to find this useful although one respondent specifically indicated that the original format was preferred. This generally acknowledged 'improvement' is quantitatively reflected in the small increase in the mean from 3.2 to 3.25 for Question 2 as shown on the table below. However, when Questions 3 and 4 were raised again in Round 2 the responses indicated a lower level of agreement that the framework/model could be a valuable tool to the Owner and NOPs respectively, compared to the model provided in Round 1. Again, the quantitative results for Questions 3 and 4 are shown in the table below.

These results suggest that whilst the revised model was seen as marginally more successful in addressing the original objective of ensuring an demonstrating $\mathrm{VfM} / \mathrm{BV}$, the value of the revised model was seen as somewhat less to Owners and significantly less for NOP's. I find this feedback a little confusing and consequently in Round $3 \mathrm{I}$ am asking some further questions to clarify whether the separation of the revision of the framework/model is perceived to be an advantage or disadvantage in addressing VfM/BV issues. 
Value for Money/Best Value in Project Alliances, Phase 2, Round 3

Delphi Review - 3 December 2009

\begin{tabular}{clll}
\hline Question no. & Question raised in Round 1 and Round 2 & $\begin{array}{l}\text { Score in Round 1 } \\
\text { mean, }(\sigma), \text { median }\end{array}$ & $\begin{array}{l}\text { Score in Round 2 } \\
\text { mean, }(\sigma), \text { median }\end{array}$ \\
\hline $\mathbf{2}$ & $\begin{array}{l}\text { The objective of developing the framework/model is } \\
\text { to ensure the achievement and demonstration of } \\
\text { VfM/BV. Do you think the framework/model } \\
\text { achieves this objective? }\end{array}$ & $3.2,(0.87), 3$ & $3.25,(0.93), 3$ \\
& $\begin{array}{l}\text { Do you think the framework/model could be a } \\
\text { valuable tool to Owners in seeking to ensure the } \\
\text { achievement and demonstration of VfM/BV? }\end{array}$ & 3.9, (0.70), 4 & $3.35,(0.78), 3$ \\
$\mathbf{3}$ & $\begin{array}{l}\text { Do you think the framework/model could be a } \\
\text { valuable tool to NOP's in seeking to ensure the } \\
\text { achievement and demonstration of VfM/BV? }\end{array}$ & $3.6,(0.80), 4$ & $2.4,(0.62), 2.5$ \\
\hline
\end{tabular}

Qualitative comments (researcher's responses):

- A comment was made that only one of the 'supplementary' flowcharts addressing the particular stages of the life cycle had been included in the revised framework/model presented in Round 2 and this made it difficult to evaluate the overall framework. This point is acknowledged and further supplementary flowcharts are now being developed.

- As commented upon in Round 1 a view was expressed by some respondents that whilst the framework/model presented current practice in a systematic manner that might not have been done before, it did not take 'a new step forward' at this point. As noted at the end of Round 1 , by careful consideration of the valuable comments some new insights may emerge.

- It was suggested by several respondents that the framework/model was a tool that would be of greater value to Owners' than NOP's and this is perhaps reflected to a degree in the responses to Questions 3 and 4. It was noted, however, that the framework/model might enhance NOPs' understanding of the issues that an Owner faces in contemplating a project alliance. Noted

- The specific identification of a separate route for multiple TOC alliances was seen to be positive step although the view was expressed that the steps identified were too similar to the single TOC route. This comment is accepted and this issue will be further developed.

- The comment was made that flow of the 'supplementary' flowcharts should run in the same direction as the 'master flowchart'. This will be revised.

- Some comments were made regarding measures that could be adopted during the Design and Construction phase of a project but this phase continues to be 'lightly populated' in terms of specific VFM/BV initiatives. It is intended to make some specific suggestions regarding form and content of regular VfM/BV reporting during this phase.

\section{Changes made to the framework/ model}

No specific changes to the model are being suggested in Round 3 of the process, although, as described above, further changes are likely to be made following a more comprehensive review of the detailed feedback from both Rounds 1 and 2.

\section{Victorian Department of Treasury and Finance research}

As described in earlier brief papers the Victorian Department of Treasury and Finance (VDTF) recently commissioned a detailed study into VfM in Project Alliances The full version of the VDTF Report can be accessed via the following link:

www.dtf.vic.gov.au/project-alliancing 
I have listed the 'key findings' from this study in Appendix 1 to this briefing paper. I will be posing some questions in Round 3 which relate to some of these key findings and whilst it is not necessary for you read either the full VDTF report or these key findings to answer these questions, you may find the contents of the appendix of interest if you are not already aware of the findings from this study.

\section{The Delphi Process - What happens now and what you need to do}

As advised in previous rounds the 'Delphi Process' involves each participant responding to questions which, for Round 3, will be based on the revised framework/model which is attached to this briefing paper. These responses will be sought and received through the web-based service 'Delphiforecastingprinciples.com' which will communicate with you to forward the questions, inform you of the times for responses and other administrative details. This will also be the medium through which responses are submitted. The collated views of all the participants for Rounds 1 and 2 are now shared, albeit anonymously, with the rest of the group, on the website.

The program for the three rounds of the process is shown in the table below:

\begin{tabular}{|l|l|l|l|}
\cline { 2 - 4 } \multicolumn{1}{c|}{} & Round 1 & Round 2 & Round 3 \\
\hline Start date & Monday 2 November & $\begin{array}{l}\text { Tuesday 17 } \\
\text { November 2009 }\end{array}$ & $\begin{array}{l}\text { Friday 4 December } \\
2009\end{array}$ \\
\hline End Date & 2009 & $\begin{array}{l}\text { Saturday 28 } \\
\text { November 2009 }\end{array}$ & $\begin{array}{l}\text { Sunday 13 } \\
\text { (December 2009 } \\
\text { (noon) }\end{array}$ \\
\hline & $\begin{array}{l}\text { amended to 15 } \\
\text { amoon) }\end{array}$ & \\
\hline & November 2009 & Now complete & \\
\hline
\end{tabular}

As explained earlier, Round 3 is commencing a little later than I indicated in the original programme for the whole exercise. Whilst being very conscious of how busy people are generally and particularly at this time of year I believe it is important that the conclusion of the process does not extend beyond the timeframe participants originally agreed to. Consequently, I propose to conclude on Sunday 13 December 2009 which means that the period for comment is somewhat foreshortened.

\section{Conclusion}

Your commitment to participate in this process is greatly appreciated and I look forward to receiving your responses through the web-based communication process. However, if you would like to clarify the content of this second briefing paper or the attached documents I would be happy to respond either by email or phone.

You will receive an email from the Delphi website shortly indicating that Round 2 has commenced. Please note the Round 2 will commence on Friday 4 December 2009 and close on Sunday 13 December 2009.

Attachments - none

Thank you once again for your very valuable input to this research

\section{Charles MacDonald}

General Manager Construction

BrisConnections Pty Ltd

RMIT Student No. 3037138

macdonald@optusnet.com.au

0412250638 
4 December 2009

\section{Appendix 1. - Victorian Department of Treasury and Finance (VDTFV), 'In Pursuit of Additional Value' - Key Findings}

Key finding 1: Business case - Defining the project's VfM proposition

Business cases often did not clearly define the project $\mathrm{VFM}$ proposition to the rigour required for investment decision making.

Particular findings of note:

- The average increase from business case cost estimate to Actual Outturn Cost (AOC) was of the order of 45-55\%.

- The business case assessment of an optimum delivery method often tended to'default' to alliancing using a non-price selection approach for Non Owner Participants (NOPs) and did not consider a range of other delivery options.

- In general a robust program and budget was not evident from the business case stage.

Key finding 2: Procurement strategy - Owner's rationale for selecting the

alliance delivery method

Having considered project specific requirements, the primary reasons for selecting the alliance delivery method, in addition to those contained in the DTF Project Alliancing Practitioners' Guide were:

- to achieve early project commencement through early involvement of the NOPs

- to progress the project development in parallel with the project approvals.

In general, Owner's specifically used alliancing and the non-price competitive selection approach to attract key resources and capabilities to a project in a buoyant construction market.

Key finding 3: Selecting the NOPs - Non-price and price competition

Non-price competition

It was found that when non-price selection approaches were used to select NOPs:

- Owner representatives generally indicated moderate to high levels of satisfaction with the selection process

- Owner representatives sometimes noted that the selected NOP team members were either not made available to the project or left prematurely.

Price competition

Noting that the number of price competition approaches examined in this Study was limited to two case studies (consistent with current industry practice), it was found that when price competition was used to select NOPs:

- Owner representatives reported a significant management demand on their organisation (compared with non-price selection approach)

- the total cost to establish a Target Outturn Cost (TOC) using price competition (two TOCs) was less (of the order of $2 \%$ of TOC) than when non-price selection (single TOC) was used

- the TOC was found to be of the order of 5-10\% (of TOC) less, relative to non-price competition on the basis that the following items were lower (in aggregate and individually) when using price competition:

- On-site overhead costs.

- Design costs.

- TOC development costs.

- NOP profit margins.

Owners on all alliances in the Study advised that good relationships had developed and that the participants worked well together as effective teams. No discernible difference was found between alliances that used price competition and non-price competition.

It was also found that generally NOPs have a strong preference for alliancing over other traditional delivery methods. Additionally, NOPs have a strong preference for non-price selection approach over price selection 
Value for Money/Best Value in Project Alliances, Phase 2, Round 3

Delphi Review - 3 December 2009

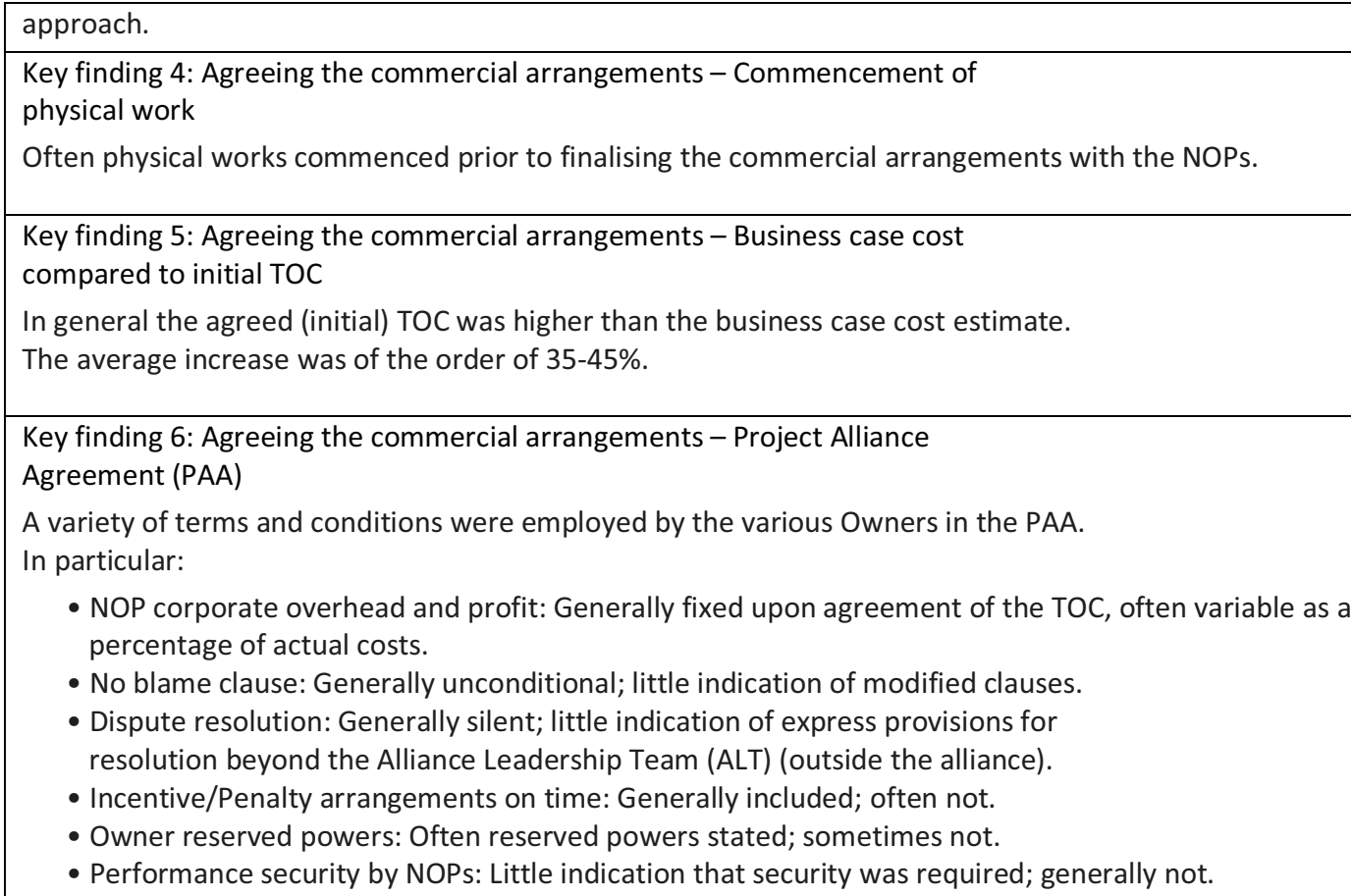

Often physical works commenced prior to finalising the commercial arrangements with the NOPs.

Key finding 5: Agreeing the commercial arrangements - Business case cost compared to initial TOC

In general the agreed (initial) TOC was higher than the business case cost estimate.

The average increase was of the order of $35-45 \%$.

Key finding 6: Agreeing the commercial arrangements - Project Alliance Agreement (PAA)

A variety of terms and conditions were employed by the various Owners in the PAA.

In particular:

- NOP corporate overhead and profit: Generally fixed upon agreement of the TOC, often variable as a percentage of actual costs.

- No blame clause: Generally unconditional; little indication of modified clauses.

- Dispute resolution: Generally silent; little indication of express provisions for resolution beyond the Alliance Leadership Team (ALT) (outside the alliance).

- Incentive/Penalty arrangements on time: Generally included; often not.

- Owner reserved powers: Often reserved powers stated; sometimes not.

- Performance security by NOPs: Little indication that security was required; generally not.

Key finding 7: Agreeing the commercial arrangements - Outstanding Outcomes

Generally it is a requirement expressed in the PAA that the parties commit to achieving outstanding (game breaking) outcomes.

The commercial arrangements generally provide financial incentives for NOPs (incentivised Key Result Area (KRAs)) to achieve outstanding (game breaking) outcomes.

It was also noted that estimated costs associated with pursuing outstanding (game breaking) outcomes are often included in the TOC.

Key finding 8: Project delivery - Non-price objectives

In general, Owner representatives (regardless of approach to selecting NOPs) rated their alliance's performance in all areas of non-price objectives as above expectations or game breaking. The areas of nonprice criteria assessed were:

- quality of work

- functionality

- safety

- environment

- community

- other stakeholders

- team dynamics

- KRA achievement

- flexibility of approach.

Key finding 9: Project delivery - Owner resources

The number of Owner resources provided to the alliances varied.

There was no clear correlation between the number of Owner resources and enhanced VfM.

It was noted that active senior level participation by the Owner provided clear direction and support to the alliance. 
Key finding 10: Project delivery - Early commencement of physical work and project completion

The project's physical works were able to be commenced many months in advance of what would have been possible using traditional delivery methods (as noted elsewhere) leading to a commensurate earlier completion date.

The majority of projects met the Owners' target completion dates as set out in the business case.

Key finding 11: Project delivery - No disputes

There were no indications of any disputes between the Owner and the NOPs that needed to be resolved outside the alliance.

Key finding 12: Project delivery - Outstanding outcomes (game breaking)

There was little indication that outstanding outcomes (game breaking / breakthrough) were being achieved within the definitions in use in this Study ('paradigm shift', 'not been done before').

This finding significantly differs with the self-evaluation of both NOPs and Owner representatives within the alliances who considered that their own alliances achieved outstanding outcomes.

Key finding 13: Project delivery - Adjustments to agreed TOC

In general there was an increase from agreed (initial) TOC to adjusted (final) TOC. The average increase was of the order of $5-10 \%$.

Key finding 14: Project delivery - Adjusted TOC and AOC

In general, the AOC was less than the adjusted (final) TOC. The average saving was of the order of $0.5 \%$. 


\section{Appendix C.9}

Round 3 Questions as posted on the Delphi website to be addressed by the participants 


\section{VfM Delphi Survey, Phase 2, Round 3 Questions}

1. You should by now have received an email from the researcher (Charles MacDonald) with the following attachment:

A new briefing paper (date 4 December2009) which describes the results of Round 2 and describes the nature of the questions that will be posed in this Round 3 of the Delphi Process. This paper contains an appendix which lists the 'conclusions' from the research report recently issued by the Victorian Department of Treasury and Finance entitled 'In Pursuit of Additional Value'.

If you have not received this email, or if you have any queries following receipt of this material please contact Charles MacDonald by email or phone (macdonald@optusnet.com.au or 0412250 638)

This is not a question and no response is required-Text only

2. In both Round 1 and Round 2 the question was asked whether the framework/model could be valuable to the Owner in seeking to ensure the achievement and demonstration of VfM/BV (Question 3 in both rounds). Following the revision of the framework/model in Round 2, which was intended to clarify the content, satisfaction with the framework/model decreased (3.9 to 3.25). In order to further test this outcome the following question is posed - Compared with the Round 1 framework/model, to what extent do you agree that the Revised Round 2 framework/model is more useful to Owners? - Scaled question plus room for comment

3. In both Round 1 and Round 2 the question was asked whether the framework/model could be valuable to the NOPs in seeking to ensure the achievement and demonstration of VfM/BV (Question 4 in both rounds). Following the revision of the framework/model in Round 2, which was intended to clarify the content, satisfaction with the framework/model substantially decreased (3.6. to 2.4). In order to further test this outcome the following question is posed - Compared with the Round 1 framework/model, to what extent do you agree that the Revised Round 2 framework/model is more useful to NOPs? - Scaled question plus room for comment

4. The VDTF Report comments that 'Alliance projects are often associated with uncertainty and complexity. This requires greater, not less, rigour in the business case to ensure that adequate anchoring, benchmarking and guidance is provided to the alliance team as the project progresses. As a minimum the business case should include the value proposition which incorporates the project objectives, agreed funding of 'externalities' (for example environmental works, stakeholder relations) and a robust cost plan. It should (barring sections subject to confidentiality) be made available to the alliance team'. To what extent do you agree with this statement? Scaled 
5. The VDTF report comments that 'Current alliance procurement guidelines recommend selecting NOPs using predominately non-price criteria. This does not always reflect good government procurement practice which requires price to be included as a significant criterion. Whilst price competition is not appropriate in all circumstances, it should be required as a default position'. To what extent do you agree with this statement? Scaled

6. The VDTF Report comments that 'Outstanding outcomes ('paradigm shift', 'not been done before') are often sought by Owners when selecting the alliance delivery method and they are generally a requirement in the PAA. However, there was little evidence that outstanding outcomes are being achieved despite significant investment in 'high performance teams'. To what extent do you agree with this statement?

7. Following the suggestion of one of your fellow research participants, would you willing to participate in a telephone conference hook-up with the other Delphi survey participants (to be scheduled for late January 2010) to further discuss the current status of the framework/model and its effectiveness in achieving and demonstrating VfM/BV? - Yes/No 


\section{Appendix D.1}

Were the following issues addressed in any review of $\mathrm{VfM}$ at these stages of the project?

\section{Question A}



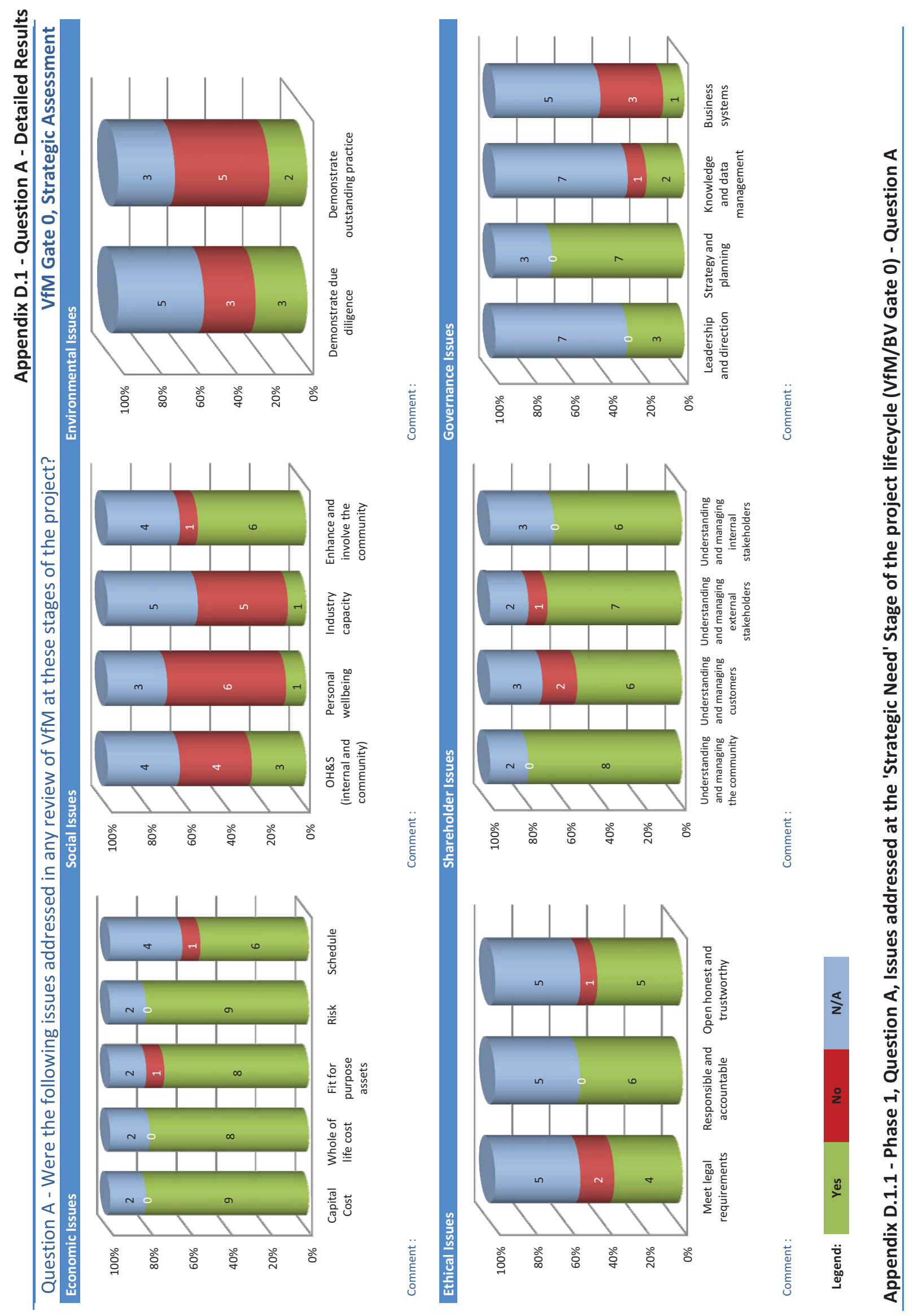


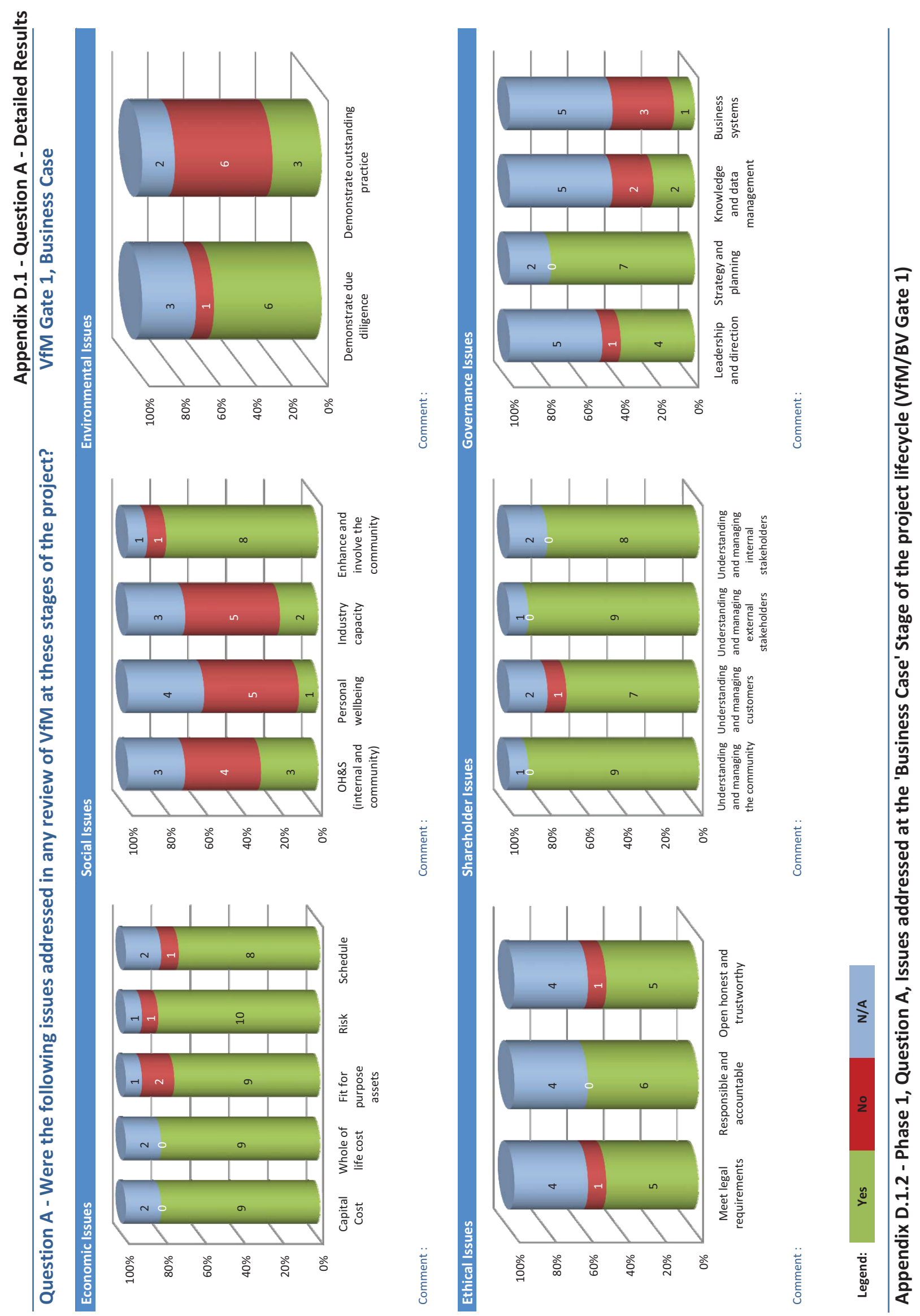




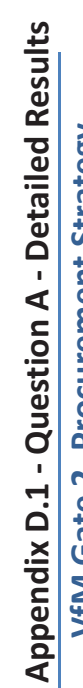

تี

응
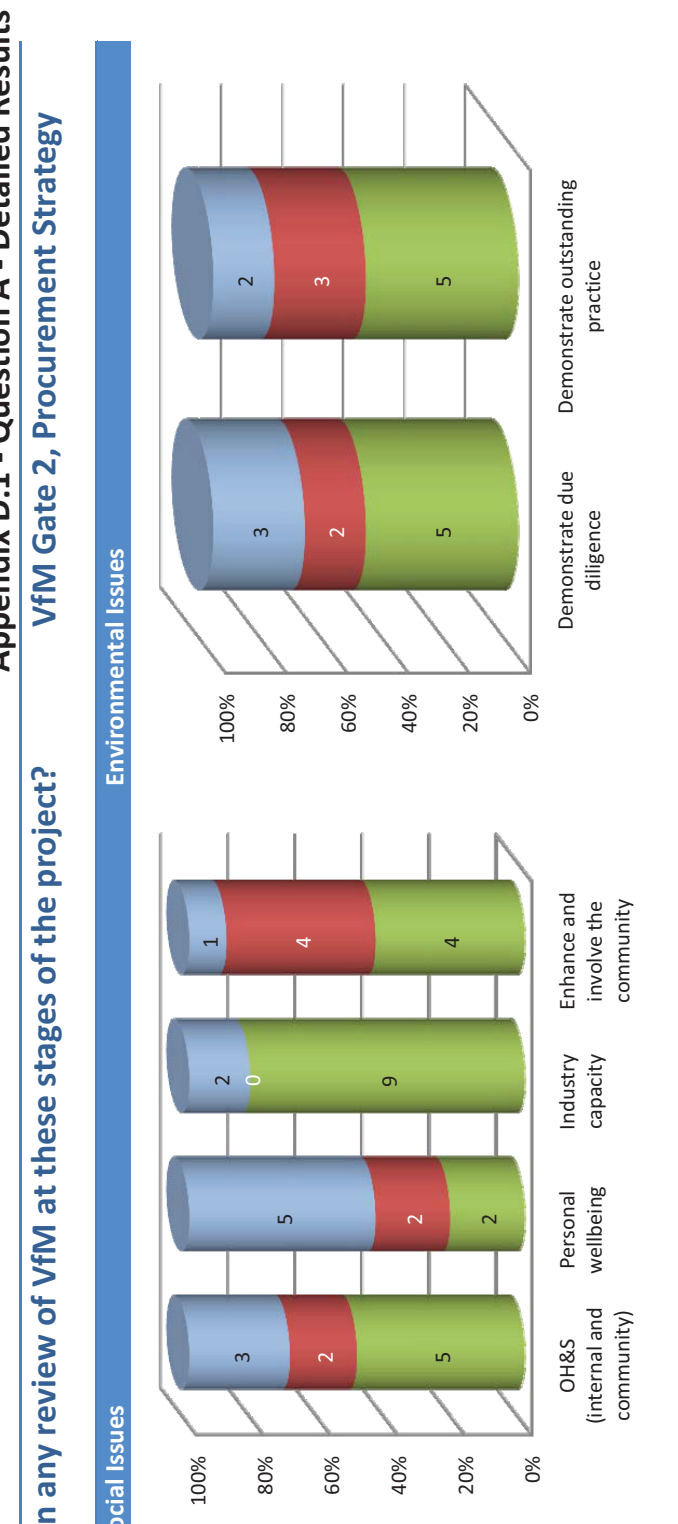
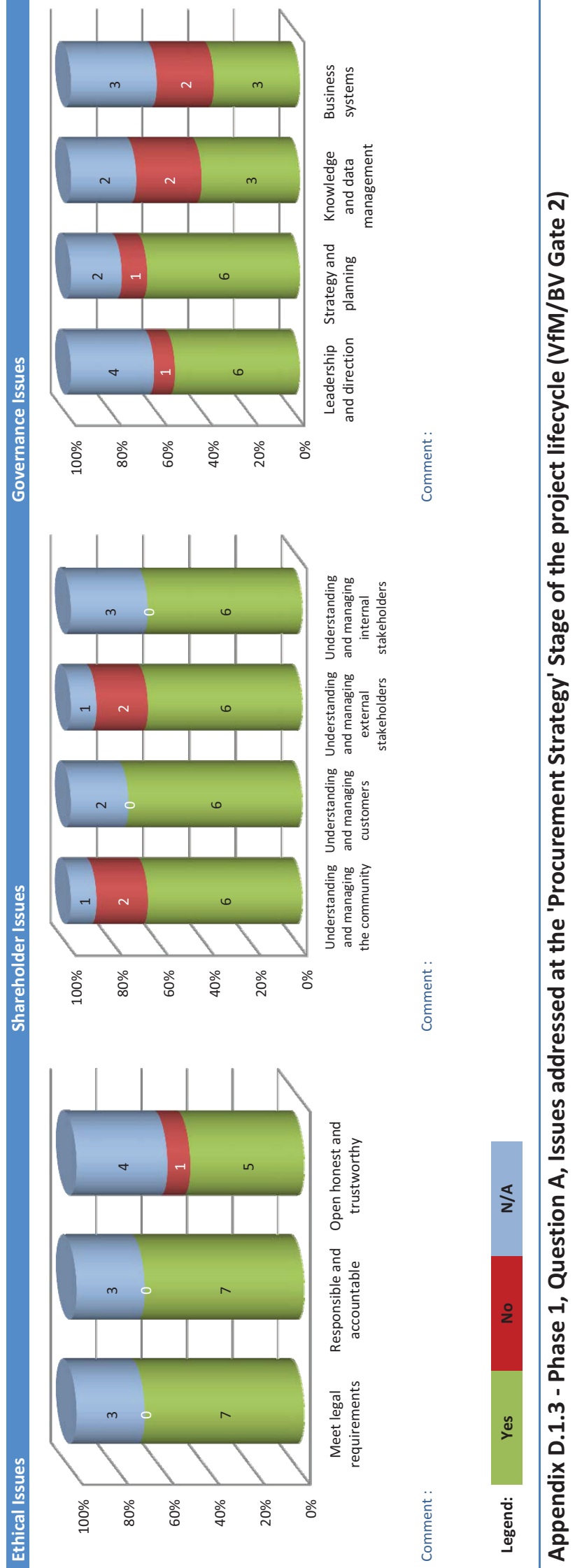


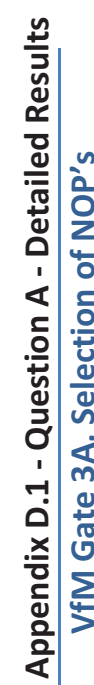

궁

응
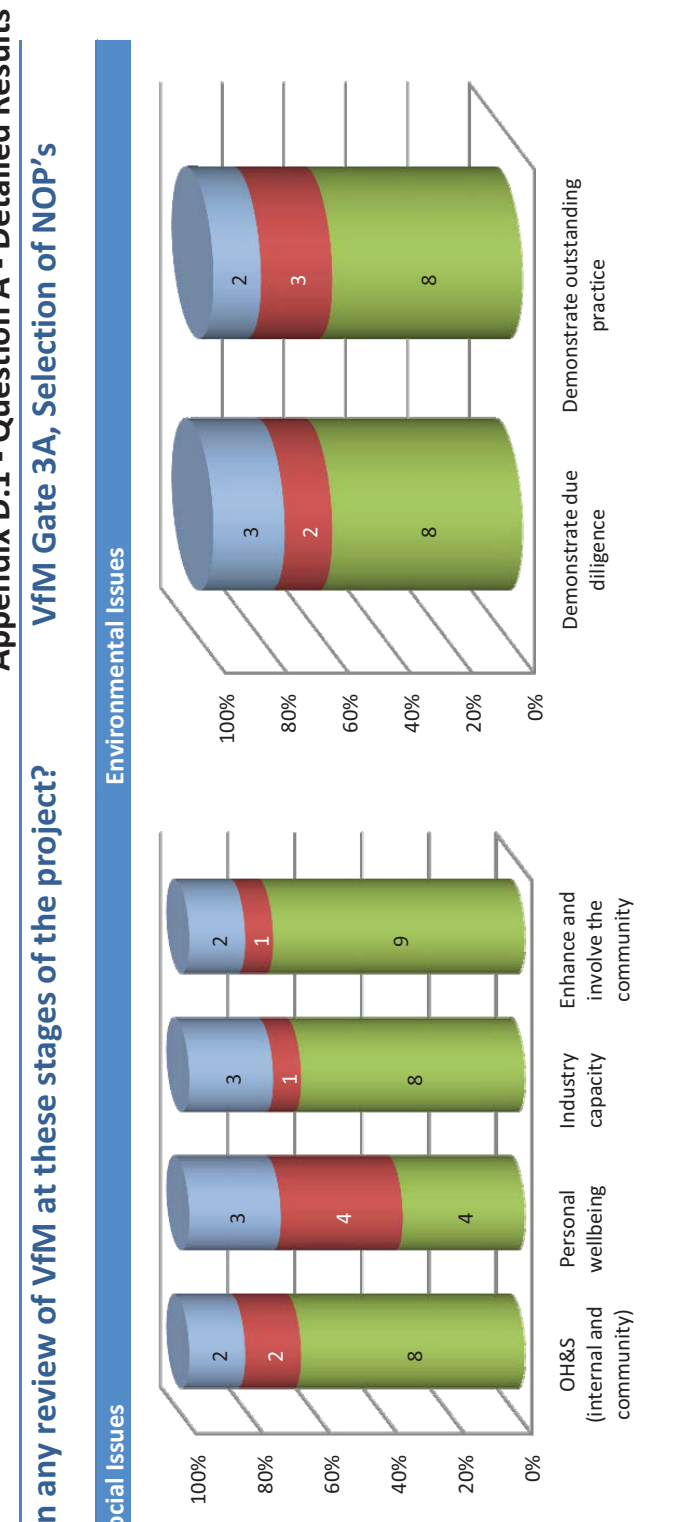
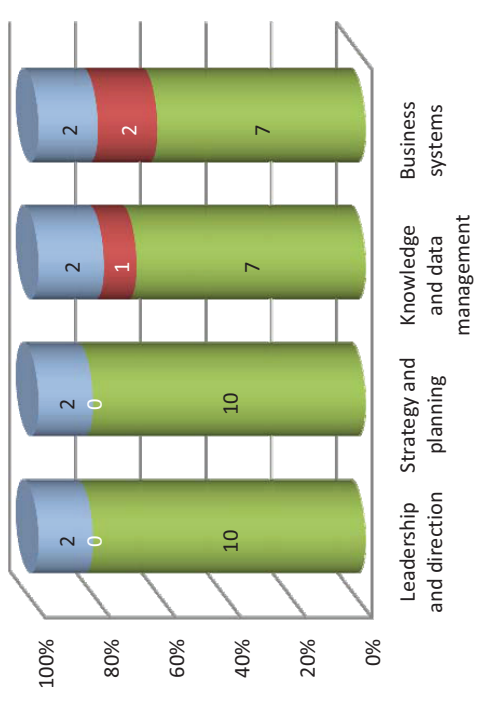

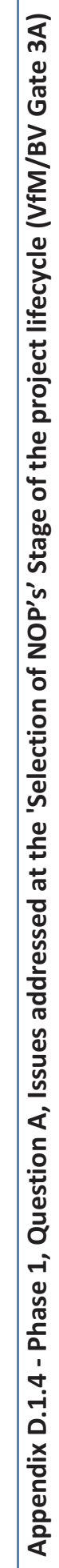




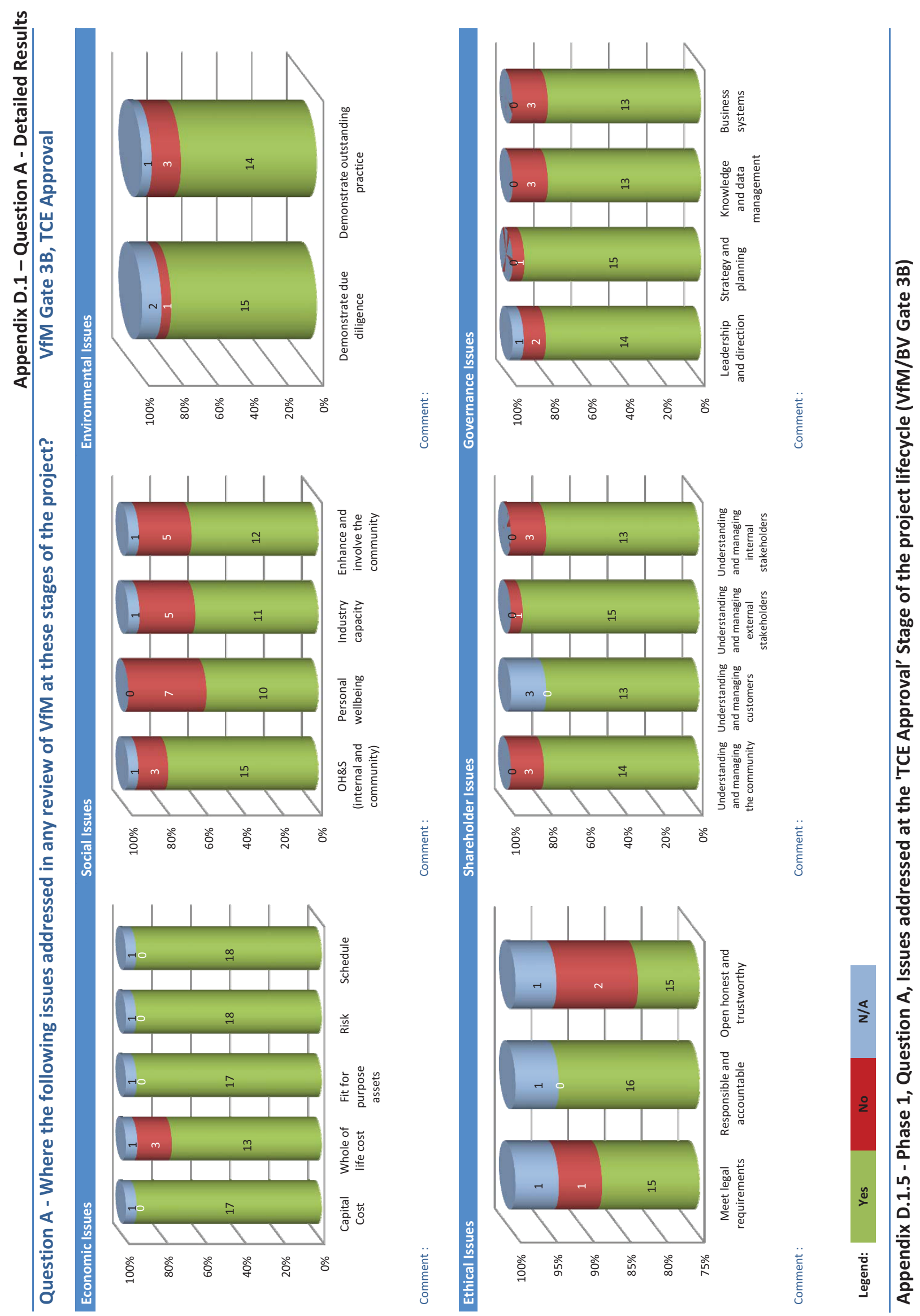




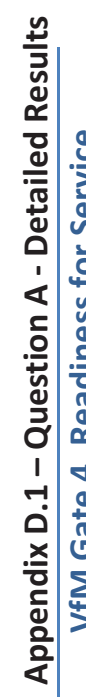

곤

.
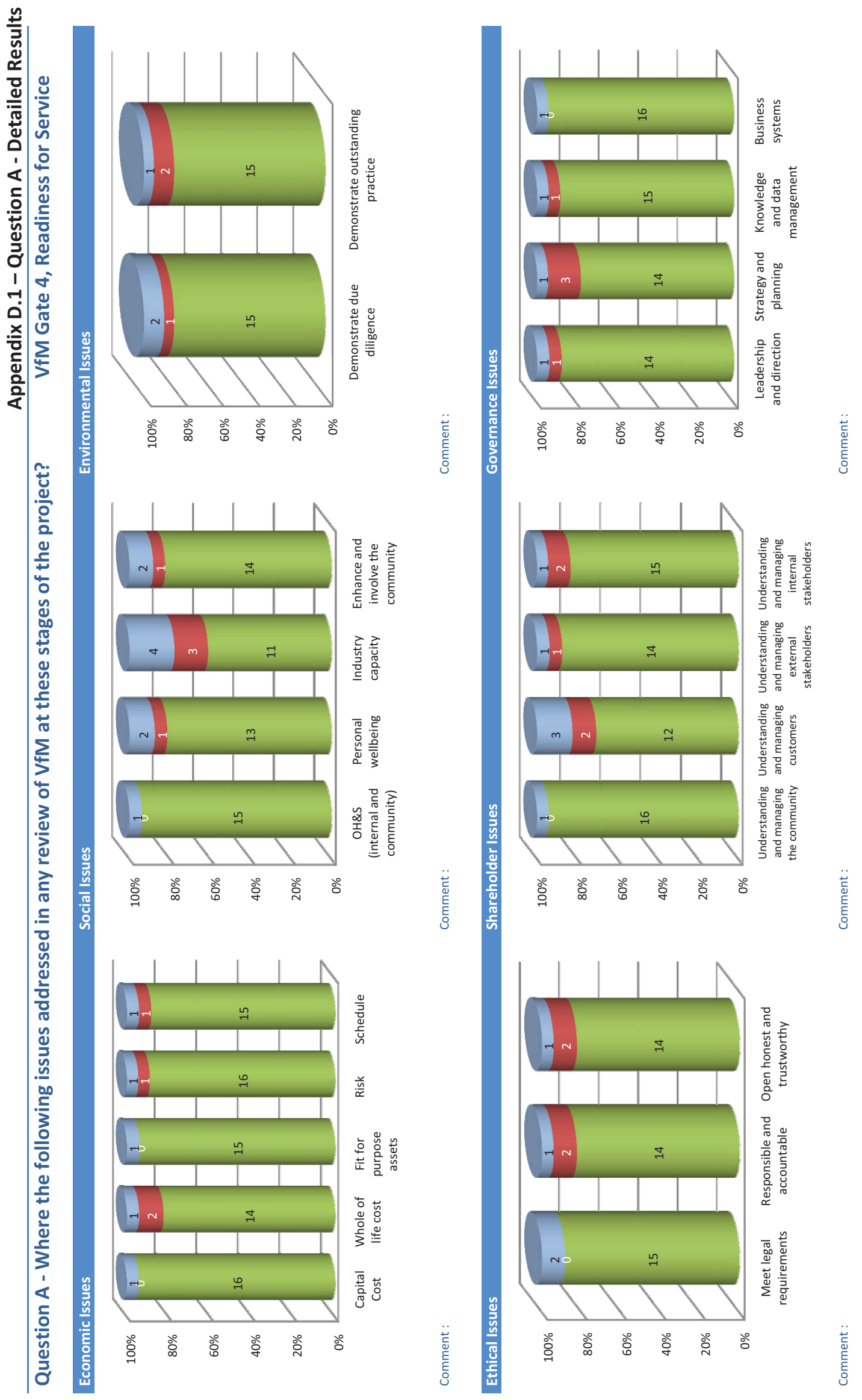

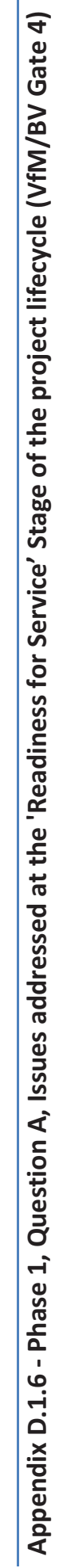



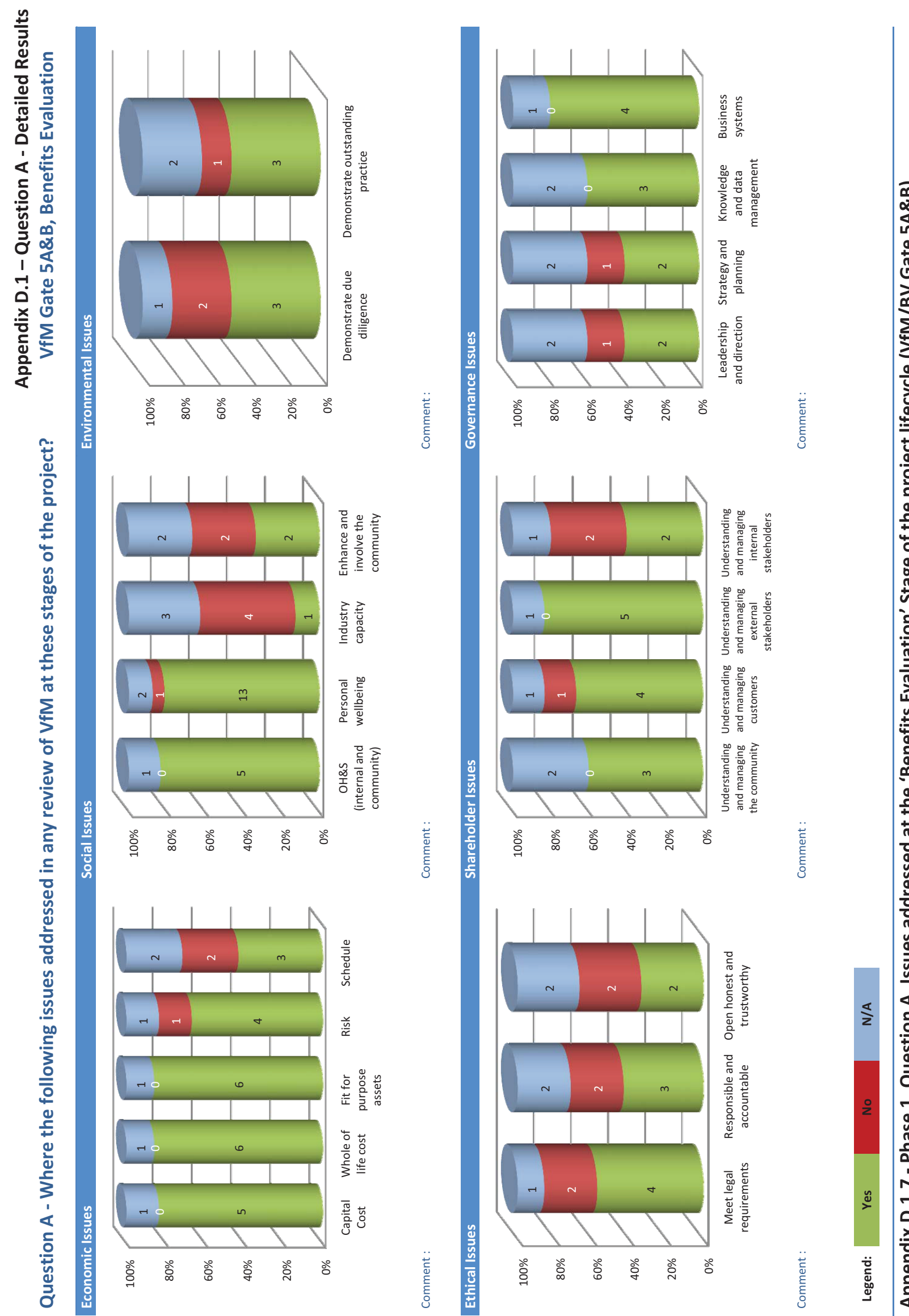

勿 


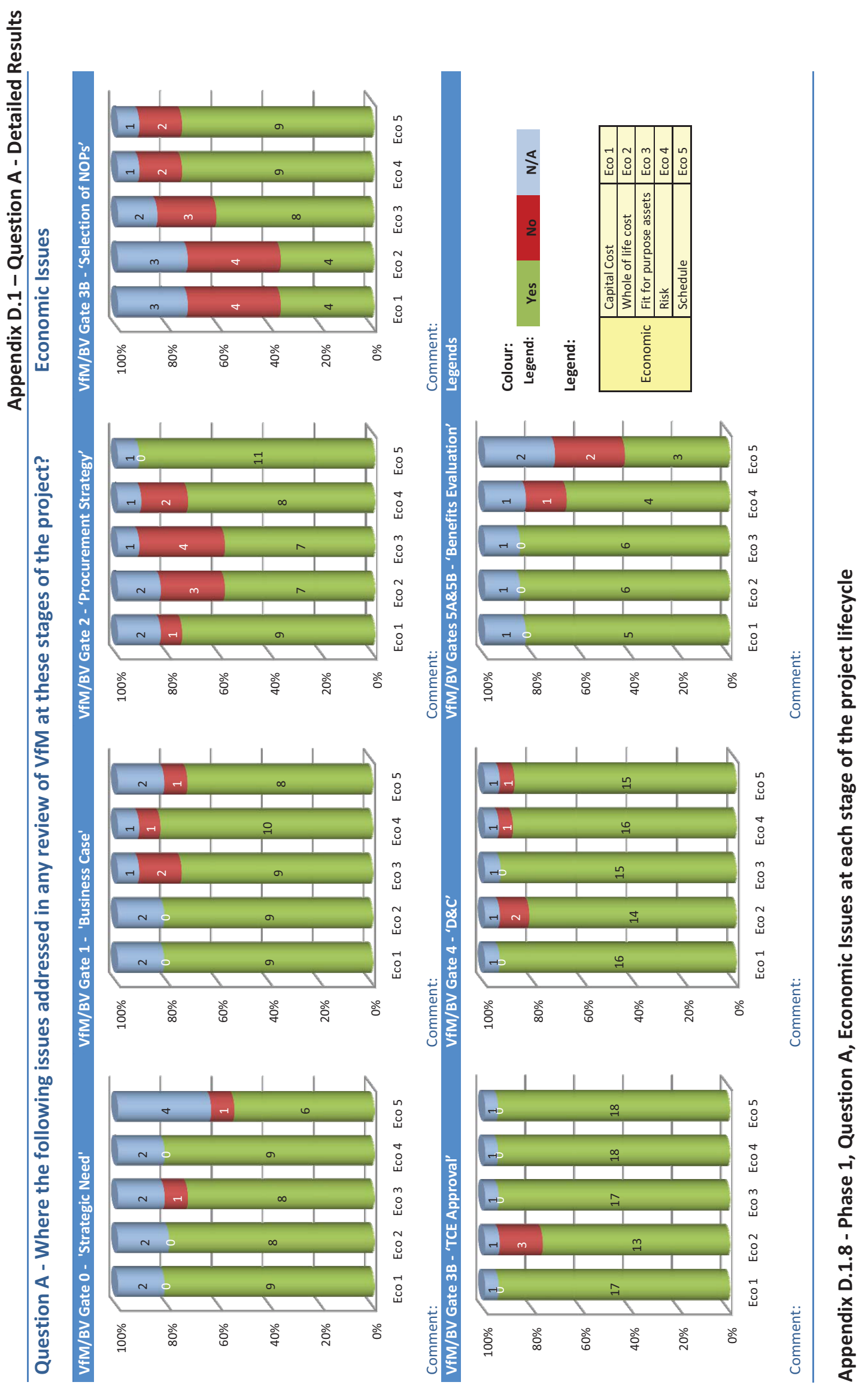




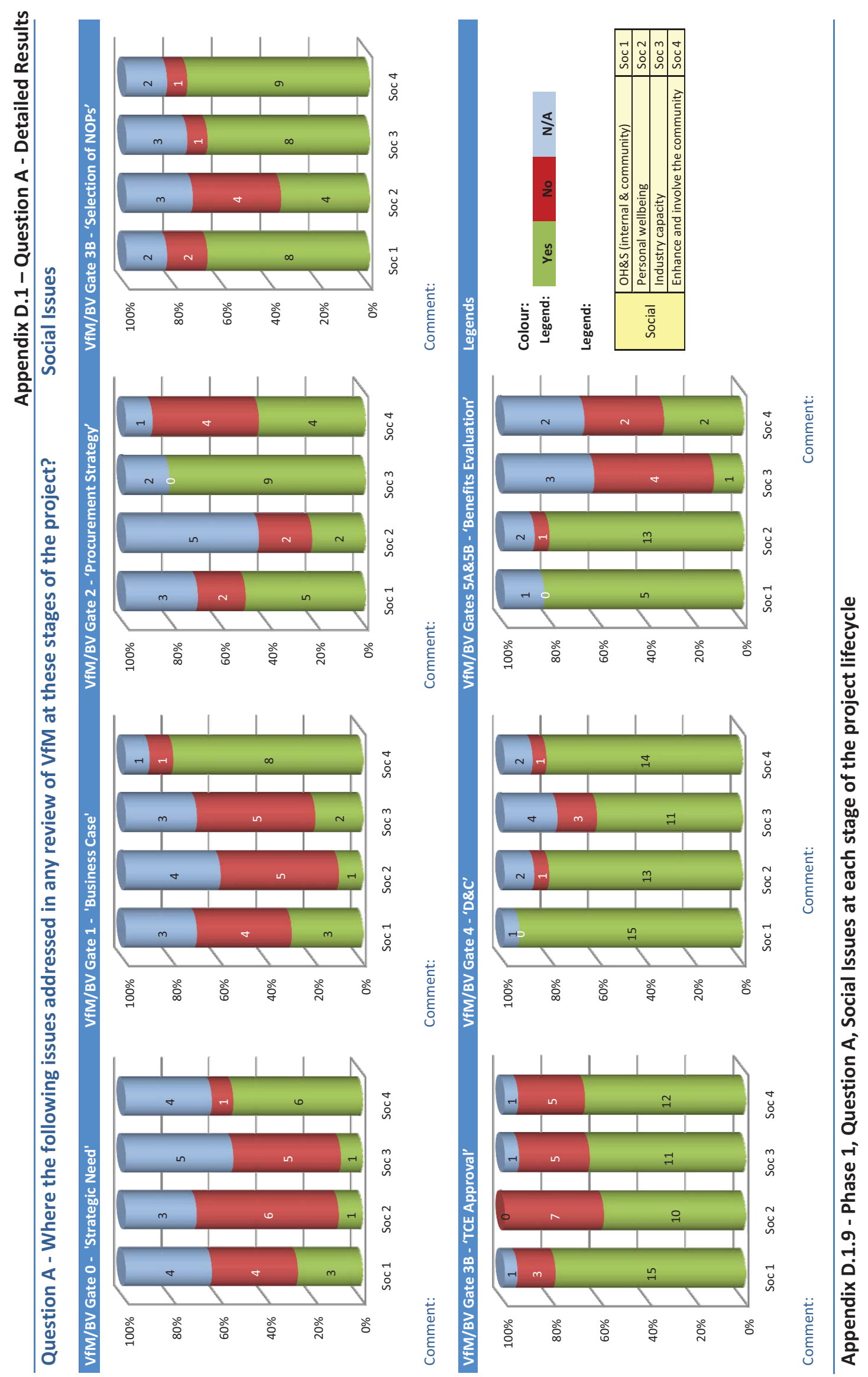




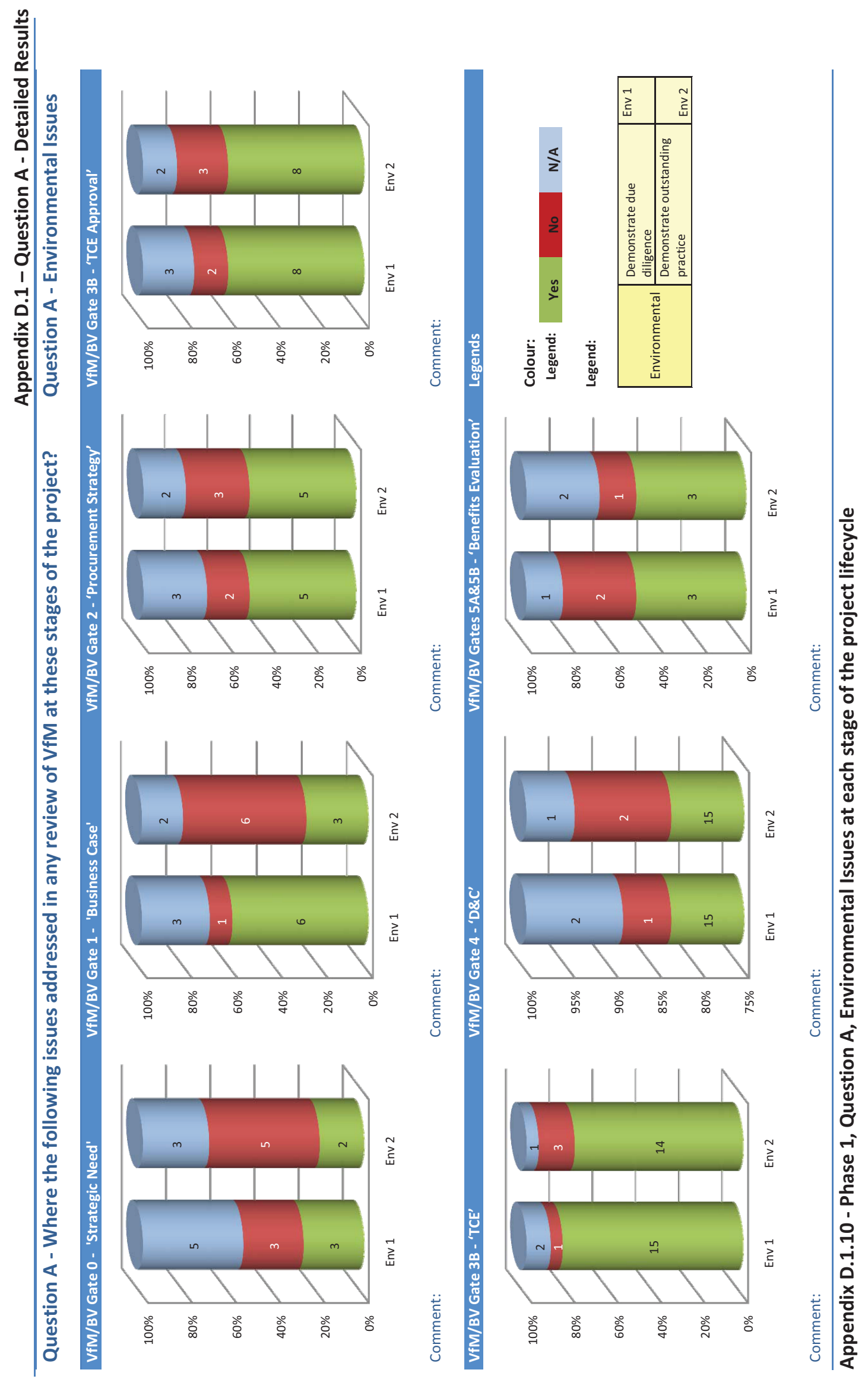




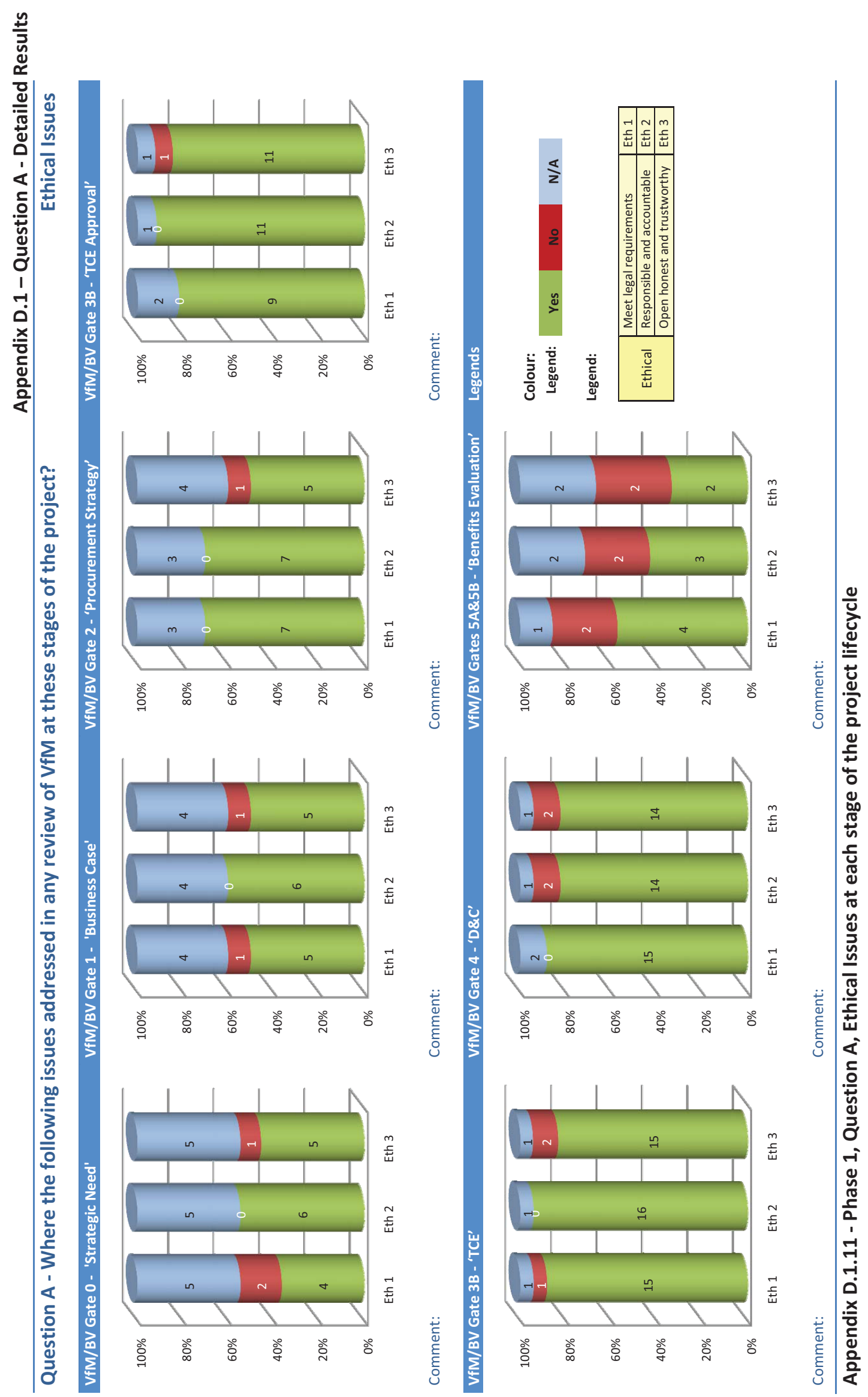




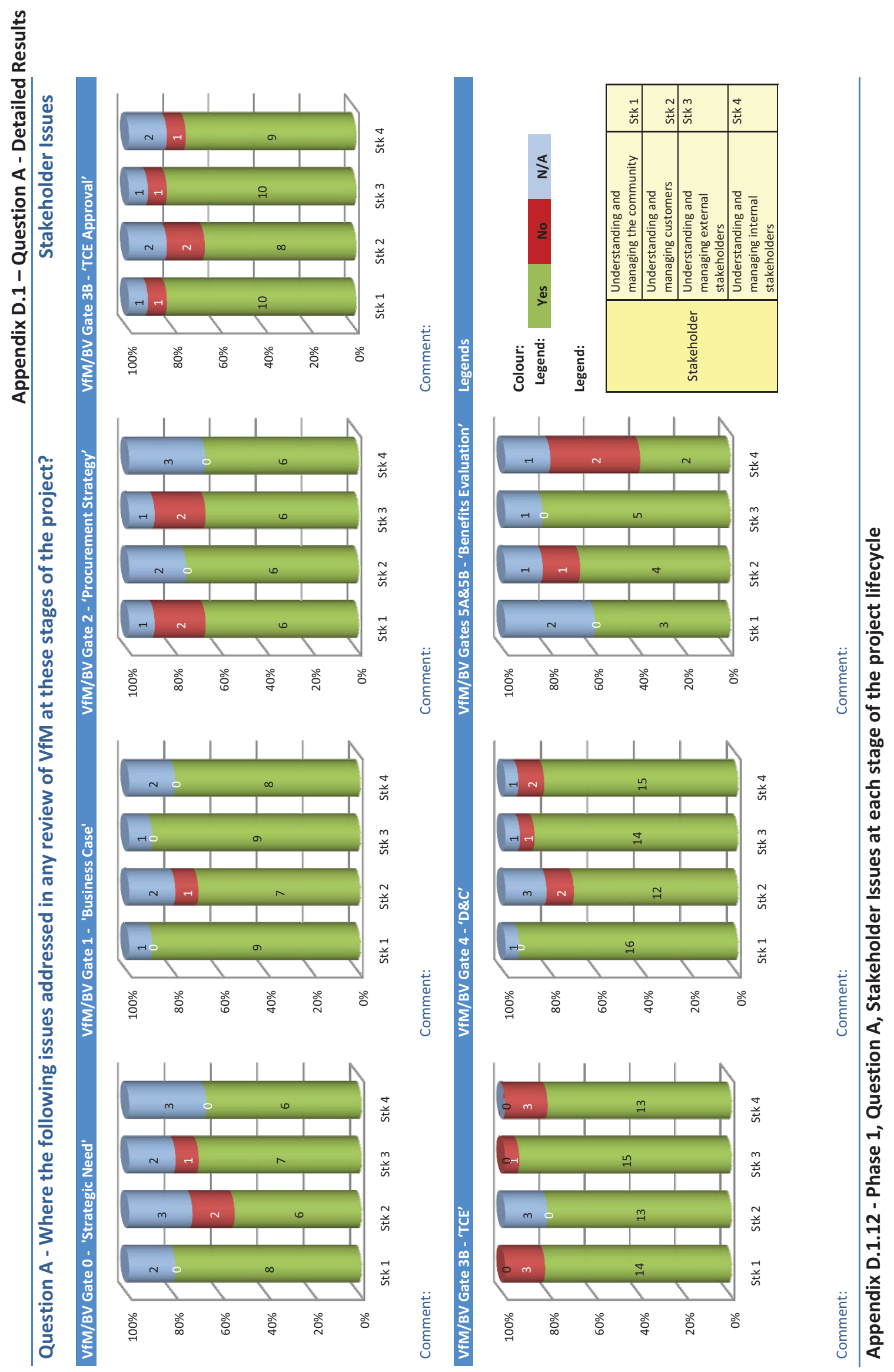



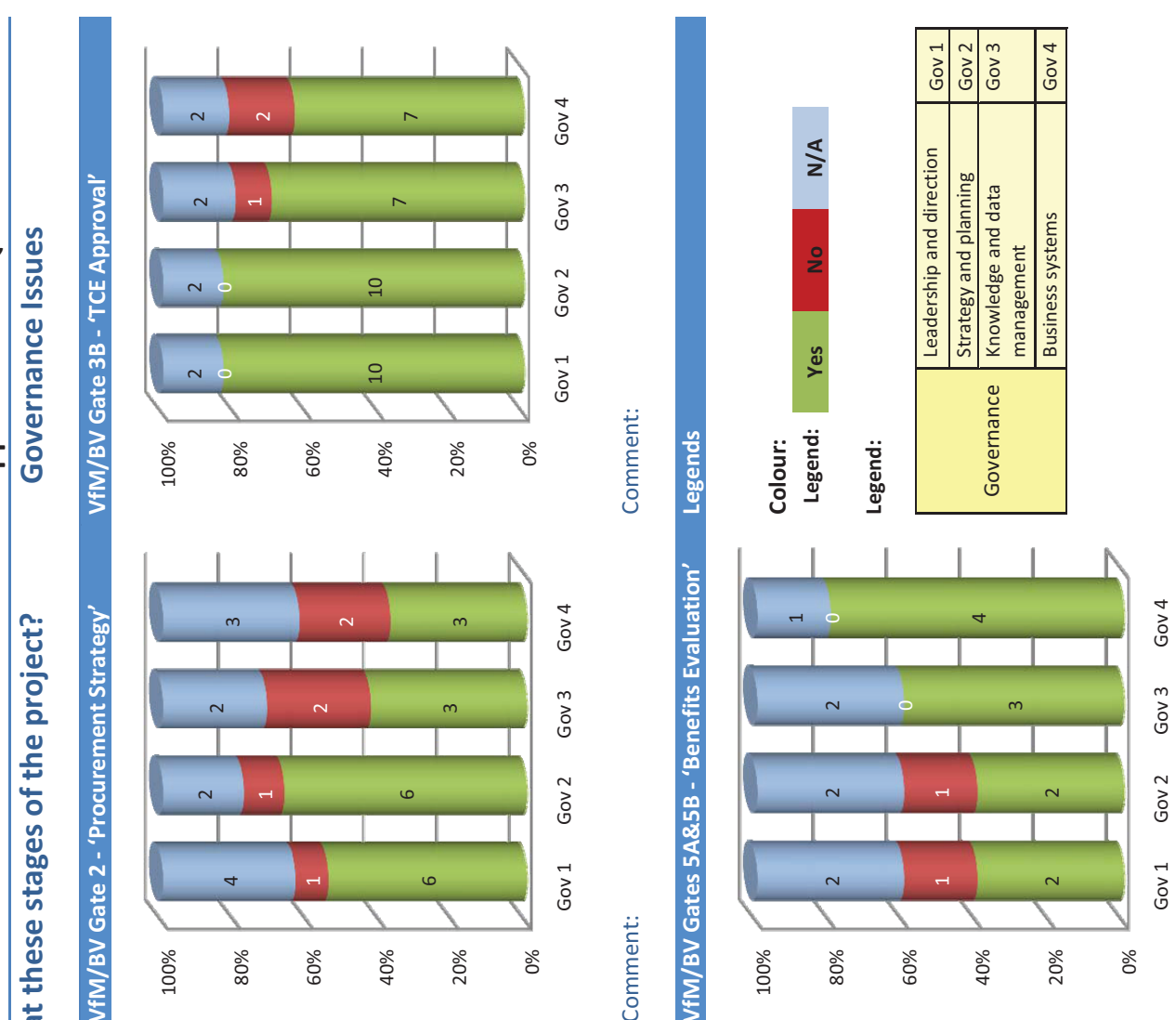

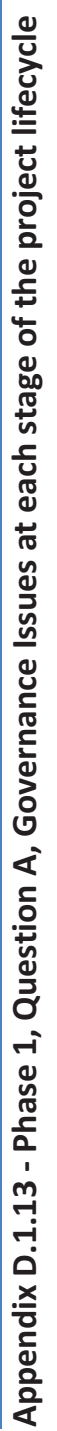




\section{Appendix D.2}

Is VfM an explicit project objective for the Alliance?

Question B 


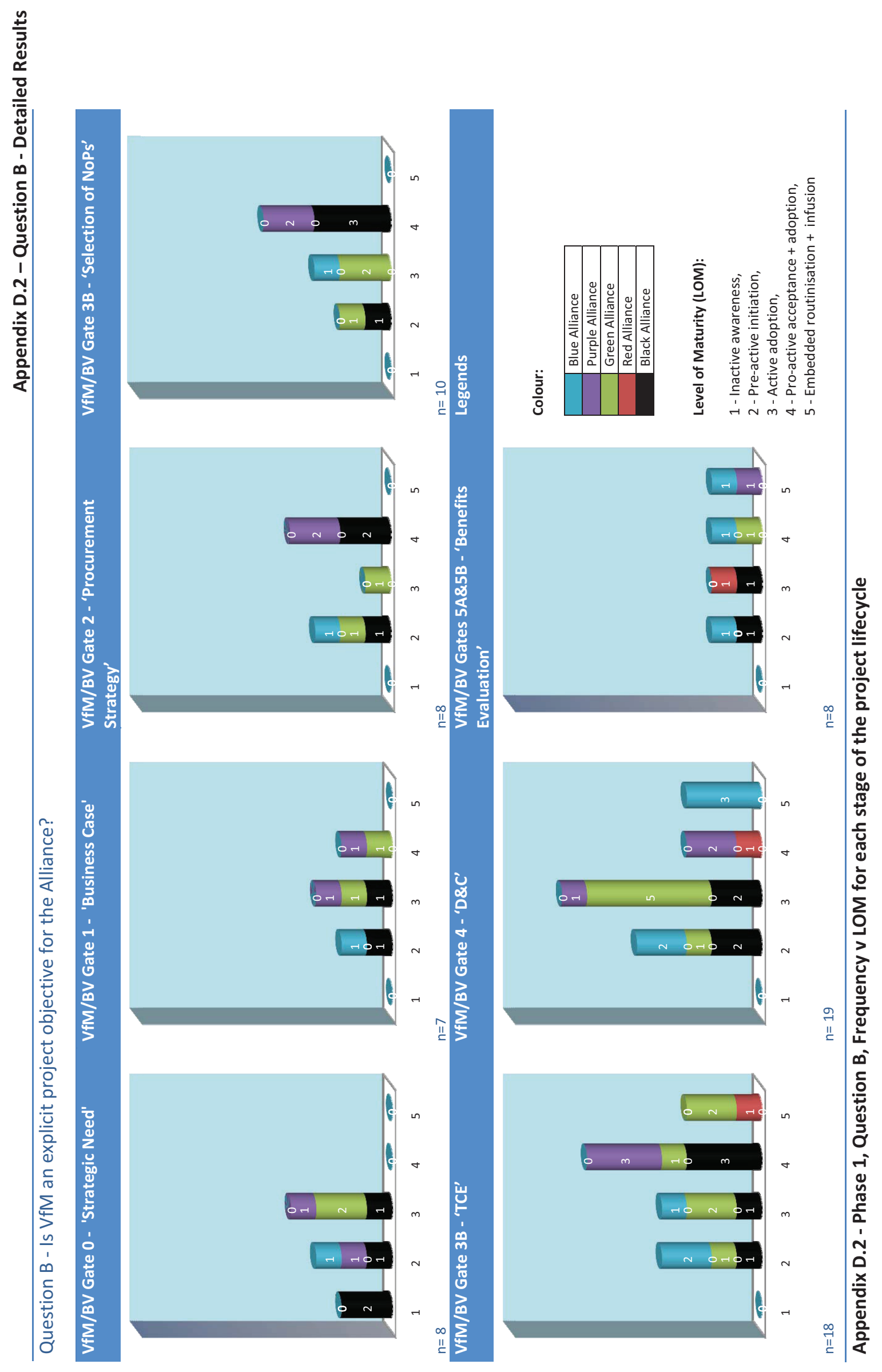




\section{Appendix D.3}

\section{Are specific measures or procedures in place to ensure that VfM is achieved? \\ Question C}



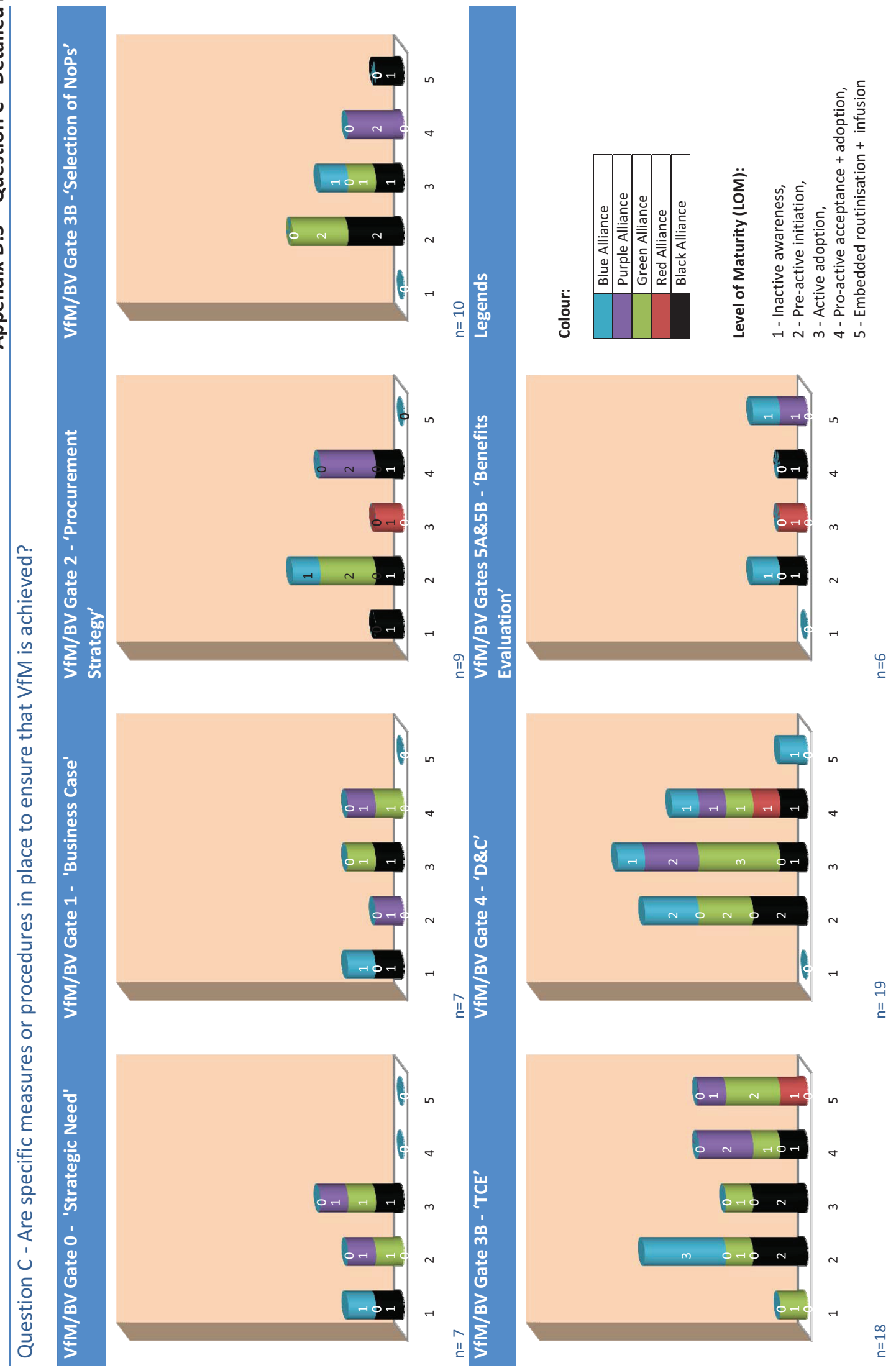

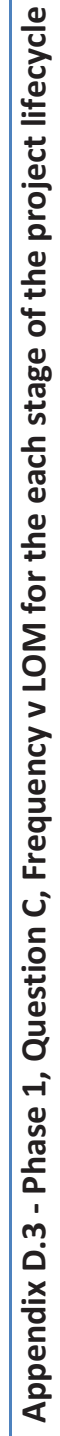




\title{
Appendix D.4
}

Are specific measures in place to ensure that $\mathrm{VfM}$ is demonstrated to have been achieved?

\author{
Question D
}




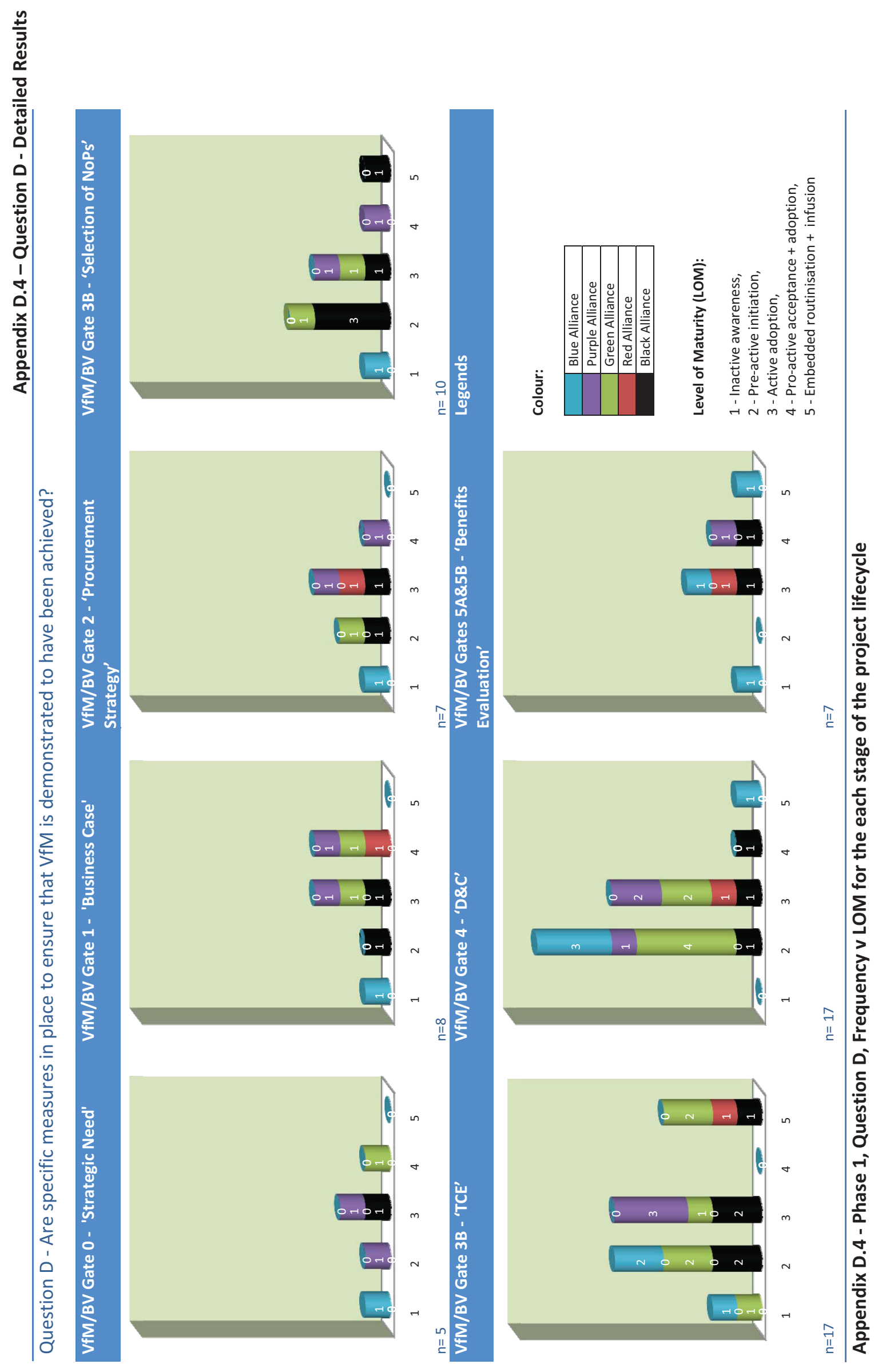




\section{Appendix D.5}

Is VfM an explicit project objective for your Orgaisation?

Question E 


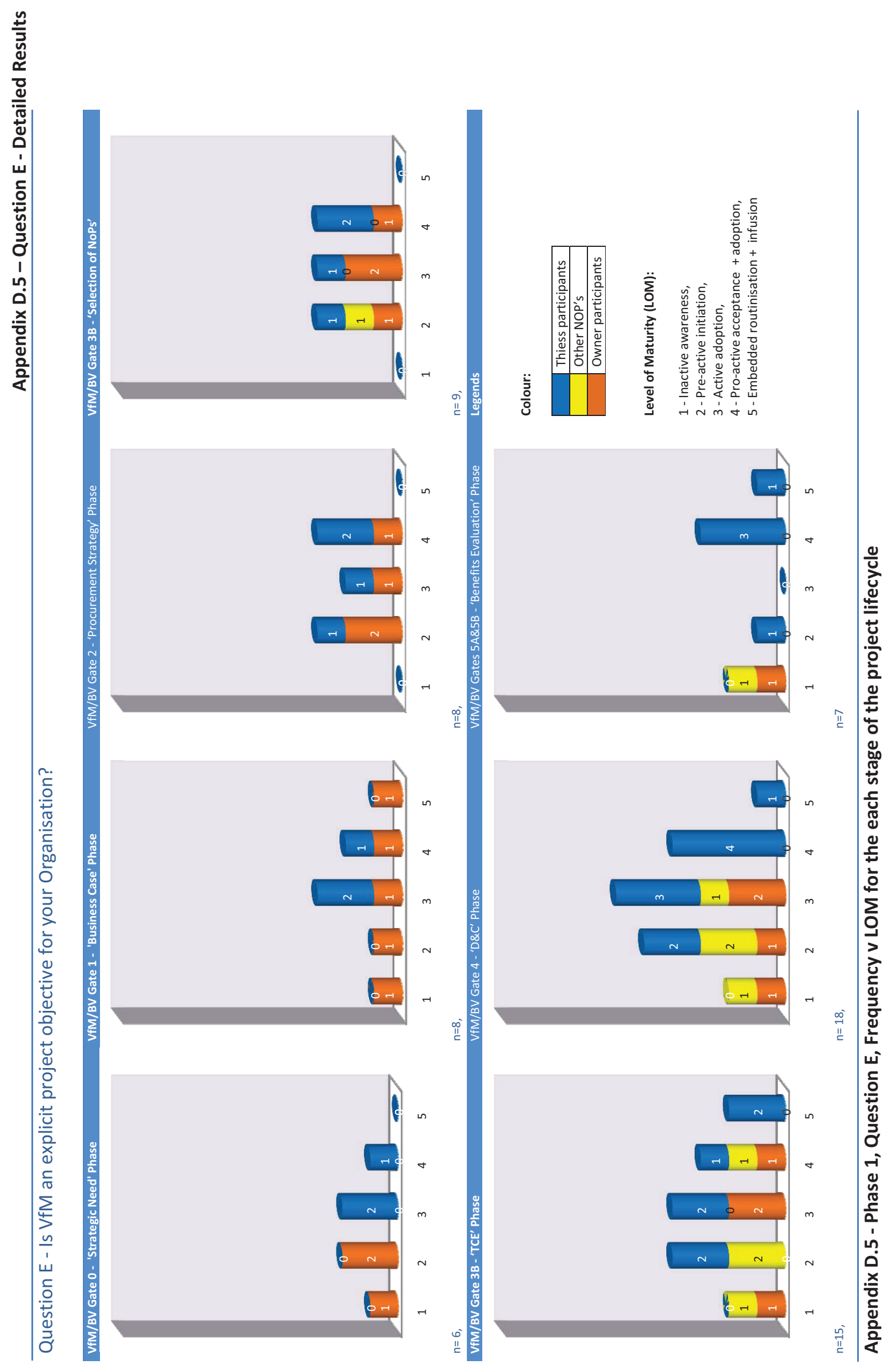


Appendix D.6

Are specific measures normally in place (within your Organisation) to ensure that VfM is achieved?

Question F 


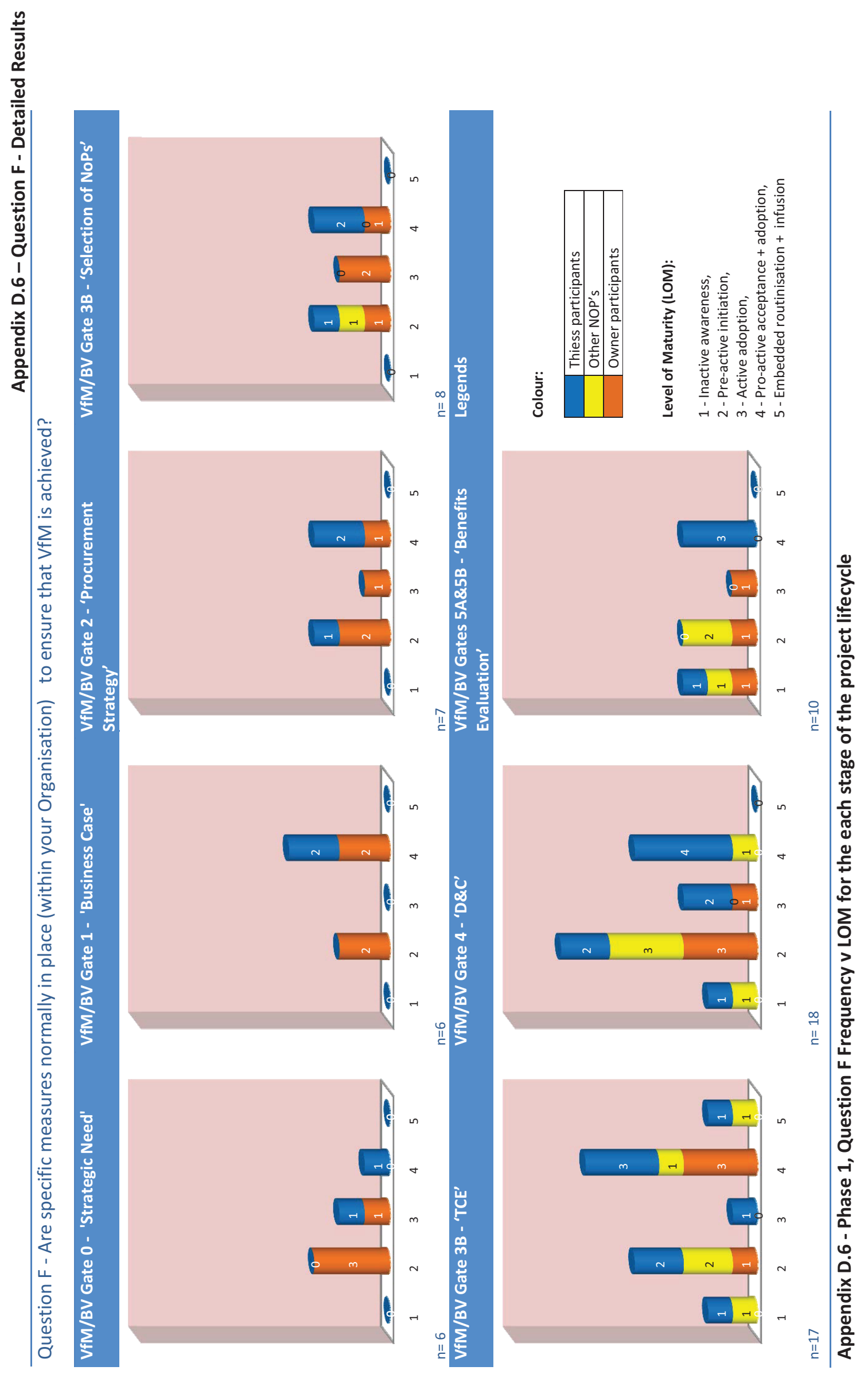




\section{Appendix D.7}

Are specific measures normally in place (within your Organisation) to ensure that $\mathrm{VfM}$ is demonstrated to have been achieved?

\section{Question G}




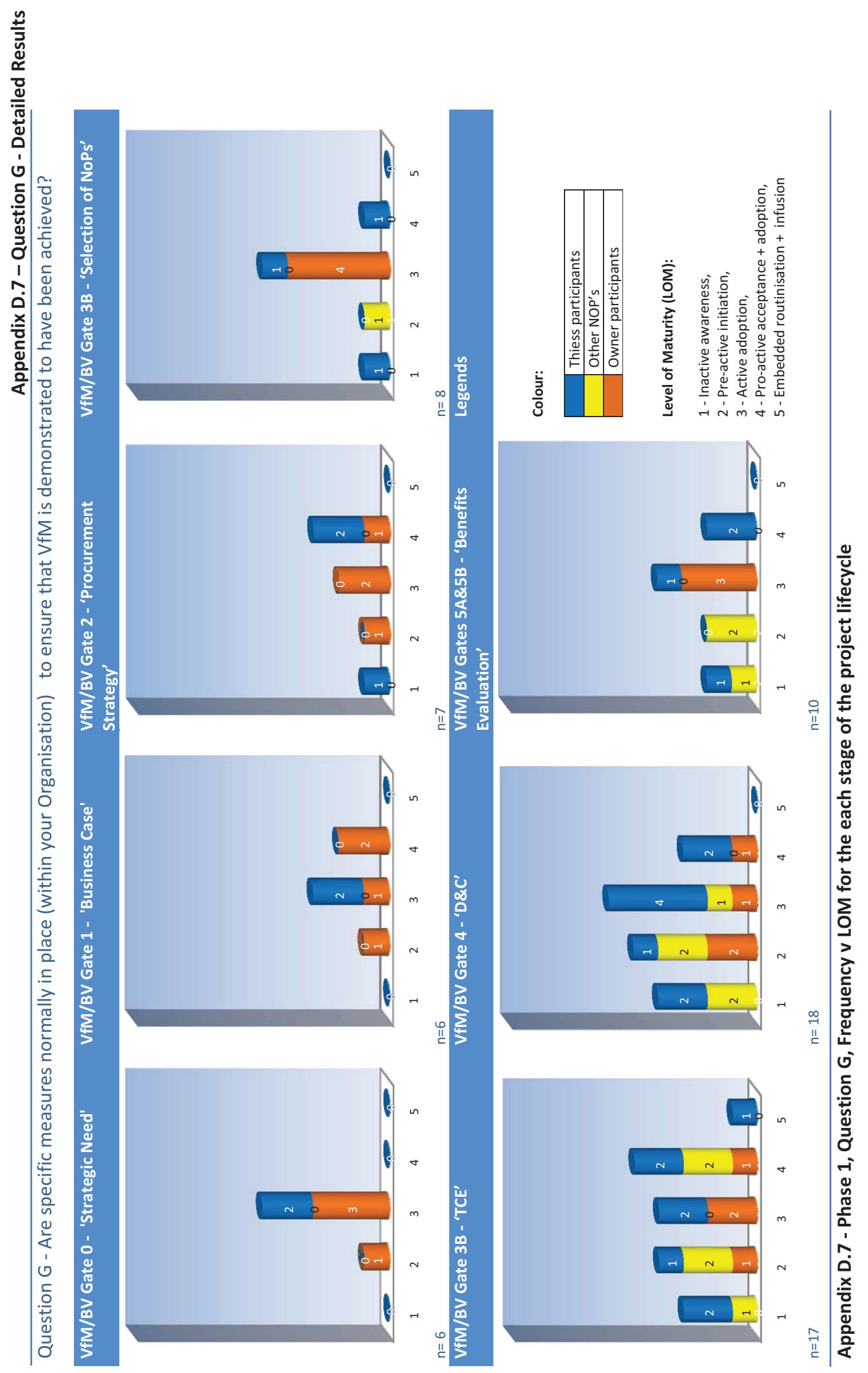




\section{Appendix D.8}

\section{Phase 1 Questionnaire \\ Open Questions}




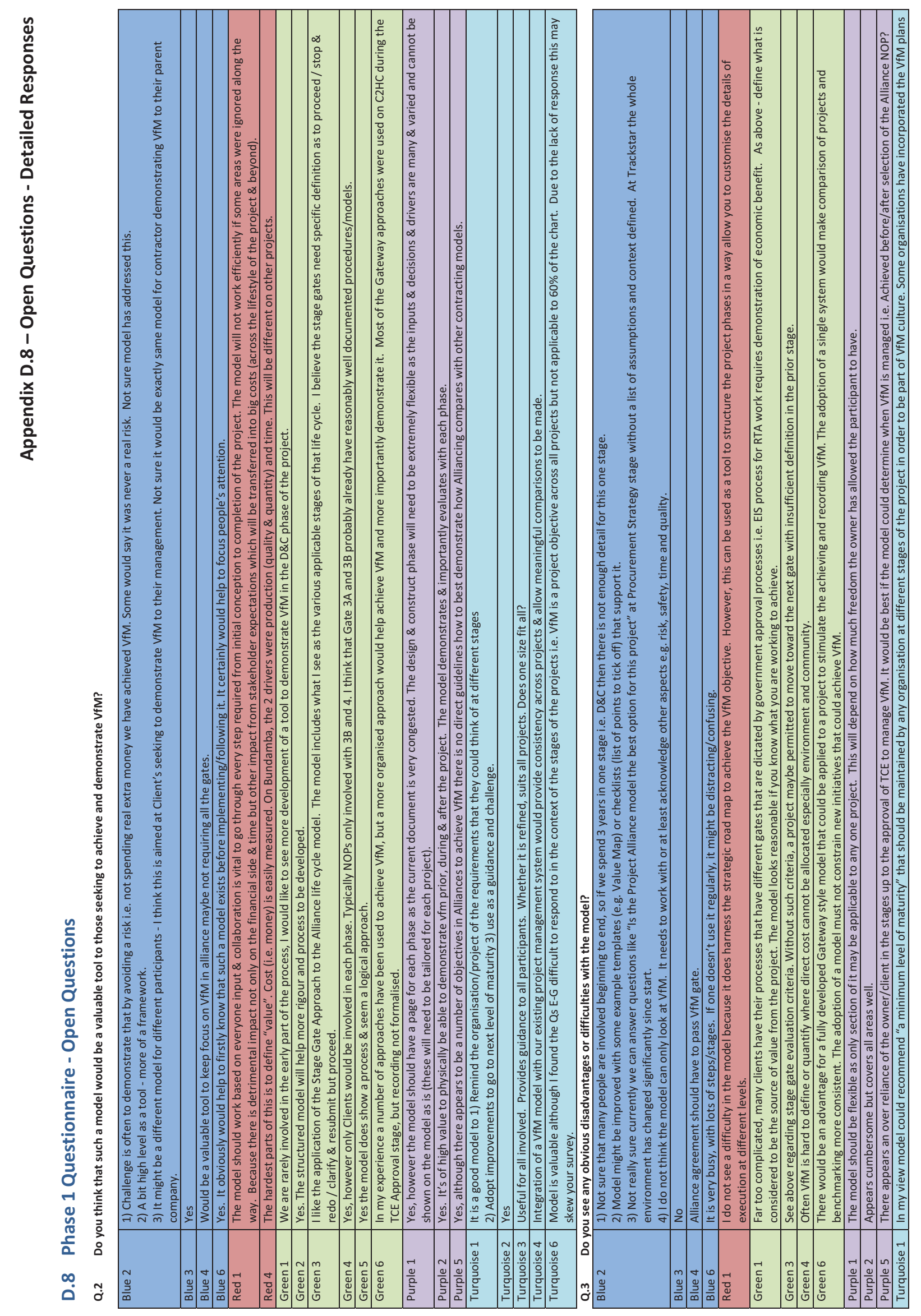




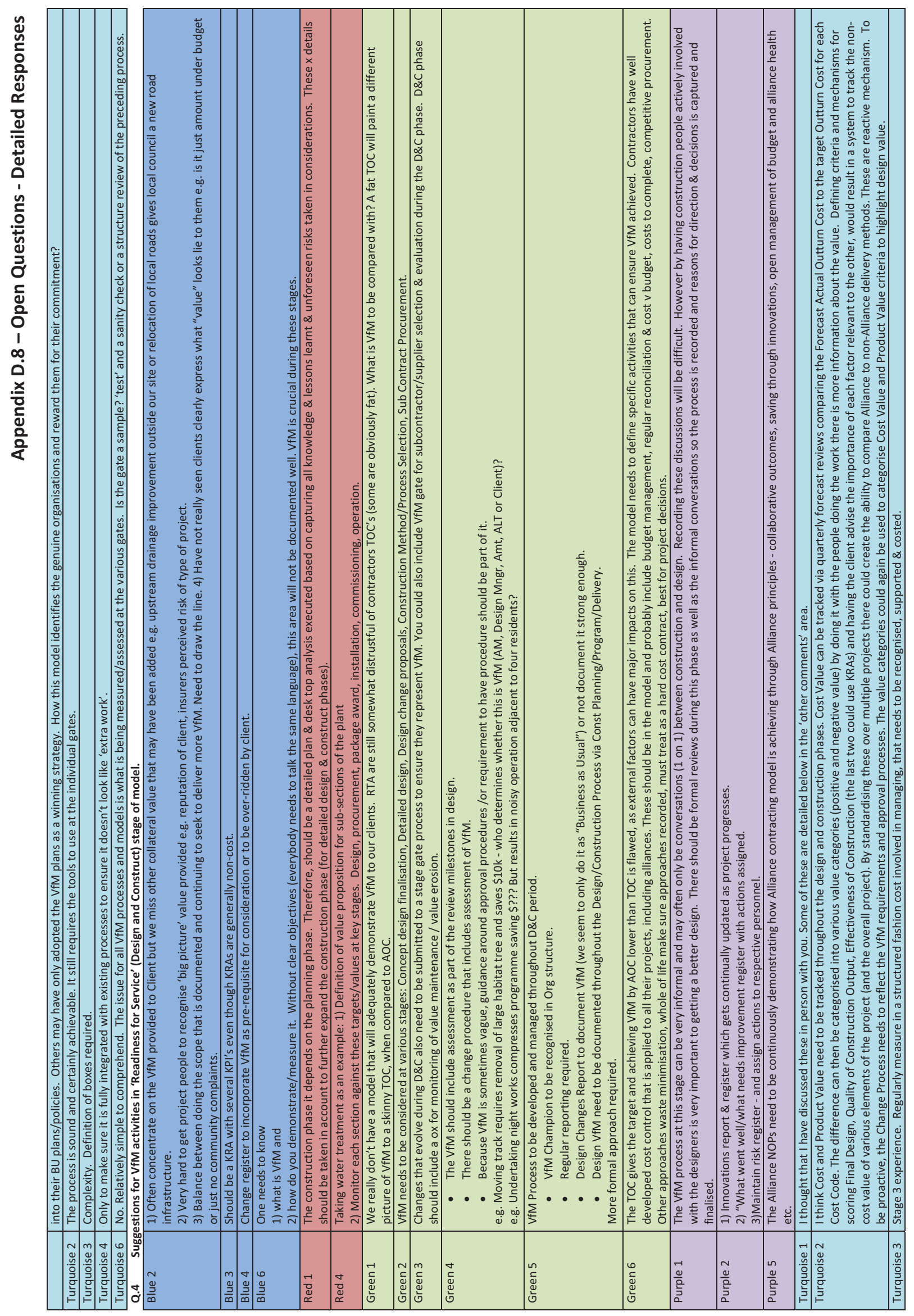



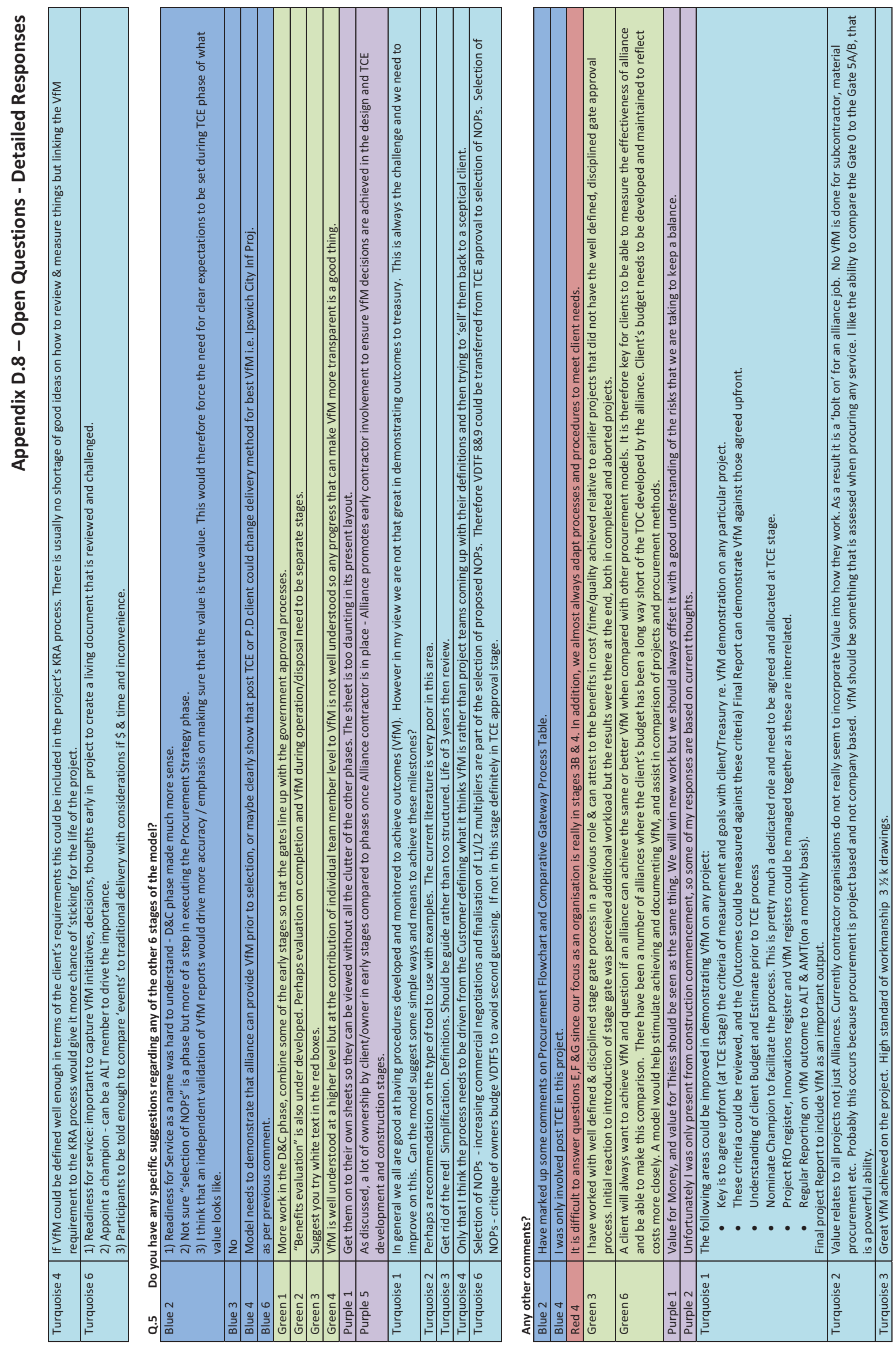


\section{Appendix E.1}

\section{Delphi Survey, Round 1}


Phase 2: Detailed Results

\section{Delphi Survey, Round 1}

\section{Appendix E.1 - Delphi Survey, Round 1, Consolidated Responses}

\section{Round 1, Question 1}

You should have received an email from the researcher (Charles MacDonald) with the following attachments:

- A briefing paper which describes the research and the details of your participation,

- The VfM/BV framework/model in the form of a flowchart and;

- A table associated with the framework/model which describes the issues to be addressed at each VfM/BV Gate.

If you have not received this email, or if you have any queries following receipt of this material please contact Charles MacDonald by email or phone (macdonald@optusnet.com.au or 0412250638 ).

During this first round a limited number of general questions are being asked to initiate the process. More specific and detailed questions are likely to be posed in the subsequent two rounds once initial responses are received and respondents become more familiar with the framework/model. No response is required to this 'question' which is really just a statement to introduce the questions for this first round of the Delphi process.

\begin{tabular}{|c|c|}
\hline Expert \# & Answer \\
\hline$\# 1$ & No response needed. \\
\hline \#2 & No response \\
\hline \#3 & The briefing note is very clear and the information is very easy to follow. \\
\hline \#4 & No answer required \\
\hline \#5 & --- \\
\hline \#6: & no response asked for \\
\hline \#7 & OK \\
\hline \#8 & Noted \\
\hline \#9 & $\mathrm{n} / \mathrm{a}$ \\
\hline \multirow[t]{2}{*}{$\# 10$} & text \\
\hline & OK \\
\hline
\end{tabular}


Round 1, Question 2

The objective of developing the framework/model is to ensure the achievement and demonstration of VfM/BV. Do you think the framework/model achieves this objective?

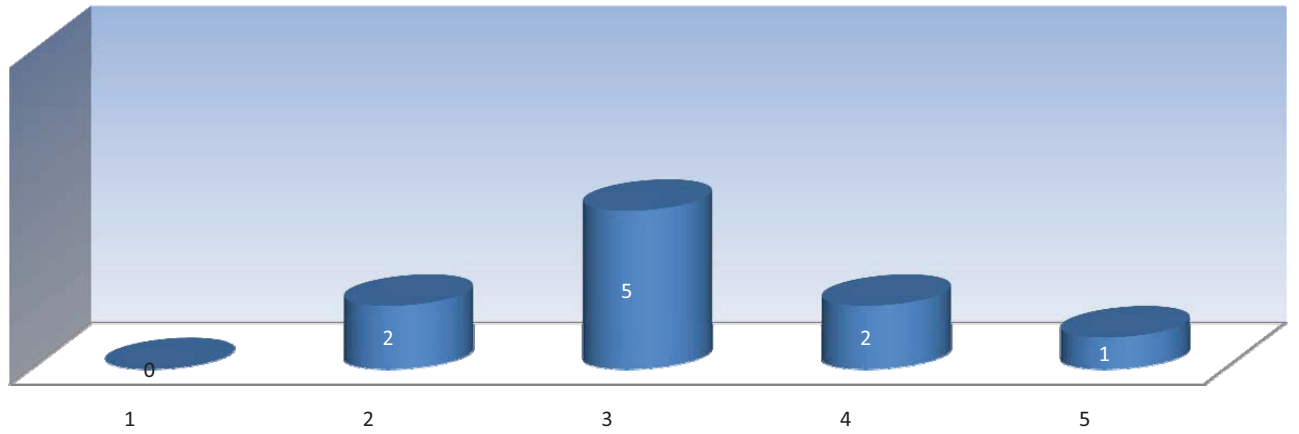

\begin{tabular}{lcc}
\hline & Scale: 1 (The model fails to achieve the objective) & Scale: 5 (The model clearly achieves the objective) \\
\hline Responses & 10 \\
Ave & 3.2 \\
SD & 0.87 \\
Median & 3.0 \\
\hline
\end{tabular}

Expert \# : Rating

\#1 : 2

2

Answer

The model as presented appears to largely summarise and consolidate the framework established in existing documents. Whilst this is potentially useful, it does not appear to go much further than current documented practice and provides no detail of each step in the process. Demonstration of VFM/BV is such a subjective issue (with deeply entrenched positions held by those on both sides of the VFM paradox) that it will require deeper consideration or perhaps a different approach. I do not see that much has changed from the current status quo and hence the VFM paradox that Charles describes. I would like to see more detail around the decision making process to decide on the most appropriate contracting strategy. On the face of the flowchart, I am not sure where this step occurs - but logically it is around the "Contract/ Procurement Strategy" step towards the end of the "Predecision to adopt a Project Alliance procurement model" stage. I suggest there is value in dealing with this process in far more depth. I do not agree that all of the "red" boxes are "critical to delivering and demonstrating VFM". Examples include "Critique of Owner's Budget Estimate" (which may not be possible or useful in many cases), "Interim Procurement Plan" (this will almost always be a "loose" document with not "teeth" or real context - it can only be a regurgitation of text book stuff or a sanitised version from the last project - adds no value in most cases just cost IMHO); "TCE launch workshop" (this is a dated concept that was useful when alliances first started - in general the industry has moved on, although there may be isolated cases where it adds value); "Financial audit (repeated as required through procurement process)" (I think this should say "Financial audit (repeated periodically over the life of the alliance)" and spread across "Detailed Design" and "Construction" as well.) I some ways, I see the addition of more and more "red boxes" likened to putting more and more bandaids on a gaping wound. Whilst most of them are required, they do not address the fundamental VFM paradox. The above comments may be unjustly harsh - there is probably a lot more detail yet to come.

\#2 : 3

I don't think any framework is capable of ensuring the achievement and demonstration of VfM/BV in any absolute way, because perceptions of what represents VfM/BV are so varied. However I think this has the makings of being a comprehensive and useful framework/model in pursuit of that goal. However in many it needs some refinement (see later comments). While it brings together a lot of approaches already being used, it does not present any new breakthroughs in the understanding or management of the VfM process.

The model provides a good process for ensuring VfM/BV but does not provide useful benchmarks for each Gate which would ensure, if achieved, that VfM has been achieved
The flow chart is a process which precisely details the steps taken to commence and conclude an alliance project. Along the way VFM should be able to be articulated. The following of the flow chart in no way guarantees that VFM will be achieved.

Firstly the model is very front end loaded to the feasibility and selection process. It is very structured to the owner or client. The large area of real measure and criticism of VFM is in the design and delivery phase but this is not well addressed. Finally a clear measure of what and who is agreeing to the yard stick of VFM is still a big issue. Before you are able to establish whether it is achieved.

The model misses a few steps that need to be considered. 1 - Reasons why a delivery method(s) was selected. This changes the "value" proposition. In recent times alliances have been selected, not because of specific project 


\begin{tabular}{|c|c|}
\hline & $\begin{array}{l}\text { scopes/timing but, because they have been seen as a means of solving lack of personnel resourcing requirements. } \\
\text { Hence value proposition client is using is wrong. If resource constraints are his real driver for a procurement } \\
\text { method then his value proposition needs to reflect this. } 2 \text { - Have assumed that selection of delivery method is } \\
\text { independent of the scope to be delivered, i.e. the scope has been bedded down before delivery method agreed. } \\
\text { Will suggest that scope and method are linked and that scope may need to change/be changed if different } \\
\text { delivery methods are being considered (e.g. choice of single or 2TOC alliances). } 3 \text { - Model inadequately addresses } \\
\text { pressures on 2TOCs. The use of independent estimate is too late in the program if 2TOC is used. Question whether } \\
\text { most clients really have the skill base to adequately assess prices from 2TOCs. This is because under D\&C if they } \\
\text { award to wrong lower price then contractor just wears it (though client gets more claims later). If client awards to } \\
\text { the wrong lower TOC (due to inability to really assess costing) then they end up with wrong TOC and having to } \\
\text { make major contributions later. Hardly a value for money proposition. In this state there have been } 3 \text { spectacular } \\
2 \text { TOCs that have gone way over original awarded lower TOC value. } 4 \text { - Use of KRA/KPI needs to be carefully vetted. } \\
\text { What are the client's real drivers for these? Real need or the "alliance consultant market" selling this is what you } \\
\text { need to add into alliances. Midway through alliances some clients are scrapping the use of KPIs as a) GFC now } \\
\text { means financial outcome is the only driver and b) the value assigned to KPI outcomes is of limited } \$ \text { amount and } \\
\text { hence not a great driver for performance in wider project context. } 5 \text { - In evaluation of benefits at the end of the } \\
\text { project should have a re-evaluation of the drivers for procurement first and then assess how project went against } \\
\text { the drivers. Drivers pre GFC were vastly different to those in a post GFC world. }\end{array}$ \\
\hline \#8:3 & Model is quite complex. \\
\hline$\# 9: 5$ & $\begin{array}{l}\text { As a flowchart there is a demonstration of activities and tasks that need to be completed to ensure a prescribed } \\
\text { VfM process is followed. In doing so an external auditor (whether favourable to the process or not) can at least } \\
\text { evaluate the outcomes to an agreed process. }\end{array}$ \\
\hline$\# 10: 3$ & The model does not seem to really specifically explain "how" BV will be achieved. \\
\hline
\end{tabular}


Round 1, Question 3

Do you think the framework/model could be a valuable tool to Owners in seeking to ensure the achievement and demonstration of VfM/BV?

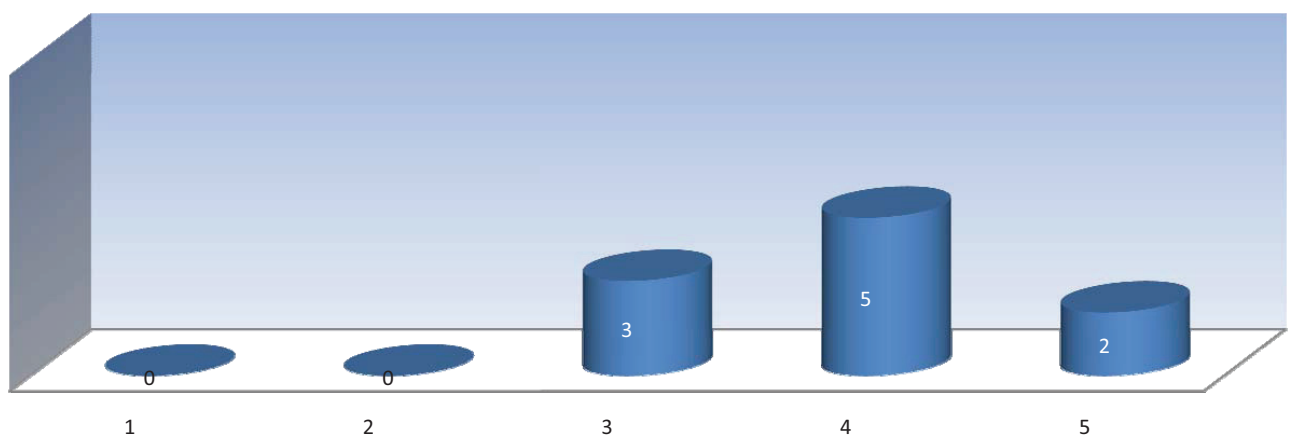
Rating: 5 Highly valuable

\begin{tabular}{|c|c|}
\hline \multicolumn{2}{|c|}{ Rating: 1 (Not at all valuable) } \\
\hline Responses & 10 \\
\hline Ave & 3.9 \\
\hline SD & 0.70 \\
\hline \multirow[t]{2}{*}{ Median } & 4.0 \\
\hline & Answer \\
\hline $\begin{array}{l}\text { Expert \#1: } \\
\text { Rating } 3\end{array}$ & $\begin{array}{l}\text { The framework as presented appears to consolidate content from other sources and therefore is a useful } \\
\text { summary of the key generic steps that should be followed in a project life-cycle. I see it as an adjunct to existing } \\
\text { documents more than a valuable tool in its own right. }\end{array}$ \\
\hline $\begin{array}{l}\text { Expert \#2: } \\
\text { Rating } 3\end{array}$ & $\begin{array}{l}\text { Refer comments in response to question } 2 \text { above. It provides a VfM roadmap for owners and is obviously a } \\
\text { valuable tool for owners. But as stated in the response to question 2, although it brings together a lot of } \\
\text { approaches already being used, it does not present any new breakthroughs in the understanding or management } \\
\text { of the VfM process. }\end{array}$ \\
\hline $\begin{array}{l}\text { Expert \#3: } \\
\text { Rating } 4\end{array}$ & $\begin{array}{l}\text { The model will provide some discipline for owners in assessing and reassessing whether VfM is being achieved. } \\
\text { The drawback is that the model does not explain how VfM will be assessed at each Gate }\end{array}$ \\
\hline \multicolumn{2}{|l|}{$\begin{array}{l}\text { Expert \#4: } \\
\text { Rating } 4 \\
\end{array}$} \\
\hline $\begin{array}{l}\text { Expert \#5: } \\
\text { Rating } 4\end{array}$ & Similar response as to Question 1 \\
\hline $\begin{array}{l}\text { Expert \#6: } \\
\text { Rating } 3\end{array}$ & $\begin{array}{l}\text { It is a good start. But the upfront measure of what is a good outcome and agreeing on that first is key. The } \\
\text { decision making process by owners alone before an ALLIANCE is established is a risk depending on the project. As } \\
\text { the owner may not get the real story from in-house or consultancy support. Greater involvement of others } \\
\text { outside of traditional design consultants would add a balanced view. When a project gets to the delivery phase } \\
\text { the shared view of VFM may change from the original desire of the client at the feasibility stage. }\end{array}$ \\
\hline $\begin{array}{l}\text { Expert \#7: } \\
\text { Rating } 4\end{array}$ & $\begin{array}{l}\text { Yes. It highlights various steps not always considered - especially those suggested in response to Question } 2 \text { that } \\
\text { should be added. Should enable tracking of drivers through each stage of the project. Clients and NOPs need to be } \\
\text { realistic about how drivers change during longer projects or program alliances. A model that enables review } \\
\text { during project lifetime is a good idea. }\end{array}$ \\
\hline \multicolumn{2}{|l|}{$\begin{array}{l}\text { Expert \#8: } \\
\text { Rating } 4\end{array}$} \\
\hline $\begin{array}{l}\text { Expert \#9: } \\
\text { Rating } 5\end{array}$ & $\begin{array}{l}\text { An Owner organisation can present the flowchart as an agreed or standardised process to all project participants. } \\
\text { The detailed process will be agreed by the project participants (in particular the Owner) there is an expectation of } \\
\text { a target in regards to the VfM to be aimed for and then measured against. }\end{array}$ \\
\hline $\begin{array}{l}\text { Expert \#10: } \\
\text { Rating } 5\end{array}$ & no doubt- BUT very hard to achieve in a "mechanistic " way \\
\hline
\end{tabular}




\section{Round 1, Question 4}

Do you think the framework/model could be a valuable tool to NOP's in seeking to ensure the achievement and demonstration of $\mathrm{VFM} / \mathrm{BV}$ ?

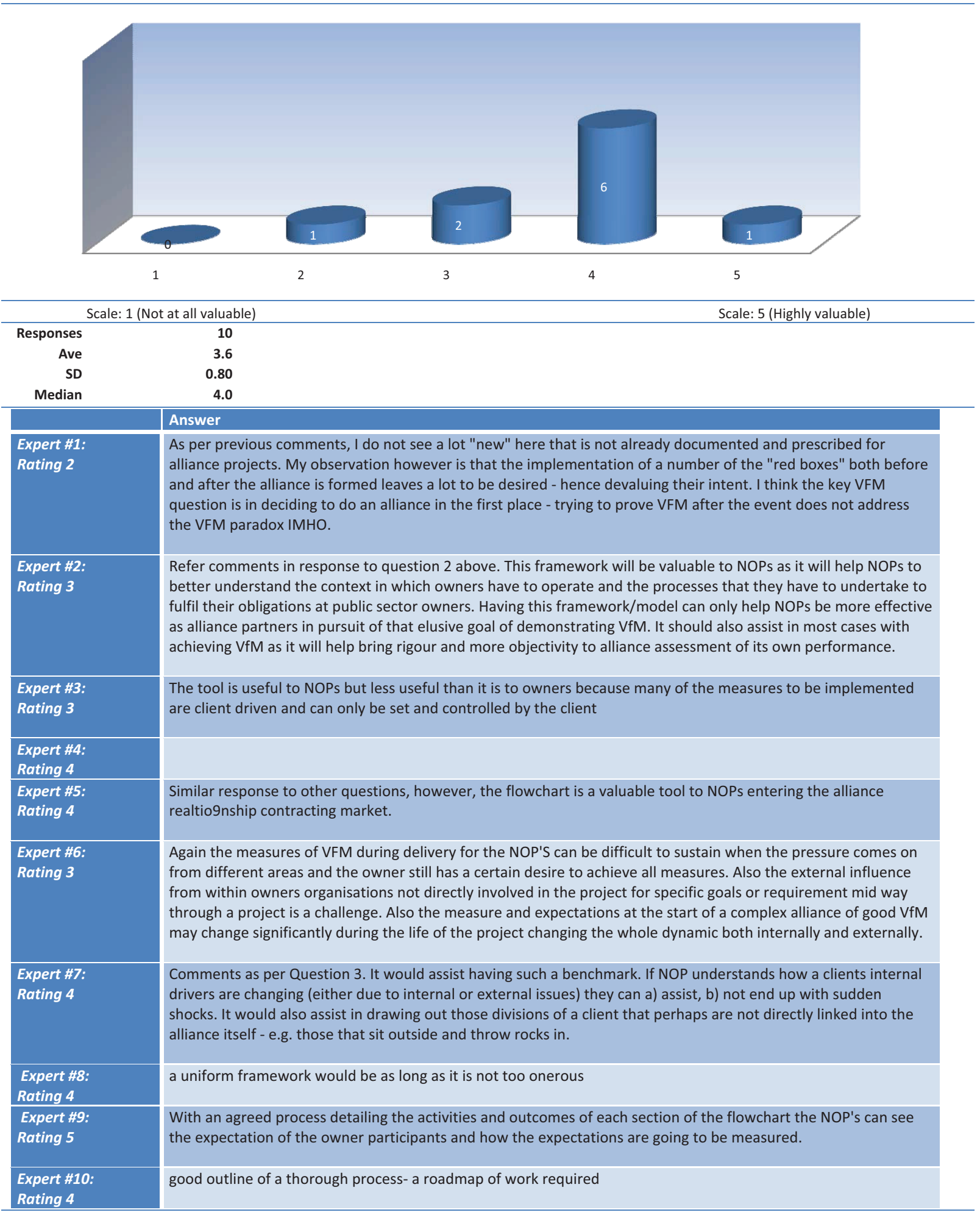




\section{Round 1, Question 5}

\section{Do you see any particular disadvantages or difficulties with the framework/model?}

\begin{tabular}{|c|c|}
\hline & Answer \\
\hline Expert \#1: & $\begin{array}{l}\text { Advantages - a good summary of required steps as per current documents (not sure how rigorous this is when } \\
\text { compared to the State Government PAF or the Gateway process). } \\
\text { Disadvantages - not a lot new and does not address the fundamental questions IMHO. }\end{array}$ \\
\hline Expert \#2: & $\begin{array}{l}\text { I think the framework/model needs refinement to address the following issues: } \\
\text { I think the model needs to consider a single TOC selection processes separately from a dual TOC process. At the } \\
\text { moment the model tries to fit them into the same flowchart but I think the VfM processes under each are } \\
\text { fundamentally different. If you have full dual TOC then you are relying heavily on price competition to ensure and } \\
\text { demonstrate VfM, in much the same way that an owner relies on the tendering process under a D\&C. While you } \\
\text { still need alliance-specific VfM steps with a dual TOC process, they are quite different to what is required with a } \\
\text { single TOC process. } \\
\text { The flowchart makes specific reference to the VfM initiatives set out in section } 5.2 .2 \text { of the VDTF Project Alliancing } \\
\text { Practitioners' Guide ("VDTF Guide"). In this respect: - These initiatives are mostly only relevant to the single TOC } \\
\text { process. [Refer previous bullet point.] - In the context of the single TOC process, there have been many } \\
\text { enhancements since the VDTF Guide was written. - The publication on 02Nov2009 of the VDTF "In Pursuit of } \\
\text { Additional Value" report heralds the death knell of the current VDTF Guide. For all these reasons I think it would } \\
\text { be better to remove the cross-references to section } 5.2 .2 \text { of the (current) VDTF Guide. } \\
\text { I note the model shows "Commercial Alignment Workshop" at the start of the pink-shaded TCE approval phase. } \\
\text { This belongs at the end of the green-shaded "Selection of NOPs" phase. } \\
\text { I would include a preliminary Target Adjustment Alignment (TAG) workshop at the end of the green-shaded } \\
\text { "Selection of NOPs" phase, and a final TAG workshop somewhere within the TCE approval phase. } \\
\text { Minor point this - I note the use of the term "Turn-out Cost Estimate", with associated acronym "TCE". Why } \\
\text { introduce yet another term into the already confusing landscape of TCE, TOC, DCT? Although not perhaps ideal } \\
\text { terminology, the term TCE is widely understood to mean "Target Cost Estimate". The use of "Turn-out Cost } \\
\text { Estimate" is likely to further confuse the understanding of TCE and get mixed up with the term "Outturn". }\end{array}$ \\
\hline Expert \#3: & $\begin{array}{l}\text { There are too many measures in several of the phases so it will be cumbersome to implement. Some of the } \\
\text { measures (e.g. procurement plan, risk/opportunity valuation, launch workshop) are unlikely to assist in measuring } \\
\text { VfM and could be removed. }\end{array}$ \\
\hline Expert \#4: & $\begin{array}{l}\text { No - It presents a structured approach. The key issue, where Alliances are used for public infrastructure Agencies } \\
\text { do not have the time to effectively develop budgets and concept designs prior to project start }\end{array}$ \\
\hline Expert \#5: & No \\
\hline Expert \#6: & $\begin{array}{l}\text { Current lack of detail during design and delivery phase Understanding why you would even look at an alliance } \\
\text { needs a front end filter to gauge VFM vs. other delivery methods The frame work is very much process without } \\
\text { getting to the core definition and measure of VFM and by whom (this may need to be looked at in sub areas } \\
\text { rather than a project) }\end{array}$ \\
\hline Expert \#7: & $\begin{array}{l}\text { With added parts suggested it will become complicated in one page document. Need a simpler } 7 \text { stage model with } \\
\text { back up pages for greater detail on each. That way could include the "Reviews" page within the relevant model } \\
\text { page rather than a separate document. Same colour coding assists. }\end{array}$ \\
\hline Expert \#8: & $\begin{array}{l}\text { One main one....it looks very complex Still need to fully understand nexus between investment justification, and } \\
\text { the proving of value to the owner. The proving of value should not be so involved as to cost money to do }\end{array}$ \\
\hline Expert \#9: & $\begin{array}{l}\text { There is a lot of detail, however the detail is needed as it shows the process is thought through for the entire } \\
\text { project and that VfM is not a calculation performed at the start of the cost calculations. }\end{array}$ \\
\hline Expert \#10: & $\begin{array}{l}\text { not really- it is a quite detail process, it looks quite linear- not sure the world proceeds like this- the challenge is } \\
\text { not so much the "what" which this process outlines but it is the "how" BV is achieved which is not so clear }\end{array}$ \\
\hline
\end{tabular}


Round 1, Question 6

\section{The table identifies specific VfM/BV issues that should be addressed at the end of each stage of the project lifecycle. Do you} have any comments regarding the issues listed e.g. are any inappropriate or have any important issues been overlooked?

\begin{tabular}{|c|c|}
\hline & Answer \\
\hline Expert \#1: & $\begin{array}{l}\text { Refer previous comments on the "red boxes". The real answer lies in the detail of key steps, how they are } \\
\text { implemented, who is involved, etc (Contract/Procurement Strategy is probably the biggest one). I suspect also } \\
\text { that the multiple TOC process has been given "lip service". This will be seen by the critics as dismissal of their } \\
\text { fundamental position on the VFM paradox and will hence devalue the credibility of the model from their } \\
\text { perspective. The fact is that we are going to see more multiple TOC alliances - if not, the model will be replaced by } \\
\text { something like the NSW ECI process I suspect. }\end{array}$ \\
\hline Expert \#4: & Very comprehensive \\
\hline Expert \#5: & $\begin{array}{l}\text { Again the table sets out the right statements questions and outputs that people should be looking for to come to } \\
\text { a view on achievement of VFM. It is the quality of the documents and the level of innovation and creativity that is } \\
\text { developed within the alliance that needs to be qualitatively and quantitatively compared to similar projects } \\
\text { delivered by varying forms of delivery method to form a view on whether VFM was achieved. Simply achieving the } \\
\text { stated purpose of the project isn't the absolute test of VFM. } \\
\text { No }\end{array}$ \\
\hline Expert \#6: & $\begin{array}{l}\text { The Gate } 1 \text { may need some additional components for review (only cost and risk) Gate } 2 \text { again may need some } \\
\text { interim gates prior to a decision on Procurement strategy as this is a big decision for an owner and ultimate VFM } \\
\text { Gate } 3 \text { - very traditional cost driven really. Between Gate } 3 \text { and } 4 \text { not much at all considering the time, cost and } \\
\text { opportunity in these phases. But also the changing beast that may need an opportunity to realign what VFM is. }\end{array}$ \\
\hline Expert \#7: & $\begin{array}{l}\text { Gate } 0 \text { "values" - are these project objective driven or organisation/cultural driven? } \\
\text { Gate } 1 \text { - Business case - is enough done on real initial budgets and adequate contingencies? } \\
\text { Gate } \mathbf{2} \text { - Under 2TOCs is the scope very clear and then how do you adjust TOC assessment / selection of NOP } \\
\text { based on different interpretations of inadequately defined scope. This is especially issue where benefit of alliance } \\
\text { can be when scope cannot be adequately defined. How does client then treat variations that do happen in 2TOC - } \\
\text { more than pure TOC? } \\
\text { Gate } 3 \text { A - Does client use single client team in 2TOC bids (security of idea) or does he have enough good people to } \\
\text { adequately provide } 2 \text { teams into the } 2 \text { TOC bids? Growing trend of under resourced clients (reason for alliance in }\end{array}$ \\
\hline
\end{tabular}


Appendix E.1- Round 1 - Consolidated Response

\begin{tabular}{l}
\hline $\begin{array}{l}\text { the first place) trying to use one client teams in 2TOC bids and not really working with either NOP team but } \\
\text { supervising two D\&C bids. Are assessment criteria really clear to client and NOPs? } \\
\text { Gate 3B - Independent estimate review in context of 2TOC alliance bids needs to be carefully thought through. } \\
\text { Gate } 4 \text { - KRA/KPI - be clear on reasons for setting them and their expected value before pursuing. } \\
\text { Gate } 5 \text { - In final assessment would client use its internal team again and would they use NOP again? } \\
\text { table looks good strongly mirrors gateway process have a concern that proving the TCE is the main issue for many } \\
\text { clients what tools or processes will achieve this too much reliance on independent estimators traditionally }\end{array}$ \\
\hline $\begin{array}{l}\text { Expert \#8: } \\
\text { "summary" for the section and assist the demonstration of value for money as a continual process. }\end{array}$ \\
\hline $\begin{array}{l}\text { Expert \#9: } \\
\text { no: it looks pretty thorough. the big current problem is } 50 \% \text { of business cases do a very poor job of defining the } \\
\text { despecially then identifying BV }\end{array}$ \\
\hline
\end{tabular}




\section{Round 1, Question 7}

In the Procurement Strategy Phase of the model it is proposed that a detailed review of procurement options is undertaken progressively considering Traditional, D\&C and EOI options before considering Project Alliance options, either single or multiple TOC. The purpose of this particular activity is to clearly establish that a project alliance is the best procurement option to deliver $\mathrm{VfM} / \mathrm{BV}$ for a particular project. Do you agree that this process of elimination would assist in arriving at the most appropriate procurement strategy?

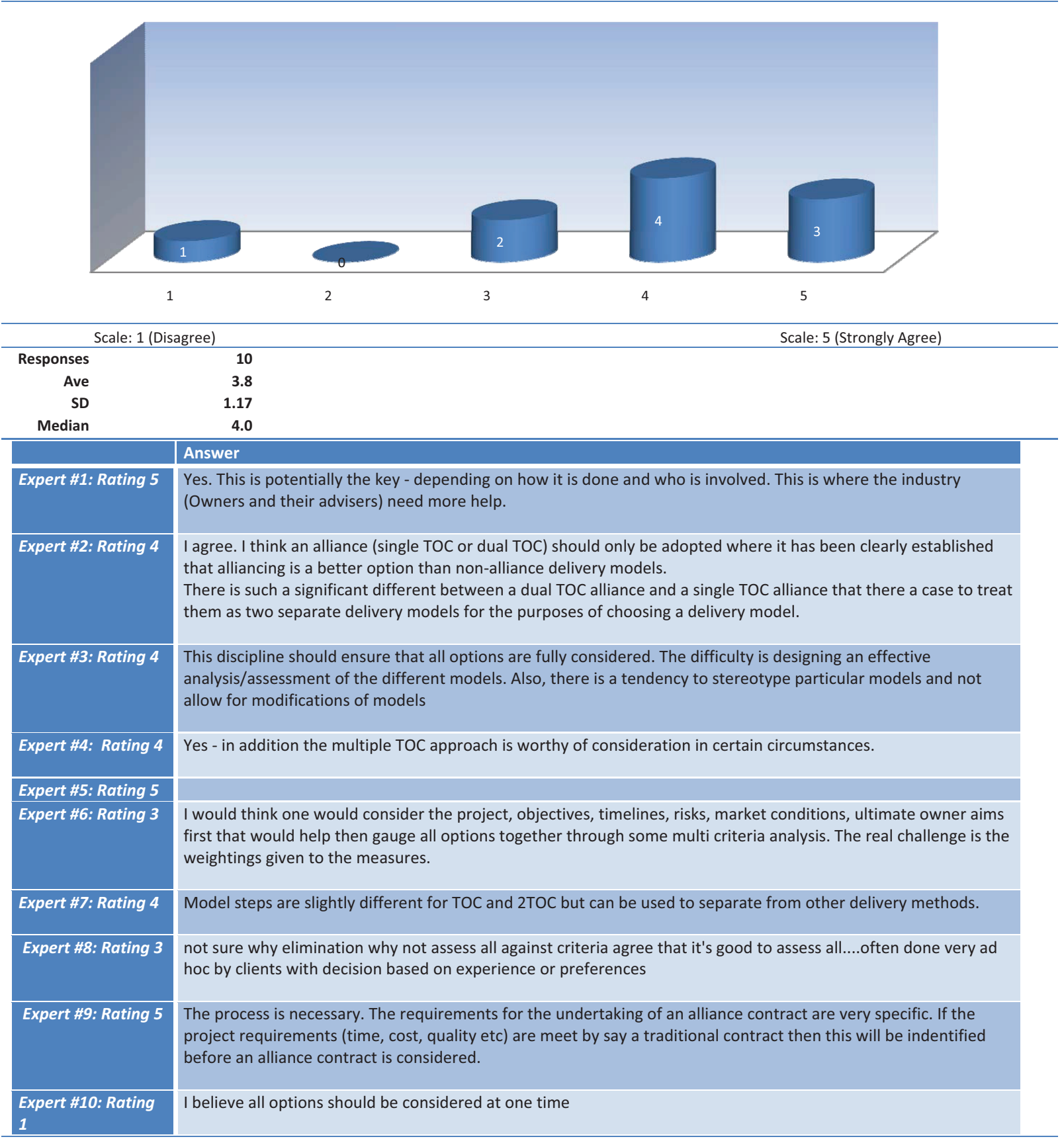


Round 1, Question 8

\section{The Readiness for Service (Design and Construct) Phase of the project lifecycle currently contains two activities: 1 ) the progressive preparation of a VfM/BV Report and 2) the continuous review of KPA's/KPI's. What specific comments do you have on the contents of these activities and are there other activities that should be adopted in this phase of the project lifecycle?}

\begin{tabular}{|c|c|}
\hline & Answer \\
\hline Expert \#1: & $\begin{array}{l}\text { These are good concepts that are rarely done well. Nothing else is needed - just to better define what is required/ } \\
\text { expected for each activity. Alliances could benefit from a "template" example of a good model rather than having } \\
\text { to try and develop something from scratch each time or use the poor effort they did on the last job as the basis for } \\
\text { moving forward. This is NOT core business for contractors or the engineering industry in general. They need some } \\
\text { help IMHO with regard to what might be a good and accepted approach. I have seen some pretty poor examples } \\
\text { of work in these areas - simply because people do their best but don't know what is required. The risk is that } \\
\text { theoretical advisers will make it harder than it needs to be! What the industry needs is a pragmatic example that } \\
\text { adds net value (i.e. it produces more value than it costs to produce!). }\end{array}$ \\
\hline Expert \#2: & $\begin{array}{l}\text { Within the progressive VfM report I suggest there should be a requirement to record any movements in the TOC } \\
\text { from initial TOC to final TOC. [The VDTF "In Pursuit of Additional Value" report refers to increases in the TOC of } \\
\text { approximately } 5 \%-10 \% \text {, but without any information to explain the reasons for such increases.] } \\
\text { Within the progressive VfM report I suggest there should be a requirement to document and categorise the } \\
\text { reasons for any differences between the (final) TOC and the AOC. }\end{array}$ \\
\hline Expert \#3: & $\begin{array}{l}\text { I am not sure of the value of a VfM report which is prepared progressively to justify an outcome. I am also not } \\
\text { sure that assessment of KPIs is useful is assessing VfM. But I have not had much to do with either and am not } \\
\text { really qualified to comment }\end{array}$ \\
\hline Expert \#4: & $\begin{array}{l}\text { The VfM proposition should be determined in the business case and taken forward into procurement strategy, } \\
\text { NOP selection etc. Based on the VfM objectives the VfM report can be developed. It is not clear if KRA,s and KPI's } \\
\text { make a contribution to VfM }\end{array}$ \\
\hline Expert \#5: & $\begin{array}{l}\text { The key to this phase is in the words, "progressive and continuous", however the review should emphase the } \\
\text { importance of intervention and resetting of KPI's if the results aren't adequately showing the achievement of the } \\
\text { KRA (project objective. This reconfirmation of the appropriateness of the KPI's and even the KRA's will increase } \\
\text { the probability that VFM will be delivered. }\end{array}$ \\
\hline Expert \#6: & $\begin{array}{l}\text { Again very traditional, the problem is on complex projects the need to balance the real needs and opportunities. } \\
\text { Obviously for NOP's ultimately they are still delivering the project with a financial driver irrespective of pain gain } \\
\text { models. The owner may well be protected ultimately by some in house contingency that enables pressure still to } \\
\text { be born on the alliance to deliver across all KRA's while the NOPs suffer some real financial pain. Also the goal } \\
\text { posts change which makes KRA measures sometimes hard to achieve. }\end{array}$ \\
\hline Expert \#7: & $\begin{array}{l}\text { Believe monthly reports should include VfM statements - if only to keep in peoples' minds and ensure capture. } \\
\text { Need to critically evaluate what drove the KRA/KPI in the first place and whether they are of ongoing value or } \\
\text { "noise" on the side. Evaluation of KRA/KPI needs to be done in context of the project and wider industry drivers. If } \\
\text { a GFC means only AOC outcome matters then be honest and address that in KRA. }\end{array}$ \\
\hline Expert \#8: & Who actually prepares it and who reads/ approves it ditto with KRAs.... who signs off \\
\hline Expert \#9: & $\begin{array}{l}\text { 1) Progressive preparation is necessary as discussed previously; VfM is a progressive process in that it is not } \\
\text { restricted to an economic calculation. As efficiencies need to be measured and an assessment on whether } \\
\text { effectiveness is being achieved, the process will be ongoing. } \\
\text { 2) KPA/KPIs also need a continual assessment to demonstrate a continual address to VfM aspects through this } \\
\text { section. }\end{array}$ \\
\hline Expert \#10: & $\begin{array}{l}\text { Should there be a checking at this point that the KPA/KPIs are still valid? The world may have changed! of course } \\
\text { this will not the assessment but may be common sense }\end{array}$ \\
\hline
\end{tabular}




\section{Appendix E.2}

\section{Delphi Survey, Round 2}


Delphi Survey, Round 2

\section{Appendix E.2 - Delphi Survey, Round 2, Consolidated Responses}

\section{Round 2, Question 1}

You should have recently received an email from the researcher (Charles MacDonald) with the following attachments:

- A new briefing paper (dated 16 November 2009) which describes the results of Round 1 and the changes that have been made to the VFM/BV framework/model to address a number of the comments that were made.

- Revised Round 2 framework/model - this is described in the briefing paper as the 'head' flowchart. This is now a much simplified flowchart which outlines the structure of framework/model and removes the detail of VfM/BV measures to supplementary flowchart/tables for each stage of the lifecycle.

- Round 2 flowchart/table - this describes VfM/BV considerations for the Procurement Strategy stage of the project lifecycle. Similar flowchart/tables will later be produced for each stage of the project lifecycle.

Questions 2, 3, 4 and 5 are a repeat of the questions posed in Round 1. They are being asked again to measure the extent to which the revised model ensures the achievement and demonstration of $\mathrm{VFM} / \mathrm{BV}$.

If you have not received this email, or if you have any queries following receipt of this material please contact Charles MacDonald by email or phone (macdonald@optusnet.com.au or 0412250 638) This 'Question 1' is not a real question and no response is required.

\begin{tabular}{|c|c|}
\hline Expert \# & Answer \\
\hline$\# 1$ & No response \\
\hline \#2 & $\mathrm{n} / \mathrm{a}$ \\
\hline \#3 & $\begin{array}{l}\text { A. It is difficult to answer the questions definitely as the new flowcharts/tables only cover the Procurement Strategy phase. } \\
\text { Without the details for the other phases I am unable to make an accurate rating of the overall framework. I have answered } \\
\text { on the assumption that the details for these other phases will be similar to what was included in the round } 1 \mathrm{VfM} / \mathrm{BV} \\
\text { reviews table. }\end{array}$ \\
\hline$\# 4$ & OK \\
\hline$\# 5$ & no response required! \\
\hline$\# 6$ & ok \\
\hline \#7 & OK \\
\hline$\# 8$ & Not applicable \\
\hline$\# 9$ & ok \\
\hline \multirow[t]{2}{*}{$\# 10$} & .. \\
\hline & No response required \\
\hline
\end{tabular}


Round 2, Question 2

The objective of developing the framework/model is to ensure the achievement and demonstration of VfM/BV. Do you think the Revised Round 2 framework/model achieves this objective?

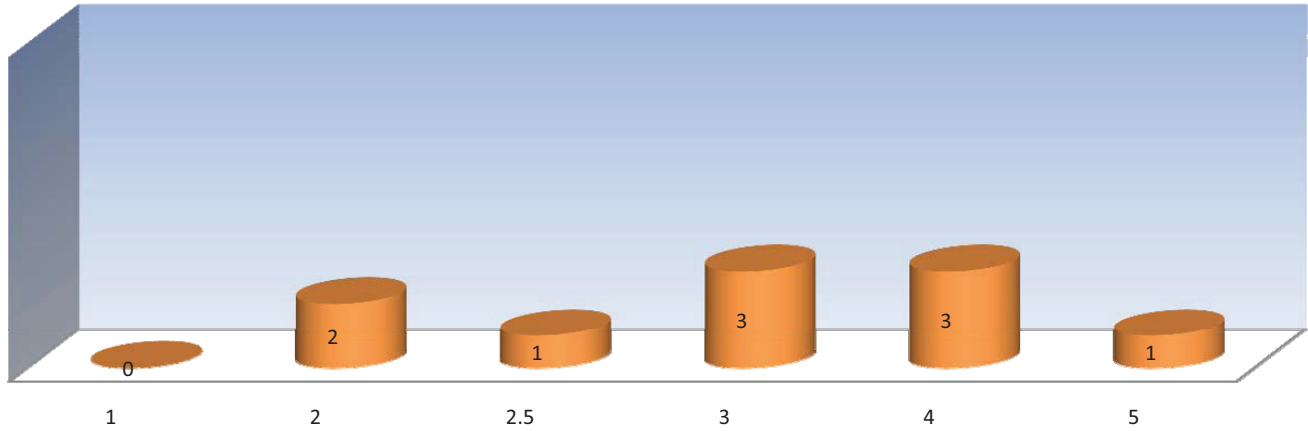

Scale: 1 (The model fails to achieve the objective)

Scale: 5 (The model clearly achieves the objective)

\begin{tabular}{|c|c|}
\hline \multicolumn{2}{|r|}{ Scale: 5 (The model clearly achieves the objective) } \\
\hline Responses & 10 \\
\hline Ave & 3.25 \\
\hline SD & 0.93 \\
\hline \multirow[t]{2}{*}{ Median } & 3.0 \\
\hline & Answer \\
\hline Expert \#1: Rating 3 & VFM and Gates still look very similar Model still quite complex but acknowledge that the process is also \\
\hline Expert \#2: Rating 3 & $\begin{array}{l}\text { The revised framework is clearer than the earlier version. The splitting of the single and dual TOC into separate streams is } \\
\text { much better. Although generally clearer, it still does not present any new breakthroughs in the understanding or } \\
\text { management of the VfM process. }\end{array}$ \\
\hline \multicolumn{2}{|l|}{ Expert \#3: Rating 4} \\
\hline Expert \#4: Rating 2 & $\begin{array}{l}\text { I know I am in the minority - I actually preferred the round } 1 \text { version- with the inclusion of the two types of TOC. To me it } \\
\text { showed more guidance about how a better VFM result may have been achieved }\end{array}$ \\
\hline $\begin{array}{l}\text { Expert \#5: Rating } \\
2.5\end{array}$ & $\begin{array}{l}\text { The question of value for money appears to centre around development of the TOC and then the remeasure at the time of } \\
\text { ready for service. the concept of VfM needs to be considered at all times and the mechanism should be available to reset } \\
\text { targets based on performance during the course of D \& C }\end{array}$ \\
\hline Expert \#6: Rating 2 & $\begin{array}{l}\text { The flowcharts are an enhancement on the previous version. However, in themselves they do not achieve the stated } \\
\text { objective. They provide a global framework of broad steps to be taken, but it is how well each step is executed that will be } \\
\text { the test of "ensure the achievement of VFM/BV". }\end{array}$ \\
\hline Expert \#7: Rating 3 & $\begin{array}{l}\text { It obviously not to different but a lot easier to understand The actual measure of whether VFM has been achieved at each } \\
\text { gate is still not clear. The gates are more just decision points along the journey What really defines VFM at these points is } \\
\text { unclear, is making a decision VFM or is it the justification of why, against an agreed framework. }\end{array}$ \\
\hline Expert \#8: Rating 4 & $\begin{array}{l}\text { What defines VfM for a client? Are they clear on it? Is it more/less than just cost? What are decision processes client goes } \\
\text { through before deciding to go multiple TOC rather than single TOC? Can client adequately assess the TOCs - especially if no } \\
\text { third party assistance is provided? Not sure clients appreciate they are more exposed if they pick wrong lower TOC provider } \\
\text { that they are under D\&C lower price. }\end{array}$ \\
\hline Expert \#9: Rating 4 & $\begin{array}{l}\text { A lot of the detail has been removed showing the steps within each project phase. With the reduced detail an uniformed } \\
\text { user cannot see which steps to take and may miss or not complete the phase correctly to achieve VfM. However, with the } \\
\text { decreased detail there is a clearer display and may provide less distraction to the user. }\end{array}$ \\
\hline $\begin{array}{l}\text { Expert \#10: Rating } \\
5\end{array}$ & $\begin{array}{l}\text { The revised model addresses the key issues: Project need High level Business case Feasibility study Business case review } \\
\text { should include cost plan and options Procurement strategy At Gate } 2 \text { the owner needs to determine the Value proposition. } \\
\text { Is the lowest cost that will provide the project functionality and level of service the value proposition or is early delivery, no } \\
\text { hassles, flexibility the value proposition? The revised model provides for the Multiple TOC approach which is refreshing. }\end{array}$ \\
\hline
\end{tabular}


Round 2, Question 3

\section{Do you think the Revised Round 2 framework/model could be a valuable tool to Owners in seeking to ensure the achievement} and demonstration of $\mathrm{VFM} / \mathrm{BV}$ ?

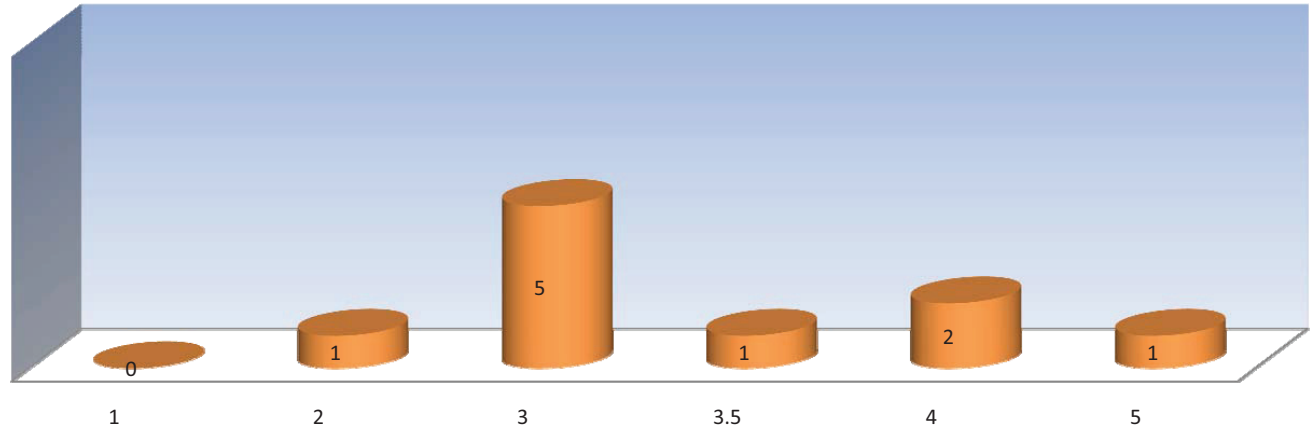

\begin{tabular}{|c|c|}
\hline \multicolumn{2}{|c|}{ Scale: 1 (Not at all valuable) } \\
\hline Responses & 10 \\
\hline SD & 0.78 \\
\hline Median & Answer \\
\hline $\begin{array}{l}\text { Expert \#1: Rating } \\
3.5\end{array}$ & $\begin{array}{l}\text { Yes...still I am struggling a bit with definition of VFM....the model will likely result in a sensible project that is not fatally } \\
\text { flawed, due to the Gates it passes through VFM/BV is a difficult concept for many people to grasp.....perhaps more is needed } \\
\text { to actually define what it is....to make it easier to the design a/the process to deliver it }\end{array}$ \\
\hline Expert \#2: Rating 3 & $\begin{array}{l}\text { As stated in round } 1 \text { feedback, it provides a VfM roadmap for owners and is obviously a valuable tool for owners. It is slightly } \\
\text { more effective because it is clearer }\end{array}$ \\
\hline Expert \#3: Rating 3 & $\begin{array}{l}\text { Tool provides a process for Owners to evaluate use of alliances and where this delivery method is selected there is choice of } \\
\text { single or multiple TOC's. }\end{array}$ \\
\hline Expert \#6: Rating 3 & $\begin{array}{l}\text { I can't remember what I scored last time, but there is no substantial change for me. Stronger recognition of the dual-TOC } \\
\text { approach is a good step. What is still missing from the information provided is the detail of what is involved in each step. } \\
\text { This is where the "rubber hits the road"! }\end{array}$ \\
\hline Expert \#7: Rating 3 & $\begin{array}{l}\text { I would suggest that the area of Contract Procurement Strategy needs a lot more detail to understand if VFM is achieved In } \\
\text { making the decision to go to an alliance then the detail around the multiple TOC decision and the selection of the preferred } \\
\text { NOP based on cost needs more measures to justify the selection The design and construction phase is still not robust to } \\
\text { change or complexity of projects and the changing objectives encountered on such projects. }\end{array}$ \\
\hline
\end{tabular}




\section{Round 2, Question 4}

\section{Do you think the Revised Round 2 framework/model could be a valuable tool to NOP's in seeking to ensure the achievement and demonstration of VfM/BV?}

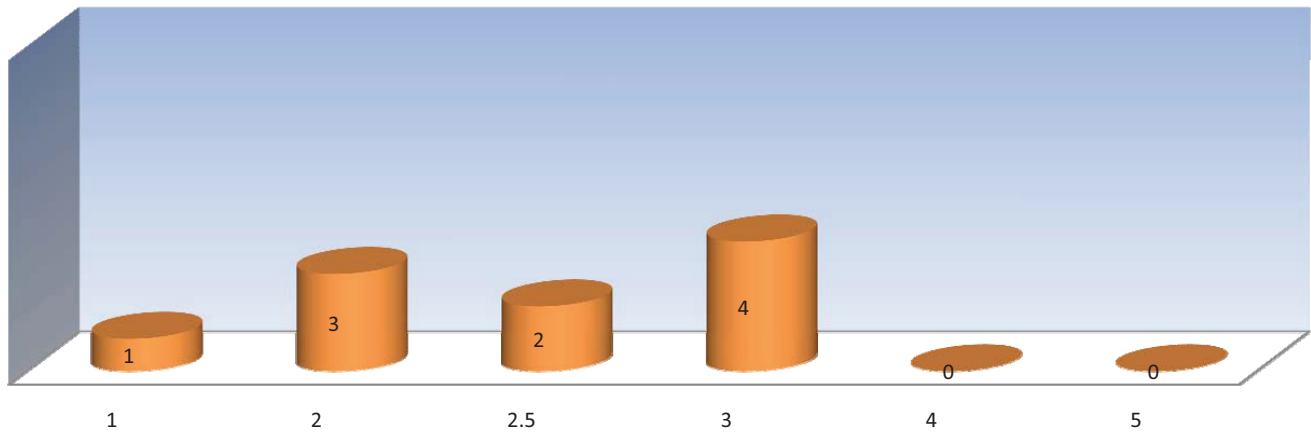

Scale: 1 (Not at all valuable)

Scale: 5 (Highly valuable)

\begin{tabular}{|c|c|}
\hline \multicolumn{2}{|c|}{ Scale: 1 (Not at all valuable) } \\
\hline Responses & 10 \\
\hline Ave & 2.4 \\
\hline SD & 0.62 \\
\hline \multirow[t]{2}{*}{ Median } & 2.5 \\
\hline & Answer \\
\hline Expert \#1: Rating 3 & $\begin{array}{l}\text { Still think a big issue is demonstrating the VFM inherent in the TOC It seems to be a historical sticking point....the perception } \\
\text { of value IE does not fully address this....need a process of review etc??? }\end{array}$ \\
\hline Expert \#2: Rating 3 & $\begin{array}{l}\text { No change from response in round } 1 \text {, although somewhat clearer than previously. Previously noted that "This framework } \\
\text { will be valuable to NOPs as it will help NOPs to better understand the context in which owners have to operate and the } \\
\text { processes that they have to undertake to fulfil their obligations at public sector owners. Having this framework/model can } \\
\text { only help NOPs be more effective as alliance partners in pursuit of that elusive goal of demonstrating VfM. It should also } \\
\text { assist in most cases with achieving VfM as it will help bring rigour and more objectivity to alliance assessment of its own } \\
\text { performance". }\end{array}$ \\
\hline Expert \#3: Rating 4 & Tool defines a process; true attainment of VFM is in documenting VFM achieved. \\
\hline Expert \#4: Rating 2 & see two previous answers \\
\hline Expert \#5: Rating 1 & $\begin{array}{l}\text { I do not see how from a NOP perspective VfM is demonstrated. the TOC either meets or fails the clients test at the time of } \\
\text { setting the TOC and similarly at the end of construction. }\end{array}$ \\
\hline Expert \#6: Rating 2 & Very little in the model for NOPs - other than stronger awareness of the upstream processes. \\
\hline $\begin{array}{l}\text { Expert \#7: Rating } \\
2.5\end{array}$ & $\begin{array}{l}\text { During the Multiple TOC process hard to understand what really are the weightings of VFM when multiple designs and prices } \\
\text { are being developed. If it is price then let the NOP no this is the real driver. During the design and construction phase not } \\
\text { that useful as cost still seems to be the real measure not all the promoted Non cost KRA'S. }\end{array}$ \\
\hline Expert \#8: Rating 3 & $\begin{array}{l}\text { Real stage NOP has to show VfM, especially in single TOC, is during the design and construct and operations phases which } \\
\text { have limited steps shown in flow chart. Reasons NOP may still need to show VfM is credibility issues especially in regards } \\
\text { client's people not directly involved in the alliance and may not see what benefits are being generated. }\end{array}$ \\
\hline $\begin{array}{l}\text { Expert \#9: Rating } \\
2.5\end{array}$ & $\begin{array}{l}\text { With the removal of the detailed information an NOP not familiar with the alliance selection process by the owner may not } \\
\text { understand what has proceeded before the alliance process was chosen or not chosen. The revised, reduced detail flowchart } \\
\text { will favour established NOP's that already have an understanding of the alliance selection process as they may not need the } \\
\text { steps clearly detailed to them as shown in the previous flowchart }\end{array}$ \\
\hline $\begin{array}{l}\text { Expert \#10: Rating } \\
2\end{array}$ & $\begin{array}{l}\text { The framework will be of interest to NOP's purely from the point of view of understanding the process. The owner is the key } \\
\text { decision maker that will determine the level of VfM. The NOP's will all encourage the Owner to select the Single TOC } \\
\text { approach as this reduces their risk and increases their level of profit }\end{array}$ \\
\hline
\end{tabular}


Round 2, Question 5

\section{Do you see any particular disadvantages or difficulties with the Revised Round $\mathbf{2}$ framework/model?}

\begin{tabular}{|c|c|}
\hline & Answer \\
\hline Expert \#1: & $\begin{array}{l}\text { As above Need to better define VFM Need to address TOC value perceptions...i.e. when is a TOC "fat" When is it not fat? If a } \\
\text { project underruns.... was the TOC fat, i.e. not VFM, or was the team high performing These things are difficult to prove/ } \\
\text { demonstrate How do you deal with risk allowances in/ out of TOC }\end{array}$ \\
\hline Expert \#2: & $\begin{array}{l}\text { Unable to comment on the details of the different phases (apart from the Procurement Strategy" phase. The "devil is in the } \\
\text { detail" but the detail is not available. } \\
\text { A minor point: in the Procurement Strategy flowchart/table the arrow pointing to "Proceed with EOI Approach" should I } \\
\text { assume refer to "ECI", not "EOI". } \\
\text { "Development of Project Proposal and TOC Approval" would be a more accurate phase description than "TOC Approval" TCE } \\
\text { development and } \\
\text { I think it would be clearer (in the case of the single TOC process) to refer to proponents or consortia (rather than NOP } \\
\text { candidates) prior to the "Select NOPs" gateway. In this respect I note the model shows "Finalisation of Commercial Terms" } \\
\text { at the start of the "TOC Approval" phase (for the single TOC process). I think more correctly there should be a step called } \\
\text { "Align on primary commercial parameters" as the final step prior to the "Select NOPs" gateway. There is then no need for a } \\
\text { separate step called "Finalisation of Commercial Terms" within the TOC Approval phase as the whole phase is about } \\
\text { developing and agreeing the remaining commercial terms (being the scope, TCE/TOC and other limb } 3 \text { targets). } \\
\text { The gateways for selection of NOPs in the } 2 \times \text { XOC process could be clearer. It would be helpful to show a separate gateway } \\
\text { for selection of the } 2 \text { final consortia. This is approx. contemporaneous with the "Select NOPs" gateway for the single TOC. } \\
\text { Then the next gateway in the case of the } 2 \text { xTOC process would be a "double gateway" incorporating "Select NOPs for } \\
\text { readiness for service phase" and "TOC Approval". } \\
\text { Within the detailed flowchart/tables for TOC Approval phase suggest you include a Target Adjustment Alignment (TAG) } \\
\text { workshop. This needs to be done for both single TOC and } 2 x T O C \text { processes (in the case of the } 2 x T O C \text { it needs to be done } \\
\text { twice, once with each team. }\end{array}$ \\
\hline Expert \#3: & $\begin{array}{l}\text { Tool defines a process; true attainment of VFM is in documenting VFM achieved. } \\
\text { Framework provides a process, albeit overly simplified and consistent with the existing processes. The VFM debate is } \\
\text { contained in the VFM Gates which there is little or no information on what it is that signifies VFM. }\end{array}$ \\
\hline Expert \#7: & $\begin{array}{l}\text { As a general layout detail and ease of reading the detail flow chart page VfM Gate } 1 \text { to VfM Gate } 2 \text { should run in the same } \\
\text { direction as the path in the main page (probably easier to change the main document). }\end{array}$ \\
\hline Expert \#8: & $\begin{array}{l}\text { In the "Contract/Procurement Strategy" box, I don't know why you wouldn't consider and evaluate all potential contracting } \\
\text { options at the same time - rather than in the order suggested. Also, I don't understand what an EOI option is supposed to } \\
\text { represent. My understanding is that EOI stands for Expression of Interest and that this process could be used to shortlist } \\
\text { contractors for any contracting strategy. In relation to the "Final Business Case" box, the recent (and widely discredited by } \\
\text { anyone other than the authors who had a clear conflict of interest) Department of Treasury and Finance, Victoria report } \\
\text { rightly points out that this is often done poorly. PPP projects spend an enormous amount of time and effort on this task but } \\
\text { still get it wrong (e.g. it is my understanding that tenders for the NSBT project in Brisbane came in around } 100 \% \text { over the } \\
\text { Business Case budget (nearly \$1B) - not sure how this stacks up to the E\&P report??). Other smaller projects will always } \\
\text { struggle - but it is worth trying to better here. I do not believe the expansion boxes on the "Contract/Procurement Strategy" } \\
\text { box of the Procurement Strategy spreadsheet add any substantial value. Suggest another dot point in the dark blue } \\
\text { Procurement Strategy column something like "Does the budget estimate appropriately reflect the project risk profile and } \\
\text { preferred contracting strategy?" }\end{array}$ \\
\hline Expert \#9: & $\begin{array}{l}\text { As detailed previously, NOP's who do not fully understand the process of the owner's selection of the procurement method } \\
\text { (whether traditional or alliance) may not learn anything new from this new flowchart. Owner participants may also miss } \\
\text { steps and therefore lose ability to demonstrate VfM throughout the process. }\end{array}$ \\
\hline Expert \#10: & $\begin{array}{l}\text { As raised before, the structured process is of benefit. Owners are the ones that will derive most benefit and enhance VfM } \\
\text { should they be motivated to put in more effort to derive greater VfM By selecting an alliance on a single TOC basis at an } \\
\text { early stage then sourcing the Budget to fund the project is not good value for Tax payers. }\end{array}$ \\
\hline
\end{tabular}




\section{Round 2, Question 6}

Does the Round 2 flowchart/table for the specific stage of the project lifecycle (Procurement Strategy) adequately address the $\mathrm{VFM} / \mathrm{BV}$ issues that need to be addressed at this stage?

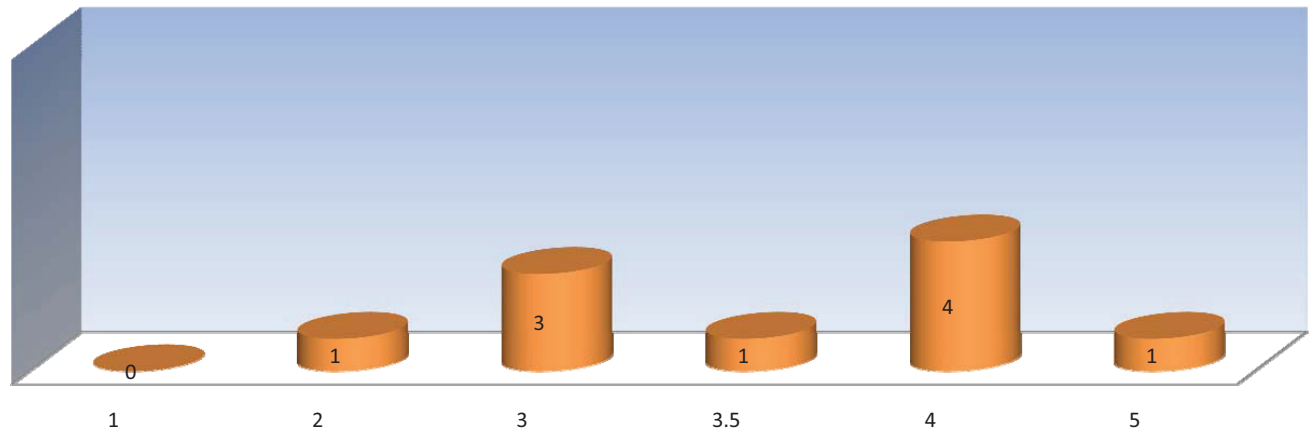

Scale: 1 (Not at all valuable)

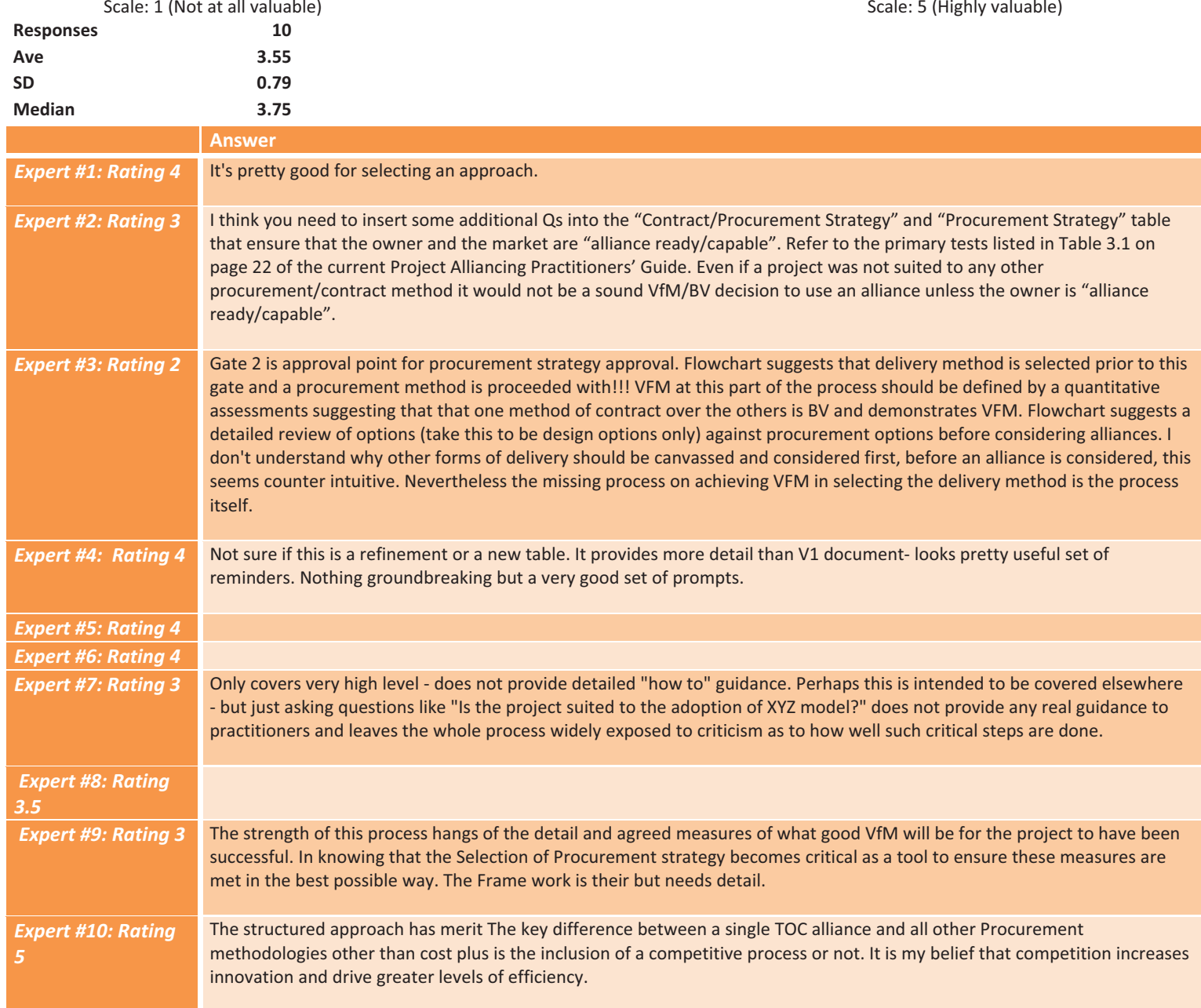


Round 2, Question 7

In the responses to Round 1, there was strong agreement that there should be a process for progressively considering Traditional, D\&C and EOI options before considering Project Alliance options (either single or multiple TOC) in the Procurement Strategy stage. Do you think that the Round 2 flowchart/table addresses the objective of arriving at the most appropriate procurement strategy?

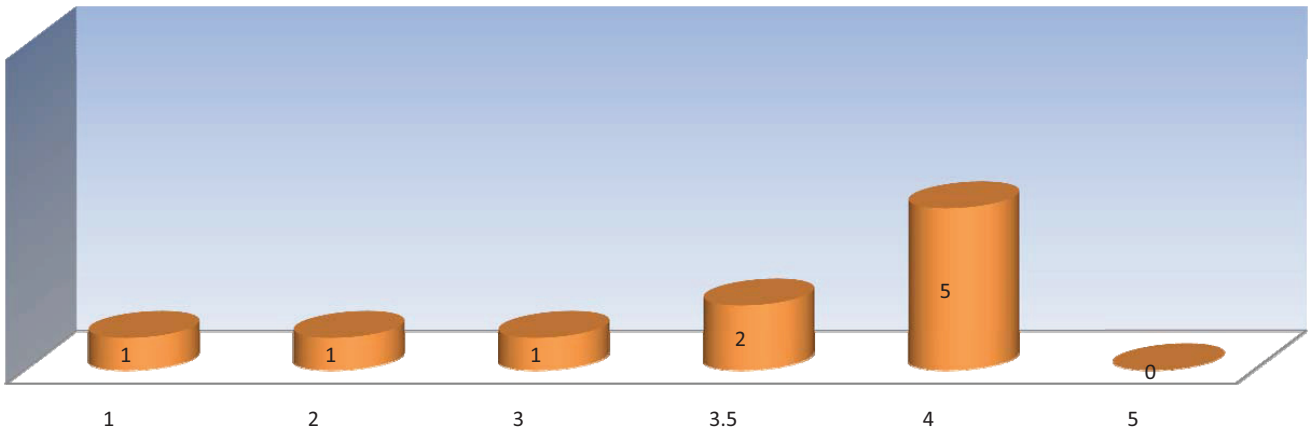

Scale: 1 (The flowchart/table does not address the objective)

Scale: 5 (The flowchart/table clearly addresses the objective)

\begin{tabular}{lr} 
Responses & 10 \\
Ave & 3.3 \\
SD & 0.98 \\
Median & 3.75 \\
\hline
\end{tabular}

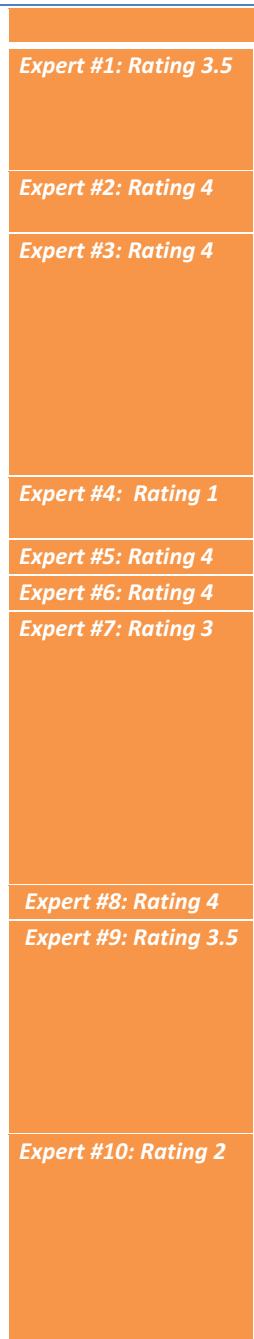

Answer

3.3

0.98

I liked considering all options Wasn't convinced Alliance was last resort option I prefer to address all options for procurement (might be caught up on semantics of "progressive"... why is it last resort?) I prefer comprehensive vs progressive.

Yes, subject to comments in response to previous question above.

Not sure why other forms of delivery method should be considered first, to me all forms of delivery method should be canvassed prior to making a recommendation. Jumping to conclusions on which method of delivery method, without some form of quantitative and qualitative assessment of why the delivery method was chosen is the key to VFM and the key to GETTING THROUGH gate 2 (or pragmatically, getting Treasury to approve business case). A more simple way of understanding this issue on VFM of delivery method chosen, would be to review business cases presented to treasury by Government Dept's. Like any thesis they will be formative in size, however the section on delivery method adopted/chosen will be on most occasions be the shortest section of the business case.

If you are going to use a progressive flowcharted model- then this one does not (for me) show how to do this.

Refer previous comment. I cannot see why you have to do this in a sequential order. I believe that all potentially viable contracting strategies should be considered at the same time. The decision is always going to be relative. Any project can be delivered under any contracting strategy. However, the risk of suitability of each contracting strategy varies greatly depending on project characteristics (that is why there is more than 1 model to choose from). Arguably, you may never get past the first box in the sequential order presented - even though subsequent methods may be superior - because you cannot answer the question "Is the project suited to the adoption of a Traditional design, tender model?" any other way than "Yes" for just about every project that I have ever been involved in (the design consultants of the world would love this!!).

Not a lot of change. In selecting the delivery method the fundamental questions of have the criteria for VfM been well defined is key. What could occur is that the traditional Cost and risk transfer elements dominate but without true understanding of other potential influences. On a case by case basis a multi criteria analysis is need to develop the sensitivities of the measures. Also if cost is a significant hurdle in getting a project off the ground (as it normally is) then the process becomes always difficult to manage around real VFM outcomes. Then when it is over the line clients want the cheap price and add back all the other VfM components.

The Value proposition should determine: The time available to develop, design, and obtain project approvals for the project. If there is time available to follow a traditional D\&CMO competitive tender approach this will deliver best value for project with a similar risk profile. If the time line does not allow for the time to go through this process an alliance will provide best value by saving 6 to 12 months at the start of the project. If the project has extraordinary risks and un realistic bids will be received an alliance will deliver best value. These high level issues need to be settled prior to going into the full analysis as these issues will force the procurement decision into a particular direction 
Round 2, Question 8

The 'head' flowchart (Revised Round $\mathbf{2}$ framework/model) now separately addresses a multiple TOC approach as well as the single TOC approach. Do you think this section of the flowchart adequately addresses the distinction between these options?

\begin{tabular}{|c|c|}
\hline 1 & 3.5 \\
\hline \multicolumn{2}{|c|}{ Scale: 1 (The flowchart/table does not adequately address the distinction) } \\
\hline Responses & 10 \\
\hline Ave & 3.8 \\
\hline SD & 0.71 \\
\hline \multirow[t]{2}{*}{ Median } & 3.75 \\
\hline & Answer \\
\hline $\begin{array}{l}\text { Expert \#1: Rating } \\
3.5\end{array}$ & I wasn't that concerned about that issue to be honest. \\
\hline Expert \#2: Rating 3 & $\begin{array}{l}\text { Could be clearer - refer earlier comments in response to question 5. Cannot answer fully without the accompanying } \\
\text { flowchart/tables }\end{array}$ \\
\hline Expert \#3: Rating 4 & $\begin{array}{l}\text { Yes - but it is an over kill and duplication of steps/process. One query though for a single NOP/TOC there is a VFM gate } 3 \mathrm{~A} \text {. } \\
\text { For a multiple NOP/TOC the preferred NOP is selected on cost etc and only the TOC goes to VFM Gate } 3 B \text {. surely in } \\
\text { Government procurement ( and even Private) approval processes there needs to be senior approval of selecting the } \\
\text { NOP???? Also current process on alliance selection utilise for a single TOC multiple NOPS to finalise commercial terms, this } \\
\text { isn't as clear on the flowchart as it could be, although this is intended!!! }\end{array}$ \\
\hline Expert \#4: Rating 3 & I am not sure as the two different streams still look quite similar?? \\
\hline \multicolumn{2}{|l|}{ Expert \#5: Rating 4} \\
\hline Expert \#6: Rating 3 & $\begin{array}{l}\text { What are the decision processes a client goes through before deciding to go multiple TOC rather than single TOC? Can a } \\
\text { client adequately assess the TOCS - especially if no third party assistance is provided? Not sure clients appreciate they are } \\
\text { more exposed if they pick wrong lower TOC provider that they are under D\&C lower price. Model also assumes that the } \\
\text { Client will have multiple teams working with the multiple TOC bidders. In my experience on } 3 \text { such multiple TOCs each time } \\
\text { the client has only used the one team going into the different bid teams (usually due to own lack of resources) - hence } \\
\text { largely "policing role" like a D\&C bid process rather than true alliance team building. Flow chart or notes should at least } \\
\text { recognise the } 2 \text { different ways multiple TOC bids could be run. }\end{array}$ \\
\hline Expert \#7: Rating 5 & It does this adequately in the context of the other detail shown on the flowchart. \\
\hline Expert \#8: Rating 5 & $\begin{array}{l}\text { There is a clear distinction now between the two alliance selection options identifying that there are also different processes } \\
\text { that need to be followed to demonstrate VfM through this phase }\end{array}$ \\
\hline $\begin{array}{l}\text { Expert \#9: Rating } \\
3.5\end{array}$ & $\begin{array}{l}\text { The simple flow chart explains the opportunity of the two paths. What is again the key decision is "why and how" do you } \\
\text { make the selection of single or multiple TOC . Suggest another vfm gate is at this box to measure the VFM BENEFITS TO MAKE } \\
\text { THE SELECTION. Also no mention of the tradition Parallel industry expert estimate with single TOC. The whole TOC process is } \\
\text { really set up around \$ which really makes the VFM process very weak (for Non Cost Elements). Especially in a fast track } \\
\text { process. }\end{array}$ \\
\hline $\begin{array}{l}\text { Expert \#10: Rating } \\
4\end{array}$ & $\begin{array}{l}\text { The Framework addresses the Single and Multiple TOC approach. The NPO's should after selection develop and design and } \\
\text { TOC. It is not the Alliances role to develop or update the Business Case. The Business Case is the domain of the owner and by } \\
\text { which the Owner will measure and evaluate the alliances performance }\end{array}$ \\
\hline
\end{tabular}


Round 2, Question 9

In the responses to Round 1 (Question 8), a number of comments were received regarding the lack of detail provided for the Readiness for Service (Design and Construct) Phase of the project lifecycle. Do you have any comments additional to those provided in Round 1 (view on website) regarding activities that should be adopted in this phase of the project lifecycle?

\begin{tabular}{|c|c|}
\hline & Answer \\
\hline Expert \#1: & $\begin{array}{l}\text { Benefits realisation exercise Did project deliver what it was supposed to? Is it ready for operations...and what are the costs/ } \\
\text { impacts? }\end{array}$ \\
\hline Expert \#2: & I am not sure which comments you are referring to. Not clear what further activities would be of value in this phase \\
\hline Expert \#3: & $\begin{array}{l}\text { Yes. Articulating the VFM process to be used during design and construct phases would be a good start. Readiness for } \\
\text { service as a VFM gate could mean the project is ready for service but did/didn't achieve VFM? }\end{array}$ \\
\hline Expert \#4: & No- sorry \\
\hline Expert \#5: & no \\
\hline Expert \#6: & $\begin{array}{l}\text { How do you show/report VFM during this phase? Suggest that NOP reports on VFM during project should link reports to } \\
\text { Client's stated VFM values, i.e. just cost, innovation reports, issues avoided etc. }\end{array}$ \\
\hline Expert \#7: & $\begin{array}{l}\text { I do not believe that this is where the fundamental problem lies (too little too late). As I said previously, industry would } \\
\text { benefit from a good "template" for a progressively constructed VFM Report to be used during this phase to save reinventing } \\
\text { the wheel each time. }\end{array}$ \\
\hline Expert \#8: & $\begin{array}{l}\text { As each project is unique it would be difficult to completely detail the steps with the design and construct phase. However, a } \\
\text { gate at the end of design to review technical governance issues within the design before proceeding to construction may be } \\
\text { appropriate. }\end{array}$ \\
\hline Expert \#9: & $\begin{array}{l}\text { Clients need to without constraining the process be held to constructive challenge by the Alliance on what they really need } \\
\text { or are prepared to accept. To many times requirements are unaligned to the opportunities that an Alliance can provide. } \\
\text { Functional Briefs and concept designs need to be challenged early in pre commencement workshops to really tease out what } \\
\text { is possible or acceptable by the client. Especially if Cost is the biggest driver then make it clear an accept to be challenged. } \\
\text { Design and associated constructability is where the real opportunities lie for (cost, program and final look and feel) Greater } \\
\text { focus is needed in this area. Greater cost planning upfront to understand the real areas of focus from a cost perspective is } \\
\text { required. Having monthly reviews of VFM CRITERIA needs to be a key role of the AMT otherwise if the final TCE is not } \\
\text { favourable the process has failed to recognise early. }\end{array}$ \\
\hline Expert \#10: & $\begin{array}{l}\text { Design and Construct value - Does this mean D\&C performance requirements The Product delivered by the NOP's should be } \\
\text { subject to a performance test? Does it provide the Business case functionality and levels of performance? }\end{array}$ \\
\hline
\end{tabular}


Appendix E.2- Round 2 - Consolidated Response

Round 2, Question 10

What other comments or suggestions do you have for improving either the Round 2 Revised Framework/Model or the Round 2 flowchart/table?

\begin{tabular}{|c|c|}
\hline & Answer \\
\hline Expert \#1: & Comments as above re defining VFM might help address distinction between a healthy project in Gateway terms, and VfM. \\
\hline Expert \#2: & No additional comments right now. \\
\hline Expert \#3: & $\begin{array}{l}\text { As suggested in briefing paper, using links (hyperlinks and the like) to additional information, sub charts and guidance notes } \\
\text { etc. Charts on their own provide little or no apparent difference from current charts provided by other alliance operatives or } \\
\text { documented in Government published delivery strategy documents. }\end{array}$ \\
\hline Expert \#4: & $\begin{array}{l}\text { Framework- put the earlier data back in Flowchart- make logic show a true progressive reduction of options through some } \\
\text { stepped decision making criteria }\end{array}$ \\
\hline Expert \#5: & none \\
\hline Expert \#6: & $\begin{array}{l}\text { In detail flow chart page VfM Gate } 1 \text { to VfM Gate } 2 \text { reference made to "Output based specification". In many cases to } \\
\text { address (?) VfM clients are providing specifications that go well beyond "output specifications" and are actually very } \\
\text { "prescriptive specifications". Main Roads provides the same full Scope of Work and Technical Criteria specification on its } \\
\text { alliances as it does on its D\&C bids. It would be worth exploring how clients view such Output based specifications. }\end{array}$ \\
\hline Expert \#7: & $\begin{array}{l}\text { The flowcharts are generally OK for the level they can effectively present on } 1 \text { page. The issue for me is lack of detail } \\
\text { regarding the "how to" of steps - this is where it really matters. }\end{array}$ \\
\hline Expert \#8: & $\begin{array}{l}\text { The benefits analysis is very brief. I'm not sure how to improve but some process on how to produce a final evaluation on } \\
\text { the achievement of VfM could be included here. However this evaluation should be ongoing throughout the projects life } \\
\text { cycle. }\end{array}$ \\
\hline Expert \#9: & nil \\
\hline Expert \#10: & $\begin{array}{l}\text { As early as possible in the Business case and prior to determining the procurement methodology the owner needs to } \\
\text { develop or employ specialists to develop the high level concepts and options and based on these develop a credible market } \\
\text { tested program and cost plan. This cost plan and program should have an accuracy of }+-10 \% \text { as measured against the actual } \\
\text { project outturn cost. This is difficult to achieve, but if not done results in decisions to proceed with the project based on } \\
\text { poor information. This usually results in significant cost over runs }\end{array}$ \\
\hline
\end{tabular}




\section{Appendix E.3}

\section{Delphi Survey, Round 3}


Delphi Survey, Round 3

Appendix E.3- Round 3 - Consolidated Response

Appendix E.3 - Delphi Survey, Round 3, Consolidated Responses

\section{Round 3, Question 1}

You should by now have received an email from the researcher (Charles MacDonald) with the following attachment:

- A new briefing paper (date 4 December 2009) which describes the results of Round 2 and describes the nature of the questions that will be posed in this Round 3 of the Delphi Process.

This paper contains an appendix which lists the 'conclusions' from the research report recently issued by the Victorian Department of Treasury and Finance entitled ' In Pursuit of Additional Value'. If you have not received this email, or if you have any queries following receipt of this material please contact Charles MacDonald by email or phone (macdonald@optusnet.com.au or 0412250 638).

This is not a question and no response is required.

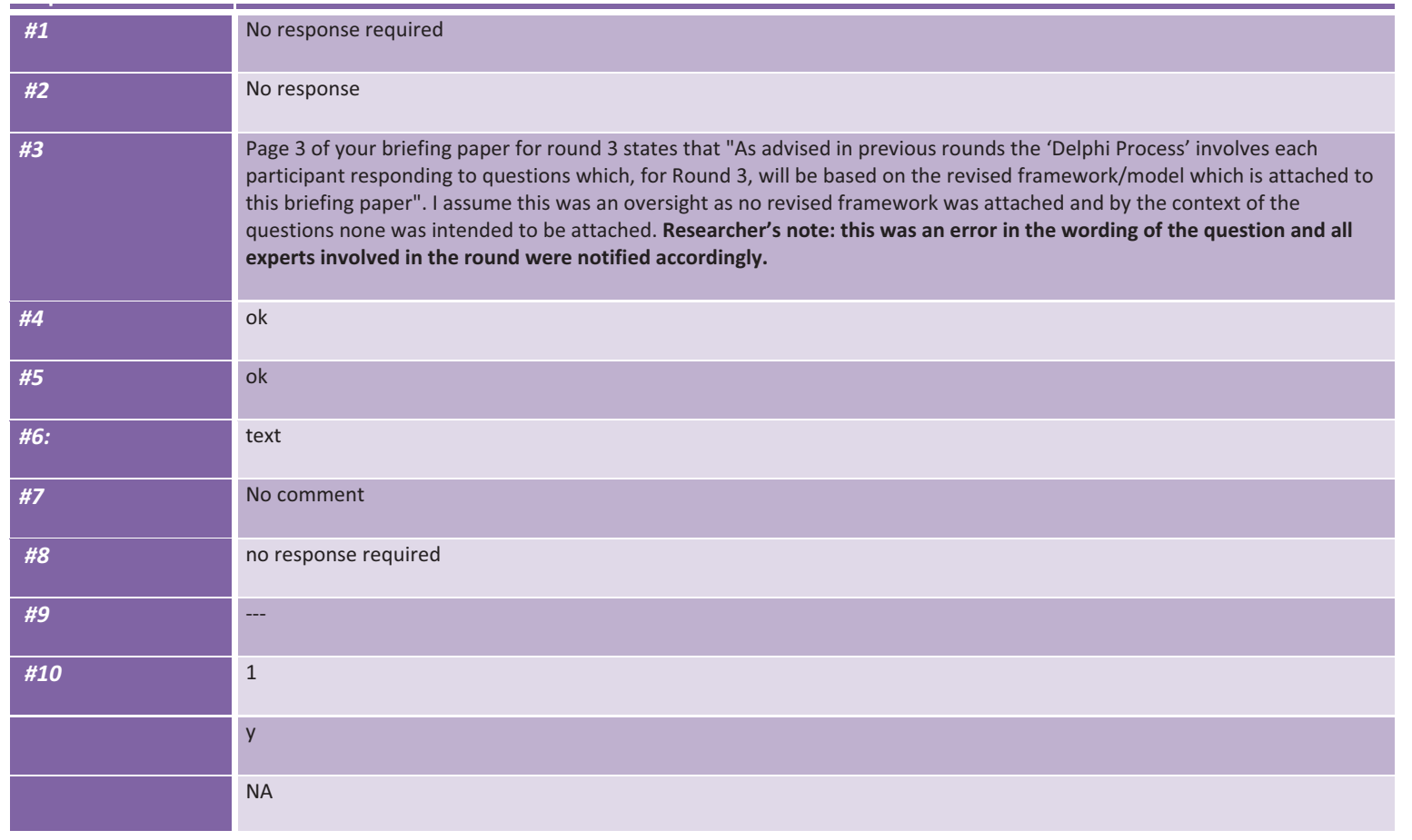


Round 3, Question 2

In both Round 1 and Round 2 the question was asked whether the framework/model could be valuable to the Owner in seeking to ensure the achievement and demonstration of VfM/BV (Question 3 in both rounds). Following the revision of the framework/model in Round 2, which was intended to clarify the content, satisfaction with the framework/model decreased (3.9 to 3.25).

In order to further test this outcome the following question is posed - Compared with the Round 1 framework/model, to what extent do you agree that the Revised Round 2 framework/model is more useful to Owners?

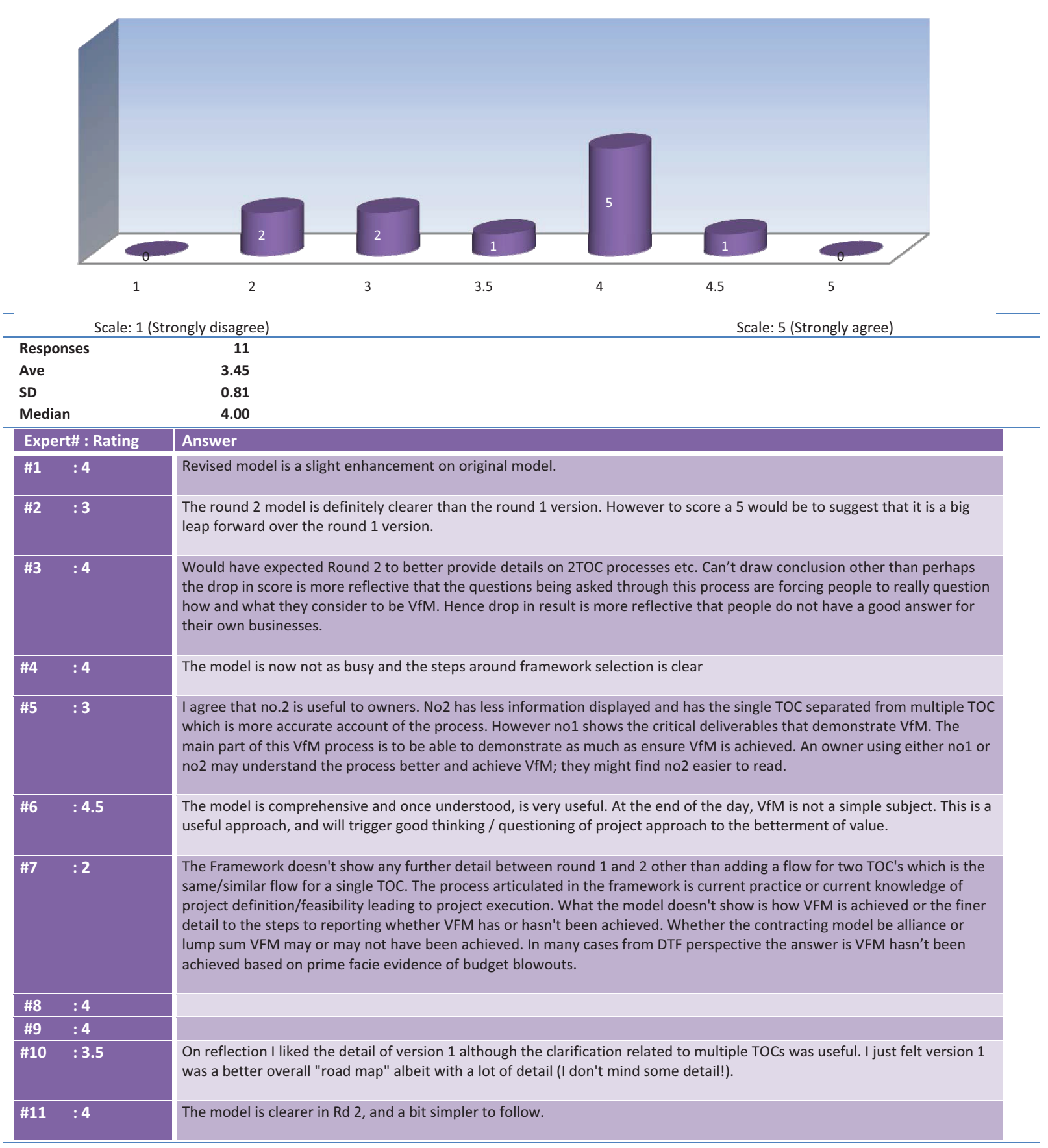


Round 3, Question 3

In both Round 1 and Round 2 the question was asked whether the framework/model could be valuable to the NOPs in seeking to ensure the achievement and demonstration of VfM/BV (Question 4 in both rounds). Following the revision of the framework/model in Round 2, which was intended to clarify the content, satisfaction with the framework/model substantially decreased (3.6. to 2.4). In order to further test this outcome the following question is posed - Compared with the Round 1 framework/model, to what extent do you agree that the Revised Round 2 framework/model is more useful to NOPs?

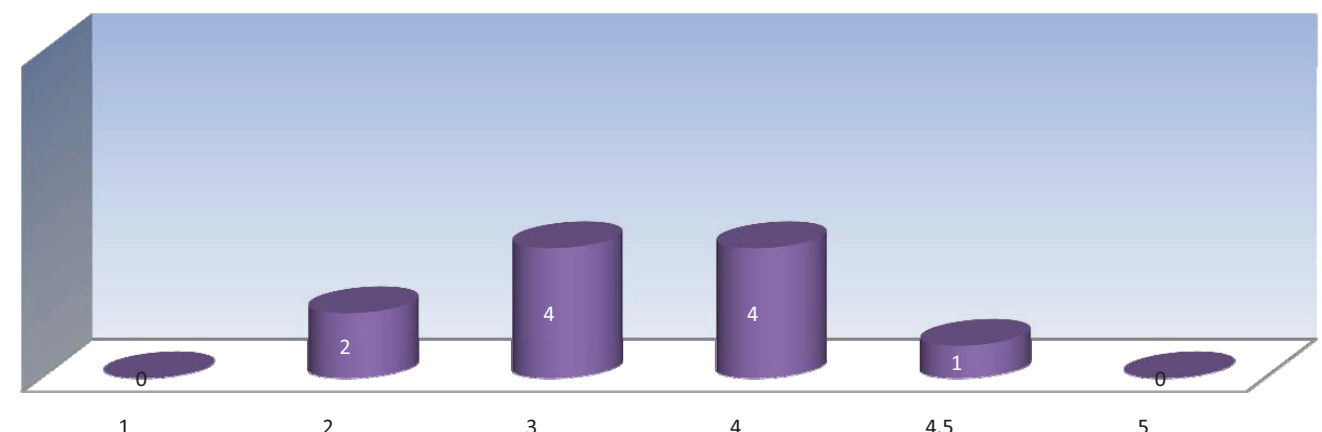

1

Scale: 5 (Strongly agree)

\begin{tabular}{|c|c|}
\hline \multicolumn{2}{|c|}{ Scale: 1 (Strongly disagree) } \\
\hline Responses & 11 \\
\hline SD & 0.81 \\
\hline Median & Answer \\
\hline $\begin{array}{l}\text { Expert \#1: } \\
\text { Rating } 3 \\
\end{array}$ & There are no fundamental differences between the models from a NOP perspective in my view. \\
\hline $\begin{array}{l}\text { Expert \#3: } \\
\text { Rating } 4\end{array}$ & $\begin{array}{l}\text { Would have expected that it raises more issues/awareness of what may go on in a client's mind/business as to what they } \\
\text { value as a means of determining VfM. One view is that VfM still normally equates to lowest price - it's easy to measure and } \\
\text { show. If Round } 2 \text { model shows importance of separate independent audit/validation of the } 2 \text { TOC bid outcomes it may stop } \\
\text { the awarding of projects to lower TOC team only to hear that the project end cost later exceeded the higher TOC bid. }\end{array}$ \\
\hline $\begin{array}{l}\text { Expert \#5: } \\
\text { Rating } 4\end{array}$ & $\begin{array}{l}\text { No1 and no2 will assist the NOP. As with the owner, the NOP will be able to see and understand the process that } \\
\text { demonstrates VfM. No2 may provide a clearer process that shows them how the owner achieves VfM without needing to } \\
\text { see all the critical deliverables in the flow chart. }\end{array}$ \\
\hline $\begin{array}{l}\text { Expert \#6: } \\
\text { Rating } 4.5\end{array}$ & $\begin{array}{l}\text { In general NOPs take time to appreciate their role as defending and increasing value for money for and on behalf of the } \\
\text { taxpayer. Many find this frustrating and it is a different role to a contracted out outsourced D\&C / traditional approach. This } \\
\text { model will go a long way to create a framework / structure around specific value for money, rather than the loose } \\
\text { commitment to VfM, which many struggle to grasp and operationalise. }\end{array}$ \\
\hline $\begin{array}{l}\text { Expert \#7: } \\
\text { Rating } 2\end{array}$ & $\begin{array}{l}\text { With VFM being the biggest issue facing NOPS in the selection process at present any assistance is greatly appreciated, } \\
\text { however the model is superficial compared to the current VFM debate and what a NOP has to articulate/discuss and agree a } \\
\text { commercial framework to win a project. Any ideas/innovation in the selection process at present is a NOP's IP around the } \\
\text { commerciality of their proposal. }\end{array}$ \\
\hline $\begin{array}{l}\text { Expert \#11: Rating } \\
3\end{array}$ & $\begin{array}{l}\text { A bit like the answer to Q 2. The model is clearer/ simpler, thus easier to understand. I've always thought the greatest } \\
\text { challenge for NOPs has been proving the TCE/TOC was VFM. All the other features are good for justifying the project/ } \\
\text { benefits (owner considerations), but the NOPs are really about delivering the required benefits/ scope for a value. }\end{array}$ \\
\hline
\end{tabular}


Round 3, Question 4

The VDTF Report comments that 'Alliance projects are often associated with uncertainty and complexity. This requires greater, not less, rigour in the business case to ensure that adequate anchoring, benchmarking and guidance is provided to the alliance team as the project progresses. As a minimum the business case should include the value proposition which incorporates the project objectives, agreed funding of 'externalities' (for example environmental works, stakeholder relations) and a robust cost plan. It should (barring sections subject to confidentiality) be made available to the alliance team'. To what extent do you agree with this statement?

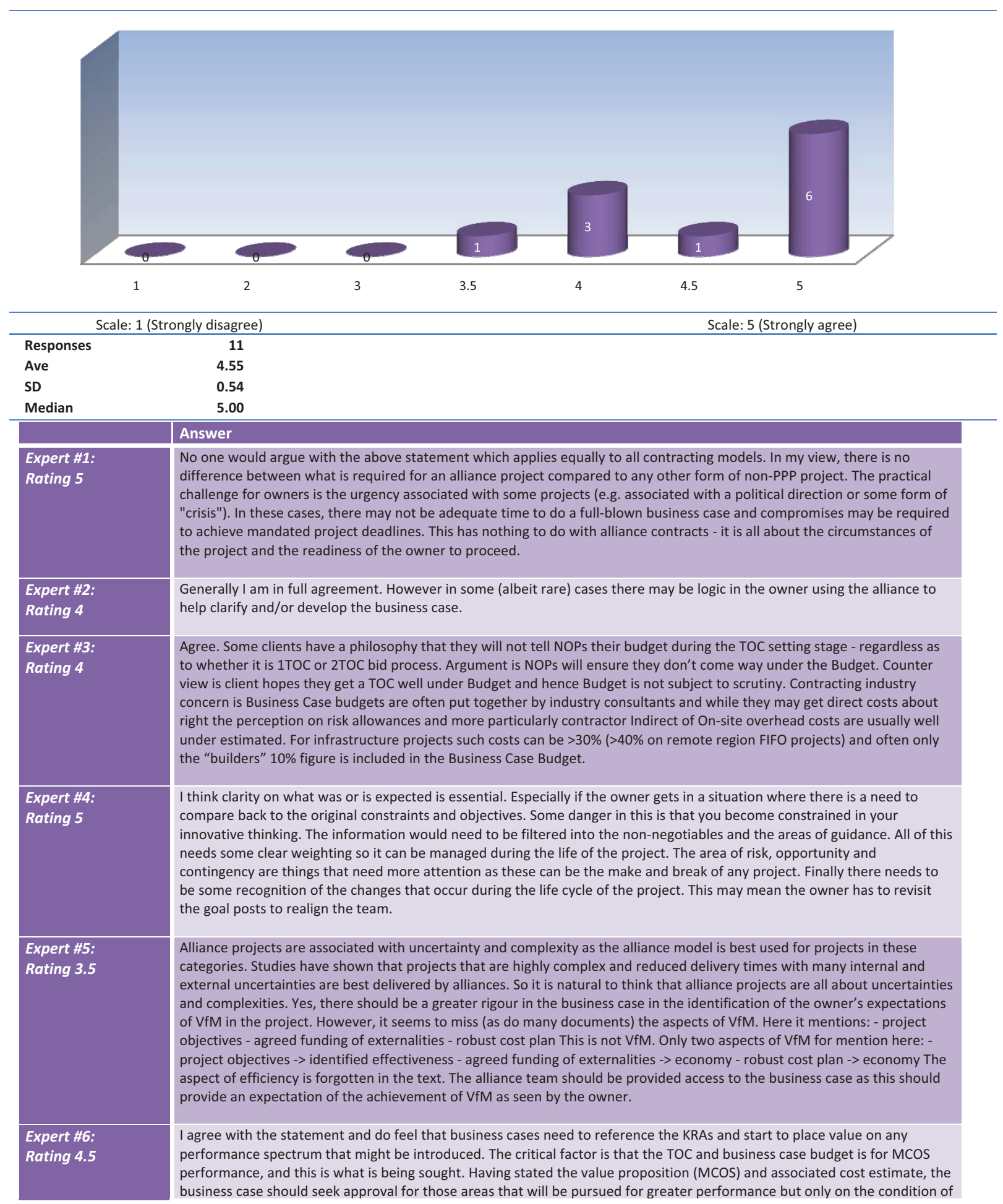




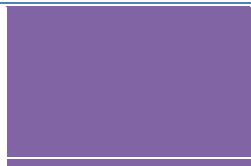

Expert \#7:

Rating 4

\section{Retting 4}

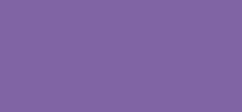

Expert \#8:

Rating 5

Expert \#9:

Rating 5

Expert \#10:

Rating 5

Expert \#11:

Rating 5 that increased level of performance being achieved for a reduced budget. Where the budget is highly uncertain - this should be flagged, and the measures / mechanisms for dealing with this stated in the business case (such as Budget Critiques / Risk \& Opportunity assessments, etc) - these should flag the timing that cost escalation may be flagged, if that is the outcome, and the possible magnitude of those outcomes.

The business case should be made available to the NOP's. In fact, some alliances are now being formed earlier than previously and thus the alliance is involved in the creation of the business case. Not sure if many State processes will allow the definition of monetary allowances to "externalities" at business case, other than a budgetary allowance. Certain departments may have policies on spending limits on things such as public art etc. Not sure the concern on how much to spend on the "externalities" is significant, the production of a robust cost plan and risk assessment at feasibility phase is vital and key to achieving VFM.

I think the VDTF report picked up some issues related to the Qld market environment rather than Alliances per see and shouldn't be over read- I disagree with many of the extrapolations of this report

Business Cases are often far too loose. Clients often rely on the Alliance to further scope the project and satisfy

stakeholders. Major scope creep usually results from owners appeasing various stakeholders, be they external, enviro or internal/ technical. NOPs should be aware of what has been promised to Govt/ funded. 
Round 3, Question 5

The VDTF report comments that 'Current alliance procurement guidelines recommend selecting NOPs using predominately nonprice criteria. This does not always reflect good government procurement practice which requires price to be included as a significant criterion. Whilst price competition is not appropriate in all circumstances, it should be required as a default position'. To what extent do you agree with this statement?

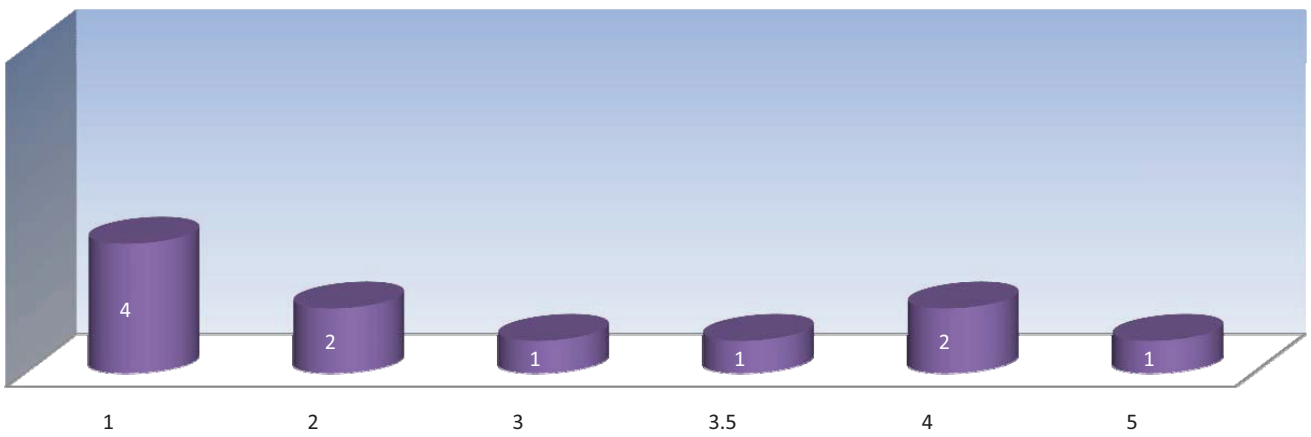

3.5

Scale: 5 (Strongly agree)

\begin{tabular}{|c|c|}
\hline \multicolumn{2}{|c|}{ Scale: 1 (Strongly disagree) } \\
\hline Responses & 11 \\
\hline SD & 1.40 \\
\hline Median & Answer \\
\hline $\begin{array}{l}\text { Expert \#1: } \\
\text { Rating } 1\end{array}$ & $\begin{array}{l}\text { Price should definitely NOT be the "default" position for procurement of alliance contracts. I would say that almost by } \\
\text { definition, projects where it makes sense for price to be the default basis of procurement should NOT be procured as an } \\
\text { alliance contract. The authors of the VDTF report have displayed a fundamental misunderstanding of what alliance contracts } \\
\text { are all about and where they are best suited. They have also not recognised the very real practical difficulties of running an } \\
\text { effective price-competitive procurement process for projects that ARE suited to an alliance contract. There is no doubt that } \\
\text { alliance contracts have been used on some projects where other contracting strategies would have been equally valid (and } \\
\text { in some cases could have resulted in lower cost). However, this is no basis for arguing that price competition should be the } \\
\text { default position! The case for price competition for procurement of alliance contracts is overly simplistic and appears to } \\
\text { have been pushed in the VDTF report by those who have either had no direct experience in managing projects in a complex } \\
\text { external environment (e.g. university researchers and Treasury representatives) or those who have a vested interest in } \\
\text { making such a recommendation because it supports their business model (E\&P). This is why the report has little overall } \\
\text { credibility outside of the authors and their client. }\end{array}$ \\
\hline $\begin{array}{l}\text { Expert \#2: } \\
\text { Rating } 2\end{array}$ & $\begin{array}{l}\text { The engagement of alliance partners using predominantly non-price criteria does offend what many might consider to be } \\
\text { "good government procurement practice" and to this extent I agree with the statement. However I strongly disagree with } \\
\text { the proposition that price competition should be required as a default position. }\end{array}$ \\
\hline $\begin{array}{l}\text { Expert \#3: } \\
\text { Rating } 3.5\end{array}$ & $\begin{array}{l}\text { Can see no reason why corporate overhead and profit margins cannot be included in the bid selection process but requiring } \\
\text { unit rates, productivity rates or even indicative pricing on selected components of project work as part of the bid seems } \\
\text { inconsistent with an Alliance delivery method selected because scope and risk cannot be adequately determined. }\end{array}$ \\
\hline $\begin{array}{l}\text { Expert \#4: } \\
\text { Rating } 3\end{array}$ & $\begin{array}{l}\text { Depending on the current models the price selection has already gained some influence. With competitive priced alliances. If } \\
\text { you looked at a D\&C model short listing is generally non price driven. The difference being the final group work in a } \\
\text { competitive arrangement to be selected around price. The default of price would need to be understood by all before } \\
\text { starting. Because it is obvious that the contractor will spend the majority of their time in achieving the outcome that suits } \\
\text { the biggest driver. This may lead to an outcome not aligned with the owner's original thoughts. The other important element } \\
\text { in the impact of the default price option is that are you really comparing apple with apple. Especially if the criteria for the } \\
\text { price is not as rigid and documented as it would be in a hard dollar environment. So the danger is the owner buy's an } \\
\text { understated price. }\end{array}$ \\
\hline $\begin{array}{l}\text { Expert \#6: } \\
\text { Rating } 4\end{array}$ & $\begin{array}{l}\text { In principle I do agree. The challenge is the practicalities of this policy. The challenge with most alliances is that price } \\
\text { competition needs to be competing on something definable otherwise there will be an apple with pear comparison. On the } \\
\text { basis of not wanting to introduce major bid costs, such as with PPPs, then this recommendation needs to be strongly } \\
\text { qualified for the purpose of appropriate implementation. }\end{array}$ \\
\hline $\begin{array}{l}\text { Expert \#7: } \\
\text { Rating } 1\end{array}$ & $\begin{array}{l}\text { Not sure on how a default position would work, nevertheless where possible some elements of price maybe able to be } \\
\text { considered within the selection process. A word of warning on this, any pricing competition for some part of the works or }\end{array}$ \\
\hline
\end{tabular}




\begin{tabular}{l|l}
\hline $\begin{array}{l}\text { Vxpert \#8: } \\
\text { VFM will be achieved by using this pricing point as the sole remedy for selection of a NOP. } \\
\text { Rating 5 }\end{array}$ & $\begin{array}{l}\text { The inclusion of price criteria in the selection process will undermine the validity of any other criteria as the default position } \\
\text { from the administrator auditor will be are we certain that we get this much benefit. by way of analogy what is an acceptable } \\
\text { cost of a human life or an environmental breach? }\end{array}$ \\
\hline $\begin{array}{l}\text { Rating 1 } \\
\text { Expert \#10: }\end{array}$ & $\begin{array}{l}\text { Commercial aspects (including price) should certainly be part of the evaluation. } \\
\text { Rating 4 }\end{array}$ \\
\hline $\begin{array}{l}\text { Expert \#11: } \\
\text { Rating 2 }\end{array}$ & $\begin{array}{l}\text { Sounds like the usual E\&P stance. It's hard to include price when you don't know what the project is. I'm not sure Govt } \\
\text { useful thing, but it may prove difficult. Are they then locked in?, or do they remain negotiable until the PAA is locked down? } \\
\text { Maybe better client understanding of estimating/ TOC development/ risk within alliances would be useful. }\end{array}$ \\
\hline
\end{tabular}


Round 3, Question 6

The VDTF Report comments that 'Outstanding outcomes ('paradigm shift', 'not been done before') are often sought by Owners when selecting the alliance delivery method and they are generally a requirement in the PAA. However, there was little evidence that outstanding outcomes are being achieved despite significant investment in 'high performance teams'. To what extent do you agree with this statement?

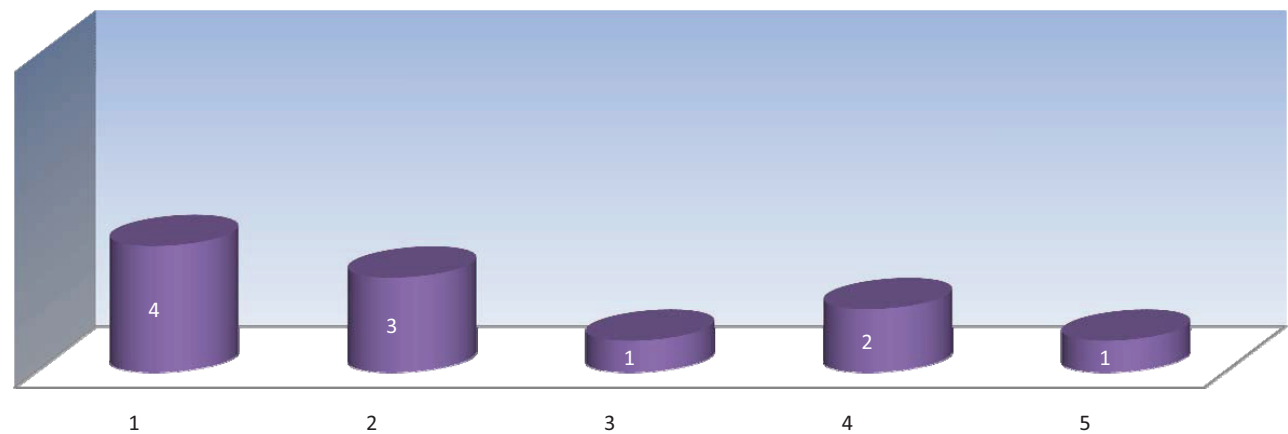

1

2

Scale: 5 (Strongly agree)

\begin{tabular}{|c|c|}
\hline \multicolumn{2}{|c|}{ Scale: 1 (Strongly disagree) } \\
\hline Responses & 11 \\
\hline SD & 1.37 \\
\hline Median & Answer \\
\hline $\begin{array}{l}\text { Expert \#1: } \\
\text { Rating } 2\end{array}$ & $\begin{array}{l}\text { For a start, "outstanding outcomes" are NOT a "requirement" of most PAAs. Perhaps they are of some, but if so, the authors } \\
\text { of those PAAs and their advisers have got it wrong. "Outstanding outcomes" are aspirational targets in areas (KRAs) where } \\
\text { the owner believes that they can gain additional VALUE without budgeting for additional investment. TOCs should only be } \\
\text { funded to achieve "Minimum Conditions of Satisfaction" outcomes - NOT "outstanding outcomes". If the alliance achieves } \\
\text { "outstanding outcomes", this is a bonus and should result in additional value for the owner (otherwise the owner has not } \\
\text { done their job in terms of setting KRAs and associated MCOS and outstanding targets). Failure to achieve "outstanding } \\
\text { outcomes" does not represent a poor outcome for the owner. Failure to achieve MCOS outcomes does. I agree that the } \\
\text { investment is "high performance teams" has been a little over-the-top, however, a certain amount of this activity is a good } \\
\text { investment. In some situations where projects are in fact really suited to alliance contracting, the mere achievement of } \\
\text { MCOS targets could be seen as an "outstanding" result compared to what would be expected from another form of } \\
\text { contract! }\end{array}$ \\
\hline $\begin{array}{l}\text { Expert \#3: } \\
\text { Rating } 4\end{array}$ & $\begin{array}{l}\text { Agree this is often driven by extensive Scope of Work and Technical Criteria documents being included by Clients in the bid } \\
\text { documents or TOC brief. Such SWTCs largely limit what can be done or changed by an Alliance team (NOP and OP). Also } \\
\text { there are often the constraints of the "Technical Standards Dept" of Clients' organisations who see their role as protecting } \\
\text { the standards and not changing them or allowing the changes from "how we always do it" to enable some innovations, eg } \\
\text { equipment supply from outside the standard approved list.. Hence part of the Client's team (usually within the alliance) is } \\
\text { constrained by their internal processes led by Client people "out of the alliance" such that other than construction } \\
\text { methodology changes to achieve the standard outcome are limited opportunities to really innovate. }\end{array}$ \\
\hline $\begin{array}{l}\text { Expert \#5: } \\
\text { Rating } 1\end{array}$ & $\begin{array}{l}\text { The investigation of outstanding outcomes needs to start at the "people" level of an alliance. I have not seen study yet that } \\
\text { investigated how the people involved in an alliance contract are changed or affected by the experience. All reports I have } \\
\text { seen discuss outcomes at a high project level discussing expenditure, what did the project achieve, how was it delivered, etc. } \\
\text { Nothing about the people within the alliance contract. Paradigm shift and not been done before relate to people based } \\
\text { activities and projects are delivered by people, they do not deliver themselves. When high performance teams are formed, }\end{array}$ \\
\hline
\end{tabular}




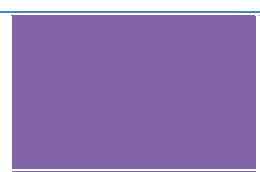

Expert \#6:

Rating 1

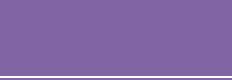

Expert \#7:

Rating 1

Expert \#8:

Rating 5

Expert \#9:

Rating 4

Expert \#10:

Rating 1

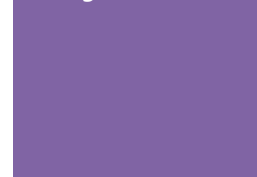

Expert \#11:

Rating 2 there needs to be an assessment of that team in relation to how they developed and worked together for the alliance contract (e.g.: forming, storming, norming, performing). This can then be related to the higher project outcomes. E.g.: the team worked very well together and achieved project outcomes under very difficult conditions. Or something to this effect of relating how the people in the team affected the outcomes.

The report does not state the academic basis for this assessment. Clearly after the event - it is difficult to recognise paradigm shifts, as once shifted, all has shifted. In many ways - this real issue was "did the outcome seem unachievable at the start? and was it eventually achieved"? If the answer to these two questions is "yes" then that indicates a paradigm shift. I have witnessed many such events on over 50 alliances. I may see what I want to see - but I would challenge that.

Statistics and evidence can be presented in many ways. One shouldn't let the truth stand in the way of a good defence! One can only rely on experience and direct involvement in alliance projects. In Victoria there are certainly cases of VFM and outstanding outcomes that wouldn't have been achieved under a lump sum contract for example. Whether they have or haven't been done before, that to me is "spin" the real issue is that they have been due to the alliance framework allowing people to achieve outcomes that policies/procedures/old wives tails wouldn't allow. Also some of these "not been done before" are being done and NOT capture in VFM reports, thus falling below the radar.

I agree with this statement as the use of the alliance model has often been driven not to obtain paradigm shift in terms of long term design \& performance of the asset, but rather to gain time resulting from the inability of government and clients to make decisions and poor planning for the future infrastructure needs or budget surplus and a political need to "fix" something

I think that this was a case of "smart alec" semantics by this review team. Generally while alliances write their goals in aspirational terms, they may be measured in slightly more down to earth fashion. The terms such as paradigm shift and game breaking are clearly aspirational and probably a good thing as they give owners some ability to keep tension on the teams KPIs. For this review team to state that they saw no evidence of outstanding outcomes (by their somewhat pedantic insistence of a literal adoption of the aspirational terms) was, I thought, arrogant smugness. Some of the projects they dismissed have been recognised by diverse industry groups as outstanding projects (just didn't fit VDTFs slavish definitional interpretation!) have i said enough??

I think a number of alliances have done great jobs with very difficult circumstances. In many instances clients are poorly prepared, have no resources and don't understand the project/ brief. Under hard dollar scenarios they would have been completely ravaged. I think alliances have saved/ dragged along some very ordinary client organisations. One area where they often fall down is in the client's willingness to embrace changes from their stds/ normal practice. Many clients want innovation in the PAA, whilst in reality they don't want any innovation. I'm also a little cautious about "innovation" . What is it? IT is only good if it either saves money, increases Whole of life/ quality/ safety. Not just for innovations sake. 
Round 3, Question 7

Following the suggestion of one of your fellow research participants, would you willing to participate in a telephone conference hook-up with the other Delphi survey participants (to be scheduled for late January 2010) to further discuss the current status of the framework/model and its effectiveness in achieving and demonstrating VfM/BV?

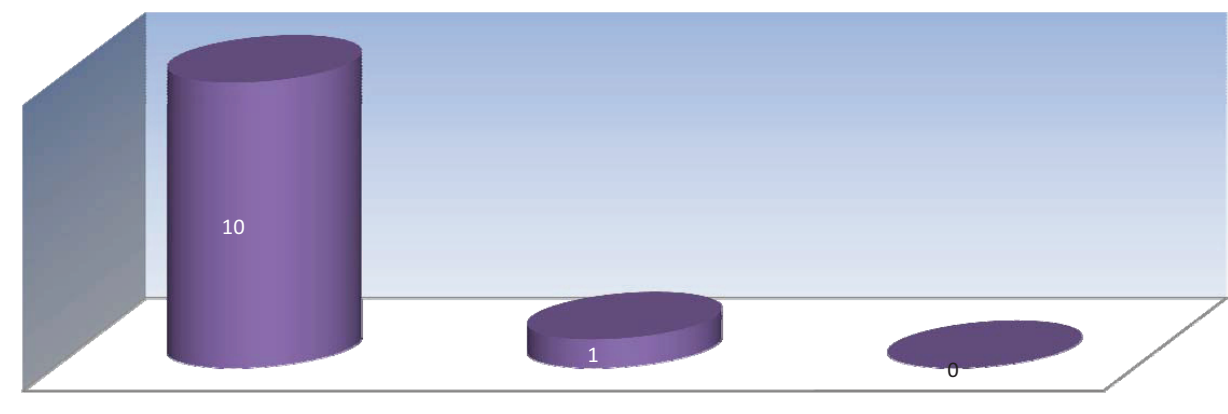

Yes

\begin{tabular}{|c|c|}
\hline Responses & 11 \\
\hline Ave & 1.05 \\
\hline SD & 0.14 \\
\hline \multirow[t]{2}{*}{ Median } & 1.00 \\
\hline & Answer \\
\hline $\begin{array}{l}\text { Expert \#1: } \\
\text { Rating Yes }\end{array}$ & $\begin{array}{l}\text { Although I have said yes to this question, I wonder about the effectiveness of such an event. I suspect that there will be such } \\
\text { diversity of commentary and opinion that it may not achieve that much. This is a very complex and difficult topic and I am } \\
\text { sceptical that a telephone hook-up based on the model/ framework presented would achieve a great deal - however it may } \\
\text { provide focus for the research paper itself. }\end{array}$ \\
\hline $\begin{array}{l}\text { Expert \#2: } \\
\text { Rating Yes }\end{array}$ & $\begin{array}{l}\text { Subject to availability, of course. I would like to know in advance who else is in the group. The conversation will also need to } \\
\text { be strongly facilitated (by Charles) to ensure diverging views are heard and respected. }\end{array}$ \\
\hline $\begin{array}{l}\text { Expert \#3: } \\
\text { Rating Yes }\end{array}$ & Yes but would need to be post 26 Jan as away before then. \\
\hline \multicolumn{2}{|l|}{$\begin{array}{l}\text { Expert \#4: } \\
\text { Rating Yes } \\
\end{array}$} \\
\hline $\begin{array}{l}\text { Expert \#5: } \\
\text { Rating Yes }\end{array}$ & I am fine for a group meeting if that is preferred. \\
\hline $\begin{array}{l}\text { Expert \#6: } \\
\text { Rating Yes }\end{array}$ & Timing could be challenge - but if I can make would appreciate the opportunity. \\
\hline $\begin{array}{l}\text { Expert \#7: } \\
\text { Rating Yes }\end{array}$ & Great idea, the agenda and objectives of the hook up, along with the facilitation of that call will need careful consideration. \\
\hline \multicolumn{2}{|l|}{$\begin{array}{l}\text { Expert \#8: } \\
\text { Rating Yes }\end{array}$} \\
\hline \multicolumn{2}{|l|}{$\begin{array}{l}\text { Expert \#9: } \\
\text { Rating Yes }\end{array}$} \\
\hline \multicolumn{2}{|l|}{$\begin{array}{l}\text { Expert \#10: } \\
\text { Rating Yes }\end{array}$} \\
\hline $\begin{array}{l}\text { Expert \#11: } \\
\text { Rating? }\end{array}$ & $\begin{array}{l}\text { I'd like to help out as far as I can. They are interesting topics but I'm not sure any major consensus will be achieved over the } \\
\text { phone, and the anonymous bit will be lost. Hard to believe, but I may not be as candid with clients/ potential clients/ } \\
\text { competitors. }\end{array}$ \\
\hline
\end{tabular}




\section{Appendix F.1}

Comments on IASC Documents

Key Findings 
Department of Treasury and Finance, Victoria, In

\section{Research Study for the Inter-jurisdictional Alliancing Steering Committee}

KEY FINDINGS

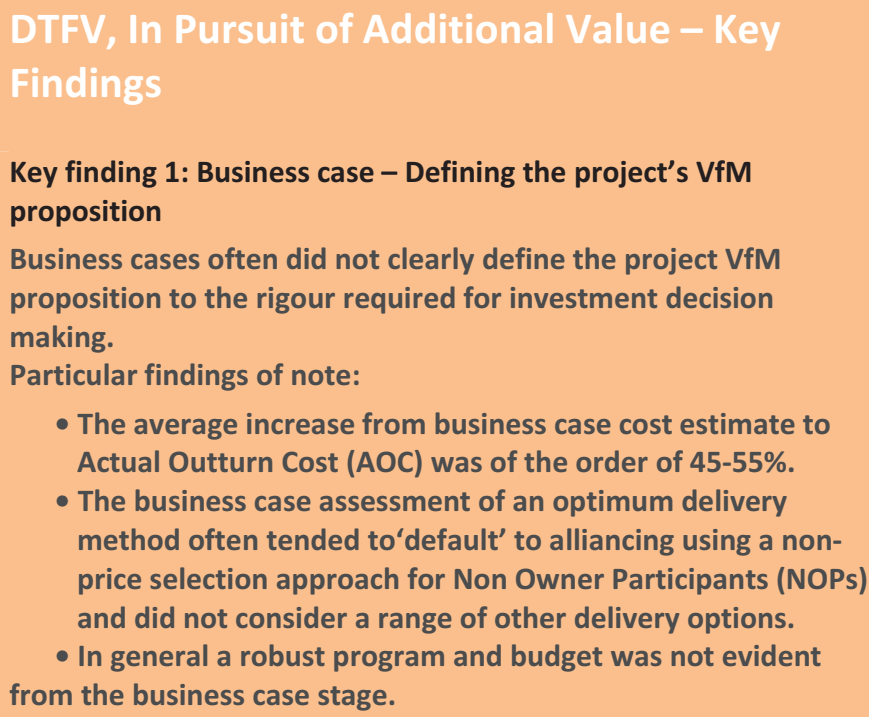

- The average increase from business case cost estimate to Actual Outturn Cost (AOC) was of the order of $45-55 \%$.

- The business case assessment of an optimum delivery method often tended to'default' to alliancing using a nonprice selection approach for Non Owner Participants (NOPs) and did not consider a range of other delivery options.

- In general a robust program and budget was not evident from the business case stage.

Key finding 2: Procurement strategy - Owner's rationale for selecting the alliance delivery method

Having considered project specific requirements, the primary reasons for selecting the alliance delivery method, in addition to those contained in the DTF Project Alliancing Practitioners' Guide were:

- to achieve early project commencement through early involvement of the NOPs

- to progress the project development in parallel with the project approvals.

In general, Owner's specifically used alliancing and the non-price competitive selection approach to attract key resources and capabilities to a project in a buoyant construction market.

\section{Researcher's comments}

Responses to each dot point are as follows:

- $\quad$ This statistic is very cryptic and such averages can be quite misleading if there a few 'outlying results' in a relatively small sample. Given the importance of the statement being made here the distribution of outcomes should be provided rather than a simple average.

- To the extent that the procurement strategy should be considered in the business case, it is agreed that there should be no default to alliancing (non-price or price selection). This is consistent with a view that more traditional methods including D\&C should be considered before a relationship based procurement process is adopted.

- Is the general absence of a robust program and budget particular to projects which proceed to an alliance or a general failing in the business case development of projects?

This statement that Owners generally use alliance in this manner does not follow directly from the points above. Is there real evidence or intelligence to support this proposition or is it just a view of the Research Team? 
Department of Treasury and Finance, Victoria, In

\section{Research Study for the Inter-jurisdictional Alliancing Steering Committee}

Key finding 4: Agreeing the commercial arrangements Commencement of physical work

Often physical works commenced prior to finalising the commercial arrangements with the NOPs.

Key finding 5: Agreeing the commercial arrangements Business case cost compared to initial TOC

In general the agreed (initial) TOC was higher than the business case cost estimate.

The average increase was of the order of $35-45 \%$.

Key finding 6: Agreeing the commercial arrangements Project Alliance Agreement (PAA)

A variety of terms and conditions were employed by the various Owners in the PAA.

In particular:

- NOP corporate overhead and profit: Generally fixed upon agreement of the TOC, often variable as a percentage of actual costs.

- No blame clause: Generally unconditional; little indication of modified clauses.

- Dispute resolution: Generally silent; little indication of express provisions for

resolution beyond the Alliance Leadership Team (ALT) (outside the alliance).

- Incentive/Penalty arrangements on time: Generally included; often not.

- Owner reserved powers: Often reserved powers stated; sometimes not.

- Performance security by NOPs: Little indication that security was required; generally not.

Key finding 7: Agreeing the commercial arrangements Outstanding Outcomes

Generally it is a requirement expressed in the PAA that the parties commit to achieving outstanding (game breaking) outcomes.
This appears to be presented in support of a view that NOP's prefer alliancing and specifically, the non-price selection as it provides them with some unfair advantage. They could prefer both alliancing and the nonprice approach because they genuinely believe that all parties are advantaged by this arrangement.

By commercial arrangement, presumably the settlement of the TOC is being referred to rather than the commercial negotiation that would normally follow immediately after the selection of the NOP's (at least for a single TOC model).

This statement needs to be used very carefully! The nature of projects that are best suited to alliancing often have a higher degree of uncertainty at the business case stage. This is likely to be the reason for this variance rather than an inherent systemic failing of the alliancing process (single or multiple TOC).

Comment links to KF1.

The TOC (and reimbursements) should be commensurate with the minimum conditions of satisfaction performance and outcomes defined in the business case requirements. 


\author{
Research Study for the Inter-jurisdictional All
The commercial arrangements generally provide financial \\ incentives for NOPs (incentivised Key Result Area (KRAs)) to \\ achieve outstanding (game breaking) outcomes. \\ It was also noted that estimated costs associated with \\ pursuing outstanding (game \\ breaking) outcomes are often included in the TOC.

\section{Key finding 8: Project delivery - Non-price objectives} \\ In general, Owner representatives (regardless of approach \\ to selecting NOPs) rated their alliance's performance in all \\ areas of non-price objectives as above expectations or \\ game breaking. The areas of non-price criteria assessed \\ were: \\ - quality of work \\ - functionality \\ - safety \\ - environment \\ - community \\ - other stakeholders \\ - team dynamics \\ - KRA achievement \\ - flexibility of approach.
}

Key finding 9: Project delivery - Owner resources

The number of Owner resources provided to the alliances varied.

There was no clear correlation between the number of Owner resources and enhanced VfM.

It was noted that active senior level participation by the Owner provided clear direction and support to the alliance.

Key finding 10: Project delivery - Early commencement of physical work and project completion

The project's physical works were able to be commenced many months in advance of what would have been possible using traditional delivery methods (as noted elsewhere) leading to a commensurate earlier completion date.

The majority of projects met the Owners' target completion dates as set out in the

business case.

\section{Key finding 11: Project delivery - No disputes}

There were no indications of any disputes between the Owner and the NOPs that needed to be resolved outside the alliance.

Key finding 12: Project delivery - Outstanding outcomes (game breaking)
Exceptional value is attained when a better outcome (exceptional or gamebreaking); or exceptional KRA performance is achieved for the same or lower cost $>$ MCOS for MCOS payment).

This would appear to be a surprising statement. All Owners believed all non-price objectives were exceeded.

Also, does above expectation really equate to gamebreaking?

Whilst it could be expected that most would be seen as successful, a $100 \%$ record of exceedance does not seem realistic! It would be interesting to see the precise questions that were asked here.

The second and third statements appear to be somewhat contradictory!

This would presumably be in marked contrast to the situation with traditional driver methods. If so, this should be acknowledged as this is a major VfM plus!

There would appear to be a significant disparity between this response and KF9 which is acknowledged. 


\section{Department of Treasury and Finance, Victoria, In Pursuit of Additional Value (2009)}

\begin{tabular}{|c|c|}
\hline \multicolumn{2}{|c|}{ Research Study for the Inter-jurisdictional Alliancing Steering Committee } \\
\hline $\begin{array}{l}\text { There was little indication that outstanding outcomes } \\
\text { (game breaking / breakthrough) were being achieved } \\
\text { within the definitions in use in this Study ('paradigm shift', } \\
\text { 'not been done before'). } \\
\text { This finding significantly differs with the self-evaluation of } \\
\text { both NOPs and Owner } \\
\text { representatives within the alliances who considered that } \\
\text { their own alliances achieved outstanding outcomes. }\end{array}$ & $\begin{array}{l}\text { This raises the prospect that Owners generally, } \\
\text { and perhaps even universally believed that } \\
\text { superior performance was delivered by } \\
\text { alliances. This does not necessarily indicate that } \\
\text { they saw performances as gamebreaking. Also } \\
\text { the researcher's definition of gamebreaking } \\
\text { might be different to the definition that was } \\
\text { agreed in each alliance. }\end{array}$ \\
\hline $\begin{array}{l}\text { Key finding 13: Project delivery - Adjustments to agreed } \\
\text { TOC } \\
\text { In general there was an increase from agreed (initial) TOC } \\
\text { to adjusted (final) TOC. The average increase was of the } \\
\text { order of } 5-10 \% \text {. }\end{array}$ & $\begin{array}{l}\text { This appears to be a very surprising result. } \\
\text { Whilst some alliance may experience scope } \\
\text { growth after (initial) this would be a rarity. Are } \\
\text { there one or two projects in this sample that } \\
\text { have experienced major a change of scope and } \\
\text { this is being averaged over the whole } \\
\text { population in manner which gives 'misleading' } \\
\text { impression regarding alliances generally? } \\
\text { Later in the report (page 49) it is stated that } \\
\text { 'The movement (of TOC) during the project is } \\
\text { also noteworthy. An adjustment to the TOC } \\
\text { almost certainly reflects an increase to the } \\
\text { alliance scope (since that is generally the only } \\
\text { grounds for adjustment) and raises doubts as to } \\
\text { the widespread perception of certainty of the } \\
\text { initial alliance TOC compared to other delivery } \\
\text { methods'. If it is the case that alliances are } \\
\text { more reliable in delivering specific scope within } \\
\text { the agreed TOC than other methods (a position } \\
\text { supported by the research), and it is also the } \\
\text { case that in alliances, increases in cost can only } \\
\text { result from the alliance undertaking additional } \\
\text { scope, this would appear to support the } \\
\text { widespread perception rather than raise doubts } \\
\text { about it. }\end{array}$ \\
\hline $\begin{array}{l}\text { Key finding 14: Project delivery - Adjusted TOC and AOC } \\
\text { In general, the AOC was less than the adjusted (final) TOC. } \\
\text { The average saving was of the order of } 0.5 \% \text {. }\end{array}$ & $\begin{array}{l}\text { Again this figure seems very surprising and } \\
\text { might result from a gross averaging process } \\
\text { which incorporates some fringe projects which } \\
\text { are disguising the typical outcome. Given the } \\
\text { importance of this issue a distribution of the } \\
\text { outcomes in the population should be provided } \\
\text { to ensure the real situation is being adequately } \\
\text { represented. This simple statistic without } \\
\text { further explanation does a great disservice to } \\
\text { the credibility of the report! }\end{array}$ \\
\hline
\end{tabular}


Appendix F.2

Comments on IASC Documents

Discussion Points 
Department of Treasury and Finance, Victoria, In

Appendix F.2

Pursuit of Additional Value (2009)

\section{Research Study for the Inter-jurisdictional Alliancing Steering Committee}

\section{DISCUSSION POINTS}

\section{DTFV, In Pursuit of Additional Value - \\ Discussion Points}

\section{Discussion Point 1 - VfM at whole of government and alliance level}

VfM definitions and the value proposition in the business case are the responsibility of investors (usually the government and Owners); not of the alliance team engaged to deliver the capital assets.

Government needs to consider optimising VfM at the whole of government level, not just at the alliance level.

Alliances should respond to, and be measured by, the VfM proposition contained in the business case.

Discussion Point 2 - Completeness of business case and clarity of objectives

The business case must be adequately developed with clearly expressed VfM proposition to allow a robust and transparent investment decision and to provide a framework for ongoing assessment of project success in meeting business case objectives.

Business case discipline and rigour should not be dispensed with in fast track projects.

Fast track processes need to be developed for those (rare) projects where timing of

commencement is of the essence. Owners should recognise that early commencement could attract a significant price premium, particularly when physical works commence prior to finalising commercial arrangements with the NOPs (see Key Finding No.4).

The business case should (barring sections subject to confidentiality) be made available to the alliance to ensure that alliance objectives can be aligned with the business case.

Discussion Point 3 - Adequacy and timing of the business case cost estimate

Estimates of $A O C$ generally increased by about $45-55 \%$ during the project lifecycle; $35-45 \%$ from business case to initial (agreed) TOC and a further 5-10\% to final adjusted TOC. Painshare/gainshare was negligible.

It would appear that PPPs provide the greatest cost certainty at business case stage (an increase of 5-10\% to final, followed by traditional $(\approx 20 \%)$ and then alliances $(\approx 50 \%))$.

Alliancing is generally associated with high risks (as in PPPs) that cannot be dimensioned upfront. They are often incomplete contracts. This uncertainty requires effective discipline in setting project objectives and controls to allow the Owner to understand and participate in decisions (including VfM) as the
Researcher's response

The text for this discussion point states: "Engagement of NOPs prior to adequate specification of the business case may also be effectively pre-judging the investment decision."

Some Owners may benefit form the early input of the NOP's to better define the business case. The investment decision is not made until the TOC is accepted.

The text for this discussion point states: "An adjustment to the TOC almost certainly reflects an increase to the alliance scope (since that is generally the only grounds for adjustment) and raises doubts as to the widespread perception of certainty of the initial alliance TOC compared to other delivery methods." There is no data presented in the study to support this statement. Experience suggests that many alliances decide to increase scope without increasing the TOC. Further, an increase to scope is seldom "the only grounds for adjustment of the TOC" - some alliances involve some risks being retained unilaterally by the owner, which (if they eventuate) can lead to adjustment of the TOC

Figure 6.1 is considered to be a very 'dangerous' diagram that could provide a misleading impression regarding each of the procurement approaches featured.

The text for this discussion point states: "A weakness is that shortcomings in a business case's VfM proposition are far less transparent under an alliance (particularly ones involving non-price selection of NOPs)."

On the contrary the, VFM proposition is probably explored in more detail in a nonprice selection alliance than in any other form of procurement. Proof of this 
Department of Treasury and Finance, Victoria, In

\author{
Research Study for the Inter-jurisdictional Alliancing \\ project progresses. \\ This uncertainty also requires the cost estimates to be even \\ more robust, not less. \\ An alliance is more forgiving of inadequate business cases than \\ traditional methods. This is both a strength and a weakness. The \\ weakness is the potential of significant price premiums which \\ may include scope and risk premiums in the absence of adequate \\ project definition at the business case stage.
}

\section{Discussion Point 4 - Fragmented multiple buyers (Owners)}

The alliance market may be characterised by multiple buyers (Owners) and few sellers (NOPs) with the possibility that the primary competition is occurring on the buyer (Owner) side to attract sellers (NOPs) to their individual projects.

$\mathrm{VfM}$ will be enhanced through a whole of government approach to the use of the alliance delivery method, engaging the market, commercial arrangements, legal agreements and selection processes.

Discussion Point 5 - Asymmetry of commercial resources and capability

Alliances require commercially complex transactions. The TOC development phase has high potential to influence VfM outcomes. During this phase there is fundamental commercial misalignment between Owner and NOPs. Owners (in the public sector) may be exposed to serious asymmetry of resources, information, and commercial capability in their commercial engagement with the NOPs particularly during the critical TOC development phase. This asymmetry has the potential for significant erosion of VfM.

\section{Discussion Point 6 - Project Alliance Agreement (PAA)}

There is a potential risk of differences between the aspirational use of alliancing terms and the practical application of these terms if a project becomes 'distressed'. A variety of PAAs exist with different terms and conditions. A national standard PAA template, tailored to project specifics, should enhance certainty, transaction efficiency and improve VfM from both an individual alliance and whole of government perspective.

The Owner and NOP require their own legal counsel during PAA establishment.

Discussion Point 7 - Characteristics for selecting the alliance delivery method have changed

The Research Team found that the characteristics for selecting the alliance delivery method have changed.

It appears that two reasons used by Owners (attracting NOPs and early commencement) are being achieved but the achievement of outstanding outcomes is not supported by the Study findings. position is not available but nor is it for

the statement above.

The text for this discussion point states: "NOPs generally have

a strong preference for the alliance delivery method over other delivery methods."

Does this suggest that NOP's have a sinister intent or simply have firm believe that alliances deliver superior outcomes for all parties in the right circumstances?

It would seem that there is far greater opportunity for commercial asymmetry to create an imbalance that could threaten VFM in other procurement approaches. Additionally has the Research Team any evidence of commercial asymmetry disadvantaging $\mathrm{VFM}$ or is this just a 'theory'?

There is no data or argument presented in the study to support this view. 
Department of Treasury and Finance, Victoria, In

\author{
Research Study for the Inter-jurisdictional Allian \\ often not directly aligned with achieving the business case \\ objectives and can potentially have an adverse impact directly \\ on VfM. \\ Owners need to understand that early commencement will \\ almost certainly attract a significant price premium and not \\ guarantee earlier completion. \\ The use of alliances to avoid the adversarial nature of traditional \\ risk allocation contract is successful. \\ There is a need for national procurement selection guidelines \\ which include an explanation of the characteristics best suited to \\ alliancing versus other delivery methods and a rationale for the \\ same.
}

\section{Discussion Point 8 - Price competition in the procurement process}

The foregoing discussion has considered the merits of price and non-price competition from multiple perspectives:

- The Research Team found no evidence to support the view that a price based selection process produced a lesser VfM outcome than a non-priced process. Indications are to the contrary.

- Price competition has led to a saving of about $5-10 \%$ in the TOC compared to non price selection processes.

- Price competition strengthens the incentive to innovate.

- The Research Team found no evidence to suggest that price competition erodes the alliance fundamentals of trust and relationships.

- There will be certain projects where contextual factors (market conditions, Owner resources, project specifics etc) mean that a non-price selection process may optimise VfM.

- The cornerstone of good procurement in government involves a significant element of competition on outturn price to demonstrate good stewardship of public funds and to optimise both the price and non-price aspects of VfM.

- It is inconsistent with broader government procurement policy for government to acquiesce (as is effectively current practice through the DTF Project Alliancing Practitioners' Guide) a non-price selection process as the recommended or default policy.

- Economic efficiency (productive, allocative and dynamic) and VfM at the whole of government level is best achieved in the long term by price competition.

The above needs to recognise the limited number of pricecompetition selection processes examined in this Study.
There is no data presented in the study to support the generalisation of "significant price premium". In any case this statement implies that it is not VFM to pay a premium for rapid responsewhich is patently untrue in a number public sector projects e.g. Northside Storage Tunnel, Bundamba Water Treatment Plant.

What are the indications to the contrary?

How can such comments be justified regarding the comparative TOC when there is no statistically valid sample. Statements such as this cast doubts over the validity of much of the excellent work in this report.

The text for this discussion point states: "It is important to note that a high performance team can be characterised by the effectiveness of its decision making, and this does not preclude vigorous debate prior to reaching a decision. In fact a lack of competitive tension may lead to poor quality decision making through the effects of group think or misinterpretation that 'trust' means 'no disagreements'."

There is no data presented in the study to support these statements.

The term 'acquiesce' implies a degree of yielding or 'conceding' to another's position. This appears to be statement of dogma rather than anything supported by any evidence presented in the report.

The text for this discussion point states: "Economic efficiency (productive, allocative and dynamic) and VfM at the whole of government level is best achieved in the long term by price 


\section{Research Study for the Inter-jurisdictional Alliancing Steering Committee competition." \\ Whilst axiomatic for market-based economies generally, there is no credible data presented in the study to support this view in relation to alliancing and the high-risk projects tackled by alliancing.}

Discussion Point 9 - Non-price criteria for selecting NOPs

Because alliancing has matured over the last ten years and a better understanding now exists amongst NOPs of the collaborative nature of alliancing, the attributes of alliance affinity of NOPs may be better assessed as hurdle criteria and the NOPs project delivery skills (design, construction, controls, design management and commercial) as differentiators.

Moreover, the maturity of alliancing should mean that any relationship risk (however real in the past) associated with a price competition can be satisfactorily managed.

A price competition selection process must also include the evaluation of non-price criteria since governments are not interested solely in lowest price as a determination of value for money.

Discussion Point 10 - Early commencement of a project through early involvement of NOPs

Compared to traditional methods, the alliance delivery method can provide significant time advantages (several months) to Owners who are under severe time imperatives to commence physical works as soon as possible.

The reason for this is the alliance undertakes many project 'front end' activities in a collaborative and more efficient manner, and in parallel rather than sequentially. Owners need to recognise that there may be a significant price premium associated with early commencement and that early completion is not guaranteed through earlier commencement.

\section{Discussion Point 11 - Insurance policies}

Insurance is a complex and costly matter, particularly for alliances, and needs specialist skills. Insurance in alliancing also raises the question of whether $\mathrm{VFM}$ is being optimised by the Owner on a whole of government portfolio basis or merely on a sub-optimal project by project basis.

The true effectiveness of insurance is tested when a claim is made and a policy responds. To date Australian alliance projects do not have a history of claims experience and therefore the effectiveness of alliance insurance has generally not been rigorously tested. This raises the question of the effectiveness of the cover obtained - if there have been few claims, and a substantial volume of projects have been delivered then what risks are being insured and how is VfM being optimised by insurance?
There is no credible data presented in the study to support this statement.

This is an important statement that is given a low weighting in the later conclusions and recommendations.

The text for this discussion point states: "...there may be a significant price premium associated with early commencement and that early completion is not guaranteed through earlier commencement."

There is no data presented in the study to support this view. 
Department of Treasury and Finance, Victoria, In

\section{In the absence of price competition, the IE role has become a default position for demonstrating the TOC represents VfM. \\ The IE role as currently practiced focuses on pricing of a settled scope and may be too narrow to optimise VfM. The IE role should be expanded to become Owner's VfM advisor including: \\ - reviewing scope, design, construction method, materials and resources \\ - preparing an estimate (possibly from first principles, risk adjusted) that parallels in detail the estimate that Owners would normally prepare under traditional delivery methods \\ - reconciling the IE estimate against business case and NOP/alliance TOC.}

Research Study for the Inter-jurisdictional Alliancing Steering Committee

\section{Discussion Point 13 - Use of 'hybrid' pricing elements}

The use of hybrid elements allows the benefits of competitive tension and comparative testing of VfM when full TOC pricing competition is not desirable.

Hybrid elements include:

- cost benchmarking against previous projects selected by the Owner

- cost benchmarking of major elements between shortlisted parties during the NOP selection process

- innovation in design and construction methodology.

Discussion Point 14 - Establishing the TOC under non-price competition

To ensure optimum VfM, the process leading to agreeing the TOC requires commitment to commercial rigour in negotiations between Owner and NOPs, based on business principles rather than alliance principles.

This requires that the commercial misalignment that exists in the TOC development phase is addressed openly by the NOPs and the Owner.

NOPs undertake extensive in-house reviews of alliance TOCs to give confidence to senior management that all corporate requirements are satisfied. Owner representatives need to take the opportunity to understand the TOC in a similar manner.

NOPs have clear corporate requirements in terms of risk and return and these are applied rigorously. The Owner also should have (but often does not have) clear outcomes, objectives and the value proposition articulated in the business case, which also need to be applied rigorously in TOC negotiations.

There was some evidence from the Study that from time to time robust commercial negotiations were undertaken that resulted in substantial TOC reductions with no adverse impact on business case objectives or on NOP margins. An Owner led improvement strategy (which will help avoid capture) could include features such as:

- Maintain a viable alternative project procurement and delivery strategy until TOC is agreed.

- Avoid physical works being undertaken under the alliance
The text for this discussion point states: "To ensure optimum VfM, the process leading to agreeing the TOC requires commitment to commercial rigour in negotiations between Owner and NOPs, based on business principles rather than alliance principles."

There is no data presented in the study to support this view. The use of "business principles rather than alliance principles" is seems to imply that alliances generally are not businesslike. And that NOP's may 'take advantage' of an uniformed or naive Owner. This does not accord with the author's experience which suggests that there need not be any incompatibility between good business practice and good alliance practice. 
Department of Treasury and Finance, Victoria, In

Appendix F.2

Pursuit of Additional Value (2009)

Research Study for the Inter-jurisdictional Alliancing Steering Committee

agreement before TOC is agreed or at least recognise the potential for price premium.

- Better Owner focus on the business case VfM proposition

prior to and during TOC development.

- Assemble an Owner's commercial team with appropriate skills and experience to drive better VfM outcomes.

- Be prepared to re-assess business case decision to proceed if the project VfM proposition is not achieved or modified beyond target ranges.

- Greater Owner participation in the TOC development phase. 


\section{Appendix F.3}

\section{Comments on IASC Documents}

Conclusions 
Department of Treasury and Finance, Victoria, In

Based on the Findings, Discussion and Observations of the Study, it can be concluded that VFM can be enhanced in the alliance delivery method.

As a collaborative delivery method, alliancing has demonstrated its ability to avoid disputes, improve non-cost outcomes and commence projects earlier than by traditional methods.

To extract the optimum VfM from alliancing, changes must be made at both the alliance and whole of government levels. There are a number of discrete conclusions that support this overall conclusion and these are discussed below.

Enhancing whole of government VfM

In this section, the conclusions relevant to enhancing VfM at the whole of government level are discussed. These are generally areas where there would only be a benefit if a whole of government approach were taken, rather than an alliance only approach.

\section{Business case}

VfM definitions and the value proposition in the business case are the responsibility of the Owner, not of the alliance which has been engaged to deliver the capital asset component of the business case at the lowest price. The role of the Owner needs to be distinguished from the Owner's representative on the alliance, who only has responsibility for delivery and has no authority to change the business case as these are normally approved by Government.

It would appear that PPPs provide the greatest cost certainty at business case stage (an increase of 5-10\% to AOC), followed by traditional $(\approx 20 \%)$ and then alliances $(\approx 50 \%)$.

The lack of accuracy in the business case cost estimate must be considerably improved to better inform the capital investment decision. Alternatively, the business case should include explicit advice to investment decision makers regarding the risk of potential increases. Fast track processes need to be developed for the minority of projects where time of commencement is of the essence and decision makers need to be alerted to the significant price premium that may be associated with fast tracking.

\section{Procurement strategy}

There is a plethora of selection guidelines on the use of the alliance delivery method that are inconsistent, confusing, do not reflect current practice and are not focussed on optimising VfM. Given a robust construction market it is possible that the primary competition is occurring on the buyer (Owner) side as they seek to attract NOPs to their own project using the alliance delivery method and non-price criteria, both of which are highly favoured by NOPs over traditional delivery methods.

The statement that there is a plethora of guidelines on the use the alliance delivery method is not correct although this may be true of procurement generally! 


\section{Department of Treasury and Finance, Victoria, In Pursuit of Additional Value (2009)}

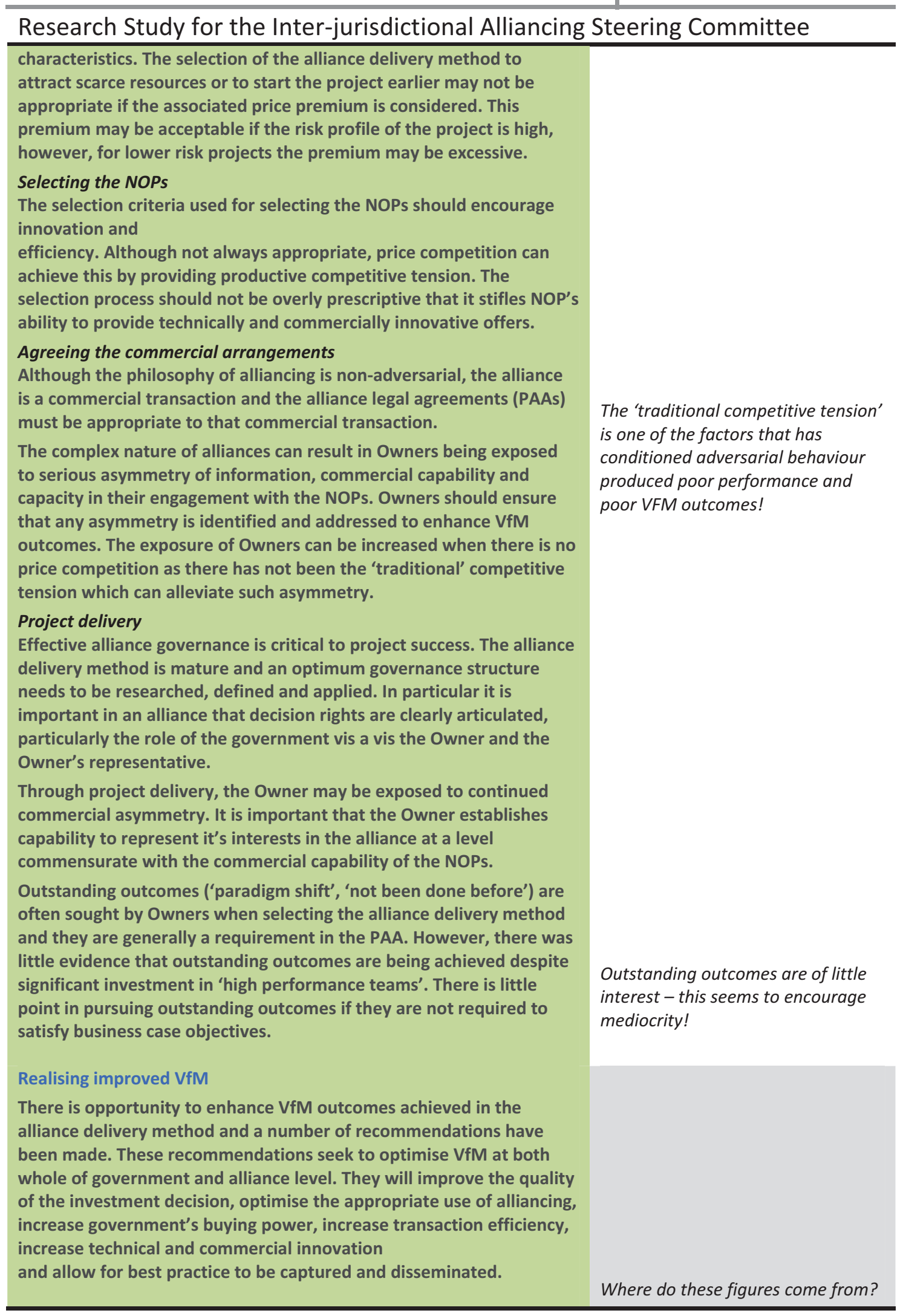


Department of Treasury and Finance, Victoria, In

Appendix F.3

Pursuit of Additional Value (2009)

Research Study for the Inter-jurisdictional Alliancing Steering Committee

If all of these recommendations are adopted, the actual outturn cost

of alliance projects could, in the judgement of the Research Team, be

improved by $5-15 \%$ without diminishing the many benefits that the

alliance delivery method is capable

of providing. 
Appendix F.4

Comments on IASC Documents

Recommendations 
Department of Treasury and Finance, Victoria, In

\section{DTFV, In Pursuit of Additional Value - \\ Recommendations \\ The following six recommendations address how VfM can be enhanced in the alliance delivery method. An incremental increase in VfM will be realised if they are implemented in their entirety. \\ If all of the recommendations below are adopted the actual outturn cost of alliance projects could, in the judgement of the Research Team, be improved by $5-15 \%$ without diminishing the many benefits that the alliance delivery method is capable of providing.}

Research Study for the Inter-jurisdictional Alliancing Steering Committee collected during the research?

\section{Policy Recommendation No. 1}

The alliance delivery method be retained and developed further as one of the mature procurement strategies for the delivery of government's infrastructure projects that are complex with significant risks that cannot be dimensioned in the business case or soon thereafter.

\section{Policy Recommendation No. 2}

The State Treasuries collaborate to develop a comprehensive Procurement Selection Guide and training materials for use by government agencies on when to use the alliance delivery method.

\section{Policy Recommendation No. 3}

The State Treasuries (and relevant line agencies) collaborate to develop common policy principles, guidelines and training for the selection of the NOPs and implementation of the alliance delivery method that reflect the outcomes of this Study.

\section{Policy Recommendation No. 4}

Governments take a greater role in ensuring that alliance best practice is captured and disseminated; and also take a greater oversight role on individual alliance projects to ensure that VfM is optimised at whole of government level.

\section{Policy Recommendation No. 5}

An adequate business case, which includes the case for the procurement decision, to be prepared and approved as required by relevant state government guidelines before the alliance selection process commences. (This will recognise the development of fast track processes for times of genuine urgency
Researcher's response

Recommendations 1 to 4 are positive initiatives but where does the 5-15\% come from? Is the judgement of the Research Team based on the evidence

Noted.

Provides support for the case of project alliances where the circumstances best suit the alliance model.

Relates to alliance procurement decision to the intent of the business case.

Noted.

Recommends a consistent well documented approach to procurement selection process

Noted.

Again, this recommendation is calling for consistency in approach particular for the selection of NOP's which based on the recommendation would be based on multiple TOC default position. Noted.

The recommendation suggests greater control agency involvement is consistent with an earlier finding in the report that suggest that the representatives of the agencies involved in an alliance are not the appropriate party to view the 'whole of government' perspective.

Advocates greater discipline in the development of the business case and the considered choice of an alliance before an alliance is formed. Stipulates minimum requirements for establishment of an alliance in 'fast 
Department of Treasury and Finance, Victoria, In

Appendix F.4 Pursuit of Additional Value (2009)

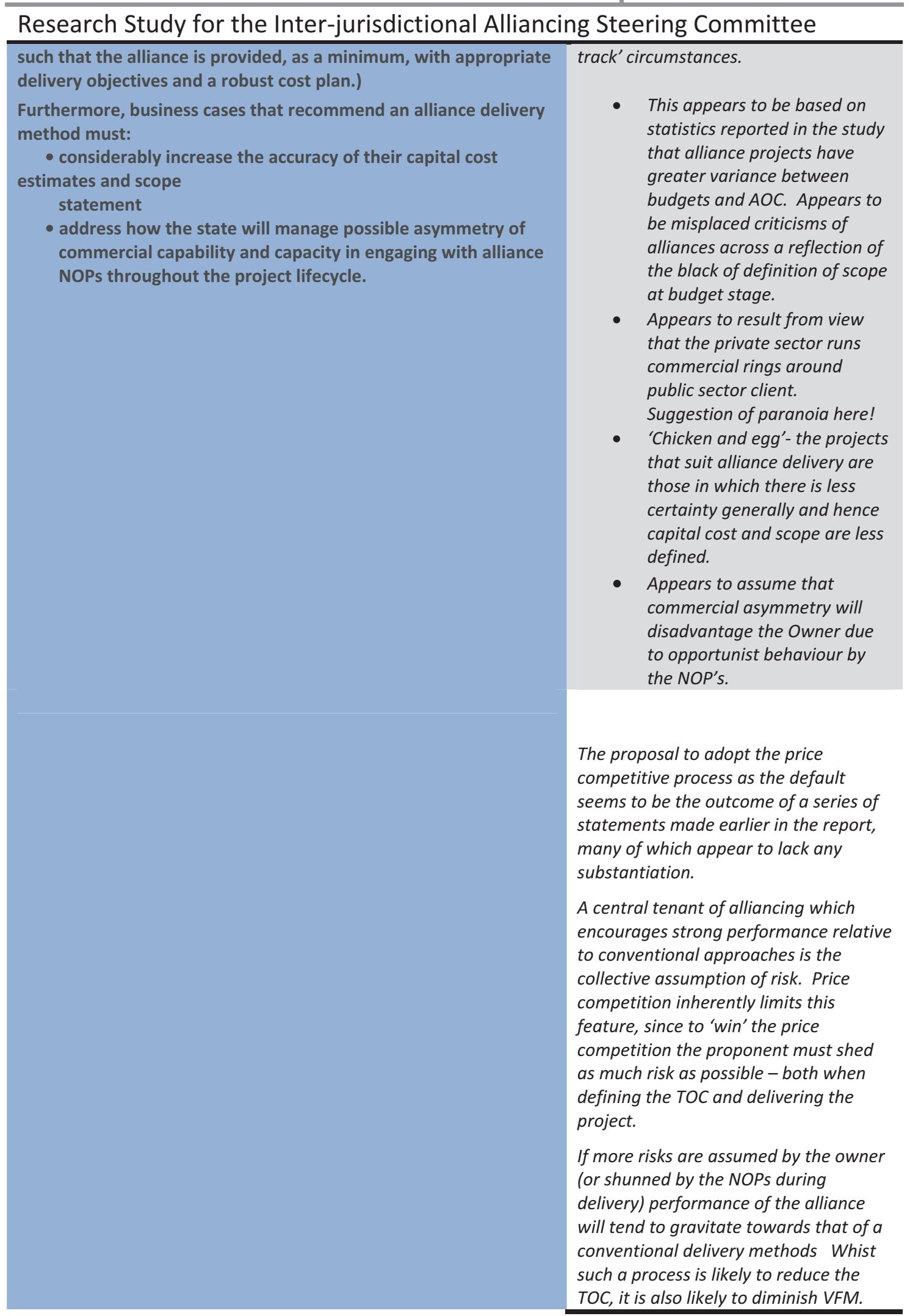


Department of Treasury and Finance, Victoria, In

Appendix F.4

Pursuit of Additional Value (2009)

Research Study for the Inter-jurisdictional Alliancing Steering Committee

Policy Recommendation No. 6

A competitive process should be used as the default approach to selecting NOP's having price (including return costs/TOC's) as the key selection criteria. This will be consistent with established government procurement policies that support a competitive process with tone of the key selection criteria being price unless compelling reasons (which are outlined in the same government procurement policies) for non-price competition can be made and approved.

This appears to be pure dogma and represents the pre stated position of Treasuries (notwithstanding to previous VDTF default position) and the methodology recommended and commercially marketed by Evans \& Peck.

There would appear to be no substantive justification for this approach from the data gathered during this study. 


\section{Appendix F.5}

Guidance Note No. 4

Reporting VfM Outcomes in Alliance Contracting 


\section{Department of Treasury and Finance, Victoria, Commercial Division}

\section{Review of Exposure Draft Guidance Note No. 4}

\section{Reporting VFM Outcomes in Alliance Contracting}

\section{Comments by Charles MacDonald}

Introduction

The author of these comments is engaged as the General Manager Construction for BrisConnections Pty Ltd, the company responsible for the construction and operation of the Airport Link Project in Brisbane. This PPP project will involve a 45 year concession and capital cost of $\$ 4.2$ billion including the Northern Busway and Airport Roundabout Upgrade elements which are delivered under design and construct contract arrangements.

The author, who has 37 years of construction experience, is also completing a professional doctorate at RMIT University which has involved research into the topic of 'Ensuring and demonstrating value for money/best value in alliance projects'.

Finally, the author is a Director of the Alliancing Association of Australasia (AAA), although the views expressed below should not be seen as representing the official view of the AAA.

Comments are provided in relation to each section of the exposure draft of the Guidance Note.

\section{Preamble}

Agreed and supported.

\subsection{Introduction}

- This section introduces the distinction between the State and the Owner which will be commented upon later in this response.

- The section also introduces reference to a VFM Report to be prepared by the Owner. It is not clear why this document should not be prepared by the Alliance and presented to the Owner. Why is it necessary to provide this report to the State if it is the Owner who is charged with the responsibility to ensure that VFM is achieved? The State may wish to view or even audit the process that generated the report.

- The suggestion that the Alliance should provide regular VFM reporting to the Owner is strongly supported. A report, no matter comprehensive, at the end of the project does not facilitate corrective action during the delivery of the project.

\subsection{Why report VFM outcomes in alliance contracting?}

- It is suggested in the text that other procurement methodologies have defined benchmarking processes to inform judgements on VFM outcomes. The author of these comments questions whether such a statement can be supported. Certainly a conventional tendering process does not establish such an outcome but merely the 
starting point for the ultimate cost for the project. It is suggested that there is less cost certainty in 'design and construct' procurement where any variations are not presented in the 'open book' fashion that is required in alliancing, which is much more likely to lead to a favourable VFM outcome.

- The suggestion that the alliance participants, which include the OP, should not have any editorial control over the VFM Report suggests a lack of trust in the integrity of the Alliance. Frankly, if such trust is absent, the parties should not be engaging in an alliance in the first place. A third party review/validation of the report could, however, be useful.

- This section contains some very useful ideas regarding reporting VFM outcomes to the Owner, particularly the three dot points identified. However, these points would be equally applicable to traditional contracts where the current mechanisms do not achieve these laudable objectives.

\subsection{The role of VFM in Government decision making.}

- Figure 2 is helpful in understanding the respective roles of the State, Owner and Alliance as understood by the authors of the Guidance Note.

- The subsection entitled 'The Alliance' describes the constitution of the Alliance and then draws distinction between the role of the Owner and the OPs. The text then states that the Owner may delegate certain limited responsibilities to the nominated OPs (underlining added). This limitation of the powers and responsibilities of the OPs is a major concern. The NOPs are typically required to nominate very senior personnel to the Alliance Board (ALT) who are specifically delegated to make significant decisions on the part of the respective organisations that they represent. If the OP is not similarly authorised, the function of the ALT and the capacity of the Alliance to respond in a timely and proactive manner could be seriously prejudiced. Indeed, it could be argued that such an arrangement would undermine some of the basic tenants of the alliance i.e. that all participants are empowered and are able to share all risks.

\subsection{The "VFM proposition"}

- This section suggests that business case will consider the identified 'solution'. Does this mean that 'solution' must be known at this stage? Surely a project can be examined through a business case process without the 'solution' being determine at that point? Indeed for complex and difficult to define projects, which are best suited to the alliance model, a solution may not be developed until the expert knowledge that can be provided by the alliance, is available to determine the best solution.

\subsection{Best for State v Best for Project}

- In the scenario provided it is clear that additional expenditure would need the specific consent of the Owner. However, if the alliance had saved \$5M would they have the discretion to spend the funds on the initiatives identified by the workshop rather than returning the funds to the respective participants in the pre-agreed proportions? It is suggested that they should have such discretion.

Comments by Charles MacDonald 


\subsection{Implementing the procurement strategy}

- In the cautionary note is suggested that 'VFM' is not an expression that can be used to ignore the impacts of price. However, nor should it be used to ignore all factors other than price which is often the manner in which it is interpreted in traditional procurement.

\subsection{Business case requirements}

- In the section entitled 'The Project Management Decision' it is stated that the Owner will need to ensure that the procurement method is structured to optimise the VFM outcomes for the cheapest price. However, it needs to be recognised that the VFM outcomes need to be appropriately defined and then communicated to all the participants in the project. A VFM outcome does not result, for instance, from a hospital being built on the cheapest land and hence lowest price but in the wrong place to successfully service the community. This cheapest price mentality, which is perpetuated by the term VFM often results in such outcomes.

\subsection{Investment decisions are made on the basis of Business Cases}

- The quotes provided from the ICAC publication 'Guidelines for managing Risks in Direct Negotiations' appear to be rather selective and do not fully reflect the statements made in this report. For instance the report actually distinguishes between joint ventures and relationship contracting which is described as 'often making sense in situations where the agency wishes to enter into a long term relationship with a contractor'. The publication also states that 'when the risks are well managed alliance contracting can be a beneficial form of project delivery'.

\subsection{The VFM Statement Process}

- The distribution of the Owners VFM Statement to bidders is welcomed as this does not appear to be common practice currently.

- It is not clear why it is insisted upon that the VfM statement should be finalised before commencing any formal market engagement process. There seems to be a concern that any early involvement with the 'outside world' may in some way 'contaminate' the process. This would seem to be a very conservative approach and frankly denies the public sector the opportunity of gaining advantage from advice or input that may enhance the VfM Statement.

\subsection{VfM Statement Requirements}

- Many of the 'business rules' as defined in the text should not be in the VFM Statement but should be in the Alliance Agreement. 


\subsection{Business Case estimate}

- Again there is an insistence that the Business Case estimate should be prepared before market engagement. There may be sufficient in-house knowledge to do this but there may not be. Consequently, the Owner should be sufficiently 'mature' to be able to seek any advice that might be necessary from the market in order to produce a sound estimate. The lack of satisfactory and realistic estimates for projects, which may ultimately proceed to be delivered by project alliances, was one of the criticisms raised by the earlier research by VDTF. Declining to obtain advice from 'outside' does not appear to be a reasonable way of addressing this perceived deficiency.

- The reconciliation of the Business Case estimate, TOC and ultimately AOC are all considered to be sound measures. It is suggested that the reconciliation of the TOC with the Business case Estimate is not a matter for the VFM Report but should be reviewed prior to approval of the TCE i.e. at the time that the alliance is sanctioned to proceed.

\subsection{Ensuring the Alliance structure optimises VFM outcomes}

- The statement that the 'Owner needs to act as an 'intelligent' client .....is a key driver of VFM and effective procurement' is strongly supported. Owners and State Agencies entering into alliance without proper preparation or careful consideration of alternative procurement approaches do a great disservice to themselves and the industry generally. Such Owners share responsibility for generating a perception in some quarters that alliances do not offer VFM and prejudice the appropriate use of alliancing for those projects which suit this procurement approach. Alliances are only likely to be suited to a limited class of projects and the broad use of the method is unlikely to be justified.

- It is unclear why the role of the Owner and the OP should be separated. It seems that the State wishes to have 3 levels of authority i.e. State, Owner and OP whilst other parties are represented by their ALT nominee alone. Whilst accepting that the State is the Client, such an imbalance may not be conducive to driving collaborative behaviours.

- If the OP is not authorised to speak on behalf of the Owner this could lead to a dysfunctional ALT.

- The use of the Gateway Review process at the appropriate points in the alliance contract is considered to be a very sound idea. The author of these comments has developed a model which adapts the Gateway Process to the alliance procurement approach.

\subsection{Governance arrangements and decision making}

- It would seem to be essential for the ALT to endorse changes to the Business Case even if the Owner retains the right to approve such changes.

- The Owner alone determining what will constitute a material change at the inception is not 'alliance' type behaviour. In practice this a matter usually addressed by the alliance at an early time and invariably NOPs take a more severe view of what constitutes a change i.e. such unilateral action by the Owner is likely to be to their disadvantage. 


\subsection{When to Report}

- Continuous monitoring is mentioned but no guidance is provided on the information or reporting that might be produced on an ongoing basis. Such guidance is essential if the VfM Report is to be a worthwhile document that addresses the Owners requirements.

\subsection{Preparing and reviewing the VFM Report}

- The argument that the VfM Report should be produced by others on behalf of the Owner is not well made. Such a report should be prepared by the Alliance for presentation to the Owner who may wish to engage a third parry to review the document prior to onward submission to the State. Engagement of independent advisors to produce the VfM Report is very unlikely to represent VfM given their lack of knowledge of the detail of the project. If the alliance has produced ongoing reviews of VfM, as suggested earlier in section 7.2, they are clearly best equipped to prepare the VfM Report.

\subsection{Benchmarking costs}

- The suggestion that the Owner engage an independent Estimator prior to market engagement to perform a similar scope of services to that usually undertaken by contractors suggest two things:

- An inherent distrust of the parties that are to be engaged in the subsequent alliance - not a good basis on which to form a relationship!

- A lack of appreciation of the extent of estimating work that will be undertaken by the contractor, the time at which it will be undertaken which is much later in the sequence, and a failure to appreciate that this information will be available on an open book basis.

The use of an Independent Estimator to review the contractor's work is a sound approach but the engagement of such a party to duplicate the estimating process is considered to be seriously misguided and suggests fundamental misunderstanding of the dynamics of a relationship based contract.

\section{Appendix A, Part B}

- The content of this section is contained in the Alliance Agreement which could be appended to the VFM Statement.

\section{Appendix B, Section 4}

- Rather than 'Achieving the right price' perhaps the more appropriate heading would be 'Achieving the right outcome at the best price'!

\section{Conclusions}

As has been the case for the earlier material issued in VDTF in this series on VFM in alliance contracting, this guidance note provides some very useful and well researched guidance to practitioners. The author is very supportive of much of the material contained in the guidance 
Appendix F.5

\section{[Comments on Exposure Draft, Guidance Note No. 4 April 16, 2010}

note and has drawn particular attention to areas where this view is held with even greater conviction. The author does, however, hold contrary views in a number of areas which are also listed. It is hoped that these comments are seen as constructive criticism even when strongly expressed,

Thank you for the opportunity to comment on the Guidance Note.

Charles MacDonald

Brisbane, 16 April 2010

Comments by Charles MacDonald 